NBSIR 82-2465

\title{
Investigation of the Kansas City Hyatt Regency Walkways Collapse
}

U.S. DEPARTMENT OF COMMERCE

National Bureau of Standards

Washington, DC 20234

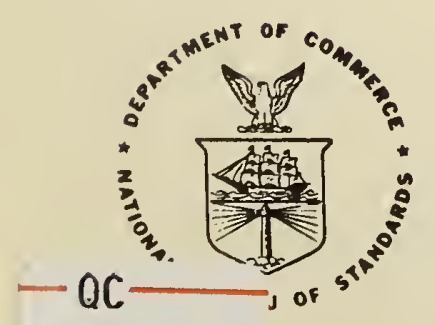

100

.456

'ARTMENT OF COMMERCE

82-2465 BUREAU OF STANDARDS

1982

C. 2 

R. D. Marshall
E. O. Pfrang
E. V. Leyendecker
K. A. Woodward

Center for Building Technology National Engineering Laboratory

R. P. Reed

M. B. Kasen

T. R. Shives

Center for Materials Science

National Measurement Laboratory

U.S. DEPARTMENT OF COMMERCE

National Bureau of Standards

Washington, DC 20234

February 1982

U.S. DEPARTMENT OF COMMERCE, Malcolm Baldrige, Secretary NATIONAL BUREAU OF STANDARDS, Ernest Ambler, Director 



\section{ABSTRACT}

An investigation into the collapse of two suspended walkways within the atrium area of the Hyatt Regency Hotel in Kansas City, Mo., is presented in this report. The investigation included on-site inspections, laboratory tests and analytical studies.

Three suspended walkways spanned the atrium at the second, third, and fourth floor levels. The second floor walkway was suspended from the fourth floor walkway which was directly above it. In turn, this fourth floor walkway was suspended from the atrium roof framing by a set of six hanger rods. The third floor walkway was offset from the other two and was independently suspended from the roof framing by another set of hanger rods. In the collapse, the second and fourth floor walkways fell to the atrium floor with the fourth floor walkway coming to rest on top of the lower walkway.

Based on the results of this investigation, it is concluded that the most probable cause of failure was insufficient load capacity of the box beam-hanger rod connections. Observed distortions of structural components strongly suggest that the failure of the walkway system initiated in the box beam-hanger rod connection on the east end of the fourth floor walkway's middle box beam.

Two factors contributed to the collapse: inadequacy of the original design for the box beam-hanger rod connection which was identical for all three walkways, and a change in hanger rod arrangement during construction that essentially doubled the load on the box beam-hanger rod connections at the fourth floor walkway. As originally approved for construction, the contract drawings called for a set of continuous hanger rods which would attach to the roof framing and pass through the fourth floor box beams and on through the second floor box beams. As actually constructed, two sets of hanger rods were used, one set extending from the fourth floor box beams to the roof framing and another set from the second floor box beams to the fourth floor box beams.

Based on measured weights of damaged walkway spans and on a videotape showing occupancy of the second floor walkway just before the collapse, it is concluded that the maximum load on a fourth floor box beam-hanger rod connection at the time of collapse was only 31 percent of the ultimate capacity expected of a connection designed under the Kansas City Building Code. It is also concluded that had the original hanger rod arrangement not been changed, the ultimate capacity would have been approximately 60 percent of that expected under the Kansas City Building Code. With this change in hanger rod arrangement, the ultimate capacity of the walkways was so significantly reduced that, from the day of construction, they had only minimal capacity to resist their own weight and had virtually no capacity to resist additional loads imposed by people.

Supplementary material is contained in an appendix to this report and published as NBSIR $82-2465 \mathrm{~A}$.

Key Words: building; collapse; connection; construction; failure; steel; walkway. 
On July 17, 1981, two suspended walkways within the atrium area of the Hyatt Regency Hotel in Kansas City, Mo., collapsed leaving 113 people dead and 186 injured. In terms of loss of life and injuries, this was the most devastating structural collapse ever to take place in the United States.

On July 20, 1981, Senator Thomas F. Eagleton's office contacted the National Bureau of Standards and requested that technical assistance be provided to Kansas City. Shortly thereafter Kansas City Mayor Richard L. Berkley asked NBS to determine the most probable cause of the walkways' collapse. Senators Thomas F. Eagleton and John C. Danforth and Congressman Richard Bolling endorsed the Mayor's request for the NBS to conduct an independent investigation. NBS researchers first arrived in Kansas City on July 21, 1981. During the course of the investigation, the NBS team of engineers and scientists inspected the Hyatt Regency atrium area and the warehouse where the walkway debris was stored.

In the early phases of the investigation, NBS involvement was limited by court order to visual and photographic observations and measurements. NBS requested permission to weigh selected walkway spans and to remove for additional study and destructive examination certain portions of the walkway box beams, hanger rods, concrete decks, and nuts and washers. The Bureau's requests were eventually granted under court orders after agreement was reached with litigants involved in various legal actions steming from the collapse of the walkways.

Documents such as drawings, specifications, inspection reports, test reports, and construction logs, as well as photographs and videotapes became available to NBS from a number of sources. These were useful in gaining information about the walkways as originally approved for construction and as modified during the construction process.

NBS conducted extensive laboratory tests on Bureau-fabricated mockups of parts of the walkways. Tests were also conducted by NBS on portions of the debris. Analytical models were developed to predict the response of the walkways to various loading conditions. Also, tests were conducted to determine material properties and weld and fracture characteristics.

The Hyatt Regency consists of three main sections: a high-rise section, a "function block," and a connecting atrium area. As built, three suspended walkways spanned the atrium at the second, third, and fourth floor levels and connected the high-rise and function sections. The second floor walkway was suspended from the fourth floor walkway which was directly above it. In turn, this fourth floor walkway was suspended from the atrium roof framing by a set of six hanger rods. The third floor walkway was offset from the other two and was independently suspended from the roof framing by another set of hanger rods.

In the collapse, the second and fourth floor walkways fell to the atrium floor, with the fourth floor walkway coming to rest on top of the lower walkway. Most of those killed or injured were either on the first floor level of the atrium or on the second floor walkway. The third floor walkway was not involved in the collapse. 
As originally approved for construction by the Kansas City Codes Administration office, the plans for the walkways called for a single set of hanger rods (attached to the roof framing) which would pass through the fourth floor box beams and on through the second floor box beams. The box beams--made up of a pair of 8-inch steel channels with the flanges welded toe to toe--were to rest on hanger-rod washers and nuts below each set of beams. Under this arrangement each box beam would separately transfer its load directly into the hanger rods.

However, during construction, shop drawings were prepared by the steel fabricator which called for the use of two sets of hanger rods rather than a single set. One set of hanger rods extended from the fourth floor box beams to the roof framing and another set extended from the second floor box beams to the fourth floor box beams. Under this arrangement all of the second floor walkway load was first transferred to the fourth floor box beams, where both that load and the fourth floor walkway load were transmitted through the box beam-hanger rod connections to the ceiling hanger rods. As indicated by their stamps, these shop drawings were reviewed by the contractor, structural engineer and architect.

Efforts were made to establish as accurately as possible the loads on the walkways at the time of the collapse. Weighing of selected walkway debris along with measurements taken on concrete cores removed from the walkway decks permitted NBS to determine that the actual walkway dead load (self-weight) was approximately 8 percient higher than the nominal dead load. (The nominal dead load is an estimate based solely on the project's contract drawings.) Estimates of the loads due to people present on the walkways at the time of collapse (live load) were much more difficult to make. Witnesses made a number of conflicting statements regarding the numbers and activities of people on the walkways just prior to the collapse. However, a television crew had videotaped parts of the walkway minutes before the collapse. By studying this videotape, NBS concluded that 63 people represented a credible estimate of combined second and fourth floor walkway occupancy at the time of collapse.

Based on field, laboratory, and analytical investigations, NBS concluded that:

1. Collapse of the walkways occurred under the action of loads that were substantially less than the design loads specified by the Kansas City Building Code.

2. The ultimate capacity of box beam-hanger rod connections can be predicted on the basis of laboratory test results.

3. Under the action of the loads estimated to have been present on the walkways at the time of collapse, all fourth floor box beam-hanger rod connections were candidates for initiation of walkway collapse.

4. Observed distortions of structural components strongly suggest that failure of the walkway system initiated in the box beam-hanger rod connection at location 9UE (east end of middle box beam in fourth floor walkway). 
5. As constructed, the box beam-hanger rod connections, the fourth floor to ceiling hanger rods, and the third floor walkway hanger rods did not satisfy the design provisions of the Kansas City Building Code.

6. The change in hanger rod arrangement from a continuous rod to interrupted rods essentially doubled the load to be transferred by the fourth floor box beam-hanger rod connections.

7. The box beam-hanger rod connection would not have satisfied the Kansas City Building Code under the original hanger rod detail (continuous rod).

8. Under the original hanger rod arrangement (continuous rod) the box beam-hanger rod connections as shown on the contract drawings would have had the capacity to resist the loads estimated to have been acting at the time of collapse.

9. Neither the quality of workmanship nor the materials used in the walkway system played a significant role in initiating the collapse. 
viii

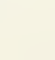




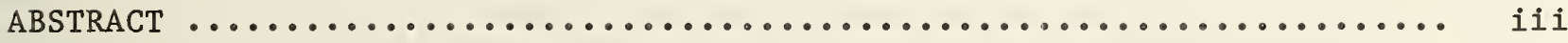

EXECUTIVE SUMMARY $\ldots \ldots \ldots \ldots \ldots \ldots \ldots \ldots \ldots \ldots \ldots \ldots \ldots \ldots \ldots \ldots \ldots \ldots \ldots$

1. INTRODUCTION $\ldots \ldots \ldots \ldots \ldots \ldots \ldots \ldots \ldots \ldots \ldots \ldots \ldots \ldots \ldots \ldots \ldots \ldots \ldots \ldots \ldots$

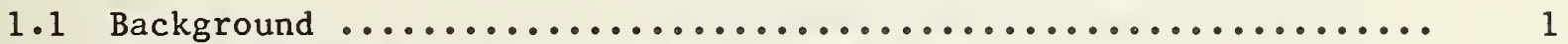

1.2 Objective and Scope of the Investigation $\ldots \ldots \ldots \ldots \ldots \ldots \ldots \ldots \ldots$

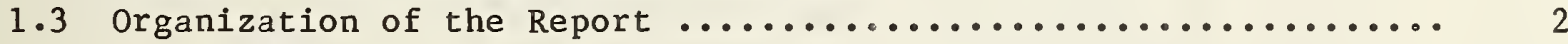

2. DOCUMENTS REVIEWED BY THE NBS INVESTIGATIVE TEAM .............. 5

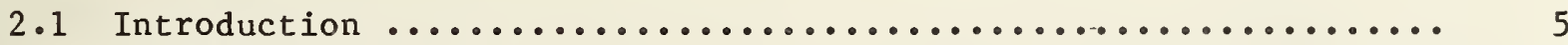

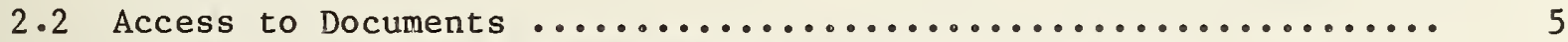

2.3 Project Specifications and Relevant Code Provisions ......... 5

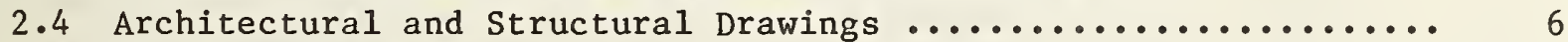

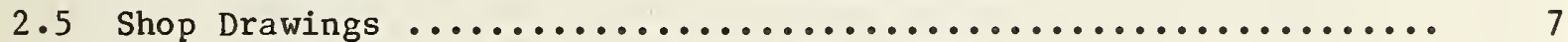

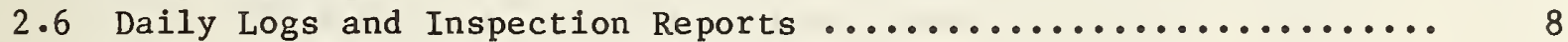

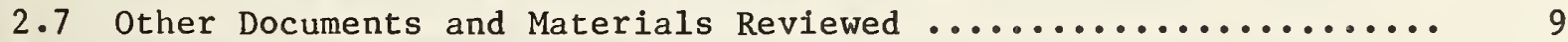

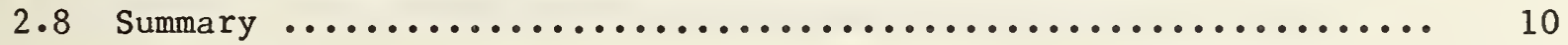

3. DESCRIPTION OF THE WALKWAY SYSTEM PRIOR TO COLLAPSE ............ 11

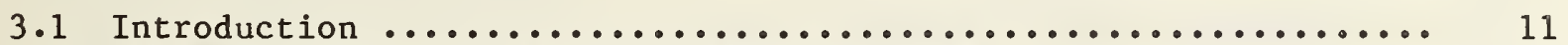

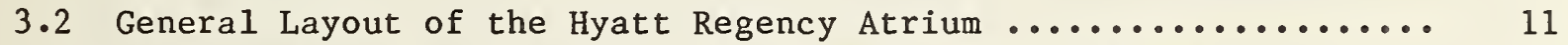

3.3 Structural and Architectural Features of the Walkways ........ 12

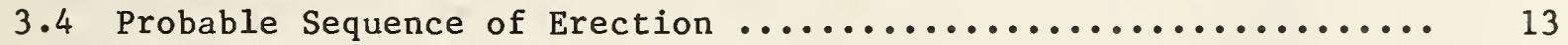

3.5 Designation of Walkway Components $\ldots \ldots \ldots \ldots \ldots \ldots \ldots \ldots \ldots \ldots \ldots$

3.6 Summary $\ldots \ldots \ldots \ldots \ldots \ldots \ldots \ldots \ldots \ldots \ldots \ldots \ldots \ldots \ldots \ldots \ldots \ldots \ldots \ldots$

4. DESCRIPTION OF THE WALKWAY COLLAPSE ..................... 31

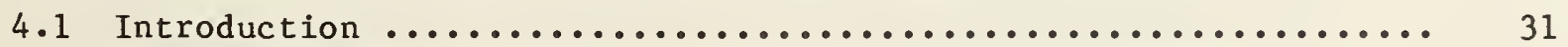

4.2 Summary of Events Preceding and Following the Collapse ....... 31

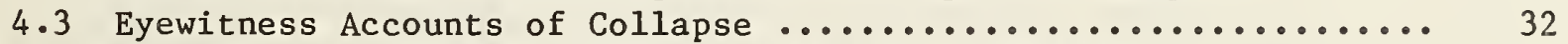

4.4 Estimate of Walkway Occupancy at Time of Collapse ........... 33

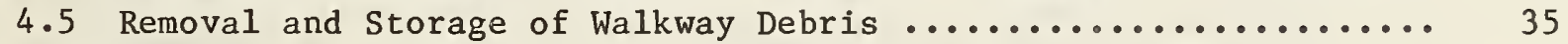

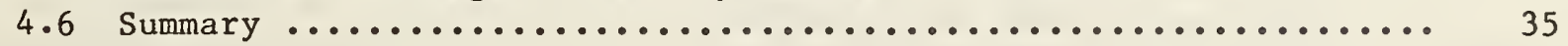

5. SITE INVESTIGATION ................................ 43

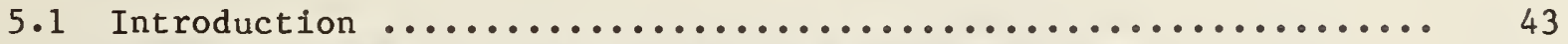

5.2 Survey of the Hyat Regency Atrium ................... 43

5.2.1 Embedded Plates and Bearing Seats ................ 44

5.2 .2 Fourth Flcor to Ceiling Hanger Rods ................ 44

5.2 .3 Impact Points on Atrium Floor .................... 45 
5.2 .4 Alignment of Walkways Prior to Collapse ............ 45

5.2 .5 Other Observations Relevant to the Investigation ...... 46

5.3 Observations of Walkway Debris $\ldots \ldots \ldots \ldots \ldots \ldots \ldots \ldots \ldots \ldots \ldots . \ldots \ldots$

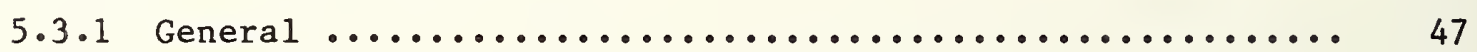

5.3 .2 Hanger Rod Pull-through ..................... 47

5.3 .3 Box Beam Longitudinal Welds .................... 48

5.3 .4 Box Beam to Clip Angle Fillet Welds ................ 49

5.3 .5 Other Observations Relevant to the Investigation ....... 50

5.3 .6 Determination of Span Weights ................... 51

5.4 Removal of specimens $\ldots \ldots \ldots \ldots \ldots \ldots \ldots \ldots \ldots \ldots \ldots \ldots \ldots \ldots \ldots \ldots \ldots$

5.4 .1 Criteria for specimen selection $\ldots \ldots \ldots \ldots \ldots \ldots \ldots \ldots \ldots \ldots \ldots$

5.4 .2 Specimen Removal ............................ 52

5.4 .3 Specimen Cataloging and Preparation for Shipment ...... 53

5.4 .4 Specimen Storage and Handling ...................... 54

5.5 Replication of Walkway Weld Fracture Surfaces ............. 54

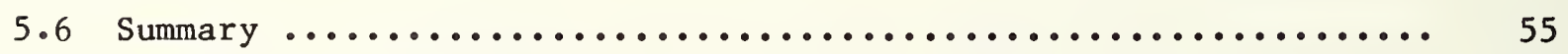

6. NBS STRUCTURAL TESTING PROGRAM ........................... 95

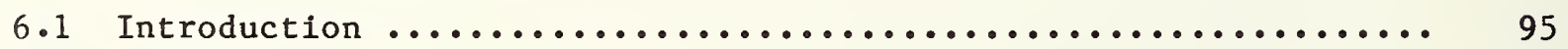

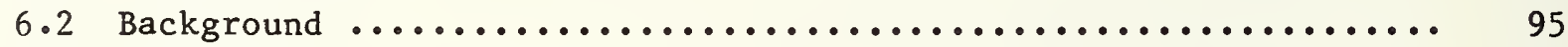

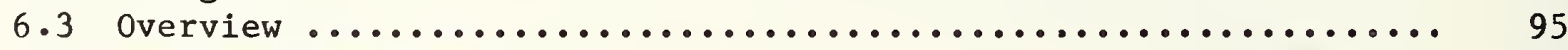

6.4 Test Specimen Description ........................... 96

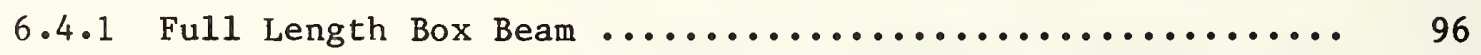

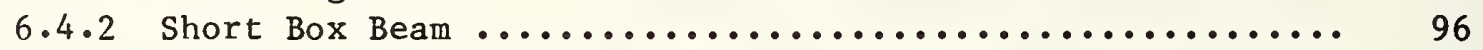

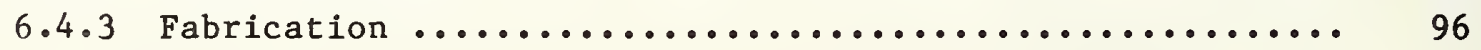

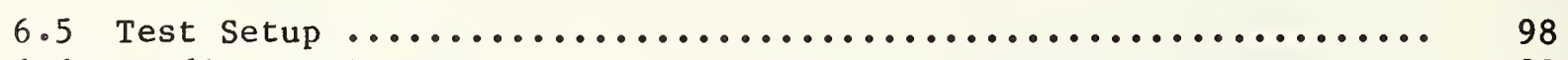

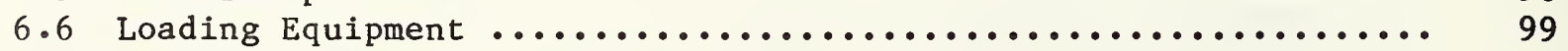

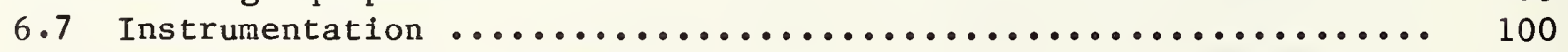

6.8 Data Acquisition and Reduction $\ldots \ldots \ldots \ldots \ldots \ldots \ldots \ldots \ldots \ldots \ldots \ldots \ldots \ldots$

6.9 Loading Sequence $\ldots \ldots \ldots \ldots \ldots \ldots \ldots \ldots \ldots \ldots \ldots \ldots \ldots \ldots \ldots \ldots \ldots \ldots \ldots \ldots 1$

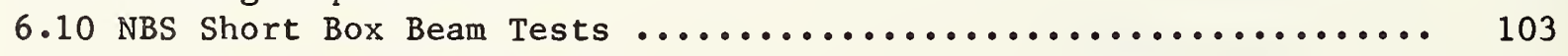

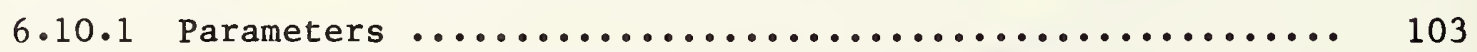

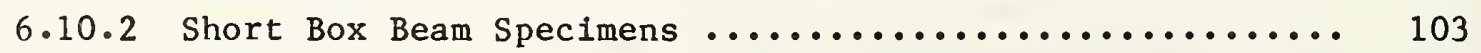

6.10 .3 Welding Process ............................ 105

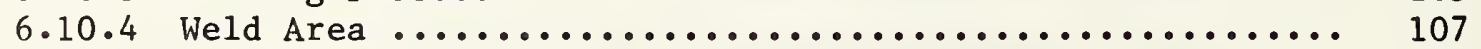

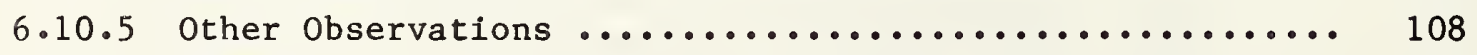

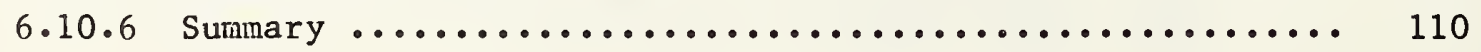




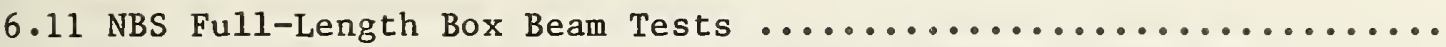

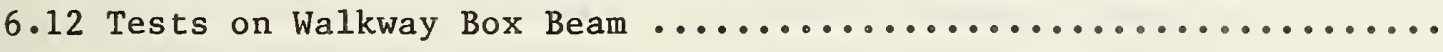

6.12 .1 Ful1-Length Box Beam Test ......................

6.12 .2 Short Box Beam Tests ........................ 112

6.13 Box Beam-Hanger Rod Connection Capacity ................ 114

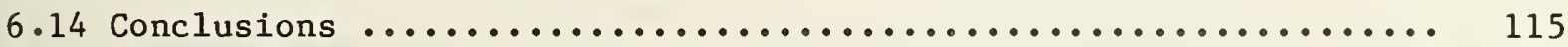

7. NBS MATERIALS EVALUATION PROGRAM ........................ 155

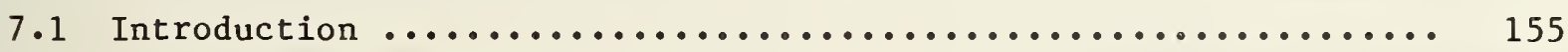

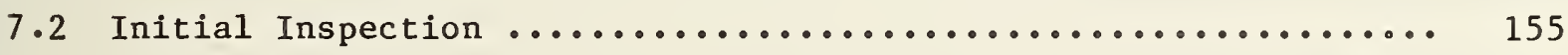

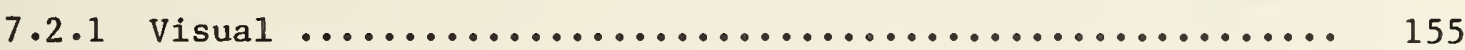

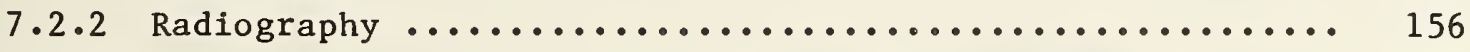

7.3 Mechanical Properties of Structural Steel and Weldments ...... 156

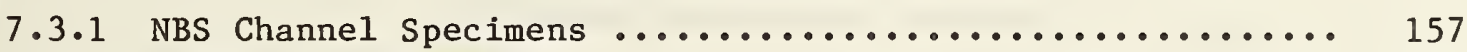

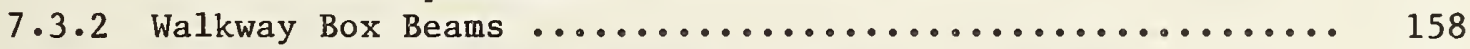

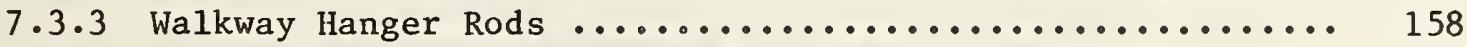

7.3 .4 Walkway Box Beam Longitudinal Welds ............... 159

7.4 Metallography and Hardness Measurements ................ 159

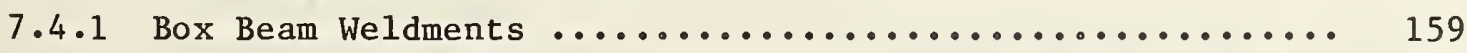

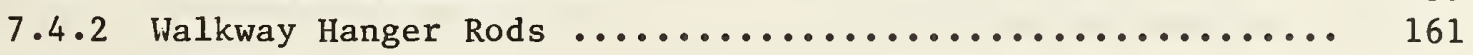

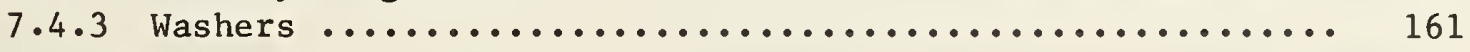

7.5 Chemical Analysis ............................. 162

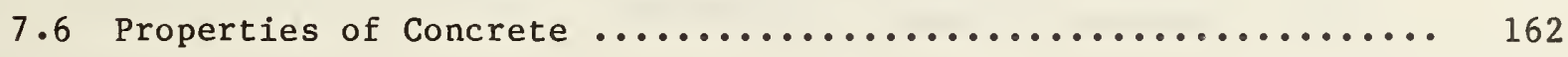

7.7 Conclusions .................................. 163

8. FRACTOGRAPHIC ANALYSIS .............................. 193

8.1 Introduction $\ldots \ldots \ldots \ldots \ldots \ldots \ldots \ldots \ldots \ldots \ldots \ldots \ldots \ldots \ldots \ldots \ldots \ldots$

8.2 Specimen Preparation and NBS Fracture Results ............. 193

8.3 Walkway Fracture Replicas .......................... 194 
TABLE OF CONTENTS (Continued)

$\underline{\text { Page }}$

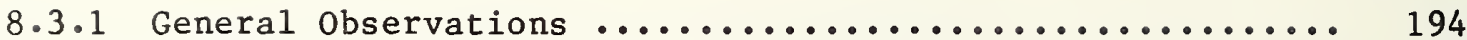

8.3.2 Box Beam Longitudinal Welds ...................... 194

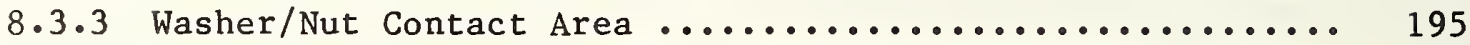

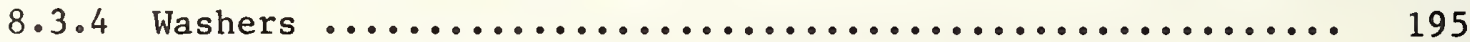

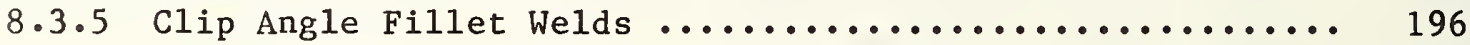

8.4 Direct Analysis of Walkway Box Beam Fractures .............. 196

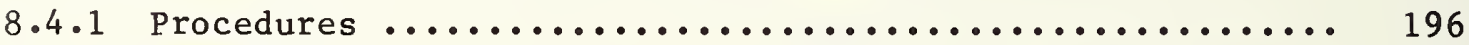

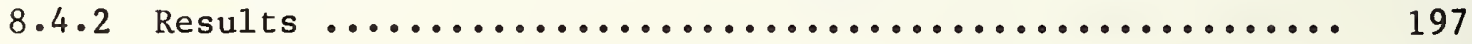

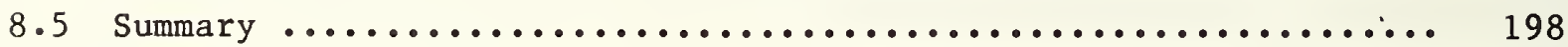

9. STRUCTURAL ANALYSIS ................................... 219

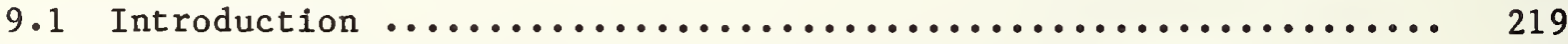

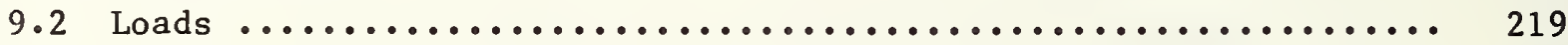

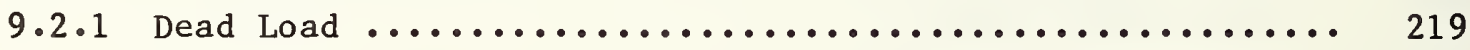

9.2 .2 Live Loads ............................... 221

9.3 Analysis of Walkway Structural Components ............... 222

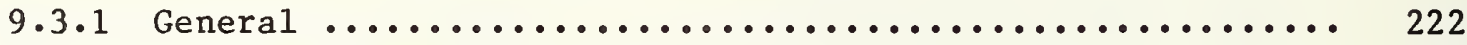

9.3 .2 Box Beam-Hanger Rod Connections .................. 222

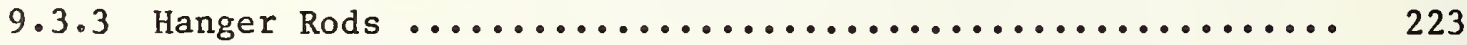

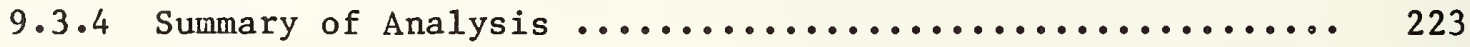

9.4 Forces Acting on the Hanger Rods at Time of Collapse ......... 224

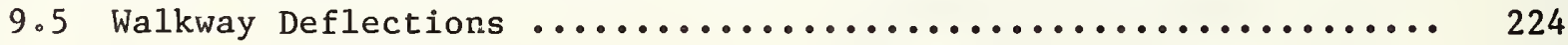

9.6 Effects of Dynamic Excitation ........................ 225

9.6 .1 Dynamic Characteristics of the Walkways ............. 225

9.6 .2 Sources of Dynamic Excitation ................... 226

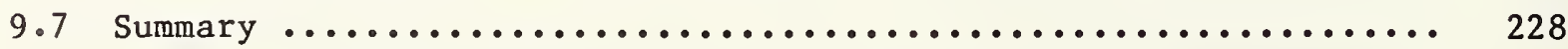

10. INTERPRETATION OF TESTS, ANALYSES AND OBSERVATIONS ............ 239

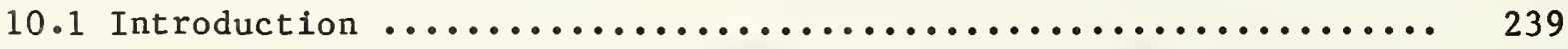

10.2 Comparison of Loads and Box Beam-Hanger Rod Connection

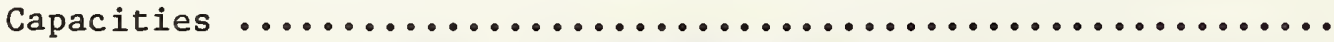

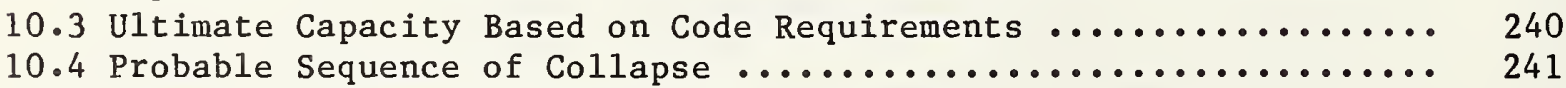

10.5 Effect of Change in Hanger Rod Arrangenent ............... 241 
10.6 Quality of Materials and Workmanship .................. 242

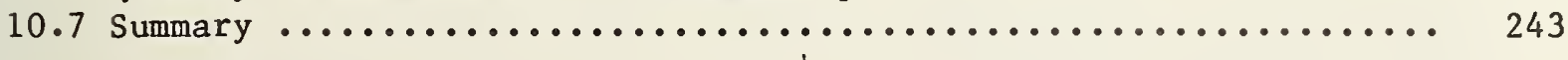

11. SUMMARY AND CONCLUSIONS ................................ 249

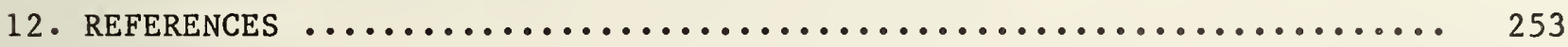

APPENDIX $\ldots \ldots \ldots \ldots \ldots \ldots \ldots \ldots \ldots \ldots \ldots \ldots \ldots \ldots \ldots \ldots \ldots \ldots \ldots \ldots \ldots \ldots \ldots \ldots \ldots \ldots$

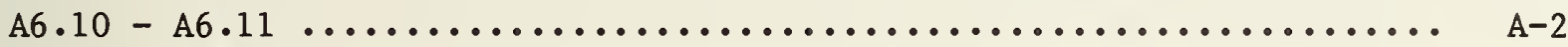

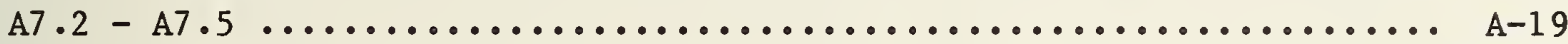

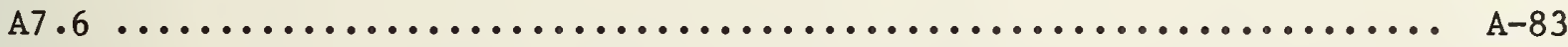

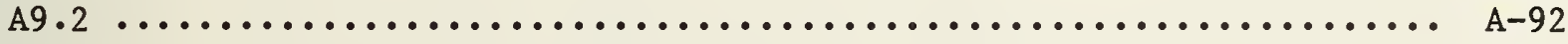




\section{INTRODUCT ION}

\subsection{BACKGROUND}

On July 17, 1981, at approximately 7:05 p.m., two suspended walkways within the atrium area of the Hyatt Regency Hotel in Kansas City, Mo., collapsed, killing 111 people and injuring 188. Two of the injured subsequently died. In terms of loss of life and injuries, this was the most devastating structural collapse ever to take place in the United States.

At the time of the collapse, the hotel had been in service for approximately 1 year. The Hyatt Regency consists of three main sections; a 40-story tower section, a function block, and a connecting atrium area. The atrium is a large open area approximately $117 \mathrm{ft}(36 \mathrm{~m})$ by $145 \mathrm{ft}(44 \mathrm{~m})$ in plan and $50 \mathrm{ft}(15 \mathrm{~m})$ high. Three suspended walkways spanned the atrium at the second, third, and fourth floor levels. These walkways connected the tower section and the function block. The third floor walkway was independently suspended from the atrium roof trusses while the second floor walkway was suspended from the fourth floor walkway, which in turn was suspended from the roof framing.

In the collapse, the second and fourth floor walkways fell to the atrium first floor, with the fourth floor walkway coming to rest on top of the second. Most of those killed or injured were either on the atrium first floor level or on the second floor walkway.

On July 20, 1981, Senator Thomas F. Eagleton's office contacted the National Bureau of Standards (NBS) and requested that technical assistance be provided to the city of Kansas City. This was followed later that day by a request to NBS from Mayor Richard L. Berkley for technical advice regarding the tragedy and its cause. Accordingly, two NBS structural research engineers arrived in Kansas City on July 21 and met with the Mayor and other city officials. On July 22, Mayor Berkley formally requested that the NBS independently ascertain the most probable cause of the collapse of the Hyatt Regency walkways. On July 24 in a letter to Mayor Berkley, Senators Eagleton and Danforth and Congressman Bolling endorsed the Mayor's request for NBS to conduct an impartial investigation.

\subsection{OBJECTIVE AND SCOPE OF THE INVESTIGATION}

The objective of this investigation was to determine the most probable cause of the collapse. As part of this investigation, it was necessary to reconstruct the events that preceded the collapse and the condition of the walkways at the time of the collapse. To carry out its study, the NBS investigative team used data obtained from on-site inspections; drawings, specifications and other records maintained by the city of Kansas City; documents and other information from parties involved in the construction and operation of the Hyatt Regency Hotel; information from those who participated in the rescue operation and from eyewitnesses; and photographs, videotapes, and other records available from the media. NBS also conducted inspections and took measurements in the atrium area and on the debris from the collapse. NBS conducted extensive laboratory studies on materials and mockups representative of materials and assemblies used in 
the walkway construction. Extensive laboratory studies were also conducted on specimens obtained from the walkway debris. NBS acquired these specimens under the terms of several court orders. These studies were in turn supported by analytical studies aimed at predicting the structural performance of the walkways.

\subsection{ORGANIZATION OF THE REPORT}

This report is organized in 12 chapters:

Chapter 2 describes the various documents reviewed during the course of this investigation and the procedures followed by the NBS investigative team in gaining access to them. Documents described include project specifications, relevant codes and standards, contract and shop drawings, daily logs and inspection reports.

Chapter 3 describes the general layout of the Hyatt Regency atrium, the structural and architectural details of the walkways, their probable sequence of erection, and the system established to designate walkway components.

Chapter 4 summarizes events preceding and following the collapse and eyewitness accounts of the collapse. This chapter also discusses the walkway occupancy prior to the collapse and presents what is believed to be a credible estimate of walkway occupancy at the time of collapse. The chapter closes with a description of the removal and storage of walkway debris.

Chapter 5 addresses the site investigation which included detailed observations of the walkway debris and a survey of that part of the atrium occupied by the walkways. The damage observed is related to probable mode of failure. Also described are the procedures followed in weighing selected walkway spans, removing specimens from the debris, and obtaining replicas of the weld fracture surfaces.

Chapter 6 describes the NBS structural testing program which involved the testing of box beams fabricated at the NBS and a box beam removed from the walkway debris. Test specimens, instrumentation, loading systems and loading sequence are described. Various parameters studied and their effects on box beam-hanger rod connection capacity are discussed in detail. The chapter concludes with an assessment of the capacities of the box beam-hanger rod connections in the fourth floor walkway.

Chapter 7 describes the NBS materials testing program and the results of tests carried out on materials used to fabricate NBS test specimens and on materials removed from the walkway debris. Included in this chapter are results of a radiographic analysis of longitudinal welds on a walkway box beam, mechanical properties of structural steel and weldments, metallographic examinations, hardness measurements, chemical analyses of structural steel and weld material, and mechanical properties of concrete used in the walkway decks.

Chapter 8 addresses the fractographic analysis of weld fracture surfaces in selected NBS box beams and in the walkway box beams. Results obtained from 
direct optical and scanning electron microscopy using replicas and actual fracture surfaces are discussed. Also addressed are washer fractures and washer/nut contact areas.

Chapter 9 addresses structural analysis. Included are dead and live loads, forces acting on the hanger rods, walkway deflections, analysis of the walkway structural components and their compliance with codes and standards, and the significance of dynamic excitation.

Chapter 10 interprets the results of structural tests and analyses and discusses the probable sequence of the walkway collapse. Also discussed is the significance of replacing the continuous hanger rod arrangement as shown on the contract drawings with interrupted rods in the second and fourth floor walkway system. The chapter closes with an assessment of the quality of materials and workmanship.

Chapter 11 summarizes the findings of the investigation and presents conclusions reached by the NBS investigative team.

Chapter 12 lists the references cited in the text. 


\section{DOCUMENTS REVIEWED BY THE NBS INVESTIGATIVE TEAM}

\subsection{INTRODUCTION}

Section 2.2 of this chapter describes the procedure followed in obtaining access to documents.

Sections $2.3,2.4$ and 2.5 discuss documents prepared during the design stage, prior to actual construction of the walkways. Section 2.6 deals with daily logs and inspection reports filed during the construction phase, while section 2.7 in large part addresses documents relating to the collapse and the rescue operation. Section 2.8 provides a summary of the findings reported in this chapter.

\subsection{ACCESS TO DOCUMENTS}

This chapter describes the various documents reviewed and the procedures followed in gaining access to them. In arranging for access to documents, the Bureau submitted its requests to the Office of the Mayor which in turn contacted the appropriate firms and agencies, requesting their cooperation and assistance. Access by NBS to the requested documents was therefore voluntary. Firms contacted by the office of the Mayor and their roles in the design, construction, and operation of the Hyatt Regency Hotel were as follows:

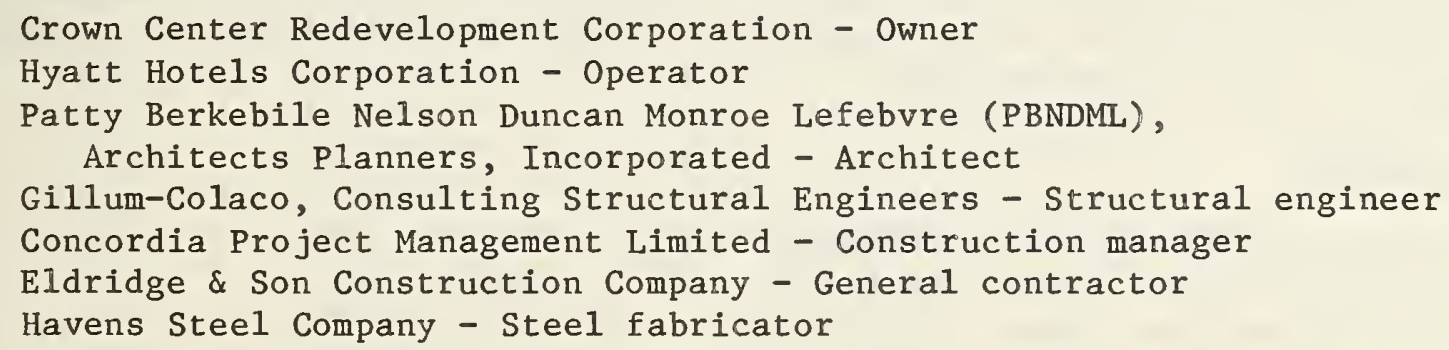

\subsection{PROJECT SPECIFICATIONS AND RELEVANT CODE PROVISIONS}

Shortly after the collapse, the Kansas City Public Works Department assembled documents in its possession related to the design, construction, and inspection of the Hyatt Regency Hotel. The Office of the City Attorney made these documents available for public review beginning July $21,1981$.

Included in these documents was a set of project specifications for the Hyatt Regency Hotel. They had been prepared by Patty Berkebile Nelson Duncan Monroe Lefebvre Architects Planners, Inc. (PBNDML), the project architects, and were dated August 28, 1978 [2.1]. Section 0510 of the project specifications covers structural steel and, among other things, refers to applicable standards, quality assurance, fabrication, erection, and field quality control. Codes and standards referenced in the project specifications include, but are not limited to, the following: 
- AISC* "Code of Standard Practice for Steel Buildings and Bridges" (No date)

- AISC "Specification for the Design, Fabrication and Erection of Structural Steel for Buildings" (No date)

- AWS**D1.1 "Structura1 Welding Code" (No date).

Also included in the documents provided by the Office of the City Attorney was a copy of the Kansas City Building Code [2.2] in effect at the time the Hyatt Regency project specifications and design drawings were reviewed by the Public Works Department. This issue of the Kansas City Building Code is, with minor exceptions, an adoption of the Uniform Building Code, 1976 Edition [2.3] . The AISC Specification for the Design, Fabrication and Erection of Structural Steel for Buildings [2.4] forms the basis for the steel design provisions of the Uniform Building Code and the Kansas City Building Code. Certain provisions of the Kansas City Building Code and the codes referenced in the project specifications are referred to later in this report.

\subsection{ARCHITECTURAL AND STRUCTURAL DRAWINGS}

In addition to the project specifications just described, the office of the City Attorney also made available sets of architectural and structural drawings. The drawings listed below were "issued for revision" or "issued for construction "during the period August 1-28, 1978, and were referred to during the course of this investigation.

\section{Architectural}

A302 Floor Plan, Leve1 106 North

A303 Floor Plan, Leve1 121 North

A304 Floor Plan, Level 136 North

A305 Floor Plan, Level 151 North

A412 Building Section

A508 Details, Expansion Joints, Bridge

\section{Structural}

S302

S303

S304

S305

S306

S405.1

S601
Framing Plan, Level 106 North Framing Plan, Leve1 121 North Framing Plan, Level 136 North Framing Plan, Level 151 North Framing Plan, Level 166 North Stee1 Details General Notes
Date prepared

March 30, 1978

March 30, 1978

March 30, 1978

March 30, 1978

March 30, 1978

May 12, 1978

March 10, 1978

\footnotetext{
* American Institute of Steel Construction

** American Welding Society
} 
Simplified versions of the framing plans at levels 106 to 166 and a sectional elevation of the atrium were developed by NBS as part of this investigation and are included in sections 3.2 and 3.3 of this report. The General Notes

(Dwg. S601) set out the design criteria, including a design live load of 100 psf $(4.8 \mathrm{kPa}$ ) for hotel corridors and lobby areas. These are interpreted by NBS to include the walkways in the atrium.

\subsection{SHOP DRAWINGS}

Shop drawings detailing the walkway structural system were made available to the NBS investigative team by the Crown Center Redevelopment Corporation, the hotel's owner. Initially, review of the drawings was by appointment at the Crown Center corporate offices with visits for such purpose occurring on August 7 and 10, 1981. Arrangements were subsequently made for NBS to take custody of the drawings until issuance of its report. The following shop drawings, prepared by the steel fabricator, Havens Steel Company, dated between January 7, 1979, and February 9, 1979, and reviewed, as indicated by their stamps on the drawings, by the contractor, structural engineer and architect, were received from the Crown Center Redevelopment Corporation on September 2, 1981:

Shop Drawing Number

Subject

E3

E4

E5

30

31

23

E2

E1

8

12

$8 \mathrm{~A}$

$12 \mathrm{~A}$

Framing plan at Elev. 121'-0" and elevation at column lines 8,9 , and 10

Framing plan at Elev. $136^{\prime}-0^{\prime \prime}$

Framing plan at Elev. $151^{\prime}-0^{\prime \prime}$ and expansion bearing detail

Box beams, cross beams, and hanger rods

Stringers, slide bearing plates, and bearing seats

Beams at Elev. 167'-1" and hanger rod brackets

Framing plan at Elev. $167^{\prime}-1^{\prime \prime}$

Truss elevation

Truss T3

Truss T3

Truss T3 member layout

Truss parts (T3)

The first five of the above listed drawings were referred to extensively during the course of this investigation. Field observations and measurements show that, in general, the structural details, member sizes, and dimensions of the as-built structure faithfully reflected that which was called for on the drawings. No attempt was made to check or confirm the details of the structural work above the upper hanger rod brackets at Elev. $165^{\prime}-7^{\prime \prime}$, this being deemed to be beyond the scope of the investigation.

* The contract and shop drawings used during the construction of the Hyatt Regency Hotel use this notation to designate the various floors within the atrium. For convenience this same system is adopted for use in this report. The second floor walkway was level 121 , the third floor walkway was level 136 , and the fourth floor walkway was level 151 . 


\subsection{DAILY LOGS AND INSPECTION REPORTS}

Portions of the daily logs maintained by the architect during construction of the Hyatt Regency Hotel were made accessible to NBS and were reviewed at the offices of Duncan Associates, Inc.* on two occasions--September 4 and 25, 1981. These portions contained limited reference to construction of the walkways. In a number of logs, reference is made to construction work in the atrium along column lines 7 and 11 and at levels 136 and 151. However, there is very little specific information on the walkways. Those logs that did refer to the walkways can be summarized as follows:

非312 September 14, 1979

Notes that Havens Steel Company completed rewelding of composite deck studs at the walkways.

非320 September 26,1979

Mentions placement of concrete for bridges 151, 136, and 121 from column lines 7 to 11 .

非344 October 30,1979

Mentions report "... that fitters were refusing to work on the 151 bridge because of a comment made by the inspection team now looking at the atrium connections."

\#372 December 7, 1979

Notes problem on 151 bridge where piping and granite hangers were in conflict.

On September 4, 1981, a visit was made to the offices of the owner's inspection agency, General Testing Laboratories, Inc., where an inspection report was reviewed which mentioned the inspection of bolted connections on August 17 and 20, 1979. The report noted that the hanging walkways were inaccessible due to metal decking or "difficulty of position" and that the connections were not checked by calibrated torque wrench. Representatives of General Testing Laboratories indicated that unless the specific dates of walkway construction were known, it would be very difficult for them to retrieve reports of interest to the NBS team.

Also on September 4, 1981, copies of inspection reports related to construction in the atrium area were reviewed in the offices of Blackwell, Sanders, Matheny, Weary, and Lombardi, legal counsel to Concordia Project Management Ltd. These reports, filed by General Testing Laboratories, did not provide any additional information on the walkways. In response to an earlier request, NBS investi-

* A member firm of PBNDML. 
gators were shown a handwritten note indicating the following schedule for walkway construction:
August 8-15, 1979
September 7-12, 1979
September 10-14, 1979
Erect bridges.
Pour bridge concrete on fourth level.
Pour bridge concrete on third level.
January $31-\mathrm{Feb} .7,1980$
Pour bridge concrete on second level.

It appears that only the erection of structural steel sometime before August 17, 1979, is consistent with dates mentioned in the various daily logs and inspection reports reviewed by the NBS team. Given the limited quantity of concrete in the walkway decks, the single-day placement indicated in the architect's daily logs seems more credible.

\title{
2.7 OTHER DOCUMENTS AND MATER IALS REV IEWED
}

In addition to the specifications, drawings, logs and reports described above, the NBS investigative team also reviewed several hundred photographs taken immediately after the collapse, during the rescue operation and on the day following the collapse. The following agencies and establishments allowed members of the NBS team to inspect and, in some cases, retain copies of their photographs:

\author{
Kansas City Fire Department \\ Kansas City Police Department \\ Crown Center Redevelopment Corporation \\ The Kansas City Star \\ The Kansas City Times.
}

Videotapes from various news services were also reviewed. of particular importance was a videotape obtained from KMBC TV, Kansas City, Mo., which contained footage taken immediately before and after the collapse. Analysis of information contained on this tape is described in chapter 4.

The NBS team also reviewed photographs and documents related to an investigation conducted by the U.S. Occupational Safety and Health Administration (OSHA) following a fatal construction accident at the Hyatt Regency Hotel in October 1979. As the OSHA investigation was not concerned with or related to the walkway construction, only limited portions of the walkways could be identified in the photographs.

With regard to construction materials, the firm of Miller and Glynn, legal counsel for Havens Steel Company, allowed the NBS team to review mill reports related to the walkway hanger rods and the MC8 88.5 shapes used to fabricate the walkway box beams. Information was also provided on welding procedures and electrodes believed by the steel fabricator to have been used in fabricating structural components of the walkways.

of particular interest to the NBS investigative team were the original structural design calculations and any change orders involving the walkway structural system. However, efforts by the Office of the Mayor to obtain 
these documents were not successful. With regard to review and modification of the walkway design, the Office of the City Attorney provided copies of two documents that are relevant to this investigation. The first document, dated March 10 and March 16, 1978, contains six pages of handwritten notes addressing the issue of fire endurance of the walkway structural steel. It was prepared in the course of a routine design review by the Codes Administration office, Kansas City, Public Works Department. The second document, dated Apri1 4, 1978, is a two-page summary of a meeting between representatives of the Codes Administration office and the architects, PBNDML. These documents, which resulted in an agreement to encase the walkway structural steel with gypsum board, are referred to in section 9.2 of this report.

One other document of considerable value to this investigation is a report describing dynamic response measurements carried out on the third floor walkway just prior to its removal during the night of July 22-23, 1981 [2.5]. These measurements made it possible to validate the dynamic modeling of the walkways as described in section 9.6 of this report. Access to this material was arranged by the Crown Center Redevelopment Corporation.

\subsection{SUMMARY}

The following summarizes the results of efforts by NBS to obtain and review documents and other materials that are relevant to the design and construction of the Hyatt Regency walkways and that provide information on events immediately preceding and following the collapse:

1. Codes and specifications applicable to the design, fabrication and erection of the walkway structural system were referenced in the project specifications.

2. The AISC Specification for the Design, Fabrication and Erection of Structural Steel for Buildings forms the basis for the steel design provisions of the Kansas City Building Code.

3. Drawings obtained for review and reference included architectural and structural drawings and the fabricator's shop drawings.

4. The project design criteria specify a design live load of 100 psf ( $4.8 \mathrm{kPa}$ ) for hotel corridors and lobby areas. This is interpreted by NBS to include the walkways.

5. Efforts to obtain copies of the structural design calculations were unsuccessful.

6. Gypsum board encasement of the walkway structural steel was added during the design review stage to meet code requirements for fire endurance.

7. A videotape containing footage of activities in the atrium immediately before and after the walkway collapse was reviewed by the NBS investigative team.

8. Results of vibration testing of the third floor walkway were provided to NBS and were subsequently used to check analytical models of the walkway dynamic response. 
3. DESCR IPTION OF THE WALKWAY SYSTEM PRIOR TO COLLAPSE

\subsection{INTRODUCTION}

This chapter describes the structural features of the walkway system and the probable sequence of construction with emphasis on those structural aspects that are believed to be of significance to the investigation of the collapse. Extensive use is made of the contract and shop drawings referred to in chapter 2. In the remainder of this report all drawings other than shop drawings will be referred to collectively as "contract drawings." Only where a specific drawing is referred to will the terms "architectural" and "structural" be used.

Section 3.2 describes the Hyatt Regency atrium and location of the walkways. Also described are the areas served by the walkways and means of access from the atrium main floor, the tower section, and the hotel function block.

Section 3.3 describes the structural and architectural features of the walkways, again with major emphasis on those features that are believed to be of importance in identifying the most probable cause of collapse.

Section 3.4 discusses the probable sequence of construction. Where possible, this is related to documents referred to in chapter 2. However, very little of the construction sequence could actually be documented, and this section is by necessity based on what is considered to be a logical progression of construction. Section 3.5 describes a unified system used in this report for designating walkway components. Findings reported in this chapter are summarized in section 3.6 .

\subsection{GENERAL LAYOUT OF THE HYATT REGENCY ATR IUM}

The atrium is centrally located between the 40-story tower section to the north and the function block directly to the south (figure 3.1). Plan dimensions of the atrium are approximately $117 \mathrm{ft}(36 \mathrm{~m})$ north-south by $145 \mathrm{ft}$ (44 m) eastwest. Clear ceiling height is approximately $50 \mathrm{ft}(15 \mathrm{~m})$. The west portion of the atrium between column lines $F$ and $I$ and part of the tower section to the north of column line 11 are shown in plan view on figure 3.2. As can be seen from figure 3.2, the main entrance is located on column line $I$, between column lines 10 and 11. The registration and cashier desks are located to the east of column line F, directly under a second floor terrace which extends over the entire east side of the atrium. Direct access to the terrace and to the shops and restaurants on the second floor of the adjoining function block (level 121) is by stairway or escalator located in the southeast corner of the atrium. An adjacent escalator provides access to the ballroom area on the third floor of the function block (level 136). A focal point of the atrium was a sunken lounge area on the main floor between column lines 8 and 10 (shown cross-hatched in figure 3.2 ).

Spanning the atrium in the north-south direction were three walkways as shown in figure 3.3. NOTE THAT THIS FIGURE IS BASED UPON AN ARCHITECTURAL DRAWING (DWG. A412) ISSUED FOR CONSTRUCTION ON AUGUST 28, 1978, AND DOES NOT ACCURATELY 
REFLECT THE SECOND AND FOURTH FLOOR HANGER ROD DETAIL ACTUALLY USED IN THE CONSTRUCTION OF THE WALKWAYS. The hanger rod detail actually used will be explained in the discussion of figures 3.9-3.11.

In addition to providing a direct traffic way between the tower section and the function block, the walkways were a dominant feature of the atrium and afforded a view of the atrium and terrace. Of the three walkways, the second floor walkway was most easily accessible from the atrium floor--by stairway or elevator (between column lines $G$ and $H$ ) in the tower section and by stairway or escalator in the atrium. The third floor walkway, which served the ballroom area, evidently was intended to carry larger volumes of traffic since it was slightly wider than the other two walkways. The fourth floor walkway (level 151) served a health club and sports area in the upper portion of the function block and was accessible only by elevator or stairway in the tower section. of the three walkways, the fourth floor walkway quite likely carried the least traffic. A schematic view of the walkways from the north end of the atrium is shown in figure 3.4 .

\subsection{STRUCTURAL AND ARCHITECTURAL FEATURES OF THE WALKWAYS}

Structural framing plans for the three walkways are shown in figures 3.5 to 3.7 . Unless noted otherwise, all structural steel is ASTM* A36. Aside from the fact that the third floor walkway is $1^{\prime}-35 / 8^{\prime \prime}(0.397 \mathrm{~m})$ wider than the second and fourth floor walkways, structural details are identical. Each walkway consisted of four spans made up of W16 x 26 stringers placed 7'-6 3/8" (2.295 m) center to center (third floor $=8^{\prime}-10^{\prime \prime}(2.692 \mathrm{~m})$ ) with w8 $x 10$ cross beams on $7^{\prime}-33 / 4^{\prime \prime}$ $(2.229 \mathrm{~m})$ centers. Details of the stringers, including a $1 / 4 \times 6$ in ( $6 \mathrm{x}$ $152 \mathrm{~mm}$ ) bent plate used to form up the edge of the $31 / 4$ in (83 mm) 1 ightweight concrete deck are shown in figure 3.8. As shown in figure 3.9, the concrete deck was placed on a $20 \mathrm{ga}(1 \mathrm{~mm}$ ) formed steel deck with 6 in (152 mm) pitch and $11 / 2$ in $(38 \mathrm{~mm})$ rib height. The walkway spans apparently were designed to act as composite beams and were constructed without shores (i.e., it is assumed that the concrete deck does not participate in resisting forces and moments due to self-weight of the concrete and structural stee1). Shear studs are $3 / 4$ in $(19 \mathrm{~mm}$ ) diameter $\times 31 / 2$ in (89 mm) long. Reinforcement is W2.1 x W2.1 welded wire fabric with 6 in (152 mm) spacing each way.

The W16 x 26 stringers were bolted to clip angles welded to box beams located on column lines 8,9 and 10 . High strength $3 / 4$ in (19 mm) bolts (ASTM A325) were used to fasten the stringer to clip angle connections. Details of the box beams and box beam to stringer clip angles are shown in figure 3.10.

The box beams were fabricated from MC8 $\times 8.5$ shapes joined toe to toe by continuous longitudinal welds. The associated welding symbols included in figure 3.10 are as shown on the shop drawing (Havens Steel Company Dwg. 30). In the absence of a backing strip and with complete joint penetration indicated, this welding symbol is interpreted to mean a prequalified partial joint

* American Society for Testing and Materials. 
penetration groove weld as defined in section 2.10 of AWS D1.1-79, Structural Welding Code-Steel [3.1]. This welding symbol and its applicability to the box beam longitudinal welds are discussed further in chapters 5 and 10 of this report.

The walkway hangers were $11 / 4$ in $(32 \mathrm{~mm}$ ) diameter rods threaded top and bottom to receive a nut and washer. Layout of the holes for the box beam-hanger rod connections is shown in figure 3.10. Layout of the box beams and hanger rods for the three walkways is shown in figure 3.11. Note that two hanger rods with a 4 in $(102 \mathrm{~mm})$ offset at the fourth floor walkway were substituted for the single continuous hanger rod arrangement shown in figure 3.3 and detailed on contract drawings $\mathrm{A} 508$ and $\mathrm{S405.1.} \mathrm{The} \mathrm{significance} \mathrm{of} \mathrm{this} \mathrm{change} \mathrm{is} \mathrm{discussed}$ in chapter 10 of this report. The second and fourth floor walkways were suspended from the $18 \times 40$ beams shown on the atrium ceiling framing plan in figure 3.12 while the third floor walkway was suspended from the bottom chord of truss $\mathrm{Tl}$, also shown in figure 3.12. A detail of the hanger rod to beam connection at Elev. 165' $-7^{\prime \prime}$ is shown in figure 3.11. A similar detail was used to connect the third floor walkway hanger rods to truss $\mathrm{Tl}$.

The south end (column line 7) of each walkway was supported by field welding the clip angles to $1 / 2$ in $(13 \mathrm{~mm})$ plates embedded in the perimeter floor beams of the function block. The north end (column line 11) was supported by expansion bearings as detailed in figure 3.13 .

The walkway handrail assembly consisted of $40 \times 571 / 2$ in ( $1.016 \times 1.460 \mathrm{~m}$ ) panels of $1 / 2$ in $(13 \mathrm{~mm})$ tempered plate glass set in extruded aluminum grips supported by $4 \times 3 \times 5 / 16$ angles running along each edge of the concrete deck as indicated in figure 3.9. Adjustment of the supporting angle was achieved by shim packs field welded to the concrete deck edging plate described previously. An extruded brass section capped the top edge of the plate glass panels and a continuous wood handhold completed the handrail assembly.

Documents on file with the Kansas City Public Works Department indicate that to satisfy requirements for fire endurance as specified in the Kansas City Building Code, the sides and bottom of each walkway were encased with two layers of $5 / 8$ in $(16 \mathrm{~mm})$ gypsum board, supported by $22 \mathrm{ga}(0.8 \mathrm{~mm})$ metal studs and nailing strips attached to the structural steel by power driven fasteners. A simplified detail of the structural system, handrail, and gypsum board encasement is shown in figure 3.14. Not shown is a lighting strip along the base of the handrail assembly and a system of $20 \mathrm{ga}$ ( $1 \mathrm{~mm}$ ) aluminum slats suspended from the bottom face of the walkways. The $11 / 4$ in (32 mm) diameter hanger rods were also encased with insulating material, resulting in an overall diameter of $31 / 2$ in $(89 \mathrm{~mm})$. A sprinkler system was suspended from the w8 $\mathrm{x} 10$ cross beams of each walkway.

\subsection{PROBABLE SEQUENCE OF ERECTION}

Although a number of documents relating to construction of the walkways were reviewed during the course of this investigation, the actual construction sequence could not be clearly established. With regard to the second and fourth floor walkways, it is likely that all structural steel was erected and bolted prior to placement of metal decking. The next step would likely have been the 
arc spot welding (puddle welding) of the formed steel deck and placement of shear studs on the $68 \times 10$ cross beams, followed by placement of concrete by pumping. The daily construction log described in section 2.6 indicates that placenent of concrete on all three walkways was carried out on September 26, 1979.

Since the concrete deck was unshored during construction and the w16 $\mathrm{x} 26$ stringers were supplied without camber, the fraction of dead load due to the structural steel, formed steel deck, and the concrete produced midspan deflections of the order of $1 / 2$ in $(13 \mathrm{~mm})$. To correct for this, a sand/cement topping course was added later. This is discussed further in chapter 5 . The above procedure meets the provisions contained in the general notes of Dwg. S601.

Upon completion of the deck, the next logical step in the construction sequence would have been the installation of the handrail system. The midspan deflections described in the previous paragraph are apparent when the vertical alignment of the handrail supporting angle is compared relative to the top flange of the W16 × 26 stringers. All increments of dead load added during this and subsequent phases of construction were resisted by composite action of the stringer/deck system. Completion of the walkways involved the installation of the nailing strips and gypsum board, sprinkler system, aluminum slats, footlights, and walkway carpeting with underlying pad.

\subsection{DESIGNATION OF WALKWAY COMPONENTS}

Various components of the three walkways will be referred to rather extensively in the remainder of this report. So that these components can be clearly and concisely identified in the text, a unified system for designating walkway components will be adopted. In this system column lines 7 through 11 will be used to designate walkway components located on or between those lines while the letters U, M, and L (for upper, middle, and lower) will be used to designate the fourth, third, and second floor walkways, respectively. The letters $E$ and $\mathrm{W}$ will be used to differentiate between the east and west sides of the walkways. For example, the designation "span U8-9" refers to the second span from the south end of the fourth floor walkway while "clip angle 10LW" refers to a clip angle on the west end of the box beam in the second floor walkway at column line 10. Where it is clear that a particular level is intended, the $U, M$, or $\mathrm{L}$ designations are not included as, for example, in discussing the fourth floor to ceiling hanger rod at location $8 \mathrm{E}$ (column line 8 , east side). This unified system applied to the fourth floor walkway is illustrated in figure 3.15 .

\subsection{SUMMARY}

The following summarizes information available to the NBS investigative team regarding the layout of the Hyatt Regency atrium, location of the walkways and their accessibility, structural and architectural features of the walkways, and the probable sequence of their erection.

1. As its name implies, the atrium is central to hotel activities. The walkways were the dominant feature of the atrium. 
2. Of the three walkways, the second floor walkway was most easily accessible from the atrium main floor. The third floor walkway served the hotel ballroom and, because of its greater width, was evidently intended to carry larger volumes of traffic than the second or fourth floor walkways. The fourth floor walkway was the least accessible and is likely to have carried less traffic than the other two walkways.

3. The walkway spans were apparently designed to act as composite beams and were constructed without shores (i.e., it is assumed that the concrete deck does not participate in resisting forces and moments due to self-weight of the concrete and structural steel).

4. In preparing the shop drawings, two hanger rods with a 4 in (102 $\mathrm{mm}$ ) offset at the fourth floor walkway were substituted for the single continuous hanger rod arrangement detailed on the contract drawings. 


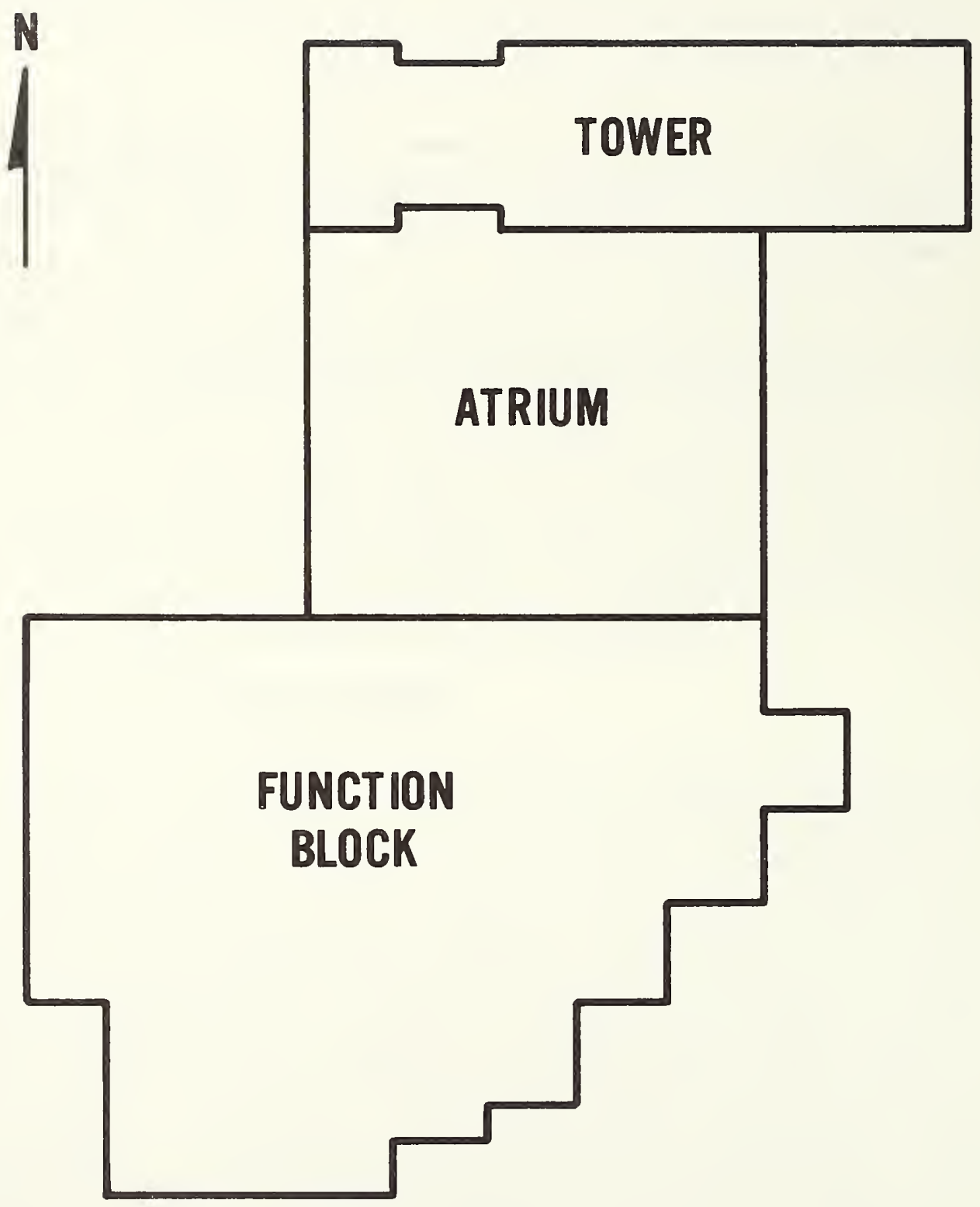

Figure 3.1 Plan showing outline of tower section, atrium, and function block. 


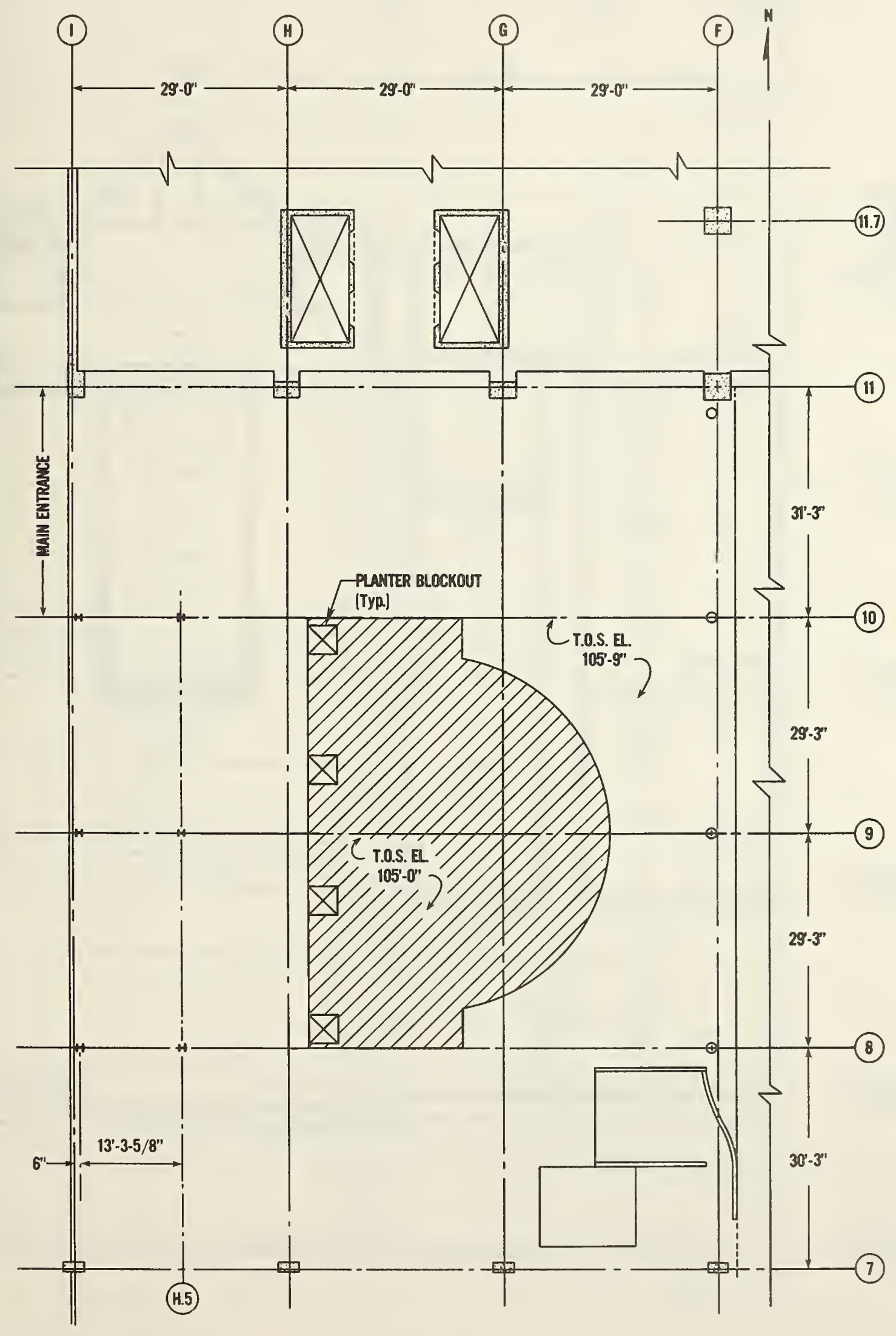

Figure 3.2 Plan view of atrium main floor (first floor) at level 106. 


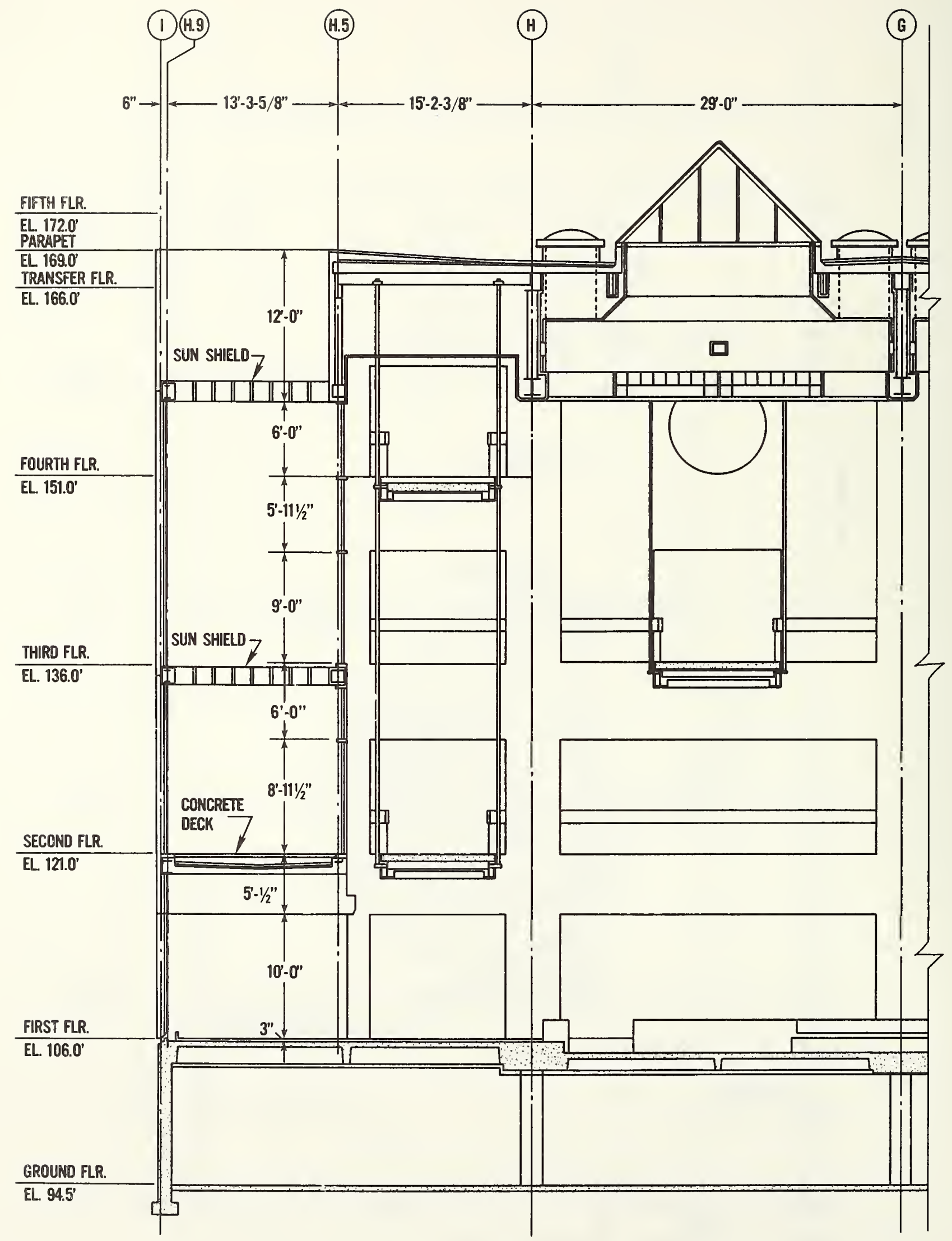

Figure 3.3 Elevation of atrium between column lines 8 and 9, looking north. 


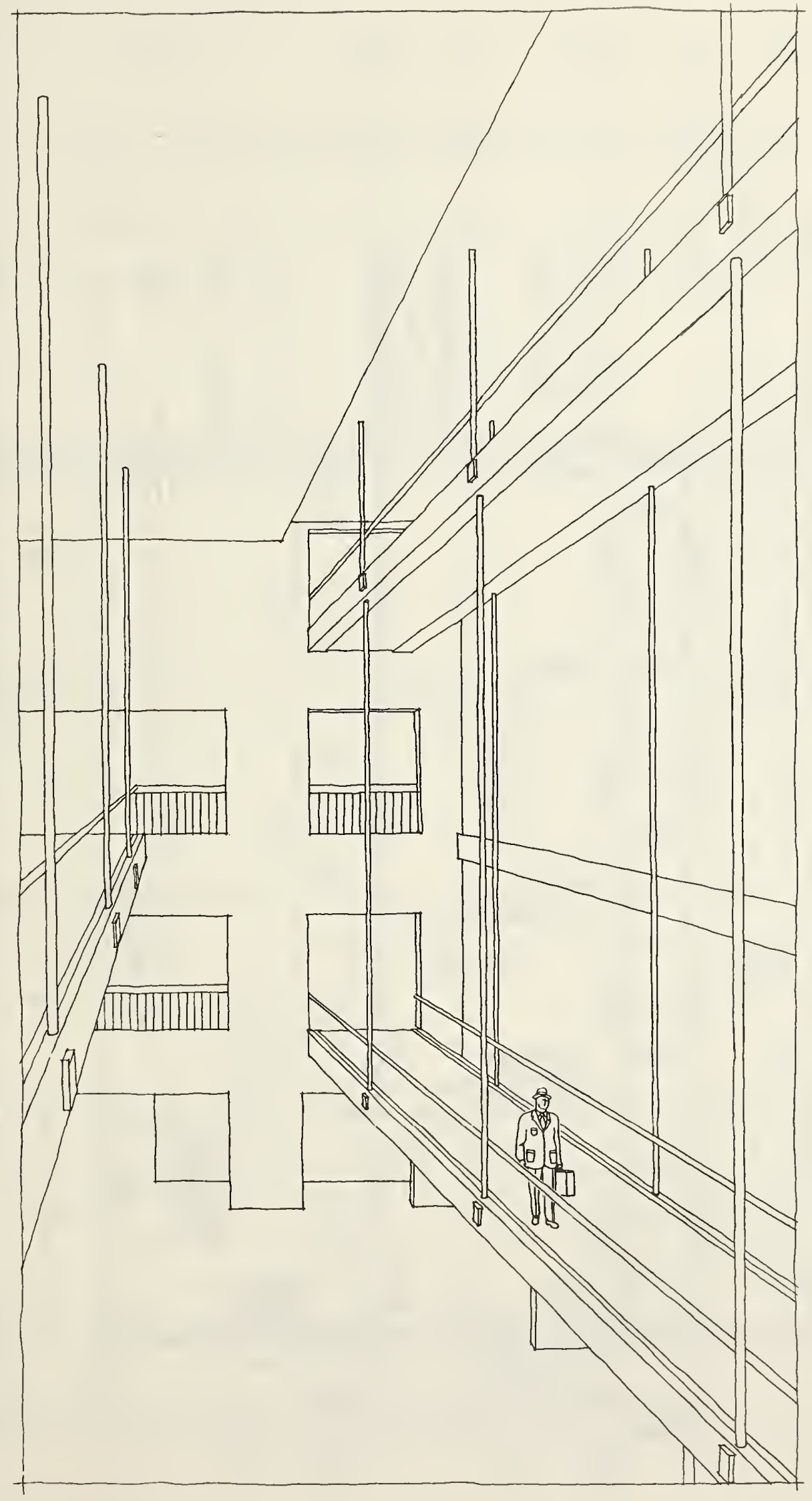

Figure 3.4 Schematic of walkways as viewed from north wall of atrium. 


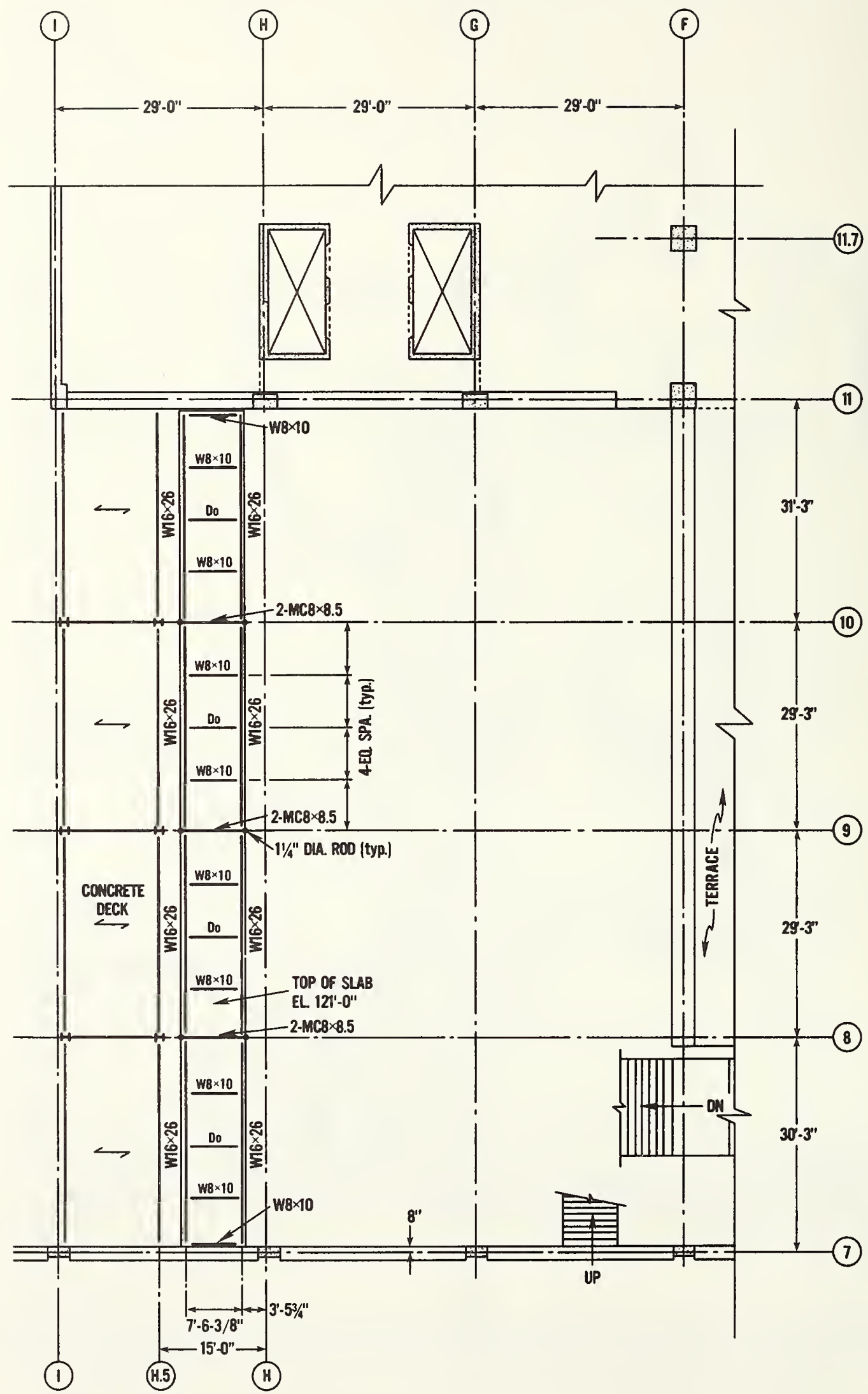

Figure 3.5 Second floor walkway framing plan - level 121. 
(1)

(1)

(a)

(F)

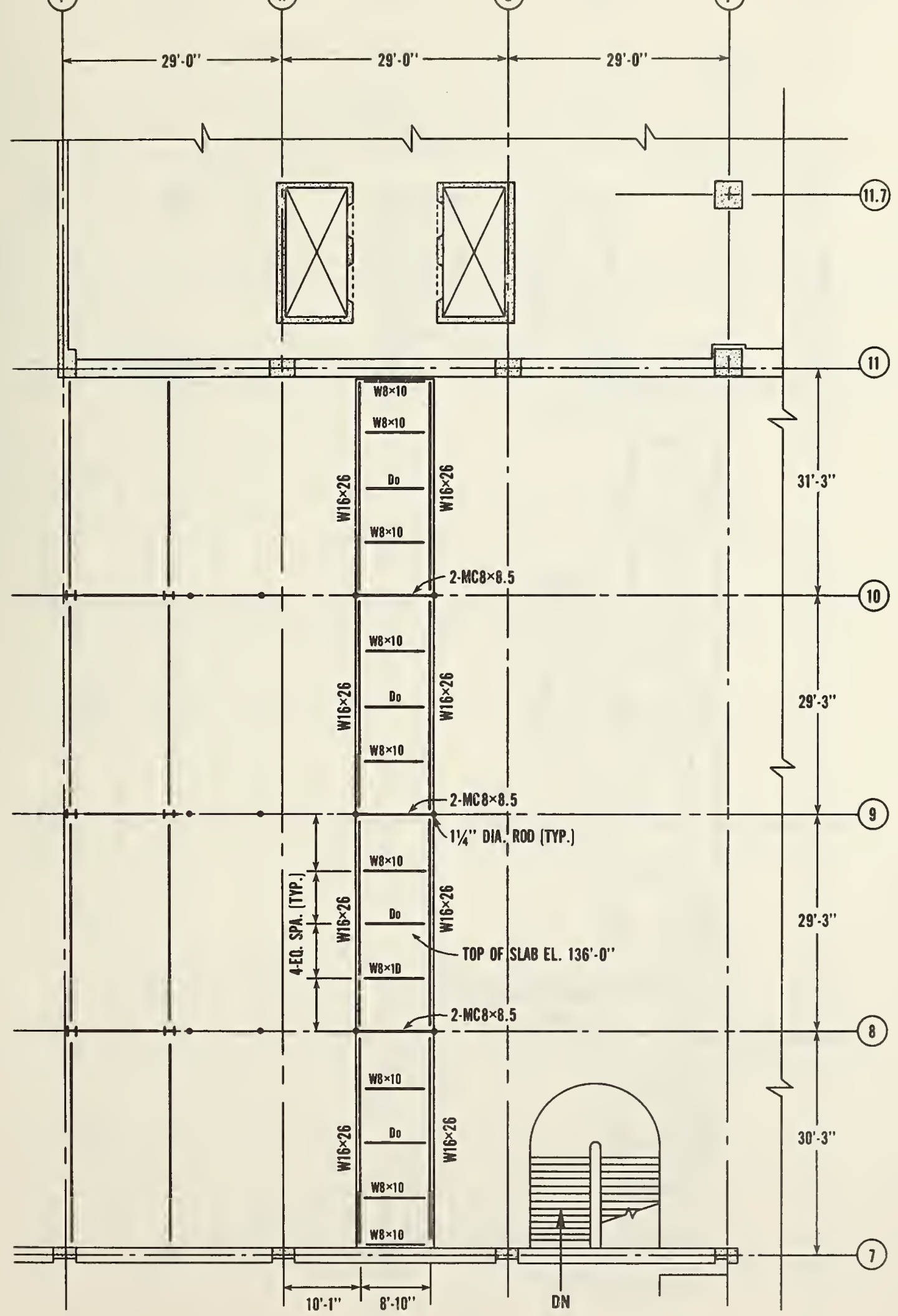

Figure 3.6 Third floor walkway framing plan - level 136. 


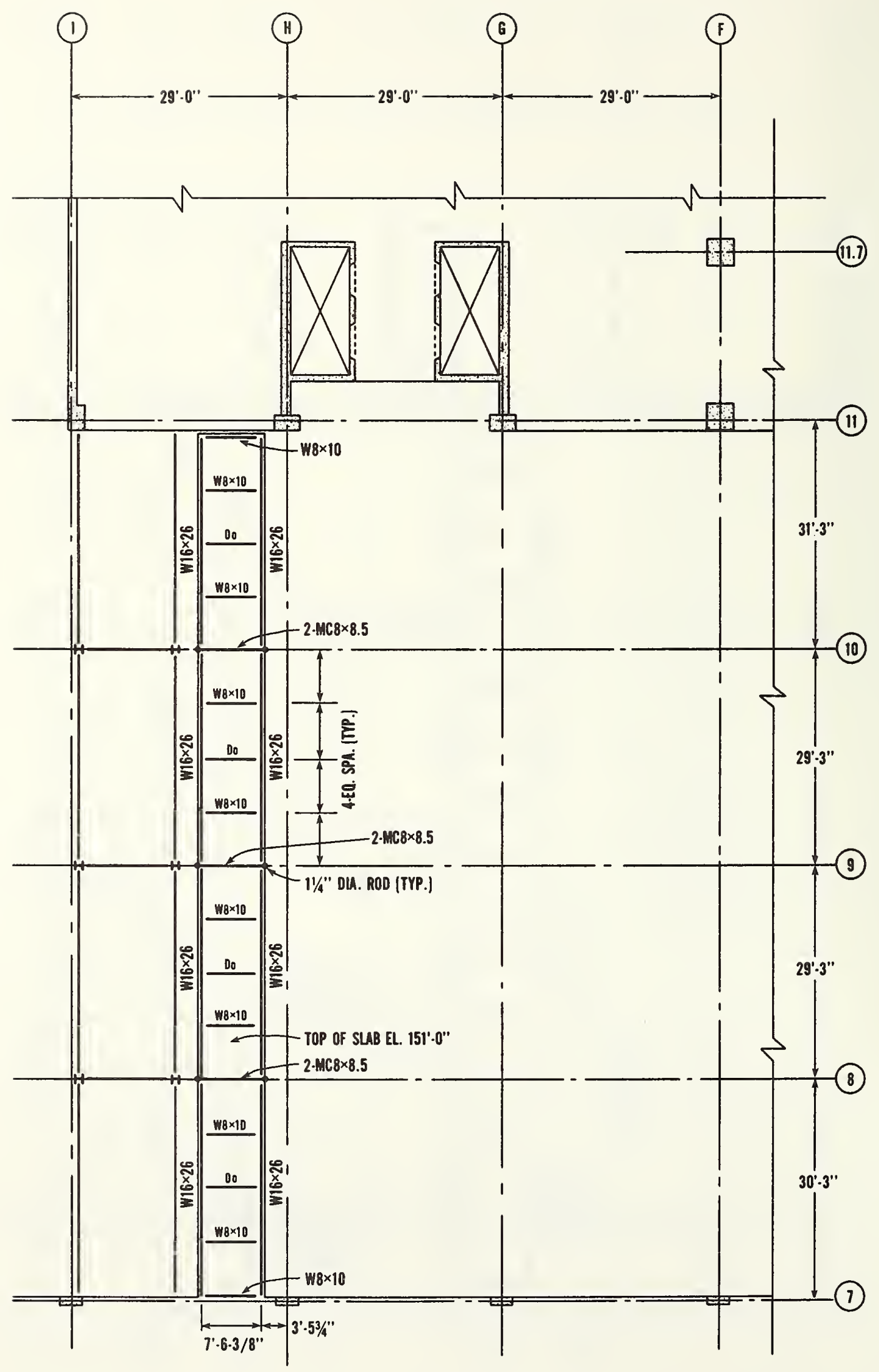

Figure 3.7 Fourth floor walkway framing plan - level 151. 

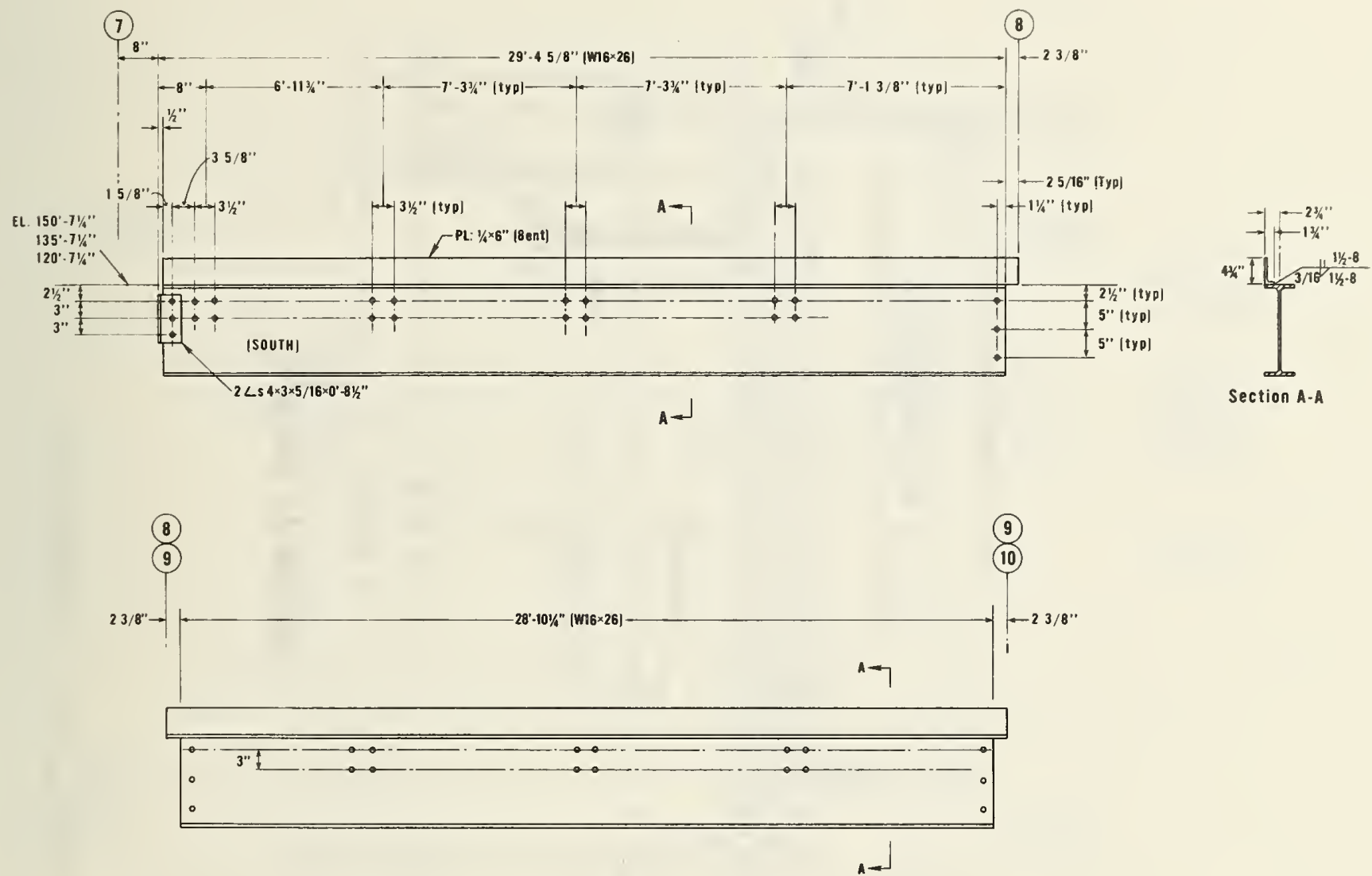

(10)

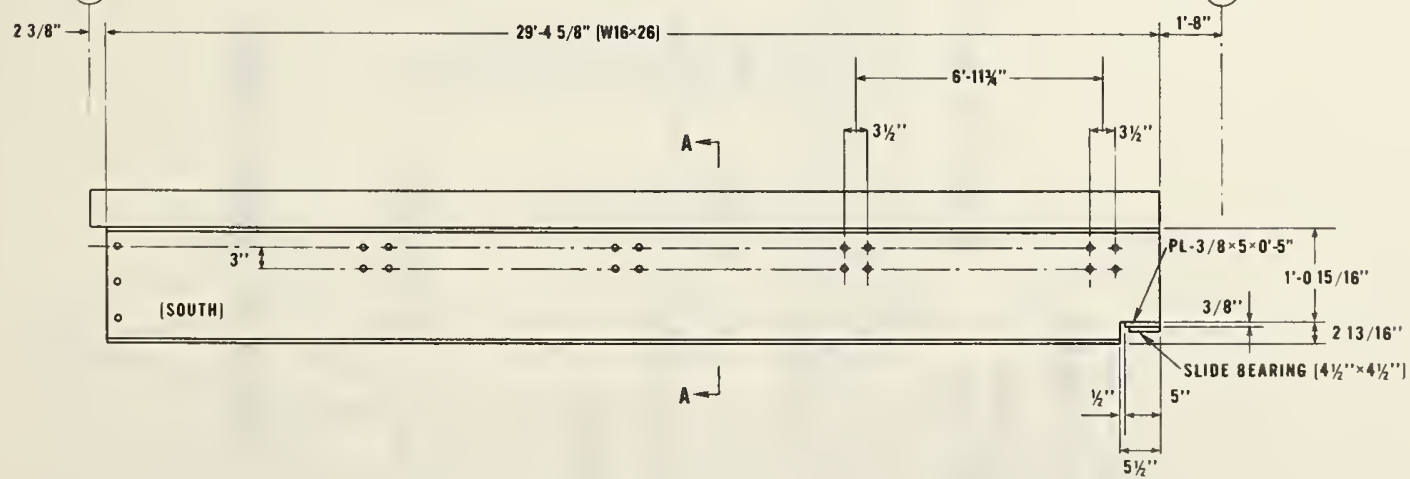

Figure 3.8 Details of walkway stringers. 


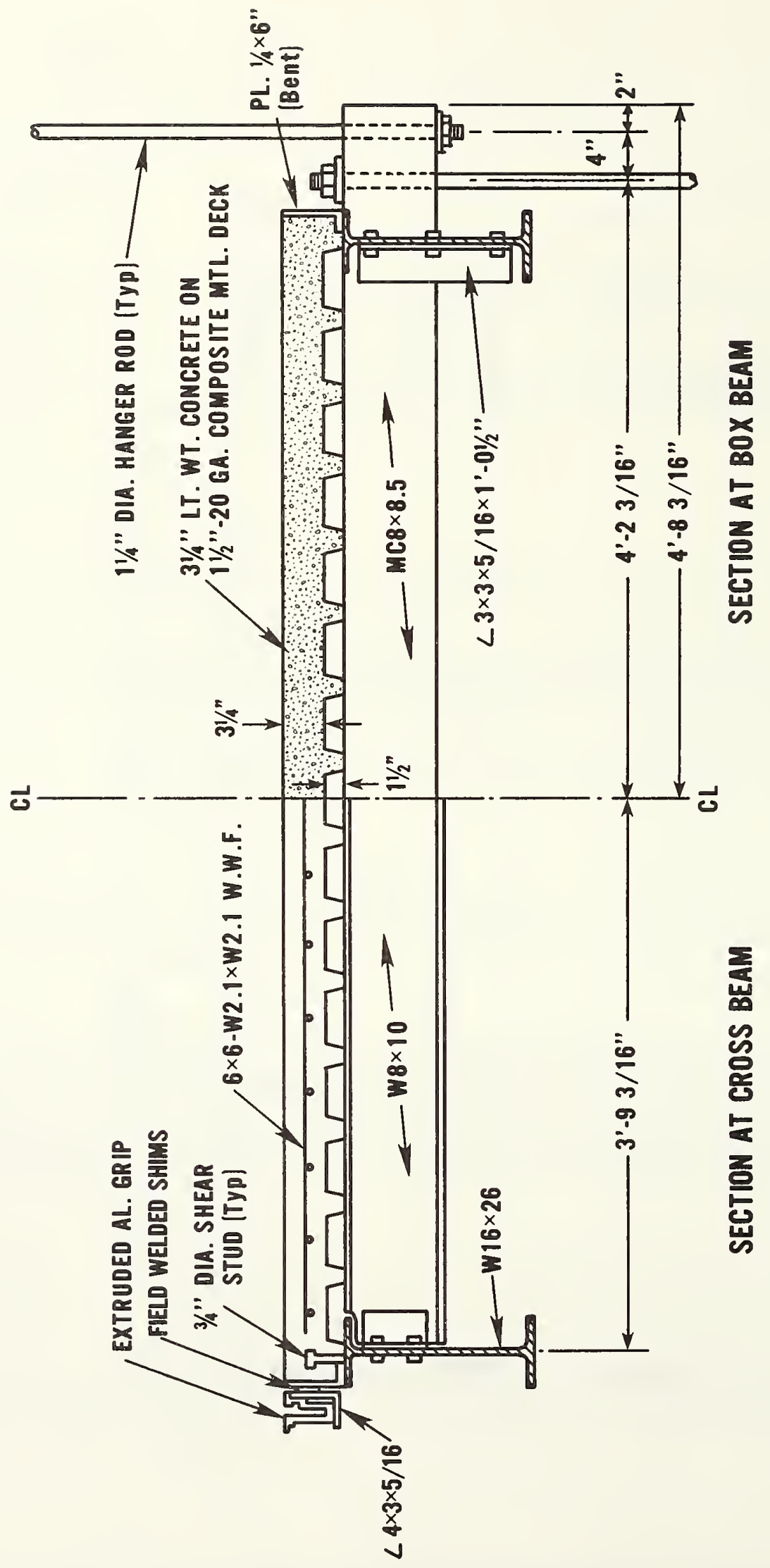

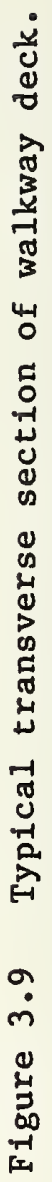



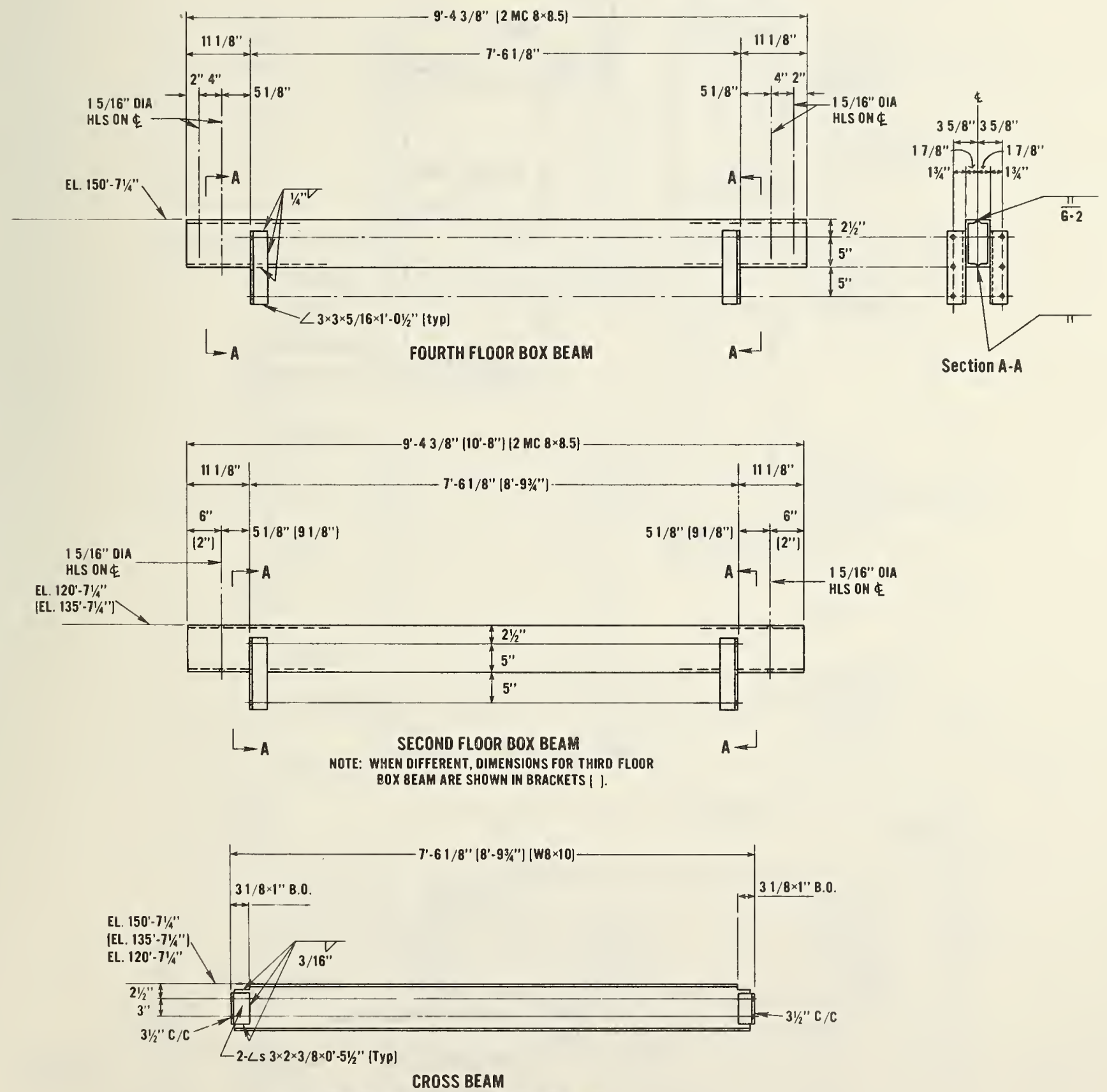

NOTE: WHEN DIFFERENT, OIMENSIONS FOR THIRO FLOOR CROSS BEAM ARE SHOWN IN BRACKETS ( ).

Figure 3.10 Details of walkway box beams and cross beams. 

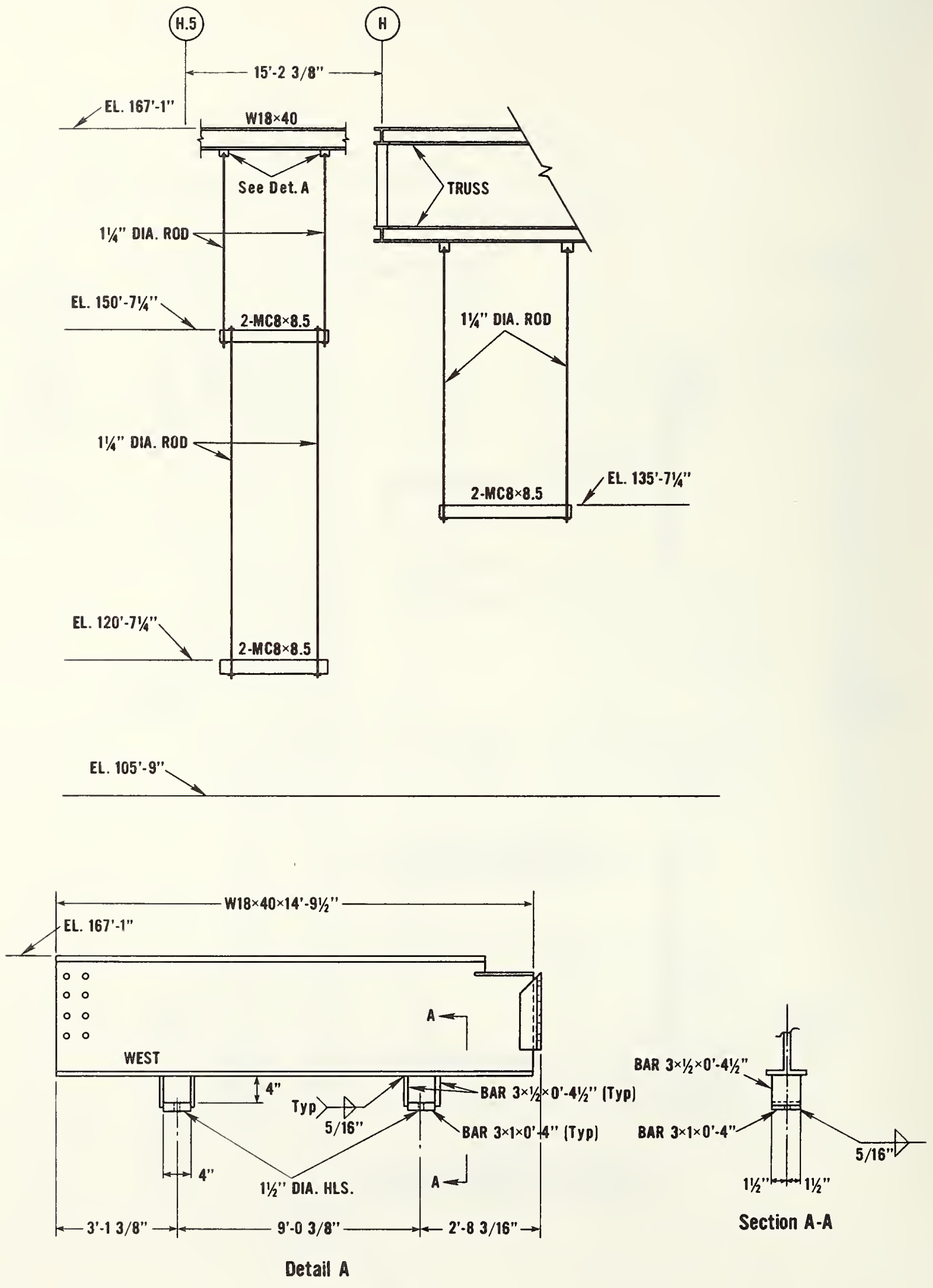

Figure 3.11 Elevation of typical box beam-hanger rod assembly. 


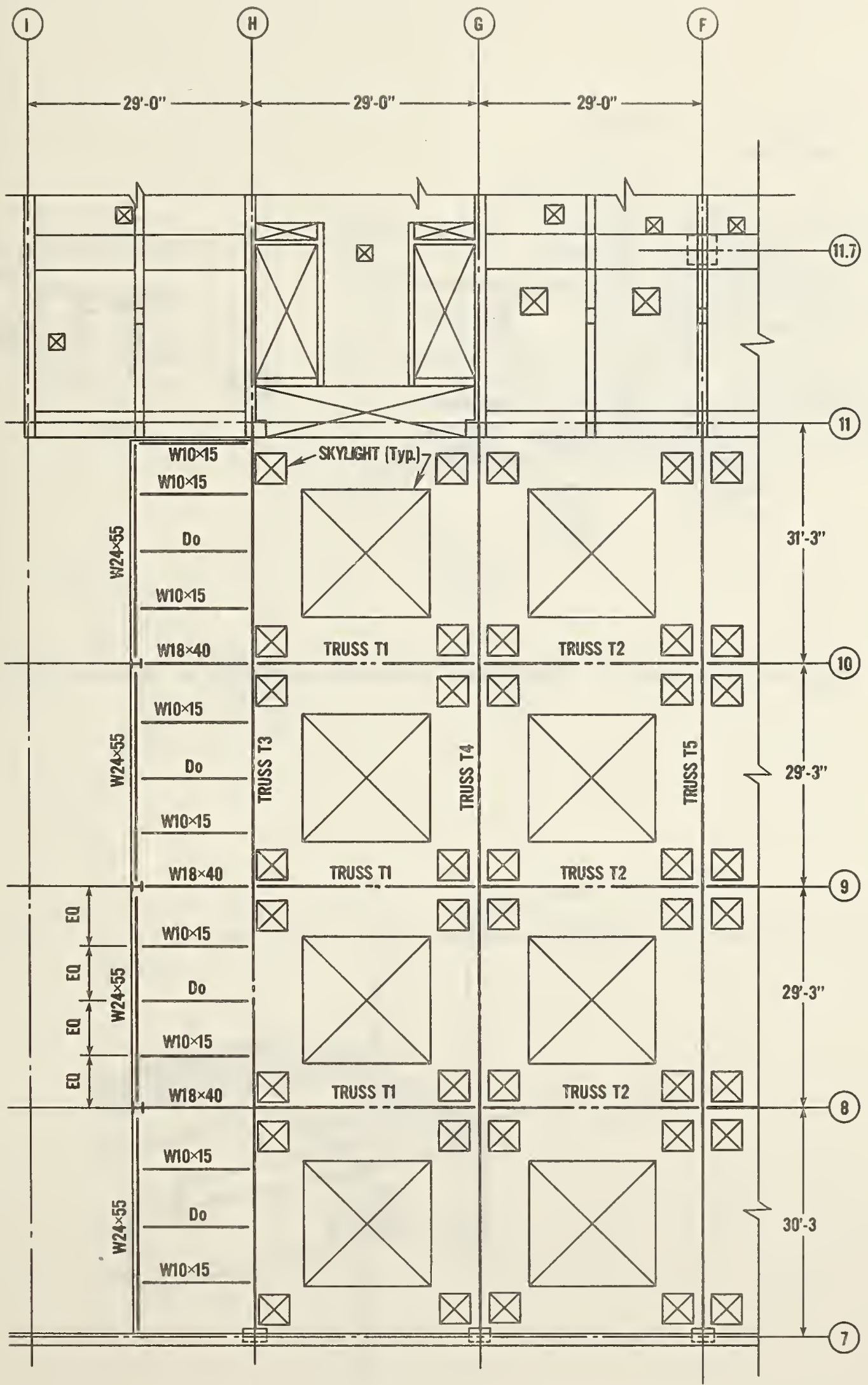

Figure 3.12 Framing plan for atrium roof. 

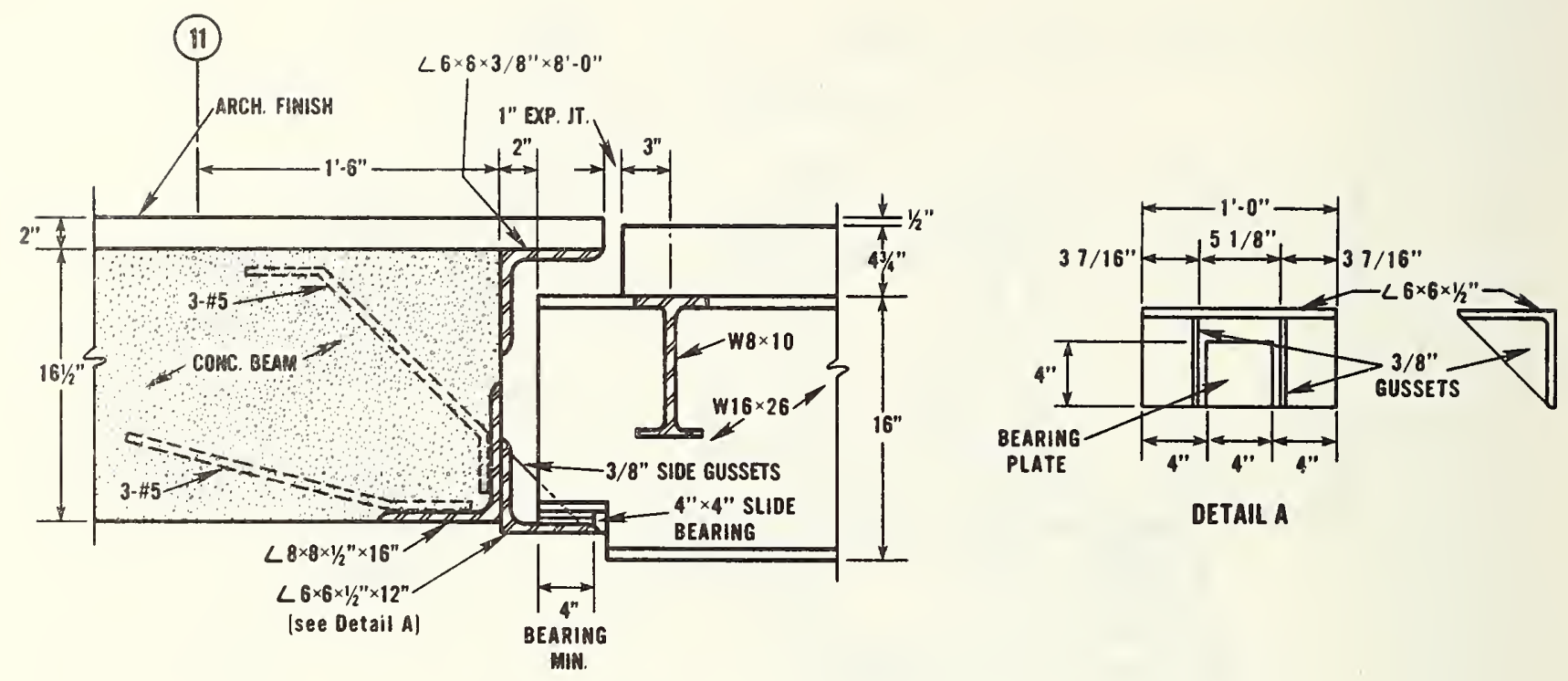

Figure 3.13 Detail of walkway expansion bearing at column line 11 .

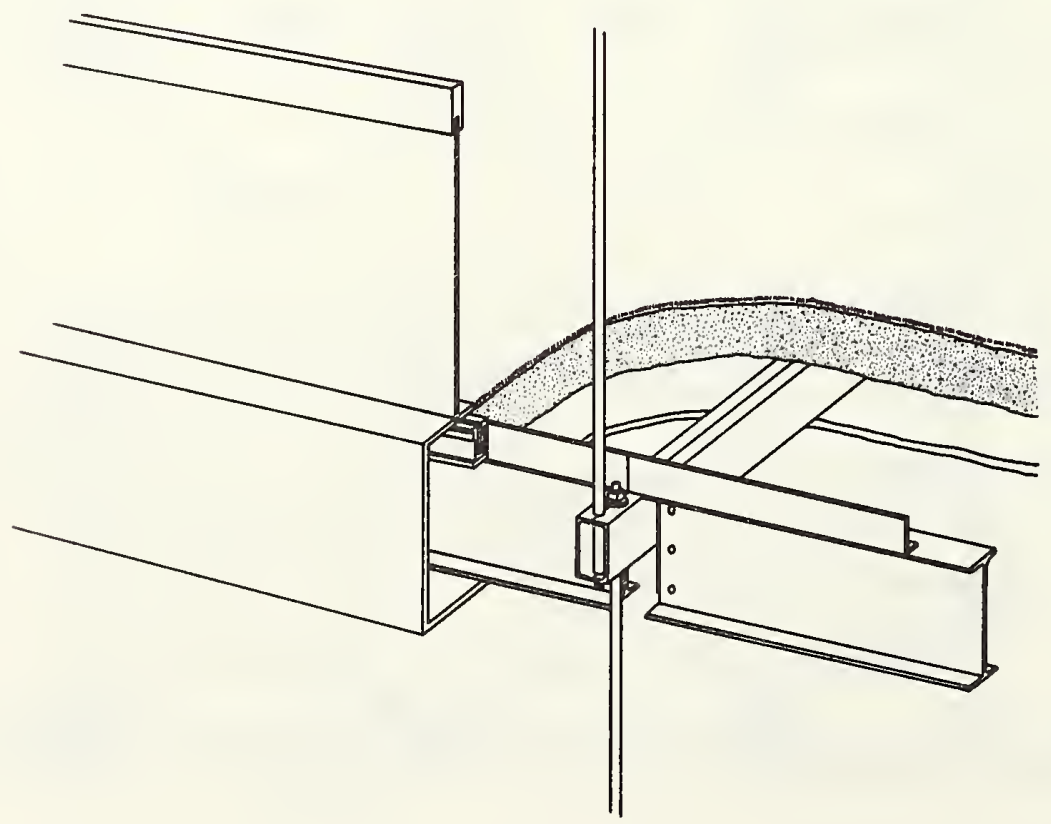

Figure 3.14 Simplified detail of walkway structural system and architectural treatment. 


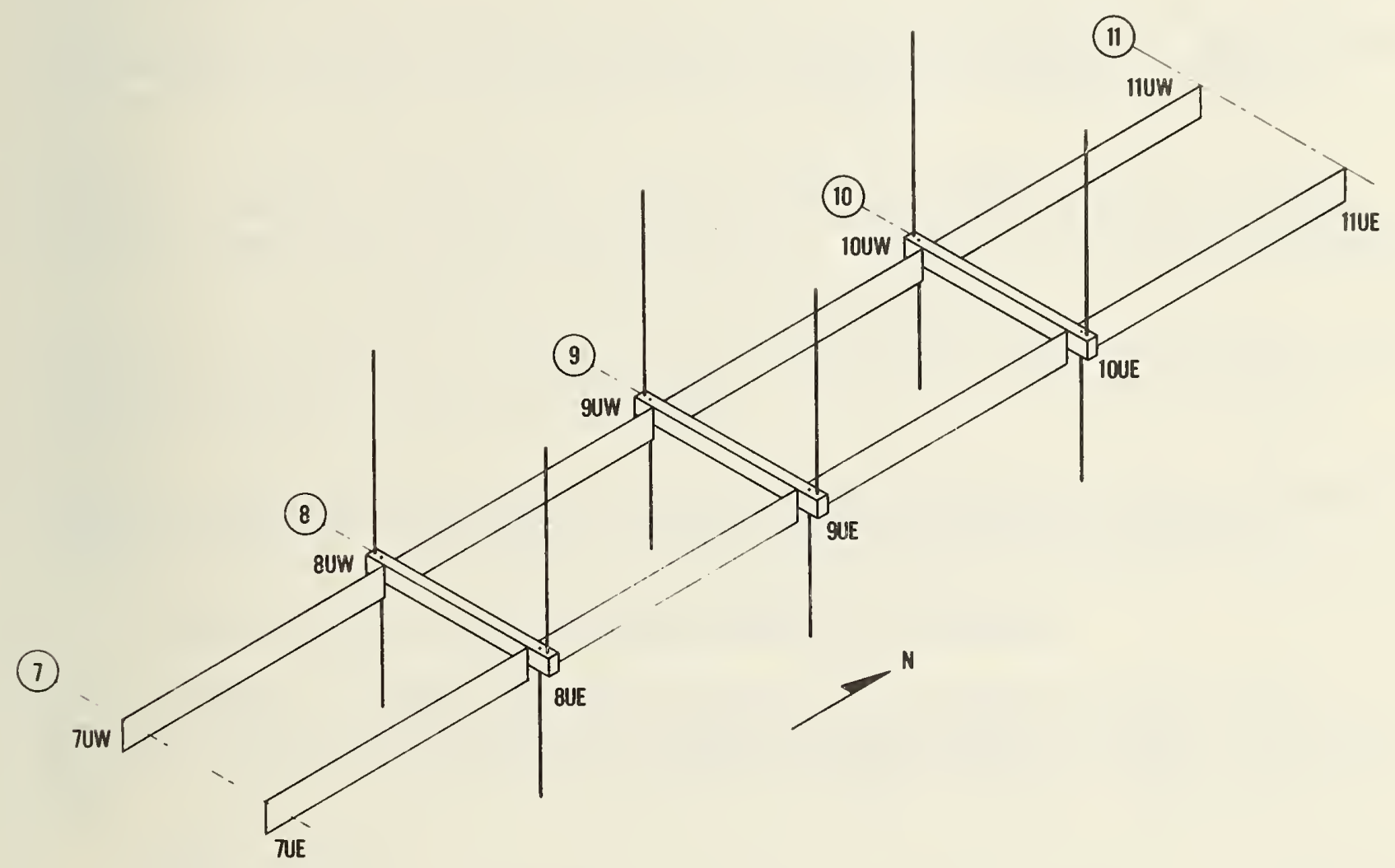

Figure 3.15 Unified designation of walkway components (fourth floor walkway shown). 


\section{DESCR IPTION OF THE WALKWAY COLLAPSE}

\subsection{INTRODUCTION}

This chapter addresses the major events related to the collapse of the walkways, the rescue operation, and the removal and storage of the debris. Walkway occupancy at the time of collapse is also discussed.

Section 4.2 gives a chronology of events during the night of July 17-18, and presents photographs showing the walkway spans immediately after the collapse and after completion of the rescue operation. Section 4.3 summarizes eyewitness accounts of the collapse as reported in local newspapers.

Section 4.4 describes the analysis of videotape footage taken just prior to the collapse and presents an estimate, based in large part on this analysis, of walkway occupancy at the time of collapse.

Section 4.5 describes the removal and storage of the walkway debris, inspection of the atrium by NBS engineers, and removal of the third floor walkway.

Findings reported in this chapter are summarized in section 4.6.

\subsection{SUMMARY OF EVENTS PRECEDING AND FOLLOWING THE COLLAPSE}

The following is a summary of events related to the walkway collapse and to the rescue operation as reported in The Kansas City Times, Metropolitan Edition, Saturday, July 18, 1981, and in The Kansas City Star, Extra, Sunday, July 19, 1981.

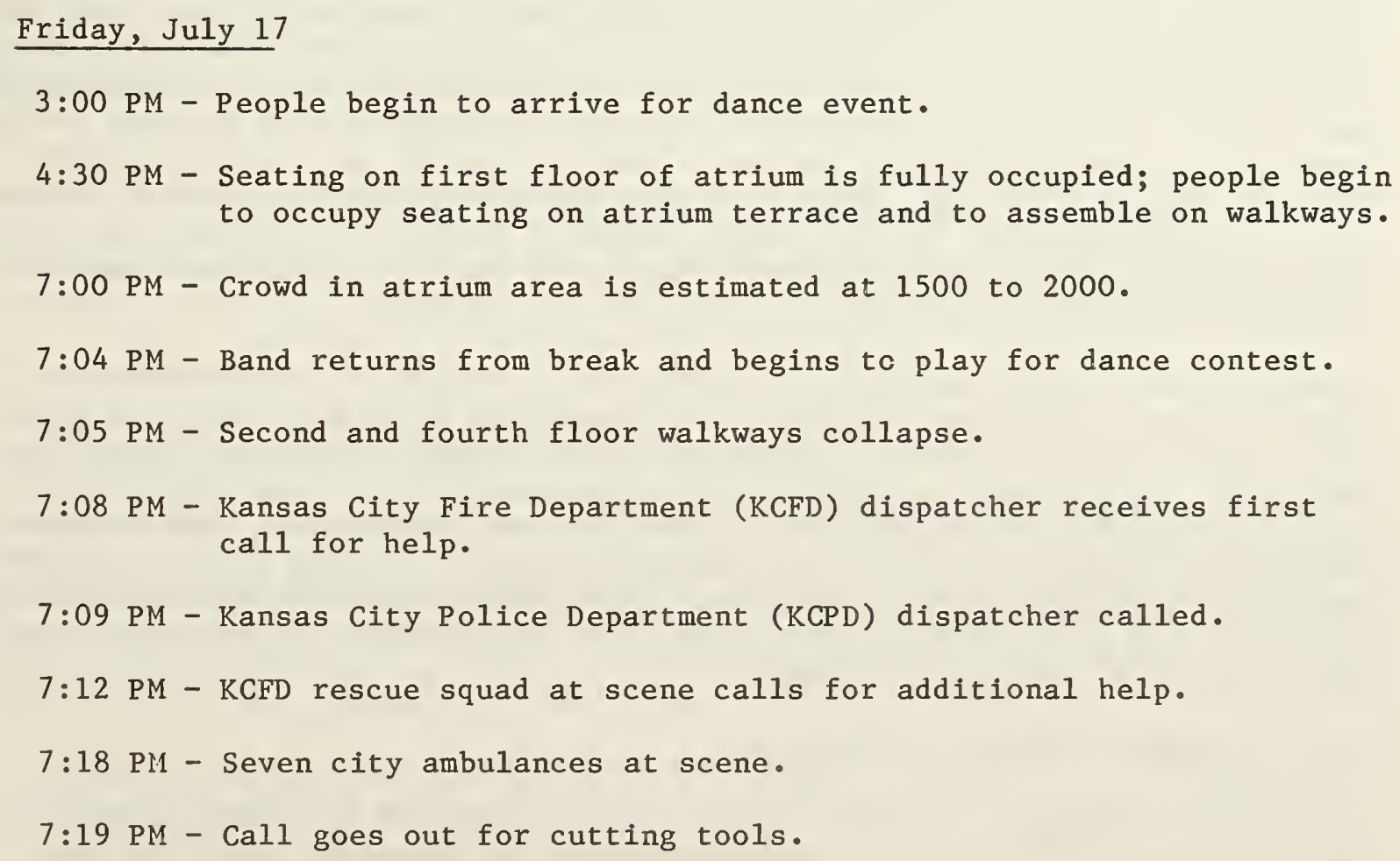


7:23 PM - Call goes out for forklift.

7:52 PM - More than 100 firefighters and emergency workers involved in rescue operation.

8:30 PM - Heavy crane arrives.

10:30 PM - Cranes moved into position near west wall of atrium.

Saturday, July 18

3:15 AM - First walkway section (span U8-9) 1ifted by cranes.

4:30 AM - Last survivor removed from debris.

6:00 AM - Span U7-8 1ifted and set aside.

7:45 AM - Last span (presumably L7-8) is lifted and 31 bodies are removed.

As of Sunday, July 19, the reported death toll was 111 . The number of injured was reported to be 188 . (Two of the injured subsequently died.)

Figures 4.1 and 4.2 show the walkways shortly after the collapse, just as the rescue operation was getting under way. The photograph in figure 4.1 appears to have been taken from the stairway landing at the south side of the atrium between the second and third floors. The view is to the west-northwest and shows part of span U7-8 which lodged in the second-floor portal originally occupied by span L7-8. Spans U8-9 and U9-10 can be seen behind the trees in the middle of the picture. The photograph in figure 4.2 was taken from the third floor with the view directly to the north along the axis of the walkways. Span U7-8 is in the foreground and the third floor walkway can be seen to the upper right. Span U10-11 is visible at the far (north) side of the atrium. The north end of this span appears to have experienced an appreciable displacement to the west during the collapse. Water is coming from walkway sprinkler pipes severed when the north walkway spans were pulled off of their bearing seats.

A general view of the walkway debris after all victims had been removed is shown in figure 4.3. The view is to the south and shows span L9-10 resting on span U9-10 in the foreground. Direct1y to the south is span U8-9 (left) and span L8-9 (right). At the upper left is the south end of span U7-8. Span L7-8 is at the top of the picture, directly below its original position in the second floor walkway. Much of the debris is timber cribbing used to support the spans during the rescue operation. Span L10-11 is out of view in the left foreground and span U10-11 has been moved through the main entrance (to the right) and into the hotel driveway.

\subsection{EYEWITNESS ACCOUNTS OF COLLAPSE}

In the same newspapers cited in section 4.2 , eyewitness accounts of the collapse are reported as well as estimates of the number of people on the 
walkways and on the atrium floor directly below. These accounts can be summarized as follows:

- Individual standing at end of walkway (level unknown) saw upper walkway collapse at center first and then fall onto second floor valkway. Estimated about 50 people standing on fourth floor walkway, 100 people on second floor walkway and 200 people on atrium floor beneath the walkways.

- Individual (vantage point unknown) observed at least 40 persons on fourth floor walkway dancing or looking at scene below. Fourth floor began to buckle and collapsed. Area under walkway in vicinity of bar was jammed. Glass exploded, hitting people 100 to $150 \mathrm{ft}$ away with shards.

- Individual on bandstand observed second floor walkway split in middle and begin to fall.

- Individual was "... sitting on steps in front part of lobby after walking across the catwalk moments before." Saw top walkway come straight down and hit second walkway which then fell. Estimated about a dozen people on fourth floor walkway, 75 to 100 on the second floor walkway, and 100 to 150 people below the walkways.

In view of the conflicting nature of eyewitness accounts and the availability of videotape showing parts of the walkways a few minutes before the collapse, this investigation did not include any organized effort to interview the injured or to solicit eyewitness accounts of the collapse. Attempts to obtain information from rescue workers regarding the numbers of dead and injured removed from the various sections of the walkways were largely unsuccessful, not because of any unwillingness to cooperate, but primarily because of great difficulty in recalling and discussing the event.

As will be discussed in chapters 5 and 10 , it is possible to partially reconstruct the mode of collapse based on physical evidence contained in the walkway debris. However, the number of people and their location on the walkways at the time of collapse can only be estimated and will never be known with certainty. Efforts to establish such an estimate are described in the following section.

\subsection{EST IMATE OF WALKWAY OCCUPANCY AT TIME OF COLLAPSE}

The most significant and helpful information regarding walkway occupancy is contained on a videotape shot by KMBC IV, channe1 9, Kansas City, Mo. The news team was in the Hyatt Regency Hotel to film activities at the dance and was in the process of changing batteries when the collapse occurred. The tape contains scenes showing portions of the second and third floor walkways a few minutes before the collapse and scenes immediately following the collapse.

Three segments of the tape provided by KMBC TV were suitable for analysis. The scene in figure 4.4 is from the third floor balcony on the north side of the atrium with the view to the southwest. All of span L7-8 and most of span 
L8-9 of the second floor walkway are visible. A portion of the third floor walkway is visible at the upper right. The time bracket is believed to be 6:50 to 7:00 PM, based on the scheduled break of the band and their absence from the bandstand which is located directly below the banner on the south wall of the atrium. There appear to be 11 people on span L7-8 and 16 people on span L8-9. Of the 11 people on span L7-8, 10 appear to be standing at the handrail. Of the 16 people on span L8-9, 12 appear to be standing at the handrail.

The scene in figure 4.5 , believed to have been taken a few minutes after the frame shown in figure 4.4 , appears to be from the landing of the main stairway in the southeast corner of the atrium, looking northwest. Part of span L8 $>9$ and all of spans $\mathrm{L} 9-10$ and $\mathrm{L} 10-11$ of the second floor walkway are visible. Eight or nine people are occupying the south portion of span L9-10 along the handrail and span L10-11 is not occupied.

The scene in figure 4.6, taken a few frames later, appears to be from the same location as that in figure 4.5 , but shows more of span L8-9. Judging from their relative heights, the people on span L9-10 have not moved from their positions shown in figure 4.5. It appears that the count on span L9-10 is now 11 , but blurring makes an accurate count difficult.

Figure 4.7 is a close-up of the southernmost span (span M7-8) in the third floor walkway. The view is from the same location as figure 4.4. Again, it is difficult to make an accurate count, but at least 11 persons can be observed.

Based on information obtained from the KMBC TV videotape, it is likely that the second floor walkway was occupied by approximately 40 people shortly before the collapse. The loading is taking place from south to north which is consistent with the location of the stairway and escalator in the southeast corner of the atrium. It is also consistent with the location of the bandstand and the dance contest in progress at the time of collapse.

In view of the relative inaccessibility of the fourth floor walkway, as described in section 3.2 of this report and the number of persons observed on the more accessible second and third floor walkways, the eyewitness accounts of from 40 to 50 people on the fourth floor walkway would appear to be an exaggeration.

Based on information obtained from the KMBC TV videotape, an occupancy of the order of 16 to 20 people with 10 to 12 of them standing along the handrail is believed to be a reasonable upper bound for a second floor walkway span. It is also believed that three to four people per span, substantially less than the number observed on the second or third floor spans, is a reasonable upper bound for a fourth floor walkway span. Given these bounds and the fact that the bandstand and dance contest could best be observed from the south spans of the walkways, the distribution indicated in table 4.1 is considered to be a credible upper-bound estimate of walkway occupancy at the time of the collapse. The combined occupancy of the second and fourth floor walkways as indicated in this table is 63. However, it must be emphasized that the actual number of walkway occupants and their distribution never will be known with certainty. 
The initial removal of debris from the atrium area involved materials such as broken glass, gypsum board and aluminum slats that could not be identified with a specific walkway span. After marking each span with a code to identify its origin, the second and fourth floor walkway spans, along with segments of handrail and hanger rods, were moved by the Crown Center Redevelopment Corporation to a warehouse located at 28 th and Warwick Streets, Kansas City, on the night of July 21-22.

On July 22, two NBS engineers were given access to the Hyatt Regency atrium and were allowed to take photographs. This visit was limited to making very general observations. The condition of the fourth floor to ceiling hanger rods was noted, including the absence of washers at locations $8 \mathrm{E}$ and $9 \mathrm{E}$. The third floor walkway was still in place and small pieces of walkway debris remained on the atrium floor.

On the night of July 22-23, the third floor walkway was removed by the Crown Center Redevelopment Corporation and transported to the warehouse for storage with the spans of the other two walkways. Just prior to its removal, vibration measurements were obtained by the Crown Center Redevelopment Corporation. These measurements are referred to later in this report.

Based on subsequent inspections of the third floor walkway spans in the warehouse, the spans apparently were removed by the use of lifting slings placed around the W8 $\times 10$ crossbeams at the quarter points of each span. This necessitated four cuts through the deck of each span to expose the ends of the cross beams. Span M9-10 appears to have been removed first since the stringers had been cut just short of the stringer to box beam connection on each end of the span. Removal then progressed each way from span M9-10 with each span retaining one box beam and remnants of the hanger rods which were cut just above the level of the handrail.

On August 13, the walkway hanger rods between the third floor and ceiling and between the fourth floor and ceiling, embedded plates at column line 7 , and the bearing seats at column line 11 also were removed from the atrium and sent to the warehouse for storage.

\subsection{SUMMARY}

The following summarizes information and findings presented in this chapter:

1. The collapse of the second and fourth floor walkways is believed to have occurred at approximately 7:05 PM, Friday, July 17, 1981.

2. Analysis of the KMBC TV videotape indicates approximately 40 people on the second floor walkway shortly before the collapse.

3. A reasonable upper bound for single-span occupancy is believed to be 16 to 20 people. 
4. It is concluded that a total of 63 people represents a credible upper-bound combined occupancy of the second and fourth floor walkways at the time of collapse.

Table 4.1 Estimated Upper Bound on Walkway Occupancy at Time of Collapse

Span Number

No. of Persons Standing at East Handrail
No. of Persons Standing

Near Walkway Center Line

Fourth Floor Walkway

$\mathrm{U} 7-8$

U8-9

U9-10

U10-11

Second Floor Walkway

L7-8

12

L8-9

12

L9-10

10

L10-11

3

2

1

1

4
0

0

0

0
8

6

4

0 


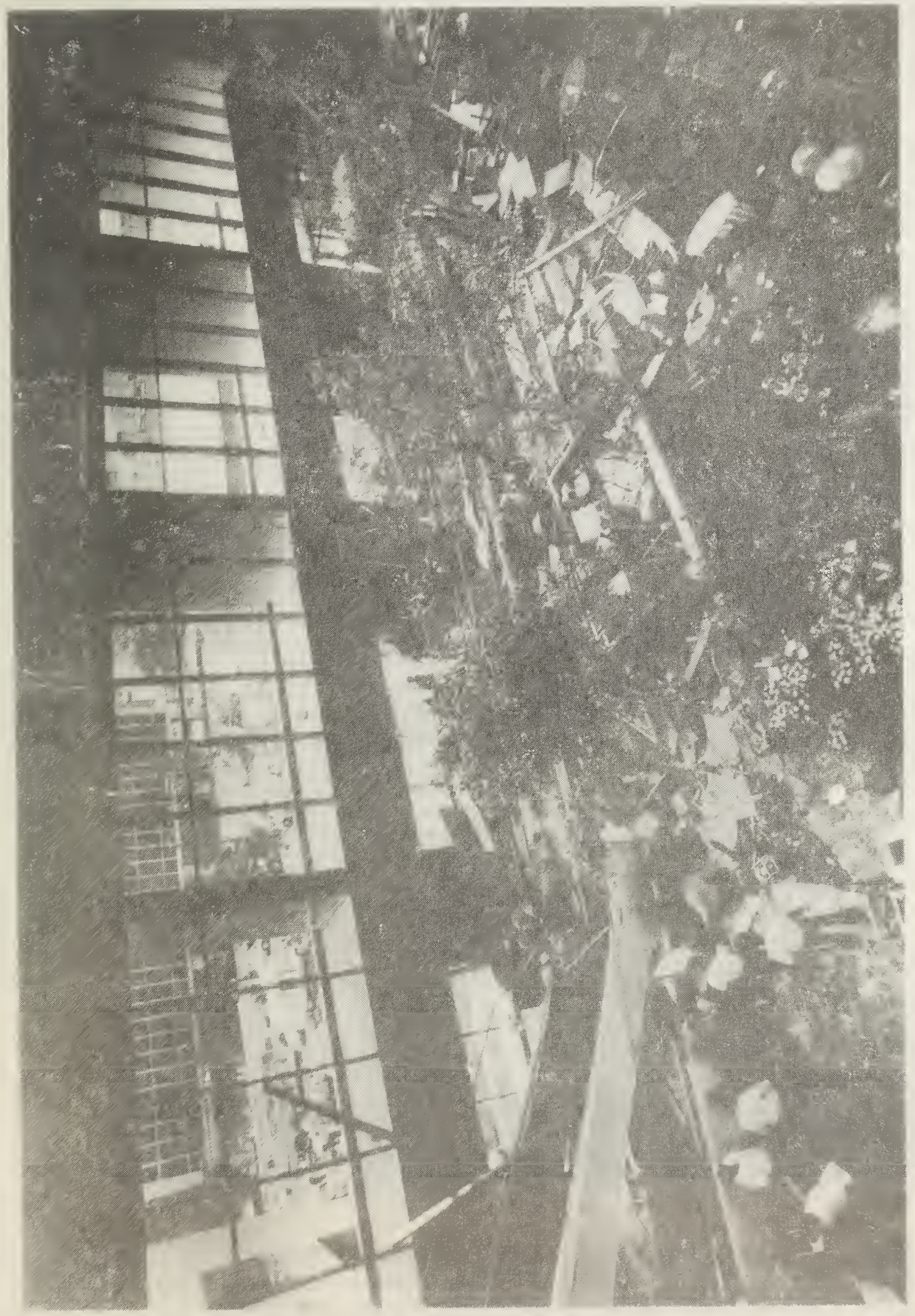

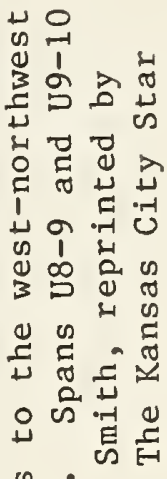

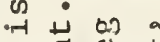

3 का

ơ

$>$ 合这

-

¿

은 오 을

बु

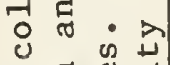

( ) है

돈윰

4 to 0

可馬 至

出 के

$>$ 元.

거 $\infty$ 당

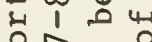

읭

ए $=5$

क

कोष की को

学至造是

$\because$

$\stackrel{1}{3}$ 


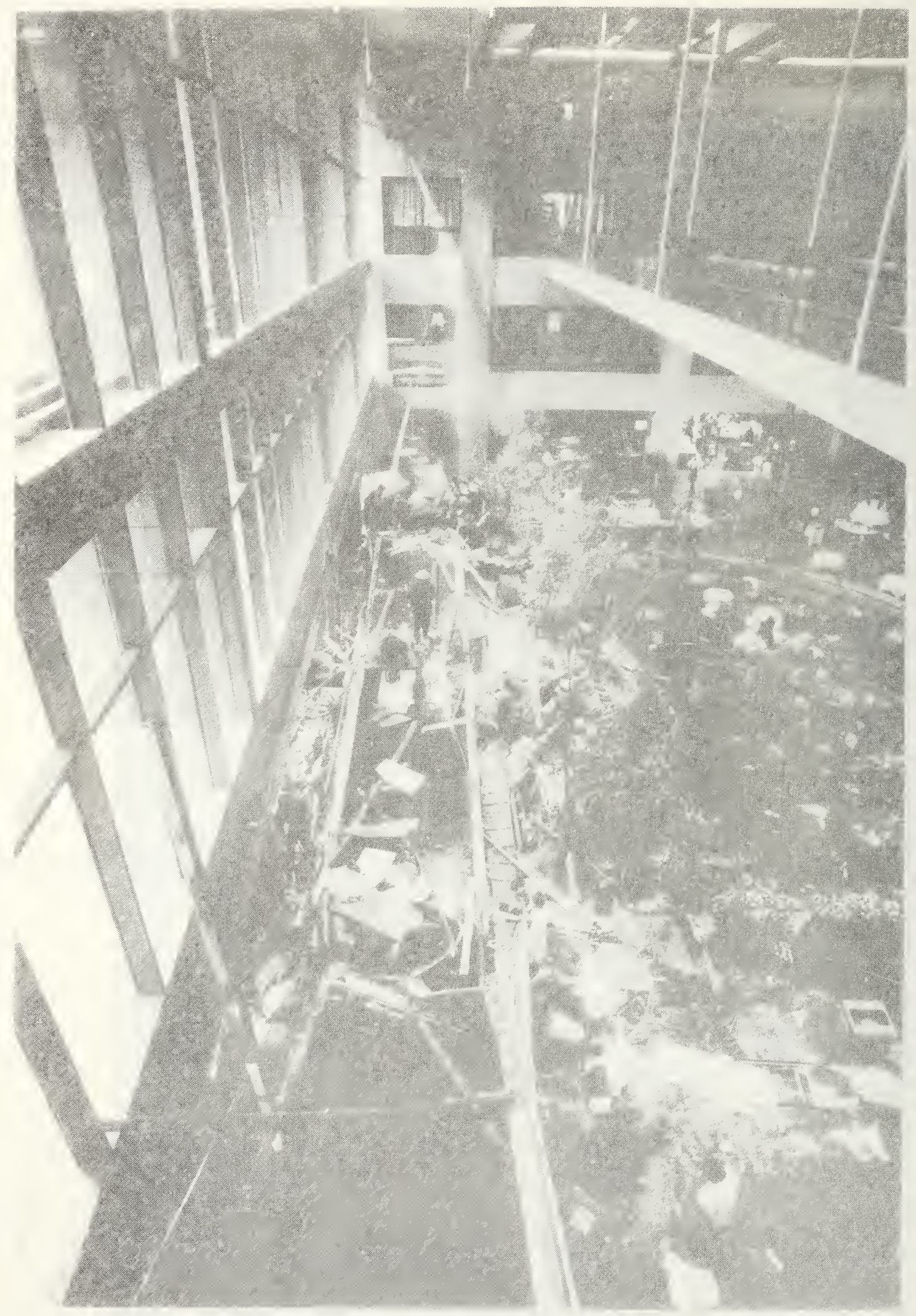

Figure 4.2 Walkways shortly after the collapse. View is directly to the north along the axis of the walkways. Span U7-8 is in foreground and third floor walkway is at upper right. Water is coming from broken sprinkler pipes. Photo by Greg Smith, reprinted by permission of The Kansas City Times, @ 1981, The Kansas City Star Company. 


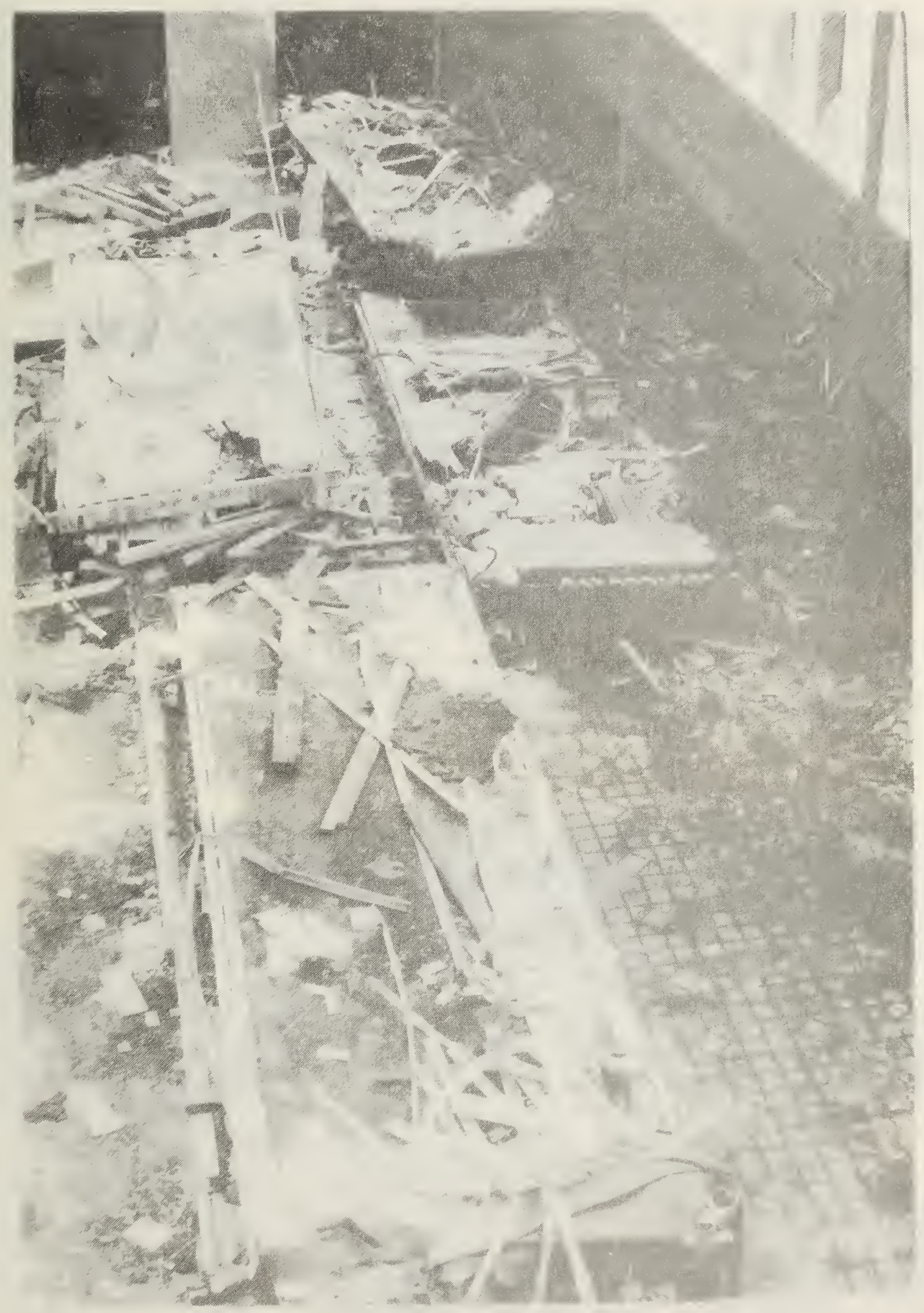

Figure 4.3 Aftermath. View is to the south with span L9-10 resting on span U9-10 in foreground. Next are spans U8-9 (left) and L8-9 (right). Span U7-8 is at upper left and span L7-8 is at upper right. Photo courtesy of Kansas City Police Department. 


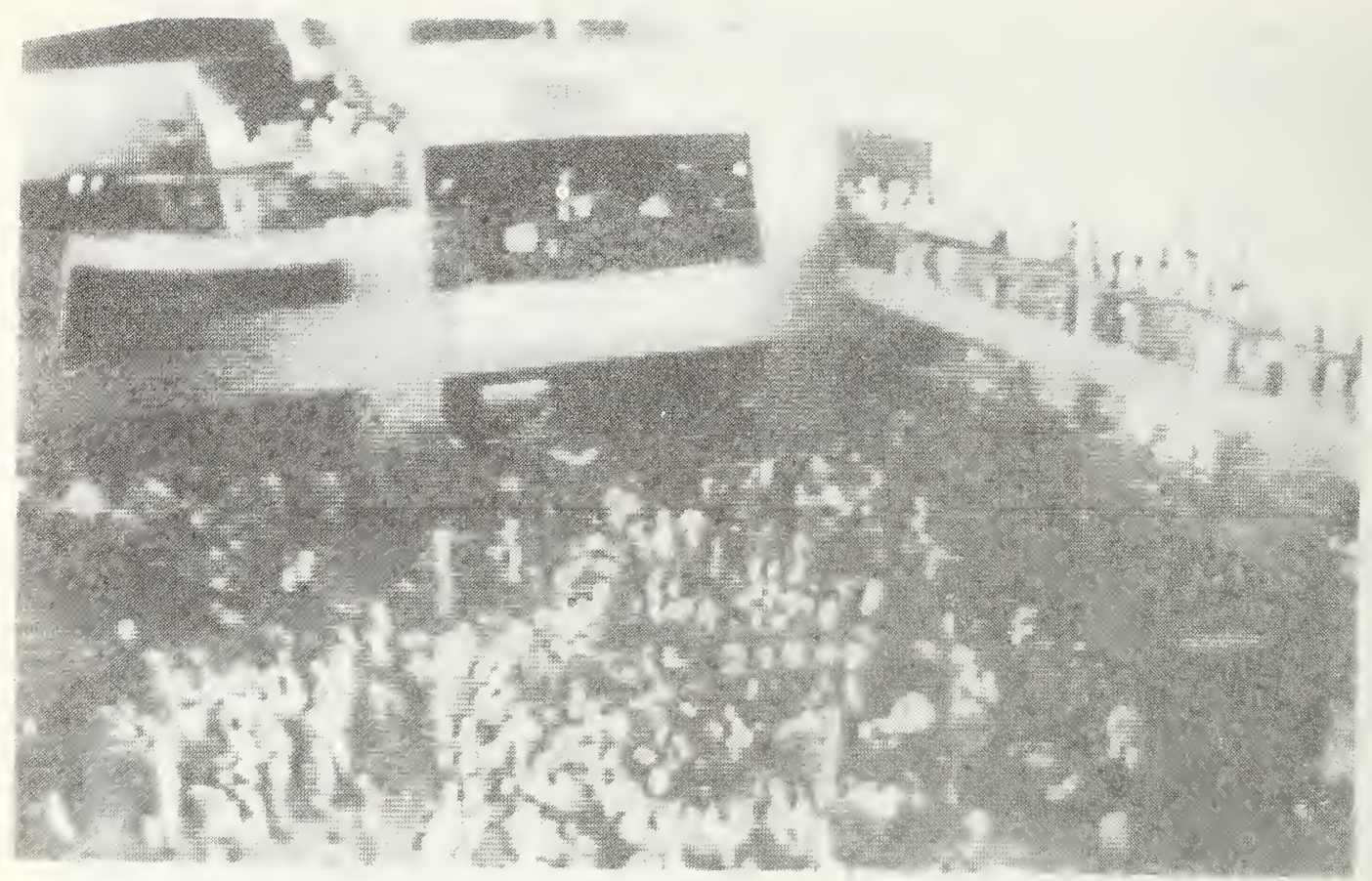

Figure 4.4 Scene from third floor balcony on north side of atrium. View to the southwest showing spans L7-8 and L8-9 of second floor walkway. Videotape courtesy of KMBC TV.

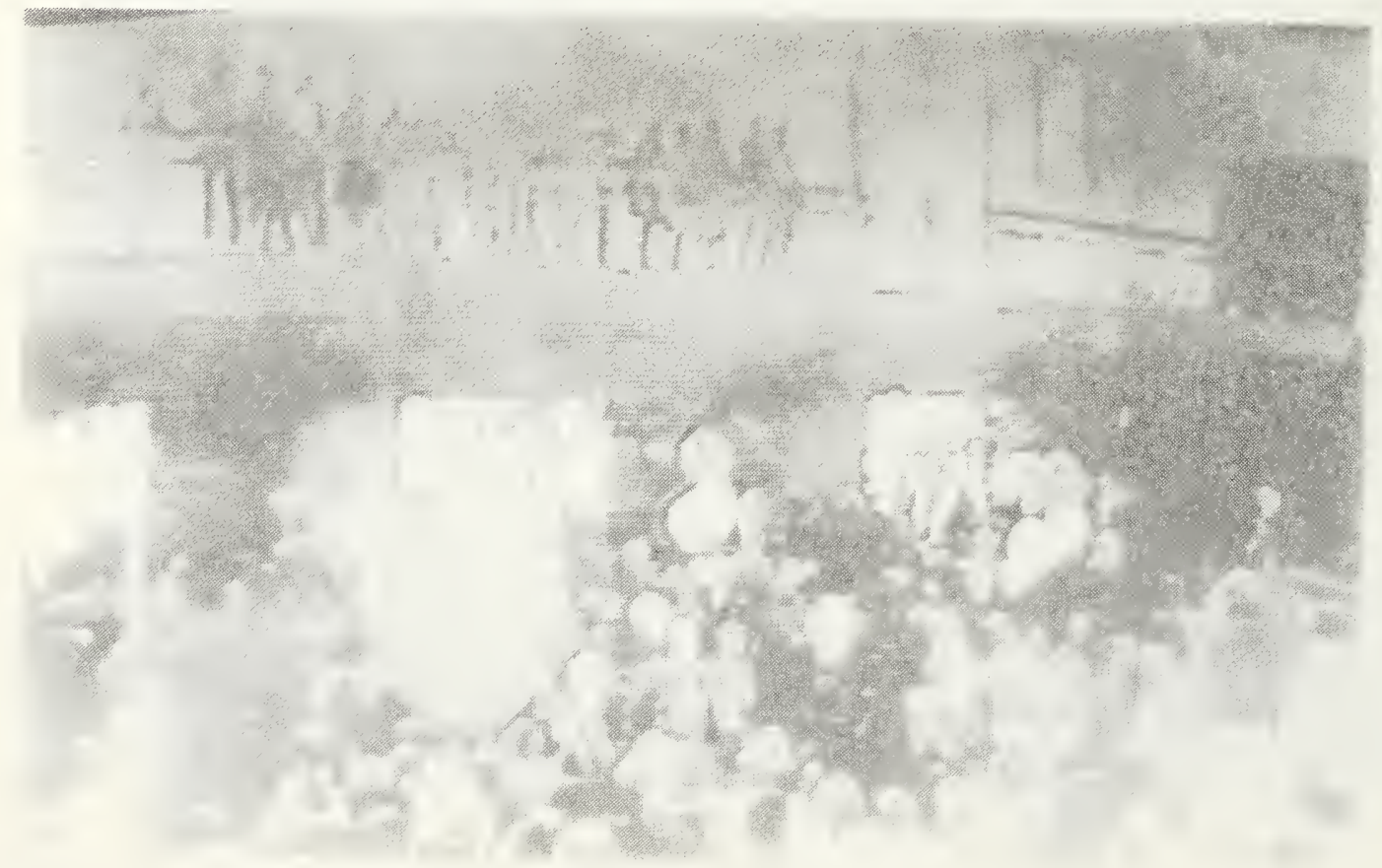

Figure 4.5 Scene from landing of main stairway in southeast corner of atrium. View to northwest shows part of span L8-9 and all of spans L9-10 and L10-11 of second floor walkway. Videotape courtesy of KMBC TV. 


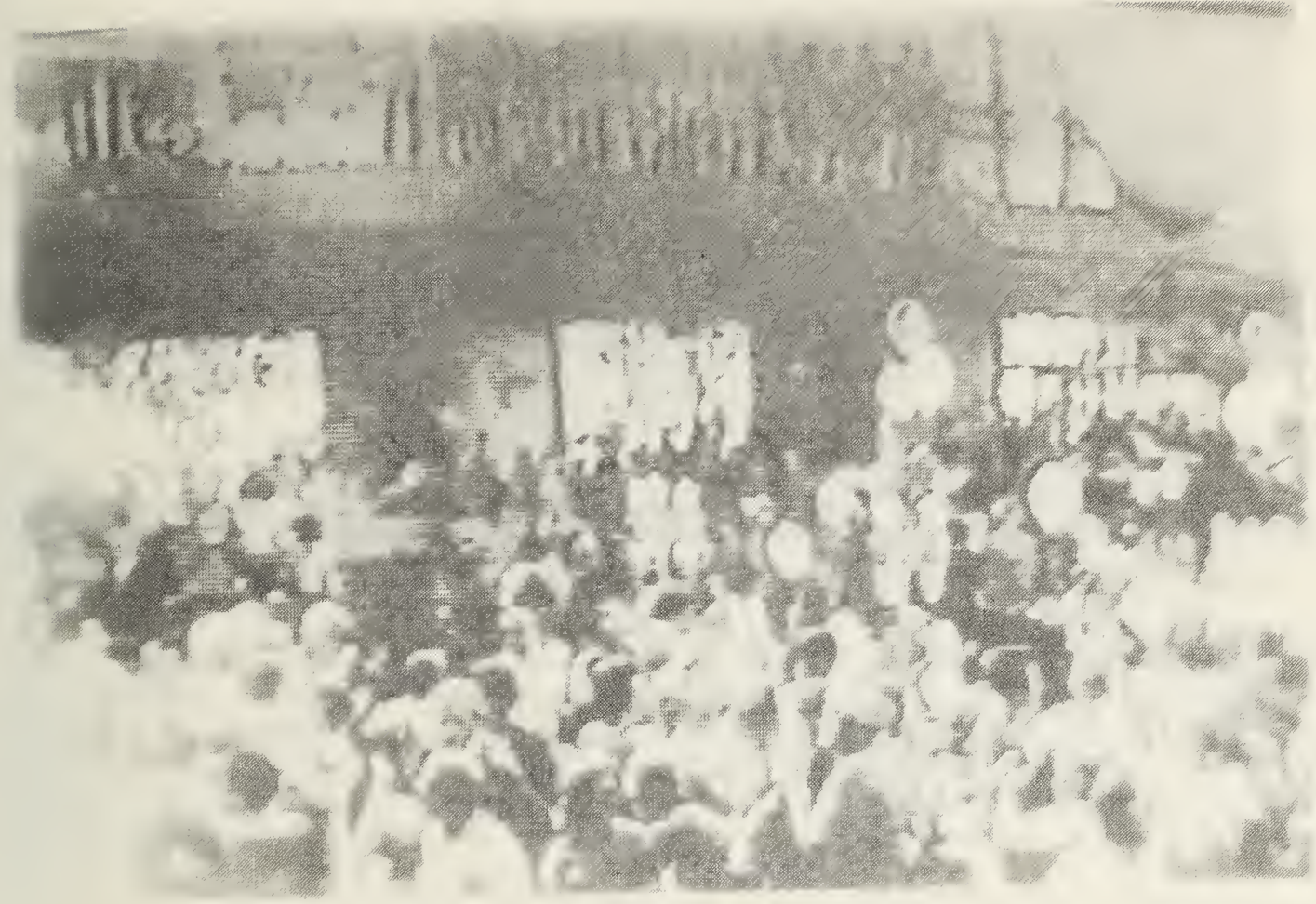

Figure 4.6 Same view as figure 4.5, but a few frames later. Videotape courtesy of KMBC TV.

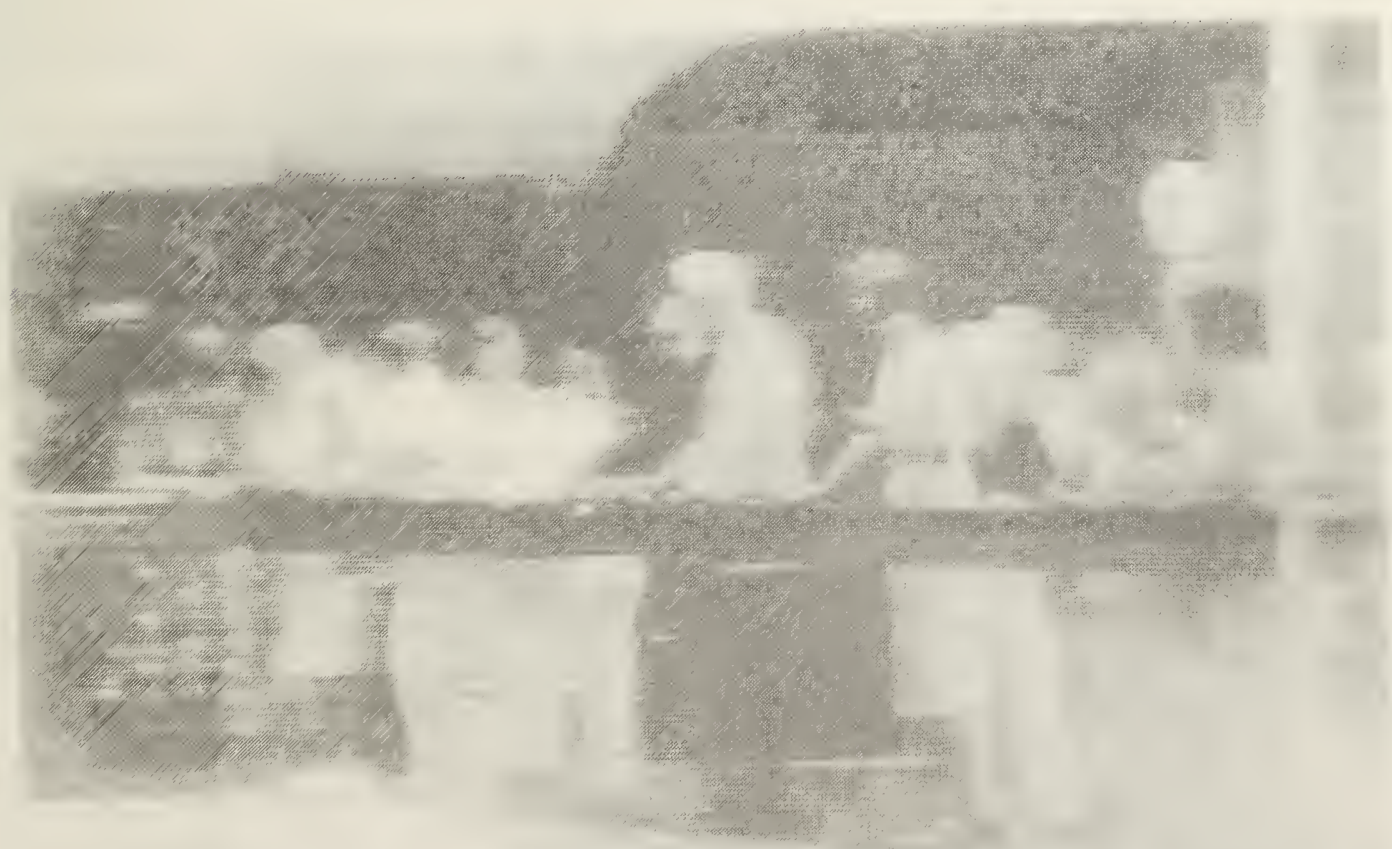

Figure 4.7 View from third floor balcony on north side of atrium. View to southwest showing southernmost span (span M7-8) of third floor walkway. Videotape courtesy of KMBC TV. 


\section{SITE INVESTIGATION}

\subsection{INTRODUCTION}

This chapter deals exclusively with measurements and observations made in the course of several visits to the Hyatt Regency atrium and to the warehouse during the period July 28 to December 17, 1981.

Section 5.2 describes the survey of the Hyatt Regency atrium and the probable alignment of the walkways prior to collapse. Initial movement of the walkway spans and their general drift during the collapse are related to observations of hanger rod distortion and points of impact on the atrium floor.

Section 5.3 describes the layout of the walkway spans in the warehouse and their general condition. Emphasis is on the box beams of the fourth floor walkway. Distortions of the box beams due to hanger rod pull-through and fractures along the longitudinal box beam welds are described in detail. Also described in this section is the procedure used to estimate the original weights of the walkway spans.

Section 5.4 describes the criteria used for selection of physical specimens, procedures followed in marking and removing the specimens, and their cataloging and handling after arrival at NBS. Section 5.5 describes the procedure used in obtaining replicas of fracture surfaces and the subsequent removal of selected fracture surfaces for scanning electron microscopy. Section 5.6 summarizes the conclusions drawn in this chapter.

\subsection{SURVEY OF THE HYATT REGENCY ATR IUM}

To establish the actual alignment of the second and fourth floor walkways prior to collapse, NBS commissioned a survey of the west portion of the Hyatt Regency atrium [5.1]. This survey was carried out on August 5, 1981, after removal of the third floor walkway but prior to removal of the fourth floor to ceiling hanger rods and the embedded plates and bearing seats at column lines 7 and 11 , respectively. No measurements were made with respect to the third floor walkway.

For convenience, a benchmark was established on the atrium floor at a point $0.15 \mathrm{ft}(45 \mathrm{~mm})$ west and $0.10 \mathrm{ft}(30 \mathrm{~mm})$ south of the southwest corner of the column located at the intersection of column lines 11 and $H$. For the purposes of this survey, the benchmark elevation was assumed to be 0.00 . To establish relative horizontal position, three transit lines (T.L.) were located on the atrium floor; (1) T.L. 1 parallel to column line 11 on the north side of the atrium. (2) T.L. 2 on a north-south line centered with the first-floor passageways directly under the walkway at column lines 7 and 11 . (3) T.L. 3 parallel to column line 7 on the south side of the atrium (see figure 5.1). Positions of hanger rods, bearing seats, and points of impact on the atrium floor are subsequently described as north-south and east-west departures from the intersection of T.L. 1 and T.L. 2. All distances and elevations were determined to the nearest $0.01 \mathrm{ft}(3 \mathrm{~mm})$. 


\subsubsection{Embedded Plates and Bearing Seats}

Locations of the embedded plates and wall openings at column line 7 (south) and the expansion bearing seats and wall openings at column line 11 (north) are shown in figure 5.1. It is apparent from figure 5.1 that the embedded plates at column line 7 on the fourth floor level (E1.45.00 with respect to the datum of this survey) are approximately $0.15 \mathrm{ft}(45 \mathrm{~mm})$ south of the corresponding plates on the second floor level. As will be discussed subsequently, this misalignment required a retrofit of the bearing pads on the stringers of the north span of the fourth floor walkway (span U10-11). North-south alignment of the bearing seats at column line 11 is far better, the fourth floor bearing seats being $0.02 \mathrm{ft}(5 \mathrm{~mm})$ north of those at the second floor level.

Each embedded plate at column line 7 is made up of two $1 / 2 \times 6 \times 14$ in ( $13 \times$ $152 \times 356 \mathrm{~mm}$ ) plates placed as shown in figure 5.2. Also shown in figure 5.2 are the locations of the fillet welds which made up the shear connection with the walkway stringers. Based on these dimensions, the east-west alignment of the walkways with respect to T.L. 2 at column 1 ine 7 was as follows:

\section{Fourth floor walkway $=0.01 \mathrm{ft}(3 \mathrm{~mm}) \mathrm{E}$ Second floor walkway $=0.04 \mathrm{ft}(10 \mathrm{~mm}) \mathrm{E}$}

The expansion bearing seats at column line 11 have already been described in section 3.3 (see figure 3.13 ). The gusset plates, in addition to increasing the stiffness of the bearing seats, also served as lateral guides for the stringer bearing pads. Assuming these pads were centered between the gusset plates, the east-west alignment of the walkways with respect to T.L. 2 at column line 11 was as follows:

Fourth floor walkway $=0.05 \mathrm{ft}(15 \mathrm{~mm}) \mathrm{E}$ Second floor walkway $=0.05 \mathrm{ft}(15 \mathrm{~mm}) \mathrm{E}$

\subsubsection{Fourth Floor to Ceiling Hanger Rods}

In table 5.1 are listed the north-south and east-west coordinates of the fourth floor to ceiling hanger rods which remained in place during the collapse. As previously noted, these coordinates are referenced to the point of intersection of T.L. 1 and T.L. 2. Two sets of coordinates are presented in table 5.1--one set for the hanger rod positions at a point approximately 18 in (460 mm) below the plane of the ceiling and one set for the lower end of the hanger rods. Ideally, the coordinates of the hanger rods at the upper hanger fixture should have been established, but this was not possible with the ceiling panels in place. The upper coordinates are based on the assumption that the hanger rods are centered in the $31 / 2$ in $(89 \mathrm{~mm})$ diameter fire resisting encasement.

The elevations of the lower rod tips and the elevations of the points at which the hanger rods pass through the ceiling are presented in table 5.2. Again, these elevations are referenced to Elev. 0.00 (assumed datum) at the first floor level. The overall length of the fourth floor to ceiling hanger rods was subsequently determined to be $15^{\prime}-111 / 8^{\prime \prime}(4.85 \mathrm{~m})$. 


\subsubsection{Impact Points on Atrium Floor}

When the second floor walkway impacted the atrium floor, the second to fourth floor hanger rods and the second floor walkway stringers punched through or otherwise damaged the floor tiles at column lines 8,9 and 10 . At column lines 9 and 10 these hanger rod impact points were clearly identifiable. The corresponding impact points at column line 8 are believed to have been caused by the stringers in the south span of the second-floor walkway (L7-8). At column line 10 there are two sets of hanger rod impact points (see figure 5.3), indicating rebound of the walkway and possibly the effect of the fourth floor walkway impacting. Coordinates of major impact points are listed in table 5.3.

\subsubsection{Alignment of Walkways Prior to Collapse}

With the survey data just presented and with measurements obtained from the walkway debris (see section 5.3 .5 ), it is possible to establish the general alignment of the walkways prior to collapse. In doing this it is convenient to use the second floor walkway as a base line because of its apparent good fit with the embedded plates and bearing seats and because it is directly related to the observed impact points on the atrium floor. It is assumed here that both walkways had no horizontal curvature and that the hanger rod holes were located in the box beams according to the dimensions indicated in figure 3.10.

Alignment of the upper hanger rods at their intersection with the ceiling and the alignment of the fourth floor walkway, all relative to the second floor walkway, are presented in table 5.4. Other than the problem with the embedded plates on the fourth floor at column line 7 as previously described, the horizontal misalignment of the walkway system was less than $0.10 \mathrm{ft}(30 \mathrm{~mm})$. It should be noted that the upper ends of the fourth floor to ceiling hanger rods were more closely aligned with the fourth floor walkway than with the second.

The survey data and measurements from the walkway debris (table 5.8) also make it possible to check the positioning of the walkway stringers on the beam seats at column line 11 prior to collapse. Typically, the 4 in $\times 4$ in (102 $x 102 \mathrm{~mm}$ ) slide bearing plates are positioned $3 / 8$ in $(10 \mathrm{~mm})$ from the south edge of the bearing seats. Based on measurements of actual member lengths as described in section 5.3.5 and accounting for the fact that retrofit of the fourth floor bearing pads extended the stringers by $21 / 4$ in (57 mm), the calculated overlap of the slide bearing plates is 4.2 in $(107 \mathrm{~mm})$ and 3.7 in $(94 \mathrm{~mm})$ at the second and fourth levels, respectively. Scratch marks observed on the slide bearing plates indicate that the actual overlap was very close to 4 in (102 mm) for both walkways.

With regard to vertical alignment of the fourth floor walkway, measurements taken on the embedded plates and bearing seats in the atrium and on the debris subsequent to its removal and storage indicate the top flanges of the W16 $\mathrm{x} 26$ stringers were positioned 0.44 to $0.48 \mathrm{ft}$ (135 to $145 \mathrm{~mm}$ ) below the level of the finished floor (Elev. 45.00). Assuming the structural steel was properly leveled during erection, the minimum protrusion of the fourth floor to ceiling hanger rods through the bottom face of the box beams would have been $0.14 \mathrm{ft}$ $(45 \mathrm{~mm})$ at hanger rod $10 \mathrm{E}$. Subsequent measurements indicated a maximum com- 
bined thickness of nut and washer equal to $0.115 \mathrm{ft}(35 \mathrm{~mm})$. Therefore, with the fourth floor properly leveled, there would have been adequate clearance to install a nut and washer on each fourth floor to ceiling hanger rod.

\subsubsection{Other Observations Relevant to the Investigation}

In table 5.5 the locations of the impact points are listed in terms of departures from the lower hanger rod positions at the second floor walkway prior to collapse. All four spans in the second floor walkway experienced a consistent drift to the west and south during the collapse. The westward drift suggests initial loss of support along the east side of the walkway system while the fixity at column line 7 would be expected to promote a southward drift of both walkways. There was no visible sign of the walkway spans contacting the north wall of the atrium, suggesting that they continued to move to the south after the stringer bearing pads cleared the bearing seats. The locations of the impact points in the vicinity of column line 8 strongly suggest that span L7-8 rotated vertically around its supports at column line 7 and that the north end of the span drifted to the west before the bottom flanges of the stringers impacted the atrium floor.

There was extensive damage to the granite paneling on the south wall of the atrium at the second floor level. It is likely that most of this damage resulted from impact of the south span of the fourth floor walkway which came to rest with its stringers positioned on the second floor edge beam and slightly west of the original alignment.

As has been noted in section 4.5 , washers were missing from the lower ends of the fourth floor to ceiling hanger rods at locations 8UE and 9UE. It was also observed during the course of the atrium survey that the washer at location 9UW had fractured along two radial lines, resulting in the loss of a short segment. This will be discussed further in section 5.3.2.

One final observation of importance is the pronounced bend to the west at the bottom end of hanger rod 10UW and a lesser bend at the bottom of hanger rod $8 \mathrm{UW}$ as can be seen in figure 5.4. Not apparent in figure 5.4 is a slight bend at the bottom of hanger rod $9 U W$ which was detected after the hanger rods had been removed to the warehouse. The absence of appreciable distortions in hanger rods $8 \mathrm{UE}$, 9UE, and 1OUE strongly suggests that failure initiated along the east line of hanger rods.

\subsection{OBSERVATIONS OF WALKWAY DEBR IS}

On July 29, 1981, the NBS investigative team was allowed its first access to the walkway debris. Under the terms of a court order dated July 24, 1981, issued by the Circuit Court of Jackson County, Mo., and covering protective custody of the debris, the taking of impressions, marking, or otherwise disturbing any of the debris was expressly forbidden. Until permission was eventually obtained to weigh the walkway spans and to remove certain physical specimens, on-site activities of the investigative team were limited to visual observations, taking of photographs, and dimensional measurements. 
The layout, orientation and identification of the walkway spans in the warehouse at 28th and Warwick Streets in Kansas City are indicated on figure 5.5. Also indicated in this figure are the locations of the box beams which remained attached to one or the other adjacent spans during the collapse. A general view of the fourth floor walkway spans is shown in figure 5.6 .

\subsubsection{General}

It was evident that the moving and storage of the debris had been carried out with considerable planning and great care. The NBS team found no reason to believe that any of the spans suffered additional damage or were otherwise altered during the move from the hotel. The NBS team also found all spans to be reasonably accessible and properly identified.

In general, the rescue operation at the hotel caused only superficial damage to the spans as can be seen from photographs taken immediately after the collapse. This included loss of some glass panels in the handrail assembly which was necessary for positioning of the lifting slings, penetration of the concrete deck by jackhammering, and various cuts in the second to fourth floor hanger rods. The one exception was span L8-9 where extensive portions of the deck had been removed and the stringers had been flame cut near the north end of the span. It also appeared that the bolts in the clip angle to stringer connections at the south end of span U7-8 had been removed and reinstalled.

\subsubsection{Hanger Rod Pull-Through}

The fourth floor to ceiling hanger rods had pulled through both the bottom and top flanges of each box beam in the fourth floor walkway (figure 5.7). The mode of failure involved the upward rotation of the bottom flanges of the MC8 $\times 8.5$ shapes and extensive localized yielding in each web directly above the fillet line (figure 5.8). This was accompanied by fracture of the lower longitudinal weld back to the inner hanger rod hole and, in some cases, well beyond the inner hole. Pull-through in the upper flange generally resulted in less distortion of the flanges and the localized yielding in the webs much closer to the fillet line. Similar plastic deformation of the box beam ends was also observed at several locations in the third floor walkway (figure 5.9).

Hanger rod pull-through was marked by substantial scraping and gouging damage to the flange surfaces adjacent to the bottom outer hanger rod holes in the fourth floor box beams. Steps in the abraded region indicated that slippage of the washer/nut combination was periodically arrested during the failure process. Figure 5.10 illustrates this "slip-stick" type of failure at location 9UE. The absence of impact marks on the inner flange surfaces around the upper hole at location $8 \mathrm{UW}$ indicates the upper longitudinal weld seam was widely separated at the time of pull-through. The mangled condition of the box beam at location loUw is believed to have been caused by the $1 / 4 \times 6$ in ( 6 × $152 \mathrm{~mm}$ ) edging plate on span U10-11 running past the box beam on impact (figures 5.11 and 5.12). A similar effect was observed at location $8 \mathrm{UW}$.

Washers were missing from the lower ends of the fourth floor to ceiling hanger rods at locations $8 \mathrm{UE}$ and 9UE. However, part of the washer at location 9UW was 
also missing (figure 5.13), suggesting that the missing washers fractured and were lost during the collapse. Figure 5.10 provides clear evidence that a washer was originally installed at location 9UE. There was also visual evidence which indicated that a washer was present at location 8UE. This was later confirmed by detailed examination of the washer/nut contact area as described in chapter 8 .

There is a symmetry to the deformation and distortion of the box beam ends in the fourth floor walkway. As illustrated by figure 5.14, there is no evidence of rotation in the north-south direction of box beam $9 \mathrm{U}$ during the collapse. Conversely, the beam ends at $8 \mathrm{UE}$ and $10 \mathrm{UE}$ display rotational distortions having a mirror symmetry around 9UE. Damage to the beam ends at locations 8UW and 10UW was much more severe as has been pointed out. It is possible that rotation of the fourth floor walkway about the west line of hanger rods, as evidenced by the previously described hanger rod distortions and impact points, contributed to this damage. Again, the distortions clearly indicate a symmetry about box beam 9U. These combined rotations strongly suggest an initial failure at box beam-hanger rod connection 9UE.

\subsubsection{Box Beam Longitudinal Welds}

Box beam longitudinal welds had been made in a single pass from the exterior by either a manual or semi-automatic process as evidenced by the rough contour of the weld reinforcement (weld cap). The reinforcements had been removed from the top surface of all box beams as called for on the shop drawings. Reinforcement had also been removed from the bottom surface of all box beams for a distance of approximately 19 in $(480 \mathrm{~mm})$ from the beam ends except for box beam $8 \mathrm{M}$ in the third floor walkway where the weld reinforcement had been entirely removed. Presumably the reinforcement was removed to provide a flat surface for arc spot welding of the formed steel deck on the top surface of the box beam and for hanger rod washer contact on the bottom surface.

In addition to the exterior welds just described, interior tack welds were observed along the longitudinal seam in the region between the outermost hanger rod hole and the end of the beam. At most locations these welds were placed along the seam in both the top and bottom flange. As these welds are not called out on the fabricator's drawings, it is assumed that their purpose was to facilitate alignment of the MC8 $\times 8.5$ shapes preparatory to placing the exterior longitudinal welds. As will be shown in chapter 6, these interior tack welds have a significant effect on resistance to hanger rod pul1-through. A summary of the length and position of these welds is presented in table 5.6. Because of gross distortions of the flange material caused by hanger rod pull-through, true longitudinal dimensions can be expected to differ from the listed values by as much as +0.1 in $(2.5 \mathrm{~mm})$. In the case of location $8 \mathrm{MW}$, saw marks are visible at the outer ends of the welds, indicating the box beam was trimmed to Einal length after placement of the welds. In other instances it was evident that no final trimming was performed.

In the case of the fourth floor box beams where the longitudinal welds had been fractured during hanger rod pull-through, it was possible to make a visual assessment of weld quantity and quality. There was no evidence of joint preparation and no evidence to indicate that any root opening (separation of members 
at root of joint) had been provided. The faying surfaces were observed to be continuously curved over the entire depth of the flange toes. In general, joint penetration did not exceed the distance from the outside face of the flange to the point of tangency of the faying surfaces. The resulting weld could, in most cases, best be described as a flare-V-groove weld as defined in reference 5.2. However, as noted in section 3.3, the welding symbol shown on the shop drawings called for a prequalified partial joint penetration groove weld. This is further discussed in section 10.6 .

In general, observed variability in penetration along a given weld (figure 5.15) was not considered excessive for a manual or semi-automatic weld, given the geometry of the flange toes of the MC $8 \times 8.5$ shapes. More variability in depth of penetration was noted from weld to weld. For example, penetration at the top longitudinal weld between the hanger rod holes at location 9UW appeared to be about $1.5 \mathrm{~mm}$ as compared to a depth of penetration of about $2.8 \mathrm{~mm}$ for the bottom longitudinal weld at that same location. The longitudinal welds appeared to contain a substantial amount of porosity in the shape of elongated pores oriented in the through-wall direction and of dimensions approximating that of the weld penetration (figure 5.16). Results of field measurements of top and bottom longitudinal and interior tack weld penetration at the ends of the fourth floor box beams are presented in table 5.7. More detailed descriptions of the box beam longitudinal welds are presented in chapters 7 and 8 of this report.

Weld fractures occurred predominantly along the center line of the welds as indicated in figure 5.16. In several cases a shear lip caused by fracture transition from the weld center line to the fusion line was observed near the inner hanger rod hole. A marked exception to this failure mode was noted at the upper longitudinal welds between the hanger rod holes at locations 8UE and 9UE. Here the weld failure appeared to have occurred predominantly at the fusion line (figure 5.17). In some cases the flange tips were curled up at the weld line, suggesting plastic weld behavior. In other cases the flanges were perfectly straight, suggesting less ductile behavior of the longitudinal welds.

What appeared to be a crack was noted in the lower interior tack weld at location 8MW (figure 5.18). Similarly, an apparent small crack was noted at the lower extremity of $8 \mathrm{ME}$ (figure 5.18), apparently having developed in a region of metal flashing left over from the beam cutting operation. There was no interior tack weld at this location.

\subsubsection{Box Beam to Clip Angle Fillet Welds}

The clip angles, which served as shear connections between the W16 $\mathrm{x} 26$ stringers and the box beams, were welded to the box beams in accordance with the detail shown in figure 3.10. Clip angles had separated from one side or the other of each box bean by fracture through the weld metal or through the heat-affected zone. In some cases (8UE, 9UE, 10UW and 9LE) cracks were observed in the bottom fillet welds of the clip angles that remained attached (see figure 5.19). Evidence of a pul1-out or tensile type failure was observed at the top fillet weld on 11 out of the 13 box beam to clip angle weld failures 
in the second and fourth floor walkways. This suggests that the fractures were, in most cases, initiated by positive bending moment at the ends of the spans causing shearing failure of the bottom fillet weld, followed by a tension failure (or mixed shear-tension failure) progressing upward and across the top Fillet weld. Figures 5.20 and 5.21 illustrate this failure mode for location 9JE. Exceptions were noted at locations 9UW and 9LW where failure of the fillet welds on the box beam web appeared to be entirely of the shear type (figure 5.22). No cracks were in evidence in the bottom fillet welds of the clip angles that remained attached at those locations.

Figure 5.23 clearly shows a tear in the upper end of the north clip angle at location 8UE, suggesting that the connection experienced a negative bending moment at some time during the collapse. However, the south clip angle at this same location appears to have separated from the box beam under the action of positive bending as is evidenced by the shape of the tear in the box beam web shown in figure 5.24. Based on these observations, it is likely that the upper spans at column Iine 8 first experienced severe negative bending, followed by positive bending prior to final separation of the clip angles from the south web of the box beam. It is also likely that the concrete deck developed a pronounced transverse tension crack, accompanied by failure of the wire reinForcement, during the negative moment phase. With moment reversal, the crack then closed and span rotation was centered about a point near mid-depth of the deck.

There is no evidence of moment reversal in the fourth floor walkway at column line 9, the connection apparently failing under continuously increasing positive moment. The situation at column line 10 is similar to that at column 1 ine 8 , but the indicators of moment reversal are not as pronounced in the clip angle distortions and fillet weld failures.

Visual examination of the intact box beam to clip angle fillet welds and the fracture surfaces of separated welds indicated welds of good quality. Leg lengths of the fillet welds were typically $5-8 \mathrm{~mm}$.

\subsubsection{Other Observations Relevant to the Investigation}

Other welds having structural significance and not previously described include the clip angle to embedded plate welds at the south ends of spans U7-8 and L7-8, and the stringer bearing pad welds at the north ends of spans U10-11 and L10-11. Attachment of the clip angles to the embedded plates at column line 7 was by field welding. Inspection of the embedded plates after their removal from the atrium showed lack of penetration into the clip angles at the bottom of connection 7UE and at the top of 7UW as can be seen from figures 5.25 and 5.26. However, distortion of the clip angles, which remained attached to the W16 26 stringers during the collapse, clearly indicates large vertical rotations of the stringers before failure of the clip angle fillet welds. Leg lengths of these fillet welds were typically 5-7 mm except for location 8 UE where leg lengths of 6-9 mm were noted.

As indicated in section 5.2.1, misalignment of the embedded plates at column Ifne 7 , fourth floor level, required a retrofit of the stringer bearing pads at 
the north end of the fourth floor walkway. This was accomplished by cutting out the original bearing pad and welding on a pair of $6 \times 31 / 2 \times 3 / 8$ angles with the short legs machined down to clear the gusset plates in the slide bearing seats. This effectively extended the fourth floor stringers by $21 / 4$ in $(57 \mathrm{~mm})$. The modification at location $11 \mathrm{UW}$ is shown in figure 5.27 .

Certain dimensional checks were made to confirm the sizes of structural shapes shown on the fabricator's shop drawings. In addition, length measurements of the stringers and stringer gaps at the box beams were made to check the longitudinal alignment of the walkways prior to collapse as discussed in section 5.2.4. These measurements are summarized in table 5.8.

A final observation is that the stringer to clip angle bolted connections performed very well. The only cases where bolt slip was evident occurred when the connection was badly distorted by direct impact.

\subsubsection{Determination of Span Weights}

Preliminary estimates of span weights prior to collapse indicated that the weight of the concrete deck could account for as much as 50 percent of the total weight, thus making such estimates particularly sensitive to measurements of deck thickness. The variability in thickness of concrete and topping material, which in some cases could only be measured at the ends of the spans, was considered too high to place any confidence in this approach, and permission was therefore requested of Crown Center Redevelopment Corporation by NBS to weigh selected walkway spans. This operation was carried out on September 3, 1981.

The weighing procedure consisted of temporarily supporting an individual span on four electronic load cells whose output signals are proportional to applied force. Transfer of support was accomplished by raising the span from its supporting timber cribs with hydraulic jacks and inserting the load cells between the bottom flange of the W16 x 26 stringers and the floor. Typically, the spans were raised $1 / 8$ to $1 / 4$ in ( 3 to $6 \mathrm{~mm}$ ) during this operation. To prevent damage to the stringer flanges, the jacks and load cells were topped with jacking pads consisting of a $1 / 2 \times 51 / 2 \times 51 / 2$ in $(13 \times 140 \times 140 \mathrm{~mm})$ steel plate faced with a $1 / 4$ in $(6 \mathrm{~mm}$ ) neoprene sheet. Since some stringers were severely distorted, hardwood wedges were used as required to ensure the level positioning of the jacking pads.

Unless otherwise indicated, the load cells were positioned directly under the center of the bolt groups for those cross beams located a nominal distance of $7^{\prime}-33^{\prime \prime}$ " $(2.229 \mathrm{~m})$ north and south of the midspan cross beam (see definition sketch, table 5.9). Tolerances on the horizontal positioning of the load cells were $\pm 1 / 4$ in $(6 \mathrm{~mm})$ in the north-south direction and $\pm 1 / 8$ in ( $3 \mathrm{~mm}$ ) in the east-west direction. Prior to recording load cell outputs, the timber cribs were checked for freedom of movement to ensure complete load transfer.

Results of the load cell measurements are summarized in table 5.9. Regression analysis of the load cell calibration data indicates a standard error of estimate of 20 lbs $(89 \mathrm{~N})$ for individual load cell readouts over the range of weights encountered. 


\subsection{REMOVAL OF SPECIMENS}

Shortly after the start of the investigation, comprehensive structural and materials testing programs were undertaken as described in chapters 6 and 7 of this report. Tests were carried out on structural assemblies and materials believed to be faithful representations of those assemblies and materials used in the actual walkway construction. To confirm this, a formal request for permission to remove and test certain specimens from the walkway debris was submitted by NBS to the Crown Center Redevelopment Corporation on September 18 , 1981. This was followed by a request to the Liaison Committee of Plaintiffs' Counsel and the Liaison Committee of Defendants ${ }^{\circ}$ Counsel on October $27,1981$. Criteria for specimen selection and details of the request are described in the following section.

\subsubsection{Criteria for Specimen Selection}

Criteria for choice of specimens to be removed from the walkway debris were as follows:

1. No truly unique specimens to be removed from the debris.

2. Specimen location and method of removal to be chosen so as to minimize disturbance of the walkway debris.

3. Amount of material to be removed from a given component or assembly to be linited so that, if necessary, similar specimens can be obtained and independentiy tested by others.

4. Specimens to be representative of materials and fabrication techniques used in the construction of the walkways.

Based on these criteria, a detailed list of specimens was developed, including the type of test or examination and purpose, as shown in table 5.10.

\subsubsection{Specimen Removal}

Permission to remove specimens from the walkway debris was granted in the form of a nodified order issued by both the Jackson County Circuit Court and the United States District Court for the Western District of Missouri on October 28, 1981. Actual removal of specimens was carried out over the period November 3-5, 1981. The first step in removing structural steel specimens was to mark the specimens in place with cut lines and specimen identification numbers. After photographing, the specimens were then removed and engraved by representatives of NBS and the Crown Center Redevelopment Corporation. The specimens were again photographed to show the specimen numbers and engraving. Although flame cutting would have been faster and more convenient, an abrasive saw was used to minimize heat effects near the cut lines. With the exception of the box beam at location 9M, all structural steel specimens were easily accessible.

To remove box beam $9 \mathrm{M}$, the remnants of the third floor to ceiling hanger rods were first removed, followed by the bolts in each of the four clip angle to 
stringer connections. Concrete around the shear studs at each end of the box beams was then removed by impact hammer, followed by separation of the arc spot welds attaching the formed steel deck to the top flange of the box beam. Hanger rod nuts and washers were retained with the box beam for subsequent use in structural tests. Photographs of specimens 1,2 and 3 before and after removal are shown in figures 5.28 - 5.30. Specimens $5 \mathrm{~A}$ and $5 \mathrm{~B}$ are shown in figure 5.31 .

Cores were removed from the concrete decks of 6 of the 12 walkway spans using a 2 in $(51 \mathrm{~mm})$ I.D. diamond coring bit as shown in figure 5.32. To obtain homogeneous cores with flat ends for subsequent density and compression tests, it was necessary to center the bit over the flat portion of the formed steel deck and, at the same time, avoid the welded wire reinforcement. Where possible, cores were removed at a point directly over a cross beam and at the quarterand mid-points in the cross beam spacing to obtain some measure of the variation in slab thickness. Considerable difficulty was encountered in obtaining complete cores from the second and fourth floor walkways because of fractures in the concrete decks. A total of 24 cores were removed, but only 19 of these were considered to be of sufficient quality for testing. Each core was assigned a specimen number on removal and the same specimen number was marked on the deck adjacent to the core hole. Table 5.11 lists the cores and their locations. The cores selected for testing and actually removed from the warehouse are shown in figure 5.33 .

At the same time the concrete cores were removed, measurements of topping thickness for each span in the second and fourth floor walkway were obtained. For those spans having most of the carpeting and footlights in place, measurements were extremely limited. Topping removed with the cores was included in the measurements to obtain the average thicknesses listed in table 5.12.

\subsubsection{Specimen Cataloging and Preparation for Shipment}

Upon removal from the debris, each specimen was measured and all identifying marks were noted. All specimens were then wrapped in clear plastic sheet to await final inspection by designated representatives of the Liaison Committee of the Plaintiffs' Counsel and the Liaison Committee of the Defendants' Counsel. Prior to this inspection a listing of all specimens, complete with descriptions of origin and physical features, was jointly prepared by representatives of NBS and the Crown Center Redevelopment Corporation.

On November 5, 1981, after representatives of the Liaison Committees had inspected and certified the specimens, custody was transferred to NBS and all specimens were then wrapped for shipment and wax seals were affixed. NBS personnel transported the specimens by van to the NBS laboratories at Gaithersburg, Maryland, arriving on November 6.

Because of problems encountered with the replication of fracture surfaces (see section 5.5), four fracture surfaces from the bottom flanges of the fourth floor box beams were removed on December 16-17, 1981. Five additional hanger rod nuts and washers were also removed at this time for the purpose of obtaining hardness 
measurements. A description of all specimens removed from the walkway debris and their corresponding NBS iaentification numbers are presented in table 5.13.

\subsubsection{Specimen Storage and Handling}

Upon arrival at NBS, the specimens were stored in a secure area to await inspection of the seals by NBS personnel and photographic documentation. After this was completed on November 9, 1981, a detailed physical description of each specimen was prepared.

Because of the many tests and operations which had to be carried out simultaneously, a chain of possession was maintained for each specimen. In the case of box beam 9M (specimen No. 3), physical descriptions were prepared and chains of possession were maintained for the five subspecimens cut from the beam for use in structural tests.

The procedure followed in subdividing a specimen was to mark clearly the cut lines and the subspecimen identification numbers on the specimen. The specimen was then photographed and the subspecimens were removed and machined to final shape. Each subspecimen identification number was unique and was coded to provide information on both the origin and orientation of the subspecimen. For example, the number "2-LN1" designates a tensile coupon removed from specimen no. 2. It is oriented in the longitudinal direction on the north face of the beam and is the first in a series of such specimens.

\subsection{REPLICATION OF WALKWAY WELD FRACTURE SURFACES}

In addition to specimens of construction materials, the request of October 27 , 1981, also addressed the field replication of certain fracture and washer contact surfaces for the purpose of fractographic analysis. This work was carried out over the period November 2-4, 1981.

The replication procedure involved the application of cellulose acetate (C.A.) tape to the fracture surface. A 1 in $(25.4 \mathrm{~mm})$ piece of tape with a thickness of 0.001 in $(0.03 \mathrm{~mm})$ was softened by applying several drops of acetone to one surface. One to two drops of acetone were applied to the fracture surface and the tape was then worked into place with light finger pressure. Entrapped air bubbles were worked out by smoothing pressure, allowing the softened tape to conform with the fracture surface. After drying for approximately 1 hour, the replica was removed by carefully lifting the edges until free.

The first replica removed from each fracture surface usually contained most of the surface corrosion products and dust. In each case this replica was retained as the archival sample. Additional replicas were stripped until no significant amount of rust was observed. Each successive replica was edge-notched to indicate the side oriented with the outside surface of the box beam.

In some cases a plastic tape (butyrate) with 0.010 in $(0.25 \mathrm{~mm}$ ) thickness and a longer drying time was applied. The details of the fracture topography replicated with butyrate and C.A. were essentially identical. After the final 
replication, each fracture and washer contact surface replicated was given two spray coats of protective acrylic (Krylon).* Table 5.14 lists the locations of fracture and washer contact surfaces and the number of replications of each surface.

Subsequent examination of these replicas by scanning electron microscope (SEM) revealed that attempts to replicate the lower fracture surfaces at the ends of the fourth floor box beams were only partially successful. This prompted an additional request to the Liaison Committees by NBS on November 30, 1981, for permission to remove portions of certain fracture surfaces for direct scanning electron microscopy.

On December 16-17, 1981, four fracture surfaces from the bottom flanges of the fourth floor box beams were removed and transported to NBS for SEM examination. The fracture surfaces, which are listed in table 5.13, were removed by cutting longitudinally along the fillet-web tangent line and then directly across the flange to a point midway between the two hanger rod holes. Details of these specimens are described in chapter 8 . Transfer of custody involved the same inspection and certification procedures described in section 5.4.3.

\subsection{SUMMARY}

Based on measurements and observations made during the site investigation, the following conclusions were drawn:

1. The walkways were properly aligned on their bearing seats prior to the collapse.

2. There was sufficient room to install a nut and washer on the lower end of each fourth floor to ceiling hanger rod with the fourth floor walkway properly leveled.

3. Observed distortions in the west line of fourth floor to ceiling hanger rods and the absence of similar distortions in the east line of fourth floor to ceiling hanger rods suggest that the collapse initiated along the east line of hanger rods.

4. Impact points on the atrium floor indicate a general drift of the walkway spans to the south and west during the collapse. This drift was approximately $1.0 \mathrm{ft}(300 \mathrm{~mm})$ south and $0.9 \mathrm{ft}(270 \mathrm{~mm})$ west.

5. With one exception, damage done to the walkway spans during the rescue operation was superficial.

* Certain commercial equipment, instruments or materials are identified in this report in order to adequately specify the experimental procedure. Such identification does not imply recommendation or endorsement by the National Bureau of Standards, nor does it imply that the materials or equipment identified are necessarily the best available for the purpose. 
6. All of the fourth floor to ceiling hanger rods pulled through both the lower and upper flanges of the fourth floor box beams.

7. Evidence indicates that all hanger rod washers were installed.

8. There is a mirror symmetry to the deformation and distortion of the box beam ends with respect to box beam $9 \mathrm{U}$ in the fourth floor walkway.

9. Observed distortions strongly suggest an initial failure at box beamhanger rod connection $9 \mathrm{UE}$.

10. The actual box beam longitudinal welds can best be described as flare-V-groove welds.

11. Variability in penetration for a given box beam longitudinal weld was not excessive, but penetration varied considerably from weld to weld.

12. Interior tack welds were highly variable in length, location, and penetration. In some cases there was no interior tack weld.

13. In general, the clip angle to box beam fillet welds were of good quality.

14. Observed clip angle failure modes strongly suggest moment reversal at column line 8 and possibly column line 10. No signs of moment reversal at column line 9 were observed.

15. The shear connections at column line 7 experienced large rotational distortion prior to failure of the fillet welds. 
Table 5.1 Coordinates of Fourth Floor to Ceiling Hanger Rods

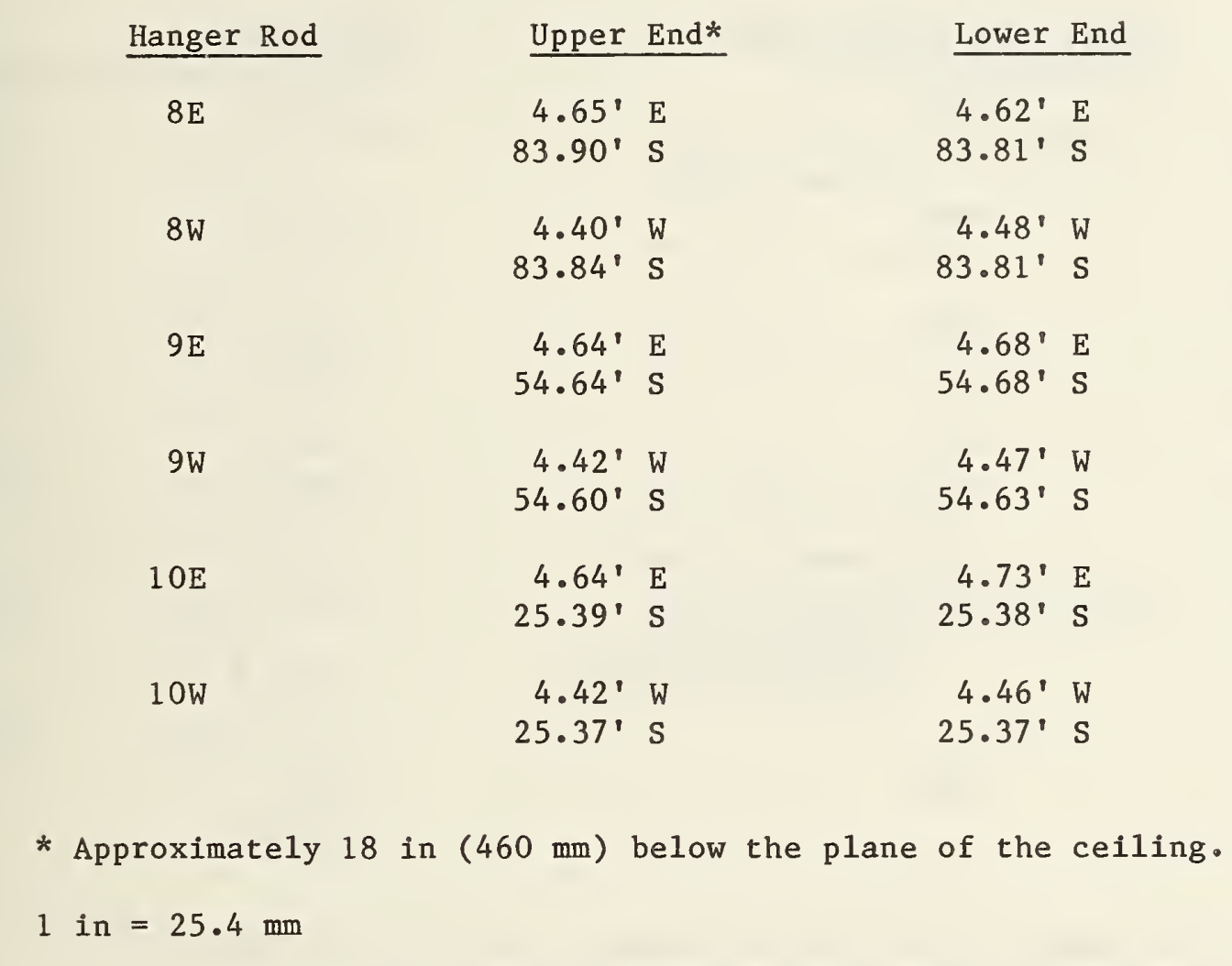

Table 5.2 Elevations of Fourth Floor to Ceiling Hanger Rods (Referenced to Elev. 0.00 assumed datum at first floor leve1)

Hanger Rod

$8 \mathrm{E}$

$8 \mathrm{~W}$

$9 \mathrm{E}$

$9 \mathrm{~W}$

$10 \mathrm{E}$

10W
Intersection with Ceiling

52.48

$52 \cdot 47$

52.44

52.45

52.44

52.43
Lower End

43.59

43.55

43.70

43.55

43.71

43.53 
Table 5.3 Coordinates of Major Impact Points on Atrium Floor

Hanger Rod Impact Point

$8 E^{*}$

$8 W^{*}$

$9 \mathrm{E}$

9W

10E (primary impact)

(secondary impact)

10W

\section{Coordinates}

$3.36^{\prime} \mathrm{E}$

$86.76^{\prime} \mathrm{S}$

$5.10^{\circ} \mathrm{W}$

$86.84^{\prime} \mathrm{S}$

$3.36^{\circ} \mathrm{E}$

$55.32^{\prime} \mathrm{S}$

$5.01^{\prime} \mathrm{W}$

$55.60^{\circ} \mathrm{S}$

$3.41^{\prime} \mathrm{E}$

$26.29^{\prime} \mathrm{S}$

$3.17^{\prime} \mathrm{E}$

$26.30 \mathrm{~S}$

$5.01^{\prime} \mathrm{W}$

$26.24^{\prime} \mathrm{S}$

* Observed tile damage in vicinity of column line 8 was probably due to impact of north end of W16 x 26 stringers in span L7-8.

1 in $=25.4 \mathrm{~mm}$ 
Table 5.4 Alignment of Upper Hanger Rods and Fourth Floor Walkway Relative to Second Floor Walkway

Upper Hanger Rods at Ceiling

\begin{tabular}{|c|c|}
\hline $8 \mathrm{E}$ & $\begin{array}{l}0.09^{\prime} \\
0.15^{\prime}\end{array}$ \\
\hline $8 W$ & $\begin{array}{l}0.07^{\prime} \\
0.09^{\prime}\end{array}$ \\
\hline $9 \mathrm{E}$ & $\begin{array}{l}0.08^{\prime} \\
0.14^{\prime}\end{array}$ \\
\hline $9 \mathrm{~W}$ & $\begin{array}{l}0.05^{\prime} \\
0.10^{\prime}\end{array}$ \\
\hline $10 \mathrm{E}$ & $\begin{array}{l}0.08^{\prime} \\
0.14^{\prime}\end{array}$ \\
\hline $10 \mathrm{~W}$ & $\begin{array}{l}0.01^{\prime} \\
0.13^{\prime}\end{array}$ \\
\hline
\end{tabular}

1 in $=25.4 \mathrm{~mm}$
Fourth Floor Walkway

$\begin{array}{ll}\text { E at South end of Walkway } & 0.03^{\prime} \text { W } \\ \text { (Co1. Line 7) } & 0.15^{\prime} \mathrm{S} \\ \text { E at Col. Line } 8 & 0.02^{\prime} \text { W } \\ & 0.16^{\prime} \mathrm{S} \\ \text { E at Col. Line } 9 & 0.02^{\prime} \text { W } \\ & 0.17^{\prime} \mathrm{S} \\ \text { E at Col. Line 10 } & 0.01^{\prime} \text { W } \\ & 0.19^{\prime} \mathrm{S} \\ \text { E at North end of Stringers } & 0.00^{\prime} \\ \text { (Col. Line 11) } & 0.21^{\prime} \mathrm{S}\end{array}$


Table 5.5 Locations of Impact Points on Atrium Floor Relative to Original Hanger Rod Positions at Second Floor Walkway

Hanger Rod Impact Point

$8 E^{*}$

$8 W^{*}$

$9 \mathrm{E}$

9 W

10E (Primary impact)

(Secondary impact)

10W
Relative Location

$0.87^{\prime} \mathrm{W}$

$3.01^{\prime} \mathrm{S}$

$0.96^{\prime} \mathrm{W}$

$3.09^{\prime} \mathrm{S}$

$0.87^{\prime} \mathrm{W}$

$0.82^{\prime} \mathrm{S}$

$0.87^{\circ} \mathrm{W}$

$1.10^{\prime} \mathrm{s}$

$0.82^{\prime} \mathrm{W}$

$1.05^{\circ} \mathrm{S}$

$1.06^{\prime} \mathrm{W}$

$1.06^{\circ} \mathrm{s}$

$0.87^{\prime} \mathrm{W}$

$1.00^{\prime} \mathrm{S}$

* Observed tile damage in vicinity of column line 8 was probably due to impact of north end of W16 x 26 stringers in span L7-8.

1 in $=25.4 \mathrm{~mm}$ 
Table 5.6 Length and Position of Box Beam Interior Tack Welds

\begin{tabular}{|c|c|c|c|c|c|c|}
\hline \multirow{3}{*}{$\begin{array}{l}\text { Connection } \\
\text { Number } \\
\text { 8UE }\end{array}$} & \multicolumn{3}{|c|}{ Bottom Flange } & \multicolumn{3}{|c|}{ Top Flange } \\
\hline & \multirow{2}{*}{$\begin{array}{c}\begin{array}{c}\text { Net } \\
\text { Length } \\
\text { (inches) }\end{array} \\
1.42\end{array}$} & \multicolumn{2}{|c|}{$\begin{array}{l}\text { Dimension } \\
\text { (inches) }\end{array}$} & $\begin{array}{c}\text { Net } \\
\text { Length } \\
\text { (inches) }\end{array}$ & $\mathrm{A}^{\mathrm{Din}}$ & $\begin{array}{l}\text { ion } \\
\text { B } \\
\end{array}$ \\
\hline & & 0 & 0 & No weld & & \\
\hline 8UW & 1.38 & 0 & 0 & No weld & & \\
\hline 9UE & 0.98 & 0 & 0.47 & 0.71 & 0.28 & 0.31 \\
\hline 9UW & 1.06 & 0.20 & 0 & 1.18 & 0 & 0 \\
\hline 1OUE & 1.18 & 0.20 & 0 & 0.87 & 0.28 & 0.24 \\
\hline 10UW & 1.30 & 0 & 0 & 1.30 & 0 & 0 \\
\hline 8LE & No weld & & & 1.97 & 0 & -- \\
\hline $8 \mathrm{LW}$ & 1.73 & 0 & 3.43 & 2.24 & 0 & 2.90 \\
\hline 9LE & 1.77 & 0 & -- & 1.57 & 0 & -- \\
\hline $9 \mathrm{LW}$ & 2.56 & 0.20 & -- & 1.50 & 0.08 & -- \\
\hline 10LE & 1.54 & 0.08 & -- & 1.73 & 0 & -- \\
\hline $10 \mathrm{LW}$ & 1.69 & 0.12 & -- & 1.57 & 0.12 & -- \\
\hline $8 M E$ & No weld & & & 1.10 & 0.35 & -- \\
\hline $8 \mathrm{MW}$ & 0.39 & 0 & -- & 0.75 & 0.12 & -- \\
\hline $9 M E$ & 1.26 & 0 & 0 & No weld & & \\
\hline $9 \mathrm{MW}$ & 0.75 & 0 & 0.67 & No weld & & \\
\hline 10ME & 1.06 & 0.08 & - & No weld & & \\
\hline $10 \mathrm{MW}$ & 1.14 & 0.08 & - & No weld & & \\
\hline
\end{tabular}

1 in $=25.4 \mathrm{~mm}$

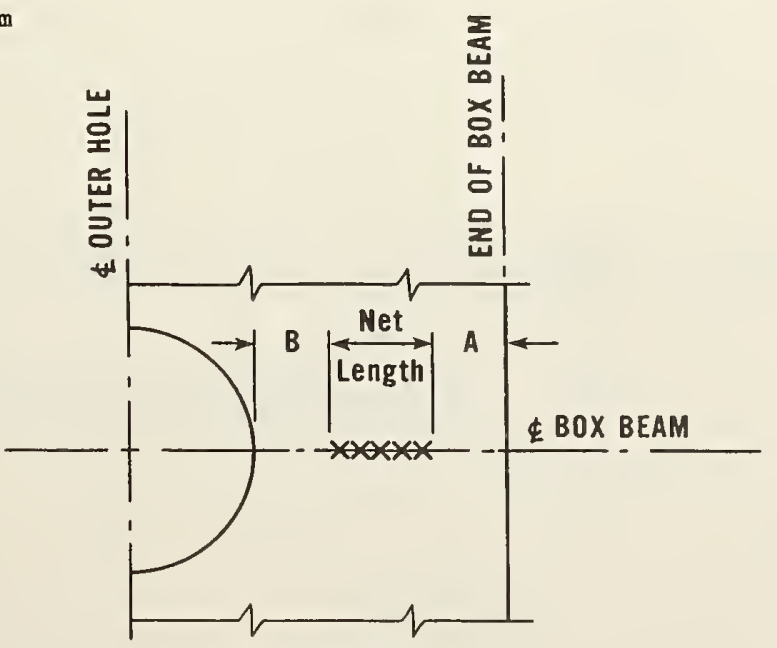

PLAN VIEW

(Definition Sketch) 
Table 5.7 Field Measurements of Weld Penetration at Ends of Fourth Floor Walkway Box Beams

\begin{tabular}{|c|c|c|c|c|}
\cline { 2 - 5 } & \multicolumn{3}{|c|}{ Weld Penetration (mm) } \\
\hline \multirow{2}{*}{$\begin{array}{c}\text { Connection } \\
\text { Number }\end{array}$} & \multicolumn{2}{|c|}{ Bottom Flange } & \multicolumn{2}{c|}{ Top Flange } \\
\hline 8UE & $1.0-1.5$ & $0-2.0$ & $1.0-1.5$ & no weld \\
8UW & Complete Penetration (a) & 2.0 & no weld \\
9UE & $1.5-2.0$ & 2.5 & 1.5 & 2.0 \\
9UW & $1.5-2.0(\mathrm{~b})$ & $1.5-2.5(\mathrm{~b})$ & $1.0-2.0$ & $1.0-2.0$ \\
\hline 10UE & 2.0 & $2.0-2.5$ & $1.5-2.0$ & $2.0-3.0$ \\
\hline
\end{tabular}

Note: (a) Exterior and the interior welds merged, leading to complete penetration.

(b) Edge of hole badly damaged by nut and washer.

1 in $=25.4 \mathrm{~mm}$ 
Table 5.8 Measured Lengths of Stringers and Stringer Connections

\begin{tabular}{|c|c|c|c|c|c|}
\hline $\begin{array}{l}\text { Connection } \\
\text { Number }\end{array}$ & $\begin{array}{c}\text { Span } \\
\text { Number }\end{array}$ & $\begin{array}{r}\text { Dista } \\
\text { Stri } \\
\text { Ad jo }\end{array}$ & $\begin{array}{l}\text { nd of } \\
\text { d of } \\
\text { nger }\end{array}$ & Length & inger \\
\hline & & East & West & East & West \\
\hline U7 & U7-8 & 0.47 & 0.35 & * & 29.38 \\
\hline U8 & U8-9 & 4.65 & 4.61 & 28.85 & 28.85 \\
\hline U9 & U9-10 & 4.72 & 4.65 & 28.84 & 28.84 \\
\hline U10 & U10-11 & * & 4.57 & 29.39 & 29.38 \\
\hline $\mathrm{U} 11$ ** & & 2.25 & 2.25 & & \\
\hline L7 & L7-8 & 0.51 & 0.51 & * & 29.33 \\
\hline L8 & L8-9 & 4.65 & 4.76 & * & * \\
\hline L9 & L9-10 & 4.84 & 4.76 & 28.88 & 28.85 \\
\hline L10 & L10-11 & 4.72 & 4.69 & 29.40 & 29.38 \\
\hline
\end{tabular}

Notes:

* Could not be accurately measured due to severe damage. Nominal values used in calculations.

** Represents extension of stringer bearing pad.

1 in $=25.4 \mathrm{~mm}$ 
Table 5.9 Measured Weights of Damaged Spans

\begin{tabular}{|c|c|c|c|c|c|}
\hline \multirow{2}{*}{$\begin{array}{c}\text { Span } \\
\text { No. }\end{array}$} & \multicolumn{4}{|c|}{ Weight in 1 bs at Indicated Load Cell } & \multirow{2}{*}{$\begin{array}{l}\text { Tota } \\
\text { (1 bs) }\end{array}$} \\
\hline & No. 1 & No. 2 & No. 3 & No. 4 & \\
\hline $\mathrm{U} 7-8(1)$ & 4,450 & 3,410 & 3,690 & 4,210 & 15,760 \\
\hline U8-9 & 4,610 & 3,250 & 4,030 & 4,060 & 15,950 \\
\hline U9-10 & 4,030 & 3,370 & 4,160 & 3,040 & 14,600 \\
\hline U10-11 & 3,570 & 3,610 & 4,230 & 2,590 & 14,000 \\
\hline $\mathrm{L} 7-8$ & 4,760 & 3,030 & 4,060 & 3,280 & 15,130 \\
\hline L8-9(2) & & & & & \\
\hline L9-10 & 3,320 & 3,790 & 3,500 & 3,550 & 14,160 \\
\hline L10-11 & 3,420 & 3,230 & 3,610 & 2,910 & 13,170 \\
\hline$M 8-9(3)$ & 5,020 & 4,190 & 5,890 & 3,720 & 18,820 \\
\hline
\end{tabular}

Notes:

(1) Load cells 2 and 3 were positioned 12 in (305 mm) north of normal positions due to inaccessibility.

(2) Span L8-9 not weighed because of excessive damage.

(3) Load cells 1 and 4 were positioned 5'-6" ( $1.68 \mathrm{~m}$ ) south and load cells 2 and 3 were positioned $7^{\prime}-01 / 8^{\prime \prime}(2.14 \mathrm{~m})$ north of normal positions due to inaccessibility.

$11 b=0.4536 \mathrm{~kg}$

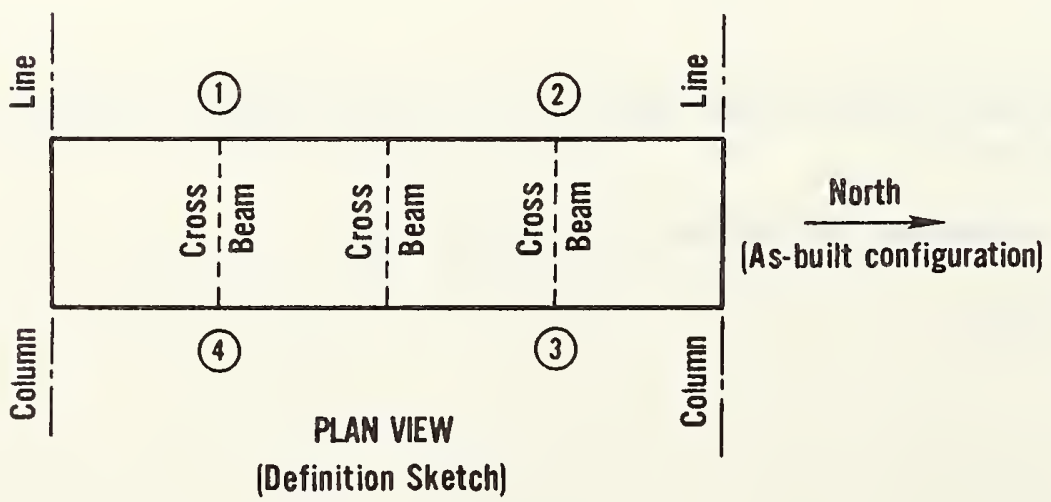




\section{MATER IALS TEST ING}

\section{Specimen Description}

1. Segment of box beam $9 U$. A 24 in longitudinal segment beginning at a point 30 in from the west end of 94 and extending inward.

2. Segment of box beam $8 \mathrm{~L}$. A 36 in longitudinal segment beginning at the west end of $8 \mathrm{~L}$.
3. Box beam 9M. The full box beam will be obtained by removing the bolts connecting the stringer to the clip angles and removal of limited concrete to allow separation of the box beam from the deck.

4. 3 in diameter cores of concrete deck. Up to 30 cores taken at random locations on walkway decks.

5. 36 in lengths of $11 / 4$ in $\phi$ hanger rod. One specimen to be removed from straight segment of 4 th floor to 2 nd floor hanger rod, and one specimen to be removed from ceiling to 4th floor hanger rod.

\section{FRACTOGRAP HY}

1. Access for field replication of:

a) lower fracture surfaces of box beams $8 \mathrm{U}, 9 \mathrm{U}$, and $10 \mathrm{U}$

b) fracture surface of clip angle at box beam 9UE

c) tack welds at level M.

2. A 2 in section of the upper fracture at connection 8UW (north surface) centered at a point 9 in from the west end. Depth of cut to extend $1 / 2$ in from fracture surface.

\section{Type of Examination}

Tensile tests per ASTM E8.

a) Transverse weld tensile tests.

b) Metallography and hardness of weld, heat-affected zone, parent metal.

c) Chemical analysis, weld metal, and parent metal.
Length of core and unit weight

determination.

Tensile tests to determine yield strength, tensile strength, elongation, and reduction of area in accordance with ASTM E8.

\section{Purpose}

Conformance to mechanical property specifications.

Weldment mechanical property variability.

Assessment of microstructure phases contributing to low weldment

toughness.

Conformance to composition specification.

Destructive structural load tests. Determine resistance of box beam to hanger rod pull-through load.

Establish average weight of concrete deck per unit of area.

To clearly establish grade and yield strength of steel used in hanger rod assemblies.

Scanning and transmission electron microscopy.

Replication and direct scanning

electron microscopy.
Validation of replication technique

for fractographic analysis.

1 in $=25.4 \mathrm{mn}$ 


$\begin{array}{ll}\frac{\text { E-W Coordinate (feet) }}{\text { (Dist. from toe }} & \frac{N-S \text { Coordinate (feet) }}{\text { (Dist. from }} \\ \text { of east handrail } & \text { north end of east } \\ \text { support angle) } & \text { stringer) }\end{array}$

$$
\begin{array}{r}
4-01 \\
02 \\
03 \\
04 \\
\\
4-05 \\
06 \\
07 \\
4-08 \\
09 \\
10
\end{array}
$$

03

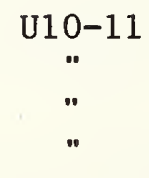

2.85

2.95

2.85

1.85

10.3

10.3

16.8

17.1

5.85

2.80

9.3

2.20

9.0

"1

2.90

2.35

14.5

L10-11

"

2.90

11.5

13.0

(Dist. from toe of west handrail support angle)

15.2

$4-11$
12
13

L9-10

2.35

2.30

2.85

(Dist. from

north end of west

stringer)

12
13

"

(Dist. from

inside face of

west handrail

glass pane1)

14.4

16.5

18.0

\begin{tabular}{cr}
2.60 & 14.0 \\
2.60 & 10.9 \\
2.60 & 8.9 \\
\hline (Dist. from & (Dist. from \\
inside face of & centerline \\
east handrail & crossbeam \\
glass panel) & south end) \\
3.00 & 3.5 \\
2.55 & 3.5 \\
2.00 & 6.9
\end{tabular}

1 in $=25.4 \mathrm{~mm}$

M8-9

"

$\because$

$4-17$
18
19
3.5

"
(Dist. from north end of west stringer)

14.0

0.9

8.9 
Table 5.12 Thickness of Topping Material

\begin{tabular}{|l|ccc|c|}
\hline & \multicolumn{2}{|c|}{ Thickness of Topping (inches) } & \\
\cline { 2 - 5 } Spanber & Average & Maximum & Minimum & $\begin{array}{c}\text { Number of } \\
\text { Observations }\end{array}$ \\
\hline U7-8 & 0.16 & 0.47 & 0 & 6 \\
U8-9 & 0.20 & 0.39 & 0 & 7 \\
U9-10 & 0.38 & 0.68 & 0 & 13 \\
U10-11 & 0.47 & 0.75 & 0 & 13 \\
L7-8 & 0.17 & 0.47 & 0 & 9 \\
L8-9 & 0.44 & 0.67 & 0.08 & 10 \\
L9-10 & 0.20 & 0.43 & 0 & 14 \\
L10-11 & 0.04 & 0.39 & 0 & 15 \\
\hline
\end{tabular}

1 in $=25.4 \mathrm{~mm}$ 
NBS Specimen

Number
Specimen Description and Origin

Specimens Removed November 3-5, 1981

1 A 23.2 in longitudinal segment of box beam $9 U$ beginning at a point 30 in from west end of $9 \mathrm{U}$ and extending inward.

2 A 35.7 in longitudinal segment from west end of box beam $8 \mathrm{~L}$. Includes bent segment of hanger rod, complete with nut and washer.

3

4-01 to 4-19

$5 \mathrm{~A}$

5B

6

Specimens Removed December $16-17,1981$

8

9

10

$11 \mathrm{~A}$

$12 \mathrm{~A}$

$13 \mathrm{~A}$

$14 \mathrm{~A}$

$15 \mathrm{~A}$

Fracture surface, location $8 \mathrm{UE}$, bottom flange, north surface. Fracture surface, location 9UE, bottom flange, south surface. Fracture surface, location $9 \mathrm{UW}$, bottom flange, north surface. Fracture surface, location lOUE, bottom flange, south surface. Nut from upper end of fourth floor to ceiling hanger rod at location 9UE.

Washer from upper end of fourth floor to ceiling hanger rod at location 9UE.

Nut from upper end of fourth floor to celling hanger rod at location 10UW.

Washer from upper end of fourth floor to ceiling hanger rod at location 10UW.

Nut from upper end of third floor to celling hanger rod at location $8 \mathrm{MW}$.

Washer from upper end of third floor to ceiling hanger rod at location $8 \mathrm{MW}$.

Nut from upper end of third floor to ceiling hanger rod at location 9ME.

Washer from upper end of third floor to ceiling hanger rod at location 9ME.

Nut from upper end of third floor to celling hanger rod at location $10 \mathrm{MW}$.

Washer from upper end of third floor to ceiling hanger rod at location 10MW. 
Table 5.14 Replicas of Fracture and Washer Contact Surfaces

Location

8UE - B

- $\mathrm{Cl}$

- Washer contact surface (south)

- Washer contact surface (north)

9UE - A

$-B$

$-\mathrm{D}$

$-E$

- Washer contact surface (south)

- Washer contact surface (north)

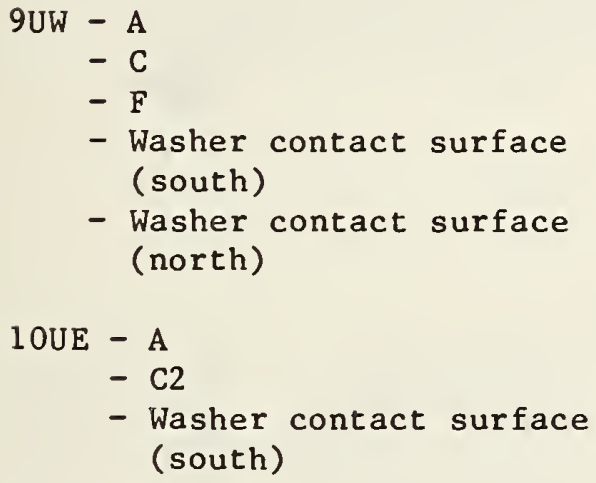

$-\mathrm{C}$

- F

- Washer contact surface (south)

- Washer contact surface (north)

- C2

- Washer contact surface (south)
9UE - North clip angle weld fracture (top)
- North clip angle weld fracture (middle)
- North clip angle weld fracture (bottom)

8MW - Interior tack weld (bottom)
Number of Replications

4

3

3

3

5

5

6

5

3

3

5

4

4

3

1

4

3

2

2

2

2

3

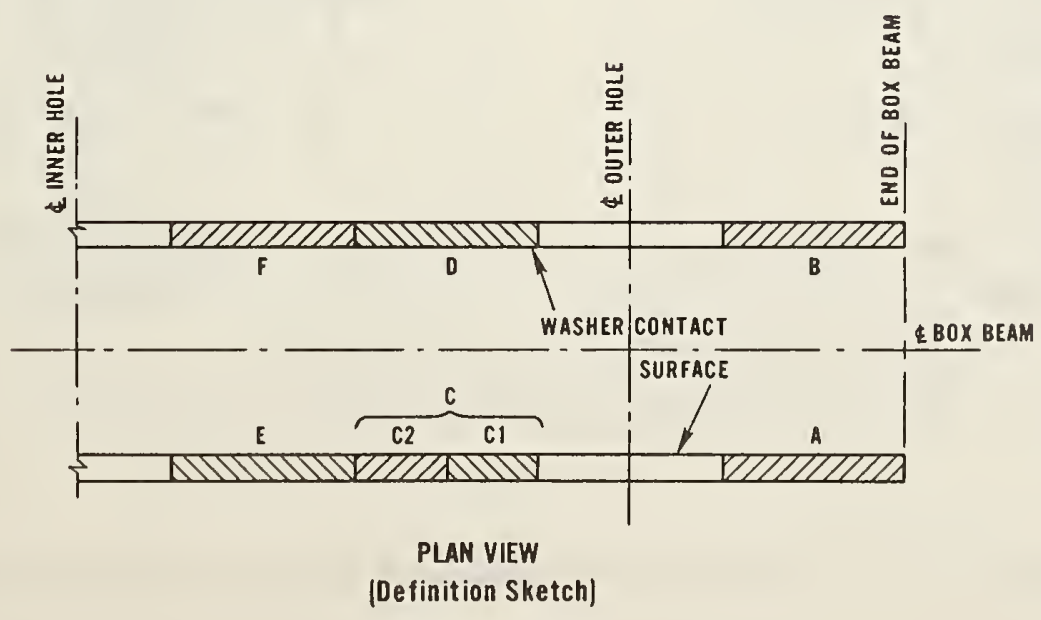



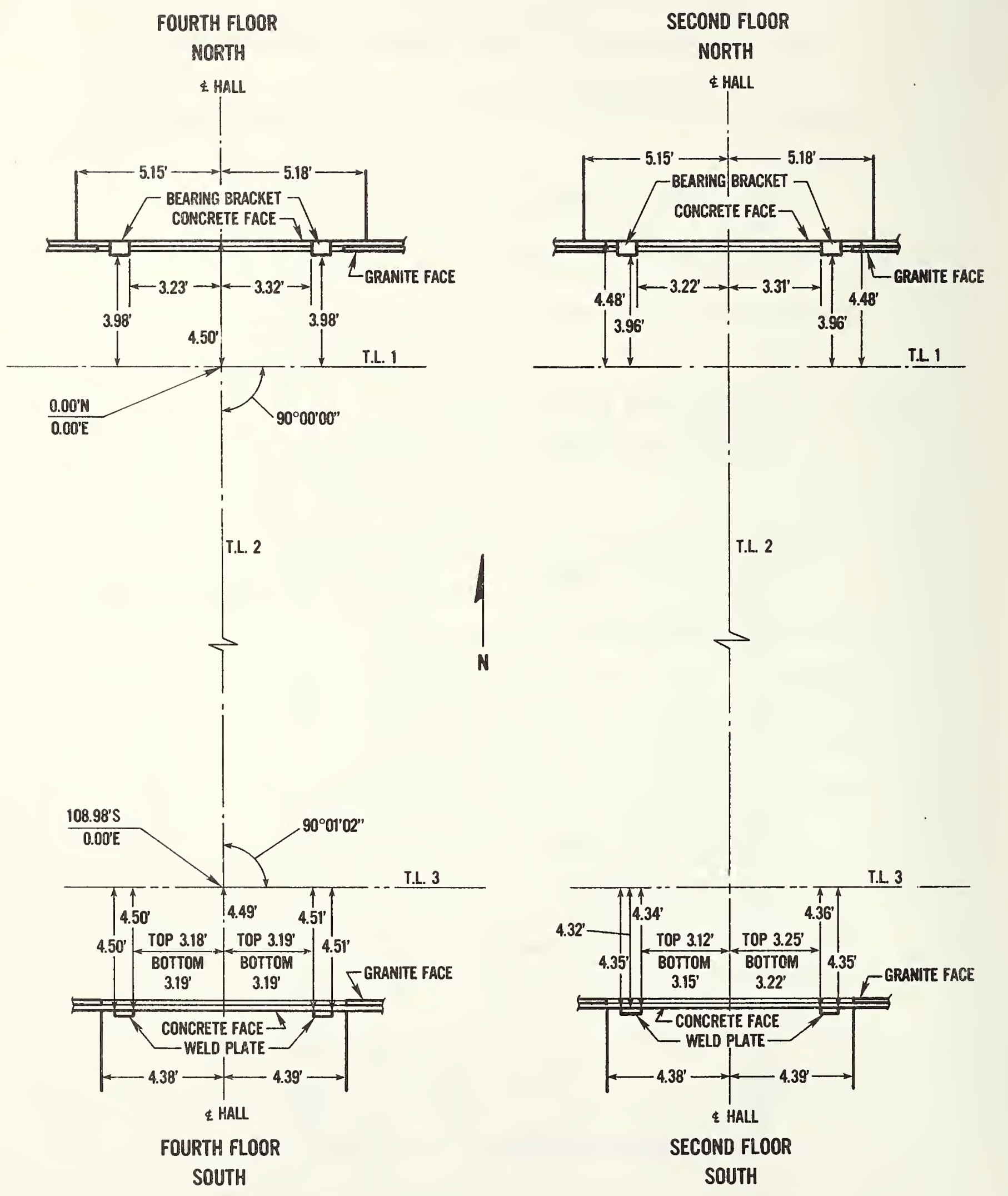

Figure 5.1 Locations of embedded plates and bearing seats. 


\section{DETAILS OF EMBEDDED PLATES - COL. LINE 7}

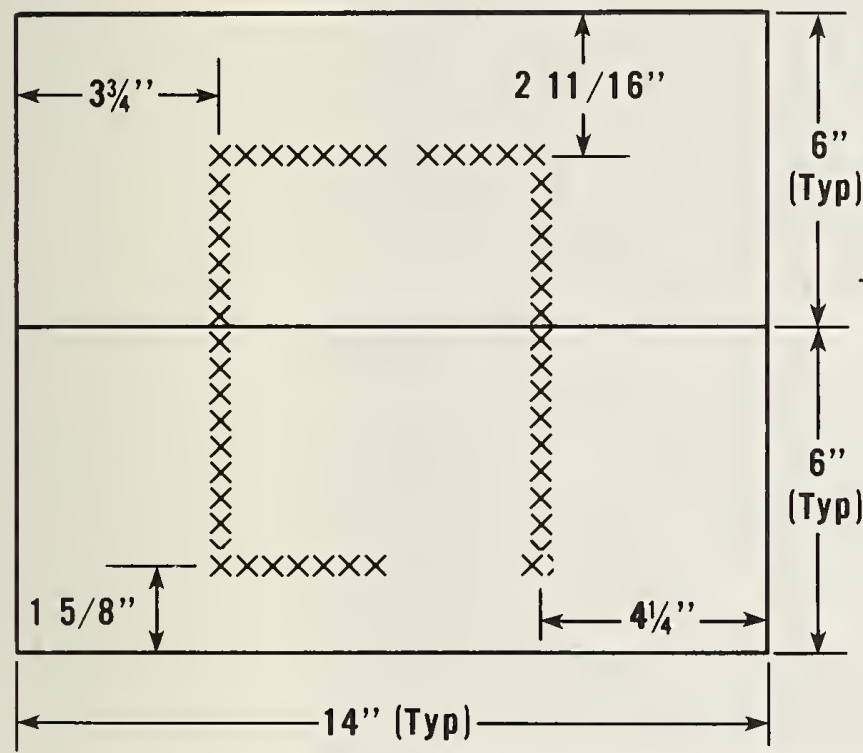

7UE

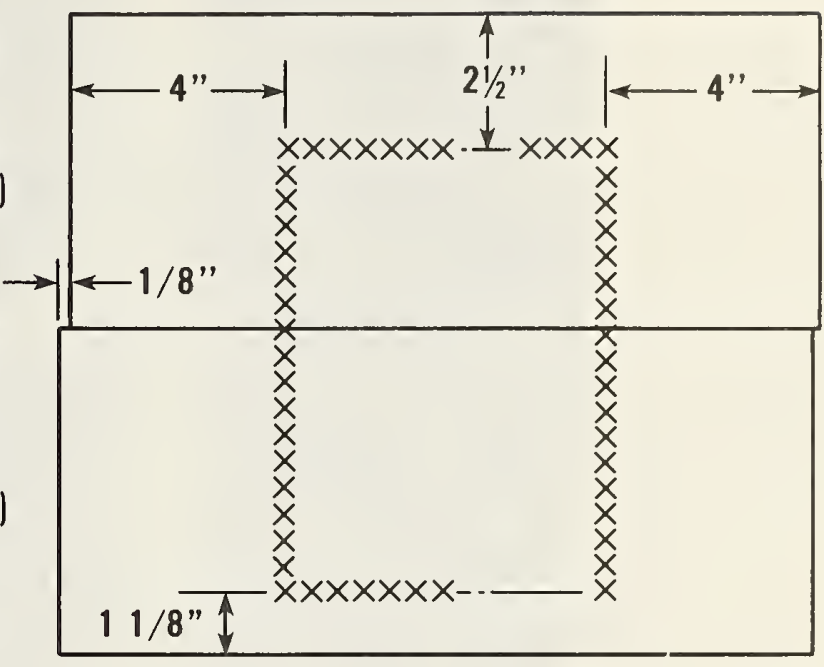

7UW

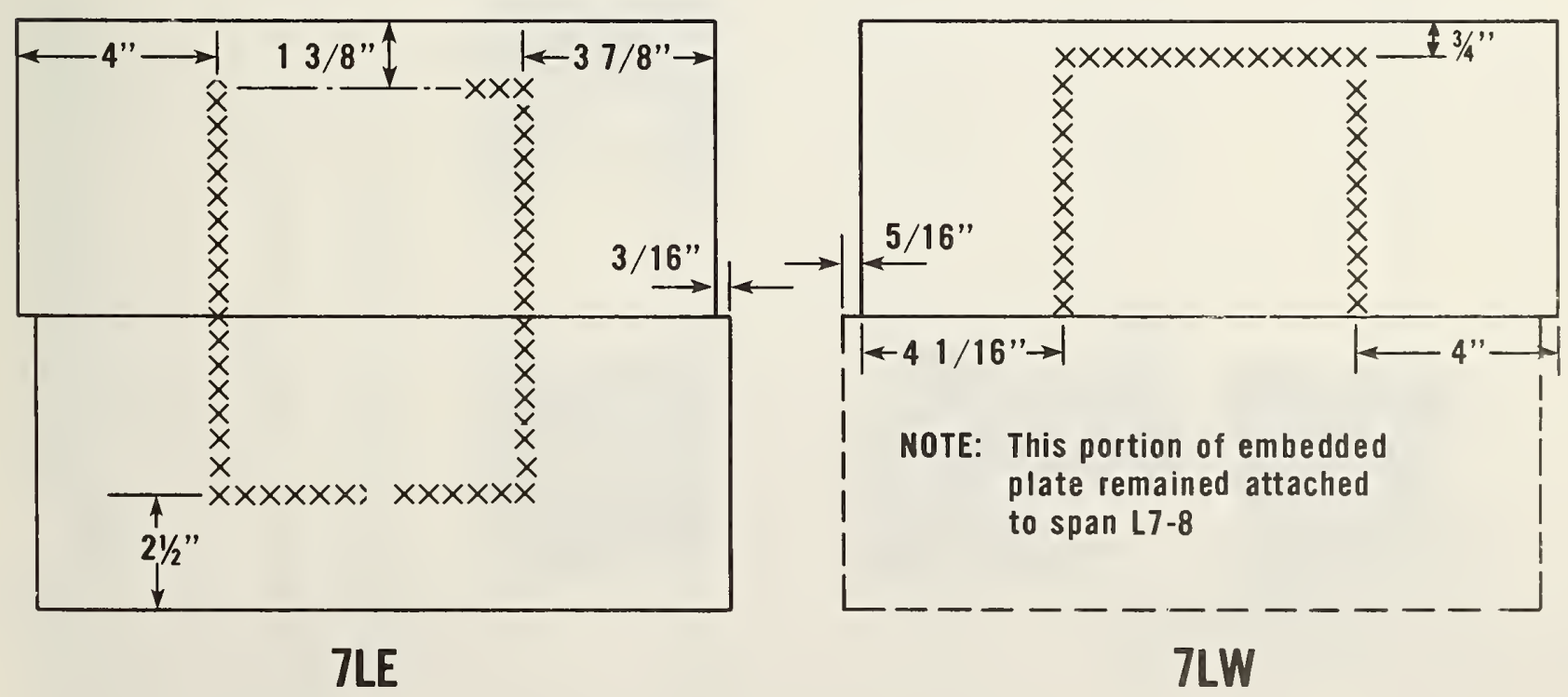

Figure 5.2 Details of embedded plates and fillet welds at column line 7. 


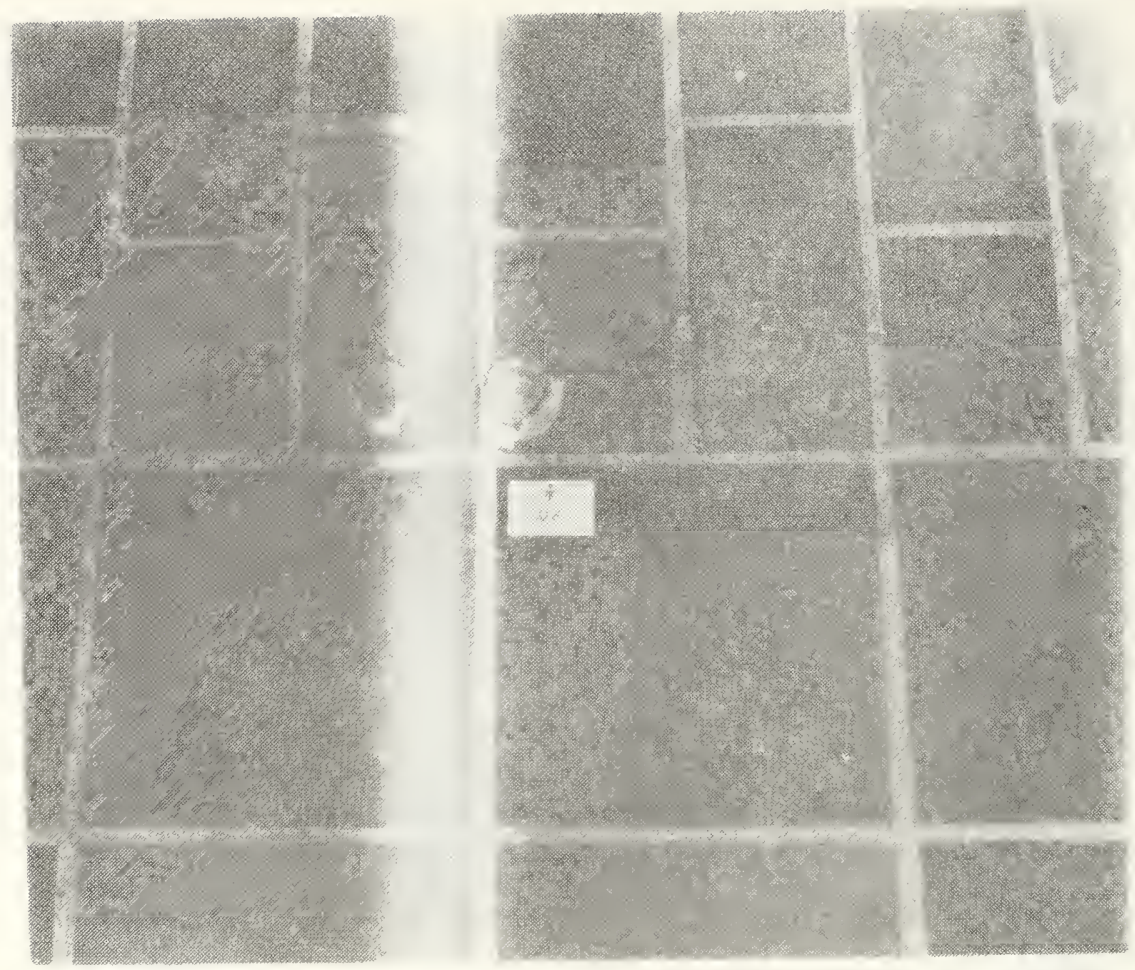

Figure 5.3 Tile damage caused by second floor hanger rod 10E.
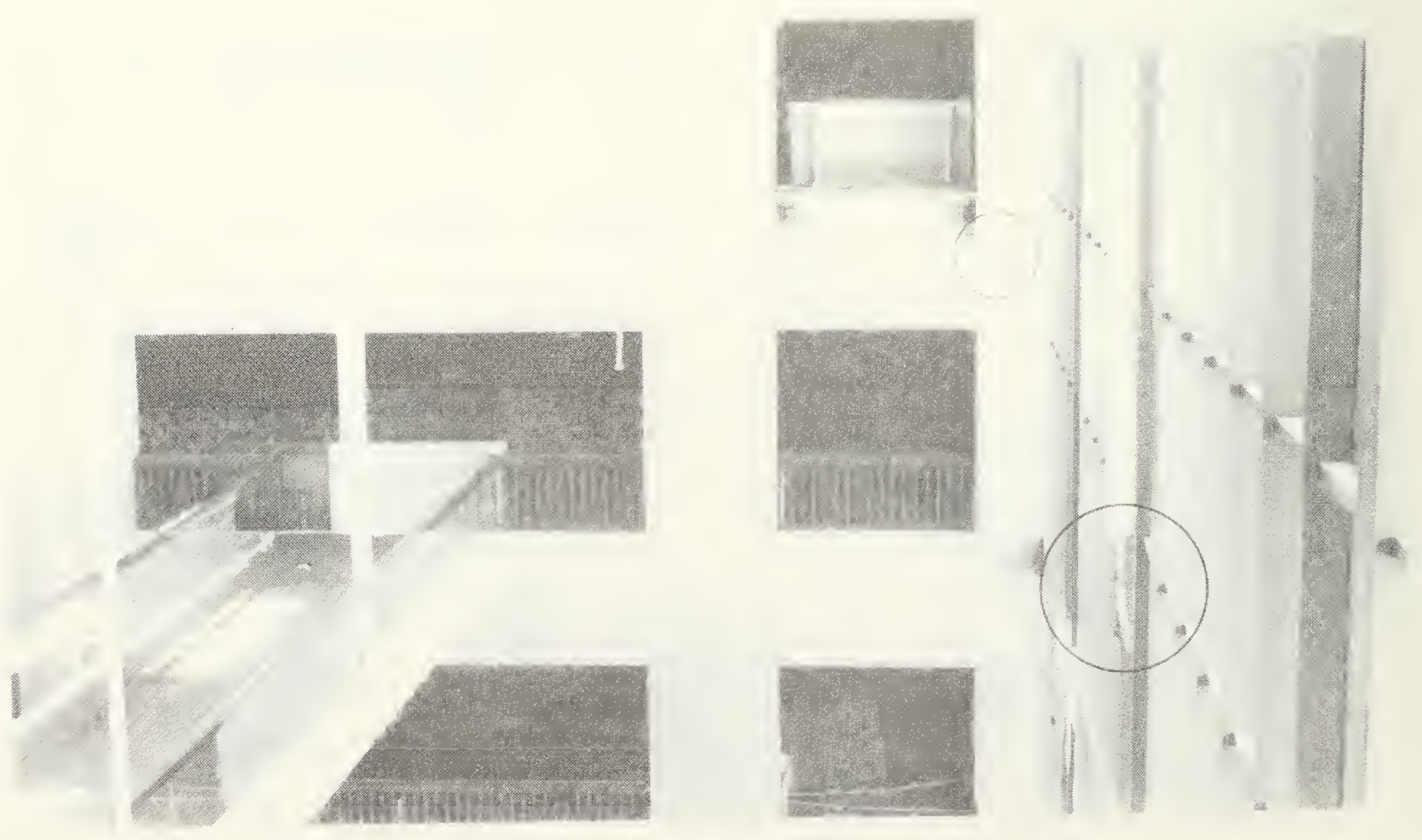

Figure 5.4 Fourth floor to ceiling hanger rods. View from fourth floor looking south. 


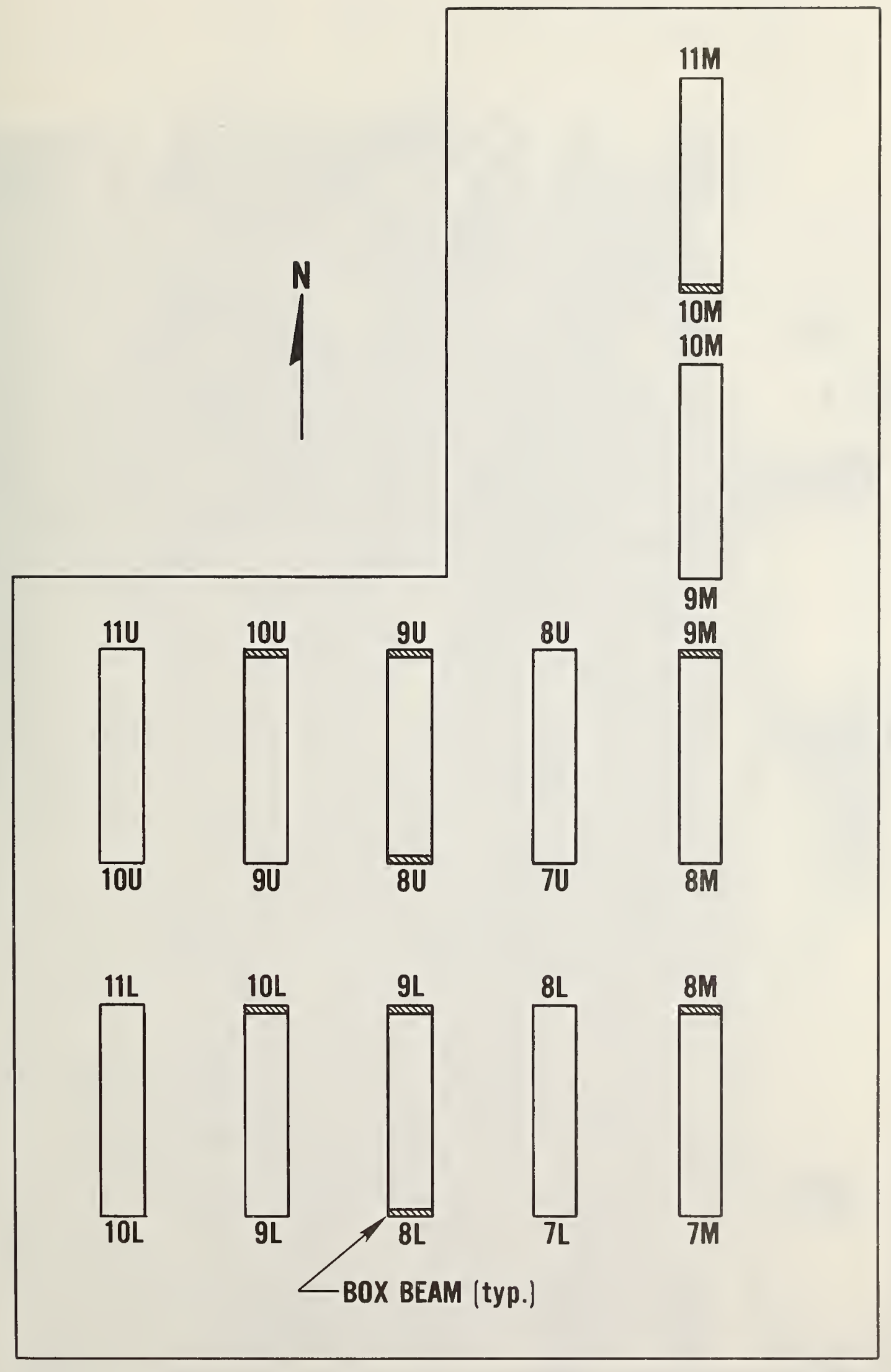

Figure 5.5 Layout of walkway spans in warehouse. 


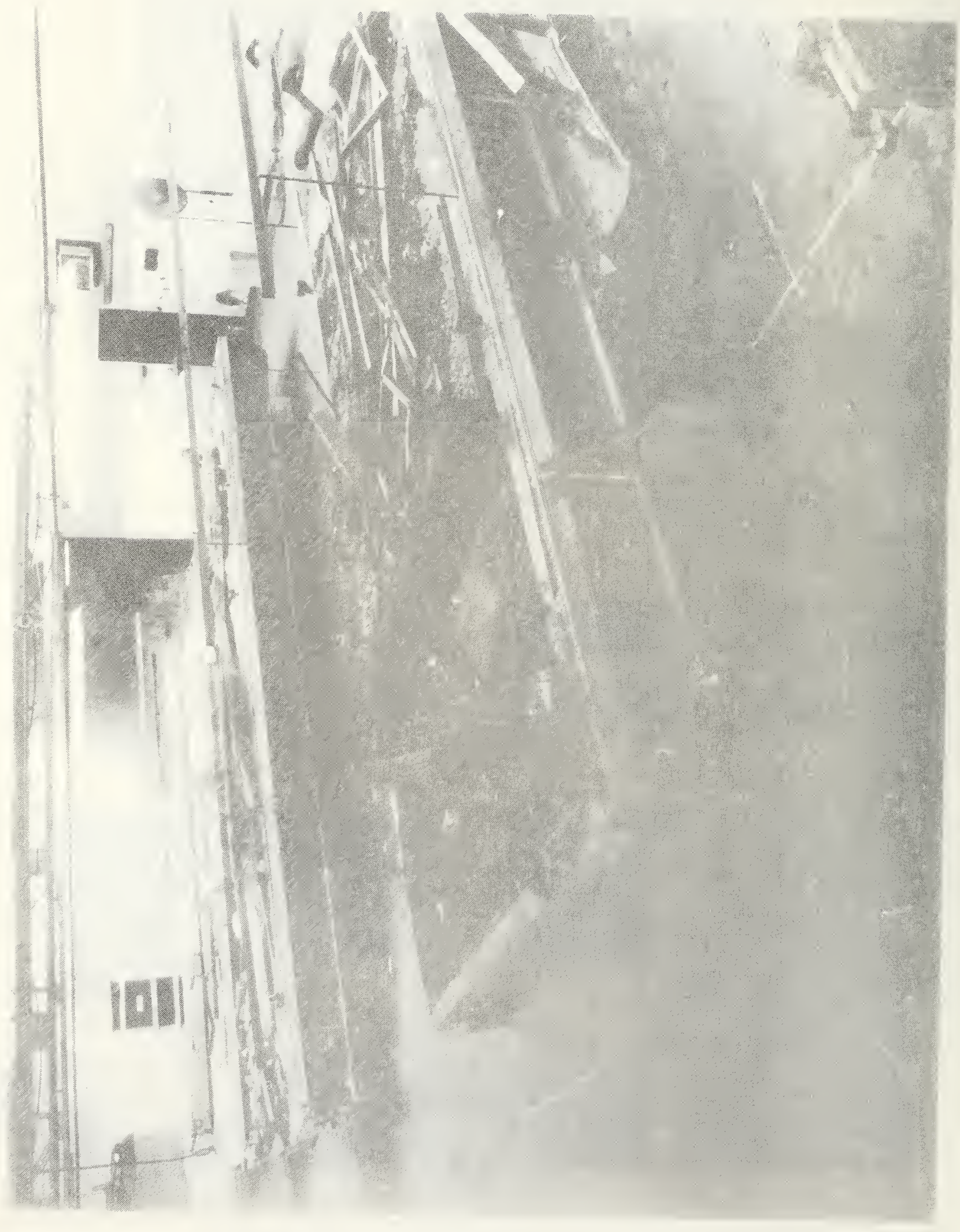

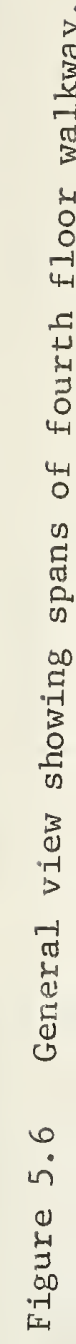




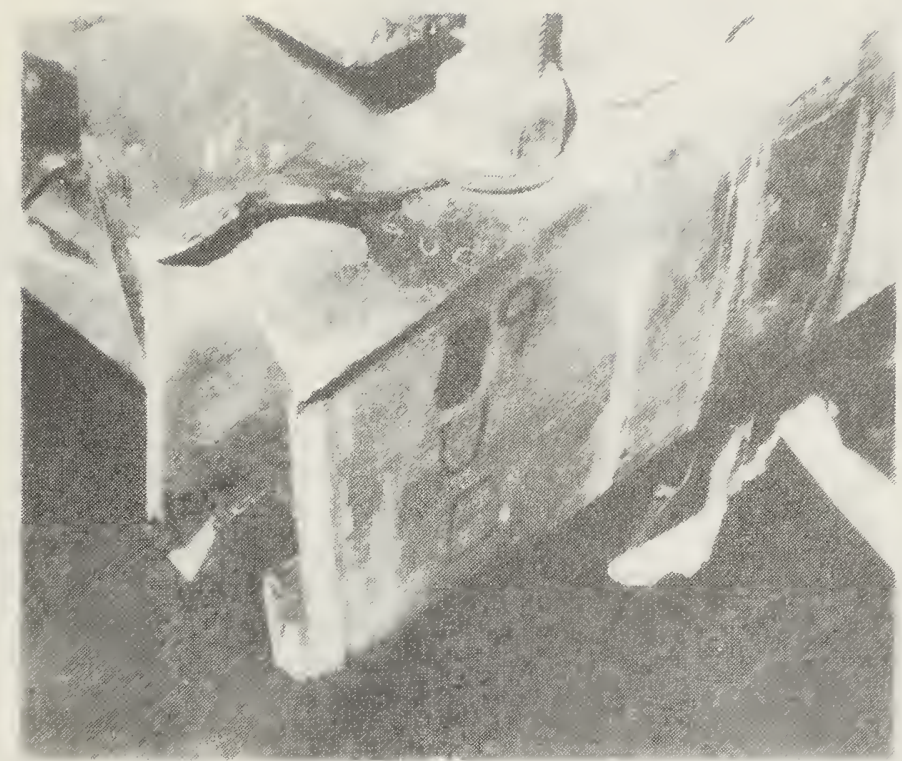

Figure 5.7 Hanger rod pull-through at location 9UE.

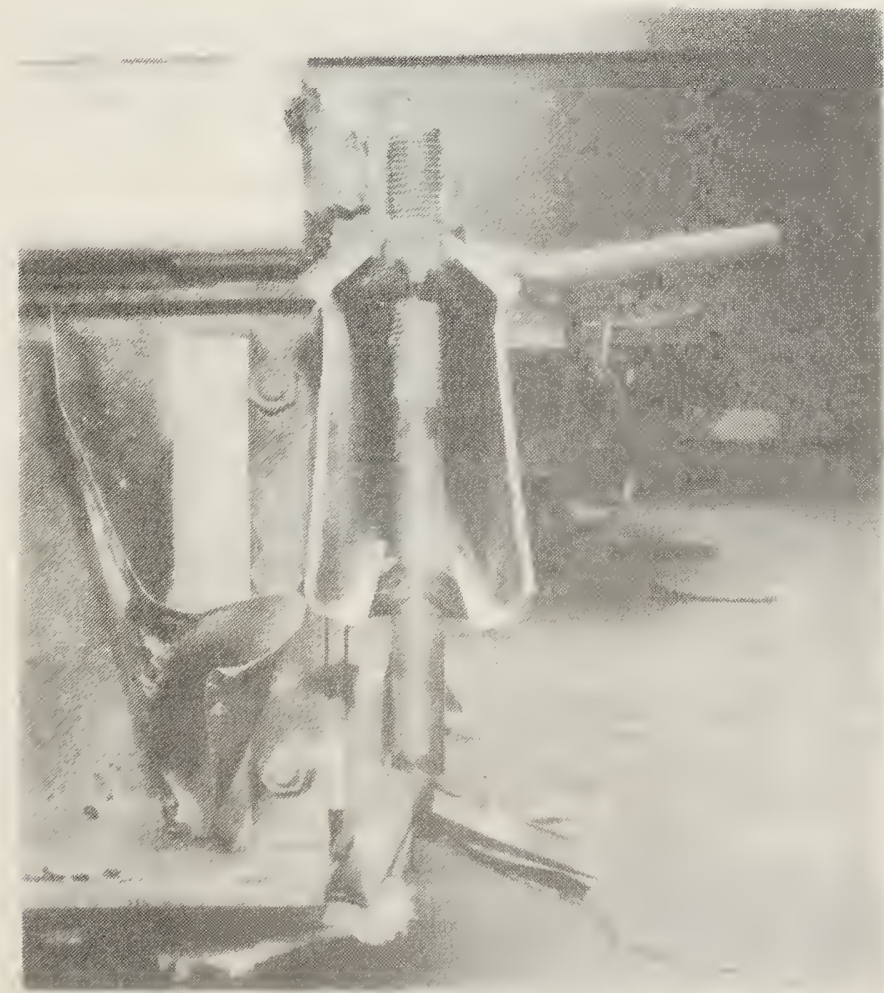

Figure 5.8 End view of box beam at location 9UE. 

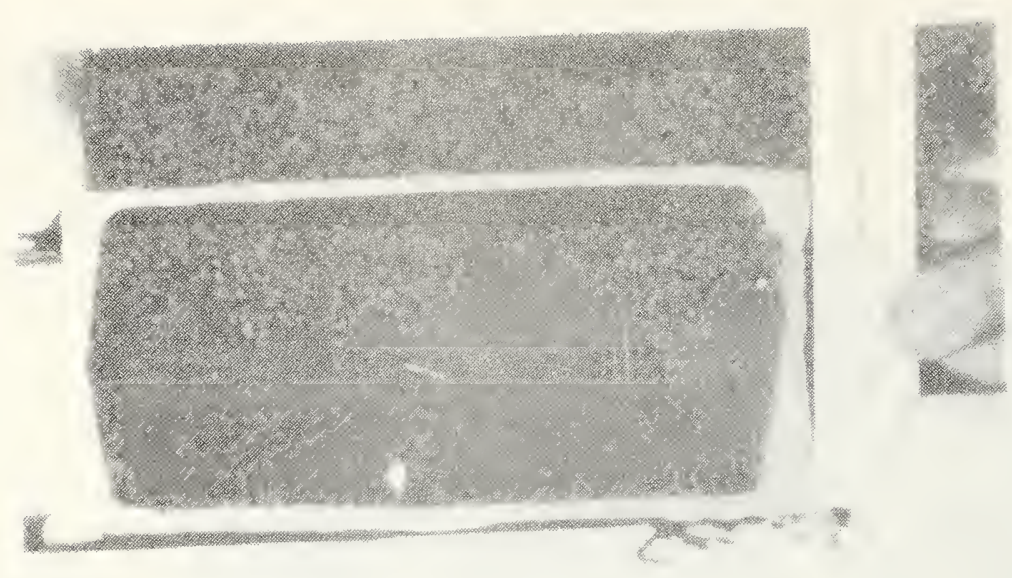

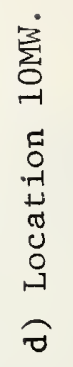

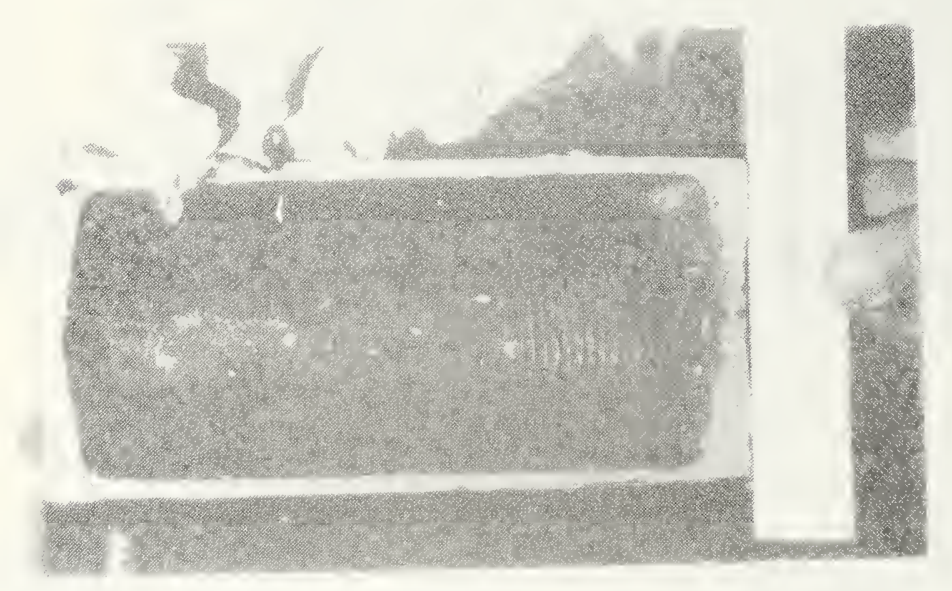

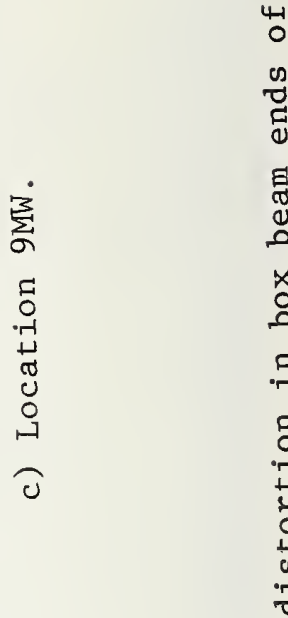
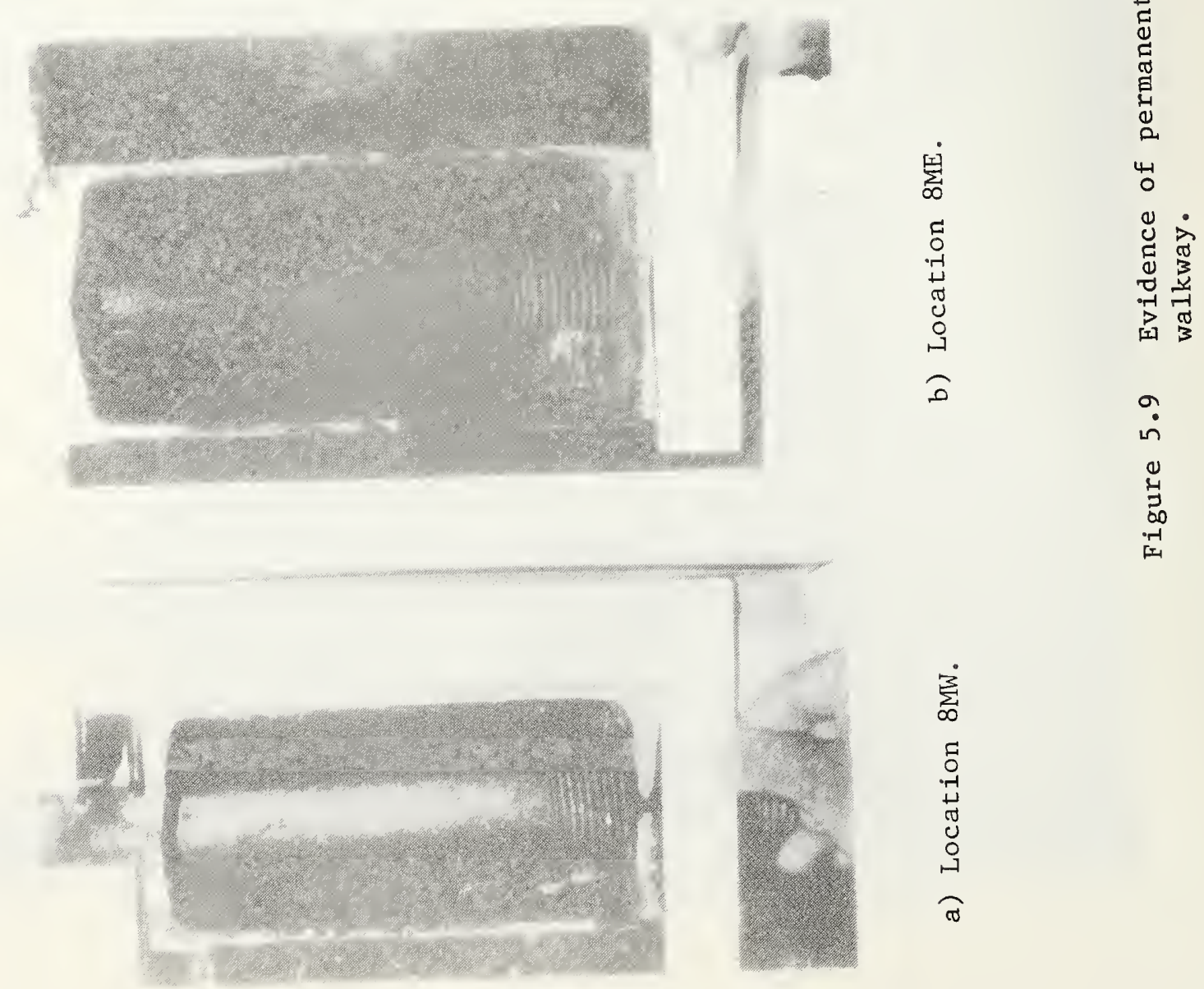


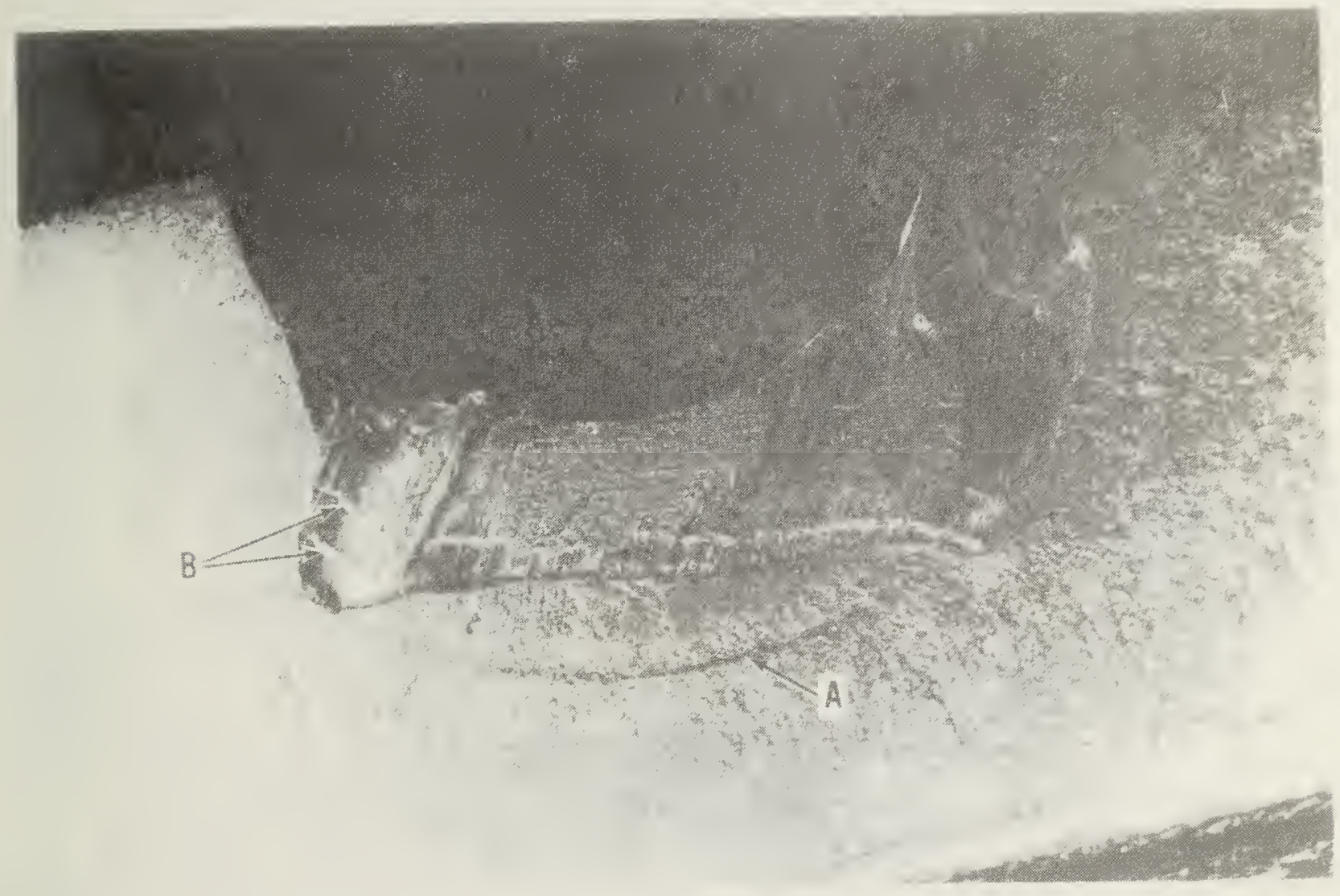

Figure 5.10 Deformation at underside, outer hole, location 9UE due to pull-through of washer/nut assembly. Note imprint of washer (A) and evidence of slip-stick progressive failure (B). 


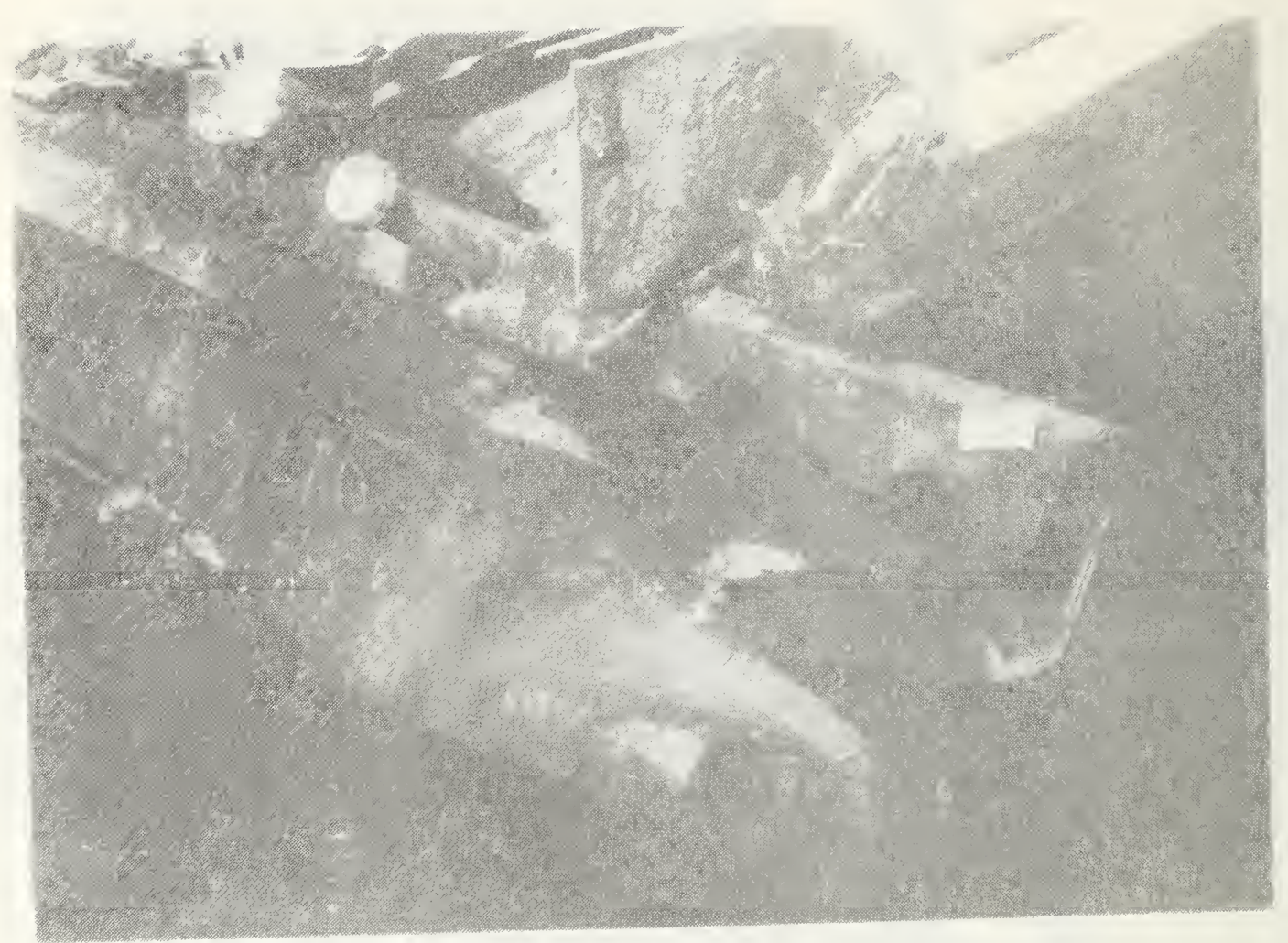

Figure 5.11 Box beam at location 10UW (Span U9-10).

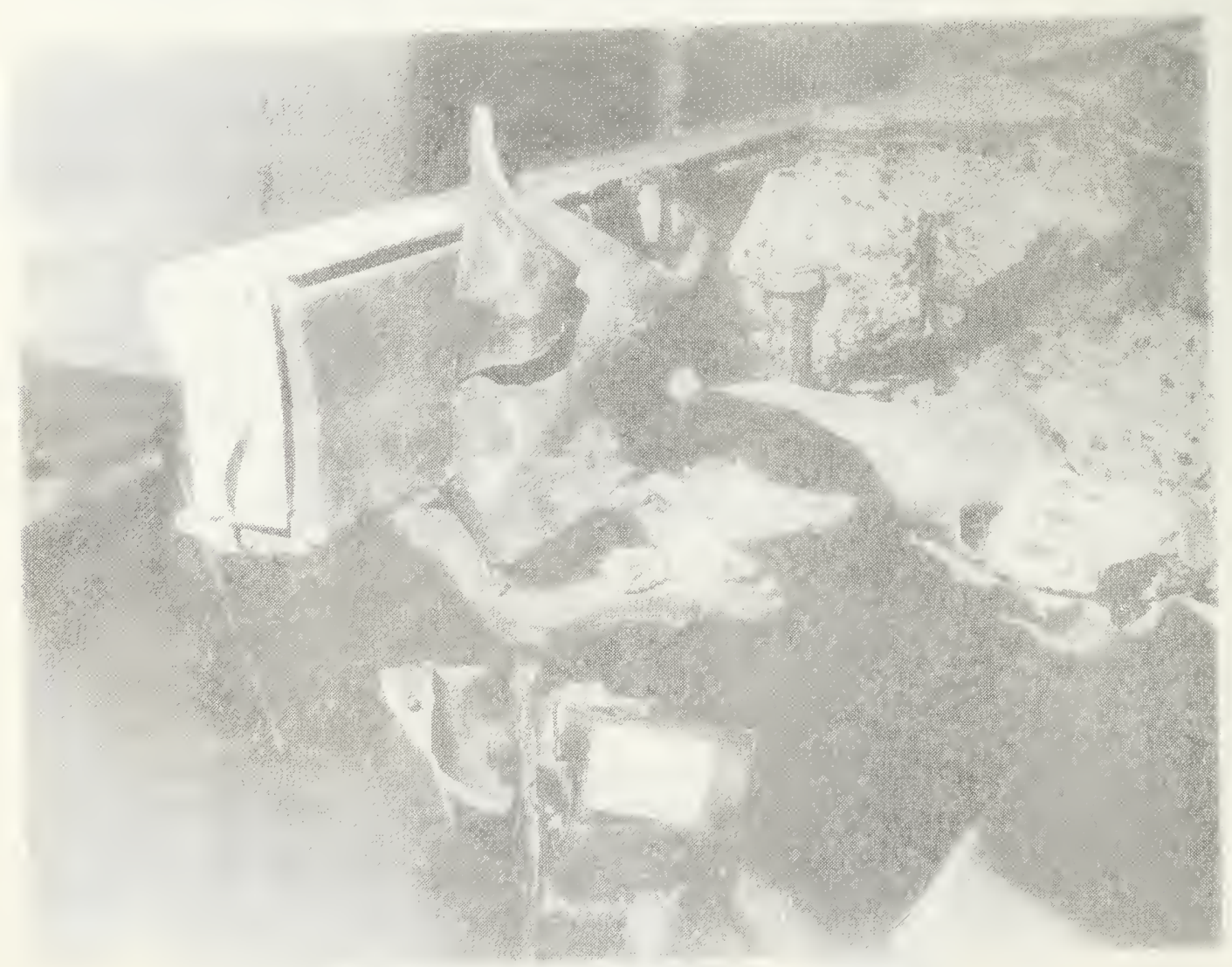

Figure 5.12 End view of $1 / 4^{\prime \prime} \times 6^{\prime \prime}$ edging plate at location IOUW (Span U10-11). 


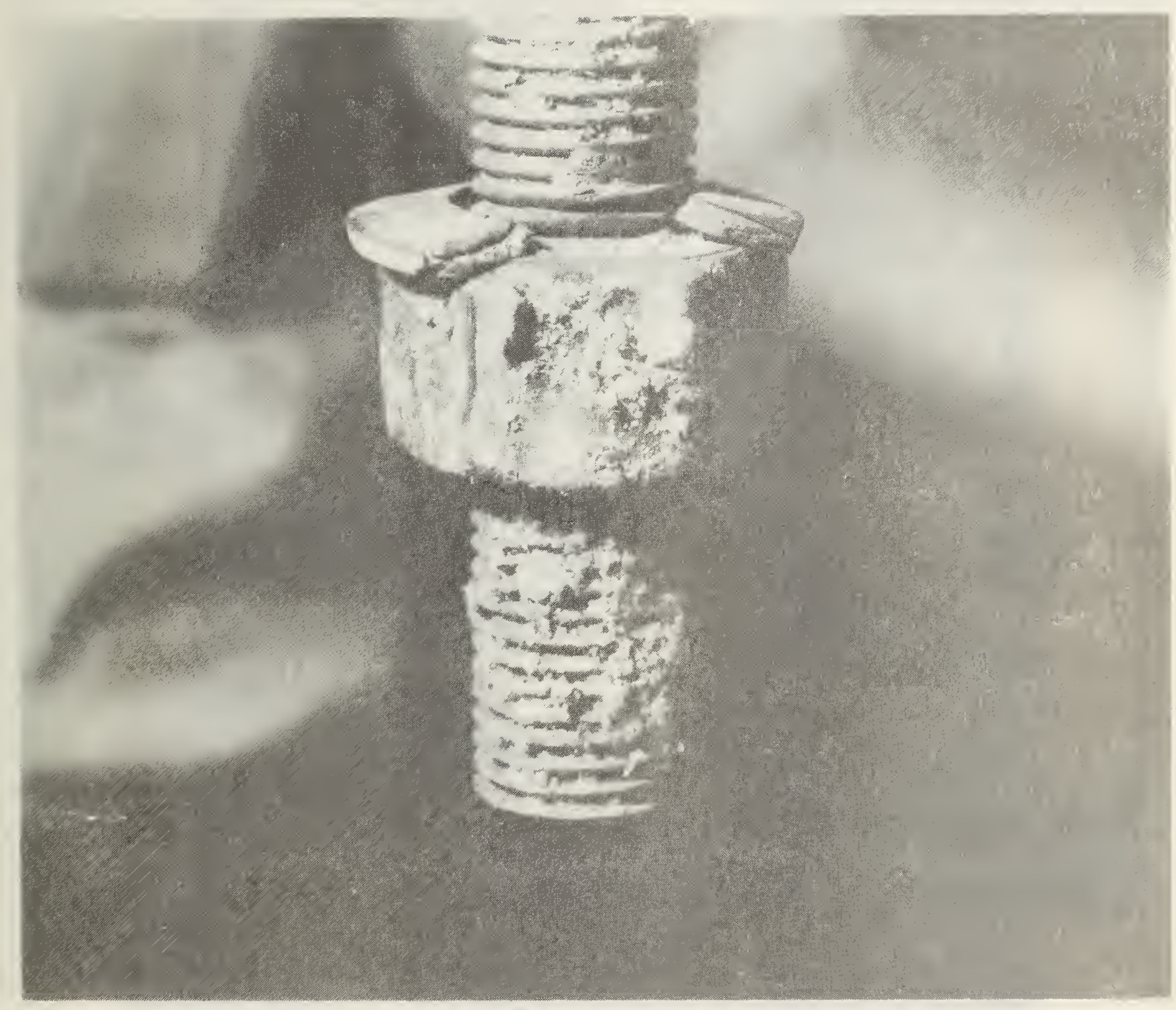

Figure 5.13 Washer at bottom end of fourth floor to ceiling hanger rod 9UW. 

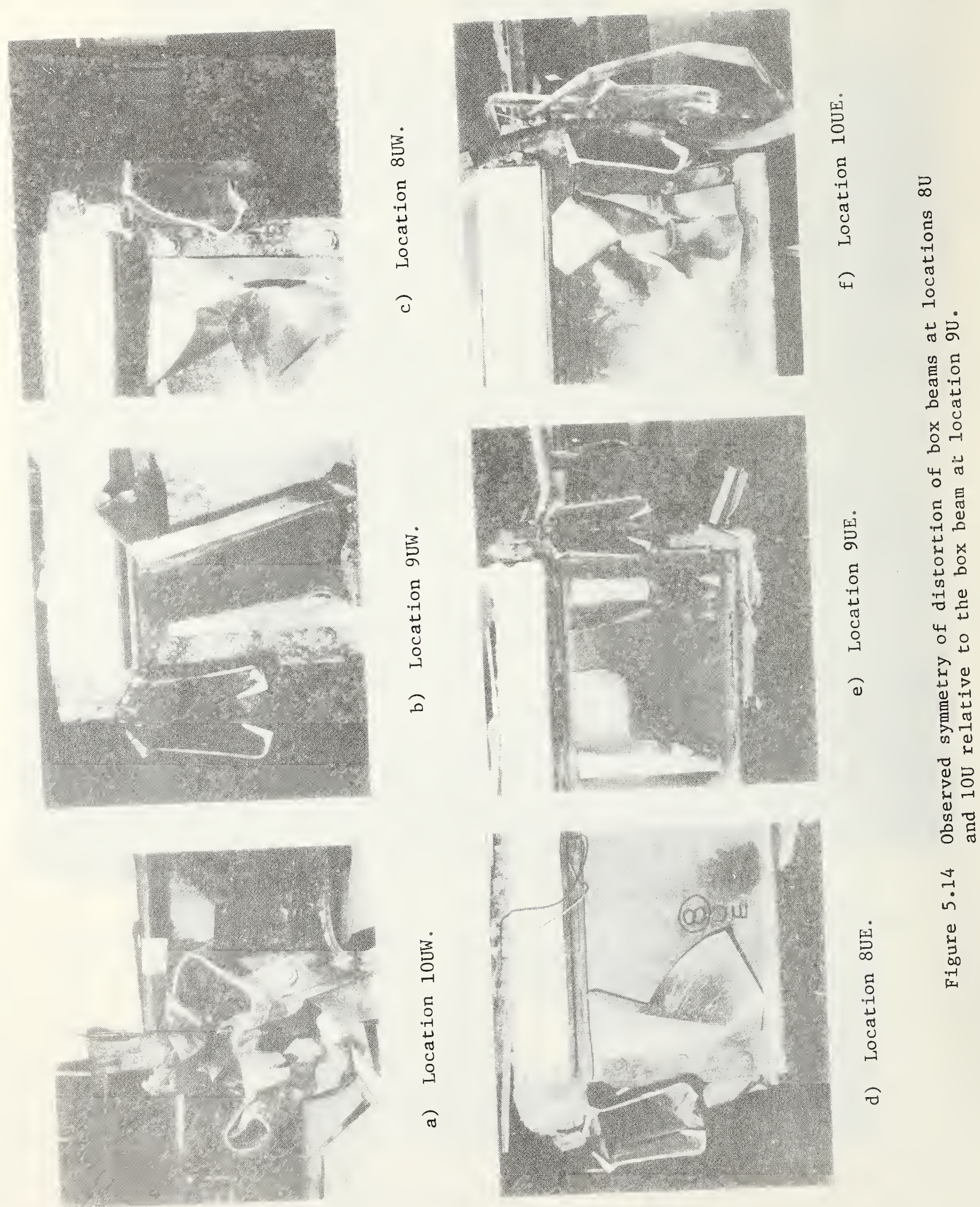


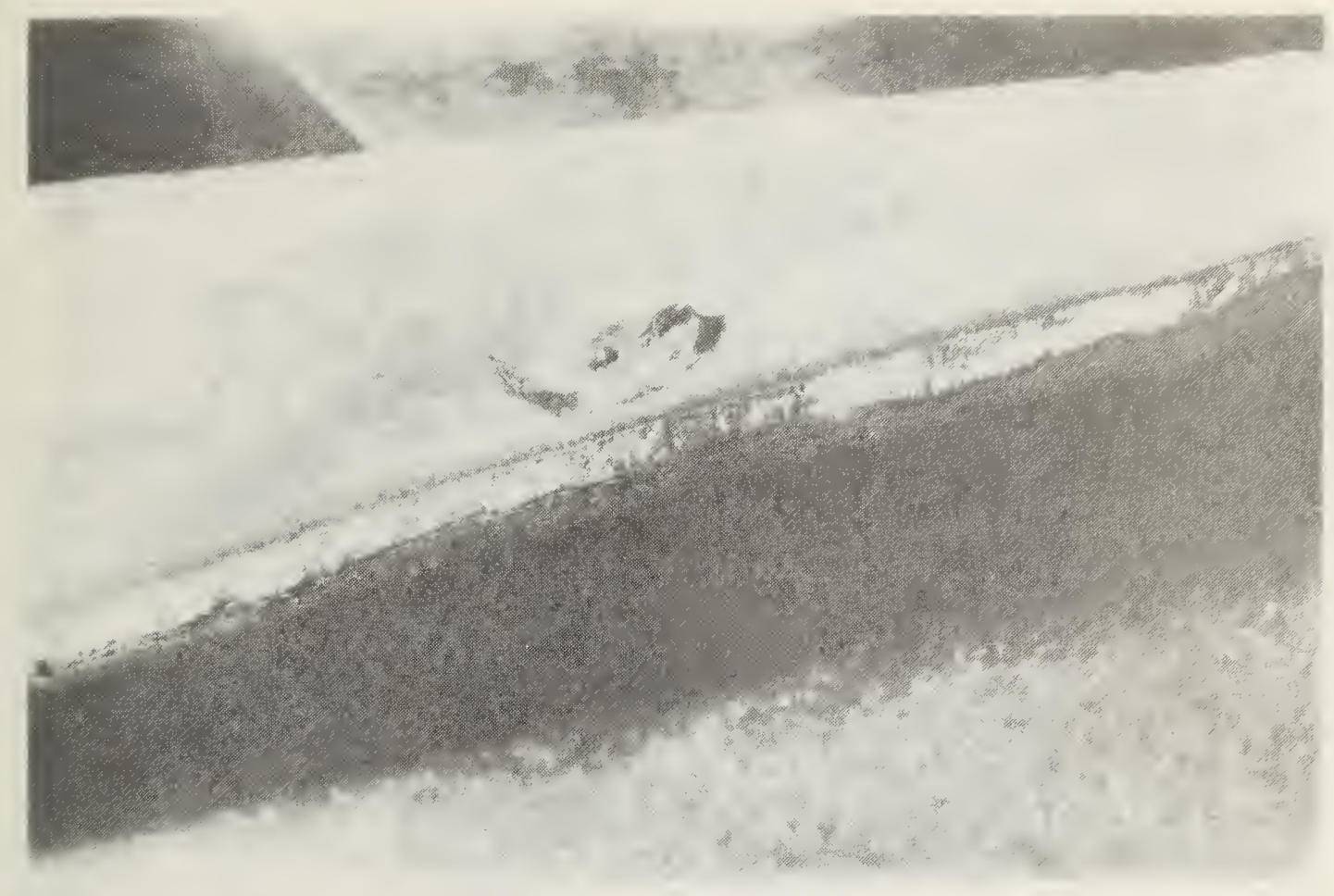

Figure 5.15 Weld penetration at location 8UW, upper flange.

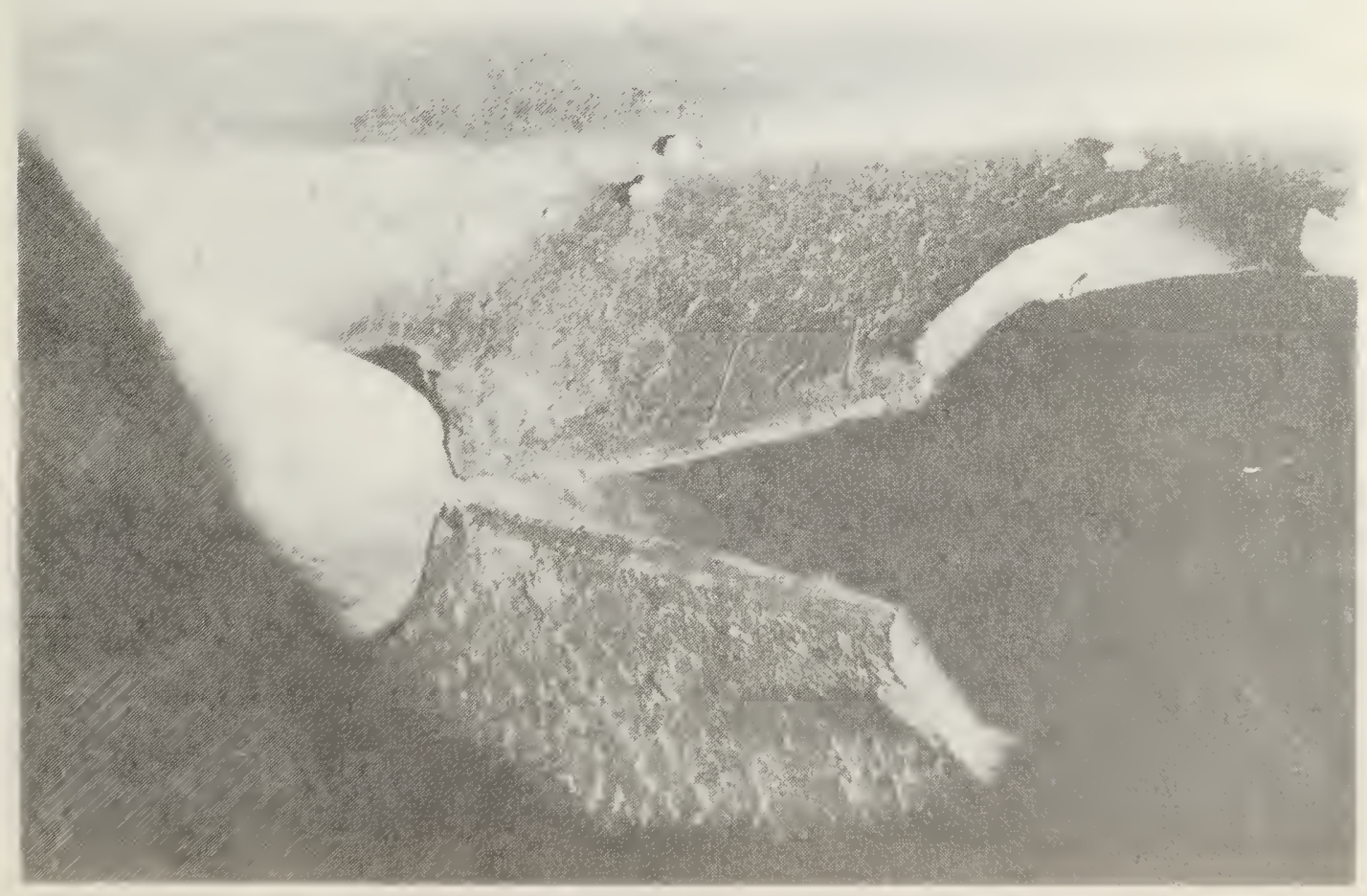

Figure 5.16 Fracture through the weld at location 9uE, lower flange. Weld porosity denoted by arrows. 


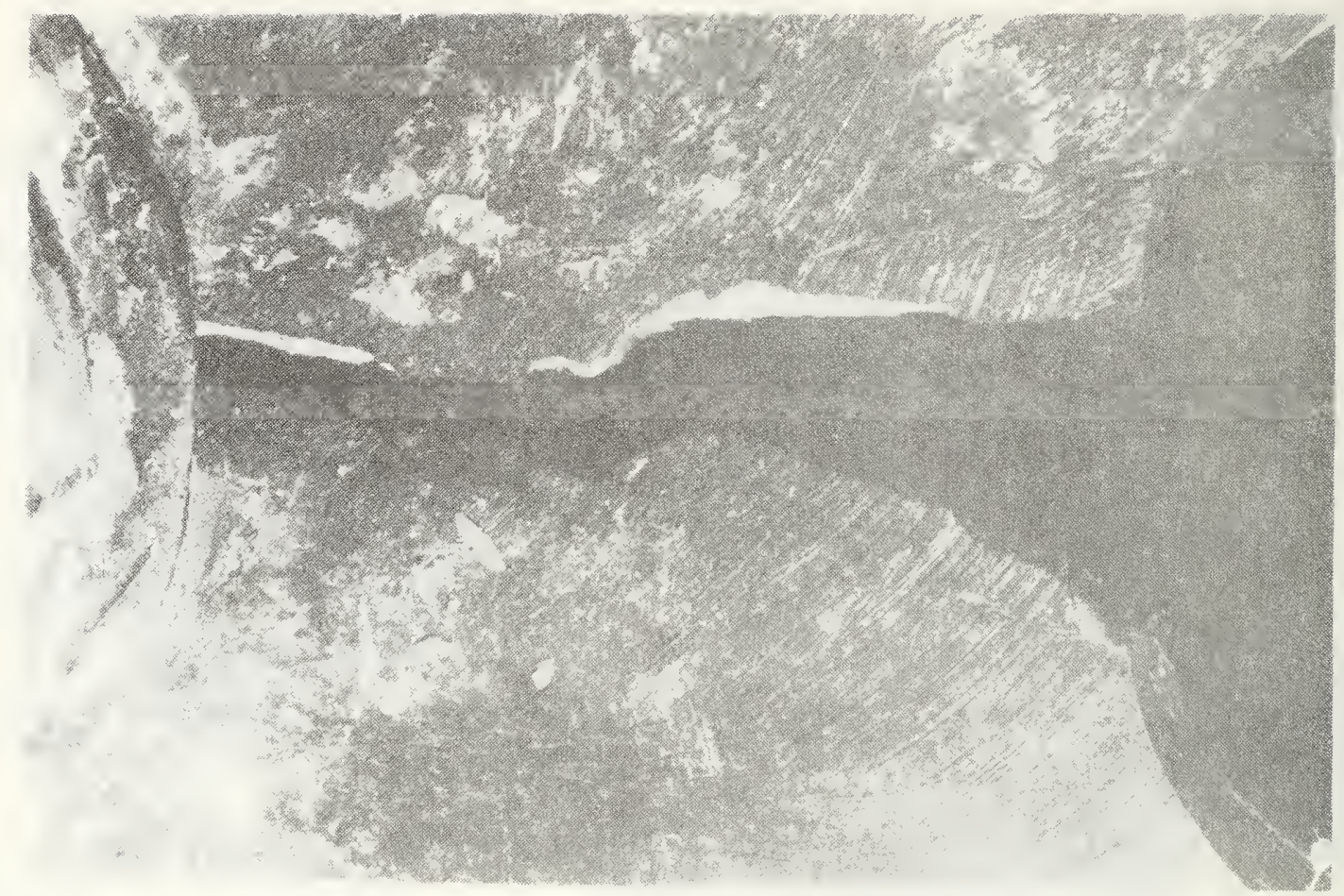

(a)

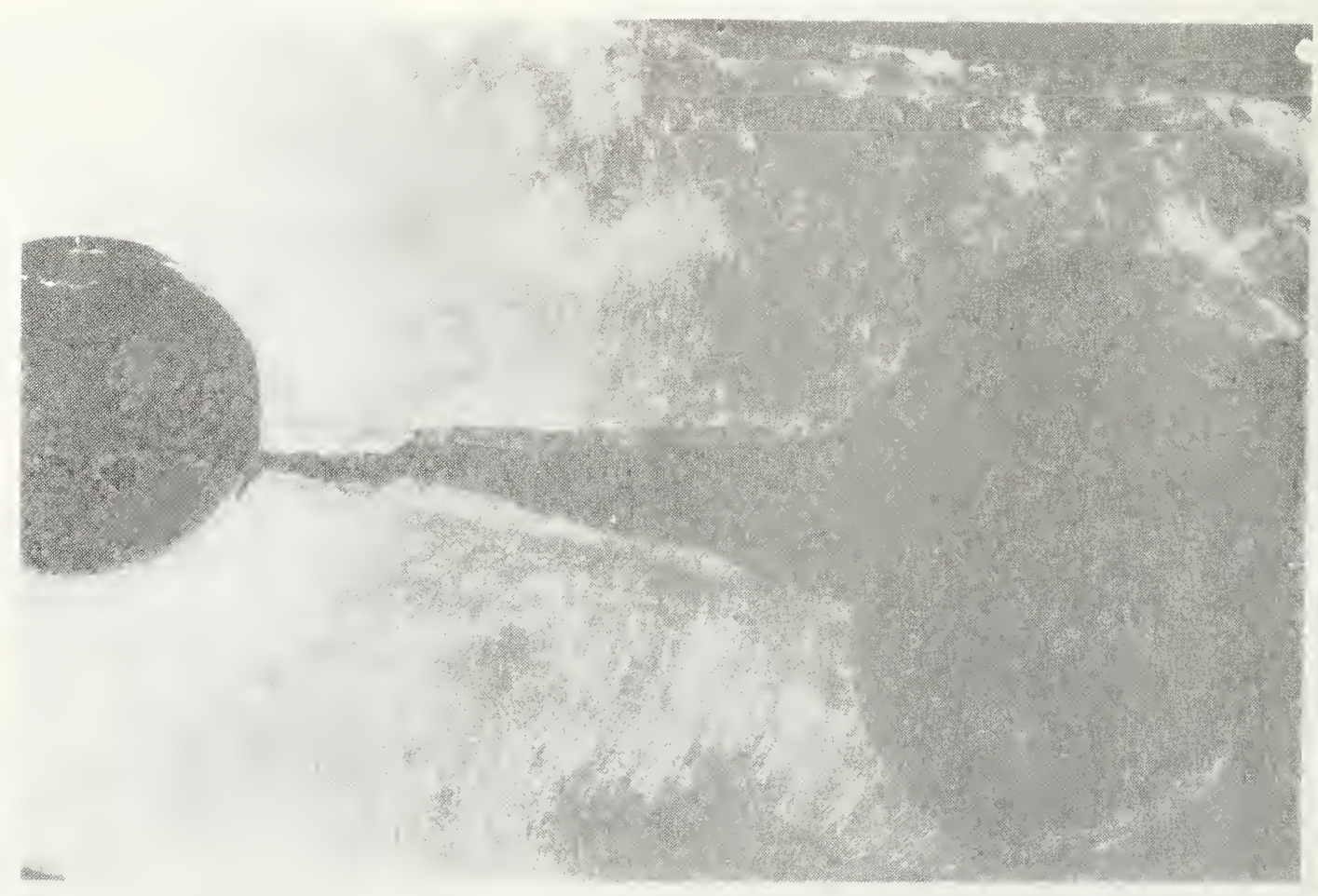

(b)

Figure 5.17 Fusion line weld fractures between hanger rod holes, upper flange weld, locations $9 \mathrm{UE}(\mathrm{a})$ and $8 \mathrm{UE}(\mathrm{b})$. 


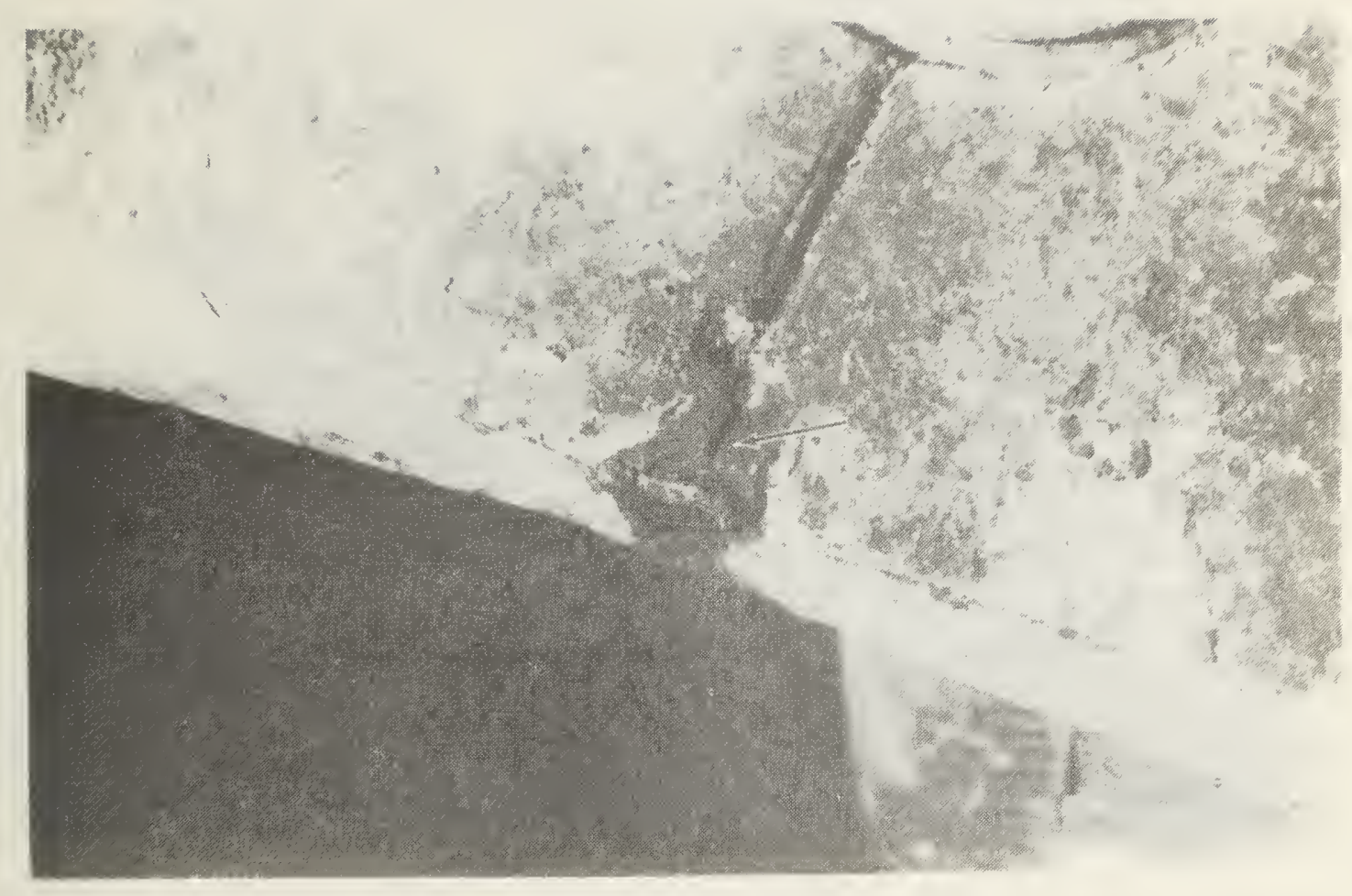

a) Location 8MW. Tack weld crack.

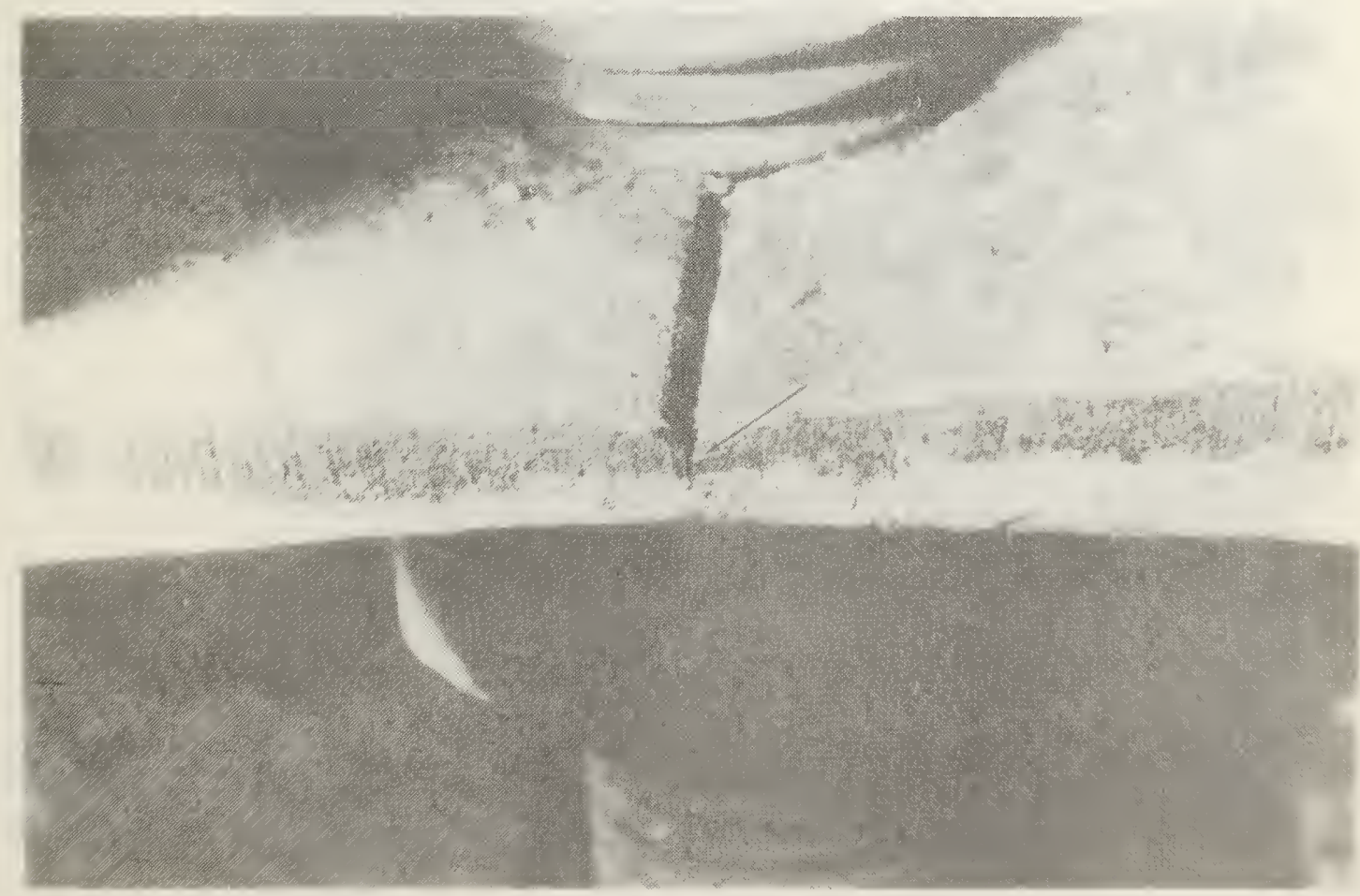

b) Location 8ME. End crack.

Figure 5.18 Apparent cracks (arrows) in lower welds of box beams in third floor walkway. 


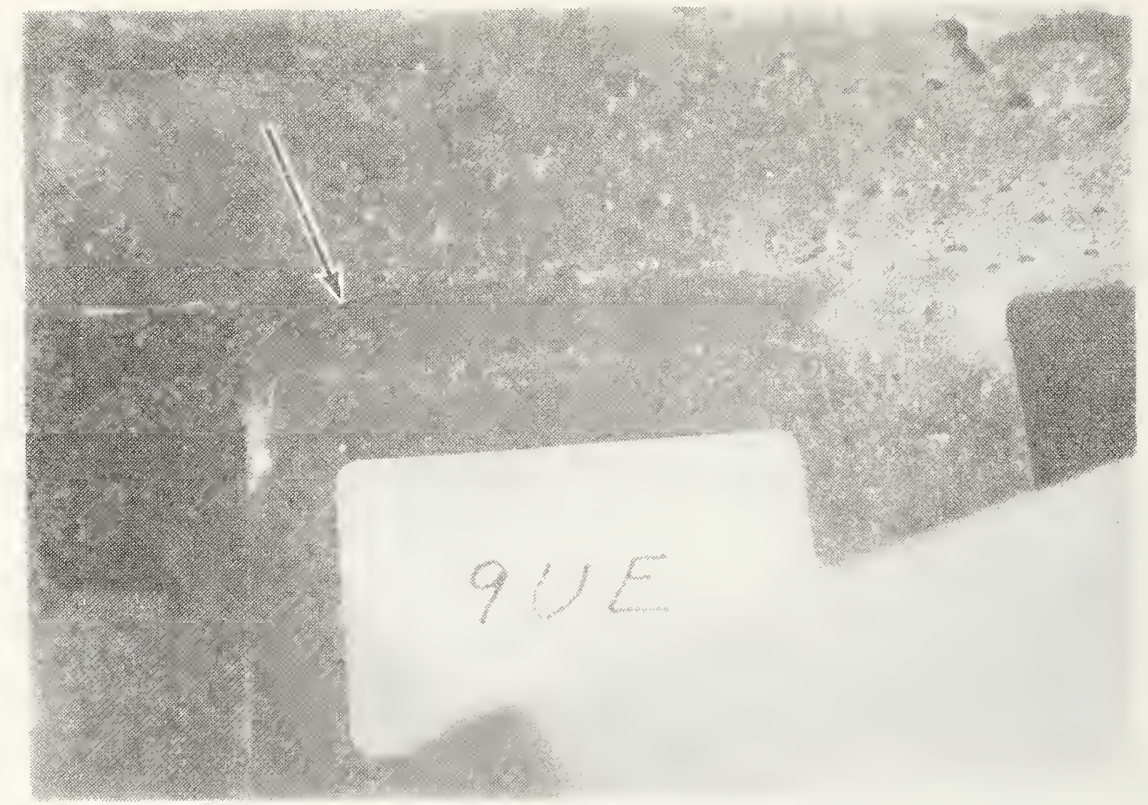

Figure 5.19 Incipient shear failure, bottom fillet weld of intact clip angle, location 9UE, south side.

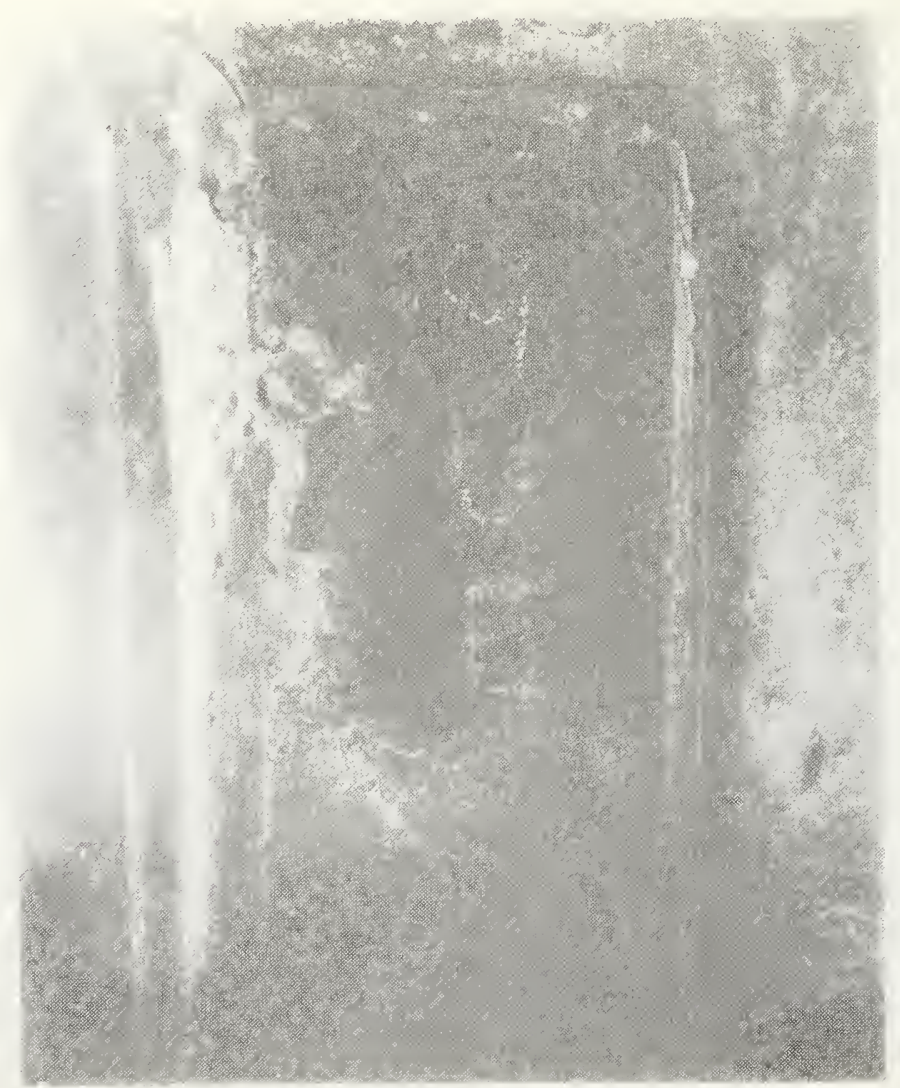

Figure 5.20 Shear failure at bottom and pull-out failure at top of clip angle, location 9UE, north side. 


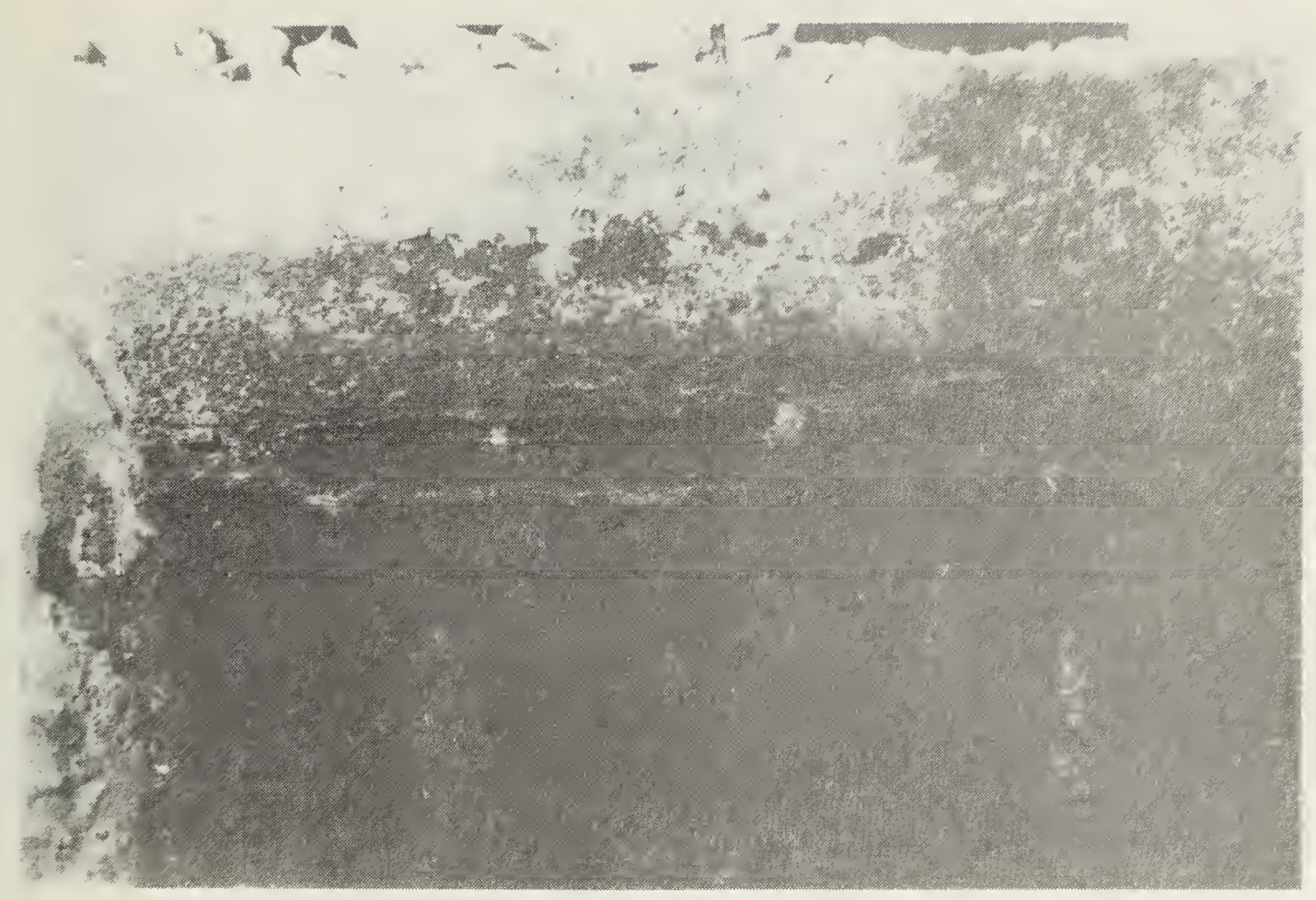

Figure 5.21 Pul1-out failure of top fillet weld on box beam web, location 9UE, north side.

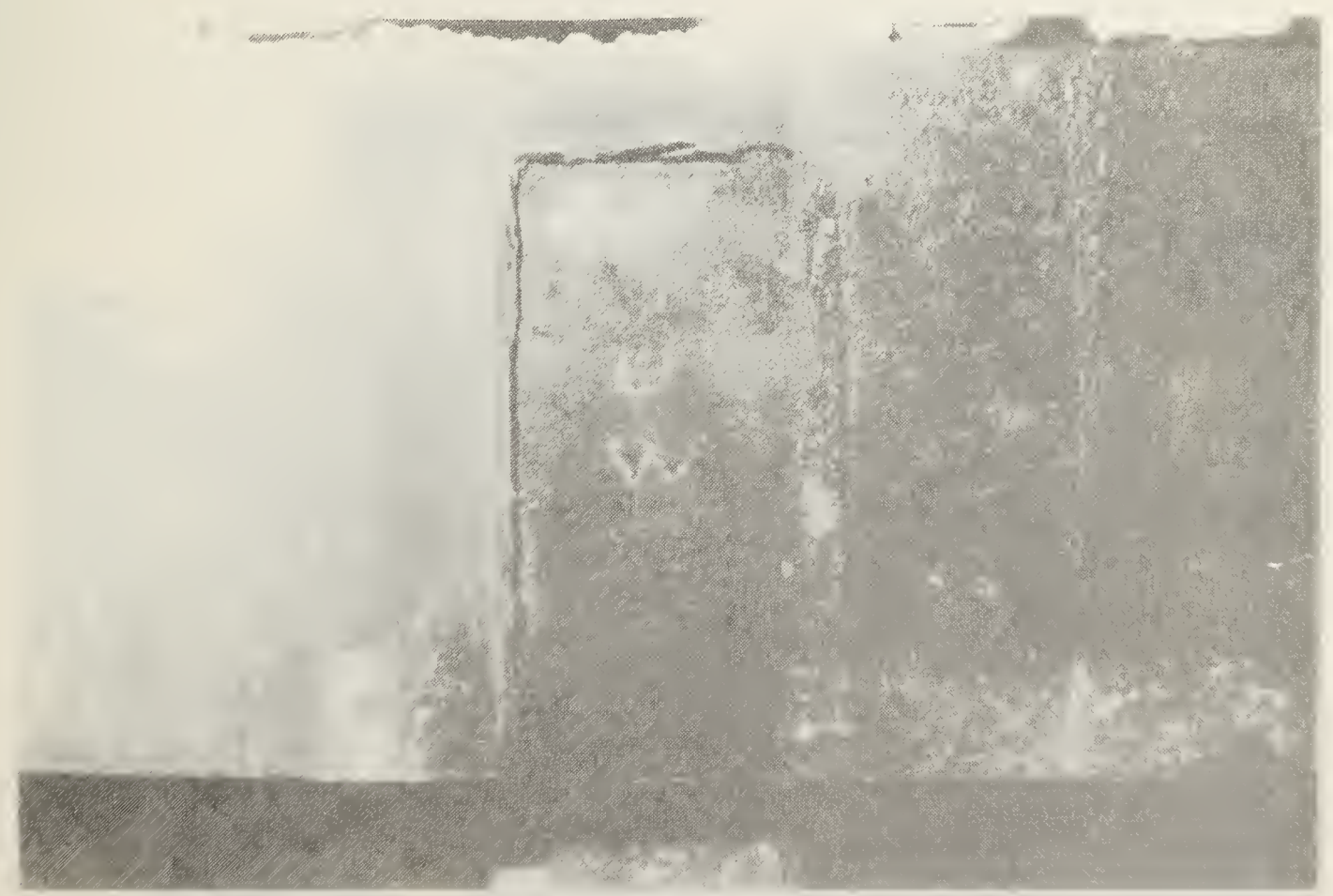

Figure 5.22 Shear failure in clip angle fillet weld at location 9UW, north side. This weld and the corresponding weld at location $9 \mathrm{LW}$ did not show evidence of a pull-out (tensile) failure at the top fillet weld. 


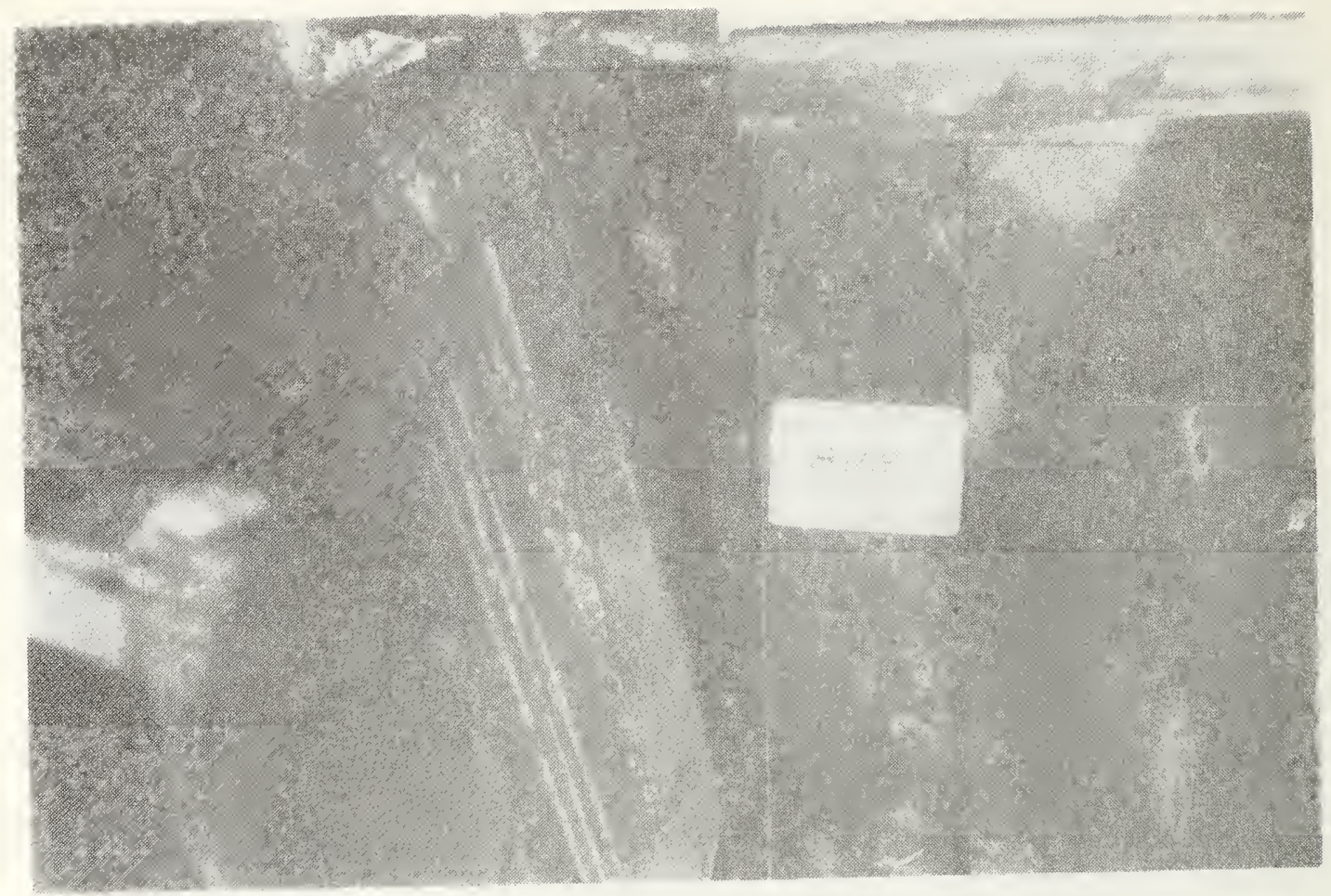

Figure 5.23 Tearing of top end of north clip angle at location 8UE.

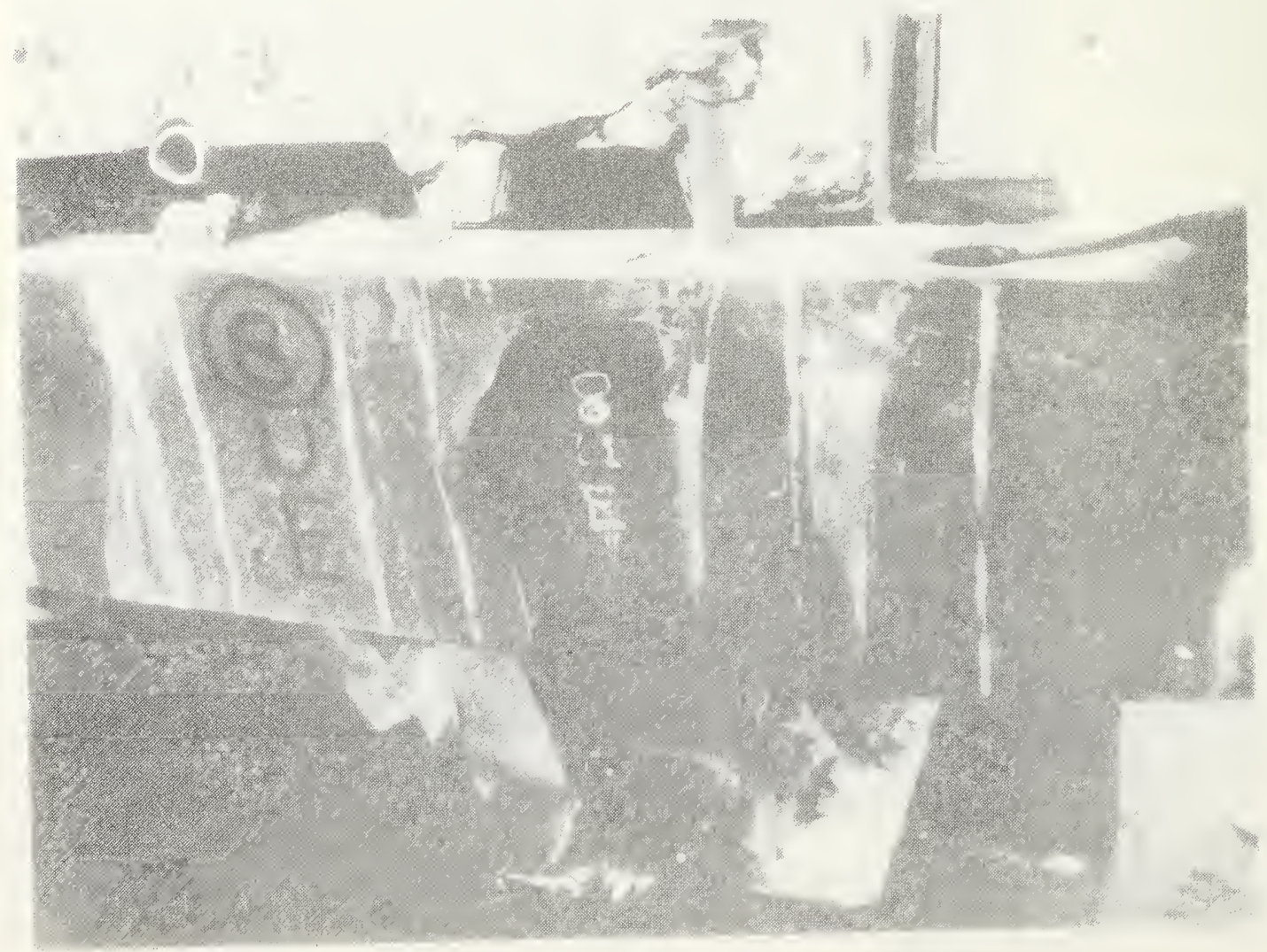

Figure 5.24 Tear in box beam web at location $8 \mathrm{UE}$. 


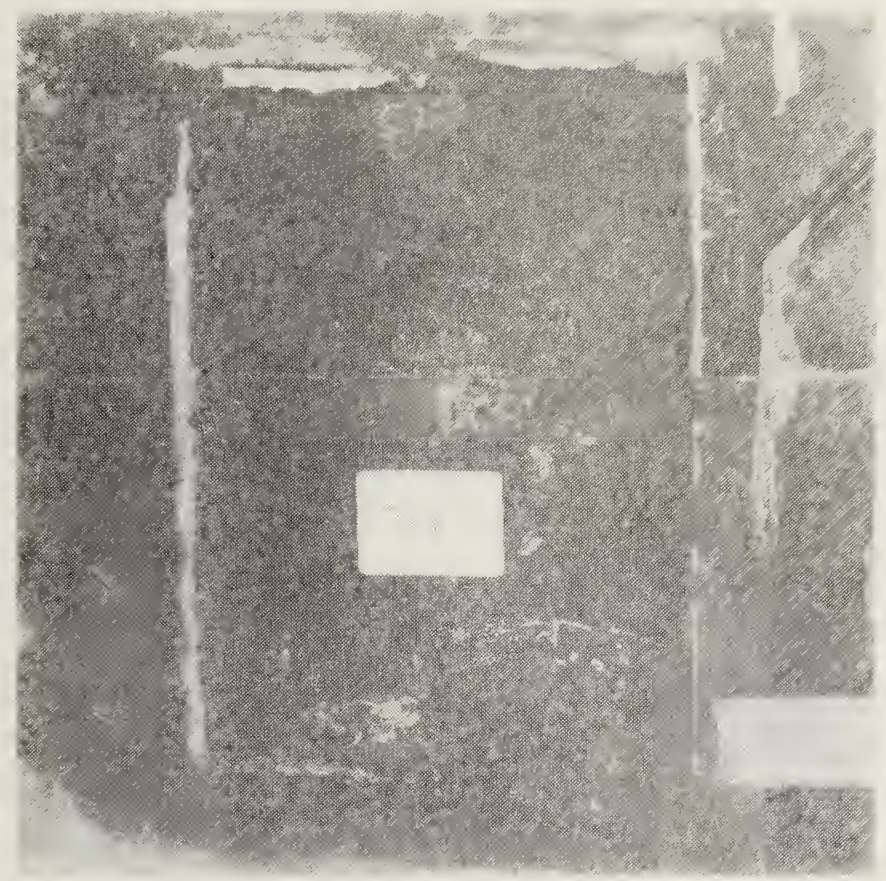

Figure 5.25 Embedded plate at connection 7UE.

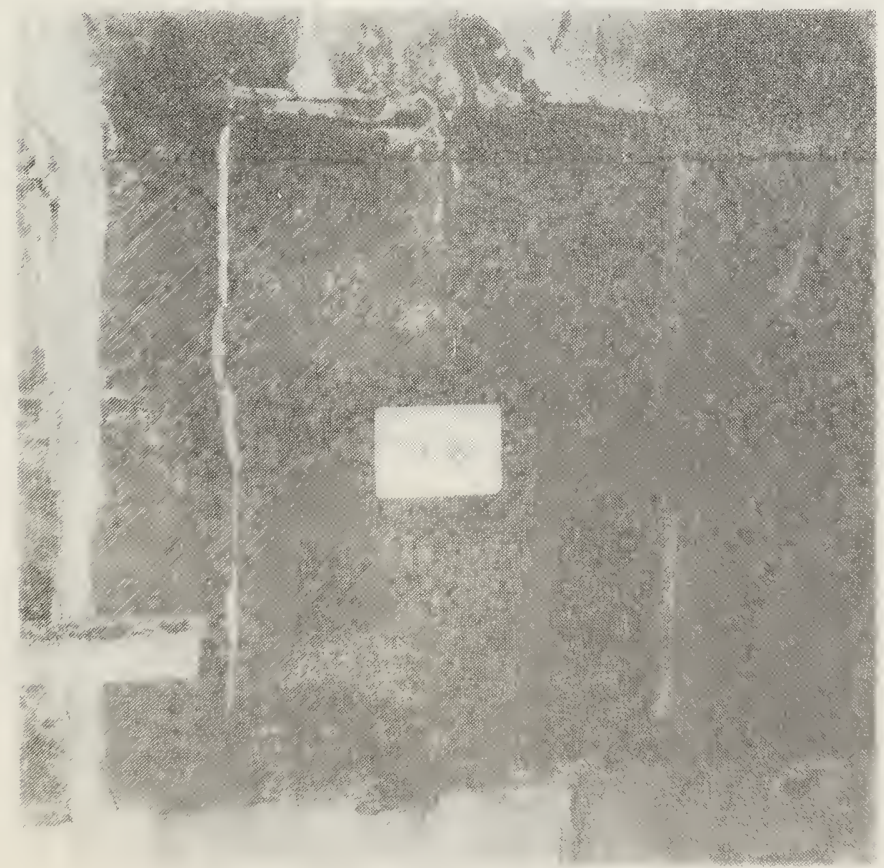

Figure 5.26 Embedded plate at connection $7 \mathrm{UW}$. 


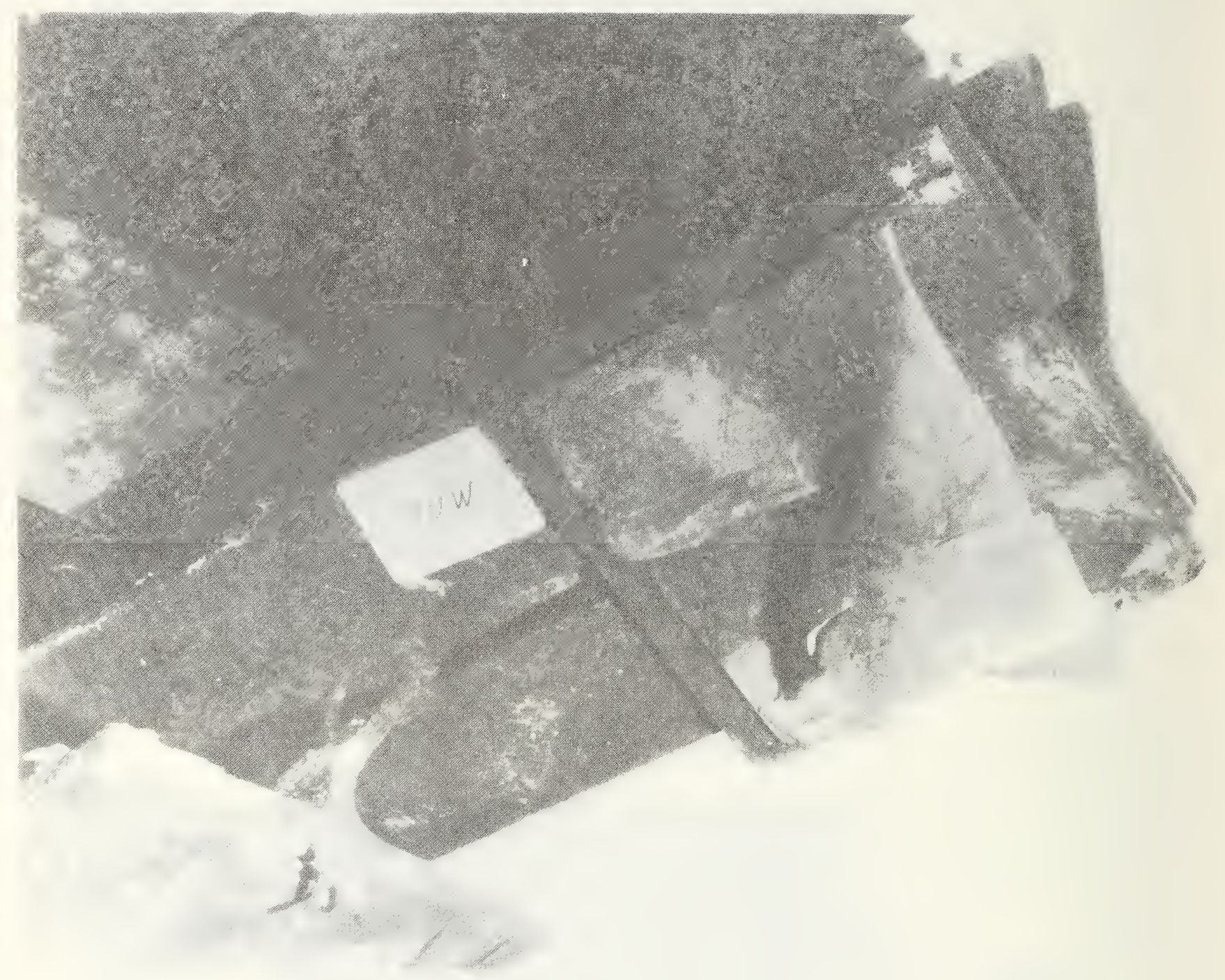

Figure 5.27 Modified bearing pad at location 11UW. 

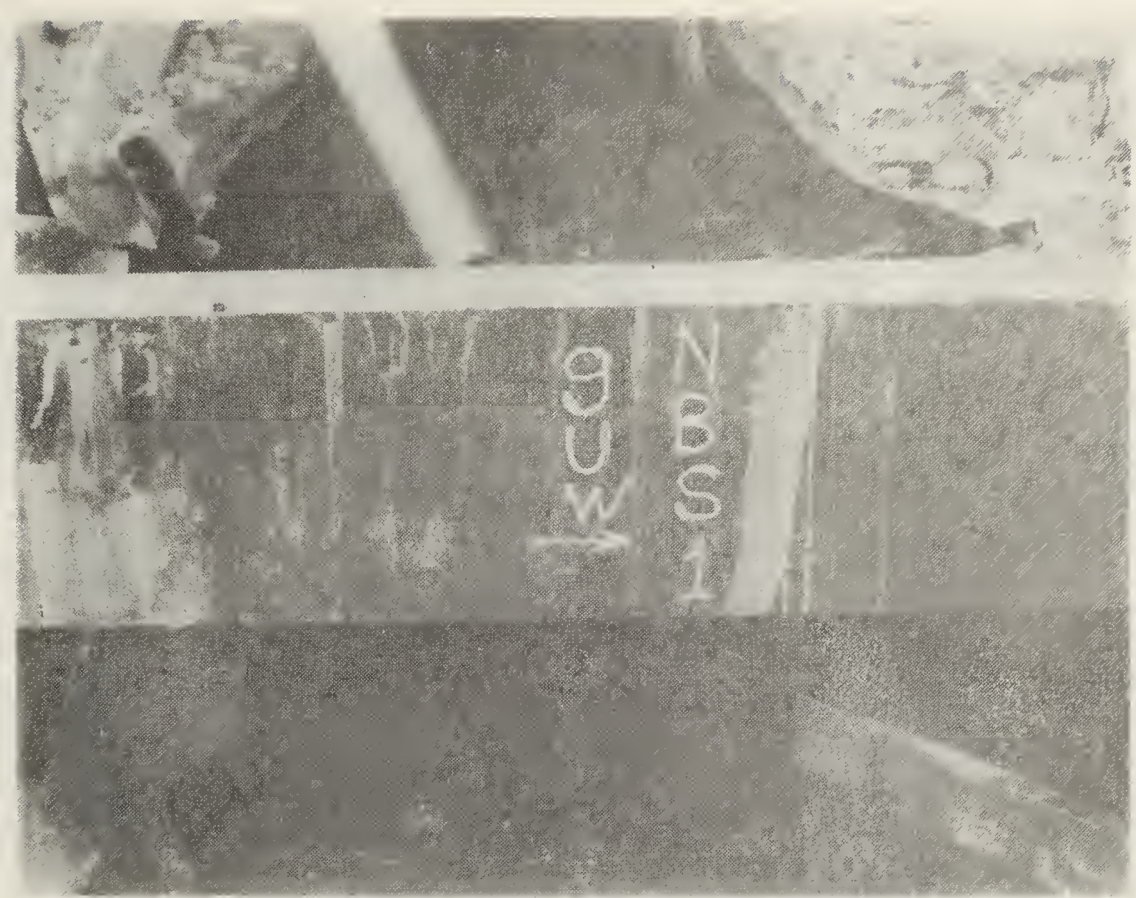

a) Before removal.

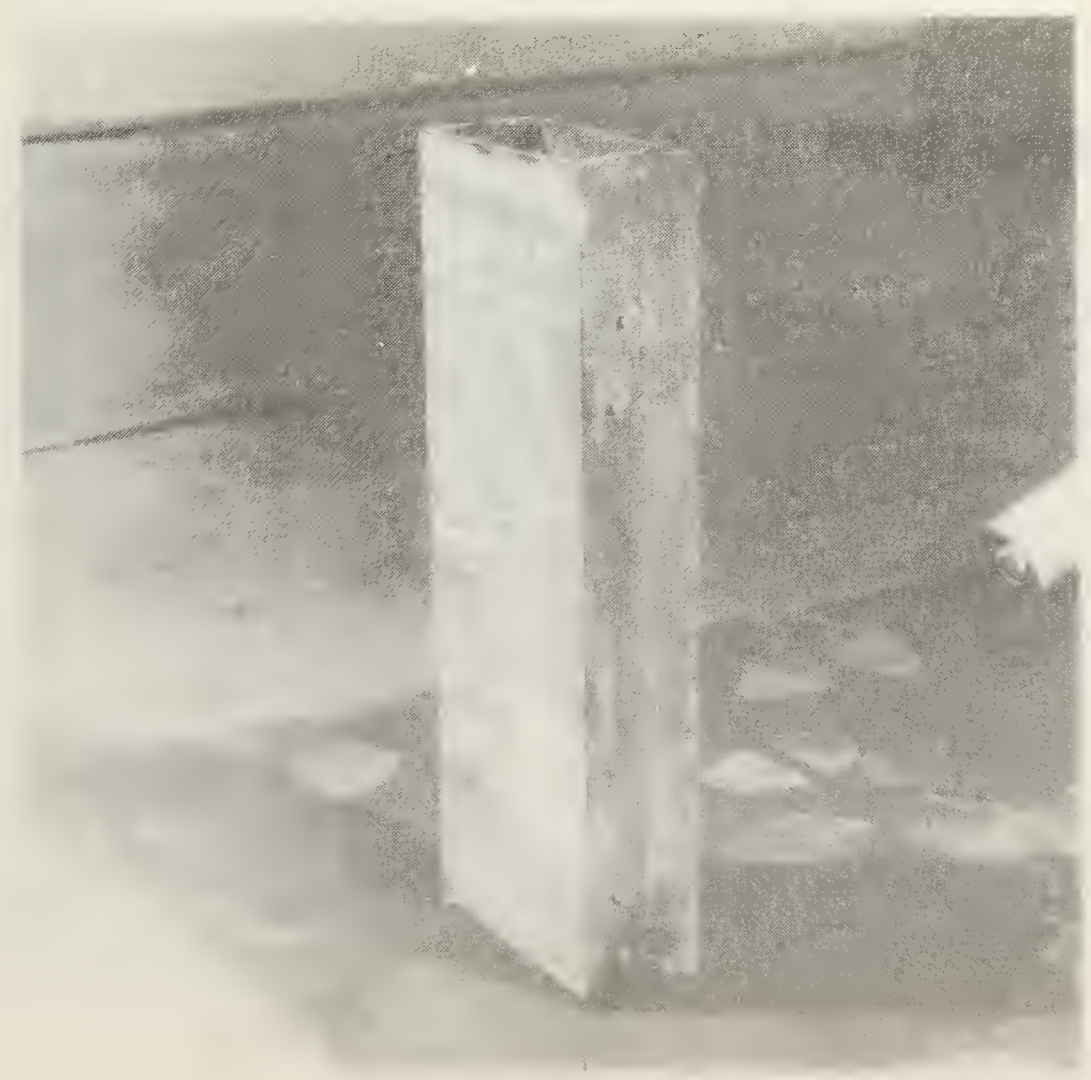

b) After removal.

Figure 5.28 Specimen no. 1 before and after removal. 


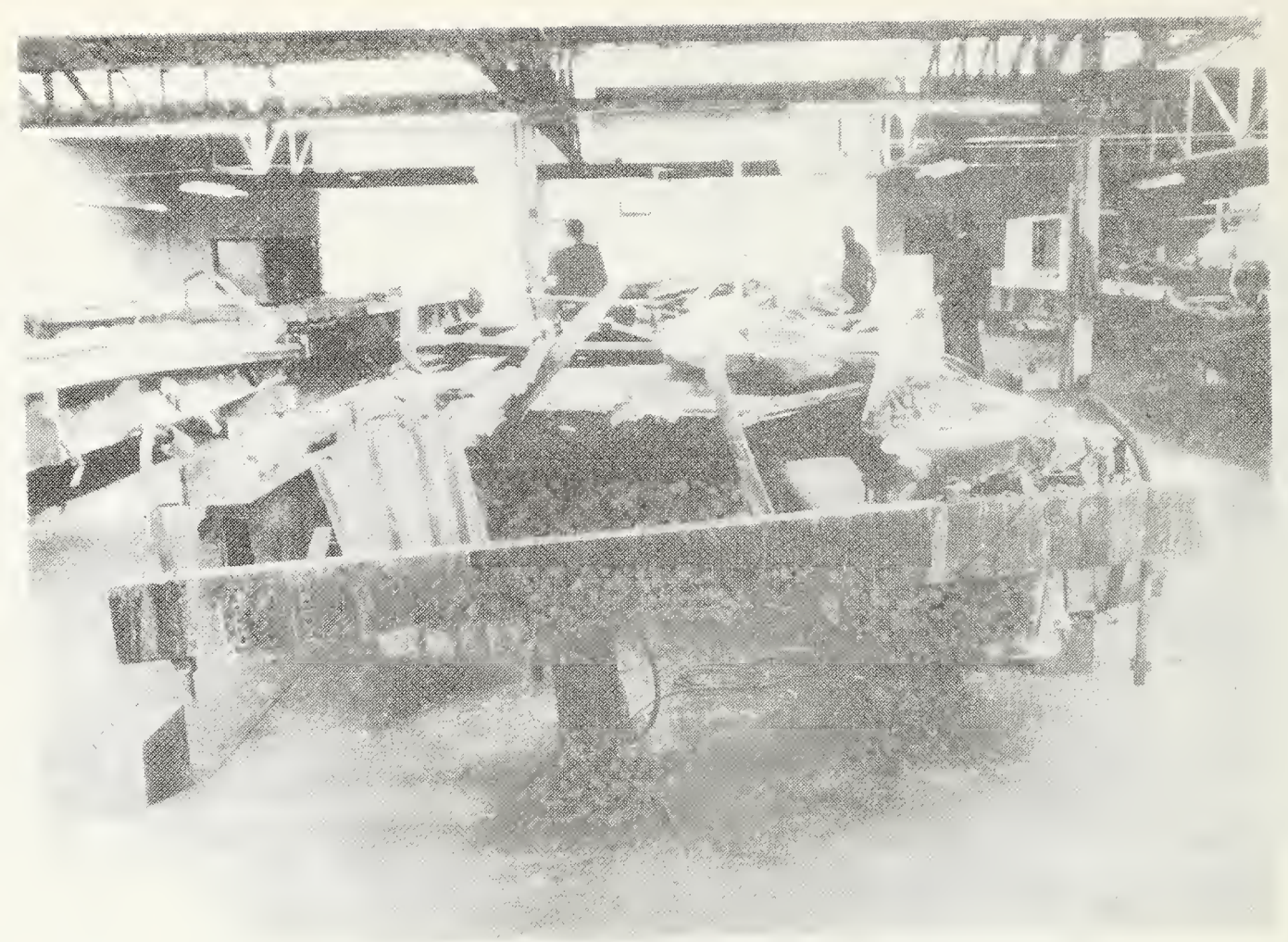

a) Before removal.

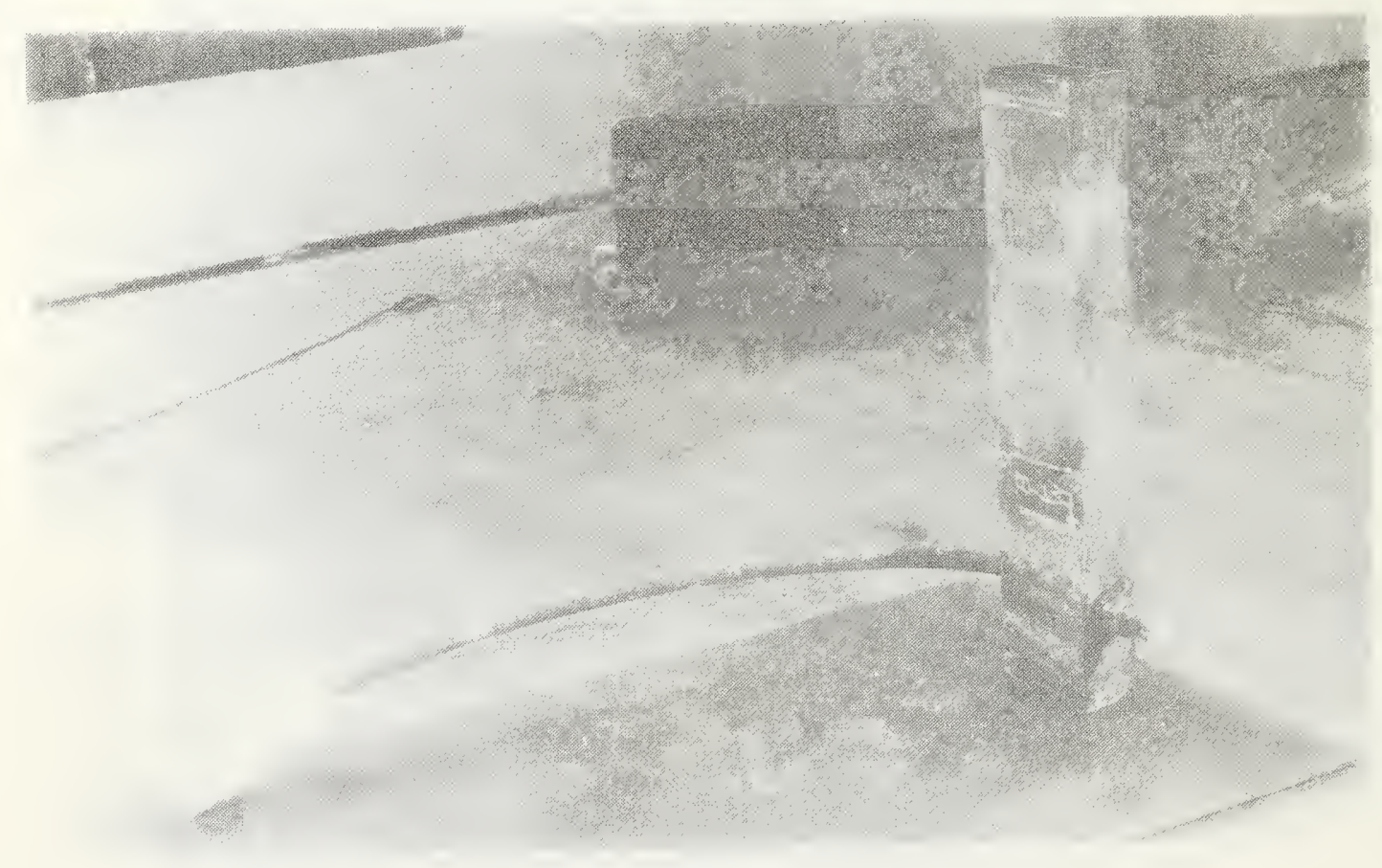

b) After removal.

Figure 5.29 Specimen no. 2 before and after removal. 


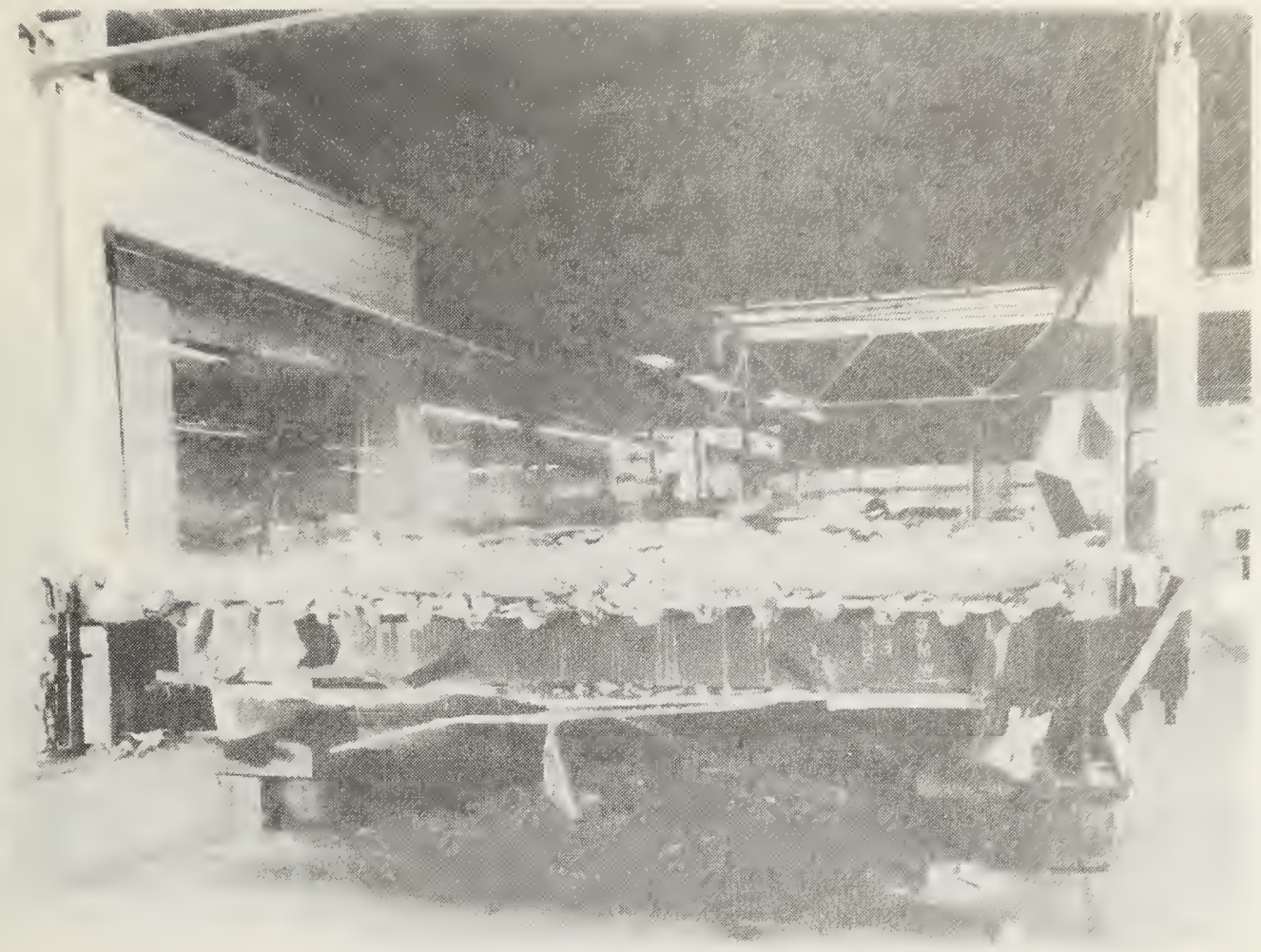

a) Before removal.

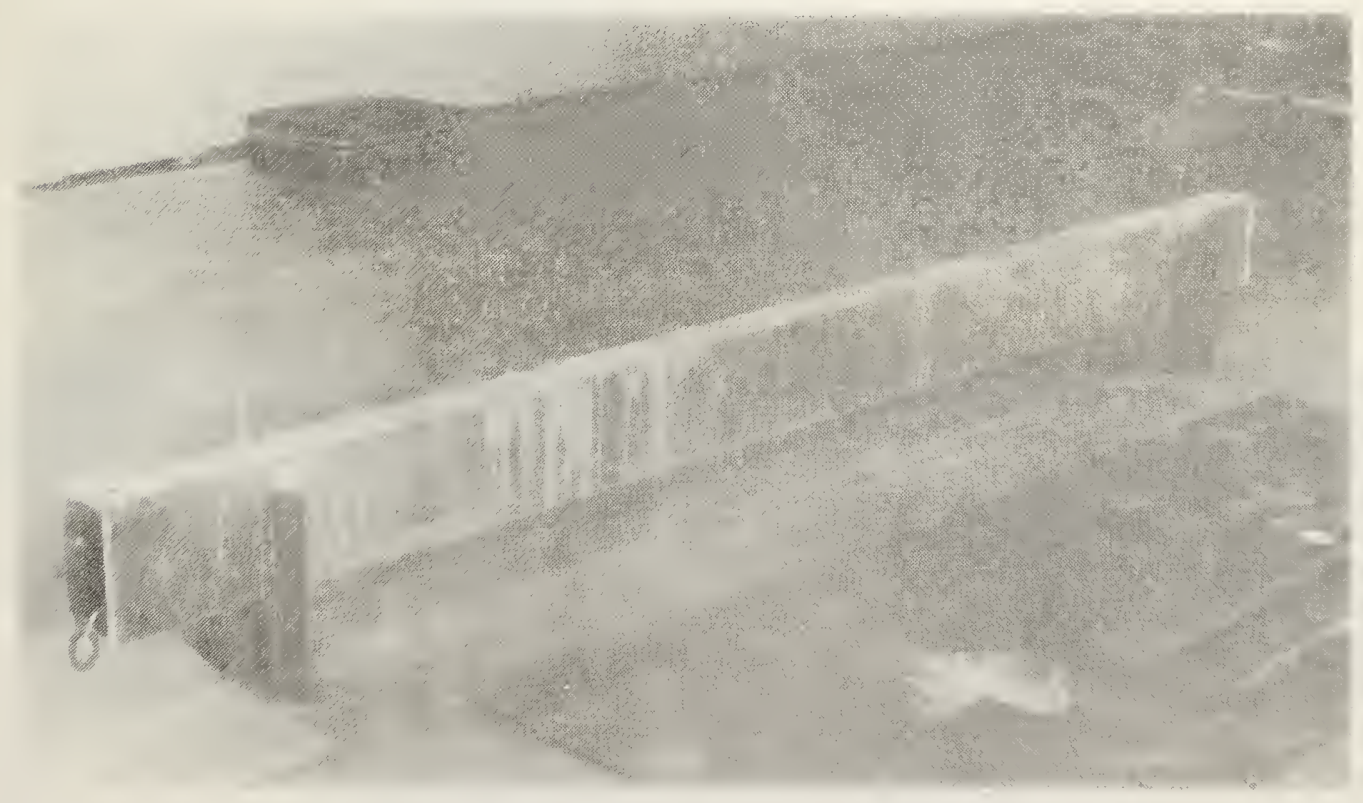

b) After removal.

Figure 5.30 Specimen no. 3 before and after removal. 
Figure 5.31 Specimen no. 5A and 5B after removal. 


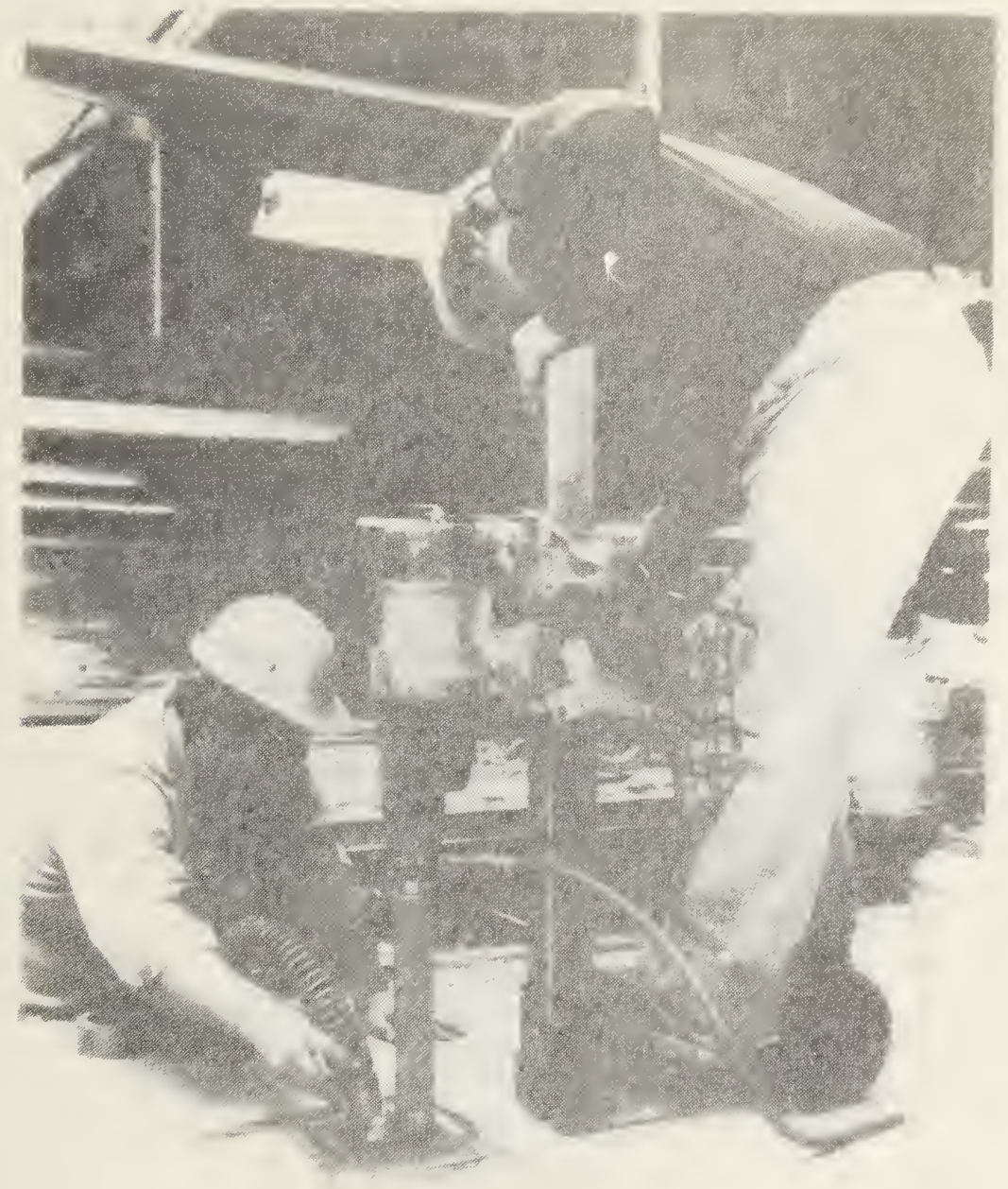

Figure 5.32 Concrete core drilling.

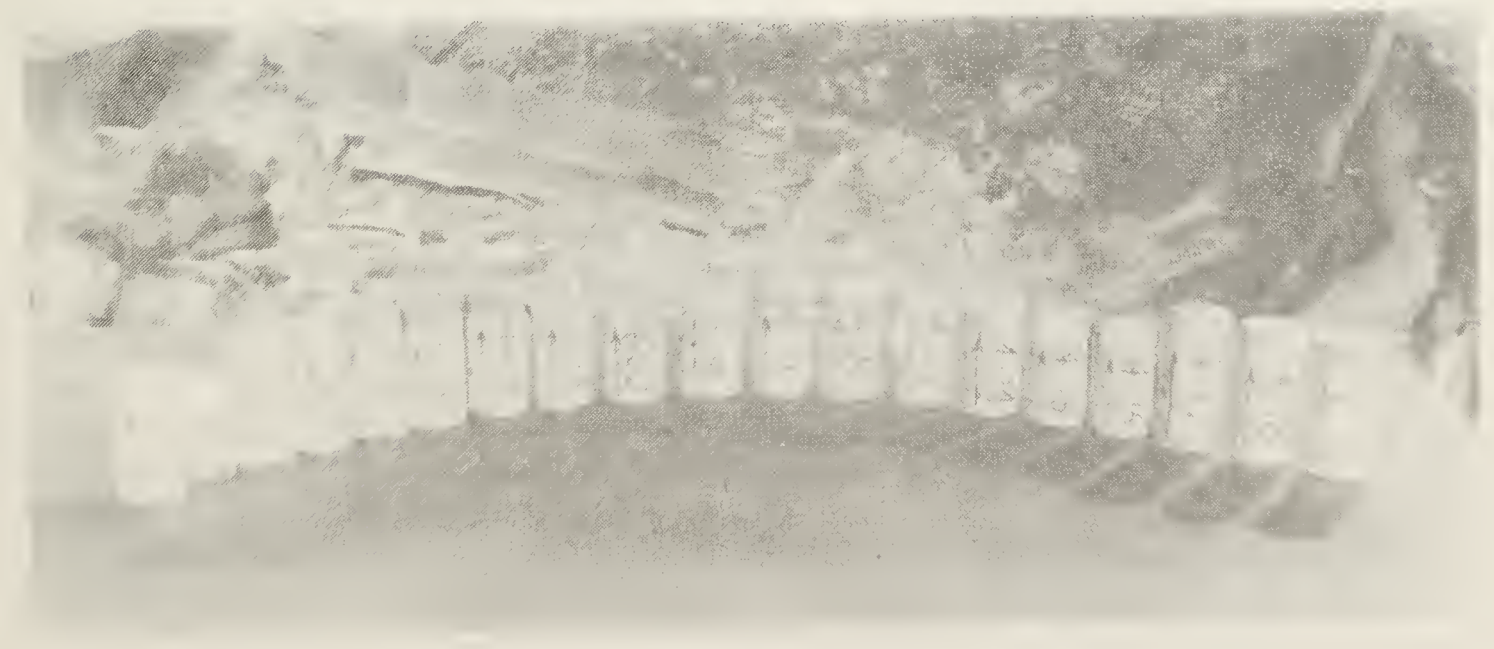

Figure 5.33 Concrete cores. 


\subsection{INTRODUCTION}

This chapter describes the NBS structural testing program relating to the walkway collapse, presents the test results, and discusses observations made based on the test results. In addition, the estimated load capacity for each of the upper walkway box beam-hanger rod connections is presented with a discussion of how the capacities were determined.

Section 6.2 presents a background to the test program and section 6.3 presents an overview of the test program. Section 6.4 describes the geometry of the test specimens and fabrication methods. Section 6.5 presents a detailed description of the physical setup for testing the specimens, while section 6.6 describes the equipment used to load the specimens. Section 6.7 describes the instrumentation used in monitoring specimen performance while section 6.8 presents the method of acquiring, storing, and processing data. Section 6.9 discusses the sequence of applying loads to the specimens. Section 6.10 presents a detailed description of the NBS-fabricated short box beam specimens and presents the pertinent test results. Section 6.11 similarly presents the NBSfabricated full-length box beam tests. Section 6.12 discusses the structural tests (both full-length and short specimens) performed on walkway box beam $9 \mathrm{M}$. Section 6.13 presents estimates of the upper walkway box beam-hanger rod connection load capacities. Section 6.14 presents the significant conclusions reached in this chapter.

\subsection{BACKGROUND}

The purpose of the test program was to estimate the walkway box beam-hanger rod connection load capacities. The load capacities could be defined adequately only by examining the influence of a number of parameters. The limitations imposed by the unavailability of as-built drawings, actual materials (in the initial stages of the investigation), and design calculations made it necessary to vary the parameters to take into account the range of variations that were likely for the actual walkway construction. The parameters were varied to examine their influence on load capacity and in this way identify and emphasize the parameters most affecting capacity.

\subsection{OV ERV IEW}

The structural test program to examine the box beam-hanger rod connection capacity used two types of test specimens: 1) short box beam and 2) fulllength box beam. The specimen types are described in more detail in section 6.4. Two sources of material were used for the test specimens. A supply of steel channel, all from a common heat, was purchased for the box beams fabricated by NBS. Welding, using several different processes, was done in the NBS shops. Additional tests, both full-length and short box beam types, were conducted on material obtained from the actual walkway structure. The short box beam specimen was developed as a simple and cost-effective alternative to the full-length box beam and was used as the main test specimen to permit 
the examination of a number of variables. The ful1-1ength box beam tests were used to validate the short box beam tests.

\subsection{TEST SPECIMEN DESCR IPTION}

Two types of specimens were tested in the investigation of box beam-hanger rod connection capacity. The full-length box beam specimens were dimensionally similar to a typical fourth floor walkway box beam (figure 3.10). The short box beams were essentially the end 22 in $(560 \mathrm{~mm}$ ) of a full-length box beam. Sixty short box beams and seven full-length box beams were fabricated by NBS and tested. Four short box beam specimens and one full-1ength box beam specimen were prepared from an actual walkway box beam and tested.

\subsubsection{Full-Length Box Beam}

The full-length box beams were fabricated using the dimensions shown on the walkway box beam shop drawing (figure 3.10). All material was nominally as specified on the shop drawing. A detailed description of the actual properties of these materials is presented in chapter 7.

\subsubsection{Short Box Beam}

Examination of the walkway debris indicated that the zone of distress in the box beam-hanger rod connection was generally limited to the portion of the box beam between the end of the box beam and the stringer connection with the box beam. The distress zone was primarily near the hanger rod locations. Based on the visual examination, the short box beam could have been made by cutting the full-length box beam at the stringer connection. However, a slightly longer test specimen was used to conform to the physical constraints of the laboratory test facility. The comparability of full-length and short box beam behavior is discussed in section 6.11 .

The actual test specimen, figure 6.1 , was approximately 22 in (560 mm) long. The specimen was mounted to a test rig through two angles welded parallel to the webs at one end of the specimen. The hole size and locations in the test specimens were as specified on the shop drawings for the walkway box beams. The first tests on specimens without stringer-box beam clip angles, using a whitewash coating on the specimen as a brittle coating, indicated that the zone of distress did not extend to the clip angle position. It was thus concluded that the effect of the clip angles was minimal and for simplicity they were omitted in all but four tests. The validity of this assumption was confirmed by four tests that are described in section 6.10 .5 .

\subsubsection{Fabrication}

All test specimens were fabricated by the same experienced welder who used different techniques until he could consistently produce a weld that was visually similar to the observed walkway box beam welds specified as part of the testing program. A supply of channel the same size as that used in the walkway was obtained in $20 \mathrm{ft}(6.1 \mathrm{~m})$ lengths from a single source and was 
specifled as being from a single heat. Each box beam, identified in tables 6.1, $6.2,6.3$, and 6.4 , was made from channel pieces taken from a single $20 \mathrm{ft}$ $(6.1 \mathrm{~m})$ length of channel.

The walkway box beams had been fabricated by laying a weld bead along the channel flange tips from the outside of the box beam over the entire length of the beam. For purposes of describing the structural tests, such a weld is termed an exterior weld in this chapter. The depth of exterior weld penetration (figure $6 . \overline{2}$ ) estimated from visual examination of the damaged walkway box beams was used as a guide in the fabrication of the short box beams. The welder fabricating the short box beams was able to produce welds having a fairly uniform penetration along the beam. However, to examine the significance of exterior weld penetration, specimens having penetration less than and greater than the estimated penetration were fabricated. The majority of short box beams were fabricated with a weld penetrating partially into the flange thickness and were termed "shallow penetration" welds. Several specimens were fabricated in which the welder was told to "fully penetrate" the flange thickness without using a backing strip. These welds were termed "deep penetration." Two specimens were fabricated with no weld bead laid along the outer 8 in (203 $\mathrm{mm}$ ) of the short box beam except for a small tack weld at the free end of the specimen (figure 6.3). These two specimens were termed "no weld" specimens and were tested to determine a lower bound strength of the box beam-hanger rod connection.

The walkway box beams had weld beads of varying lengths on the interior of the flange joint outboard of the exterior hole (figure 6.4). These weld beads are termed interior welds in this chapter. Short box beams were fabricated having several variations of the interior weld length. Insofar as possible, the penetration of the interior weld was kept constant. The penetration was such that the interior weld and the exterior weld roots were separated by a small gap (figure 6.4). The lengths of interior weld were nominally equal to zero, $1 / 2$ in (13 $\mathrm{rm}), 1$ in $(25 \mathrm{~mm})$, and $13 / 8$ in $(35 \mathrm{~mm})$. In the NBS beams the interior weld was laid prior to boring the rod holes. The $13 / 8$ in (35 mm) length resulted from welding to the centerline of the exterior rod hole ( 2 in or $51 \mathrm{~mm}$ ) and removing the weld in the hole location during the hole boring operation to obtain the actual length of $13 / 8$ in $(35 \mathrm{~mm})$. In the NBS beams the interior welds were laid after the exterior weld and were done by the same process as that used for the exterior weld.

Al1 short box beams in series A through $\mathrm{R}$, excluding I3 (listed in table 6.5) were cut to length prior to welding. The remaining short box beams (except for the $S$ series described below) were cut 1 in (25 mm) 1onger than their final length and then welded. This was done in an effort to control possible variation in welding due to startup of the welding process at the beam end. After all welding was completed the extra length was removed at the ends and the hanger rod holes bored. Full-length box beams (table 6.4) L1 and L2 were cut to length, while L3 through $\mathrm{L} 7$ were cut 2 in ( $51 \mathrm{~mm}$ ) longer than their final length. After welding, 1 in $(25 \mathrm{~mm})$ was cut off from each end of the beam.

The S-series short box beam with stringer-box beam clip angles were fabricated by removing the unfailed ends of four full-length box beams as is discussed 
further in section 6.10.5. Specimens L5, L4, L6 and L3 were used to fabricate S1 through 54 respectively.

The sequence of fabrication for both NBS short and full-length box beams was as follows:

- Tack weld the interior of the ends of the box beam, top and bottom

- Weld along the exterior of the box beam seam, top and bottom

- Weld along the interior of the box beam seam (if specified), top and bottom

- Weld on the attachment clip angles used to fasten the specimen to a reaction buttress described in section 6.5

- Grind off the exterior weld bead flush with the surface completely along the top and at least 12 in $(305 \mathrm{~mm})$ from the end(s) on the bottom

- Bore a pilot hole for each hanger rod hole. Finish the hole using a numerically controlled milling machine. Each hole was made in a separate operation.

\subsection{TEST SETUP}

Full-Length Box Beam. A photograph of the test setup simulating a fourth floor box beam is shown in figure 6.5. A drawing with the various parts of the test setup labeled is shown in figure 6.6. The full-length box beam test setup was contained within a self-reacting structural steel test frame. The test frame was bolted to a structural tie-down floor. The frame columns were 12 in (305 $\mathrm{mm}$ ) deep wide flange shapes and each reaction beam was made of two 36 in $(915 \mathrm{~mm}$ ) deep wide flange sections placed side by side with a $11 / 2$ in (38 mm) gap between the flanges to permit the loading rods to pass through. The two load transducers for the upper loading rods rested on a 1 in $(25 \mathrm{~mm})$ thick steel plate which spanned the gap between the beam flanges. A hardened steel washer and heavy hex nut terminated the upper loading rods and rested against the top surface of the load transducer.

Each hydraulic cylinder was held in place against the lower surface of the lower reaction beam by a frame bolted to the reaction frame. The load transducers were separated from the hydraulic cylinder piston by a $1 / 2$ in $(13 \mathrm{~mm})$ thick steel piate. The lower end of the loading rod was terminated by a hardened washer and a heavy hex nut.

The upper walkway loading system applied the simulated fourth floor dead load to the box beam through the stringer-box beam clip angles (figure 6.7). The system used a spreader beam with three pinned attachment points which enabled the spreader beam to rotate while keeping the applied load acting vertically. A plate was bolted between and below the clip angles to permit attachment of the clevis to the box beam (figure 6.8 ). The middle pin was the connection 
point for the loading rod. The attachment of the spreader beam to the clip angle was through a pin and clevis arrangement as shown in figure 6.9 .

Short Box Beam. The test setup, figures 6.10 and 6.11 , used an existing structural tie-down floor and reaction buttress plus two specially made vertical reaction supports. The vertical reaction supports provided the reaction for the hydraulic cylinders applying load to the upper (fourth floor) and lower (second floor) hanger rods. The reaction supports were bolted to the tie down floor to resist both shear and overturning forces. The test specimen was bolted to the reaction buttress. Prior to each test the bolts holding the test specimens were pretensioned using an impact wrench.

The assembled test specimen was rotated 90 degrees from its normal orientation. The webs of the box beam were parallel to the floor. The hanger rods (loading rods) were also parallel to the floor. Each loading rod passed through the specimen, reaction support, center-hole hydraulic cylinder, and center-hole load transducer and was terminated with a hardened washer and heavy hex nut.

\subsection{LOADING EQUIPMENT}

Full-Length Box Beam. The loading equipment included three 100 ton $(890 \mathrm{kN}), 10$ in $(254 \mathrm{~mm})$ travel, double acting hydraulic cylinders; an electric hydraulic pump; and a ten channel hydraulic pressure maintainer. The hydraulic pump had a discharge rate of 0.26 gallons per minute $\left(16.4 \times 10^{-6} \mathrm{~m}^{3} / \mathrm{s}\right)$.

The hydraulic cylinders were of the center hole type to permit the loading rod to pass through the cylinder. The loading rod was centered in the cylinder by a wooden sleeve. The lower walkway hydraulic cylinders were connected by manifolds to common pressure and return lines. Thus, while there were three hydraulic cylinders, there were only two pressure channels, one for the upper walkway hydraulic cylinder and one for the two lower walkway hydraulic cylinders. The hydraulic cylinders were supplied with oil by means of the hydraulic pressure maintainer and the hydraulic pump. The hydraulic pump supplied oil to the maintainer at a nominal pressure of 5000 psi (35 MPa). The maintainer controlled the hydraulic pressure actually applied to each cylinder. The operator adjusted the pressure in each pressure channel independent of the other.

Short Box Beam. The loading equipment consisted of two 60 ton (534 kN),

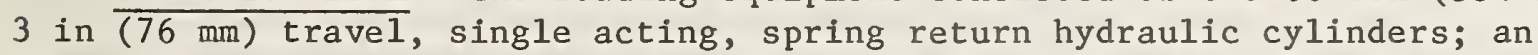
electric hydraulic pump; and a ten-channel hydraulic pressure maintainer. The hydraulic pump and pressure maintainer were the same as used for the fulllength box beam tests.

The hydraulic cylinders were of the center hole type to permit the loading rod to pass through the cylinder. The loading rod was centered in the cylinder by two teflon sleeves. The hydraulic cylinders rested on a wooden cradle fabricated so that the cylinder centerline was in line with the box beam-hanger rod hole centerline. 


\subsection{INSTRUMENTATION}

Ful1-Length Box Beams. The instrumentation included five load transducers, one for each loading rod, two pressure transducers, four linear potentiometers (LPs), two rotary potentiometers (RPs), and four linear variable differential transformers (LVDTs). All devices were connected to a common DC power supply. The load transducers were of a full bridge resistance strain gage type. The load transducers were center holed with machined steel bearing surfaces fabricated to center the transducer on the loading rod.

The displacement measuring devices were placed as shown in figure 6.12. The instrumentation was identical on each end of the beam so only one end is described. Two mounting beams were bolted to each test frame column, one above and one below the box beam. These beams served as attachment points for the displacement measuring LPs and RPs. The linear potentiometers had 10 in (254 mm) travel. One LP was attached to the box beam about 1 in (25 mm) from the end and to the upper mounting beam such that it was vertical. Similarly the other LP was attached to the lower loading rod nut and the upper mounting beam. The rotary potentiometer measured linear displacement through a cable and spring mechanism. The RP had a total travel of over 20 in (508 mm). The mechanism was attached to the lower mounting beam and the cable ran vertically to the upper loading rod. The cable was attached to the rod by a hook screwed into a hole tapped in the end of the rod. Two LVDTs measured the transverse (out-of-plane) distortion of the box beam webs. The LVDTs were mounted on one web of the box beam and spanned to plates mounted on the other web. One LVDT was mounted near the middle of the box beam depth and the other LVDT was mounted near the bottom of the box beam.

One pressure transducer was placed in the common pressure line for the two lower loading rod hydraulic cylinders and the other pressure transducer was placed in the pressure line for the upper walkway loading rod.

Short Box Beam. The instrumentation consisted of two load transducers, one for each loading rod, and up to six linear variable differential transformers (LVDTs) for measuring displacements. All devices were connected to a common DC power supply.

The load transducers were placed between the hydraulic cylinders and terminating nut (figure 6.11) with a 1 in $(25 \mathrm{~mm}$ ) thick plate between the transducer and the cylinder and a hardened washer placed between the transducer and the nut. The load transducers were of a full bridge resistance strain gage type. The transducers were also center holed with machined steel bearing surfaces fabricated to center the transducer on the loading rod.

The LVDTs were ordinarily placed as shown in figure 6.13. Three LVDTs measured the out-of-plane or transverse distortion of the box beam webs and three LVDTs measured the in-plane displacement of the loading rods and box beam free end. All tests used the in-plane LVDTs. However, when photographs or videotapes were taken of the tests in progress the specimen had either no transverse LVDTs or only the middle transverse LVDT. The transverse LVDTs were mounted on one web of the box beam and spanned to plates mounted on the other web. 
The in-plane LVDTs were mounted on stands resting on the tie-down floor and spanned to either the specimen end of the rods or the upper flange of the box beam near its free end.

\subsection{DATA ACQUISITION AND REDUCTION}

Both data acquisition and reduction were computer based operations. The hardware components of the system consisted of a minicomputer with a variety of peripherals and a high speed amplifier/multiplexer analog-to-digital converter. The software component was a test executive which interfaced the operator and the hardware. The software performed the data conversion and reduction as well as controlled the acquisition of the data.

The analog-to-digital converter had a sample rate of $50 \mathrm{kHz}$. The time required to sample all data channels (maximum of 9) once (a scan) was about 180 microseconds. In most of the tests a scan was acquired every three seconds except during breaks in loading when no scans were required. All data signals were amplified by the analog-to-digital converter such that the maximum expected analog signal was at least half of the converter's full scale (10 volts) range. The analog-to-digital converter transferred binary representations of the input analog signal to the minicomputer through direct memory access. Software then stored the data on disk and manipulated the data to produce converted and reduced data.

The binary representation of the analog signal is converted to a decimal number knowing the amplifier gains and the full scale range of the converter. The decimal voltages are reduced by using a selected scan as a zero reference and adjusting all subsequent values to reflect the zero reference value. The zero reference scan is a data scan acquired prior to activating the hydraulics. The reduced values for the load transducers are corrected for excitation voltage changes. The voltages are supplied by a regulated power source and do not vary during a test. However, the load transducers are calibrated at a 6.00 volt excitation level, but the test excitation level is generally slightly different (e.g., 6.08 volt). The reduced values also include a multiplicative coefficient which expresses the voltage in terms of any desired unit (e.g., kips).

\subsection{LOADING SEQUENCE}

The stress state in the box beam-hanger rod connection region is dictated by the loads from both the lower and upper walkway hanger rods. The exact distribution of load between the two rods is influenced by a number of factors, but it can be approximated by the assumption that all of the load from the lower walkway hanger rod is transferred to the adjoining upper walkway hanger rod in addition to the contribution due to upper walkway loads. The general loading sequence used in most of the box beam tests is based on applying only dead load to the upper walkway and dead load plus all live load to the lower walkway. This loading is not an exact simulation of the actual situation but, as discussed in section 4.4 , is reasonably consistent with the small number of people believed to have been present on the fourth floor walkway at the time of collapse. The test results also indicate that the load capacity is not 
significantly affected by small variations in loading sequence, as pointed out in section $6 \cdot 10 \cdot 5$.

The hydraulic loading system used in the tests applies load as long as there is resistance to the stroke of the hydraulic cyclinder. As failure begins to occur, the applied load decreases until the movement of the cylinder can "catch up" with the movement of the structural member. The actual walkway loading was a gravity-type loading. That is, the loads remained in place regardless of the deformation of the structure. Thus, as the structure begins to fail the gravity load remains constant although the resistance of the structure is decreasing with deformation. These two methods of loading, that is, hydraulic vs. gravity, will produce little difference in structural response until deformations become large. At that point, the gravity-type loading causes a more rapid failure of the structure than the hydraulic loading. The ultimate capacity which would be obtained by either method of loading would be expected to be the same. The load-deformation curves would also be expected to be the same up until the maximum load is reached.

Full-Length Box Beam. The upper walkway dead load was applied to the box beam through the upper walkway loading system. The lower loading rods were kept unloaded. After the upper walkway dead load was reached the hydraulic pressure maintainer kept the load constant. The load in the lower rods was then gradually increased until failure occurred. Using this loading procedure the load carried by the upper rod was equal to dead load from the fourth floor and dead load plus live load from the second floor. In most tests the loading was terminated after lower flange failure at the location of an upper walkway hanger rod while in other tests loading was continued until failure also occurred in the upper flange. The upper flange failure load was always smaller than the lower flange failure load and the large deformations involved following lower flange failure made additional distortion measurements of questionable value.

Short Box Beam. The loading sequence used in nearly all short box beam tests was as follows:

1. Load the upper rod to a value representing the nominal fourth floor dead load contribution keeping the lower rod unloaded.

2. Once the nominal dead load value was reached in the upper rod, load was added equally to both rods until the test was terminated when full piston stroke for the upper rod was reached. The load carried by the upper rod was then equal to dead load from the fourth floor and dead load plus live load from the second floor. The maximum load capacity was achieved in all but one test prior to reaching the stroke limit. 


\subsubsection{Parameters}

A range of parameters was studied in order to define adequately the load carrying capacity of the box beam-hanger rod connection. A number of parameters were required for reasons such as:

- variability of details among the walkway box beams (e.g., interior weld length)

- uncertainty of conditions at the onset of failure (e.g., nut orientation, washer presence), and

- unavailability of walkway box beam properties at early stages of the test program (e.g., welding process, washer hardness).

The parameters studied in the short box beam tests were:

- Welding Process

- Exterior Weld Penetration

- Interior Weld Length

- Interior Weld Position

- Washer Presence

- Washer Hardness

- Washer Thickness

- Nut Shape

- Nut Orientation

- Loading Configuration

- Initial Upper Rod Load

- Stringer-Box Beam Clip Angle Presence

These are discussed in detail in the following subsections along with the test results.

\subsubsection{Short Box Beam Specimens}

The characteristics of each short box beam specimen along with the peak load resistance for each specimen determined by the load in the upper rod are listed in tables $6.1,6.2$, and 6.3. Data for specimens which used hardened washers 
beneath the fourth floor rod connecting nut are listed in table 6.1 while specimens which used unhardened washers are listed in table 6.2. Three specimens tested without washers are listed in table 6.3 .

Three different failure types, assigned the identifiers I, II, and III, were observed and are shown in figure 6.14. The bottom flanges of specimen K2, and others exhibiting type I behavior, fold back about a plastic hinge in the web and do not show any discernible bending. The flanges in type III behavior, illustrated by $\mathrm{J} 1$, fold back about the plastic hinge in the web but also show pronounced bending in the flange. Type II behavior exhibits slight bending in the flange tips as illustrated by specimen Ml. None of the washers fractured in these tests.

Three typical in-plane load-deflection curves for the short box beam specimens are shown in figure 6.15. (A complete set of load-deflection curves is presented in appendix A.6.10.) Each curve is a plot of the load measured by the upper rod load transducer versus the displacement of the rod measured by the LVDT at the box beam terminus of the upper loading rod (LVDT no. 2 in figure 6.13). The peak load achieved by each of the specimens is shown on their respective curves. The asterisk on each curve indicates the end of reliable measurement by the displacement device and does not necessarily denote final rod pull-through.

The in-plane load-deflection curves in figure 6.15 illustrate specimen behavior usually associated with failure types I, II, III and are again illustrated by specimen $\mathrm{C} 3$, specimen $\mathrm{T} 3$, and specimen $\mathrm{F} 2$, respectively.

Type I behavior is characterized by a load-deflection curve which shows a relatively sharp peak at maximum load. In addition to general observations which were made on the behavior of all specimens, several specimens were subjected to detailed observations during their entire loading sequence. Observation of the inside of the box beam, which was whitewashed, indicates that the exterior weld between the two rod holes begins to crack at an upper rod load of between 5 to $7.5 \mathrm{kips}$ ( 22 to $33 \mathrm{kN}$ ). The interior weld (or exterior weld if no interior weld was present) between the outer hanger rod hole and the beam end begins to crack adjacent to the outer hanger rod hole at an upper rod load of from 8 to 10 kips ( 36 to $44 \mathrm{kN}$ ). Web deformation became visible at 10 to 12 kips ( 44 to $53 \mathrm{kN}$ ). The achievement of maximum load is accompanied by fracture of the interior weld (or exterior weld if no interior weld is present) between the exterior hole and the beam end. After the exterior weld breaks the bottom flanges fold back about a plastic hinge in the web. The bottom flanges exhibit no discernible bending.

Type III behavior is usually characterized by a load-deflection curve which has a relatively rounded shape (as compared to type I) at maximum load. Visual observation of a few specimens indicates that the exterior weld between the lower flange hanger rod holes also cracks between 6 to 8 kips ( 27 to $36 \mathrm{kN}$ ) of upper rod load. Cracking of the interior weld begins adjacent to the outer hanger rod hole at between 10 to $12 \mathrm{kips}$ ( 44 to $53 \mathrm{kN}$ ) and progresses to the end of the beam by about $15 \mathrm{kips}(67 \mathrm{kN})$. Shortly after this stage of cracking the deformations become visible. At the maximum load the interior weld has 
not yet fractured between the exterior hole and the beam end. The resistance to load decreases with increased deflection, but at a constant rate. The rate is quite similar to the load loss rate following the peak load in the type I behavior. The gradual loss in resistance to load continues with progressive cracking until the interior weld between the outer hole and the beam end fractures, at which point there is a sharp drop in load resistance. The bottom flanges exhibit pronounced bending as illustrated by specimen J1 in figure 6.14.

Type II behavior is between the two extremes (figure 6.15). Initially it exhibits the characteristics of type III behavior. However, the interior weld between the exterior hanger rod hole and beam end fractures at or just after the peak load, unlike the type III beams. The bottom flanges appear more like type I but show a small amount of bending as for specimen T3 in figure 6.14.

The out-of-plane load-deflection curves show the same trends as exhibited by the in-plane load-deflection curves. The out-of-plane load-deflection curves for the above described specimens are shown in figure 6.16. Each curve is a plot of the same load described for figure 6.15 versus the displacement measured by the middle transverse LVDT (figure 6.13). These data show that the web is beginning to deform outward shortly after the application of dead load from the second floor is started.

A complete discussion of the effects each parameter has on the ultimate capacity is presented in the following subsections.

\subsubsection{Welding Process}

Since there was uncertainty regarding the welding process actually used in the box beam fabrication, the influence of welding process was examined by using several different procedures to fabricate the short box beams. The selection was made by visually comparing the results of welds made using several types of electrodes used in shielded metal arc welding (SMAW) [6.1] with the visual observations of the walkway box beam welds. Specimens were fabricated with AWS class E7014 and E7018 stick electrodes to give an indication of the effect electrodes had on load carrying capacity. Both the E7014 and E7018 electrodes were $5 / 32$ in $(3.97 \mathrm{~mm})$ in diameter.

After a number of specimens had been fabricated and tested, information was received from legal counsel (section 2.7) to the steel fabricator indicating either SMAW, or "MIG welding" was used in the walkway fabrication. Legal counsel further stated that if "MIG welding" were used, the electrode was flux cored. "MIG welding" was taken to include flux cored arc welding (FCAW) or gas metal-arc welding (GMAW). Visually, the GMAW process with a mild steel electrode most closely resembled the walkway welds. Therefore, a mild steel electrode was used in fabricating the bulk of the remaining short box beams. However, four short box beams were also fabricated using a flux cored electrode. These four specimens provided additional indications as to the effect of different electrodes. The mild steel electrode, AWS class E70S-3, was manufactured by Racco and was 0.045 in $(1.14 \mathrm{~mm}$ ) in diameter. The flux cored electrode, AWS class E70T-1, was a Hobart Fabco 81 electrode also 0.045 in $(1.14 \mathrm{~mm})$ in diameter. 
The four processes are summarized below:

Process 1

GMAW - Gas metal arc welding process using a 0.045 in (1 mm) diameter mild steel electrode.

In all cases the gas was carbon dioxide delivered at $20 \mathrm{cfm}$ $\left(0.009 \mathrm{~m}^{3} / \mathrm{sec}\right)$.

In all cases the voltage was 26 volts and the current was 150 amps.

\section{Process 2}

FCAW - Flux cored arc welding process using a 0.045 in ( $1 \mathrm{~mm}$ ) diameter flux cored electrode.

In all cases the gas was carbon dioxide delivered at $20 \mathrm{cfm}$ $\left(0.009 \mathrm{~m}^{3} / \mathrm{sec}\right)$.

In all cases the voltage was 26 volts and the current was 150 amps.

\section{Process 3}

S14 - An E7014 stick electrode was used without preheat

In all cases the rod diameter was $5 / 32$ in ( $4 \mathrm{~mm}$ )

In all cases DC straight polarity was used

In the $C, F$, and $G$ series the current was 150 amps

In the $A$ and $E$ series the current was 185 amps

In the $D$ series the current was 180 amps

Process 4

S18 - An E7018 stick electrode was used without preheat

In all cases the rod diameter was $5 / 32$ in ( $4 \mathrm{~mm}$ )

In all cases DC reverse polarity was used

In all cases the current was 140 amps

Comparisons between specimens in which the only intentional difference is the welding process appear in figure 6.17. Six sets of data, each consisting of comparable specimens, are shown enclosed in the figure. Hardened washer data are used where possible since it was found (section 6.10.5) that hardened washers were used in the actual walkway construction. The specimens compared for a particular process were fabricated at the same time. This selection of data was done to maintain as much similarity as possible since there was variation in the amount of weld material deposited and, as discussed in section 6.10.4, the peak upper rod load was later found to vary in proportion to weld area.

Data for deep penetration welds (no interior weld) are used to compare process 3 and 4 (specimens $A 1, A 2$, and $B 1$, table 6.1). There is no difference between the average for process 4 data and the process 3 test specimen.

Two further data sets with no interior weld are compared. For specimens with hardened washers (specimens $\mathrm{C} 1, \mathrm{C} 3, \mathrm{I} 1$, and $\mathrm{I} 2$, table 6.1) the average peak 
upper rod load for process 1 is only $5001 \mathrm{~b}(2.2 \mathrm{kN})$ more than process 3 . For unhardened washers (specimens LS1, LS2, P1, and P2, table 6.2) the maximum difference in the average is $7001 \mathrm{~b}(3.1 \mathrm{kN})$ comparing processes 1 and 2 . Even this difference is only about five percent of the peak upper rod load.

The $1 / 2$ in $(13 \mathrm{~mm}$ ) interior weld data set (specimens $\mathrm{K} 1, \mathrm{~K} 2, \mathrm{G} 1$, and $\mathrm{G} 2$, table 6.1) comparing process 1 and 3 differs by only an average of $3001 b$ $(1.3 \mathrm{kN})$. The two data sets for a $13 / 8$ in $(35 \mathrm{~mm})$ interior weld are for hardened (specimens J1, J2, F1, and F2, table 6.1) and unhardened washers (specimens $\mathrm{M} 2, \mathrm{~N} 1$, and $\mathrm{N} 2$, table 6.2). The average difference is zero for the comparison of process 1 and 3 with hardened washers. The comparison of process 1 and 2 for unhardened washers differs in the average by only $4001 \mathrm{~b}(1.8 \mathrm{kN})$.

Because of these small differences it is concluded that the welding process itself, within the range of variation considered by NBS, does not have a significant effect on the peak upper rod load for the short box beams. Based on this result data comparisons are not differentiated by weld process.

\subsection{0 .4 Weld Area}

Exterior Weld Penetration. The exterior weld penetration depth for specimens without an interior weld has a significant effect on the peak upper rod load of the short box beams, as shown in figure 6.18. The average peak loads for specimens E1 and E2 having no weld (no penetration), C1 and C3 having a shallow penetration weld, and A1 and A2 having a deep penetration weld are shown in the figure to illustrate that there is significant difference in load resistance between the case of shallow penetration and deep penetration. The difference is about $2.5 \mathrm{kips}(11.1 \mathrm{kN})$.

Interior Weld Length. The length of interior weld has a significant effect on load resistance of the short box beams. A limited comparison of test results is shown in figure 6.19 to illustrate this point. Data shown include shallow penetration weld specimens shown in table 6.1 except for variations due to weld position, washer thickness, nut shape, nut orientation, clip angle presence, initial rod load, and number of rods. Although a regression analysis was not done it is apparent that increasing the interior weld length increases the load resistance. The increase in load resistance is roughly linearly proportional to the increase in interior weld length. However length of interior weld alone is insufficient to account for load variation since it does not consider penetration of either the interior or exterior welds.

Weld Area. The effect of weld length and depth of penetration of the exterior and interior weld was examined by determining the interior and exterior weld areas between the beam end and the hole for the fourth floor rod. Fracture surfaces between the exterior hole and beam end were examined under magnification for all short box beam specimens. Lengths and depths were measured. Depths were measured at five locations and averaged. These average measurements are summarized in tables $6.1,6.2$, and 6.3 , and 6.4 for the NBS tests. Weld area was determined as the sum of the products of the average depth and length for the exterior and interior welds. The peak upper rod load is plotted in figure 6.20 against the weld area. Weld area is used as a measure or index 
for effectiveness of the weld material to resist load although it is realized that this is a simplification. The trend of the data is as expected; an increase in capacity occurs with the addition of weld metal.

The data shown in figure 6.20 include all tests on short box beams with hardened washers as listed in table 6.1 except for round nut bevel, initial rod load, single rod and clip angle presence. These latter parameters are discussed in section $6 \cdot 10.5$.

The correlation coefficient, $r$, is 0.90 for the equation for the mean peak upper rod load [6.2]. An $r$ value of 1.0 indicates perfect correlation. The $\mathrm{r}^{2}$ value is 0.80 , indicating that 80 percent of the total variation in the peak upper rod load is accounted for by the regression line. The other 20 percent is unaccounted for by the weld area alone. Thus the equation for the mean based on the weld area is a reasonable representation of the load resistance within the range of the test data. A 95 percent confidence band for the data is also shown in figure 6.20. Ninety five percent of the test results for individual specimens are expected to be within the limits of the band.

\subsection{0 .5 Other Observations}

Stringer-Box Beam Clip Angle Presence. Four short box beam tests were conducted to examine the influence of stringer-box beam clip angles on load resistance. These specimens were obtained by cutting off the outside 22 in ( $560 \mathrm{~mm}$ ) of full-length beams L3 through L6 that did not fail during the fulllength box beam tests described in section 6.11. Except for the presence of clip angles and the fact that the specimens had been loaded during full-length box beam tests, tests were conducted in the same manner as used for typical short box beam specimens.

The presence of clip angles does not significantly affect the peak upper rod load capacities of the short box beams as is apparent from the data for specimens S1-S4 shown in figure 6.21 compared to the mean peak upper rod load and the 95 percent confidence band. This observation was expected based on the zone of distress observed on the white-washed box beams since the zone of distress did not extend to the location of the stringer-box beam clip angle.

Initial Upper Rod Load. The short box beam tests began prior to the weighing of the walkway spans. The nominal upper walkway dead load was calculated on the basis of the contract drawings and thus for this part of the laboratory test program the dead load contribution to the upper hanger rod was set at 7500 pounds $(33 \mathrm{kN}$ ) in all but three of the short box beam tests. The two remaining specimens were tested using an initial upper rod load of 9000 pounds $(40 \mathrm{kN})$ to examine the effect of the initial rod load on the load resistance of the box beam-hanger rod connection. As evidenced by a comparison of these two tests (figure 6.22) with the regression analysis from figure 6.20 , the influence of initial upper rod load on peak load capacity is insignificant for the range of 7500 pounds $(33 \mathrm{kN})$ to 9000 pounds $(40 \mathrm{kN})$. 
Loading Configuration. The bulk of the short box beam tests used a two rod loading configuration as discussed in section 6.5 . The two-rod configuration best modelled the actual upper walkway box beam loading. However, the original design of the second and fourth floor walkways called for a continuous hanger rod and the third floor walkway connections had a single-rod configuration. For purposes of comparison, four short box beams were loaded using only a single hanger rod. All loads were applied through the upper loading rod. The lower floor loading rod was omitted for the single rod tests although the hole was bored.

A comparison of the single rod data for $\mathrm{B} 2, \mathrm{H} 1, \mathrm{X} 1$ and $\mathrm{X} 2$ listed in table 6.1 is presented in figure 6.23. These data are consistently about $2.0 \mathrm{kips}$ ( $9 \mathrm{kN}$ ) higher than the mean for double rods for a given weld area. Thus the single rod tests are considered to be outside the range of the regression analysis and were not used as part of the data base in estimating load resistance of connections loaded by two hanger rods.

Nut Shape. Based on the observed dimensions of the walkway hanger rod nuts it was determined that they were $11 / 4$ in $(32 \mathrm{~mm}$ ) heavy hex nuts. Such nuts were procured locally and their dimensions were similar to the walkway hanger rod nuts. However, the amount of bevel at the intersection of corners and bearing surface was greater on the actual walkway hanger rod nuts (figure 6.24). The effect of nut shape was explored by testing two specimens with nuts which were altered to a geometry similar to the walkway hanger rod nuts. This is referred to as a "round" nut bevel while the nut used on most tests has a "square" bevel.

The comparison of data for specimens V1 and V2 is presented in figure 6.25 for the hardened washer tests. The comparison indicates that nut shape may have an effect on peak upper rod load, with the rounded nuts reducing the load resistance. Although the reduction is within the data scatter the two specimens are considered to be outside the range of the regression analysis and were not used as part of the data base in estimating load resistance.

Washer Presence. Early in the investigation it was uncertain whether or not washers were present on all of the upper walkway box beam-hanger rod connections since two were missing from the debris.

The majority of the short box beams were tested with washers, but three specimens were tested without a washer between the upper rod nut and the box beam. Washers were always used between the second floor loading rod nut and box beam. The absence of a washer on the upper floor rod reduces the peak upper rod load by about $2.5 \mathrm{kips}(11 \mathrm{kN}$ ) for a given weld area as shown in figure 6.26 . As noted in section 8.3 .3 of this report, there is strong evidence that washers were present prior to the collapse. Thus these data are not used as part of the data base in estimating capacity.

Washer Hardness. Prior to obtaining material from the walkway debris it was not possible to determine whether the washers were hardened or unhardened. Initially, the short box beam specimens were tested using hardened steel washers. These were followed by a series of short box beams tests using unhardened washers. 
Based on the data shown in figure 6.27 it is estimated that an unhardened washer reduces the load resistance by approximately $2.0 \mathrm{kips}(9 \mathrm{kN}$ ) below that of the hardened washer. Since all of the tests on debris indicated hardened washers were used, these data were not used in estimating load resistance.

Seven unhardened washer data points are identified separately in figure 6.27. This was done for convenience in discussing subsequent parameters.

Interior Weld Position. In all but two short box beams with interior welds, the weld began at the box beam free end and extended inwards (termed the edge position). The two remaining specimens ( $R 1$ and $R 2$ ) with unhardened washers had the interior weld extending from the exterior hole edge outwards (termed the hole position). The weld position was varied to explore the importance of weld material at the hole position as compared to weld material near the free end.

The lengths of interior weld beginning at the edge of the hole are $1 / 4$ in ( $6 \mathrm{~mm}$ ) and $5 / 16$ in $(8 \mathrm{~mm})$. Comparison of these data with other unhardened washer data in figure 6.27 indicates that the location of the interior weld within the length between the edge of the exterior hole and the beam end is not a significant parameter within the range of variation studied.

Washer Thickness. All but one short box beam was tested with washers having a thickness of about 0.15 in $(3.8 \mathrm{~mm}$ ). Specimen N6 (table 6.2) was tested using an unhardened washer having a thickness of about 0.18 in ( $4.6 \mathrm{~mm}$ ).

The data in figure 6.27 shows that the test result for N6 is within the overall scatter of the data. Although a thicker washer should improve the load resistance, the small variation tested appears to make no difference.

Nut Orientation. The orientation of the nuts on the walkway hanger rods at the time of failure could not accurately be ascertained. For purposes of the investigation a uniform orientation was used for most tests, but three specimens (N3, N4, and N5) with unhardened washers were tested using a different orientation. The normal nut orientation was with two nut faces parallel to the short box beam longitudinal axis. The alternate orientation had two nut faces perpendicular to the short box beam longitudinal axis (figure 6.28).

The data points for nut orientation are shown in figure 6.27. Based on these data nut orientation is not considered a significant parameter.

\subsection{0 .6 Summary}

The short box beam data base was discussed in sections 6.10 .4 and 6.10.5. After review of the parameters it is concluded that additional data may be used as part of the data base used to develop figure 6.20. Specifically, all of the data for hardened washers should be used except that for single rod tests (B2, $\mathrm{H} 1, \mathrm{X} 1$, and $\mathrm{X} 2$ ) and nut shape tests (V1 and V2). All of the data in tables 6.2 and 6.3 for tests using unhardened washers and no washers are also excluded. 
A regression line is shown in figure 6.29 based on these 28 tests. This regression line for the mean peak upper rod load is shown with a 95 percent confidence band for the data and has a correlation coefficient, $r$, of 0.91 and an $\mathrm{r}^{2}$ of 0.84 . This line of best fit characterizes the NBS short box beam test results.

\subsection{NBS FULL-LENGTH BOX BEAM TESTS}

Seven full-length box beams fabricated by NBS were tested with the parameters shown in table 6.4. All seven were dimensionally identical. All full-1ength box beams were fabricated using the GMAW process and the same mild steel electrode used in the short box beam tests. The first two full-length box beams (L1 and L2) had a $1 / 2$ in (13 mm) interior weld extending from each end of the top and bottom flanges while the remaining five full-length box beams (L3-L7) were constructed similarly except that the interior weld extended $13 / 8$ in ( $35 \mathrm{~mm}$ ). Load-deflection curves are presented in appendix A6.11.

The full-length box beam data are compared to the regression analysis results for the short box beam tests (from figure 6.29) in figure 6.30. Based on the comparisons between the full-length and short box beam tests, it was concluded that there is good agreement between the results obtained using either type of test specimen. Therefore, a regression analysis was performed using the short box beam data shown in figure 6.29 along with the full-length box beam data points shown in figure 6.30. The results of this analysis, which incorporates all of the applicable results of the NBS test program as indicated ( 35 tests), are shown in figure 6.31. The correlation coefficient, $r$, is 0.87 and the $\mathrm{r}^{2}$ value is 0.76 .

\subsection{TESTS ON WALKWAY BOX BEAM}

One full-length box beam was obtained from column line 9 of the third floor walkway (figure 6.7). One full-length box beam test and four short box beam tests were conducted on this beam. Specimen characteristics are shown in table 6.5 .

\subsubsection{Full-Length Box Beam Test}

The third floor walkway box beam, designated $\mathrm{KCL}$, was longer than the second and fourth floor walkway box beams and only had holes for a single hanger rod at each end (figure 3.10). The holes for the lower loading rods were made at NBS in the same way as holes in the NBS box beams were made. The nuts and washers used on the exterior (upper) loading rods at the box beam were those taken by NBS from the walkway box beam during removal. The interior (lower) loading rods were fitted with NBS rounded nuts and hardened washers.

The extra beam length was located between the clip angles and was accommodated in the test setup by repositioning the loading rods and hydraulic cylinders. A longer spreader beam was used to span between the clip angles. The instrumentation was identical to that used in the NBS full-length box beam tests except that for purposes of videotaping the transverse LVDTs were omitted. 
The first failure occurred at the west lower flange exterior hole. The interior weld on this flange did not extend to the exterior hole while the interior weld on the east lower flange did extend fully to the exterior hole. The rod load (upper west rod) at first failure was approximately $19.4 \mathrm{kips}(86 \mathrm{kN})$. The second failure occurred at the west upper flange exterior hole. No interior weld was observed on this flange. The rod load at failure was approximately 16.2 kips $(72 \mathrm{kN})$. The upper rod loads versus channel tip displacements are shown in figure 6.32 .

Specimen KCL was recorded on videotape, which included a record of load on the videotape image. Thus, the load-deflection behavior in figure 6.32 may be described by correlation with the videotape. Due to the test setup it was not possible to observe directly the weld surfaces on the interior of the box beam. However, based on observations of other NBS tests, cracking probably occurred in the exterior welds between the two rod holes on the lower flange by a load of $7.5 \mathrm{kips}(33 \mathrm{kN}$ ) representing the dead load from the fourth floor walkway. By approximately 11 kips ( $49 \mathrm{kN}$ ) cracking probably started in the interior weld near the outer hanger rod hole and progressed towards the end of the box beam. Observation of the videotape showed that at about $16 \mathrm{kips}$ (71 kN) the web bending was pronounced. At about that load level the load-displacement curve is beginning to show increasing nonlinearity.

The videotape which included an audio track indicated, based on noise emitted, that considerable weld fracturing occurred between 18.1 and $15.5 \mathrm{kips}$ (81 and $69 \mathrm{kN}$ ) on the descending portion of the load-displacement curve with complete fracture (visible on the video portion of the tape) occurring at about 15.5 kips (69 kN) with the load dropping rapidly to $12.8 \mathrm{kips}(57 \mathrm{kN})$. At about 8 kips ( $36 \mathrm{kN}$ ) on the descending portion of the curve the washer fractured with the load dropping almost immediately to $5.9 \mathrm{kips}(26 \mathrm{kN})$.

\subsubsection{Short Box Beam Tests}

After the full-length box beam test, the box beam was sawn into four lengths which were made into short box beams. The first short box beam included the unfailed east end of the full-length box beam. The other three short box beams were taken in succession along the length of the box beam. The longitudinal welds were not modified. The first short box beam included the stringer connection clip angles. A fifth short box beam was included in this series and was fabricated using the NBS channel sections.

The first short box beam ( $\mathrm{KCl}$ ) was a continuation of the test of the full-length box beam's east end. The next three short box beams were similar except for the nut and washer used on the upper loading rod. The fifth box beam was an NBS box beam (I3), but the nut and washer on the upper loading rod was from the walkway debris.

The in-plane load deflection curves for the short box beam tests are shown in figure 6.33. Each curve is a plot of the upper rod load transducer versus the displacement of the rod measured by the LVDT at the box beam terminus of the upper loading rod. The peak load achieved by each of the specimens is shown 
on their respective curves. The asterisks on each curve indicate the end of reliable measurement by the LVDT.

Specimen KCl exhibited a double peak load deflection curve as shown in figure 6.34. This is a continuation of the data shown in figure 6.33. The unloading shown in figure 6.34 at about 1.8 in $(46 \mathrm{~mm}$ ) of displacement was necessary since the stroke of the piston in the hydraulic ram had been reached. After repositioning the piston, load was reapplied. After exhibiting typical behavior through about the first 1.8 in $(46 \mathrm{~mm}$ ) of displacement, another resistance mechanism took effect which enabled the load to increase again. As larger deformations occurred the web buckling progressed further into the length of the box beam. Apparently the progression was stopped by the clip angles which stiffened the web. The load increased again to a second peak of 23.6 kips $(105 \mathrm{kN})$. The weld between the outer rod hole and the beam end cracked but never completely fractured. Pull-through was achieved only after full separation of the flanges between the rod holes occurred. An end view of the $\mathrm{KCl}$ deformed shape is shown in figure 6.35 .

It is emphasized that the fourth floor walkway box beams that failed on July 17 did not exhibit the same behavior mechanism described for KC1. Their behavior, as shown by the end views in figure 6.36 was much more typical of the NBS specimens (figure 6.14) as were the other specimens sawn from specimen KCL.

Specimens $\mathrm{KC1}, \mathrm{KC} 2$, and I3 also used washers obtained from the walkway debris. The washers fractured in all three instances but only after the peak upper rod load had been reached (figure 6.33). The $\mathrm{KCl}$ washer fractured at a load of about 15 kips ( $67 \mathrm{kN}$ ) while the washers for $\mathrm{KC} 2$ and $\mathrm{I} 3$ fractured at about 7 kips $(31 \mathrm{kN})$ and 6 kips $(26 \mathrm{kN}$ ) respectively. In I3 only a sector of the washer fractured as compared to complete fractures for $\mathrm{KCl}$ and $\mathrm{KC} 2$. Washers did not fracture in the KC3 and KC4 tests which used NBS hardened and unhardened washers respectively.

Specimen KC4, which consisted of a walkway short box beam tested with an NBS unhardened washer, is shown plotted in figure 6.27. When compared with the results of NBS box beams tested with unhardened washers, KC4 appears to give consistent results.

The remainder of the box beam test results involving walkway materials are shown in figure 6.37. Since the weld of specimen KCl never fully fractured the weld area recorded for this specimen is an estimate based on the area of the weld at the center line of the longitudinal seam rather than the weld area actually measured on the fracture surface. Since the regression analysis was based on weld fracture area, direct comparison of the $\mathrm{KCl}$ test with other data is difficult. Specimen I3, which consisted of an NBS short box beam tested with a walkway washer, shows a load resistance which is consistent with the other NBS box beam test data.

Specimen KC3, which consisted of a walkway short beam tested with an NBS hardened washer, similarly shows a load resistance which is consistent with the NBS box beam data. Specimens $\mathrm{KCL}, \mathrm{KCl}$, and $\mathrm{KC} 2$, which were the only tests 
conducted on specimens with the box beam, nut, and washers of walkway origin, fall within or near the 95 percent confidence band for the NBS test data. However, two of the three specimens are either at or just outside the upper boundary of the 95 percent confidence band.

The size of the data base for NBS box beams with NBS hardened washers is of reasonable size ( 35 specimens shown in fig. 6.31), and thus, can be used with reasonable confidence as a tool for predicting ultimate strength of box beam hanger rod connections having similar characteristics. While the walkway test results generally fall within the 95 percent confidence band for the NBS data base, it must be recognized that the walkway data base is extremely limited (three specimens with walkway box beams, nuts and washers) and does show a tendency toward the upper boundary of the 95 percent confidence band of the NBS data base.

As noted earlier, and as shown in table 6.6 , the walkway box beams had a somewhat heavier cross-section which might be expected to slightly increase load resistance. Recognizing this limitation, the NBS data base is used as the basis for estimating the ultimate strengths of the fourth floor walkway box beam-hanger rod connections. The validity of the ultimate strengths thus derived is further discussed in chapter 10.

\subsection{BOX BEAM-HANGER ROD CONNECTION CAPACITY}

The regression equation shown in figure 6.38, along with the 95 percent confidence band for single values of pullout load, is used to estimate ultimate strengths for the fourth floor box beam-hanger rod connections. The figure is the same as the one shown in figure 6.31, but with the data points omitted. It was developed based on the short box beam data described in section 6.10.6 and the full-length box beam data described in section 6.11. Furthermore, the regression analysis was validated by the use of actual walkway test specimens.

The meaning of figure 6.38 is amplified by discussing box beam-hanger rod connection 9UE as an example. Simply described, if many specimens like 9UE were tested, their average should fall close to the regression line. However, for a single test one can be 95 percent confident that the test result would fall within the 95 percent confidence band. Thus each connection should be thought of in terms of the range of ultimate strength as well as the average.

Weld areas were determined by examination of the actual fracture surfaces for 8UE, 9UE, 9UW, and 10UE. The weld lengths and depths were measured, the depths being measured at 5 locations along the weld length. Computed areas are shown in table 6.7. Weld areas for fracture surfaces 8UW and 10UW are based on field measurements since the actual fracture surfaces were not obtained. These weld areas are also shown in table 6.7 .

These ultimate capacities are summarized in figure 6.39 on a layout of the six box beam-hanger rod connections. A bar diagram is shown adjacent to each hanger rod. Location $8 \mathrm{UE}$ is described to denote the meaning. The range from 16.3 to 20.2 kips ( 73 to $90 \mathrm{kN}$ ) is the 95 percent confidence interval estimate 
for this particular box beam-hanger rod connection. The mean ultimate capacity of 18.2 kips $(81 \mathrm{kN})$ is also shown. The mean capacity for all connections is 18.6 kips $(83 \mathrm{kN})$.

Although these comparisons indicate that the regression analysis based on the data shown in figure 6.31 reflects the trend of the walkway data, the walkway section is slightly heavier than the section used in the NBS tests, as shown in table 6.6. Thus, somewhat greater ultimate strength might be anticipated for the walkway cross-sections. This heavier cross-sectional area may explain why the test data fall essentially between the average and the upper portion of the confidence band with none below (recall that KC4 was tested with an unhardened washer).

The regression analyses were developed for the double or interrupted rod connection that was actually used in the walkway. Based on the results in section 6.10 .5 the original continuous hanger rod arrangement would have been about $2.0 \mathrm{kips}(9 \mathrm{kN})$ higher than the arrangement actually used. Thus the average ultimate capacity would have been about $20.5 \mathrm{kips}$ (91 kN).

\subsection{CONCLUSIONS}

The following conclusions are made subject to the limitations on the range of variables tested.

1. The welding process has little effect on ultimate capacity.

2. Three types, of washers were used during the test series. Hardened and unhardened washers were used in the NBS test program. A third type of washer which exhibited a hardness similar to that of the NBS hardened washer was obtained from the walkway debris. However, this washer differed from the NBS washer in that it fractured during testing. However, the fracture occurred after the peak load had been reached and at a load smaller than the peak load. None of the washers tested by NBS other than those from the debris fractured.

3. Ultimate capacity of the double rod connection varies linearly with an index weld area consisting of the sum of the exterior and interior weld area in the region between the outer hanger rod hole and the beam end. The variation for hardened washers is $P=13.18+0.0391 \mathrm{~A}$ with a correlation coefficient of 0.87 .

4. Test results for box beam samples from the walkway debris were within or near the 95 percent confidence interval estimate based on the use of the linear equation developed using the NBS test data.

5. The ultimate capacity of box-beam hanger rod connections can be predicted on the basis of laboratory test results. Estimates for the mean box beam-hanger rod connection ultimate capacities and a 95 percent confidence interval estimate for the walkway box beam-hanger rod connections are listed below. 


$\begin{array}{ccc}\text { Connection } & \begin{array}{c}\text { Mean Ultimate Capacity } \\ \text { kips }(\mathrm{kN})\end{array} & \begin{array}{c}95 \% \\ \text { Confidence Range } \\ \text { kips (kN) }\end{array} \\ \text { 8UE } & 18.2(81) & 16.3 \text { to } 20.2(73 \text { to } 90) \\ \text { 8UW } & 19.3(86) & 17.3 \text { to } 21.4(77 \text { to } 95) \\ \text { 9UE } & 18.2(81) & 16.2 \text { to } 20.2(72 \text { to } 90) \\ \text { 9UW } & 18.3(81) & 16.3 \text { to } 20.3 \text { (73 to } 90) \\ \text { 1OUE } & 19.1(85) & 17.1 \text { to } 21.1 \text { (76 to } 94) \\ \text { 1OUW } & 18.3(81) & 16.3 \text { to } 20.3(73 \text { to } 90)\end{array}$

These capacities ranged from 18.2 kips $(81 \mathrm{kN})$ to $19.3 \mathrm{kips}(86 \mathrm{kN})$ with an average of $18.6 \mathrm{kips}(83 \mathrm{kN})$.

6. Ultimate capacity for the single rod connection is about $2.0 \mathrm{kips}$ ( $9 \mathrm{kN}$ ) higher than for a double rod connection or an average value of about 20.5 kips $(91 \mathrm{kN})$. 


\begin{tabular}{|c|c|c|}
\hline & Nähi $ว 3 \mathrm{dS}$ & 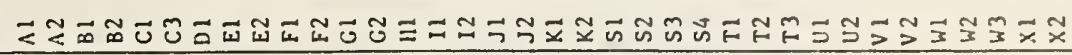 \\
\hline 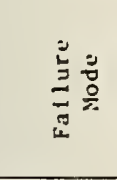 & II & $\bullet \bullet$ \\
\hline & 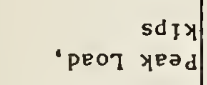 & 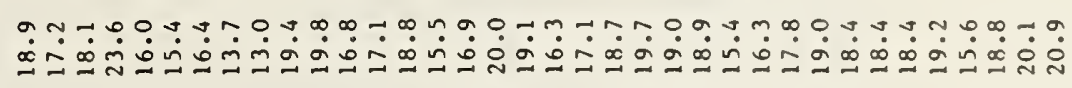 \\
\hline \multirow{3}{*}{ 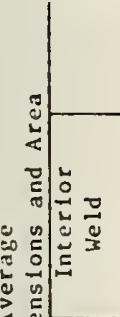 } & 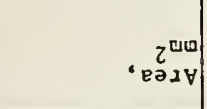 & 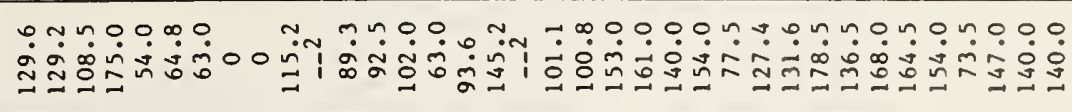 \\
\hline & 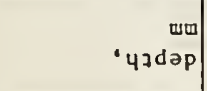 & 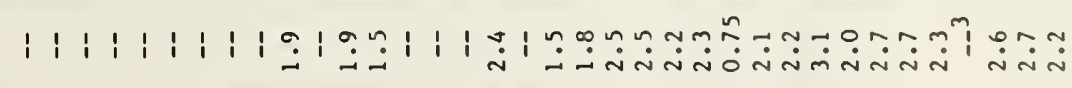 \\
\hline & ‘478นә & 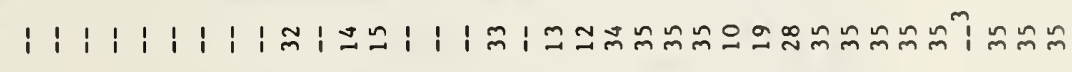 \\
\hline \multirow{2}{*}{ 点 } & ‘utdap & 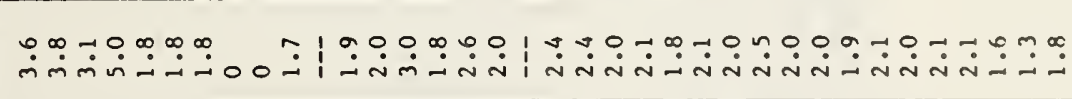 \\
\hline & 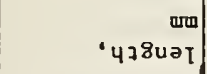 & 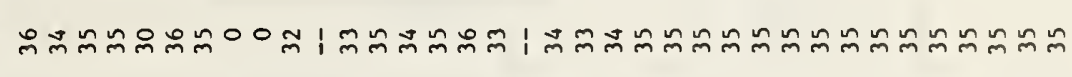 \\
\hline 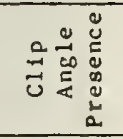 & $\begin{array}{c}\text { zuәsqu } \\
\text { Juəsadd }\end{array}$ & 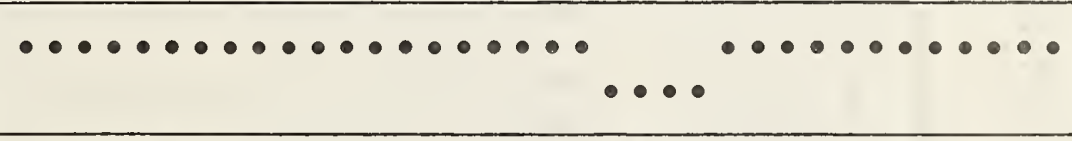 \\
\hline 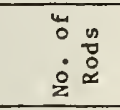 & spoy of & 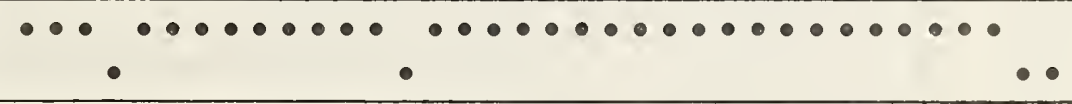 \\
\hline 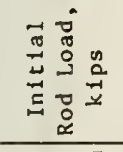 & $5 \cdot 4$ & 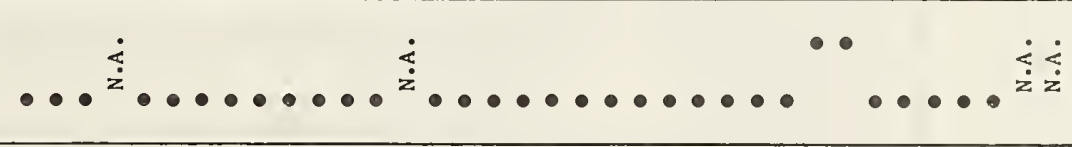 \\
\hline 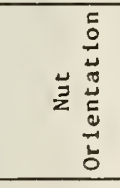 & 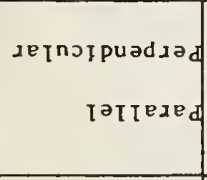 & $\bullet \bullet \bullet \bullet \bullet \bullet \bullet \bullet \bullet \bullet \bullet \bullet \bullet \bullet \bullet \bullet \bullet \bullet \bullet$ \\
\hline 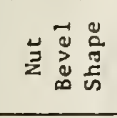 & puno \& & $\bullet \bullet \bullet \bullet \bullet \bullet \bullet \bullet \bullet \bullet \bullet \bullet \bullet \bullet \bullet \bullet \bullet \bullet \bullet \bullet \bullet \bullet \bullet \bullet \bullet \bullet \bullet \bullet, \bullet \bullet \bullet \bullet \bullet$ \\
\hline 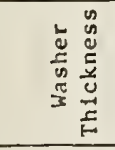 & Үग & $\bullet \bullet \bullet \bullet \bullet \bullet \bullet \bullet \bullet \bullet \bullet \bullet \bullet \bullet \bullet \bullet \bullet \bullet \bullet \bullet \bullet \bullet \bullet \bullet \bullet \bullet \bullet \bullet \bullet \bullet \bullet \bullet \bullet \bullet \bullet \bullet$ \\
\hline 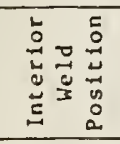 & $\begin{array}{l}\text { ә } 1 \text { 애 } \\
\text { ә9р3 }\end{array}$ & 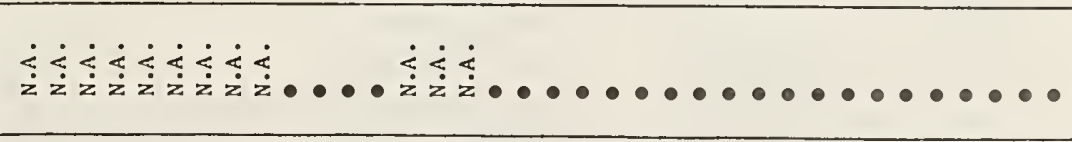 \\
\hline 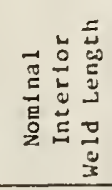 & 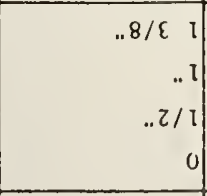 & 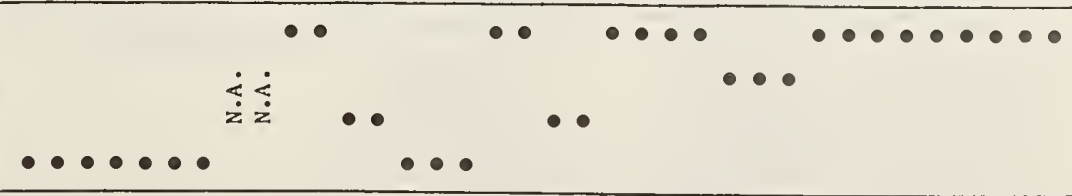 \\
\hline 点 & $\begin{array}{r}\text { doad } \\
\text { molleys } \\
\text { PIOM }\end{array}$ & $\bullet \bullet \bullet \bullet \bullet \bullet \bullet \bullet \bullet \bullet \bullet \bullet \bullet \bullet \bullet \bullet \bullet \bullet \bullet \bullet \bullet \bullet \bullet \bullet \bullet \bullet \bullet \bullet \bullet \bullet \bullet \bullet$ \\
\hline 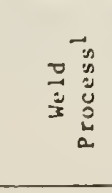 & $\begin{array}{l}7 \\
\varepsilon \\
i \\
1\end{array}$ & 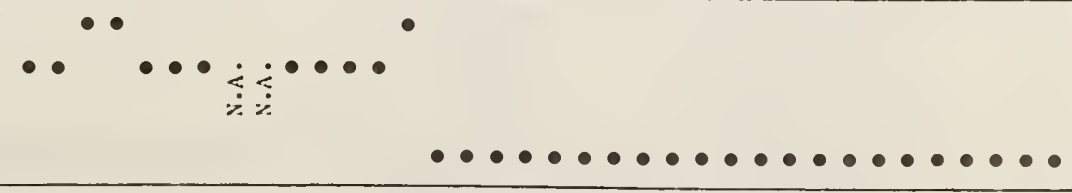 \\
\hline & $\because$ :IVI JAdS & 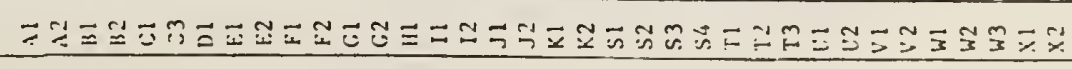 \\
\hline
\end{tabular}



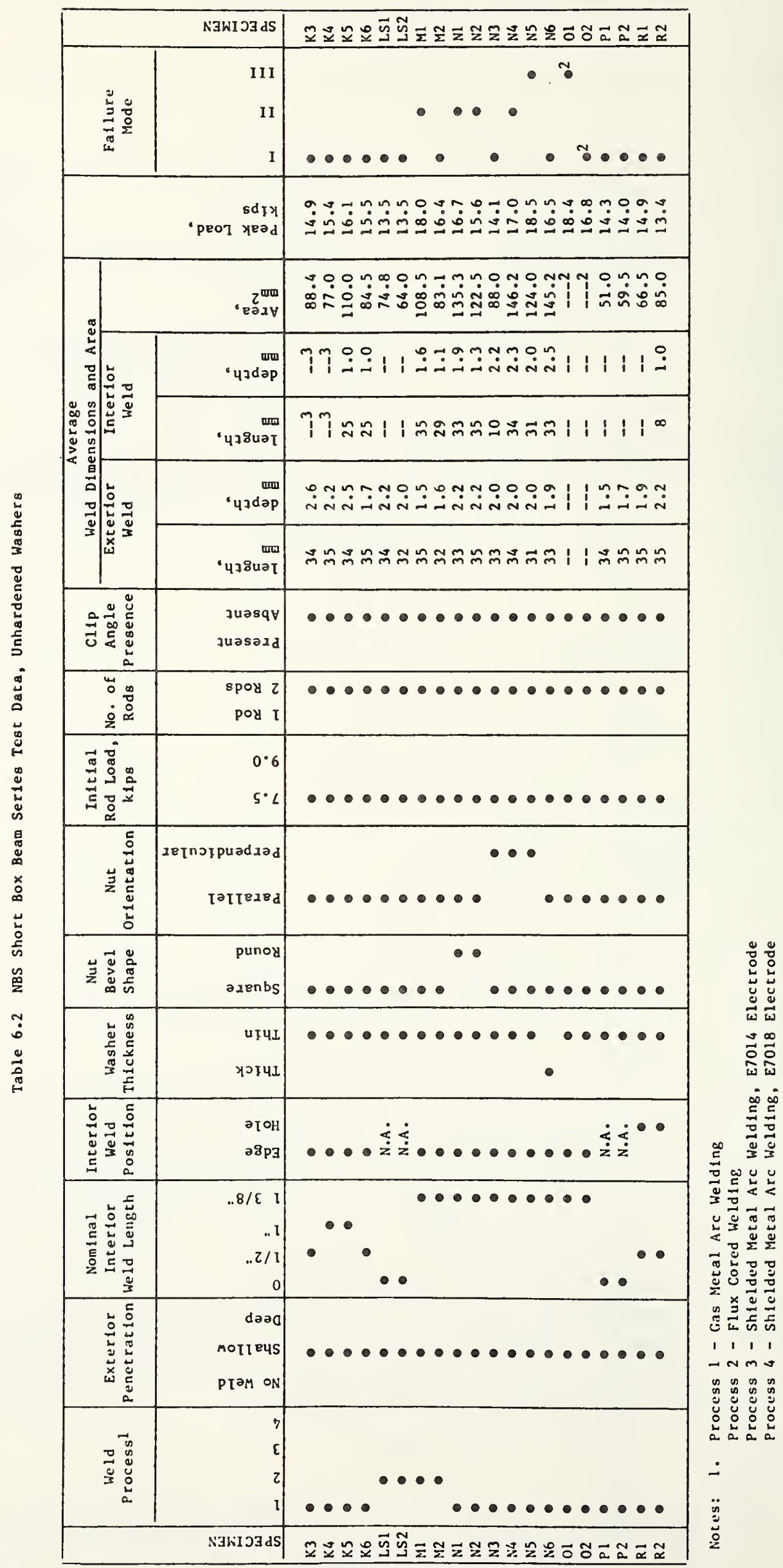


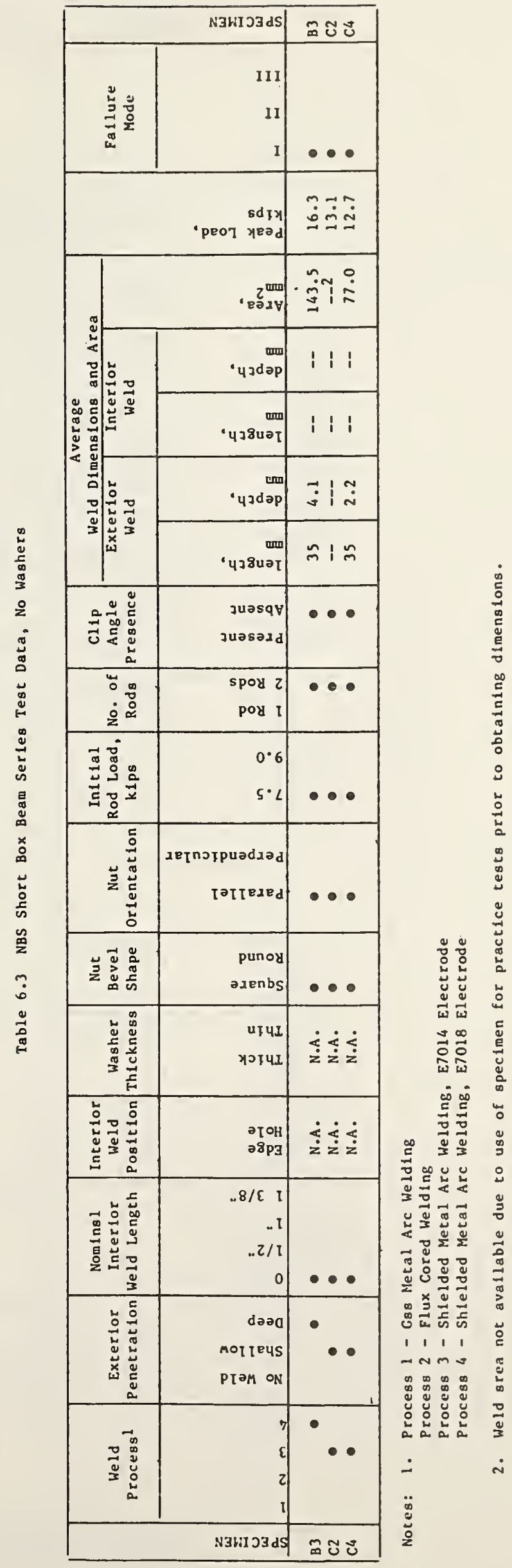




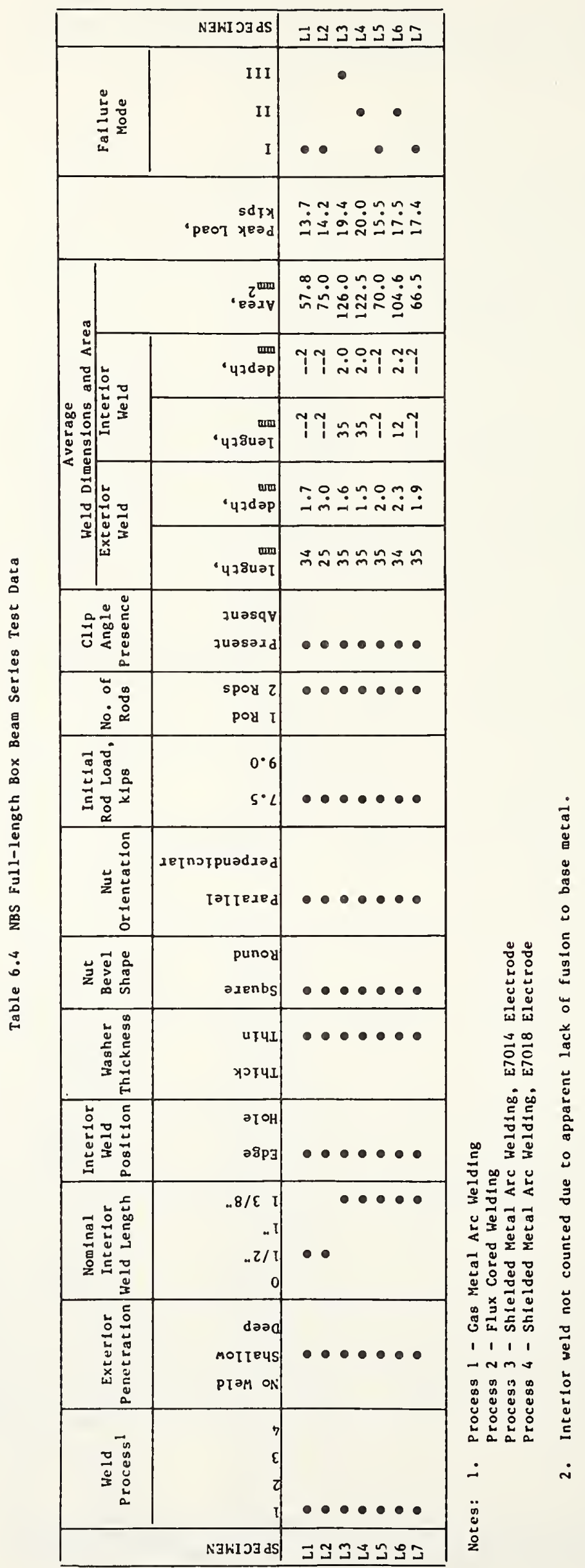



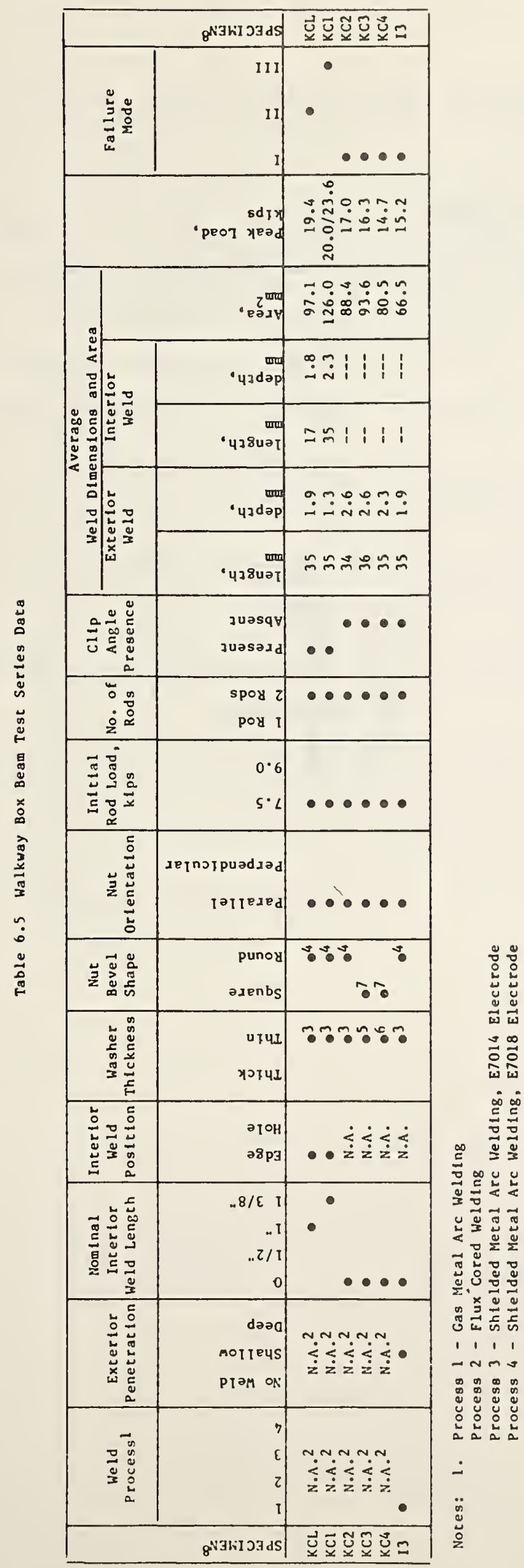

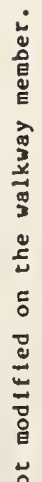

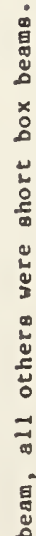

. . .

$$
\text { 总 }
$$

至

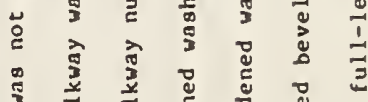

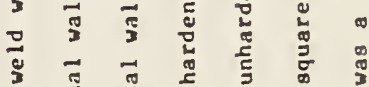

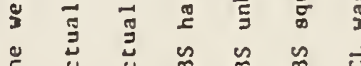

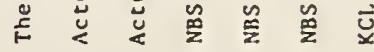

$\dot{i} \dot{m} \dot{\sim} \dot{\sim} \dot{n} \dot{0}$ 
Table 6.6 Cross-sectional Dimensions

\begin{tabular}{llcccc} 
Sec. Property & $\begin{array}{l}\text { Weight } \\
\text { lb/ft }\end{array}$ & $\begin{array}{c}\mathrm{d} \\
\text { (in) }\end{array}$ & $\begin{array}{c}\mathrm{b}_{\mathrm{f}} \\
(\mathrm{in})\end{array}$ & \multicolumn{2}{c}{$\mathrm{Max}_{\mathrm{w}}(\mathrm{in})$} \\
\hline Nominal & 8.5 & 8.00 & 1.874 & 0.179 \\
Walkway Specimens & 8.84 & 8.050 & 1.860 & 0.194 & 0.185 \\
NBS Section & 8.43 & 7.975 & 1.833 & 0.186 & 0.182 \\
& &
\end{tabular}


Table 6.7 Walkway Box Beam Weld Measurements

\begin{tabular}{|c|c|c|c|c|c|}
\hline \multirow{2}{*}{$\begin{array}{c}\text { Box Beam- } \\
\text { Hanger Rod } \\
\text { Connection }\end{array}$} & \multicolumn{2}{|c|}{ Exterior Weld } & \multicolumn{2}{c|}{ Interior Weld } & Length, mm \\
\cline { 2 - 6 } & $\begin{array}{c}\text { Average } \\
\text { Depth, mm }\end{array}$ & Length, mm & $\begin{array}{c}\text { Average } \\
\text { Depth, mm }\end{array}$ & $\begin{array}{c}\text { Total } \\
\text { Area, mm }\end{array}$ \\
\hline 8UE & 36 & 1.8 & 36 & 1.8 & 129.6 \\
\hline 8UW & 35 & 4.5 & -- & -2. & 157.5 \\
\hline 9UW & 38 & 1.8 & 25 & 2.4 & 128.4 \\
\hline 10UE & 32 & 1.7 & 16 & 3.4 & 130.2 \\
\hline 10UW & 33 & 1.5 & 33 & 2.5 & 132.0 \\
\hline
\end{tabular}

* A portion of $9 U W$ was deeply penetrated. 


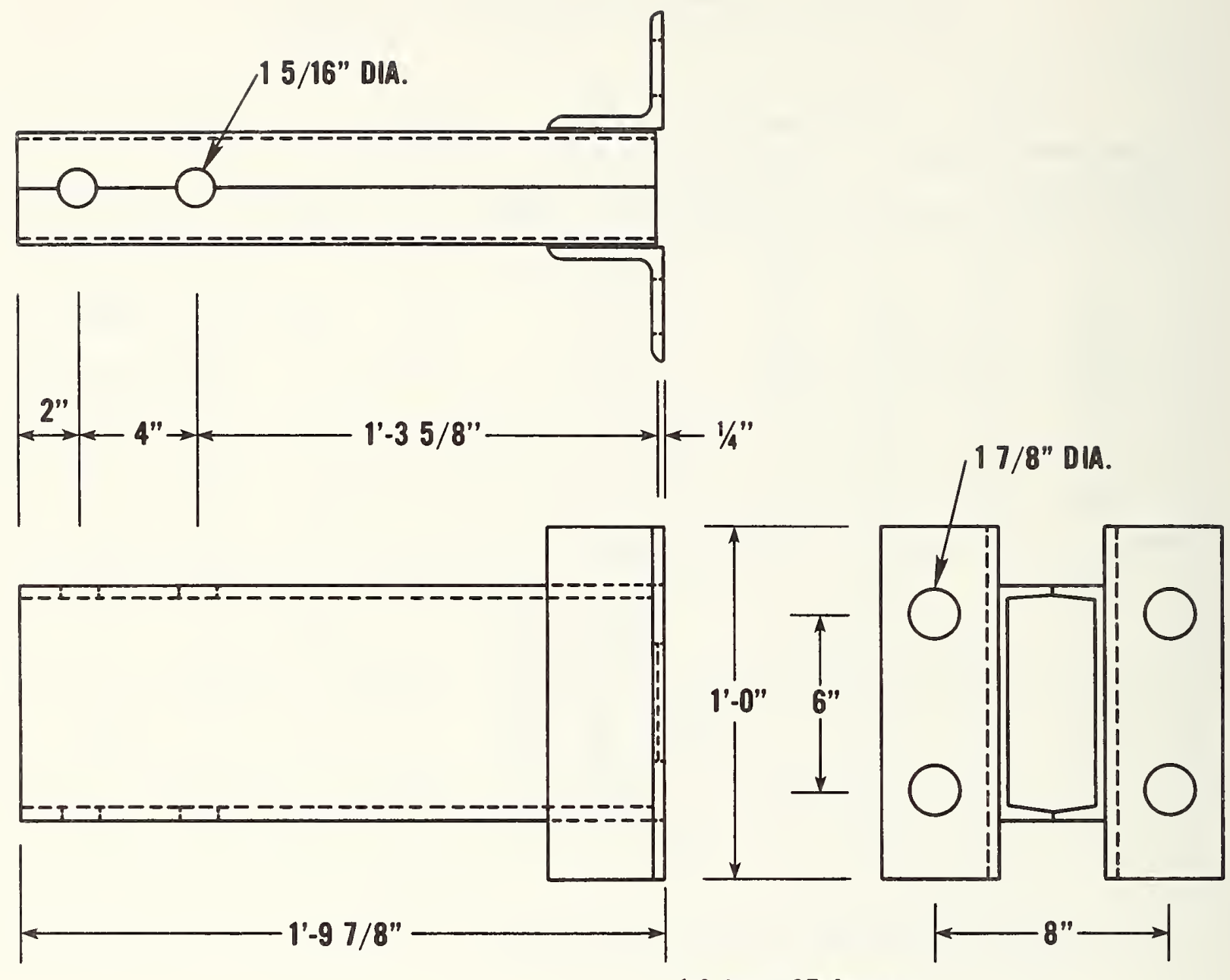

1.0 in. $=25.4 \mathrm{~mm}$

Figure 6.1 Short box beam test specimen. 


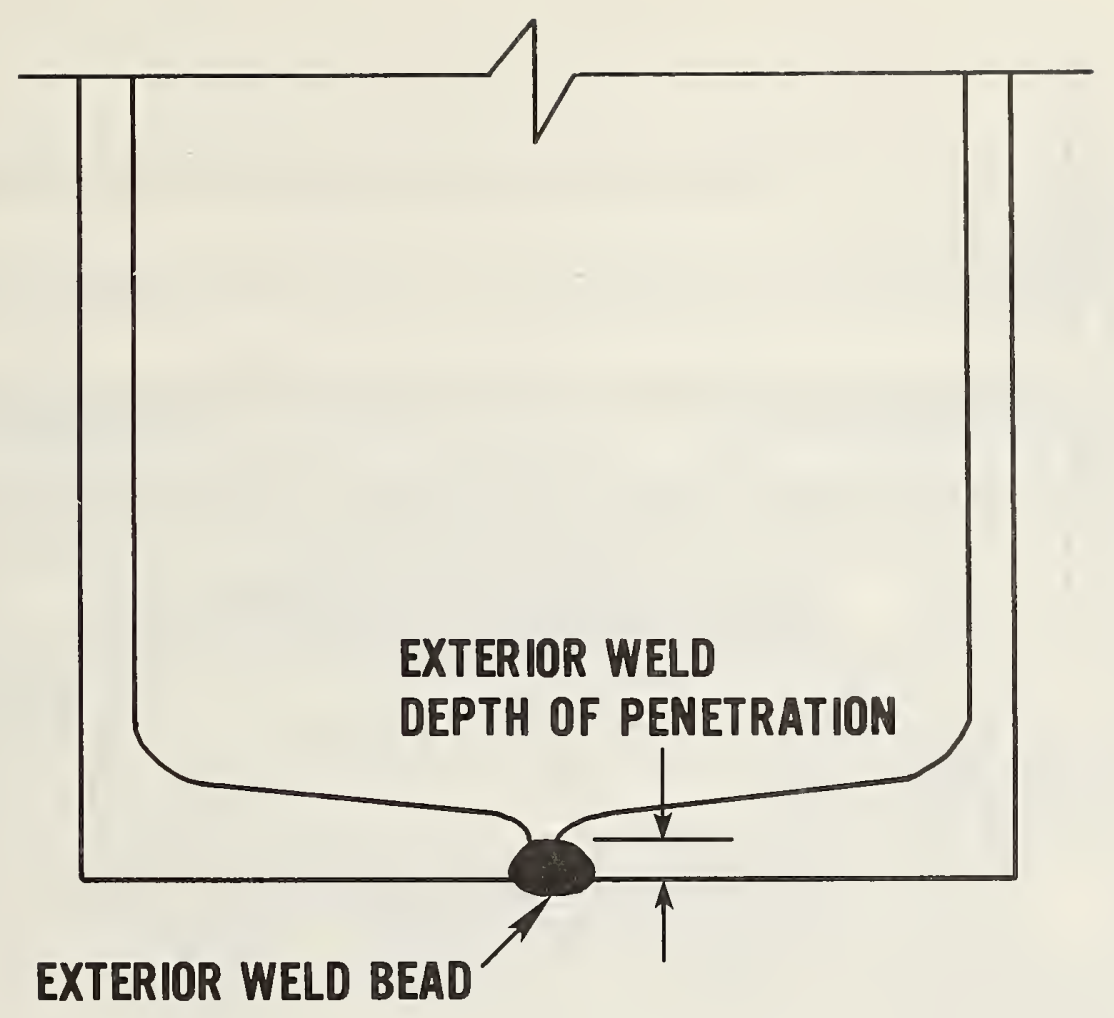

Figure 6.2 Exterior weld penetration.

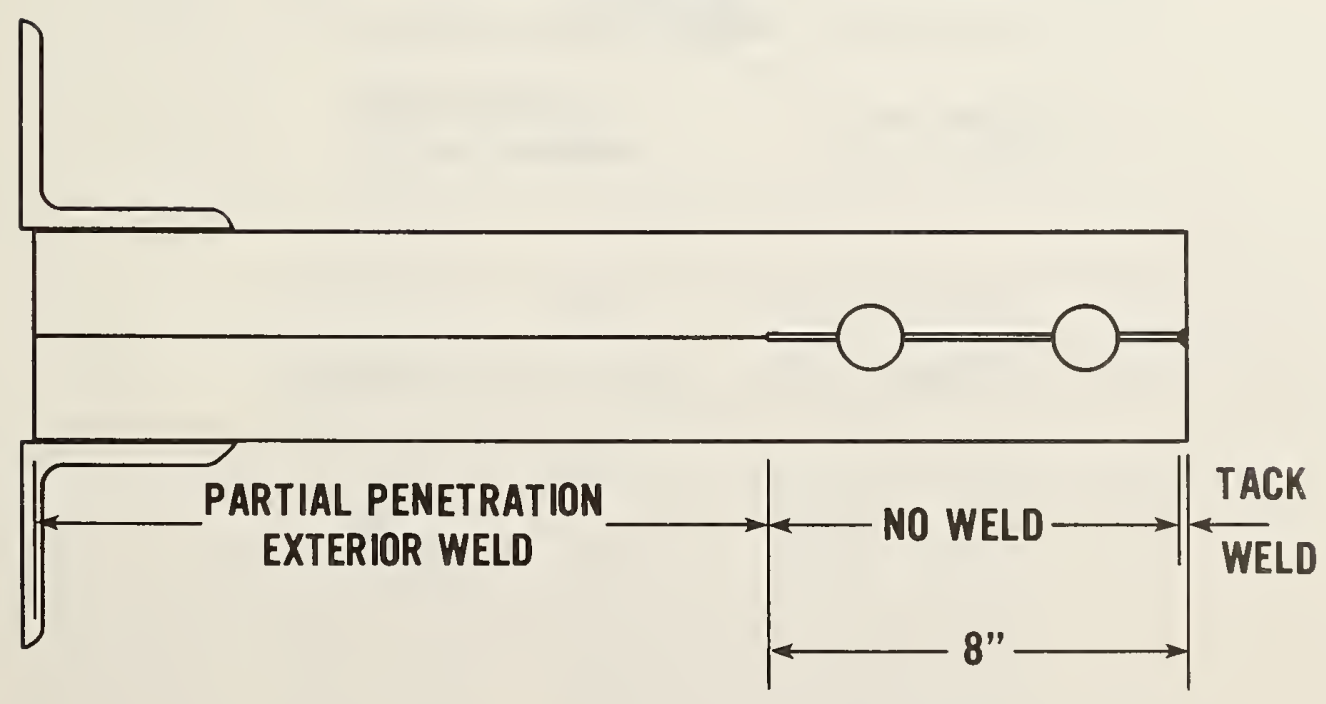

Figure 6.3 No weld specimen. 


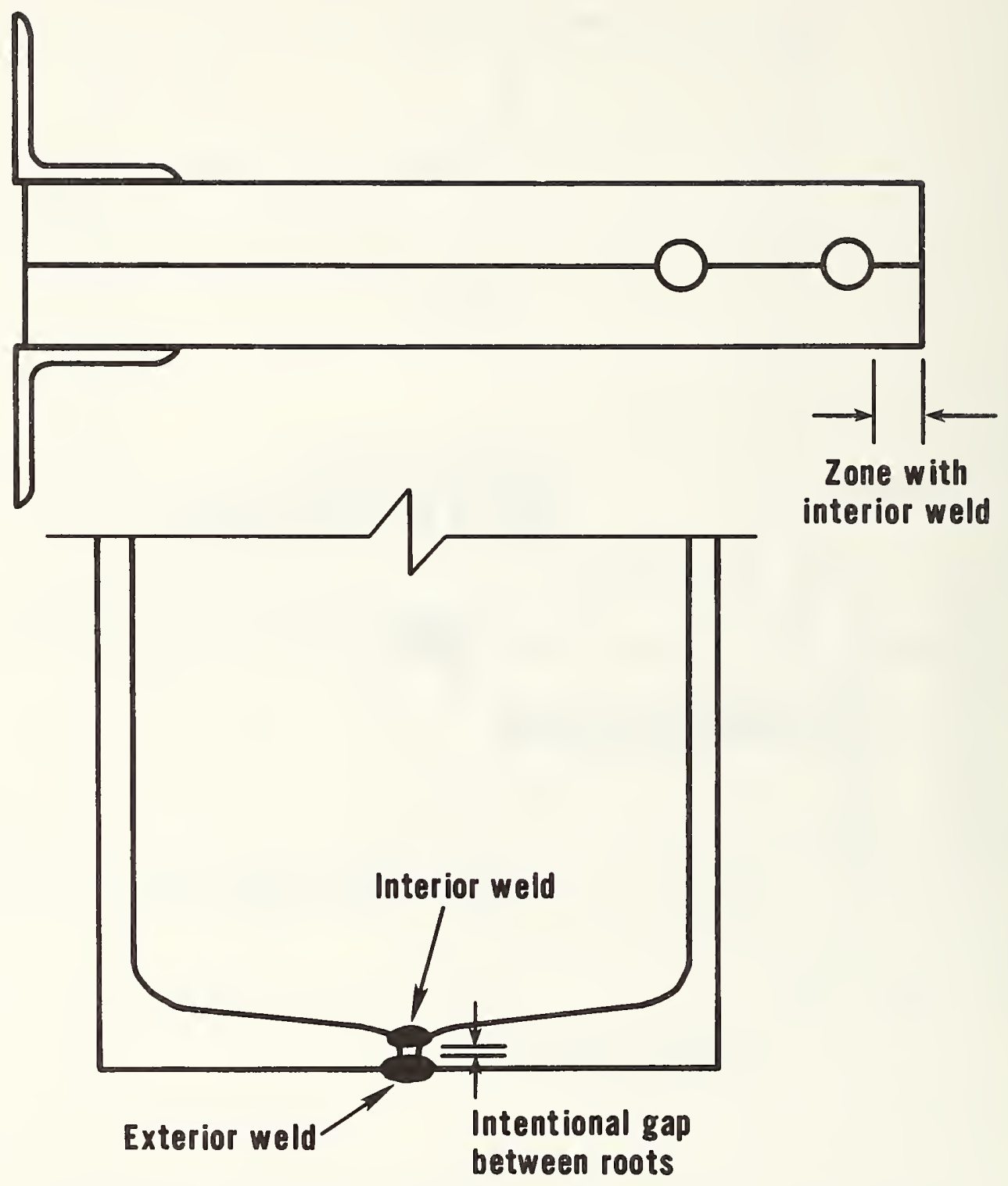

Figure 6.4 Interior weld location. 


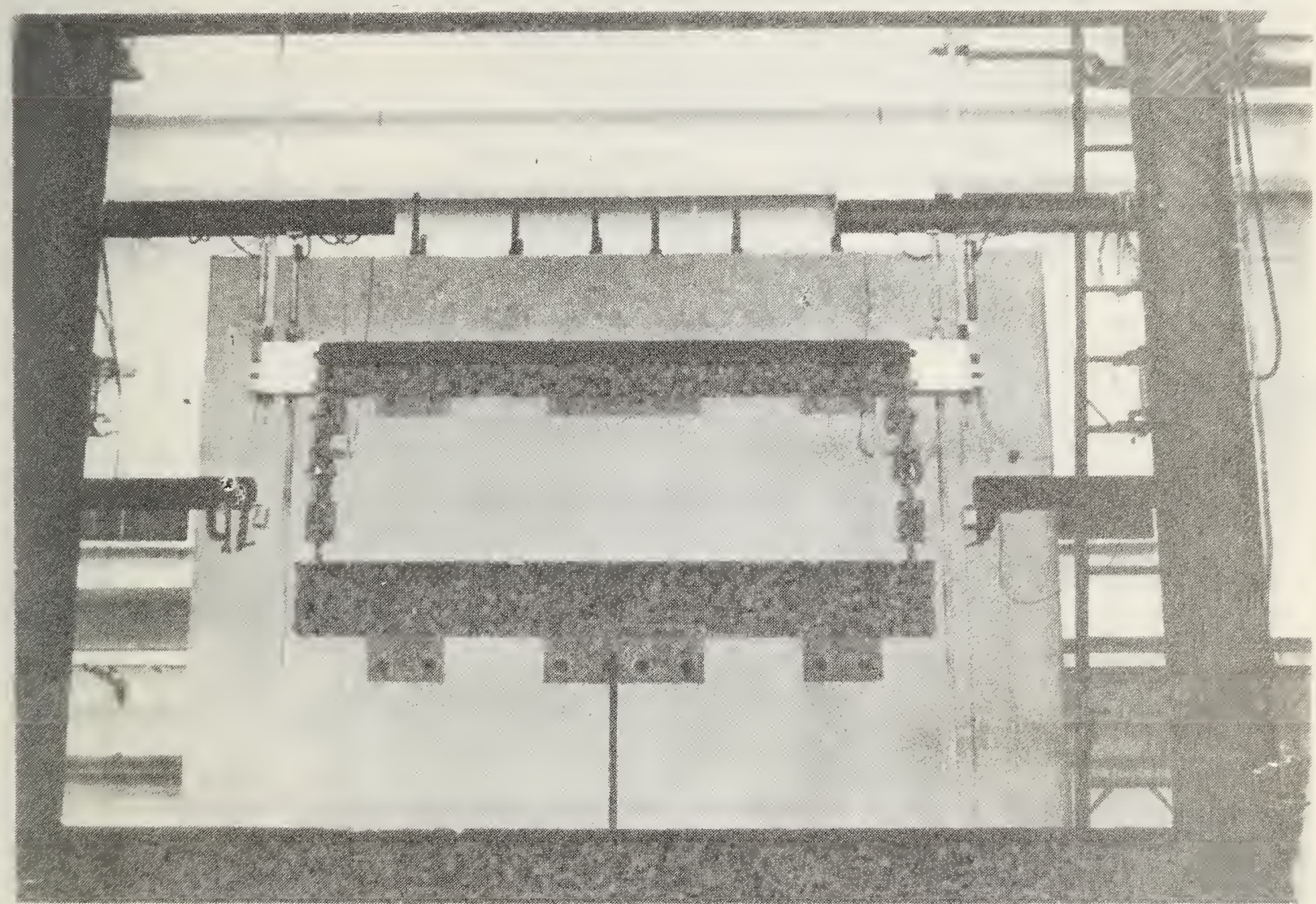

Figure 6.5 Full length box beam test in progress. 


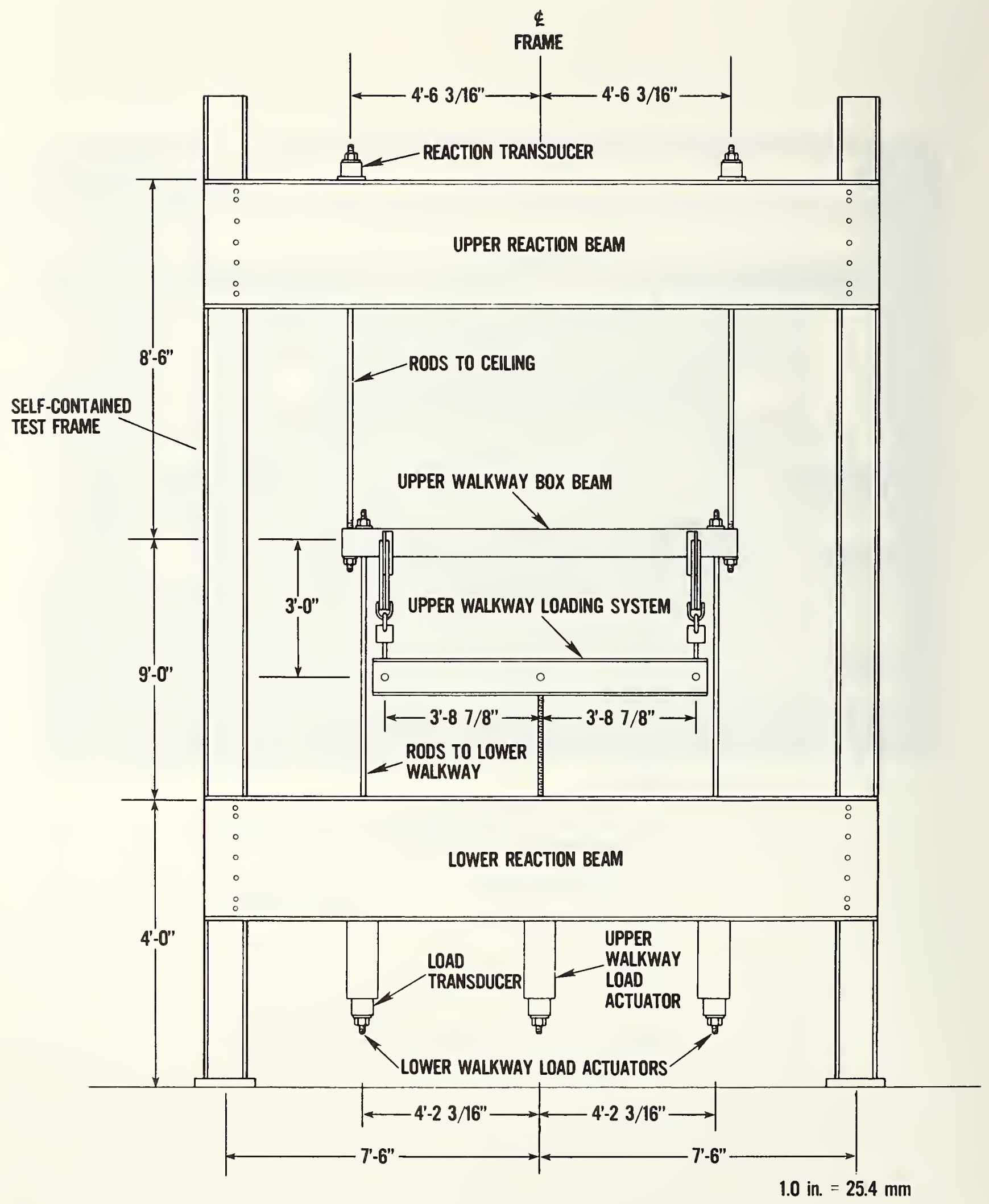

Figure 6.6 Detail of full length box beam test setup drawing. 


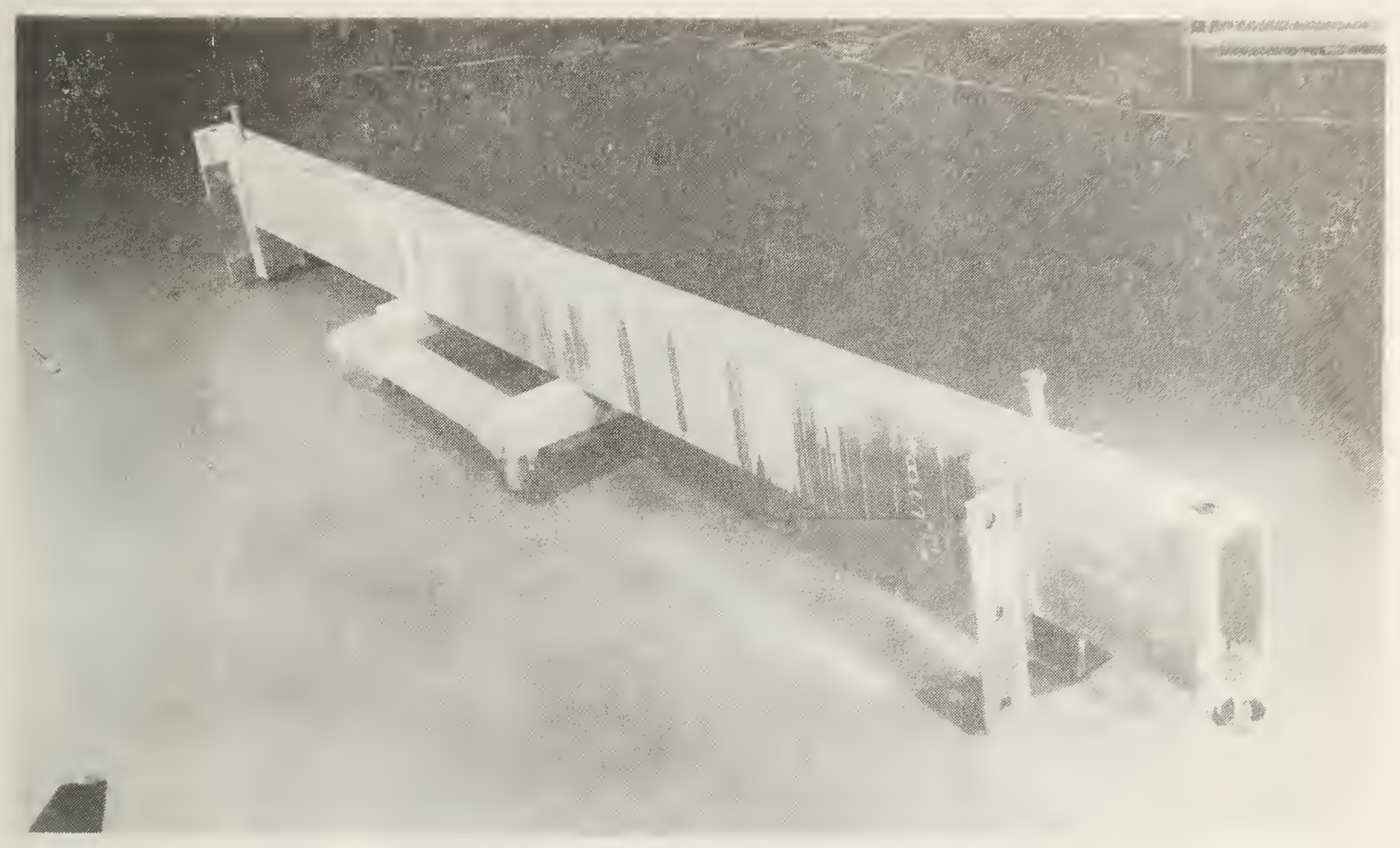

Figure 6.7 Full length box beam showing stringer-box beam clip angles.

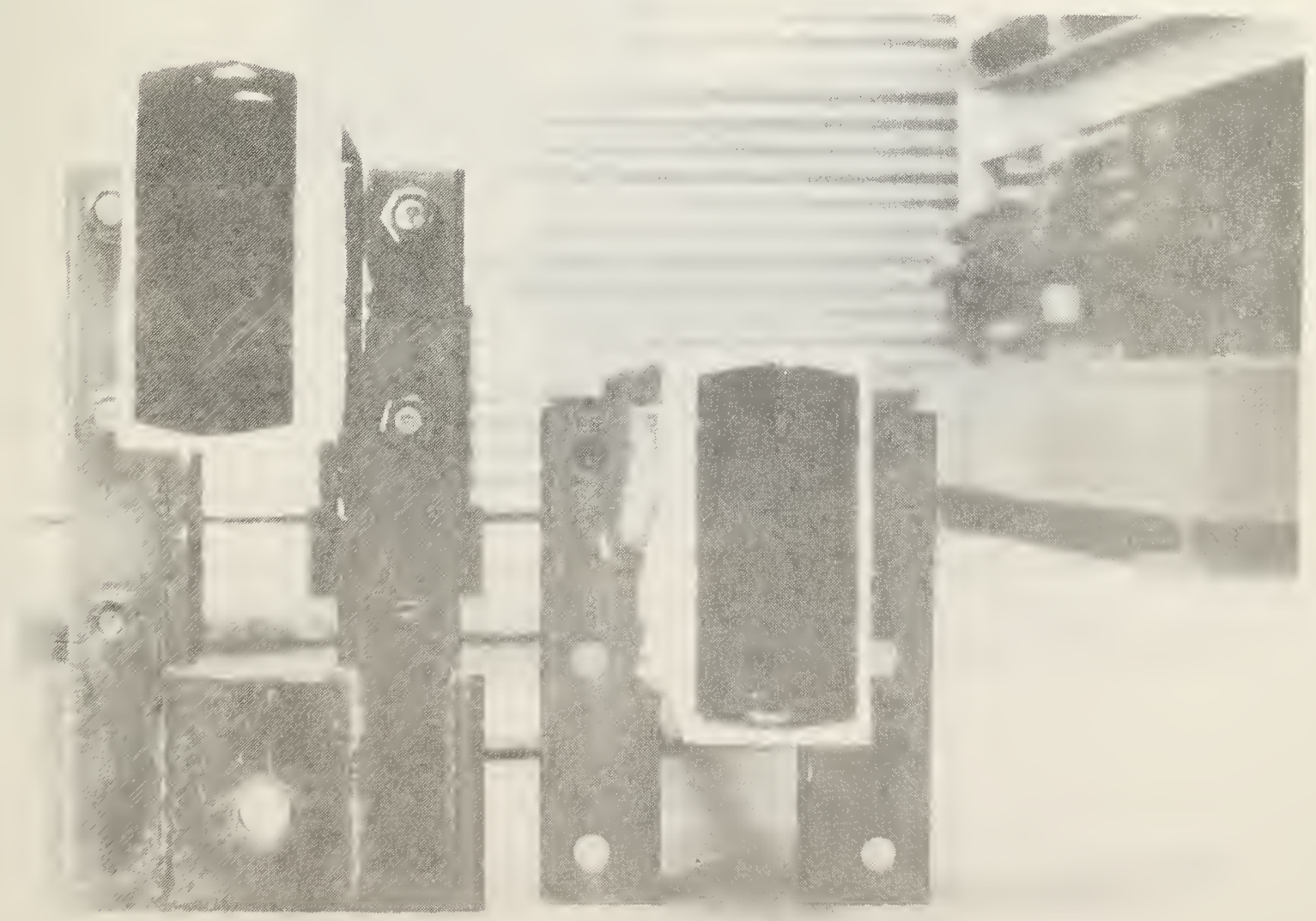

Figure 6.8 Clip angle strap on full length box beam. 


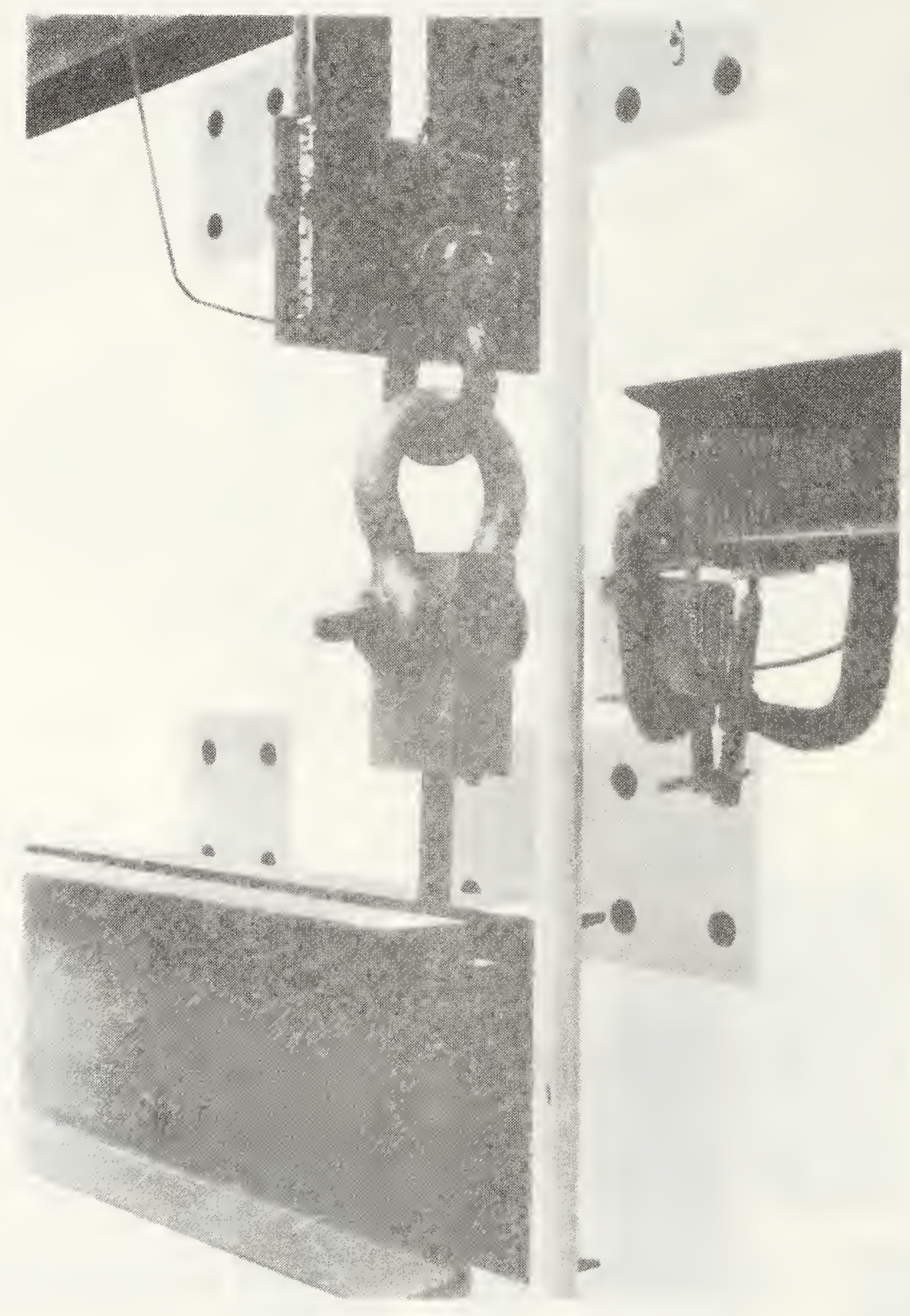

Figure 6.9 Pin and clevis arrangement on full length box beam. 


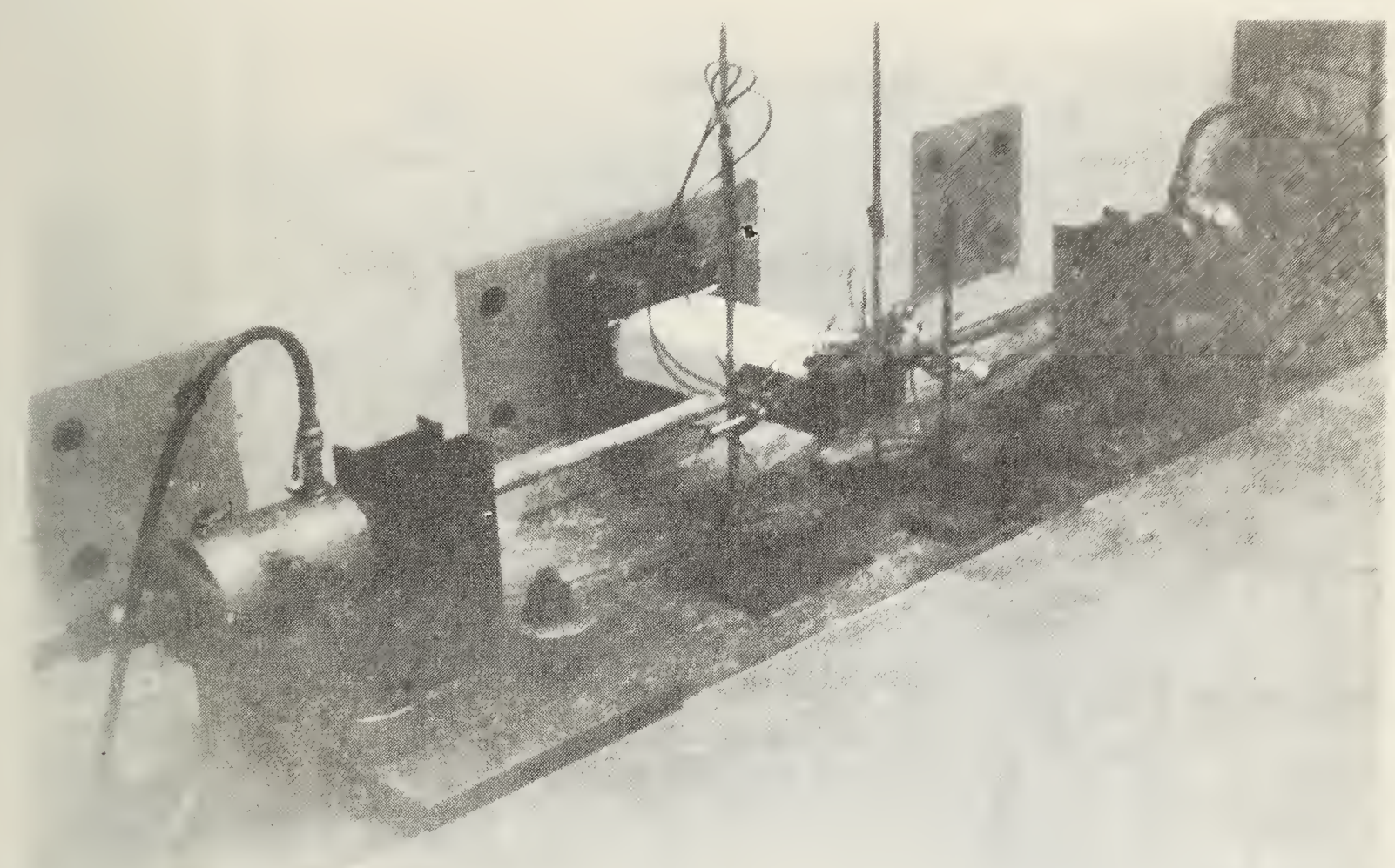

Figure 6.10 Short box beam test.

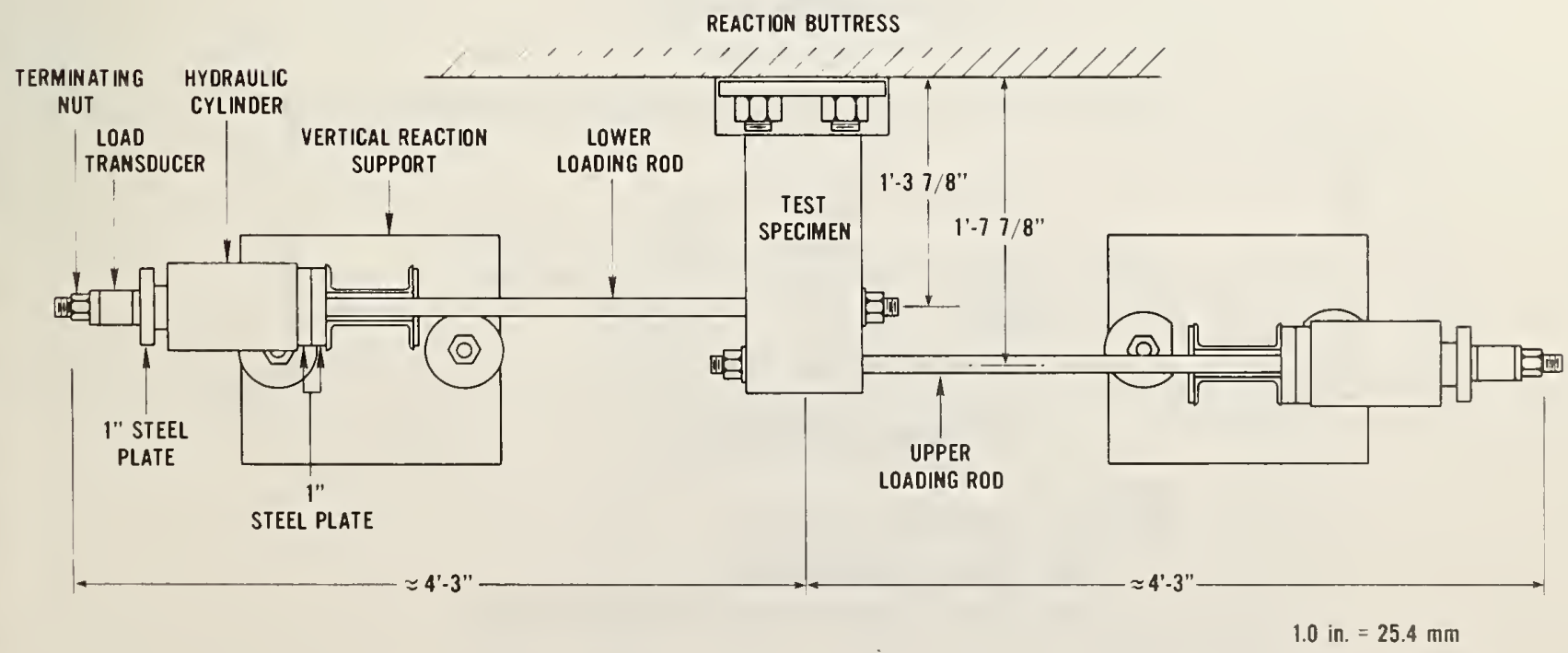

Figure 6.11 Short box beam test setup. 


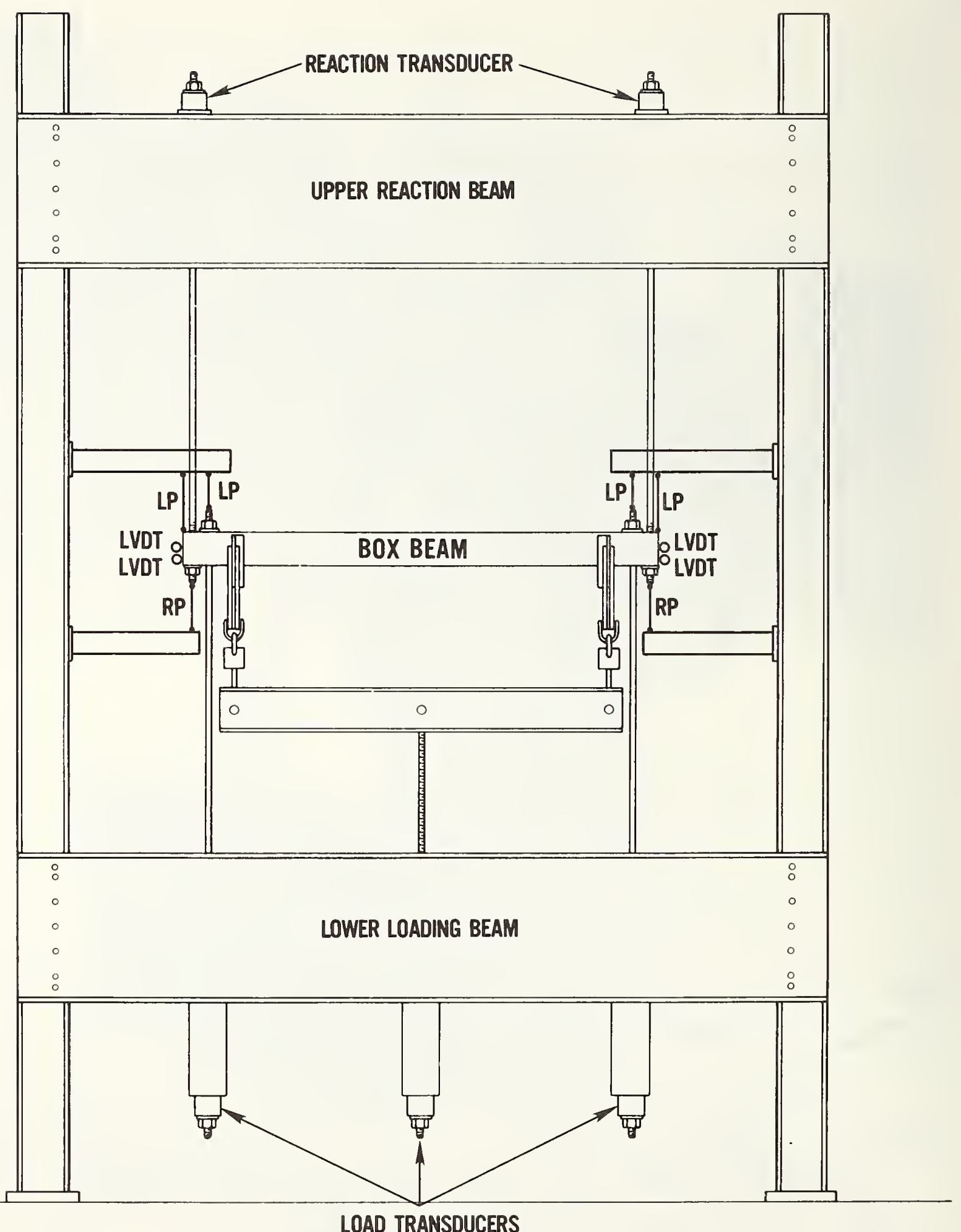

NOTE: LP - Linear Potentiometer

RP - Rotary Potentiometer

LVDT - Linear Variable Differential Transformer

Figure 6.12 Ful1 length box beam instrumentation. 

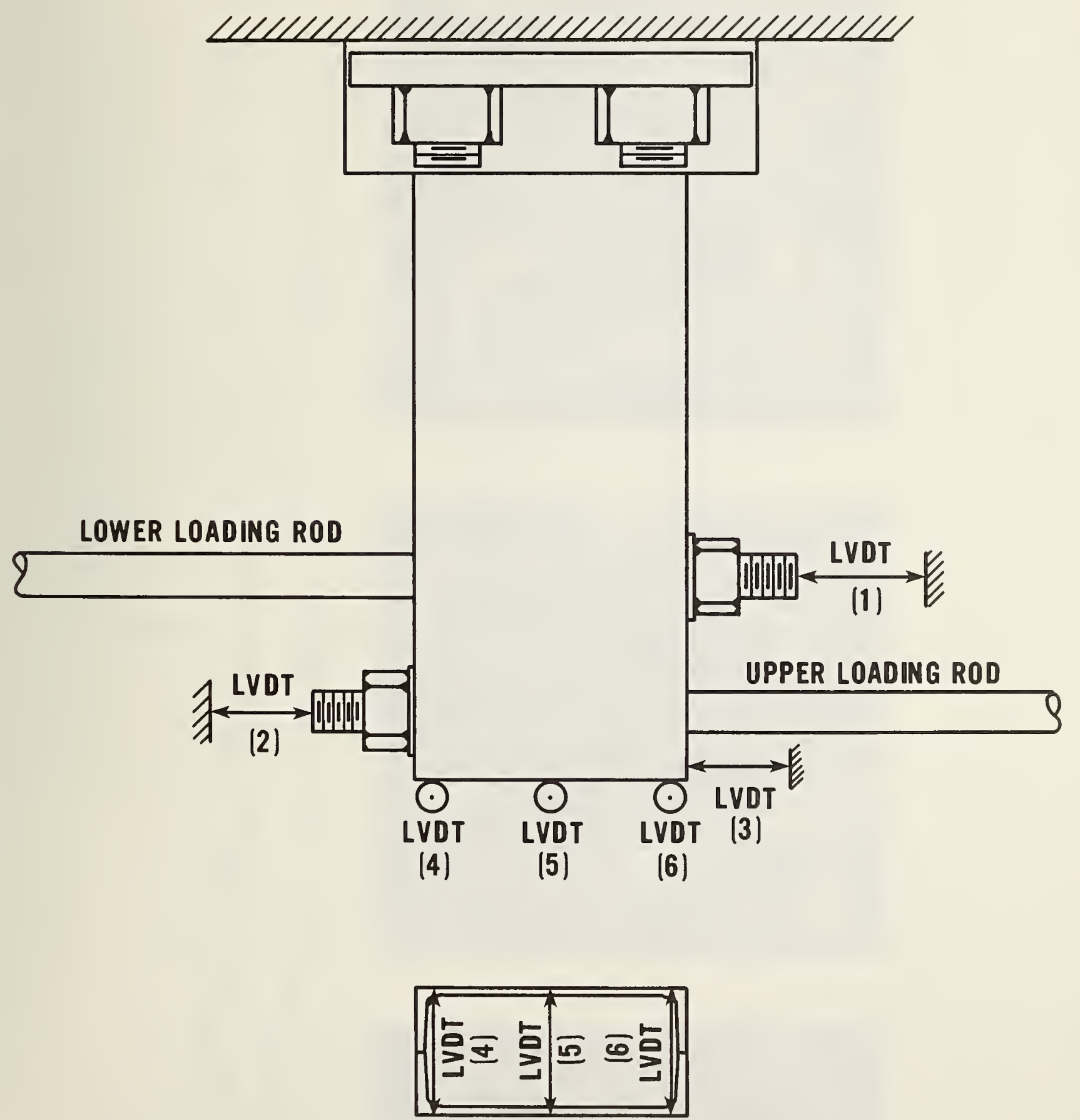

TRANSVERSE LVDTS

Figure 6.13 Short box beam instrumentation. 

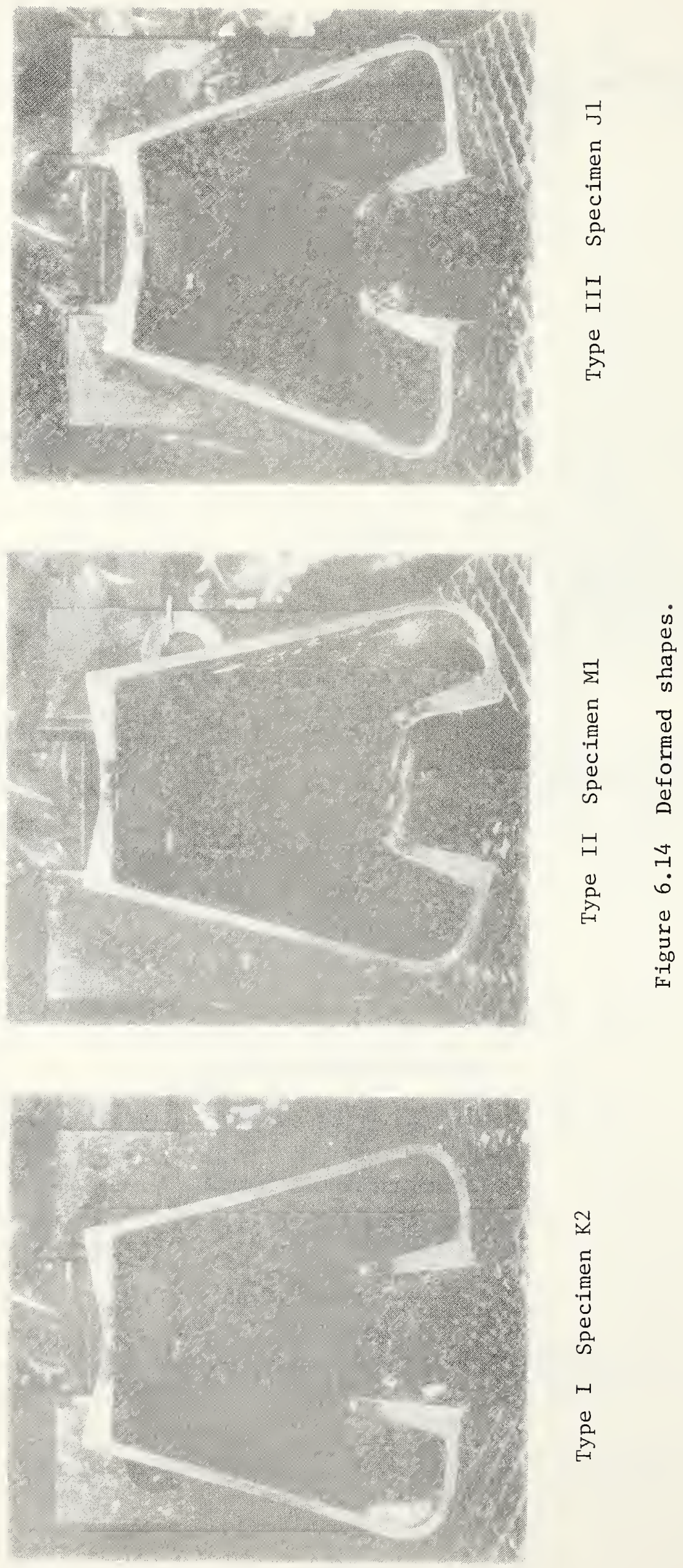

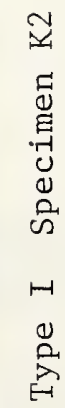




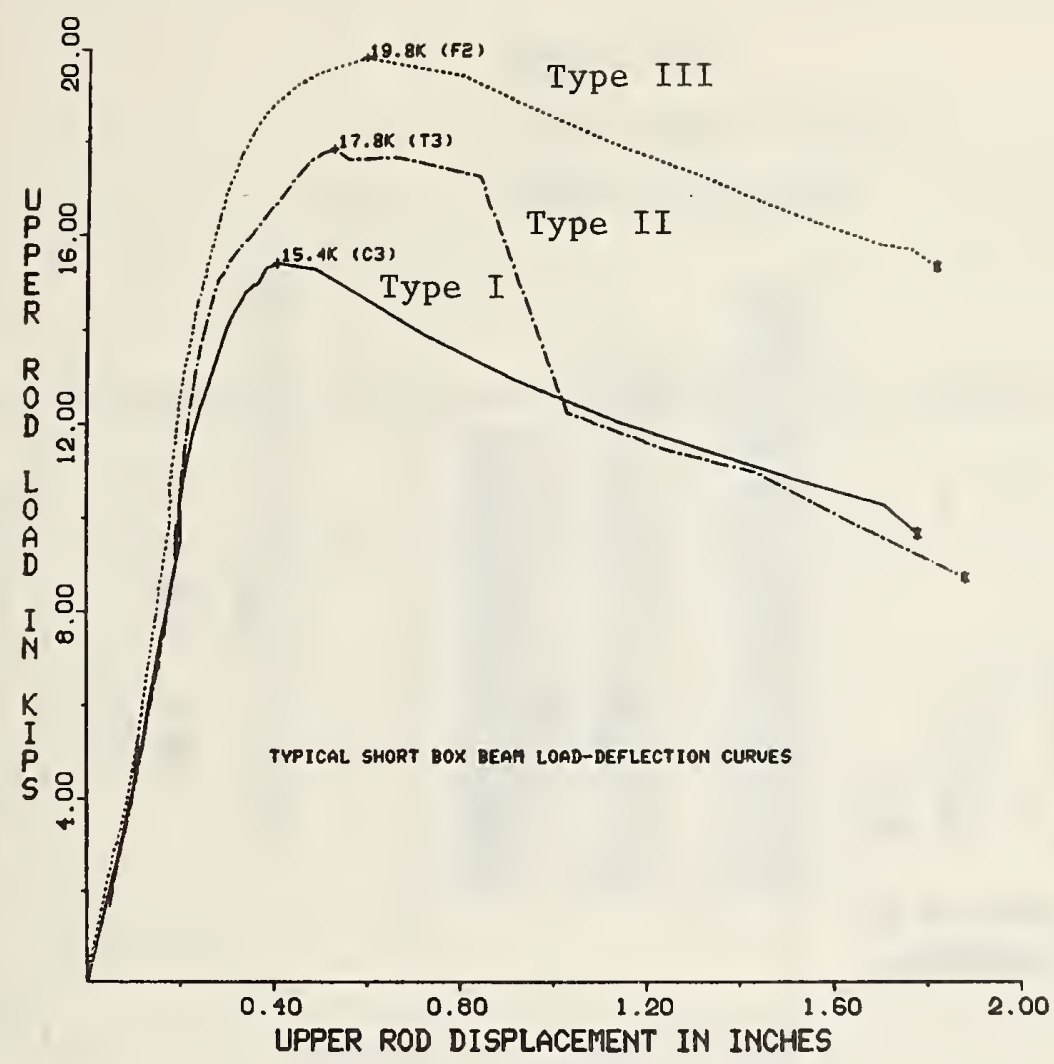

Figure 6.15 In-plane load deflection curves for specimens C-3, F-2, and $\mathrm{T}-3$.

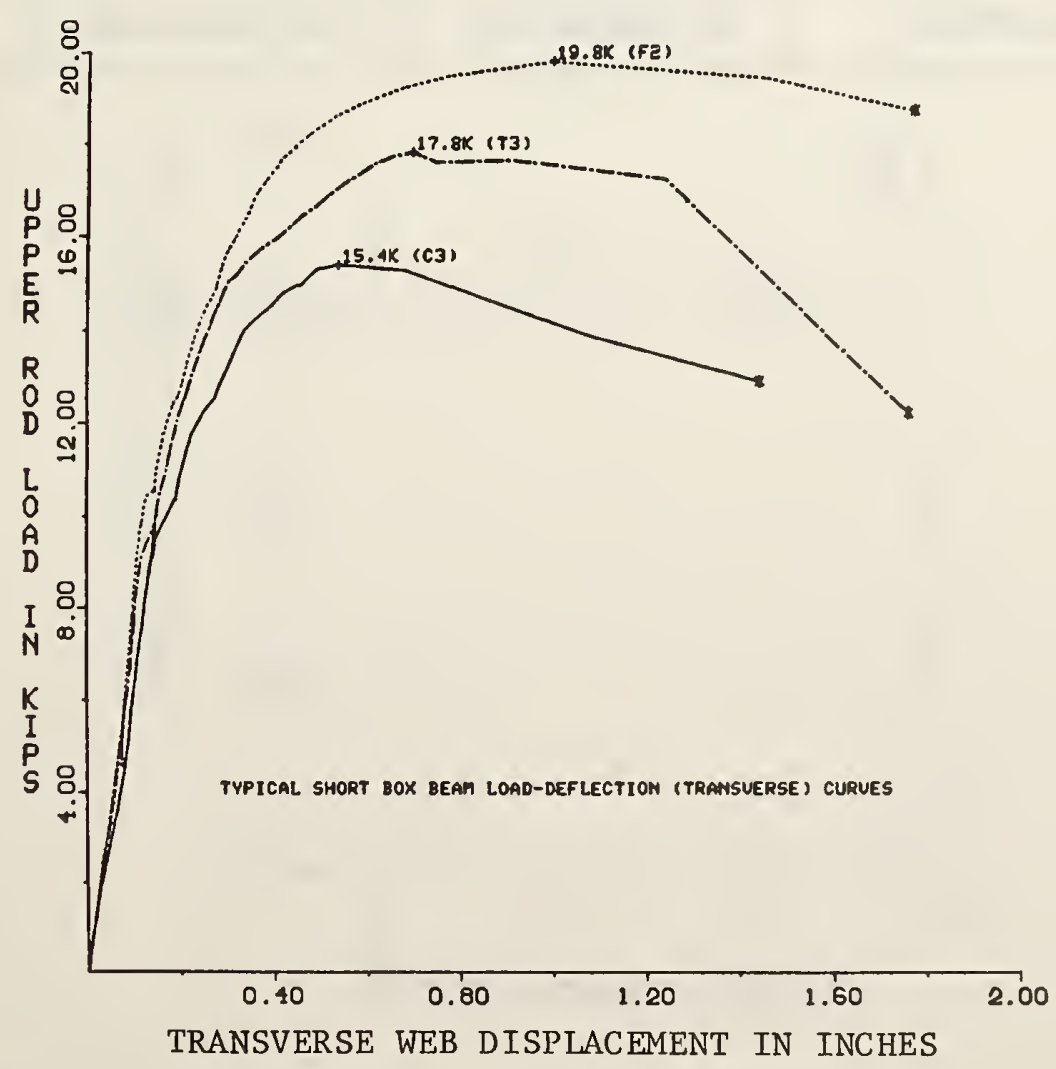

Figure 6.16 Out-of-plane web load displacement curves for specimens $\mathrm{C}-3, \mathrm{~F}-2$, and $\mathrm{T}-3$. 


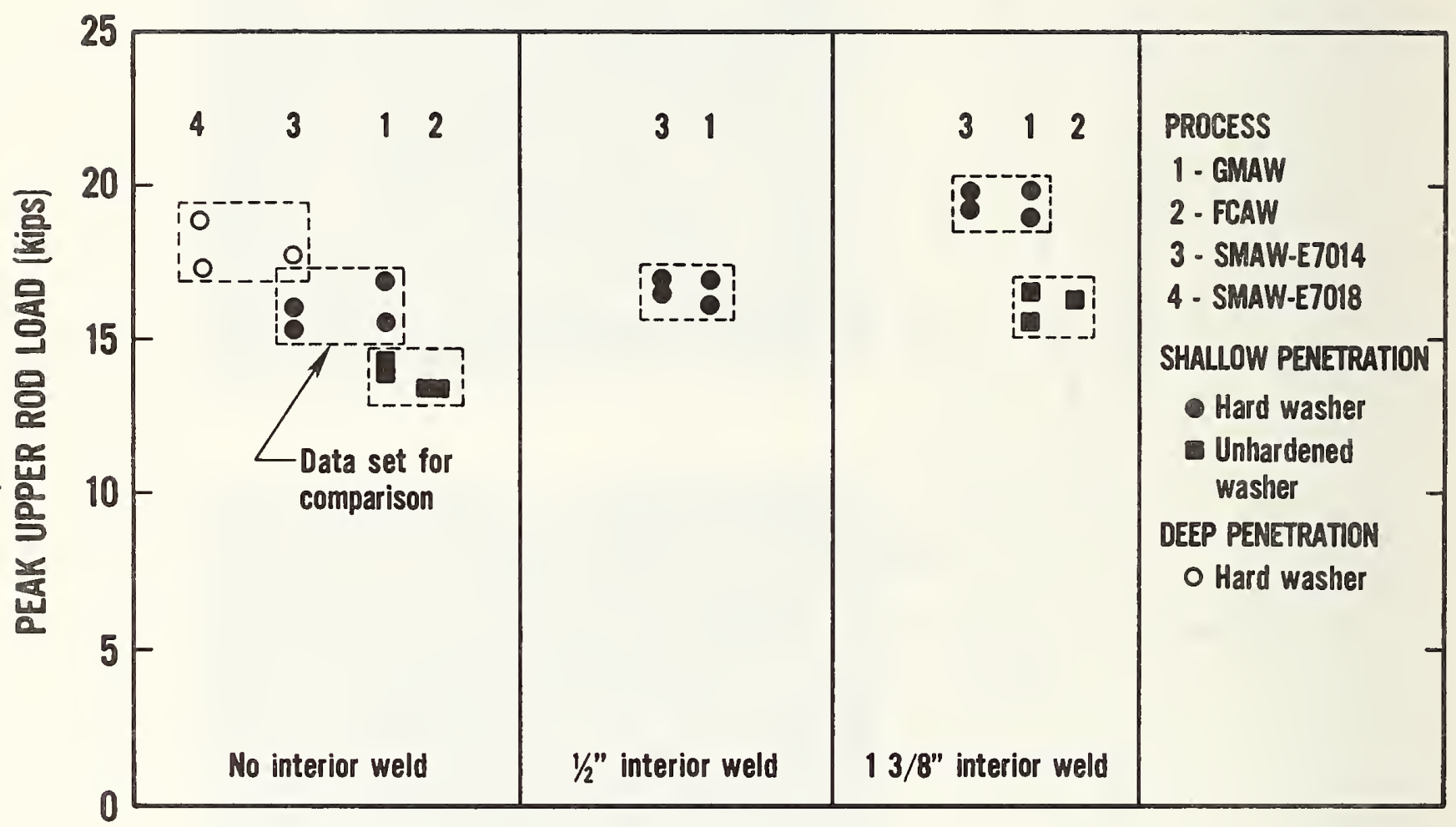

Figure 6.17 Effect of weld process. 


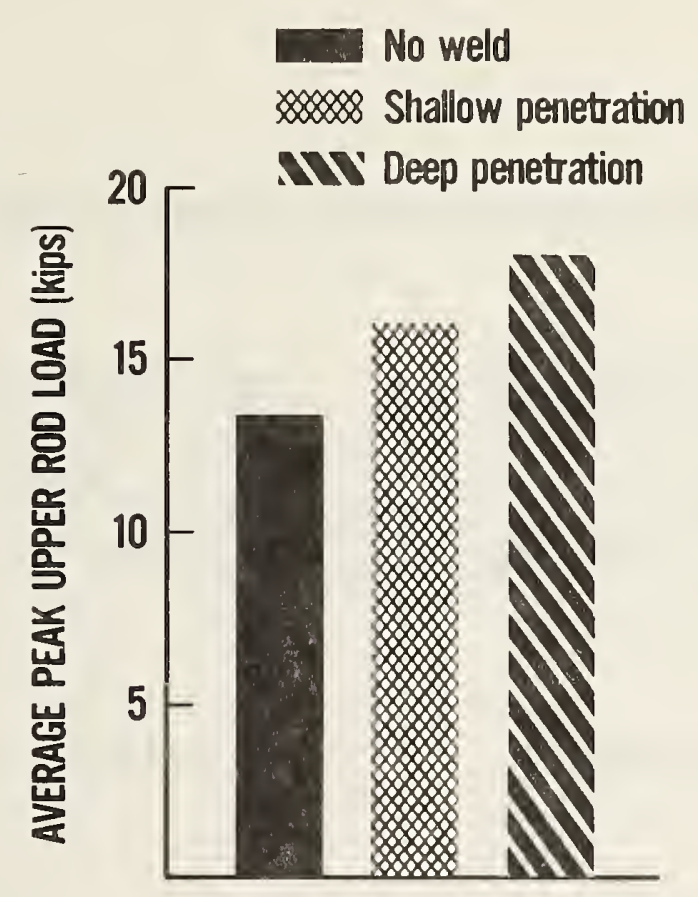

Figure 6.18 Effect of exterior weld penetration.

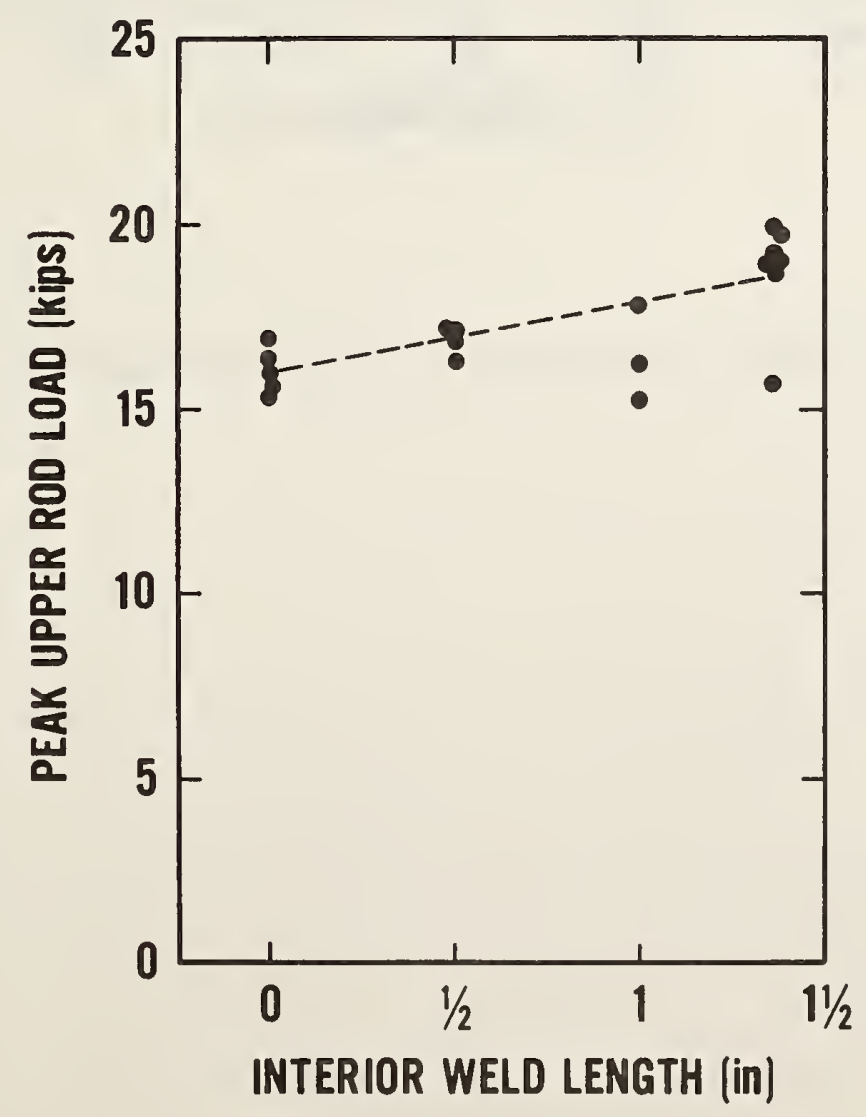

Figure 6.19 Effect of interior weld length on peak load. 


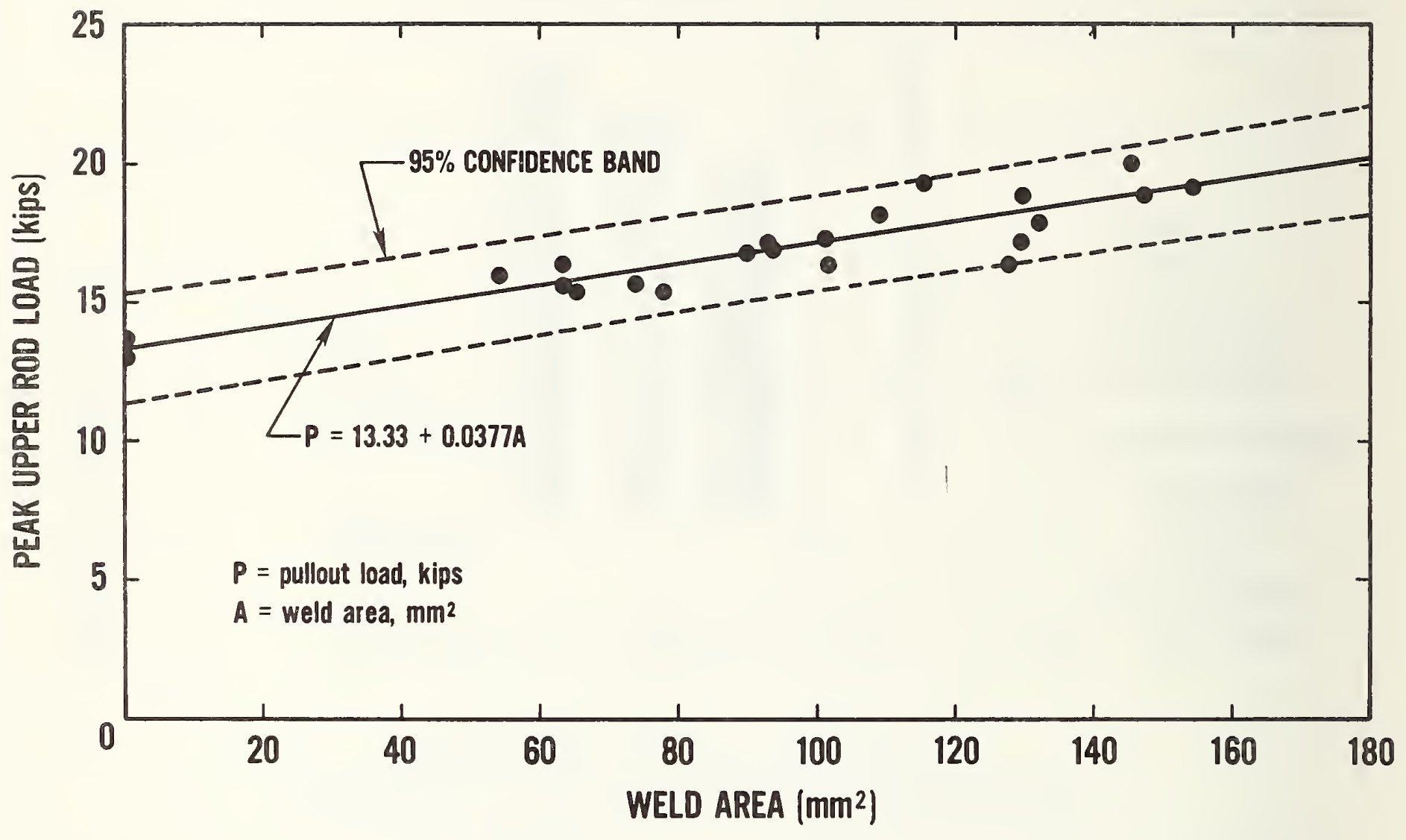

Figure 6.20 Effect of weld area on peak load, hardened washers. 


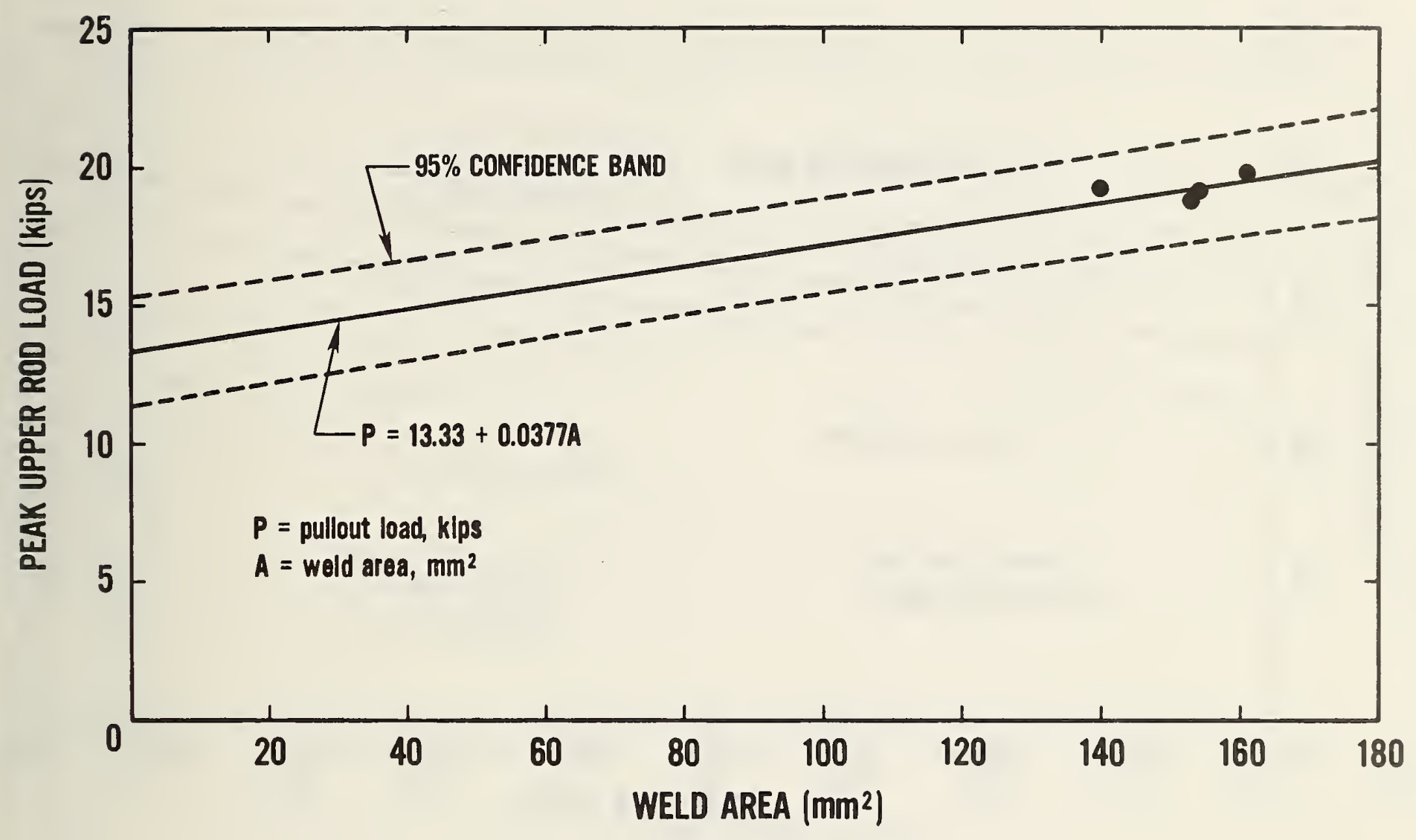

Figure 6.21 Effect of clip angles. 


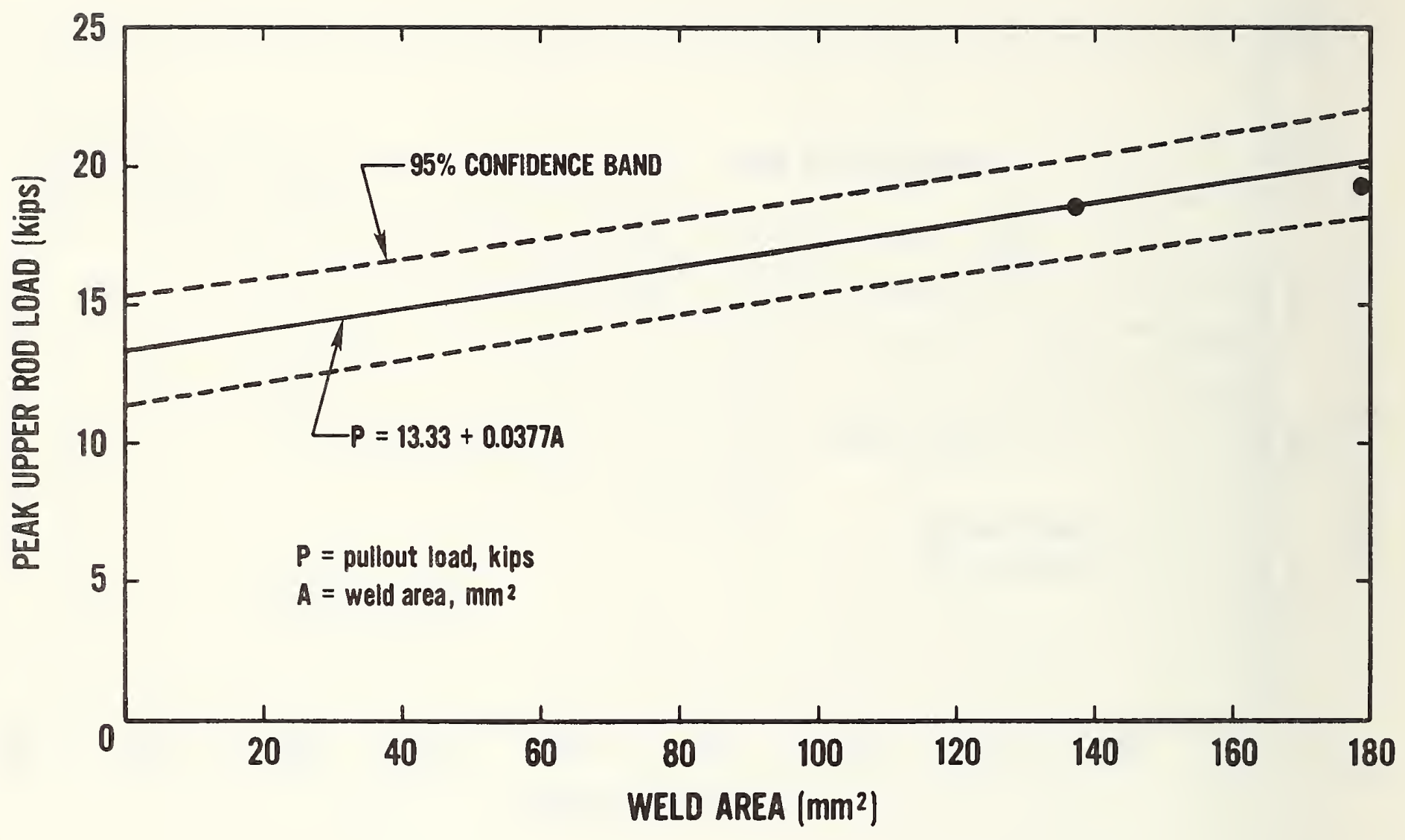

Figure 6.22 Effect of initial upper rod load. 


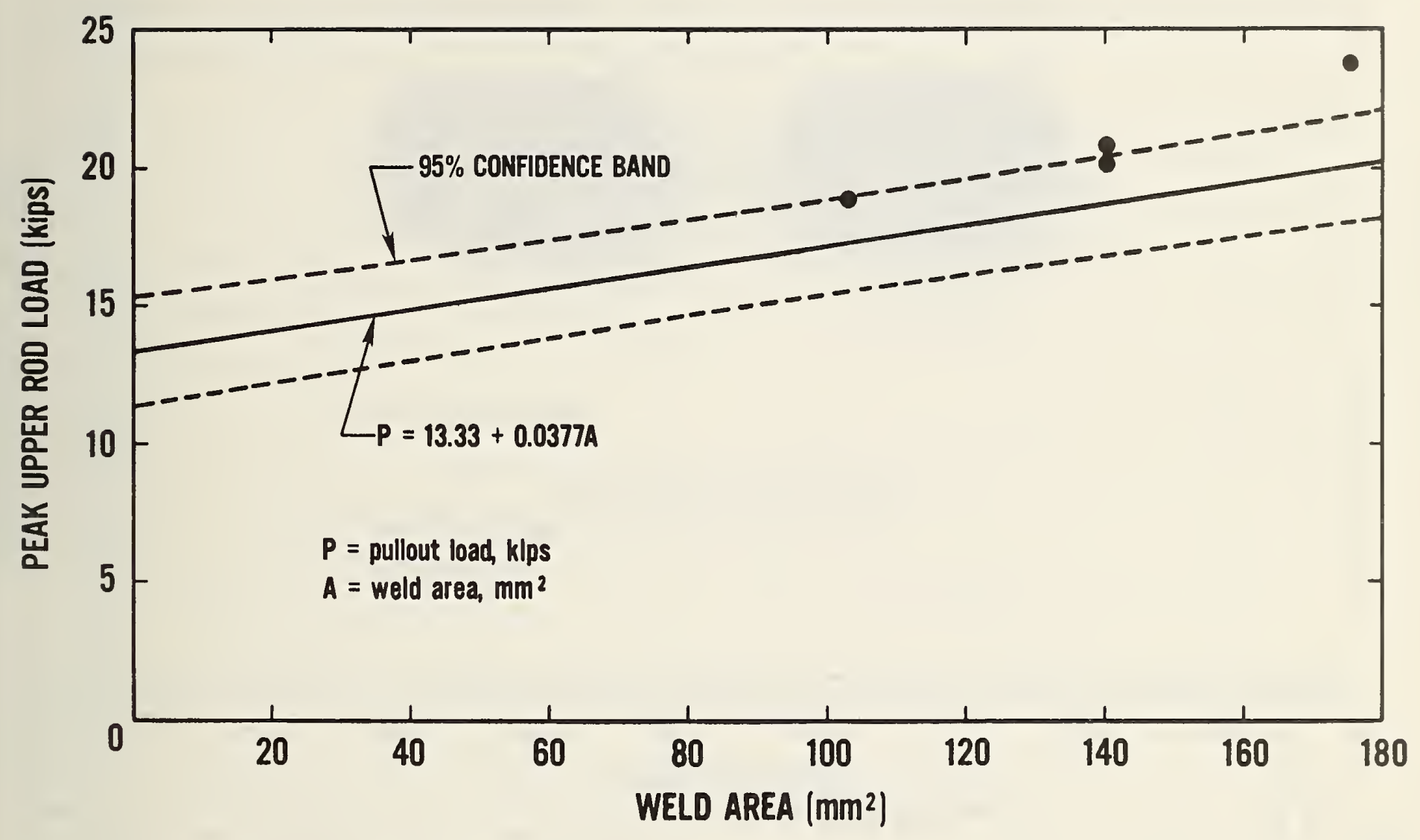

Figure 6.23 Effect of loading configuration. 

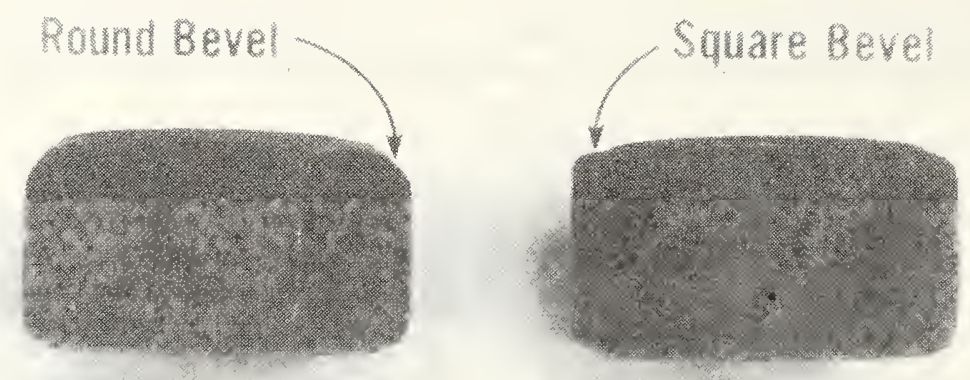

Figure 6.24 Nut shape.

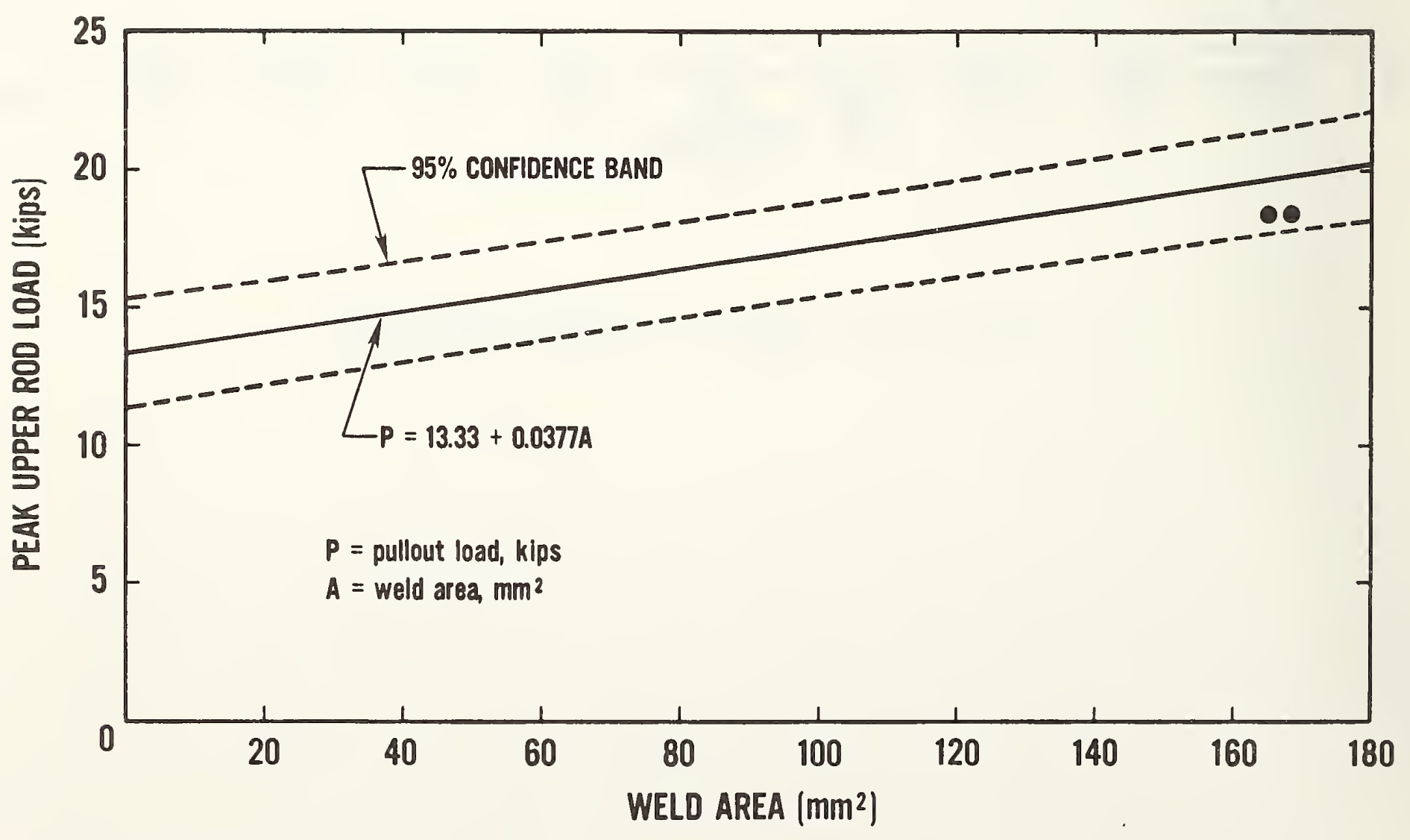

Figure 6.25 Effect of nut shape. 


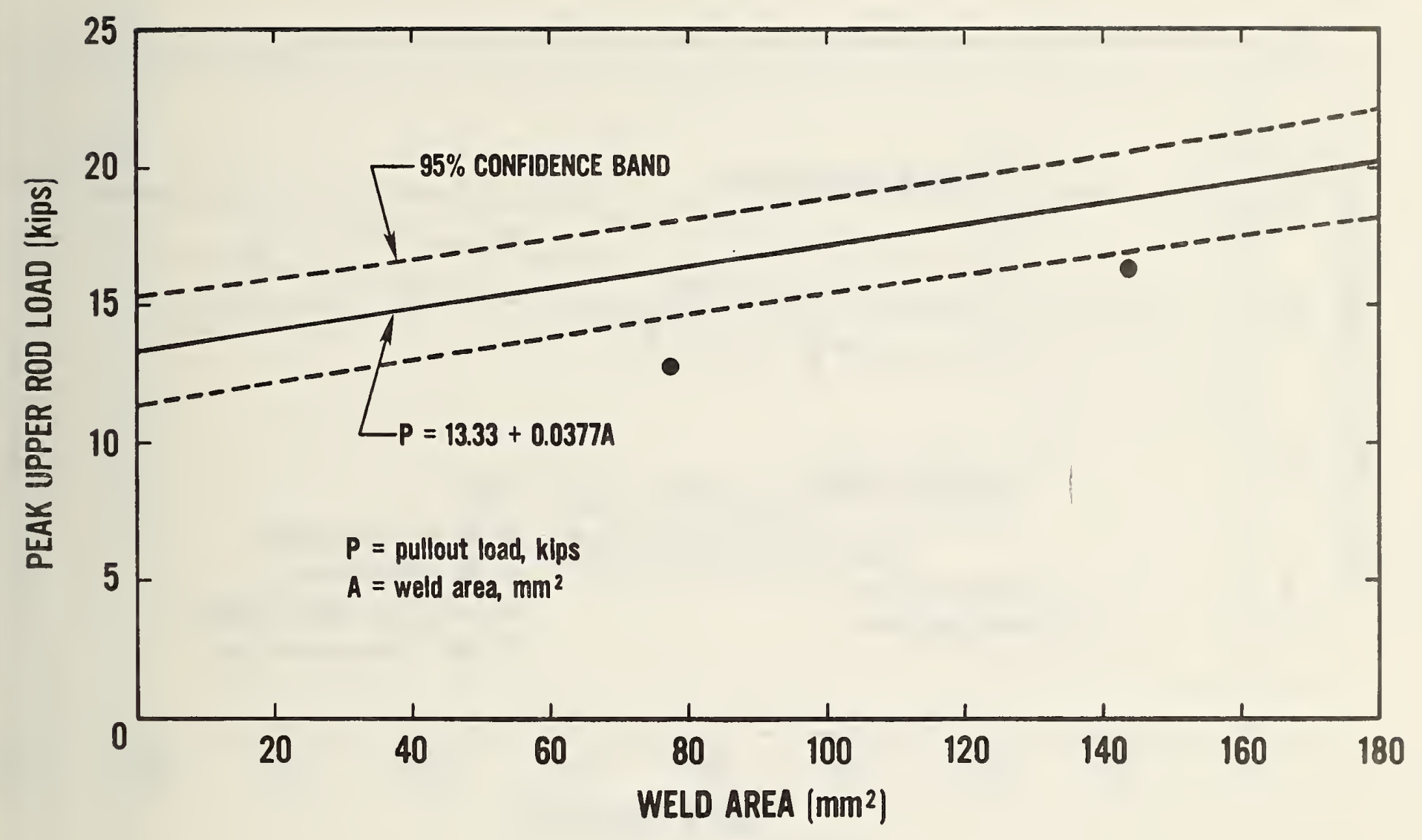

Figure 6.26 Effect of washer presence. 


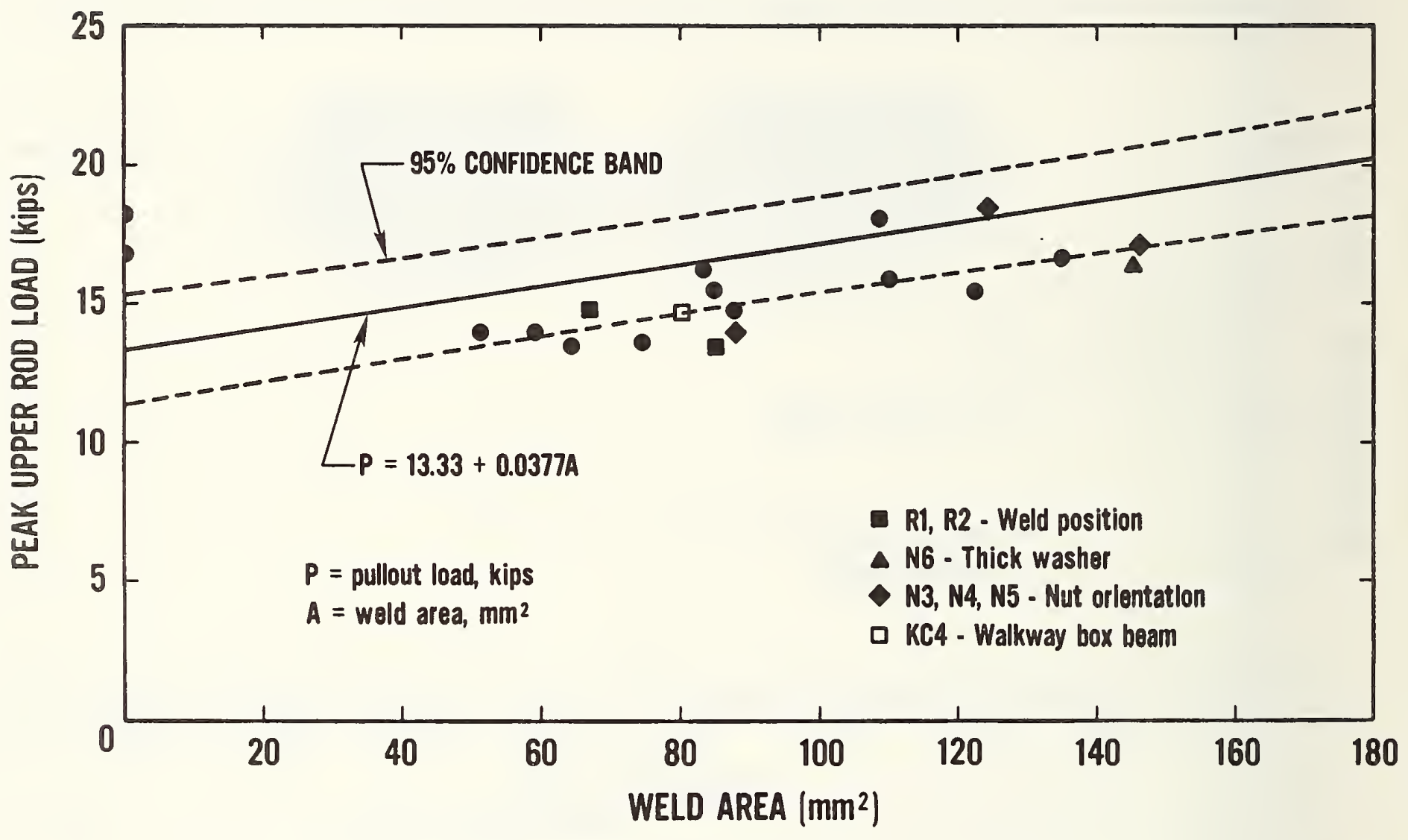

Figure 6.27 Effect of unhardened washers. 


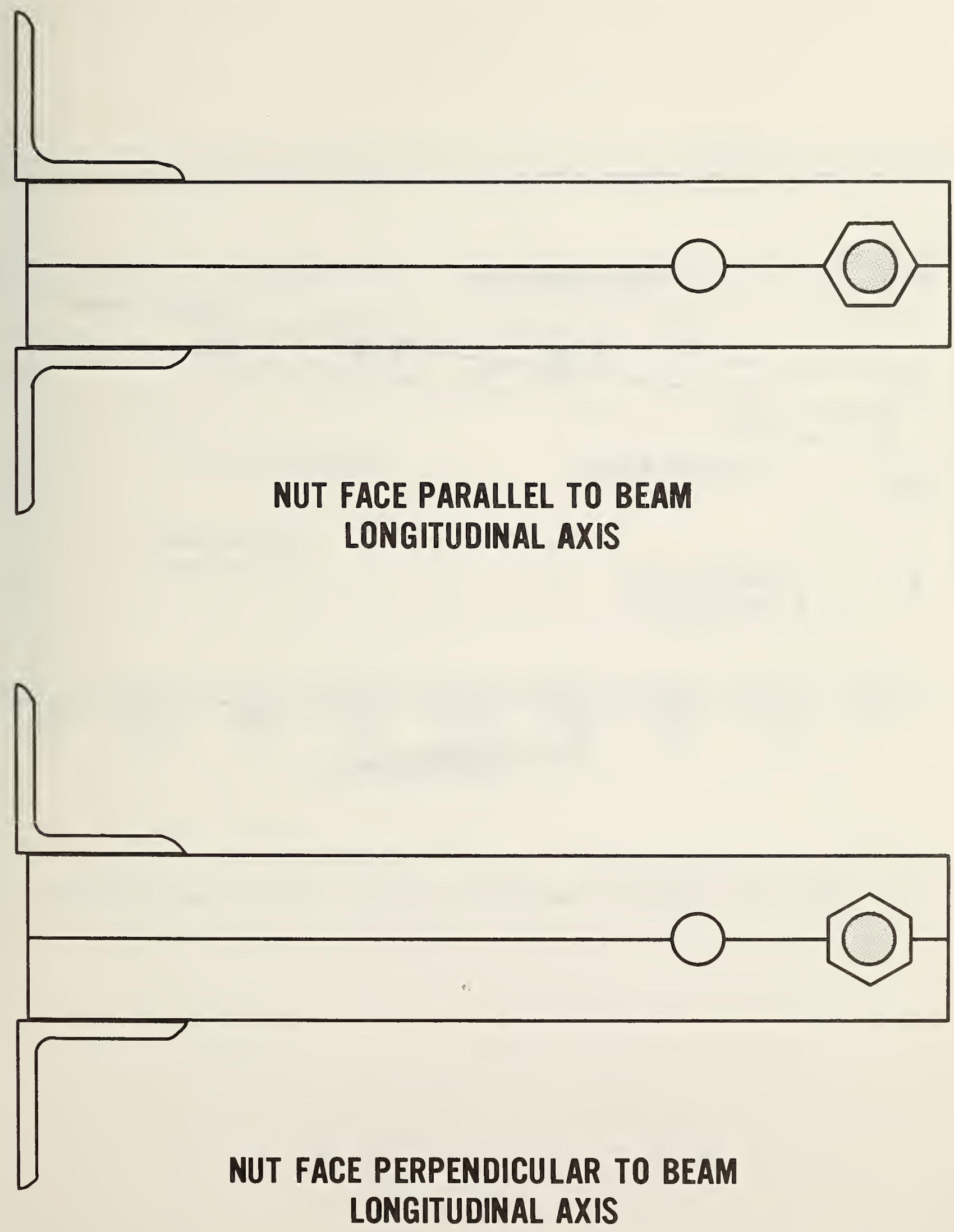

Figure 6.28 Nut orientation. 


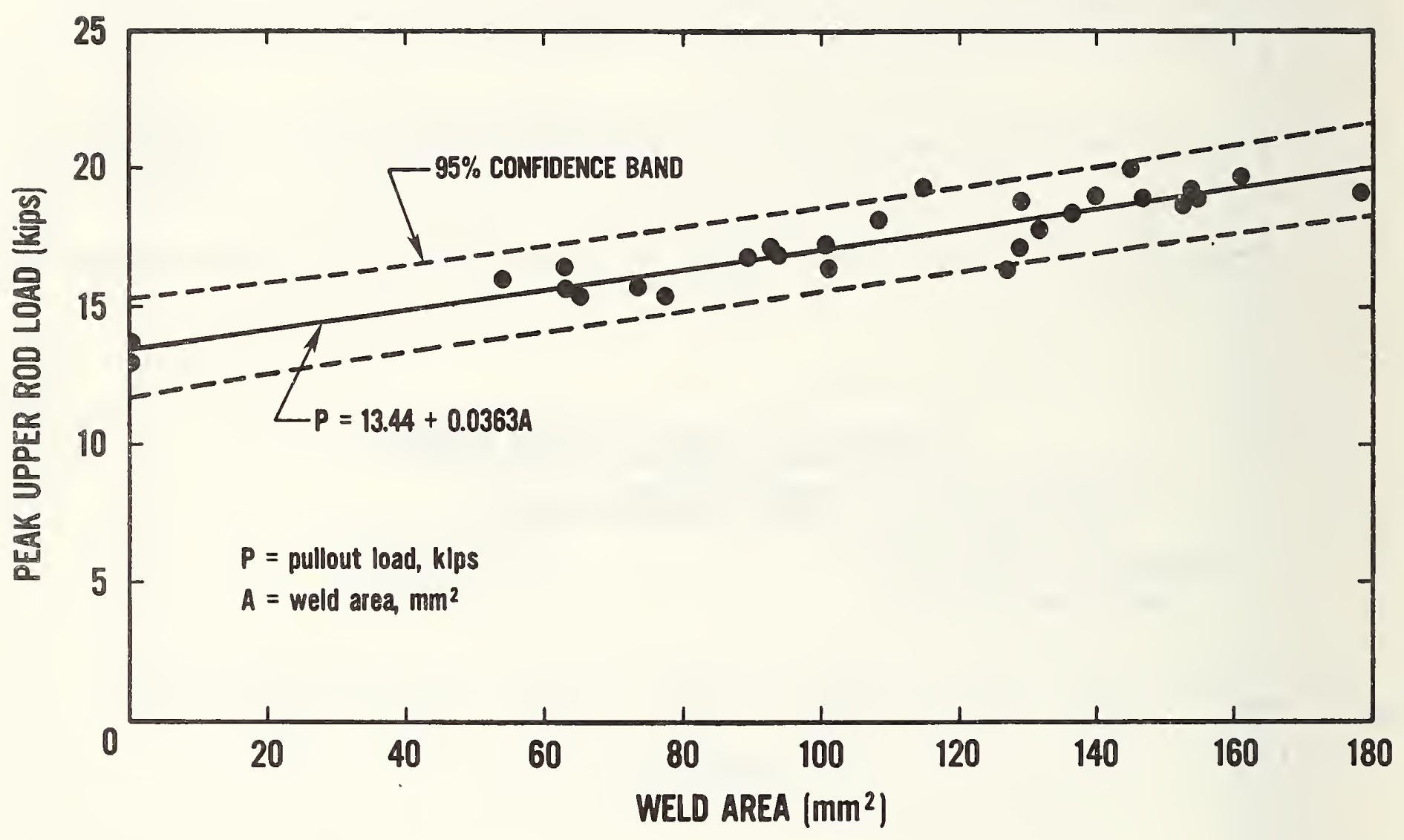

Figure 6.29 Effect of weld area on pullout load for short box beams. 


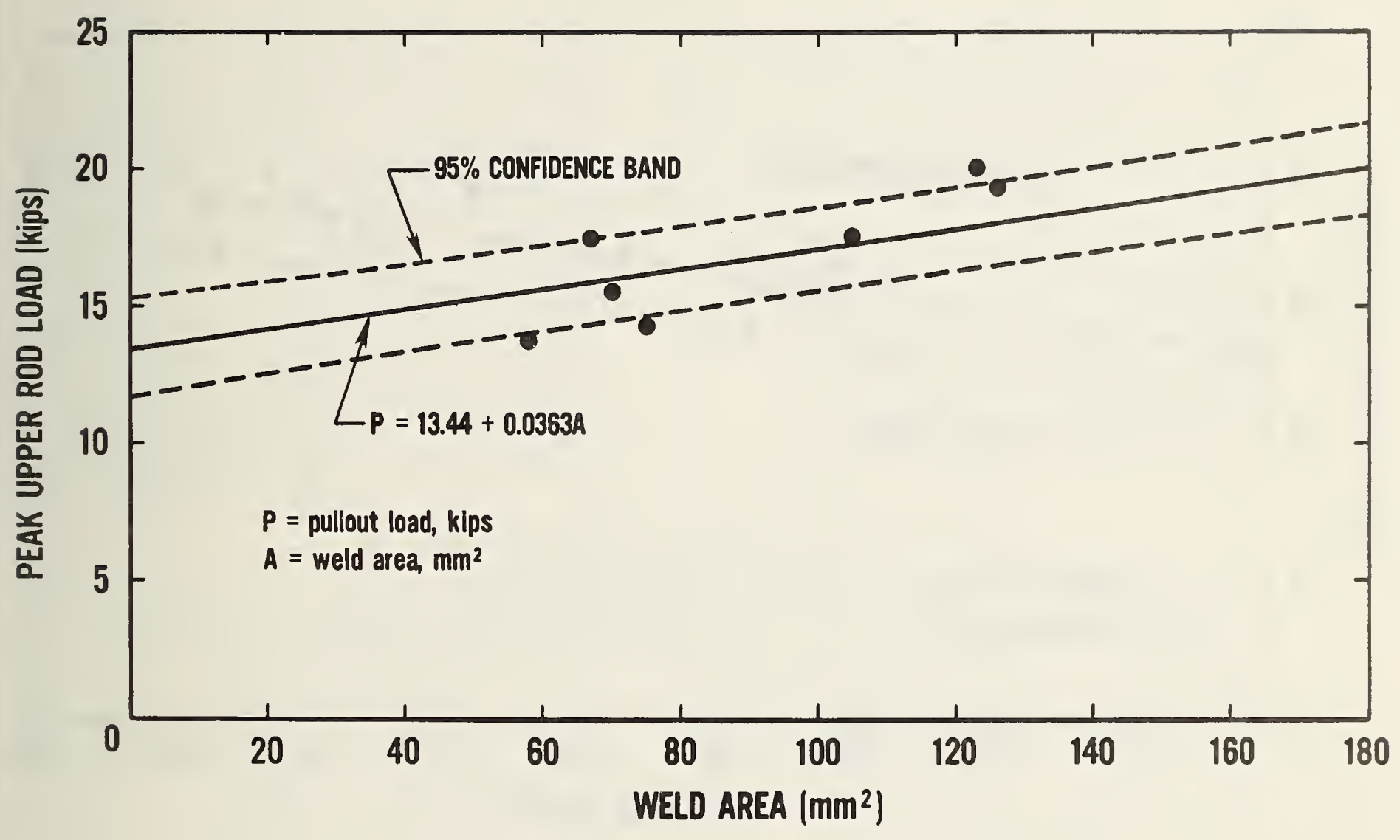

Figure 6.30 Comparison of full-length box beams with short box beam results. 


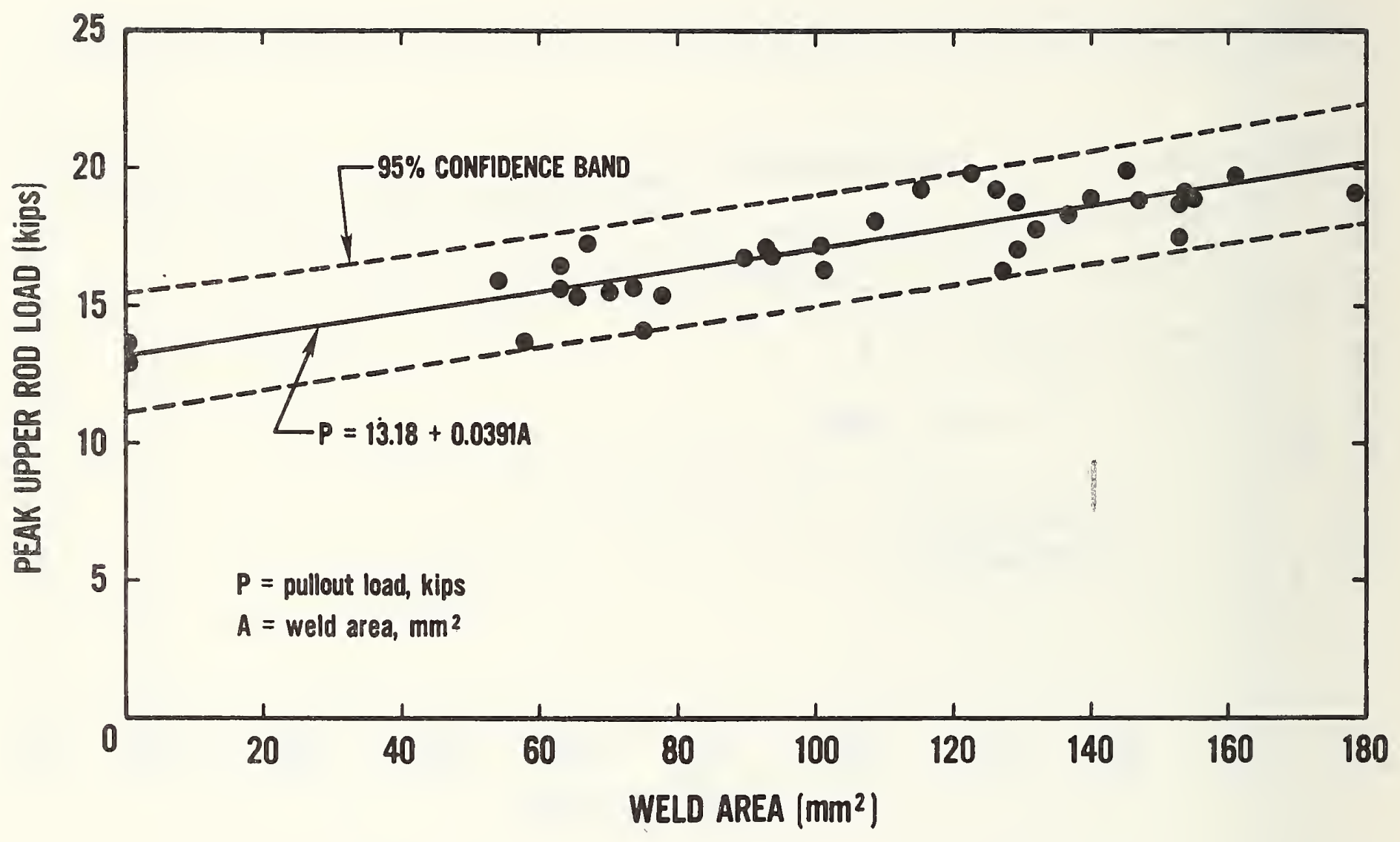

Figure 6.31 Effect of weld area on pullout load for NBS tests. 


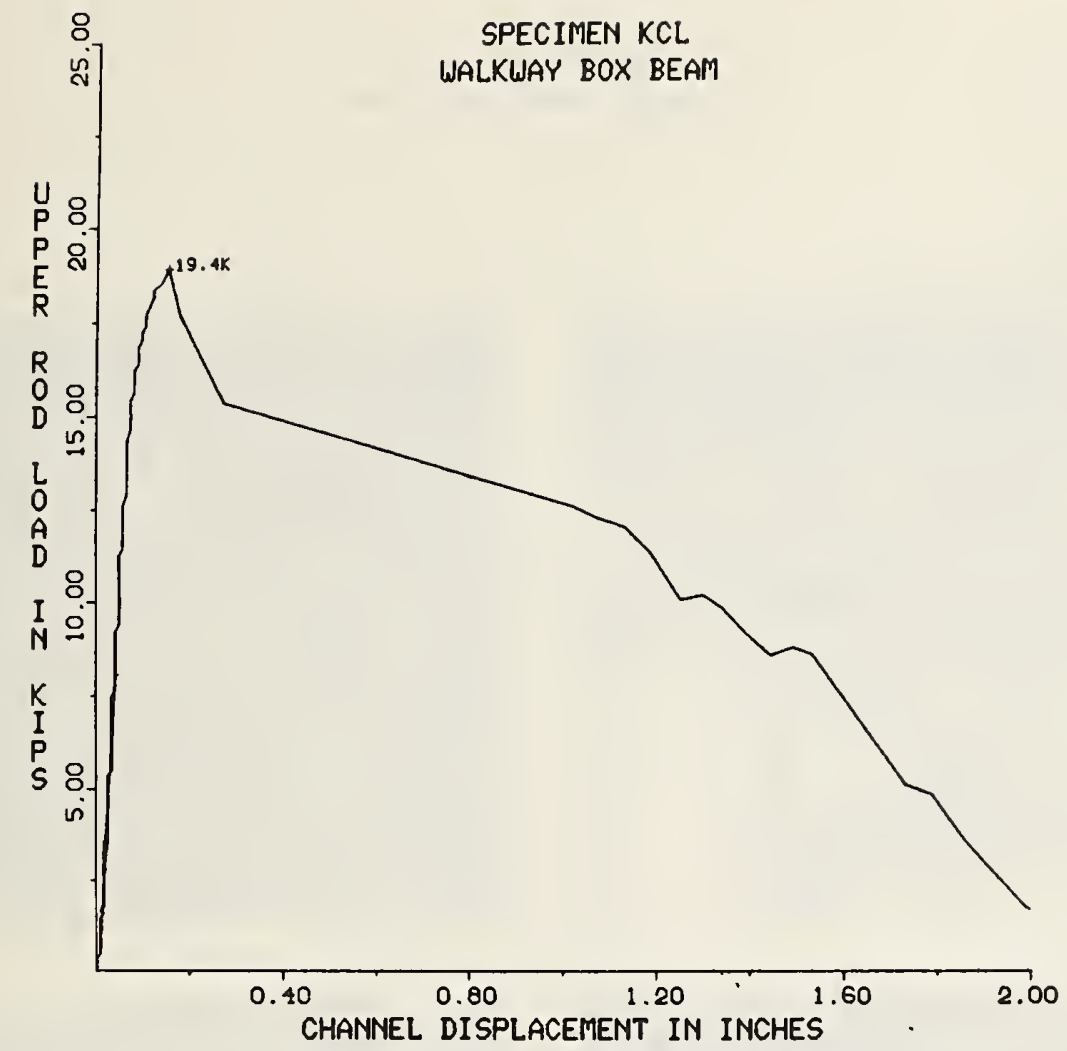

Figure 6.32 In-plane load vs deflection curve for full length box beam specimen taken from third floor walkway.

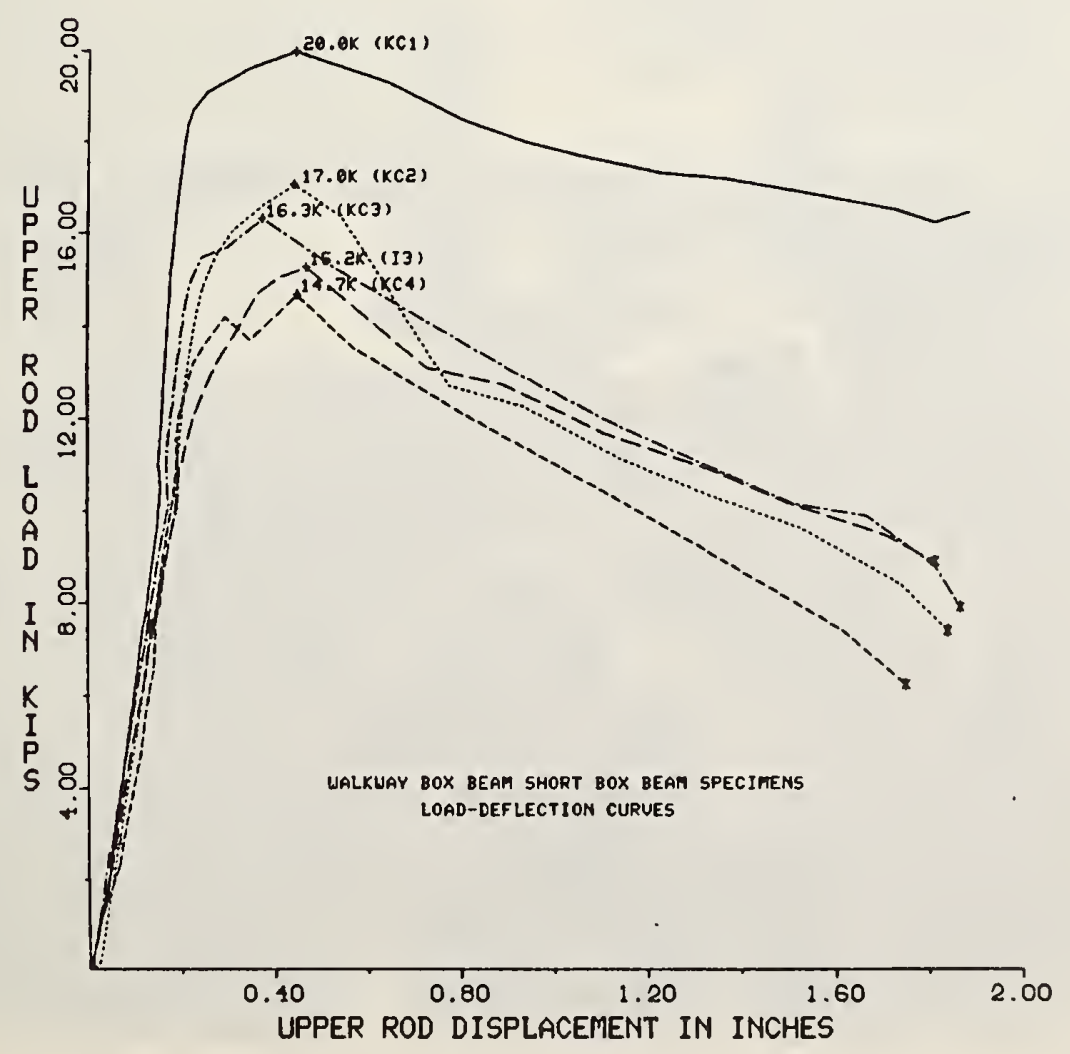

Figure 6.33 In-plane load vs displacement curves for specimens $\mathrm{KCl}-\mathrm{KC} 4$ and 13 . 


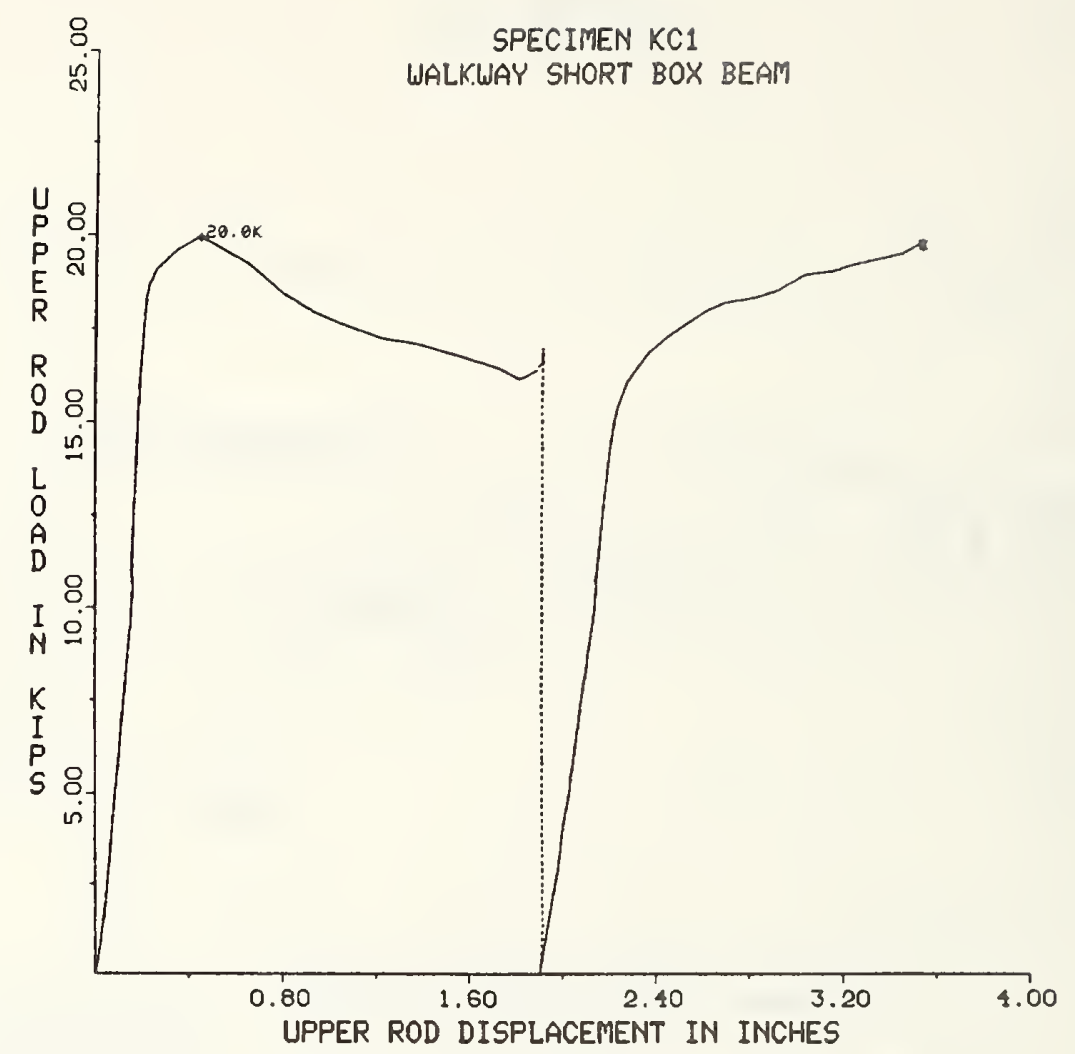

Figure 6.34 In-plane load vs deflection curve for specimen KC1.

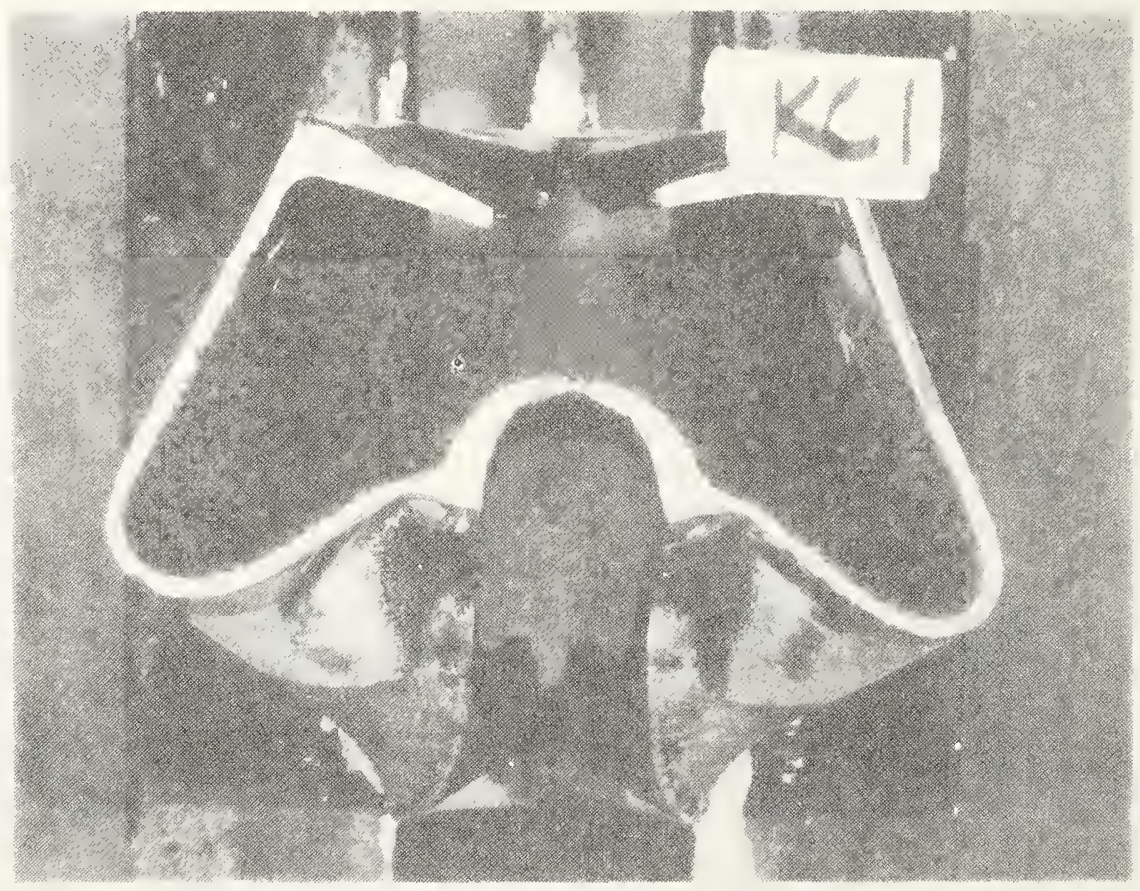

Figure 6.35 Deformed shape of walkway specimen KC1. 

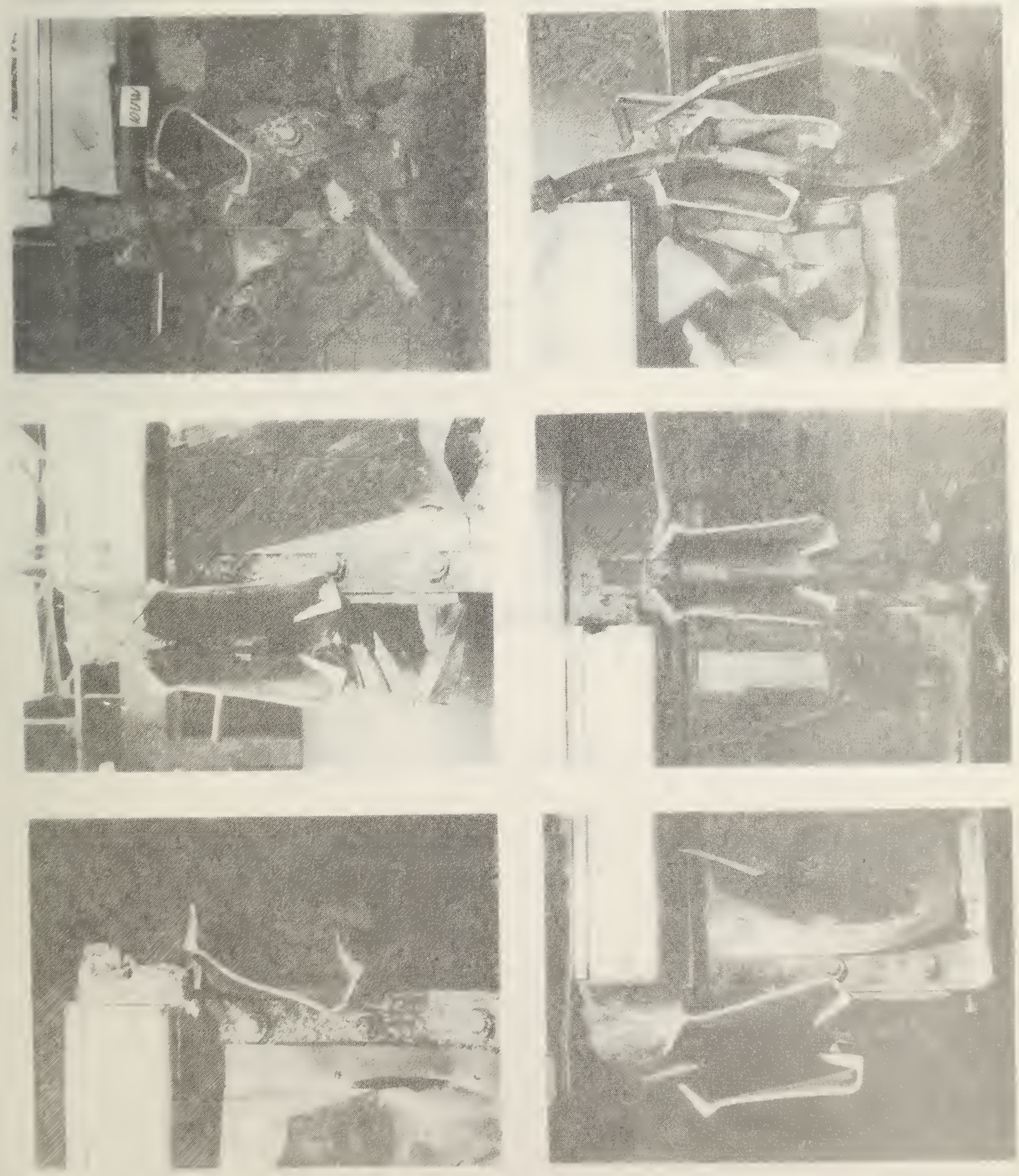

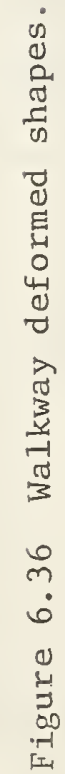




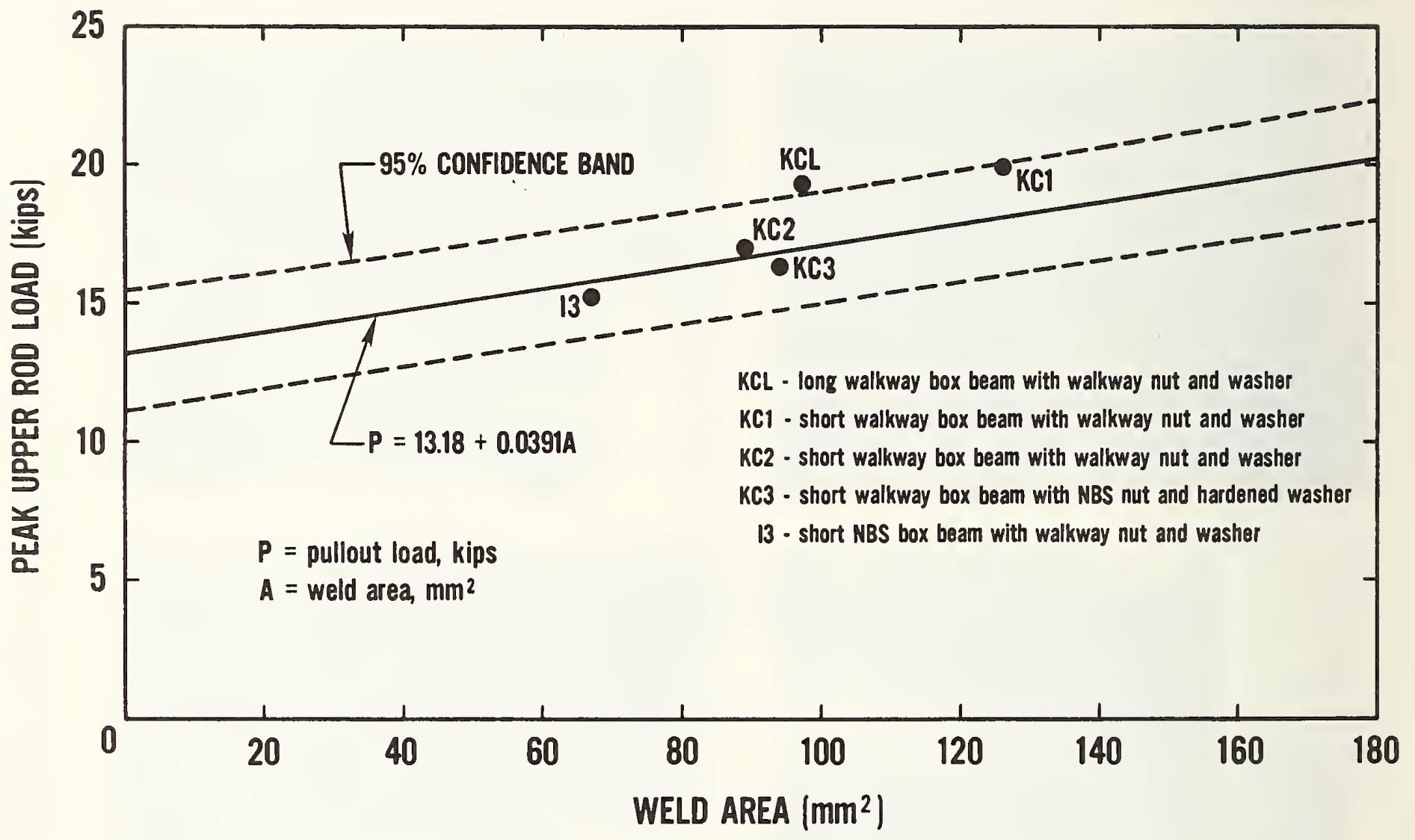

Figure 6.37 Comparison of walkway test series with NBS test results. 


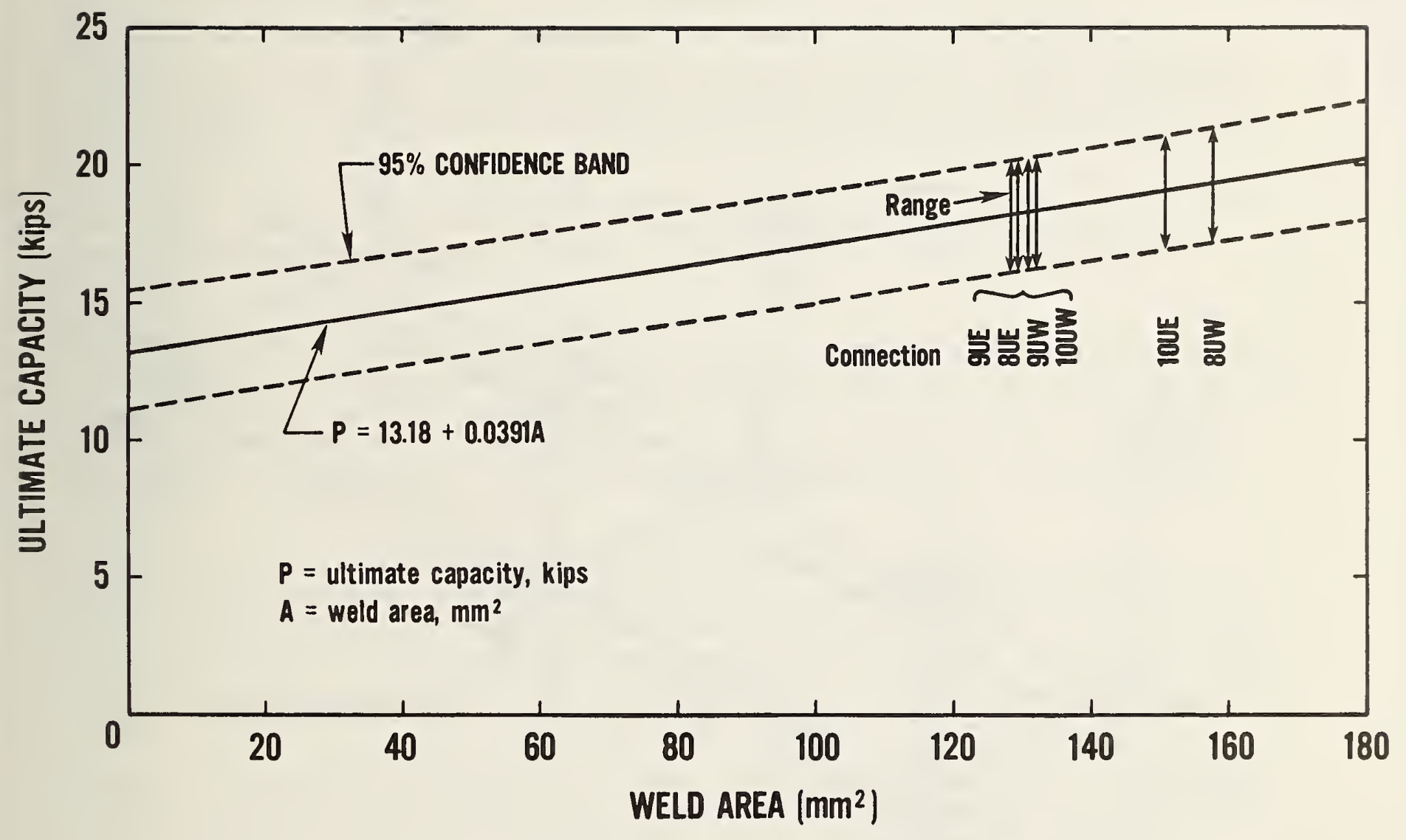

Figure 6.38 Estimated ultimate capacity for walkway box beam-hanger rod connections. 


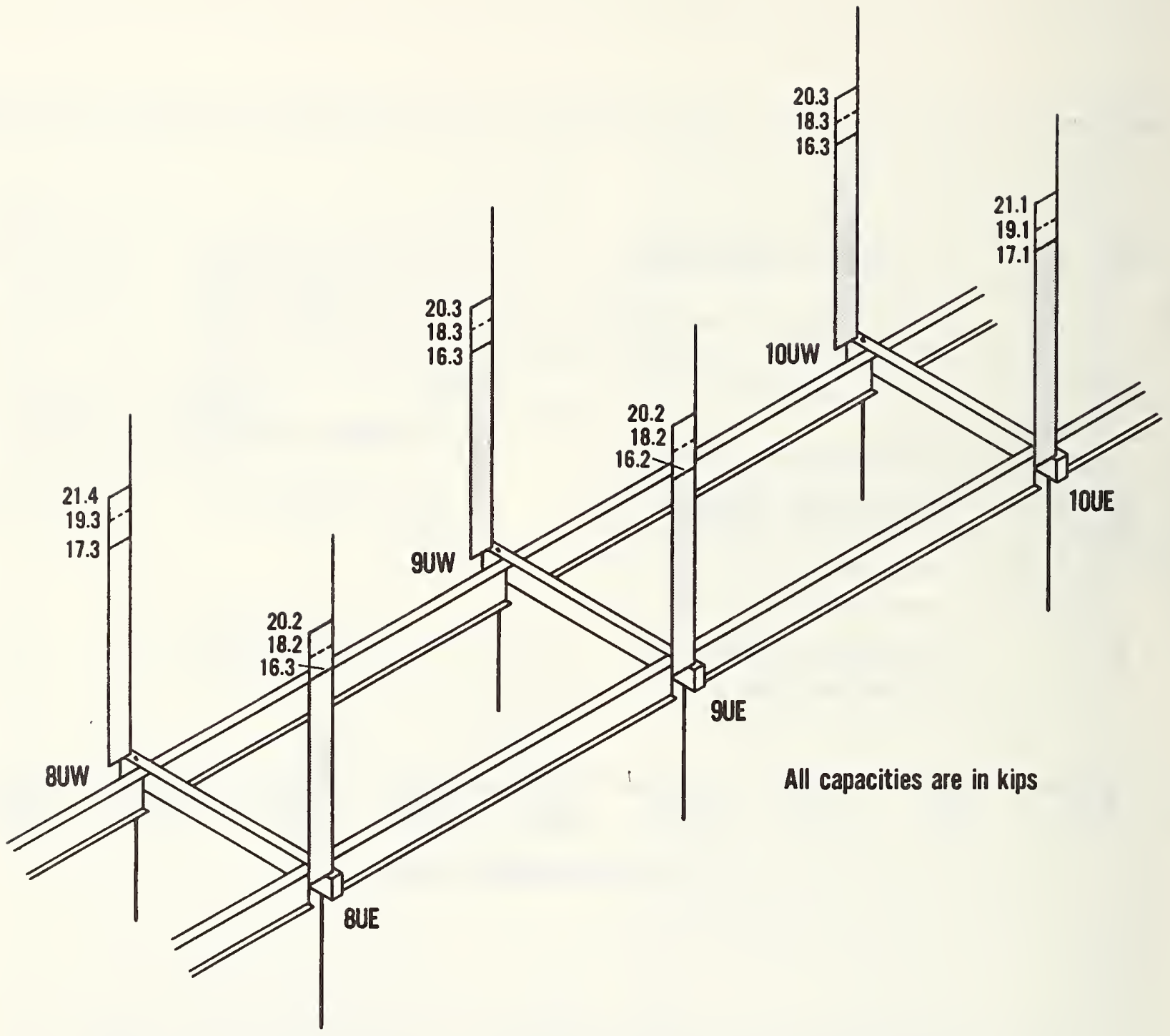

Figure 6.39 Summary of ultimate capacities. 


\subsection{INTRODUCTION}

This chapter describes the procedures and results of various tests and evaluations of NBS test materials and of materials obtained from the walkway debris. The objective was to determine compliance with appropriate codes and standards and to characterize the construction materials and the weldments.

Section 7.2 describes visual inspection and the radiographic examination of the longitudinal welds in a box beam removed from the walkway debris and assesses conformance of weld quality to AWS D1.1-79, Structural Welding Code-Steel [3.1].

Section 7.3 describes the tests to determine the mechanical properties of the structural steel and weldments. These tests were performed to characterize the materials and to determine whether the materials conformed to the requirements of ASTM A36 (Standard Specification for Structural Steel) [7.1]. Properties determined by these tests include ultimate tensile strength, yield strength, elongation and reduction of area.

Section 7.4 describes the results of metallographic examinations and hardness measurements carried out on parent material and on weld material and heat affected zones associated with the box beam longitudinal welds. Also included in this section are metallographic and hardness data obtained from hanger rod specimens, from steel washers used in the walkway construction and from washers used in the NBS structural testing program described in chapter 6 .

Section 7.5 presents the results of chemical analyses to determine conformance of the structural steel to the requirements of ASTM A36 and to determine, if possible, the type of electrode used to fabricate the walkway box beams.

The results of physical tests carried out on concrete cores removed from the walkway decks are described in section 7.6. Included here is the determination of bulk specific gravity, modulus of elasticity and compressive strength of the concrete. Also included is the bulk specific gravity of the topping material used to level the walkway decks.

Section 7.7 summarizes the conclusions drawn in this chapter.

\subsection{INITIAL INSPECTION}

\subsubsection{Visual}

Section 0510 (Parts $1.4 \mathrm{~b}$ and 3.3d) of the project specifications [2.1] allows for the visual inspection and nondestructive spot testing of shop and field welds by the owner's inspection agency. As noted in section 2.6 of this report, inspection reports that were made available to the NBS investigative team contained very little information that was relevant to the construction of the walkways. Therefore, it is not known what, if any, nondestructive testing was carried out on the walkway box beam welds. In the absence of 
such information, the criterion used by NBS to determine weld quality was visual inspection as described in Par. 8.15.1 of AWS D1.1-79. No cracks or piping porosity were observed. Weld profiles were normal. The weld quality therefore conformed to the welding code requirements under visual inspection.

\subsubsection{Radiography}

A radiographic examination was made of the top and bottom longitudinal welds in box beam 9M (NBS 3). The top longitudinal weld had been ground flush for the entire length of the beam and the bottom weld had been ground flush for a short distance from each end as discussed in section 5.3.3.

The welds were marked off in $1 \mathrm{ft}$ (300 mm) sections and numbered sequentially beginning with the bottom weld at location 9MW (No. 1), traversing to 9ME (No. 11), beginning again at the top weld at location 9MW (No. 12) and continuing along the beam to $9 \mathrm{ME}$ (No. 22). Two exposures were made at each section; one to achieve 2 percent radiographic sensitivity through the toe of the flange adjacent to the center of the weld and another to achieve a readable radiographic density at the center of the weld. Radiography was performed at $140 \mathrm{KV}$ using a $2 \mathrm{~mm}$ aluminum filter, a source-to-film distance of 1 meter with focal spot of $0.4 \mathrm{~mm} \times 0.4 \mathrm{~mm}$. Two sheets of Kodak type M film were used in flexible cassettes containing a 0.005 in $(0.13 \mathrm{~mm})$ thick front lead screen and a 0.010 in $(0.25 \mathrm{~mm})$ thick back lead screen. Exposure conditions varied from 8 to 36 milliampere-minutes, depending on results desired for a particular section. A reproduction of the radiographs of sections $1,11,12$ and 22 encompassing the beam ends appears in figure A7.2.2-1 of the appendix.

The radiographs revealed porosity lying along the weld centerline in all sections. Study of the fracture surface of a small length of weld at section 11 confirmed the presence of porosity. More porosity was evident between the beam ends and the outer hanger rod holes than between the hanger rod holes. Portions of the welds were free of porosity, suggesting that its development coincided with the start of a weld run.

Linear indications on the radiographs apparently deviating from the weld centerline at locations 7 in $(178 \mathrm{~mm})$ and 10 in $(254 \mathrm{~mm})$ from the end of beam at section 1 had the appearance of cracks. These were not confirmed by metallographic sectioning and fracturing the welds at these locations.

\subsection{MECHANICAL PROPERTIES OF STRUCTURAL STEEL AND WELDMENTS}

As has been described in chapter 6, all NBS box beam replicas were fabricated from MC8 x 8.5 structural channel believed to have been produced from a single heat. Tensile tests were performed to establish consistency within the lot and to determine conformance to the requirements of ASTM A36. Components from which specimens were machined included two walkway box beam segments, the full-length walkway box beam, hanger rod segments, and NBS box beam channels. Tests were also carried out to determine the tensile properties of the walkway box beam longitudinal weldments. 


\subsubsection{NBS Channel Specimens}

Specimens were machined from two NBS channel segments coded B and Y. Three specimens transverse to the rolling direction and three longitudinal specimens were machined from the web region and one longitudinal specimen was prepared from each of the two flange regions of the B-coded channel. Two transverse and two longitudinal specimens were machined from the web region and one longitudinal specimen was prepared from each of the two flange regions of the Y-coded channel. All specimens conformed to ASTM E8-81 (Standard Methods of Tension Testing of Metallic Materials) [7.1]. A representative specimen is shown in figure 7.1 , left side. These specimens were 8 in (200 mm) long, $0.500 \pm$ 0.010 in $(12.70+0.25 \mathrm{~mm})$ wide at the reduced section and had a $2.000 \mp$ 0.005 in $(50.80 \mp 0.13 \mathrm{~mm}$ ) gage length. The web specimens were tested $\overline{\mathrm{f}} \mathrm{fl}$ thickness (ranging from 0.180 to 0.183 in ( 4.57 to $4.65 \mathrm{~mm}$ )) whereas the flange specimens were machined to a uniform nominal thickness of 0.24 in ( $6.1 \mathrm{~mm})$ to remove the taper.

Specimens were tested to failure in tension in one of three testing machines: (A) a $25,000 \mathrm{kgf}(245 \mathrm{kN})$ capacity Satec Systems machine (NBS No. 184093), calibrated 0ctober 14, 1981, (B) a 50,000 1bf (222 kN) capacity Gilmore testing machine (NBS No. 172647), calibrated October 12, 1981, or (C) a 10,000 1bf $(44.5 \mathrm{kN}$ ) capacity Gilmore testing machine (NBS No. 172648), calibrated October 15, 1981. Estimated load inaccuracy is \pm 1 percent.

Strain data were recorded during the initial part of each test by an LVDT extensometer attached to the reduced section of the specimen. Estimated strain inaccuracy was +3 percent. The extensometer was removed from the specimen when the strain exceeded the yield point of the material. The testing machine crosshead speed was maintained at 0.02 in $(0.5 \mathrm{~mm})$ per minute until the extensometer was removed from the specimen. Subsequent crosshead speed was 0.05 in $(1.3 \mathrm{~mm})$ or 0.10 in $(2.5 \mathrm{~mm})$ per minute. Ultimate tensile strength, 0.2 percent offset yield strength, percent elongation in 2 in $(50.8 \mathrm{~mm})$, and reduction of area at the fracture were calculated. Individual test results are listed in table 7.1. Load-strain plots are given in section A7.3.1 of the appendix. Representative load-strain curves for a longitudinal web specimen, a transverse web specimen, and a longitudinal flange specimen are given in figures 7.2 7.4. Increasing load as a function of strain beyond $1.5-2$ percent strain noted on these curves reflects the onset of work hardening.

There were no significant variations of tensile properties between channels nor were there significant differences between longitudinal and transverse tensile properties or between the web and flange region tensile properties. The average ultimate tensile strength for all specimens was 71,000 psi ( $490 \mathrm{MPa}$ ) with a range of 70,500 to 71,500 psi ( 486 to $493 \mathrm{MPa}$ ). The average yield strength for all specimens was 44,800 psi (309 MPa) with a range of 43,700 to 45,500 psi (302 to $314 \mathrm{MPa}$ ). Average elongation was 33.5 percent with a range of 30.4 to 36.8 percent. Variation in strength was minor.

ASTM Standard A36 for structural steel requires an ultimate tensile strength of 58,000 to 80,000 psi ( 400 to $552 \mathrm{MPa}$ ), a minimum yield strength of 36,000 psi (248 $\mathrm{MPa})$, and a minimum elongation of 21 percent in 2 in $(50.8 \mathrm{~mm})$. All values 
for tensile strength, yield strength and elongation satisfy the requirements of ASTM A36.

\subsubsection{Walkway Box Beams}

Two longitudinal and two transverse specimens were machined from the web regions and one longitudinal specimen was machined from the flange region of each channel piece of each of the two box beam segments (9U, 8L) and the full-length box beam (9M) obtained from the walkway debris. The specific locations of the specimens in the box beams are shown in section A7.3.2 of the appendix. Specimen identification, specimen orientation, and the face of the box beam from which the specimen was machined are listed for each specimen in table 7.2.

Specimens were prepared in accordance with ASTM Standard E8-81 for rectangular tension specimens and have the same dimensions as the specimens prepared from the NBS channel. The web specimens were tested full thickness ( 0.180 to 0.189 in ( 4.57 to $4.80 \mathrm{~mm})$ ), whereas the flange specimens were machined to a uniform nominal thickness of 0.24 in $(6.1 \mathrm{~mm})$ to remove the taper. Operation of the LVDT extensometer and the machine crosshead speeds were as described in section $7 \cdot 3 \cdot 1$.

The results are presented in table 7.3. Load-strain plots are presented in section A7.3.2 of the appendix. Representative load-strain curves are given in figures $7.5-7.7$ for a longitudinal web specimen, a transverse web specimen, and a longitudinal flange specimen, respectively.

Neither the ultimate tensile strength nor the yield strength varied significantly between the beam segments. In addition, there was no discernable variation between longitudinal and transverse orientations in the web or between the web and flange regions. Ultimate tensile strength values ranged from 69,000 to 71,500 psi (476-493 MPa) with an average of $70,100 \mathrm{psi}$ (484 MPa). Yield strength values ranged from 41,900 to 47,100 psi (289 to $325 \mathrm{MPa}$ ) with an average of 44,400 psi (306 MPa).

Average elongation for all tests was 32.3 percent, ranging from 27.6 to 38.0 percent. The average elongation for longitudinal specimens was about 10 percent greater than that for transverse specimens in the case of box beam $9 \mathrm{U}$ and about 18 percent greater in the case of box beam $8 \mathrm{~L}$. The difference in average elongation between transverse and longitudinal specimens from beam $9 \mathrm{M}$ was less (about 4 percent).

The results from all tests fell well within the requirements of ASTM A36 as stated in section 7.3 .1 of this report for tensile strength, yield strength and elongation. The results from these tests agree very well with the results from the NBS channel tests.

\subsubsection{Walkway Hanger Rods}

Two round test specimens were prepared from each of the two hanger rod segments obtained from the walkway debris. These specimens were machined in accordance with ASTM E8-81 for round tension specimens with a 5 in (127 mm) length, 
$0.500+0.010$ in $(12.70+0.25 \mathrm{~mm})$ reduced section diameter and a gage length of $2.0 \overline{0} 0+0.005$ in $(50 . \overline{8} 0+0.13 \mathrm{~mm})$. The locations of the specimens from hanger ro $\bar{d}$ segments NBS $5 \mathrm{~A}$ and NBS $5 \mathrm{~B}$ are shown in section $\mathrm{A} 7.3 .3$ of the appendix. A representative specimen is shown in figure 7.1. The testing procedure was the same as that used for the NBS channel and the walkway box beam specimens. The results of these tests are given in table 7.4 and a representative load-strain plot for one of the specimens is shown in figure 7.8. Load-strain plots for all of the specimens are given in section $\mathrm{A7.3.3}$ of the appendix.

The ultimate tensile strength ranged from 62,500 psi (431 $\mathrm{MPa}$ ) to 69,000 psi (476 MPa), meeting the ASTM A36 requirement of strength specified as 58,000 psi ( $400 \mathrm{MPa}$ ) to $80,000 \mathrm{psi}(552 \mathrm{MPa})$. The 0.2 percent offset tensile yield strength ranged from 35,900 psi ( $248 \mathrm{MPa}$ ) to 46,900 psi ( $324 \mathrm{MPa}$ ) with three of the four specimens giving values over the ASTM A36 specified minimum of $36,000 \mathrm{psi}(248 \mathrm{MPa})$. The yield strength of the remaining specimen was within $100 \mathrm{psi}(690 \mathrm{KPa})$ of the specified minimum and is considered to have met the criterion in view of the estimated $+360 \mathrm{psi}(2.48 \mathrm{MPa})$ measurement inaccuracy. Elongation values ranged from 36 to 42 percent, thereby conforming to the ASTM A36 specification of 21 percent minimum.

It is concluded that the tensile properties of the walkway hanger rod material satisfied the requirements of the ASTM A36 specification.

\subsubsection{Walkway Box Beam Longitudinal Welds}

Variation in the transverse strength of the walkway box beam longitudinal welds was determined by testing 1.0 in $(25.4 \mathrm{~mm})$ wide tensile coupons to failure. Weld caps were machined flush to simulate conditions near the beam ends. The results, summarized in table 7.5 , show a substantial variation in breaking load among specimens taken from the same beam. The observed variability is not unusual for the type of weldment tested considering the small weldment area sampled by each specimen. Figure 7.9 shows the variability in the amount of weld metal from specimen to specimen at the fracture. This variability correlates reasonably well with the specimen breaking loads (table 7.5). Differences in the amount of porosity found on the fracture surfaces of the specimens also contribute to the ultimate strength variation.

\subsection{METALLOGRAPHY AND HARDNESS MEASUREMENTS}

This section summarizes the results of metallographic examination and hardness tests performed on box beam longitudinal welds, on walkway hanger rods and on washers used in the box beam-hanger rod connections. Details of these studies appear in section $\mathrm{A} 7.4$ of the appendix.

\subsubsection{Box Beam Weldments}

Metallographic and hardness studies were performed on cross sections taken from the longitudinal weld region of an NBS weldment and from walkway beams $9 \mathrm{U}$, $8 \mathrm{~L}$ and 9M. The regions examined included the channel flanges and portions of the channel web as well as the weld and heat-affected zone. 
Figure 7.10 illustrates the appearance of an NBS weldment made by the GMAW process, while figures 7.11-7.13 illustrate the appearance of weld regions in box beams 9U, 8L and 9M, respectively. Basic walkway weldment hardnesses were normal. Maximum hardnesses were 92-95 Rockwell B (HRB) for the weld regions, 85-93 HRB for the heat-affected zones and 70-79 HRB for the unaffected parent metal. Small zones of increased hardness (28-33 HRC) were noted in the heataffected zones of one section taken from location $9 U$ and one section taken from location $8 \mathrm{~L}$. The structure of the hard zones appeared to be tempered martensite.

Walkway weldment microstructure was normal and comparable to the NBS weldment microstructure. The weld metal structure was primarily bainitic; the heataffected zones contained ferrite primarily as a network in prior austenite grain boundaries plus bainite, partially spheroidized carbides and tempered martensite; while the base metal structure contained ferrite and pearlite in a normalized structure.

Figures 7.10 to 7.13 illustrate a substantial variability in the contour of the mating flange ends forming the faying surfaces for welding. The effect, coupled with differences in weld penetration, creates regions of varying notch acuity in the weld region. However, no cracks were observed to have initiated from such notches in any of the sections studied.

A series of optical and metallographic measurements of longitudinal weld penetration in the interiors of box beams $9 \mathrm{U}, 8 \mathrm{~L}$ and $9 \mathrm{M}$ and at the ends of box beams at locations 8UE, 9UE, 9UW and 10UE are summarized in figure 7.14. The latter set was taken in the lower flange region between the beam end and the outer hanger rod hole following weldment fracture. From figure 7.14 the weld penetration data from the sectional specimens average about $2.2 \mathrm{~mm}$. The data from the fracture surface at location $10 U \mathrm{E}$ average about $2.4 \mathrm{~mm}$, while the average weld penetration at locations 8UE, 9UE, and 9UW is near $1.5 \mathrm{~mm}$. All weld penetration data from fractures represent minimum values, considering that the surfaces examined represent final reductions in area at fracture.

It is known that the depth of weld penetration will be less at the beginning of a weld run than it is after steady welding conditions have been attained. Progressively increasing penetration from the beam ends toward the outer hanger rod holes at locations 8UE, 9UE and 9UW (figure 7.14) suggests that a "run-on" tab was not used in walkway beam fabrication. Weld penetration at location lOUE suggests that this beam was cut to length after the welding operation. Evidence of such an operation was also noted at location 8UW during the site investigation ( $\operatorname{section} 5 \cdot 3 \cdot 3$ ).

Interior tack welds were present at the bottom flanges of all beam ends examined. The location of these welds relative to the beam ends and their approximate overall depth as measured from photographs of the fractures are shown in figure 7.15. Estimates were made of the total area of interior tack weld plus the longitudinal weld in the box beam length between the outer hanger rod hole and the box beam end. The data in table 7.6 were compiled by measuring the penetration depth of the longitudinal and tack welds along the fractures at 
$1 \mathrm{~mm}$ intervals on 10X photographic enlargements. Areas of both welds were calculated from the profiles. As illustrated by the sketch accompanying table 7.6, the total cross-sectional area ( $T$ x B) was taken as the projected area of the flange toes and the additional weld metal due to tack weld buildup beyond this area was not considered. Had this been considered, the percent weld area reported in table 7.6 would have been substantially increased.

In summary, typical box beam longitudinal weld penetration averages about $2.2 \mathrm{~mm}$, approximately the depth from the flange surface to the point of tangency of the mating sides. At some beam ends, due probably to weld start-up, the depth of weld penetration is less than $2.2 \mathrm{~mm}$. At these locations, however, there is always an interior tack weld present and the cross-sectional area produced by a combination of longitudinal plus interior tack weld areas exceeds the area achieved with only a longitudinal weld of penetration depth equal to $2.2 \mathrm{~mm}$.

\subsubsection{Walkway Hanger Rods}

Transverse and longitudinal sections removed from two walkway hanger rod segments (NBS 5A and 5B) were examined metallographically and were tested for hardness. The microstructure, consisting of ferrite and pearlite in a normalized condition, is considered typical of A36 structural steel. The microstructure in NBS $5 B$ was slightly coarser (ASTM grain size 7.5-8) than in NBS 5A (ASTM grain size 9), but this variation is not significant. Hardness values were normal at $66-76$ HRB.

\subsubsection{Washers}

Metallographic and hardness studies on washers from the walkway and washers used in NBS tests proceeded in two stages. The initial effort was a general characterization of the walkway washers associated with the initial components of the debris removed for analysis. These were identified as the upper washer from the fourth floor to ceiling hanger rod at location 8UE, the lower washer from location $8 \mathrm{LW}$, and the two lower washers from box beam 9M. Two washers from the NBS tests, one hardened and one unhardened, were included in this initial study. Additional hardness tests were conducted on (1) three walkway washers obtained as a result of a petition for access to additional debris material, (2) a walkway washer identified as 9MW that had been used in an NBS test on box beam $9 \mathrm{M}$ and had fractured during the test, and (3) three additional NBS hardened washers. Results of the hardness tests, summarized in table 7.7, confirmed that hardened washers had been used in the walkway construction.

Core hardness (obtained after removal of the soft decarburized layer) was also measured on selected specimens and the data are included in table 7.7. The data in table 7.7 indicate that the walkway washers were, on the average, slightly harder than the NBS washers; walkway washer average was 41.6 HRC with a range of 34.5-45.0 HRC and NBS washer average was 39.1 HRC with a range of 36.0-41.9 HRC. Little difference was noted between surface and core hardness. 
Photomicrographs of the fractured washer (9MW) and of the NBS hardened washer in figure 7.16 show a tempered martensite interior and a thin decarburized layer on the surface. This is typical for hardened washers.

\subsection{CHEMICAL ANALYS IS}

Chemical analysis was performed on the base metal and on longitudinal welds of box beams from the walkway and from box beams fabricated by NBS. An interior. tack weld from the walkway and specimens removed from the walkway hanger rods were also analyzed. Details of the locations analyzed and of analytical procedures used are given in section $A 7.5$ of the appendix.

Table 7.8 shows that the NBS and walkway structural channel and the walkway hanger rod compositions are within the specifications of ASTM A36 for structural steel.

Table 7.9 compares the chemical composition of weld metal in NBS box beam longitudinal welds made with various processes with the composition determined for the walkway box beam longitudinal welds from $9 \mathrm{U}, 8 \mathrm{~L}$ and $9 \mathrm{M}$ and the interior tack weld from location $8 \mathrm{LW}$. NBS welding procedures have been discussed in section 6.10 .2 .

Similarity in composition between the walkway longitudinal and interior tack welds suggests they were made by the same welding process. Similarity of composition between the walkway welds and the NBS weld made with the flux-cored electrode suggests this process was used in welding the walkway box beams. The evidence is not conclusive, however, because solid welding wire giving the same chemical composition is available. The lower manganese and silicon contents determined for weld metal deposited with the E7018 and E7014 stick electrodes as compared to that of the walkway welds indicate that these electrodes were not used in the fabrication of the walkway box beams.

\subsection{PROPERTIES OF CONCRETE}

Laboratory tests were carried out on the 19 cores removed from the concrete decks to determine modulus of elasticity, compressive strength and bulk specific gravity. The bulk specific gravity of the topping material recovered with the cores was also determined. Prior to conducting these tests, each core was photographed, weighed, and measured. In most cases the topping material had separated from the main body of the core during the coring operation. In those few cases where it remained attached, the topping was removed and the weight and length measurements were repeated. After noting its general condition and subjectively classifying its quality based upon surface smoothness, distribution of aggregate, and flatness of ends, each core was closely examined for the presence of surface cracks or wire reinforcement. Results of this examination are summarized in table-7.10.

Bulk specific gravity of the concrete and of the topping material was determined for two conditions: (1) air dry as received from the warehouse and (2) after oven drying for 24 hours. Sample preparation and weighing were carried out in accordance with the provisions of ASTM C642-75 (Standard Test Method for 
Specific Gravity, Absorption, and Voids in Hardened Concrete) [7.1] except for the determination of saturated weight after boiling.

A total of nine cores was used to determine modulus of elasticity and compressive strength. Each core was instrumented with two resistance strain gages oriented in the lengthwise direction and positioned 180 degrees apart. Gage length was 2 in $(51 \mathrm{~mm})$ and the gages were operated in a full-bridge configuration. The cores were capped and tested in accordance with ASTM C617-76 (Standard Method for Capping Cylindrical Concrete Specimens), C469-79 (Standard Test Method for Static Modulus of Elasticity and Poisson's Ratio for Concrete in Compression) and C39-72 (Standard Test Method for Compressive Strength of Cylindrical Concrete Specimens) [7.1]

Table 7.11 lists the unit weights, the modulus of elasticity (E) and the compressive strength $\left(f_{c}^{\prime}\right)$ for the various cores tested. The unit weights for the concrete in the air dry condition are very consistent with an average of $113.5 \mathrm{pcf}\left(1,820 \mathrm{~kg} / \mathrm{m}^{3}\right)$ and a range of 109.0 to $118.4 \mathrm{pcf}\left(1,750\right.$ to $\left.1,900 \mathrm{~kg} / \mathrm{m}^{3}\right)$, based on results from 10 cores. For the oven dry condition the average was $108.1 \mathrm{pcf}\left(1,730 \mathrm{~kg} / \mathrm{m}^{3}\right)$ and the range was 104.0 to $112.1\left(1,670\right.$ to $\left.1,800 \mathrm{~kg} / \mathrm{m}^{3}\right)$. The variation in unit weights obtained for the topping material is greater. For the air dry condition the average of eight specimens was $116.8 \mathrm{pcf}\left(1,870 \mathrm{kgm}^{3}\right)$ and the range was 101.5 to $135.2 \mathrm{pcf}\left(1,630\right.$ to $\left.2,170 \mathrm{~kg} / \mathrm{m}^{3}\right)$. For the oven $\mathrm{dry}$ conditions the average was $113.7 \mathrm{pcf}\left(1,820 \mathrm{~kg} / \mathrm{m}^{3}\right)$ and the range was 99.1 to $133.9 \mathrm{pcf}\left(1,590\right.$ to $\left.2,150 \mathrm{~kg} / \mathrm{m}^{3}\right)$.

Based on nine cores tested, the modulus of elasticity (secant modulus at 40 percent of compressive strength) averaged $1.86 \times 10^{6} \mathrm{psi}\left(12.8 \times 10^{3} \mathrm{MPa}\right.$ ) and ranged from 1.75 to $2.08 \times 10^{6}$ psi ( 12.1 to $14.4 \times 10^{3} \mathrm{MPa}$ ). The average compressive strength based on these same nine cores and corrected for core aspect ratio was $5,030 \mathrm{psi}(34.7 \mathrm{MPa})$ and ranged from 4,440 to 5,520 psi ( 30.6 to $38.1 \mathrm{MPa}$ ). Measurements upon which the values listed in table 7.11 are based can be found in section A7.6 of the appendix.

The average unit weight for concrete of $113.5 \mathrm{pcf}\left(1,820 \mathrm{~kg} / \mathrm{m}^{3}\right)$ compares with a nominal value of 110 pcf $\left(1,760 \mathrm{~kg} / \mathrm{m}^{3}\right)$ for lightweight concrete. The average compressive strength of $5,030 \mathrm{psi}(34.7 \mathrm{MPa})$ is well above the $3000 \mathrm{psi}$ (20.2 MPa) minimum for lightweight concrete fill on metal deck indicated in the General Notes (Dwg. S601). There are no specific requirements stated for modulus of elasticity.

\subsection{CONCLUSIONS}

The following conclusions are made subject to limitations of the materials evaluated and the test variables selected:

1. Quality of the box beam longitudinal welds conformed to the visual inspection requirements of AWS D1.1-79 Structural Welding Code-Steel.

2. There were no significant differences in tensile properties and chemical compositions between NBS and walkway box beam channel material. 
3. Tensile properties and chemical compositions of NBS channels, walkway box beam channels and hanger rod materials satisfy the requirements of ASTM Standard A36 for structural steel.

4. Microstructure and hardness of the NBS channels, walkway box beam channels and hanger rod materials were normal. Differences were noted in grain size and in apparent pearlite-to-ferrite ratio in the two hanger rods examined; however, the differences are not considered to be significant.

5. Microstructure and hardness of longitudinal and interior walkway box beam welds were normal.

6. Longitudinal weld penetration in the box beam interior averaged about $2.2 \mathrm{~mm}$, approximating the distance from the point of tangency of the mating flange surfaces to the outside face of the channel flanges. Some lesser penetration was noted near the beam ends in regions reinforced with interior tack welds; however, the presence of interior tack welds considerably increased the total weldment cross-sectional area at these locations.

7. Hardened washers had been installed in the walkway. The hardness of these washers was slightly higher than that of hardened washers used in the NBS test series.

8. Compressive strength of lightweight concrete used in the walkway decks exceeded the requirement of the project design criteria. 


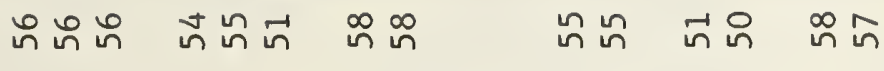

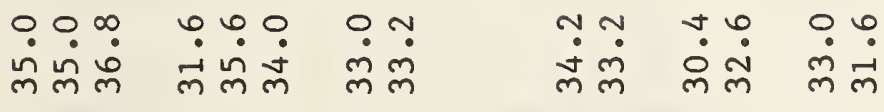



0ี

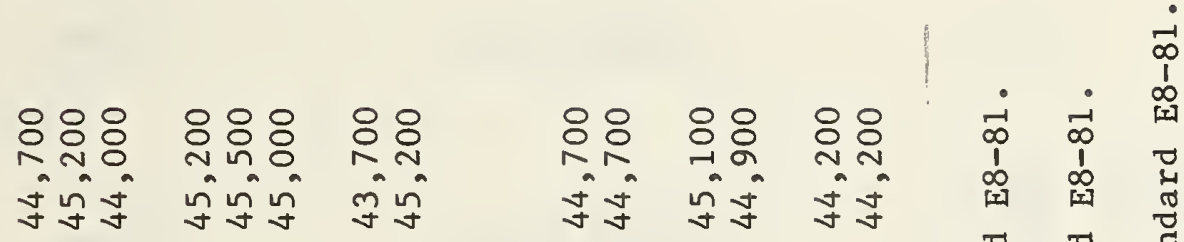

चु $\begin{gathered}4-1 \\ -1\end{gathered}$

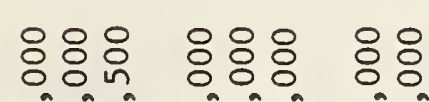
न-10

요요요

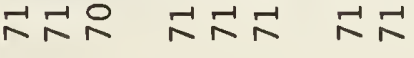

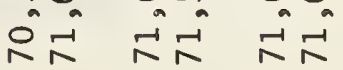

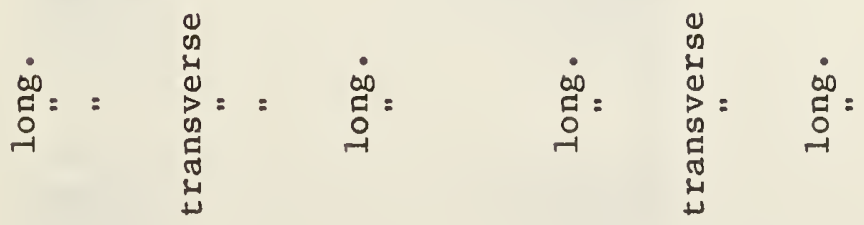

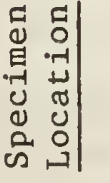

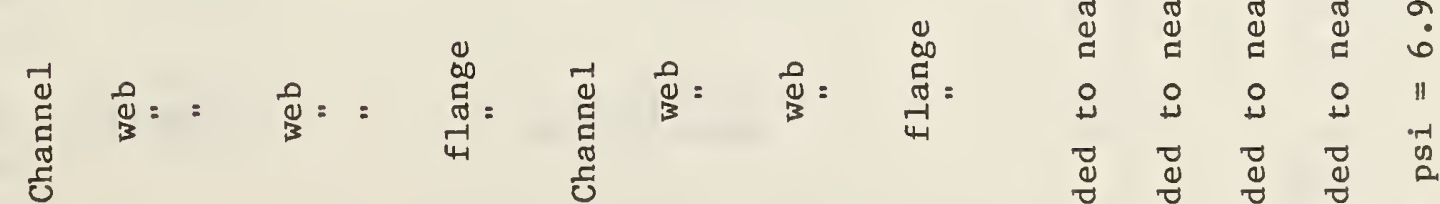

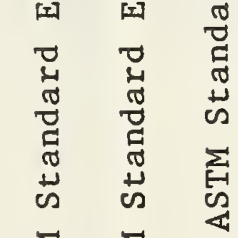

ज呫

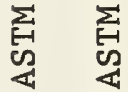

$\prod_{\substack{n-1 \\ 3}}^{+2}$

竞

$\begin{array}{ll}\frac{5}{4} & \frac{5}{4} \\ -1 & -1 \\ 3 & 3\end{array}$

ป

表

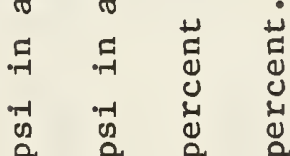

ㅇํㅇำ

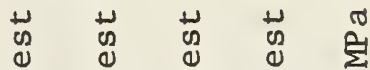

完

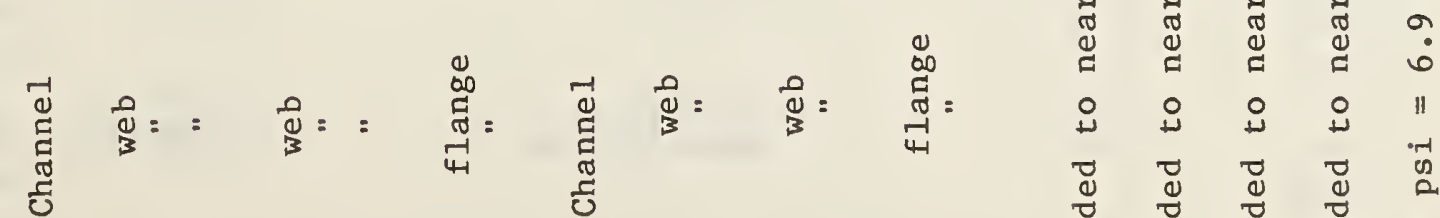

罗

๑

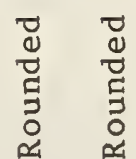

क

몰

옹

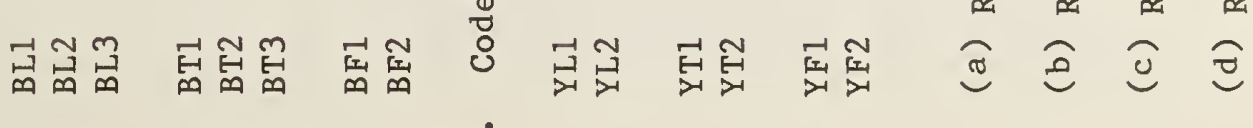


A. Box Beam 9U (NBS 1)

$$
\begin{aligned}
& 1-\mathrm{LS} 1 \\
& 1-\mathrm{LS} 2 \\
& 1-\mathrm{LN} 1 \\
& 1-\mathrm{LN} 2 \\
& \\
& 1-\mathrm{TS} 1 \\
& 1-\mathrm{TS} 2 \\
& 1-\mathrm{TN} 1 \\
& 1-\mathrm{TN} 2 \\
& 1-\mathrm{TFS} \\
& 1-\mathrm{TFN}
\end{aligned}
$$

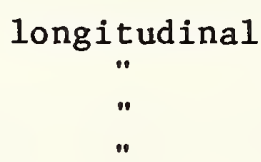

transverse

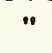

"

"

longitudina1

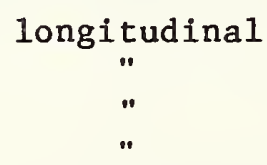

transverse

"

๑

ฯ

longitudinal

2-TFS

2-TFN

C. Box Beam 9M (NBS 3)

3-LS1

3-LS2

3-LN1

3-LN2

3-TS1

3-TS2

3-TN1

3-TN2

3-TFS

3-TFN

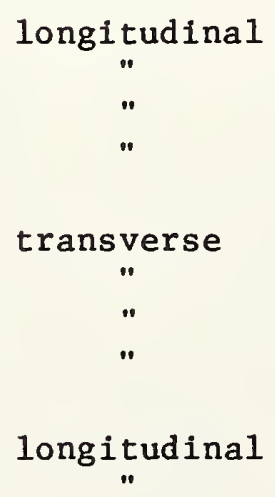

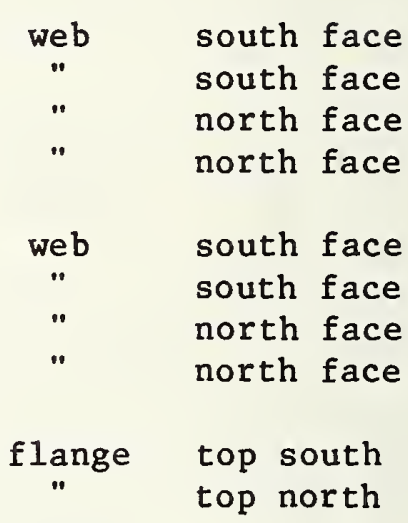

$$
\begin{gathered}
\text { web } \\
\text { " } \\
\text { ". }
\end{gathered}
$$

web

"

"

flange

" south face south face north face north face

south face south face north face north face

top south top north 
Table 7.3 Tensile Test Results - Walkway Box Beam Channel

Ultimate Tensile

$\underline{\text { Specimen }}$
Yield Strength $0.2 \%$ offset, psi (b)
Elongation, \%(c)

Reduction of

Area, $\%(d)$

A. Box Beam 9U (NBS 1)

$\begin{array}{lllll}1-\text { LS1 } & 69,000 & 44,200 & 36.0 & 56 \\ 1-\text { LS2 } & 70,000 & 43,700 & 32.6 & 55 \\ 1-\text { LN1 } & 70,000 & 44,400 & 32.4 & 54 \\ 1-\text { LN2 } & 71,000 & 45,300 & 33.4 & 54 \\ 1-\text { TS1 } & 69,000 & 44,600 & 31.0 & 47 \\ 1-\text { TS2 } & 69,500 & 45,800 & 30.4 & 48 \\ 1-\text { TN1 } & 71,000 & 47,100 & 29.6 & 48 \\ 1-\text { TN2 } & 71,000 & 44,700 & 33.8 & 47 \\ & & & & 57 \\ 1-\text { TFS } & 69,500 & 43,400 & 36.6 & 61 \\ 1-\text { TFN } & 70,000 & 43,200 & 35.2 & \end{array}$

B. Box Beam 8L (NBS 2)

$\begin{array}{ll}2-\mathrm{LS} 1 & 71,000 \\ 2-\mathrm{LS} 2 & 69,500 \\ 2-\mathrm{LN} 1 & 71,000 \\ 2-\mathrm{LN} 2 & 70,500 \\ & \\ 2-\mathrm{TS} 1 & 71,500 \\ 2-\mathrm{TS} 2 & 70,500 \\ 2-\mathrm{TN} 1 & 71,000 \\ 2-\mathrm{TN} 2 & 71,000 \\ & \\ 2-\mathrm{TFS} & 70,000 \\ 2-\mathrm{TFN} & 70,000\end{array}$

C. Box Beam 9M (NBS 3)
45,900

43,700

46,800

44,300

45,600

45,200

44,500

46,000

45,400

43,200
28.4

33.0

33.6

34.8

29.6

27.6

29.8

29.0

38.0

37.0
54

53

54

56

48

46

48

48

59

60

$\begin{array}{ll}\text { 3-LS1 } & 70,000 \\ \text { 3-LS2 } & 70,000 \\ \text { 3-LN1 } & 69,500 \\ \text { 3-LN2 } & 69,500 \\ & \\ \text { 3-TS1 } & 70,000 \\ \text { 3-TS2 } & 70,000 \\ \text { 3-TN1 } & 69,000 \\ \text { 3-TN2 } & 69,000 \\ \text { 3-TFS } & 70,500 \\ \text { 3-TFN } & 69,500\end{array}$

43,200

31.4

44,400

43,000

44,600

31.4

30.8

33.0

54

54

54

54

44,300

31.6

51

44,100

30.2

51

43,500

31.6

50

41,900

30.6

51

42,400

33.8

58

43,500

33.4

61

(a) Rounded to nearest 500 psi in accordance with ASTM Standard E8-81.

(b) Rounded to nearest 100 psi in accordance with ASTM Standard E8-81.

(c) Rounded to nearest 0.2 percent in accordance with ASTM Standard E8-81.

(d) Rounded to nearest 1.0 percent. 

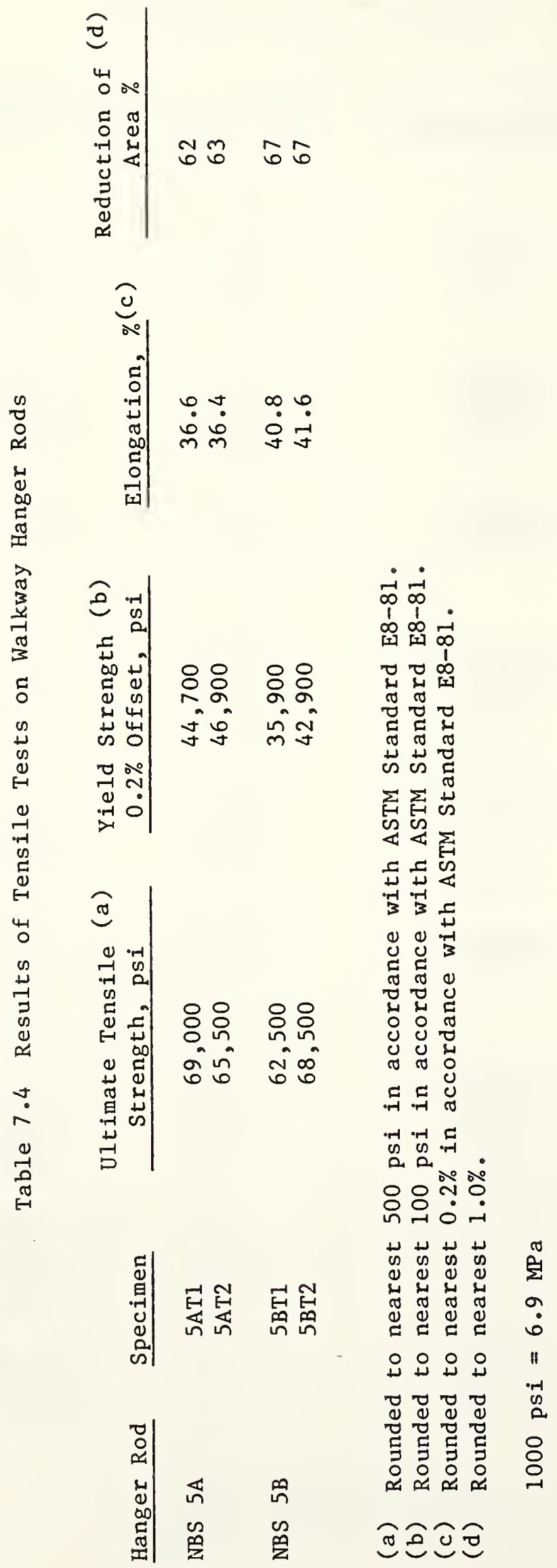
Table 7.5 Results of Tensile Tests on Walkway Box Beam Weldments

$\begin{array}{ccc}\text { Box Beam } & \text { Specimen } & \text { Maximum Load (1bs) } \\ 9 \mathrm{U} & \text { 1BX3W2 } & 6740 \\ & 1 \mathrm{BX} 3 \mathrm{~W} 4 & 5890 \\ 8 \mathrm{~L} & 2 \mathrm{BX} 3 \mathrm{~W} 2 & 4790 \\ & 2 \mathrm{BX} 3 \mathrm{~W} 4 & 2200 \\ 9 \mathrm{M} & 3 \mathrm{BW1} & 3920 \\ & 3 \mathrm{BW} 4 & 5100 \\ 10001 \mathrm{bs}=4.448 \mathrm{kN} & \end{array}$


Table 7.6 Percent of Longitudinal Box Beam Weld Plus Interior Tack Weld Area as a Function of Total Cross Sectional Area for Walkway Beam Weldments

Beam End to Outer Hanger Rod Hole

Location

$8 \mathrm{UE}$

9UE

9UW

1OUE

Penetration to $2.2 \mathrm{~mm}$
Percent Weld Area

63

55

58

92

48

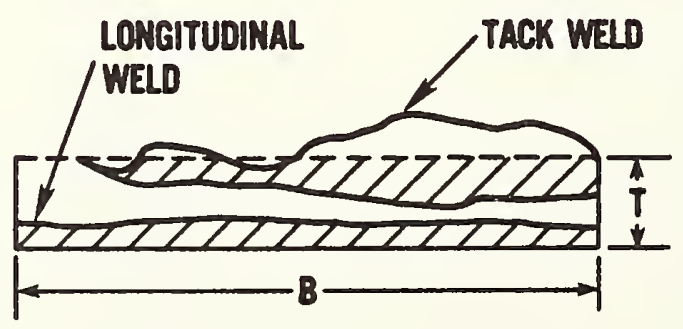


Table 7.7 Results of Washer Hardness Tests

\begin{tabular}{|c|c|c|c|c|c|}
\hline \multirow{3}{*}{$\begin{array}{c}\text { Washer } \\
\text { Identification } \\
\end{array}$} & \multirow{3}{*}{$\begin{array}{c}\text { Number of } \\
\text { Measurements } \\
\end{array}$} & \multicolumn{4}{|c|}{ Hardness } \\
\hline & & \multicolumn{2}{|c|}{ HRC (surface) } & \multicolumn{2}{|c|}{ HRC (core) } \\
\hline & & Average & Range & Average & Range \\
\hline 8UE Top & 8 & 40.2 & $39 \cdot 0-41 \cdot 0$ & & \\
\hline 8LW Top & 8 & 43.0 & $40 \cdot 0-45 \cdot 0$ & & \\
\hline 9ME Top & 8 & 37.5 & $34 \cdot 5-40 \cdot 5$ & & \\
\hline 9MW Top & 8 & 44.0 & $42 \cdot 5-45 \cdot 0$ & & \\
\hline $8 \mathrm{MW}$ & $5 / 5 *$ & 40.0 & $39.0-41.0$ & 40.3 & $39.7-40.7$ \\
\hline 9UE & $5 / 5$ & 43.6 & $42 \cdot 5-45 \cdot 0$ & 43.3 & $40 \cdot 7-44 \cdot 2$ \\
\hline $10 \mathrm{MW}$ & $5 / 5$ & 40.2 & $39 \cdot 0-41 \cdot 5$ & 42.7 & 42.7 \\
\hline NBS Hardened (1) & 5 & 39.6 & $38 \cdot 5-41.9$ & & \\
\hline NBS hardened (2) & $4 / 5$ & 39.0 & $38 \cdot 5-39 \cdot 5$ & 39.8 & $37.7-40.7$ \\
\hline NBS hardened (3) & $5 / 5$ & 37.5 & $36 \cdot 0-38 \cdot 5$ & 39.2 & $37 \cdot 7-39 \cdot 7$ \\
\hline NBS hardened (4) & $4 / 5$ & $40 \cdot 5$ & $40 \cdot 0-41 \cdot 0$ & 41.9 & $41 \cdot 7-42 \cdot 2$ \\
\hline NBS Regular Grade & 5 & {$[60.7] * *$} & {$[58 \cdot 9-61 \cdot 3] * *$} & & \\
\hline * surface/core & & & & & \\
\hline * Rockwell Hardness & ( HRB) & & & & \\
\hline
\end{tabular}

Microhardness Survey

Washer

Identification

$8 \mathrm{MW}$

9UE

10MW

NBS hardened (1)

NBS hardened (2)

NBS hardened (3)
Average $\mathrm{HK}_{500}$ (HRC)

$456(44.3)$

$516(48.4)$

$456(44.5)$

$457(44.5)$

$444(43.5)$

$442(43.1)$
Range HK500(HRC)

395-476 (39.5-45.5)

485-532 (46.5-49.5)

450-457 (44.0-44.5)

$323-465(32.0-45.0)$ 
Table 7.8 Chemical Composition Range of Base Materials

Percent by Weight*

\begin{tabular}{|c|c|c|c|c|}
\hline Element & $\begin{array}{r}\text { NBS Box }(a) \\
\text { Beam Channel }\end{array}$ & $\begin{array}{c}\text { Walkway Box }(\mathrm{b}) \\
\text { Beam Channel } \\
\end{array}$ & $\begin{array}{l}\text { Walkway }(c) \\
\text { Hanger Rod } \\
\end{array}$ & $\begin{array}{c}\text { ASTM A36 } \\
\text { Specification } \\
\end{array}$ \\
\hline Carbon & $0.179-0.183$ & $0.181-0.188$ & $0.159-0.200$ & $\operatorname{Max} 0.26$ \\
\hline Phosphorus & $0.012-0.013$ & $0.016-0.017$ & $0.009-0.038$ & $\operatorname{Max} 0.04$ \\
\hline Sulfur & $0.022-0.023$ & $0.016-0.017$ & $0.033-0.046$ & $\operatorname{Max} 0.05$ \\
\hline
\end{tabular}

Notes:

(a) Eight channels, two analyses per channel.

(b) Six channels, two or three analyses per channel.

(c) Two rods, one or two analyses per rod.

* Encompasses specimens 1BX4, 2BX1, 3BX1 and 2TFX4 (cf, table A7.5-1). 


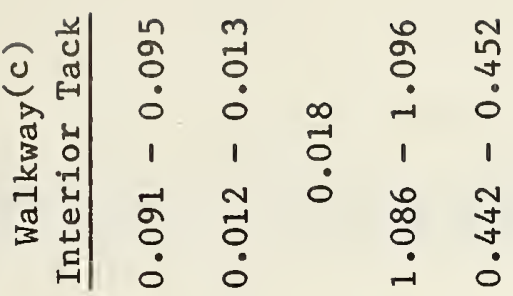

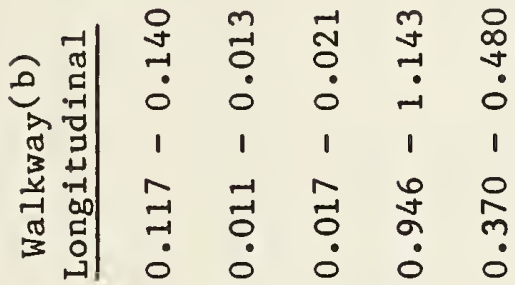

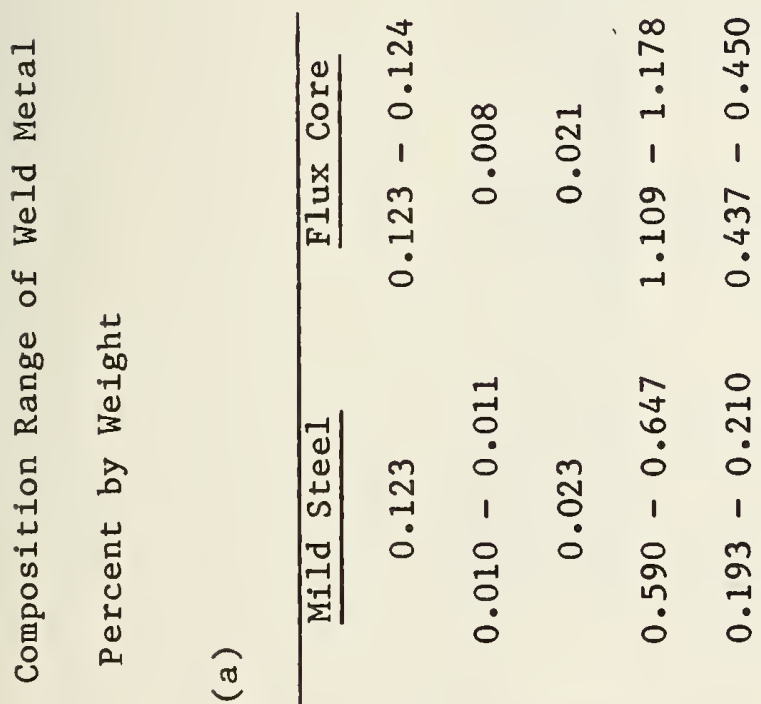

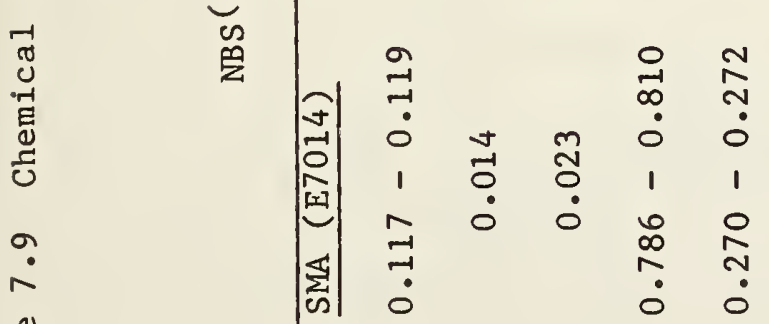

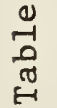




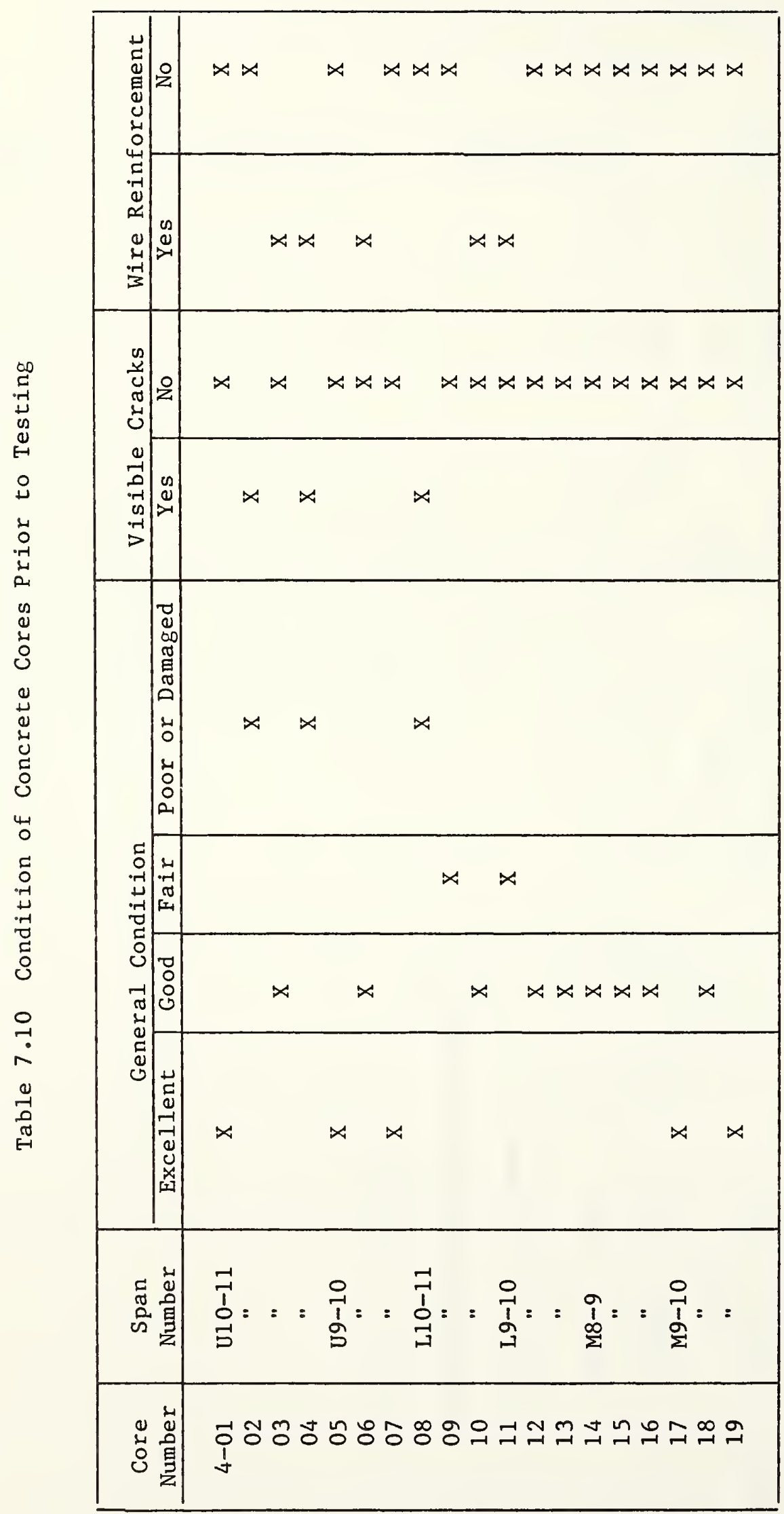


Table 7.11 Properties of Concrete Cores

\begin{tabular}{|c|c|c|c|c|c|c|c|c|}
\hline \multirow{3}{*}{$\begin{array}{c}\text { Core } \\
\text { Number } \\
\end{array}$} & & & \multicolumn{4}{|c|}{ Unit Weight ( $p c f)$} & \multirow{3}{*}{$\begin{array}{c}E^{(a)} \\
\text { (psi) }\end{array}$} & \multirow{3}{*}{$\begin{array}{l}f_{c}^{\prime}(b) \\
(p s i)\end{array}$} \\
\hline & \multicolumn{2}{|c|}{ Thickness (in) } & \multicolumn{2}{|c|}{ Concrete } & \multicolumn{2}{|c|}{ Topping } & & \\
\hline & Concrete & Topping & Air Dry & Oven Dry & Air Dry & Oven Dry & & \\
\hline $4-01$ & 3.55 & 0.35 & --- & -- & --- & $-\infty$ & $2.08 \times 10^{6}$ & 5,450 \\
\hline 02 & -- & 0.60 & 114.0 & 109.0 & 128.3 & 125.8 & -- & $-\infty$ \\
\hline 03 & 3.43 & 0.53 & 113.4 & 107.8 & 127.8 & 125.8 & -- & -- \\
\hline 04 & 3.44 & 0.44 & 114.6 & 109.0 & 101.5 & 100.9 & - & --- \\
\hline 05 & 3.38 & 0.67 & -- & ---- & --- & --- & 1.78 & 4,940 \\
\hline 06 & 3.43 & 0.53 & 114.0 & 109.6 & 128.3 & 122.7 & -- & --- \\
\hline 07 & 3.43 & 0.68 & --- & --- & --- & --- & 1.96 & 5,110 \\
\hline 08 & 3.25 & -- & 118.4 & 112.1 & --- & --- & -- & --- \\
\hline 09 & 3.16 & -- & 114.6 & 109.0 & --- & --- & -- & -- \\
\hline 10 & 3.18 & - & -- & --- & -- & --- & 1.88 & 5,140 \\
\hline 11 & 3.24 & 0.38 & 110.9 & 105.9 & 135.2 & 133.9 & -- & -- \\
\hline 12 & 3.35 & 0.41 & --- & -- & --- & --- & 1.81 & 4,790 \\
\hline 13 & 3.45 & 0.38 & --- & -- & --- & --- & 1.75 & 4,440 \\
\hline 14 & 3.08 & 0.58 & 109.0 & 104.0 & 104.0 & 99.7 & -- & --- \\
\hline 15 & 2.92 & 0.73 & 113.4 & 107.8 & 103.4 & 99.1 & -- & --- \\
\hline 16 & 2.91 & 0.68 & --- & --- & --- & --- & 1.75 & 4,550 \\
\hline 17 & 3.59 & 0.72 & 112.8 & 107.2 & 105.9 & 101.5 & -- & --- \\
\hline 18 & 3.45 & 0.84 & --- & --- & -- & -- & 1.90 & 5,520 \\
\hline 19 & 3.47 & 0.78 & -- & -- & -- & --- & 1.80 & 5,290 \\
\hline
\end{tabular}

(a) Secant modulus at 40 percent of $f_{c}^{\prime}$

(b) Reduced to nearest $10 \mathrm{psi}$ in accordance with ANSI/ASTM Standard C $42-74$.

1 in $=25.4 \mathrm{~mm}$

$1 \mathrm{pcf}=16.02 \mathrm{~kg} / \mathrm{m}^{3}$

$1000 \mathrm{psi}=6.9 \mathrm{MPa}$ 

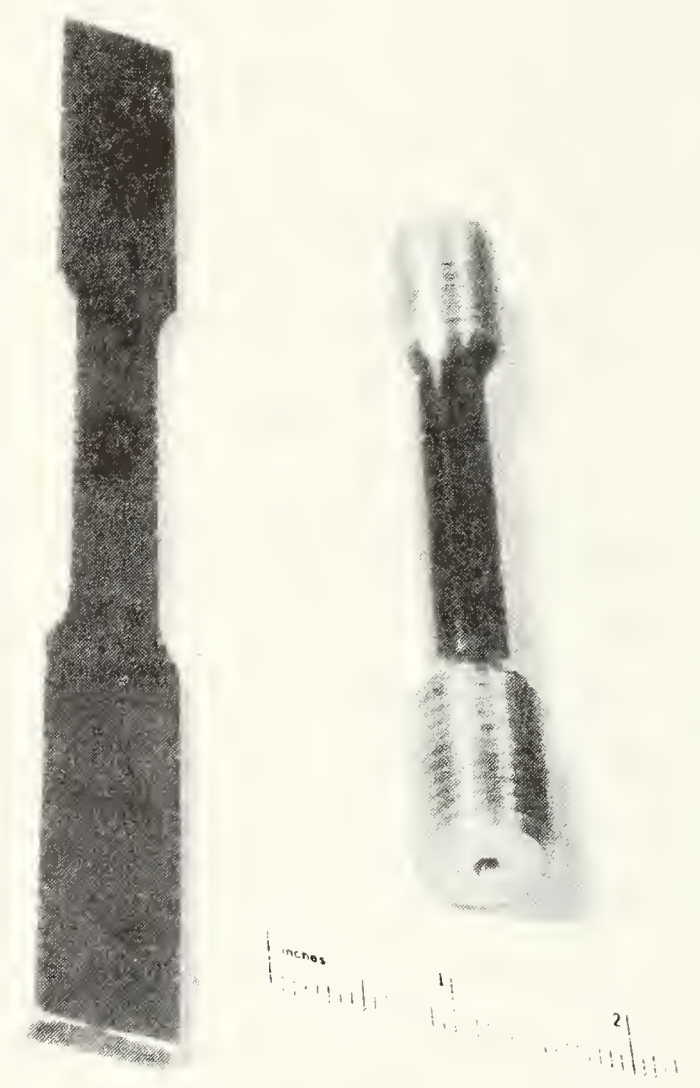

Figure 7.1 ASTM E8-81 tension test specimens. The rectangular specimen on the left was obtained from channel material and the round specimen on the right was obtained from hanger rod material. 


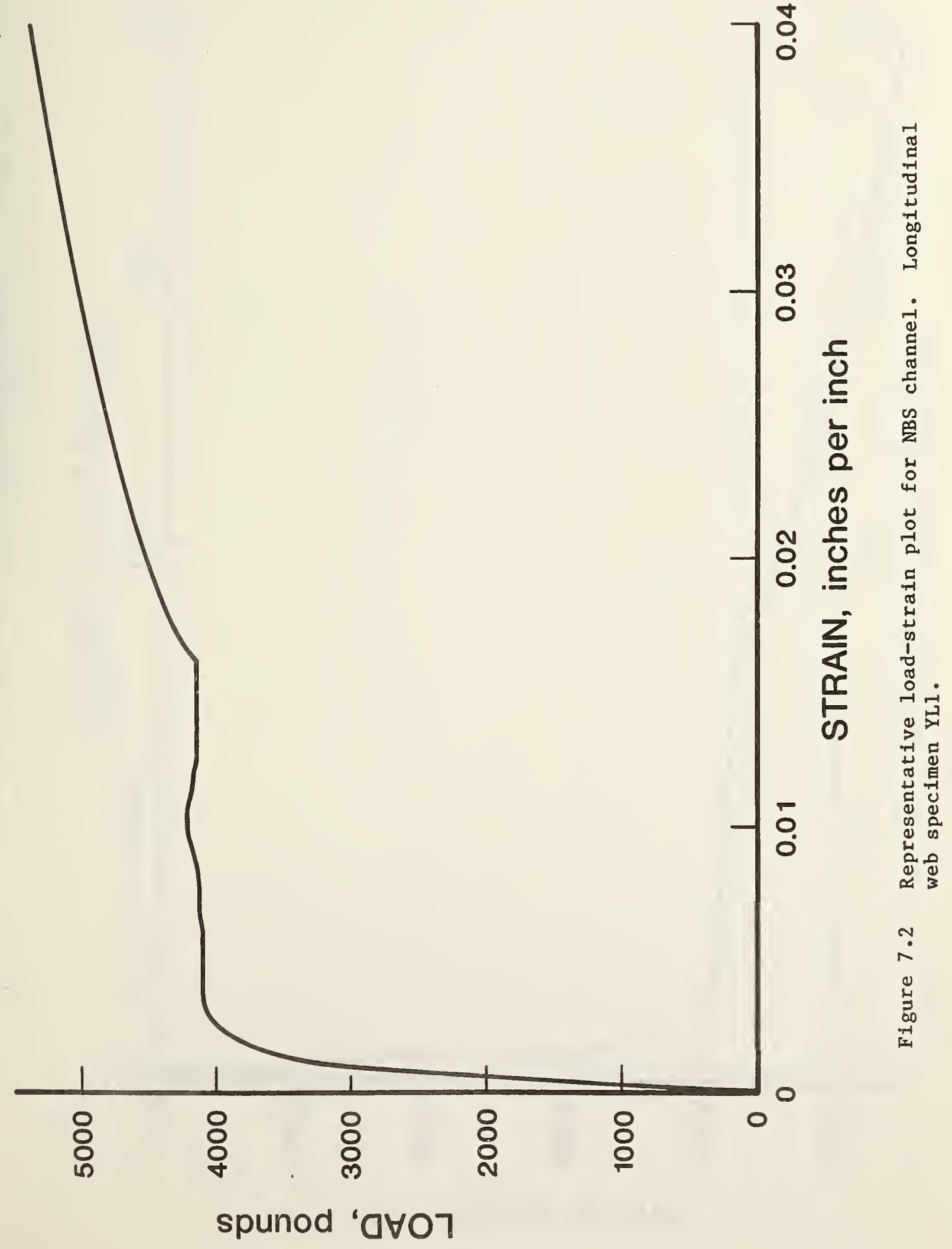




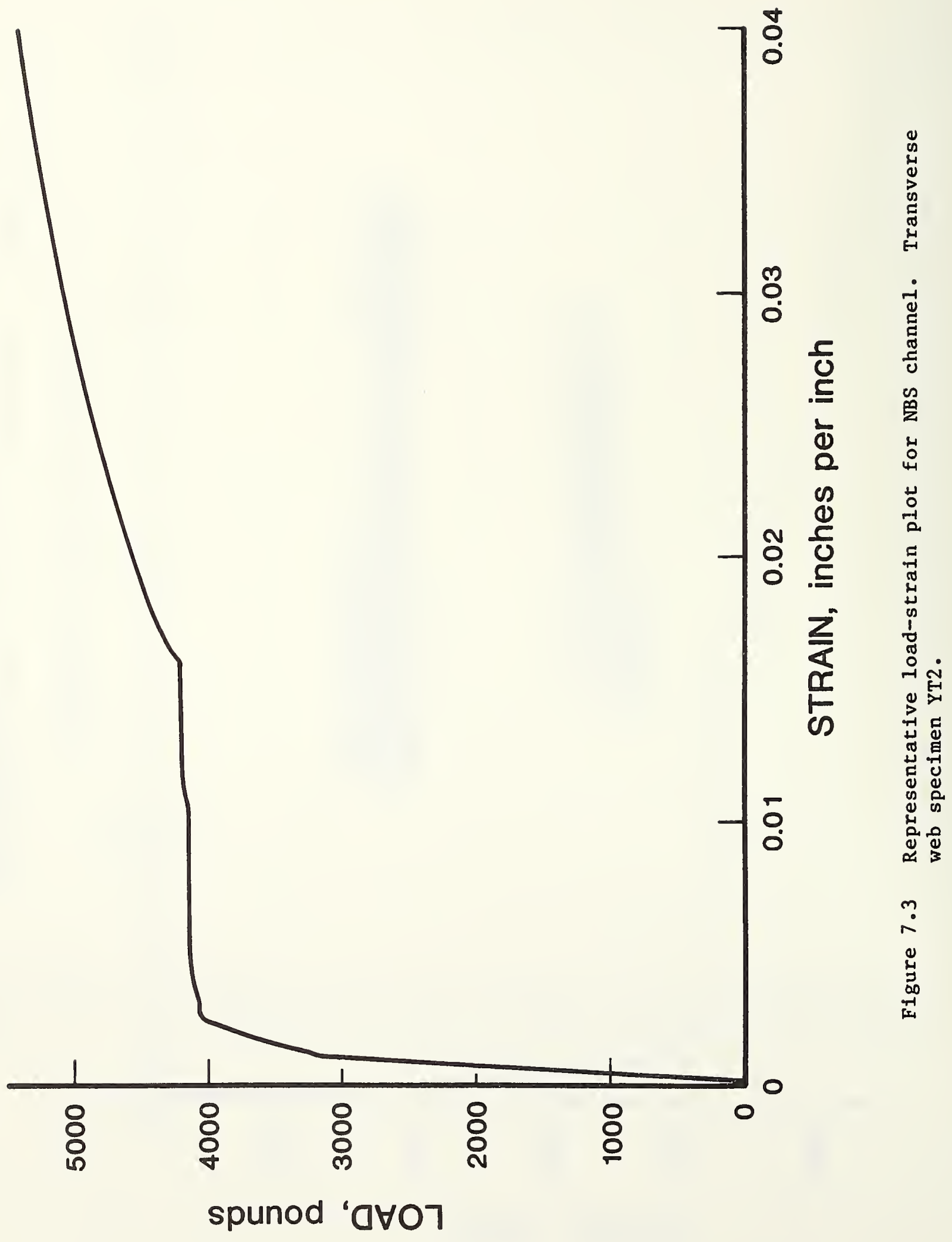




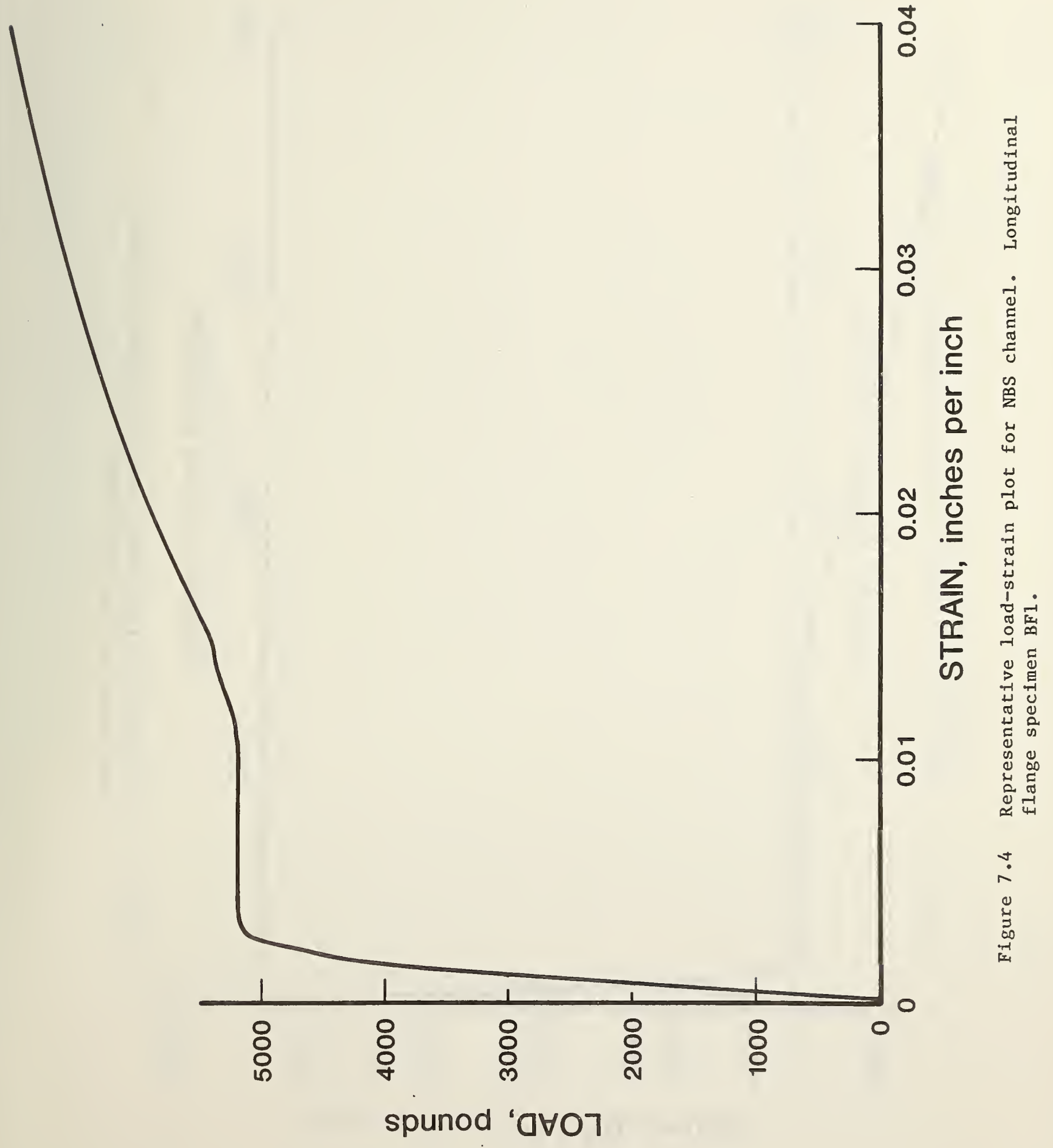




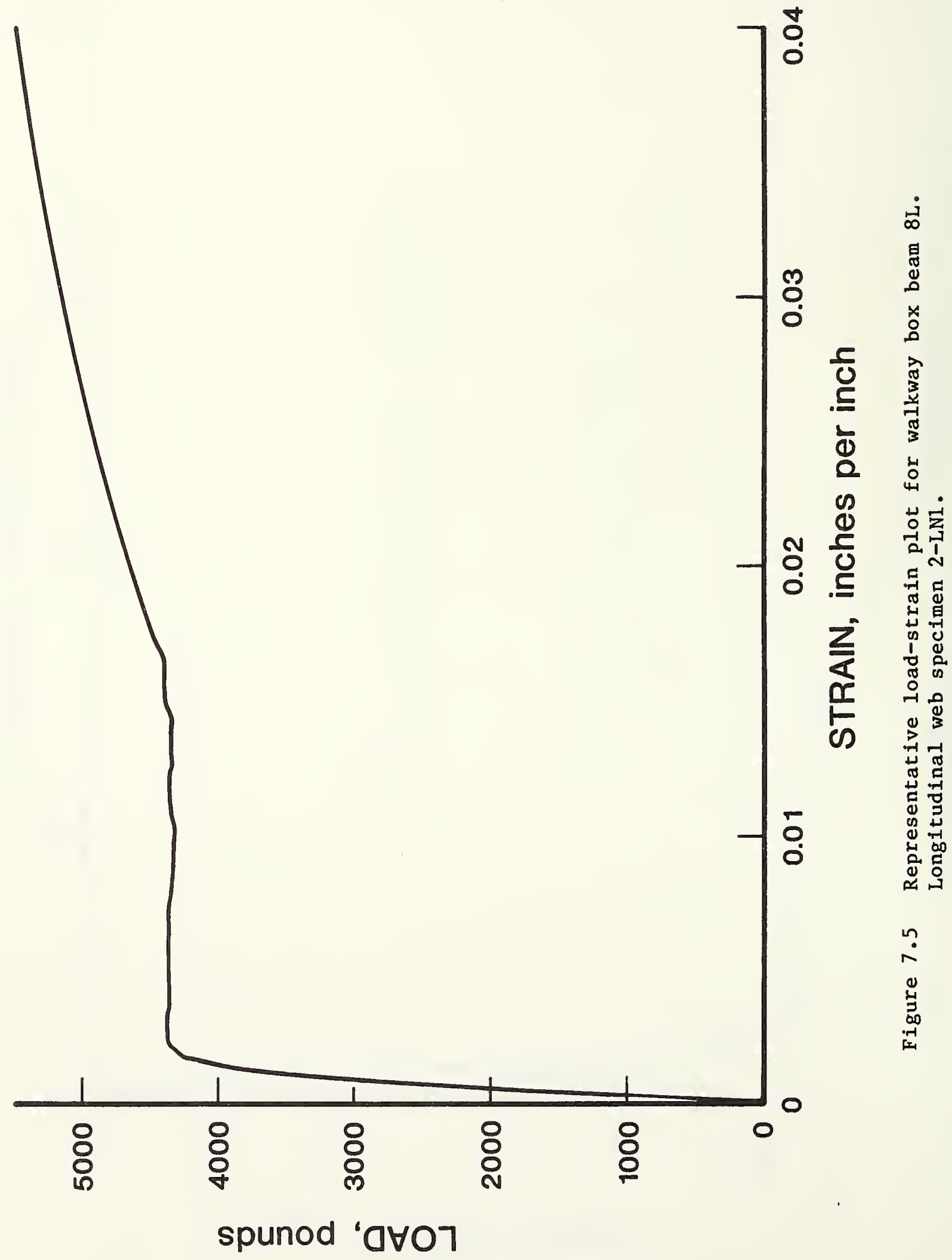




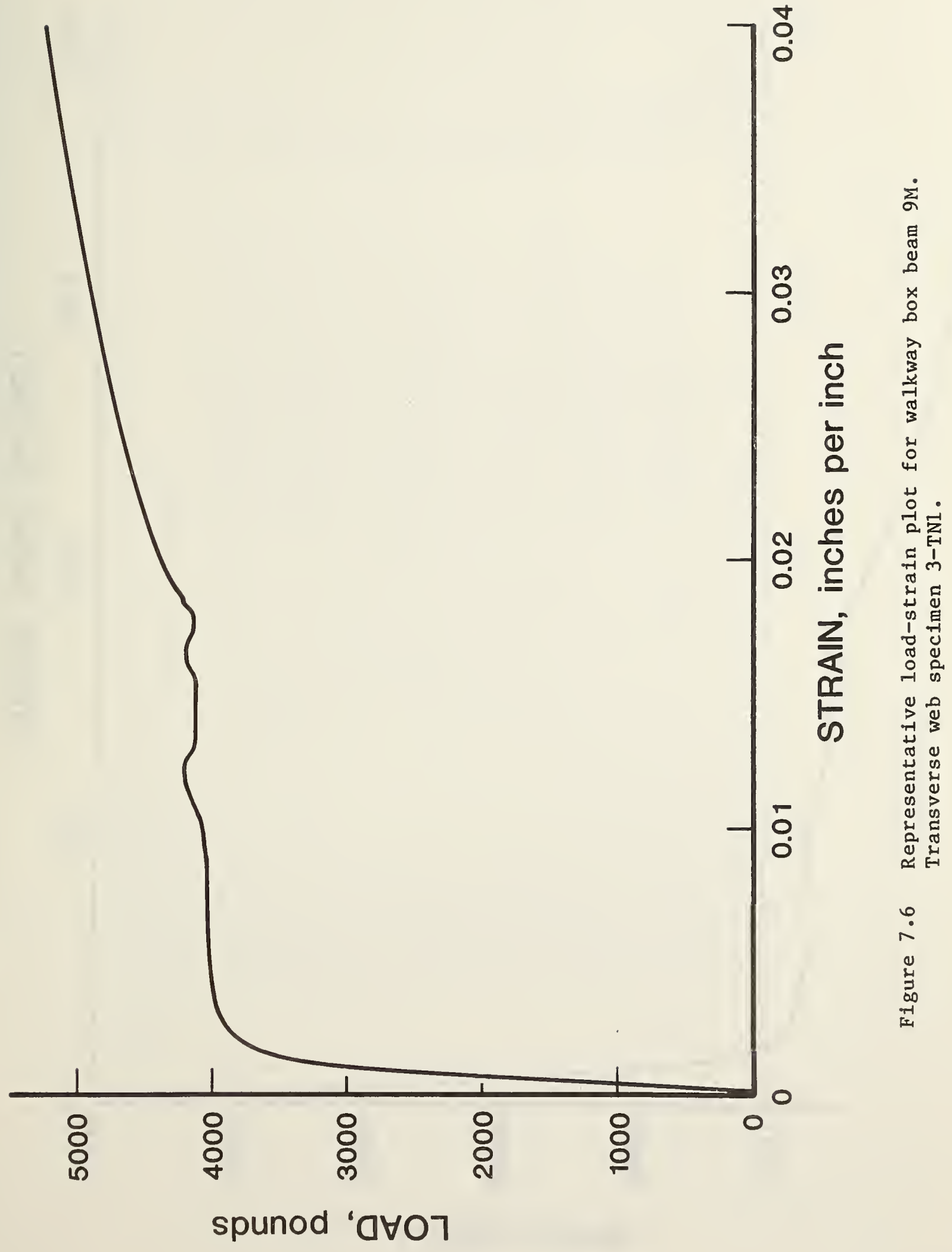




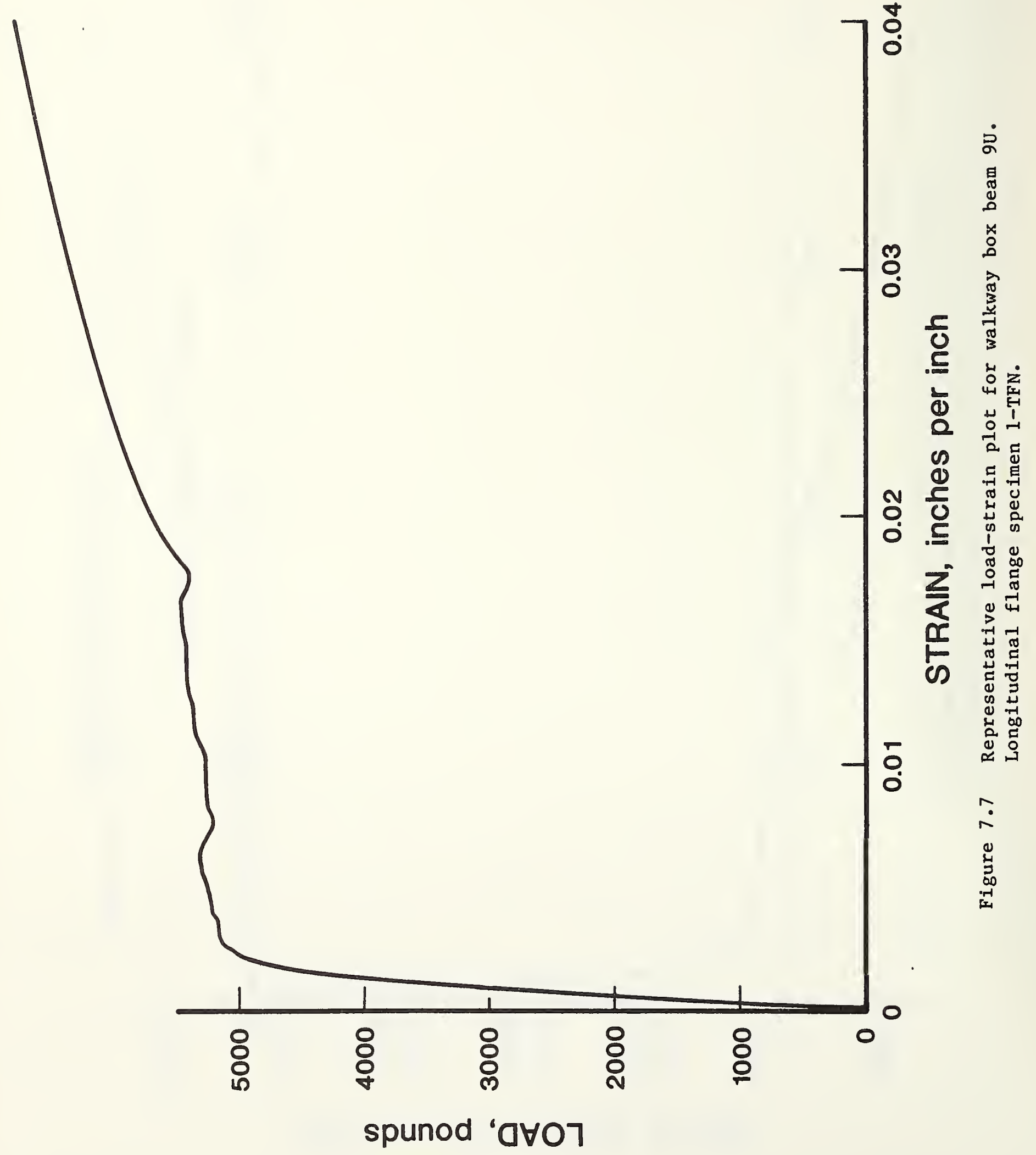




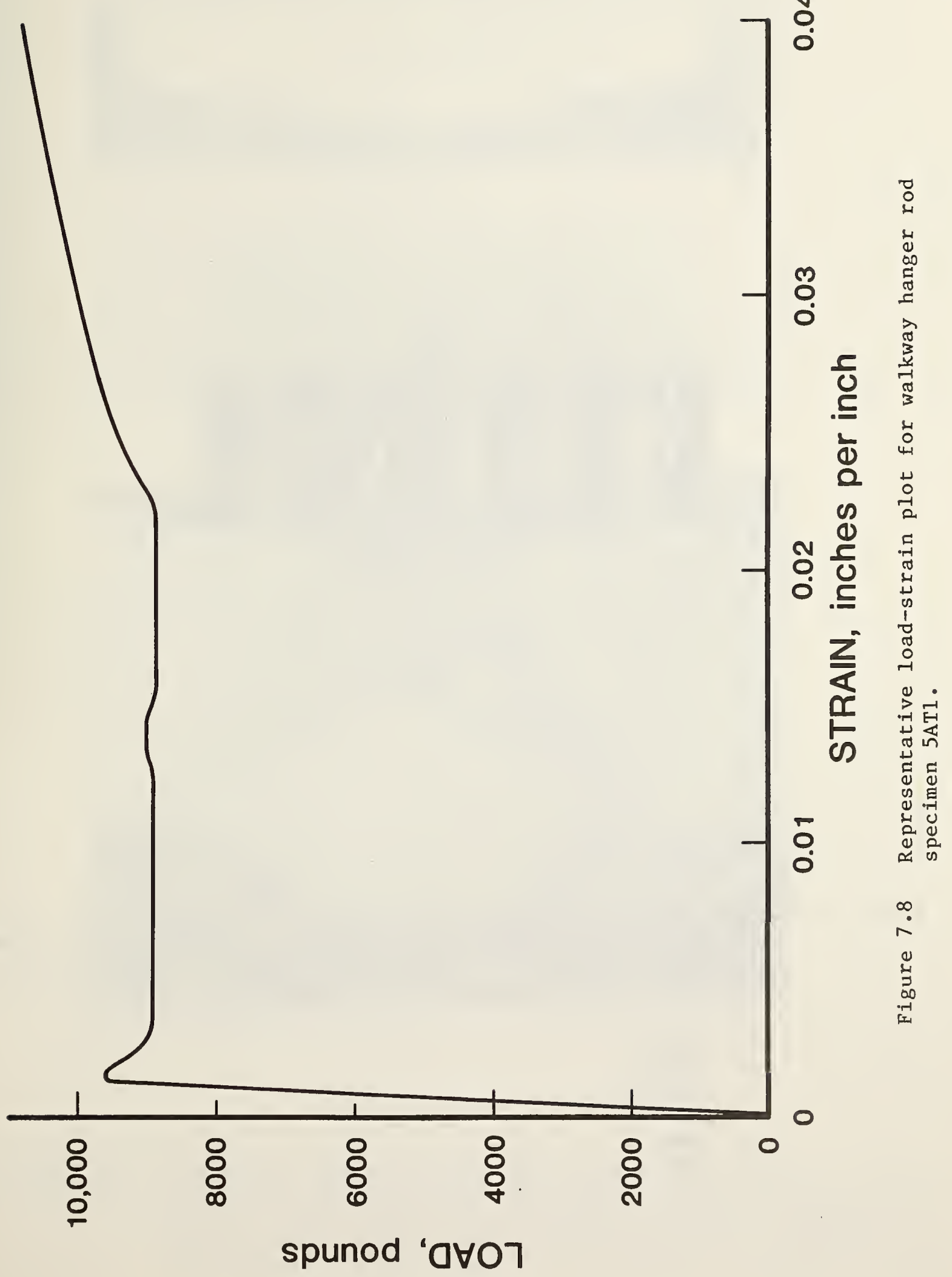



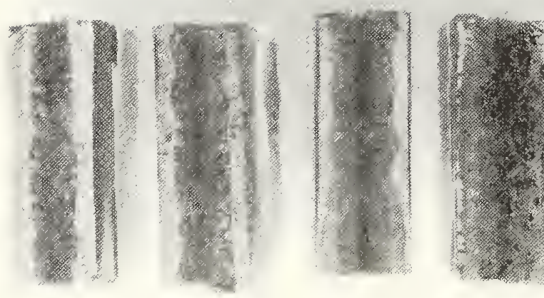

2

\section{3}

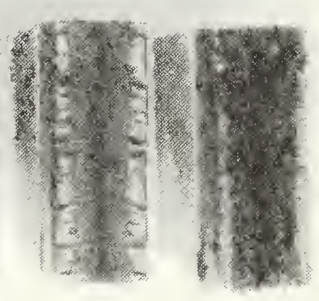

$5 \quad 6$

Figure 7.9 Fracture surfaces of walkway weldment tensile specimens. Both halves of each fracture are shown. The bright regions represent fracture and indicate the depth of weld penetration. Specimen key is as follows. $\mathrm{X} 1$

1. $1 \mathrm{BX} 3 \mathrm{~W} 2$

2. $1 \mathrm{BX} 3 \mathrm{~W} 4$

3. $2 \mathrm{BX} 3 \mathrm{~W} 2$

4. $2 \mathrm{BX} 3 \mathrm{WW}$

5. $3 \mathrm{BWW}$

6. $3 B W 1$ 


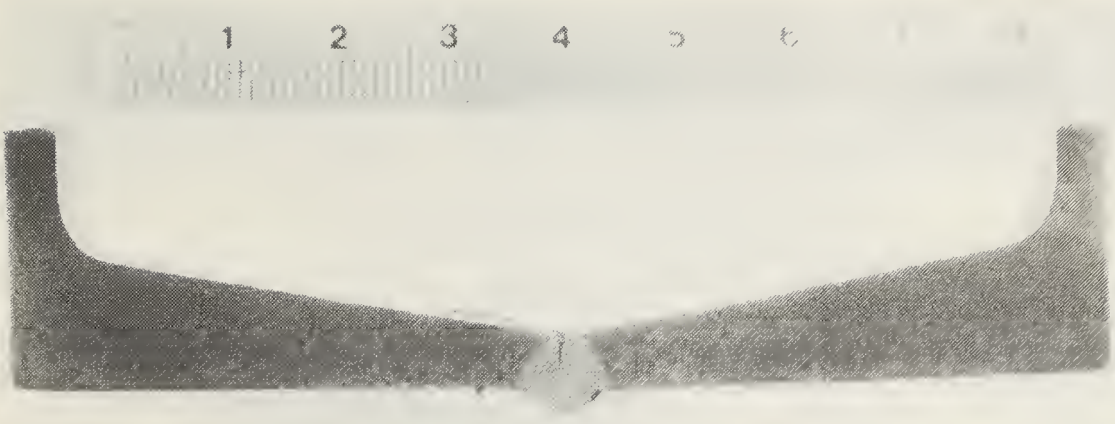

a

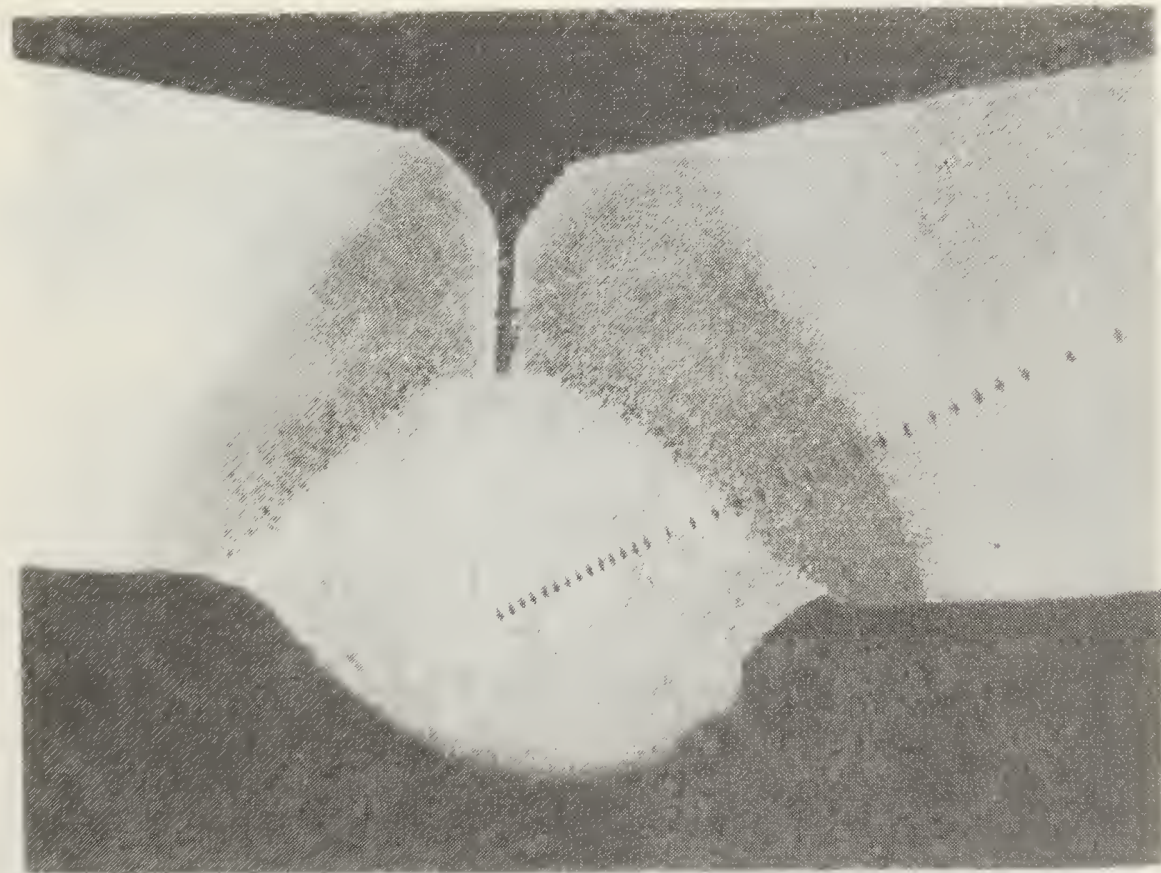

$\mathrm{b}$

Figure 7.10 Transverse section through NBS weldment IC welded by the GMAW process. Dark regions separating weld metal from flange base metal are heat-affected portions of base metal. Aligned indentations are microhardness measurements. a, Xl; b, X8 1/2 

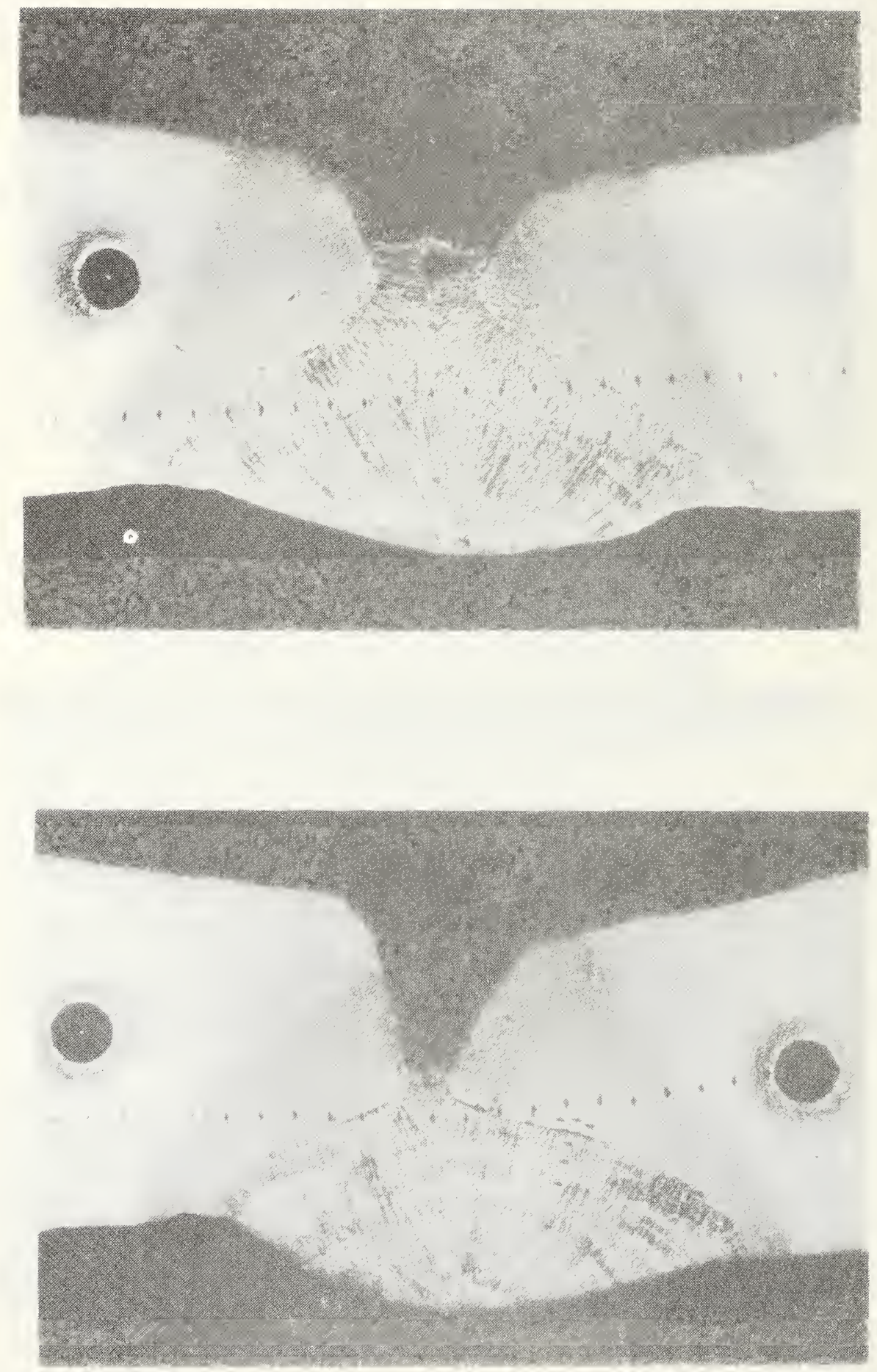

Figure 7.11 Cross sections through weld regions of box beam 9U (NBS 1). Sections were separated about 7 in (180 mm) along the beam length. Microhardness indentations traverse the surfaces. $\times 81 / 2$ 

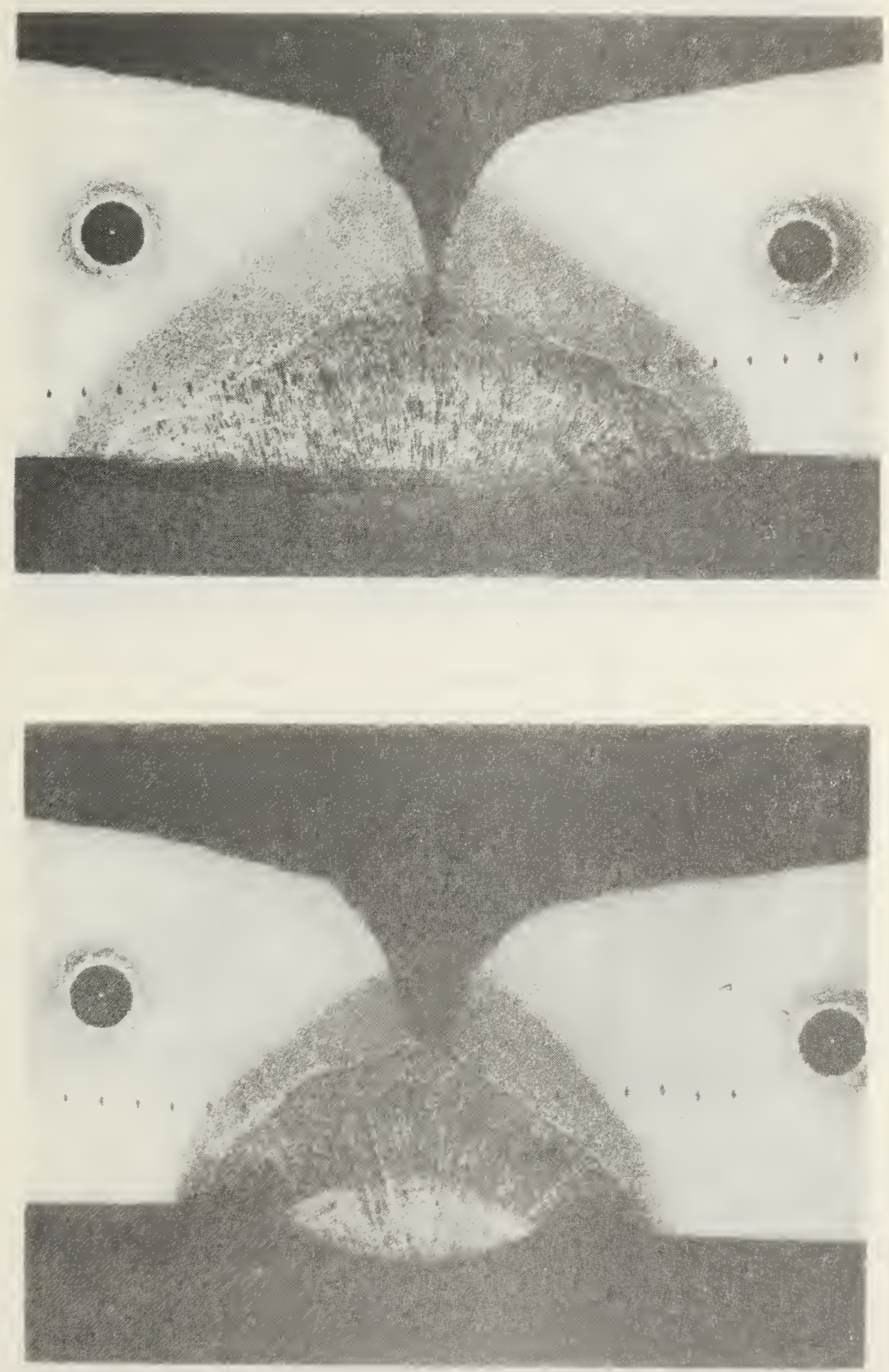

Figure 7.12 Cross sections through weld regions of box beam 8L. Sections were separated about 7.5 in (190 mm) along the beam length. Microhardness indentations traverse the surfaces. X8 $1 / 2$ 

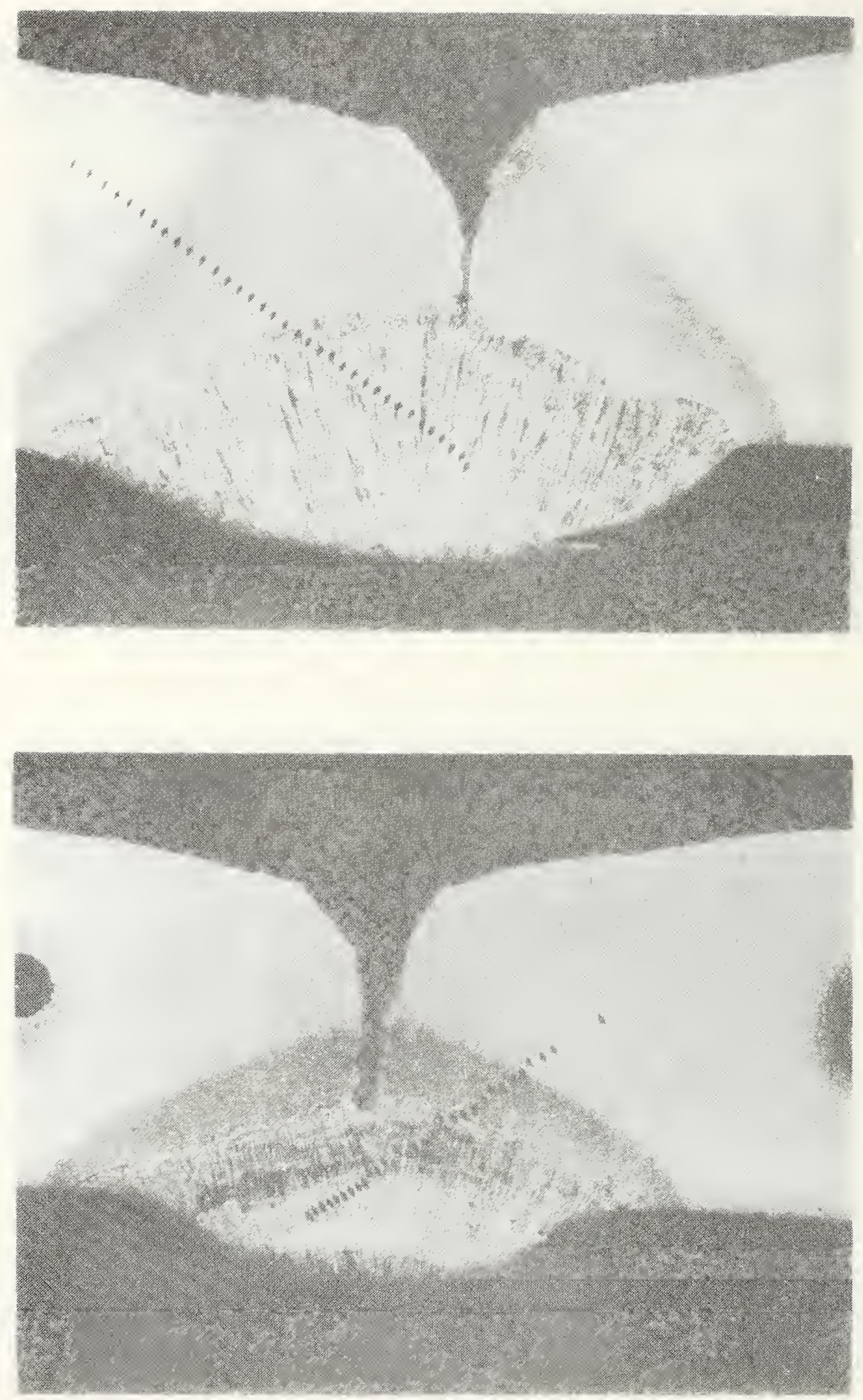

Figure 7.13 Cross sections through weld regions of box beam 9M. Sections were separated about 7.5 in $(190 \mathrm{~mm})$ along the beam length. Microhardness indentations traverse the surfaces. X8 $1 / 2$ 


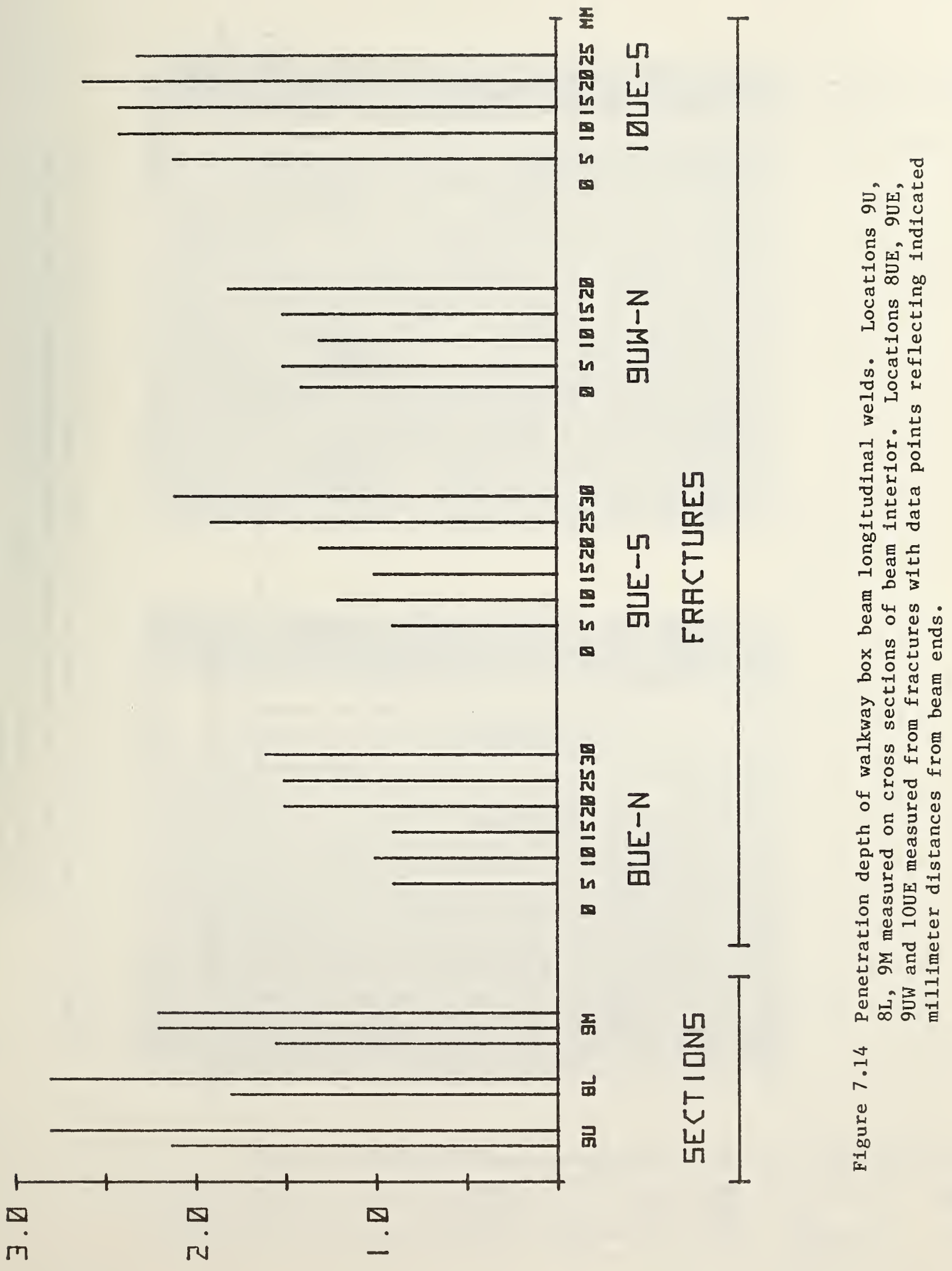

(WW) HLd JO NDI LUyLJN3J 


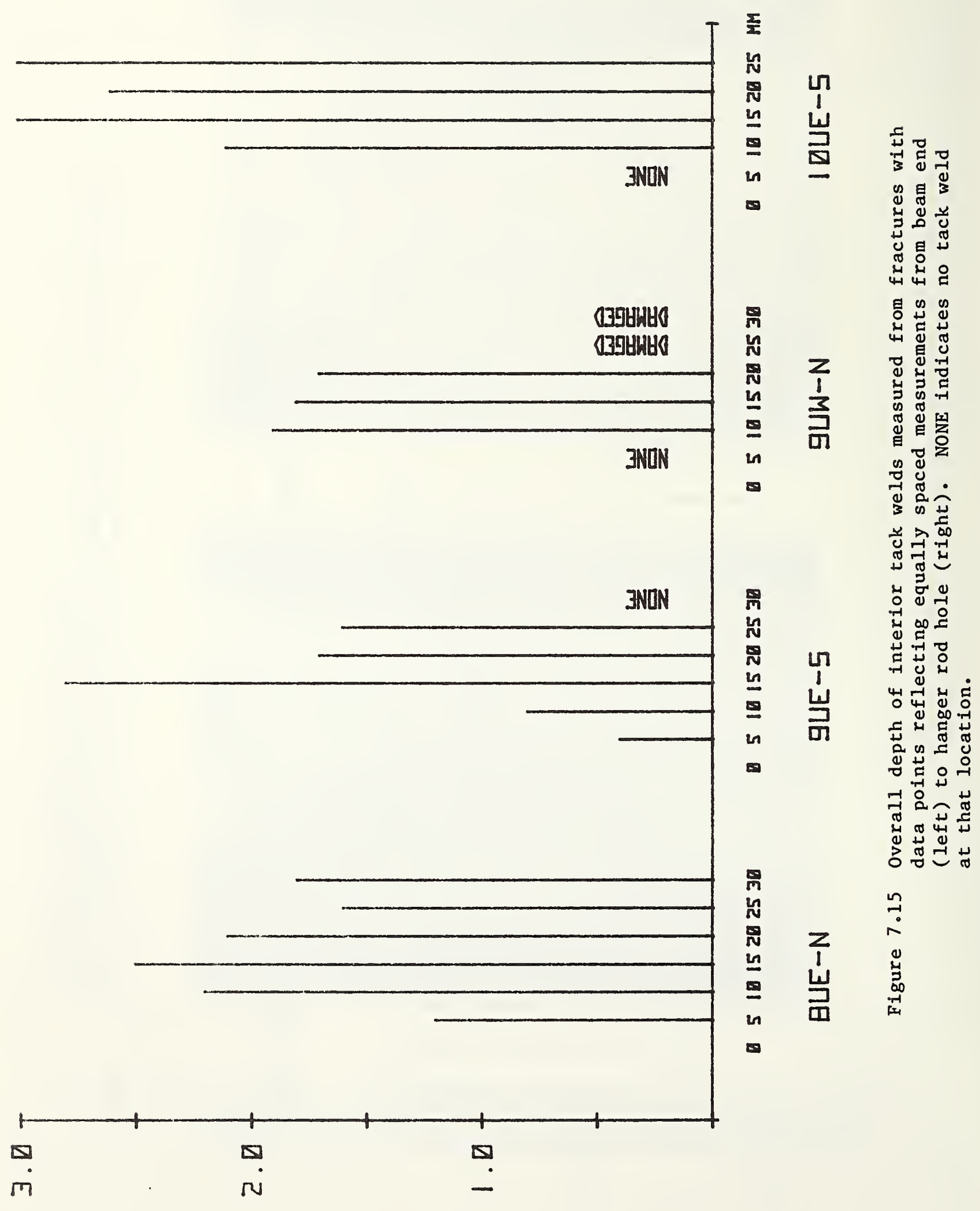

(WW) HId JO NDILHULJNJd 


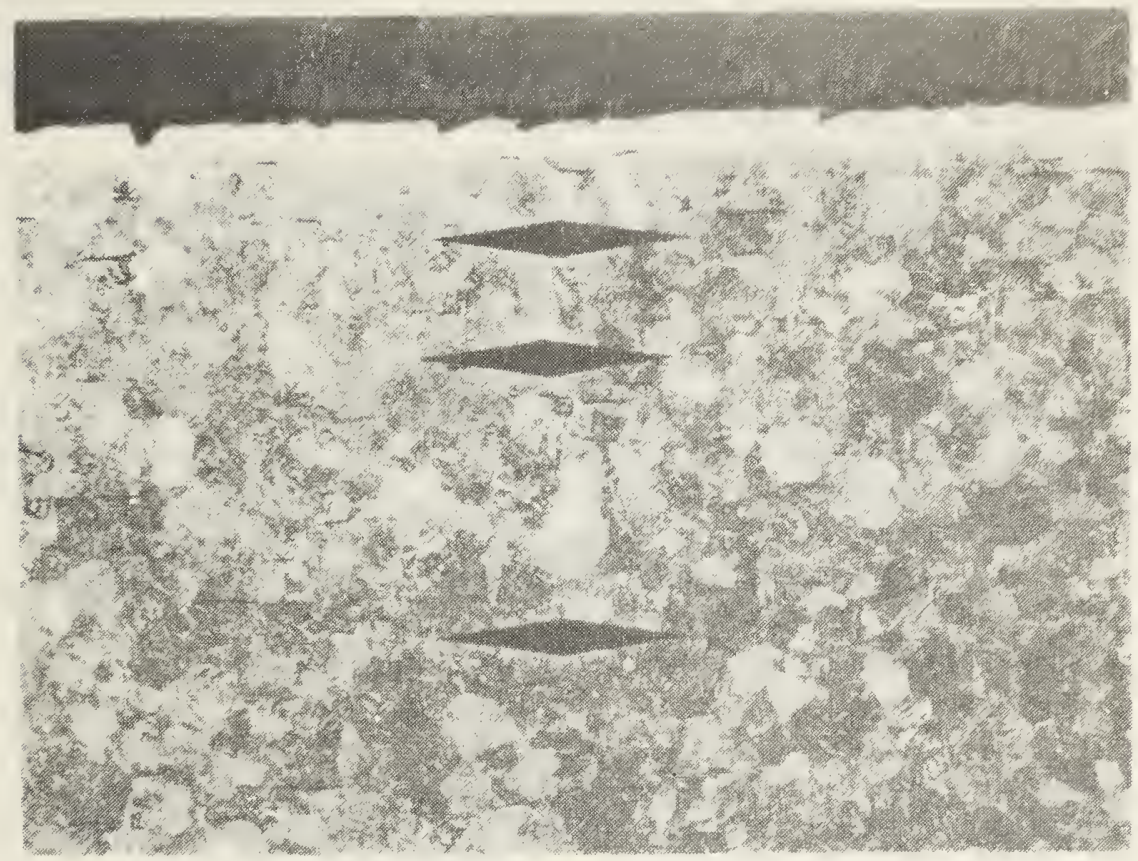

a
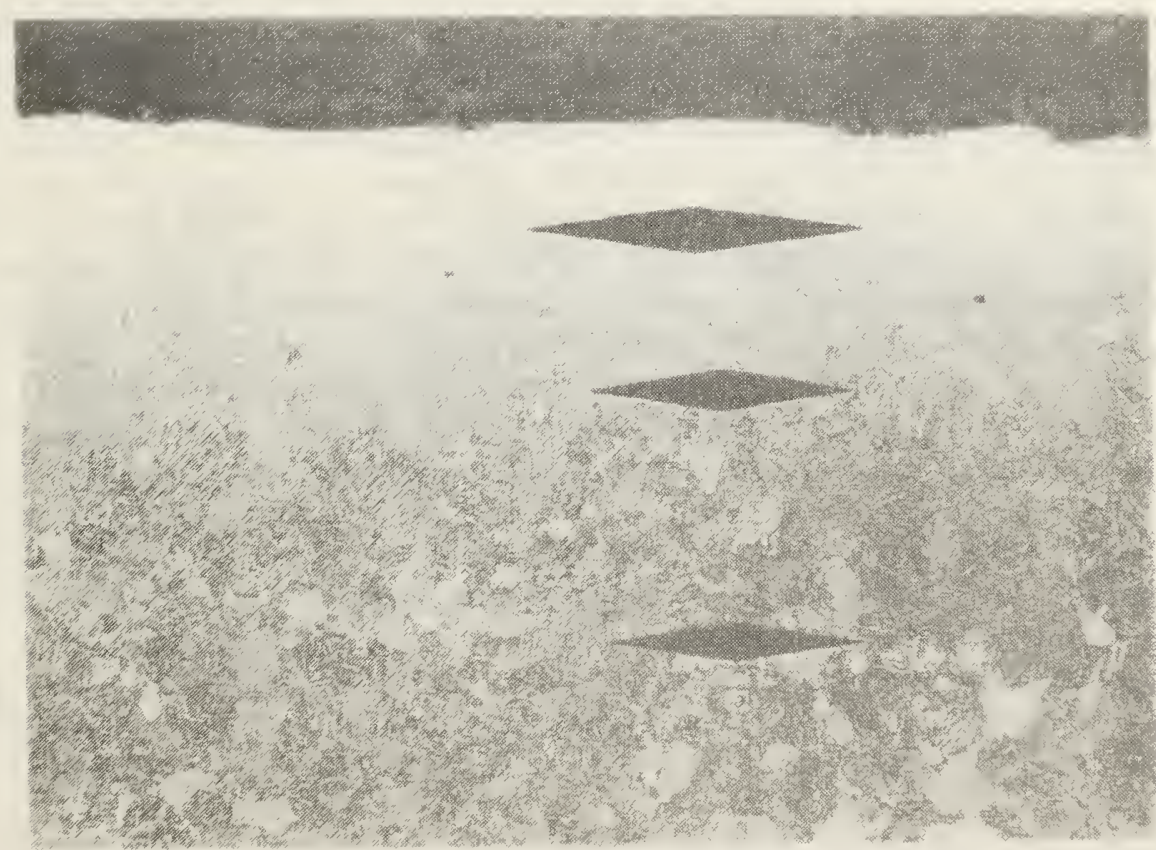

b

Figure 7.16 Microstructures of washers from 9MW (NBS specimen 3), (a), and of hardened washer used in NBS tests, (b). Whiter layer near surface (top of illustrations) is decarburized layer. Interior structure is tempered martensite. Etchant: Picral. X200 


\section{FRACTOGRAPHIC ANALYSIS}

\subsection{INTRODUCTION}

This chapter describes the specimen preparation and application of optical and scanning electron microscope (SEM) fractography to relate the microstructural features of fractured or deformed portions of the walkway structure to the mode of failure.

Section 8.2 reviews studies conducted on fractures of longitudinal welds produced during testing of box beams fabricated in the NBS shops. Replica and metal specimen preparation for fractography are discussed. Experience was gained in replicating fractures under conditions similar to those in the field and data were obtained which allowed comparison of the macroscopic aspects of the fractures with those of the actual walkway structure.

Section 8.3 describes studies of fracture surface replicas from the walkway debris.

Section 8.4 reviews the results obtained from direct optical and scanning electron microscopy on selected fractures removed from the walkway box beams.

Section 8.5 summarizes fractographic analysis results.

\subsection{SPECIMEN PREPARATION AND NBS FRACTURE RESULTS}

Procedures used to replicate the fracture surfaces have been described in section 5.5. The replication technique is capable of reproducing details of the fracture surface with reasonable fidelity, provided that intimate contact is achieved between the replication media and the surface (figure 8.1). Failure to achieve contact produces artifacts in the replica that must be discounted in the analysis. The replica is a mirror image of the original surface and may have a different sense of image contrast--in one case the image contrast is due to both topography and composition variation ( $8.1 \mathrm{a})$ and in the other the image contrast is due to topography alone ( $8.1 \mathrm{~b})$. Selection of a specific replica from each surface for study was based on visual evaluation of the largest intact replica contact area and on the least amount of embedded rust and other debris. The replicas were trimmed of excess plastic and attached to a 1 in $(25 \mathrm{~mm})$ diameter SEM support stub by a small piece of doublesided adhesive tape. Three point contacts of either carbon or silver paint were then made between the SEM stub and the replica corners to increase their support and to provide electrical contact to the sputter coating later applied to the replicas. A replica identification was also inscribed on the stub at this time.

Replicas were sputter coated by placing three replica-mounted stubs on the pedestal of a DC sputter coating unit. The coater electrode was a circular planar magnetron triode having a pulse mode deposition capability which allowed a 5 second $\mathrm{ON}-\mathrm{OFF}$ cycle. This maintained specimen temperature below $25^{\circ} \mathrm{C}$. After reducing chamber pressure to 30 millitorr ( $40 \mathrm{kPa})$, argon gas was bled into the system to produce a stable pressure of 95 millitorr $(127 \mathrm{kPa})$. A 
deposition time of 5 to 7 minutes with a 60 Au-40 Pd alloy at a target-tospecimen distance of 1 in $(25 \mathrm{~mm}$ ) and a plasma current of $15 \mathrm{~mA}$ was used. These conditions produced an electrically conductive and thermally protective film allowing examination and SEM photomicrography at magnifications ranging from $5 \mathrm{X}$ to $2,000 \mathrm{X}$. Stereo pair views of the fracture surfaces and washer contact areas were made by tilting the replicas approximately 5 to 6 degrees between the first and second exposure from a nominal tilt angle of 0 degrees. These were used for the analysis of the spatial relationships of the topographic features.

Metal specimens for direct SEM examination were cleaned in an ultrasonic tank containing acetone or ethyl alcohol. The cleaning solution was changed as required to remove all water, oil, and loosely adhering debris. These specimens were then mounted on a spring-clip holder stub for SEM observation. All residual magnetization was removed by passing the mounted specimens through a demagnetizing coil several times in different directions.

Figure 8.2 illustrates that the gross features of the fracture in the lower longitudinal weld between the outer hanger rod hole and beam end of box beams tested to failure were similar, regardless of whether the beam had been fabricated at NBS or had been obtained from the walkway debris. Rounded and piping porosity are evident in both fractures. The sharply delineated weld region in these figures indicates the absence of rust on the freshly fractured surfaces.

\subsection{WALKWAY FRACTURE REPLICAS}

Replicas from the walkway fracture and washer contact surfaces have been described in section 5.5 and are listed in table 5.13.

\subsubsection{General Observations}

Rounded gas porosity (both large and fine) and piping (elongated) porosity similar to that illustrated in figure 8.2 were evident in the fracture areas of the interior tack and exterior longitudinal welds at locations 8UE, 9UE, 9UW, and 10UE. Fractographic examination indicated that these flaws did not serve preferentially as crack initiation sites. It appears that, in the case of the lower exterior welds, cracks initiated at the root of the weld and propagated through the porosity (figure 8.3). While many of the replicated sections provided reasonable resolution of the fractographic features, figure 8.4 illustrates that in some cases a very tight oxide layer had modified the original fracture surface.

\subsubsection{Box Beam Longitudinal Welds}

Different textures in the fracture topography provided evidence that cracks had existed in the weld roots in the regions between the hanger rod holes and in the regions between the outer hanger rod holes and beam ends prior to gross weld failure at the time of collapse. Figures $8.5(\mathrm{a}-\mathrm{c})$ illustrate the appearance of several such regions in the exterior longitudinal welds at locations 9UW, 9UE and 8UW. 
As opposed to the lower exterior welds, fracture in the lower interior tack welds initiated at the weld surface and propagated towards the weld root. An example is shown for location 9UE in figure 8.6. Topographic features developed by momentary crack front arrest and changes in crack propagation direction are helpful in defining the crack path (figure 8.3 ), while interpretation of microdimple patterns in the ductile fracture are useful in defining the point of origin. These observations suggest that the crack observed in the tack weld. at location $8 \mathrm{MW}$ during the site investigation (figure 5.18a) indicated an initial stage of weldment failure. Fractures in the lower exterior longitudinal welds were found to initiate at the root of the weld with the crack front propagating towards the outside surface of the box beam where the shear 1 ip is observed. These observations are consistent with deflection of the flange regions upward during deformation prior to structural collapse.

No indications of fatigue failure were observed. The predominant failure mode in the weld metal was ductile rupture, although small areas of cleavage were observed in the vicinity of the weld center line at locations 9UW and 10UE (figure 8.7 ).

\subsubsection{Washer/Nut Contact Area}

Two regions of washer contact were typically observed on the lower surface of the box beam flanges. The outermost region contains imprints of the washer edge and shows relatively shallow striations reflecting slippage of the washer in the initial deformation phase. Transition to a more intensely abraded region was observed nearer the hanger rod hole (figure 8.8) for location 9UE.

Evidence for a slip-stick mode of failure in which the washer and/or nut combination was periodically arrested was observed in the deeply abraded region at all locations examined. One indication of this mode can be seen at location 9UE (figure 8.8 ), while multiple indications can be seen at location 10UE (figure 8.9). This indicates that pull-through of the washer/nut assembly proceeded in a slip-stick manner, with the hardened steel washer digging into the comparatively soft steel of the flange.

Washers at locations $9 U \mathrm{UE}$ and $8 \mathrm{UE}$ were missing after the collapse. However, figures 8.8 and 8.10 provide clear evidence that washers had been installed at both locations.

\subsubsection{Washers}

As noted in chapter 6 , some washers obtained from the walkway debris fractured in the course of NBS beam tests while hardened washers purchased by NBS did not fracture under similar test conditions. Examination of the fracture surface of a walkway washer at location 9MW that failed during an NBS test conducted on walkway box beam 9M revealed that the washer had failed in a predominantly brittle manner. This is evidenced by the dominant intergranular and cleavage modes of failure illustrated in figure $8.11 \mathrm{~b}$. This is a magnified photomicrograph of the central region of the fracture surface shown in figure 8.11 . By contrast, figure $8.11 \mathrm{c}$ shows predominantly ductile failure at the surface decarburized layer of the washer. 
Prominent elongated MnS inclusions can be observed on the fracture surfaces in figures $8.11 \mathrm{a}$ and $8.11 \mathrm{c}$. Hardened washers bent around a direction paralle1 to such inclusions could be expected to display low ductility.

Other comparisons were made of the fracture characteristics of the walkway and NBS washers. Walkway washers included for study were identified as NBS 11B, 13B and 15B. Their original locations are described in table 5.13. Two randomly selected hardened washers purchased by NBS for in-house studies were also included. These are designated NBS 2 and 3 . These washers were initially intact and were fractured by bending to provide surfaces for examination. In addition, a section of a walkway washer that fractured into two pieces during an NBS shortbeam test on walkway box beam $9 \mathrm{M}$ was also included. This latter washer was designated $\mathrm{KCl}$ to correspond to the designation of the test in which it fractured (chapter 6). Photomicrographs of the fractured surfaces of some of these washers are shown in figures 8.12 to 8.15 . Macroscopic features are illustrated by low magnification views while the microscopic features at mid-thickness are detailed in higher magnification views.

These figures show that the fracture characteristics of the walkway and NBS washers were basically similar. Both contained elongated stringers of MnS (figures $8.12 \mathrm{a}$ and $8.14 \mathrm{a}$ ). Fracture characteristics of the walkway and NBS washers varied from predominantly ductile (figures 8.12 and 8.14 ) to predominantly intergranular (figures 8.13 and 8.15 ). However, the walkway washers displayed a higher percentage of intergranular fracture.

\subsubsection{Clip Angle Fillet Welds}

Replicas taken from the failed clip angle fillet weld surfaces at location 9UE indicated ductile failure and that: a) the bottom fillet weld failed primarily by shear normal to the box beam axis, b) the vertical side fillet weld failed by shear with the top weld acting as a hinge, and c) the top fillet weld failed primarily in tension. Figure 8.16 illustrates that failure of the top weld initiated at the lower edge (location A), propagated upward, and terminated at a shear lip at the upper edge (location $C$ ).

\subsection{DIRECT ANALYSIS OF WALKWAY BOX BEAM FRACTURES}

\subsubsection{Procedures}

As has been noted in chapter 5, one half of the lower fracture surfaces at the following box beam-hanger rod connections were removed from the debris for direct optical and SEM fractographic analysis:

$$
\begin{array}{r}
\text { 8UE - north half } \\
9 U E \text { - south half } \\
9 U W \text { - north half } \\
\text { 10UE - south half }
\end{array}
$$

Each specimen consisted of a section of the bottom flange cross cut to the flange fracture surface, then cut $41 / 4$ in (108 mm) inward from the beam end 
along the web toe of the fillet as indicated on figure 8.17. Two layers of duct tape were applied to the fracture surfaces for protection prior to cutting. Upon delivery to the NBS laboratories the duct tape was removed, the specimens were cleaned with paint thinner, rinsed in petroleum ether and photographed. A third cut (figure 8.17) was then made with a jeweller's saw. Sections containing the fracture surfaces from the beam end to the outer hanger rod hole were then prepared for fractographic analysis by ultrasonic cleaning under acetone.

\subsubsection{Results}

Figures 8.18 and 8.19 illustrate the overall appearance of the 1ower longitudinal weld fractures between the outer hanger rod hole and beam end at locations 9UE, 9UW, 8UE and 10UE, respectively. Figures 8.20 and 8.21 illustrate the weld fractures between the two hanger rod holes running from the outer hole to cut 非 (figure 8.17 ). The weld regions and other salient features are identified on these figures.

A much higher concentration of piping porosity is observed in the region from the beam end to the outer hanger rod hole than between the two holes. This was also noted in the radiographic examination of walkway box beam 9M (section 7.2 .2 ) and suggests that the porosity is associated with the beginning of a weld run. There was no evidence of cracks preferentially initiating from this porosity.

Figure $8.18 \mathrm{~b}$ suggests that the length of weld from the outer hanger rod hole to the beam end was less at location 9UW than at other locations. However, this was not the case because the outer hole region at 9UW had been severely damaged during pull-through of the hanger rod and some of the original metal at that location had been fractured away or distorted out of the plane of the weld. The fracture surface at 10UE (figure $8.19 \mathrm{~b}$ ) shows similar damage in the outer hole region.

Evidence of cracks existing prior to final weld failure was observed at location 9UE in both the lower exterior longitudinal and lower interior tack weld regions between the outer hanger rod hole and beam end (figure 8.18a). A very small area of preexisting crack was identified at location $8 \mathrm{UE}$ in the interior tack weld region (figure 8.19a). Areas of preexisting cracks were noted in the longitudinal weld regions between the hanger rod holes at locations 9UE, 8UE and 10UE (figures $8.20 \mathrm{a}$ and $8.21 \mathrm{a}, \mathrm{b}$ ). The difference in topography in the preexisting crack region and in the region through which the final crack propagated at location 9UE is illustrated on figure 8.22 . The preexisting crack region was heavily oxidized while the final fracture surface was relatively clean and exhibits fine ductile fracture dimples. It is not certain whether these preexisting cracks were formed during fabrication of the beams, during construction of the walkways or after the walkways were put into service. However, their locations in regions of maximum stress support the premise that they were formed during construction or during service. While the final fracture generally initiated at the root of the lower exterior longitudinal weld and propagated toward the exterior beam surface, and in the upper surface of the interior tack weld and propagated toward its root, no specific evidence was noted that preexisting cracks at these locations initiated the final fracture preferentially. 


\subsection{SUMMARY}

1. Gross features of the fractures of the lower longitudinal exterior welds of both NBS fabricated box beams and walkway box beams were similar.

2. Rounded and piping porosity were observed in all lower longitudinal exterior welds in the fourth floor walkway box beams, but no evidence was noted of preferential crack initiation from such flaws.

3. The predominant failure mode in the lower longitudinal exterior welds was ductile rupture. Between the beam end and outer hole, crack initiation appeared to be at the top of the interior tack weld with propagation toward the weld root. Failure in the lower longitudinal exterior welds at these locations initiated at the root and propagated toward the exterior beam surface in a direction normal to the flange surface.

4. Evidence was obtained of cracks existing in the welds prior to final weld failure during collapse. Their location supports the premise that these cracks were formed during construction or during service. There is no specific evidence that these preexisting cracks were the preferential sites of final fracture initiation.

5. No evidence of a fatigue failure mode was observed.

6. Evidence indicates that washers at locations 8UE and 9UE, missing after the collapse, had been initially installed.

7. Two regions of washer imprints were observed on the bottom surfaces of the box beam flanges. The outermost region contains the imprint of the washer and shows shallow striations. Nearer the hanger rod hole, there was a transition to a more deeply abraded region. This region showed evidence that the failure proceeded in a slip-stick manner.

8. The fracture characteristics of the walkway and NBS washers varied from predominantly ductile to predominantly brittle. However, the walkway washers displayed a higher percentage of intergranular fracture. 

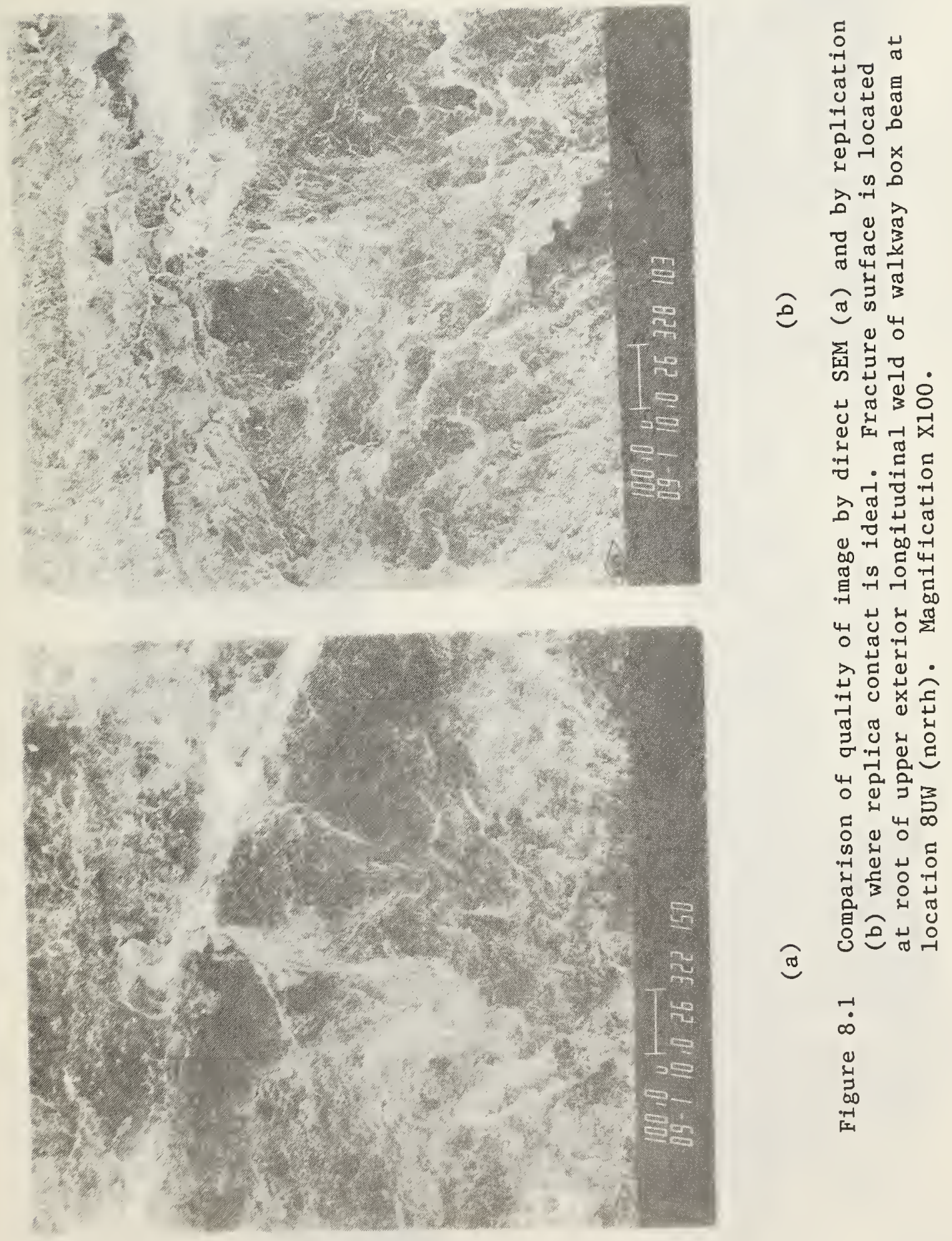

- 

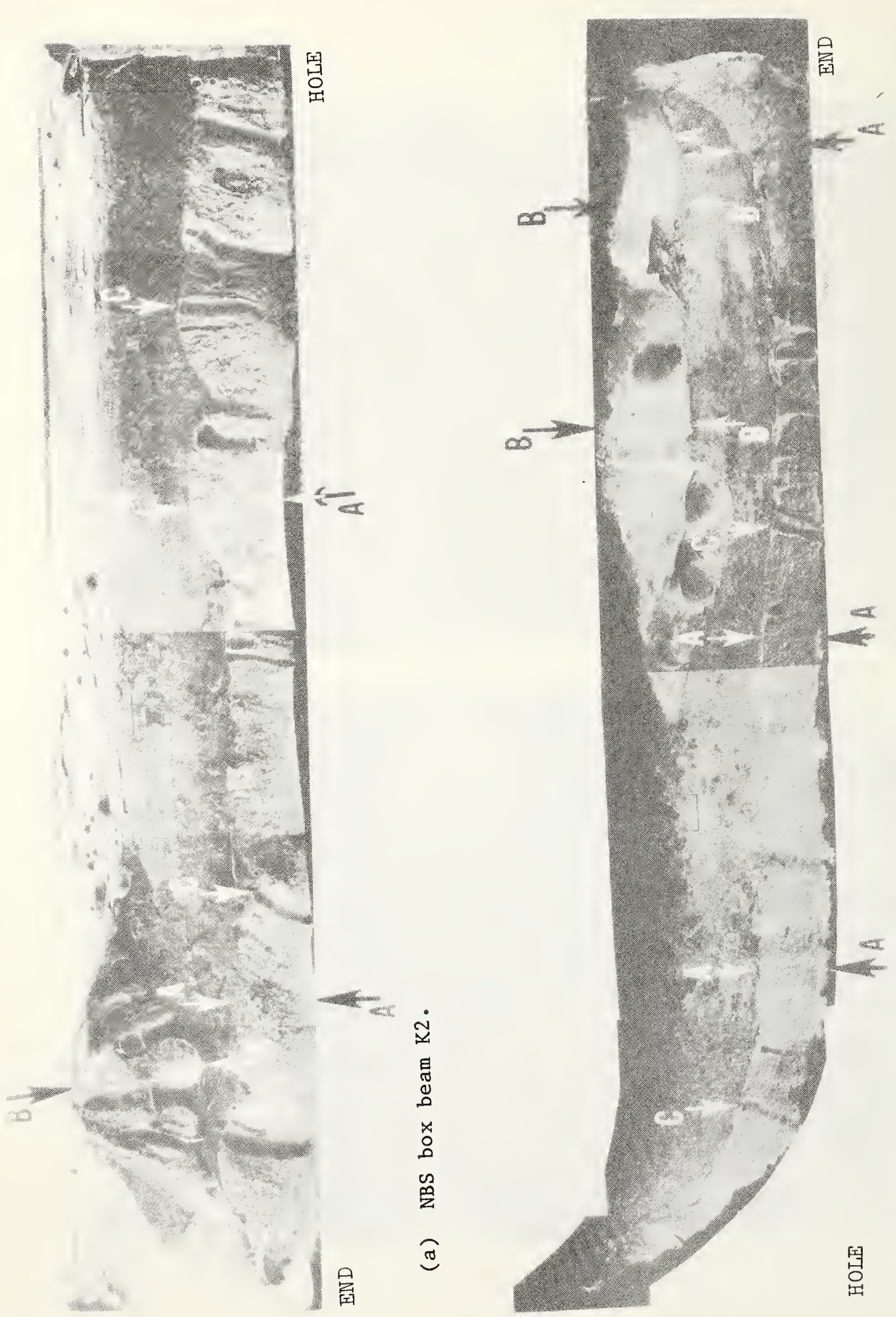

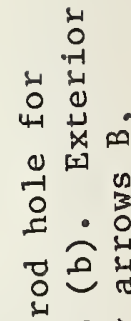

调

实

䒕

ฮ

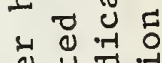

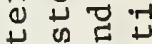

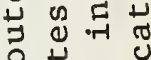

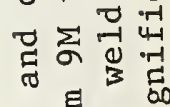

च

สี

造

永出要

造䓵

每

व

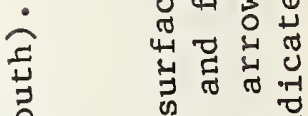

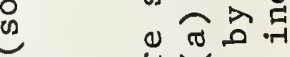

空

可

Uี

政

Б

요의

ปึ.

年

这

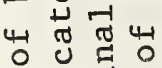

4

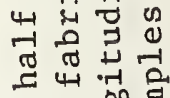

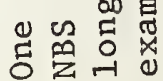

0
0
0
0
0
0
0
0
2

웅

告

త্

옹

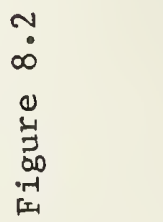



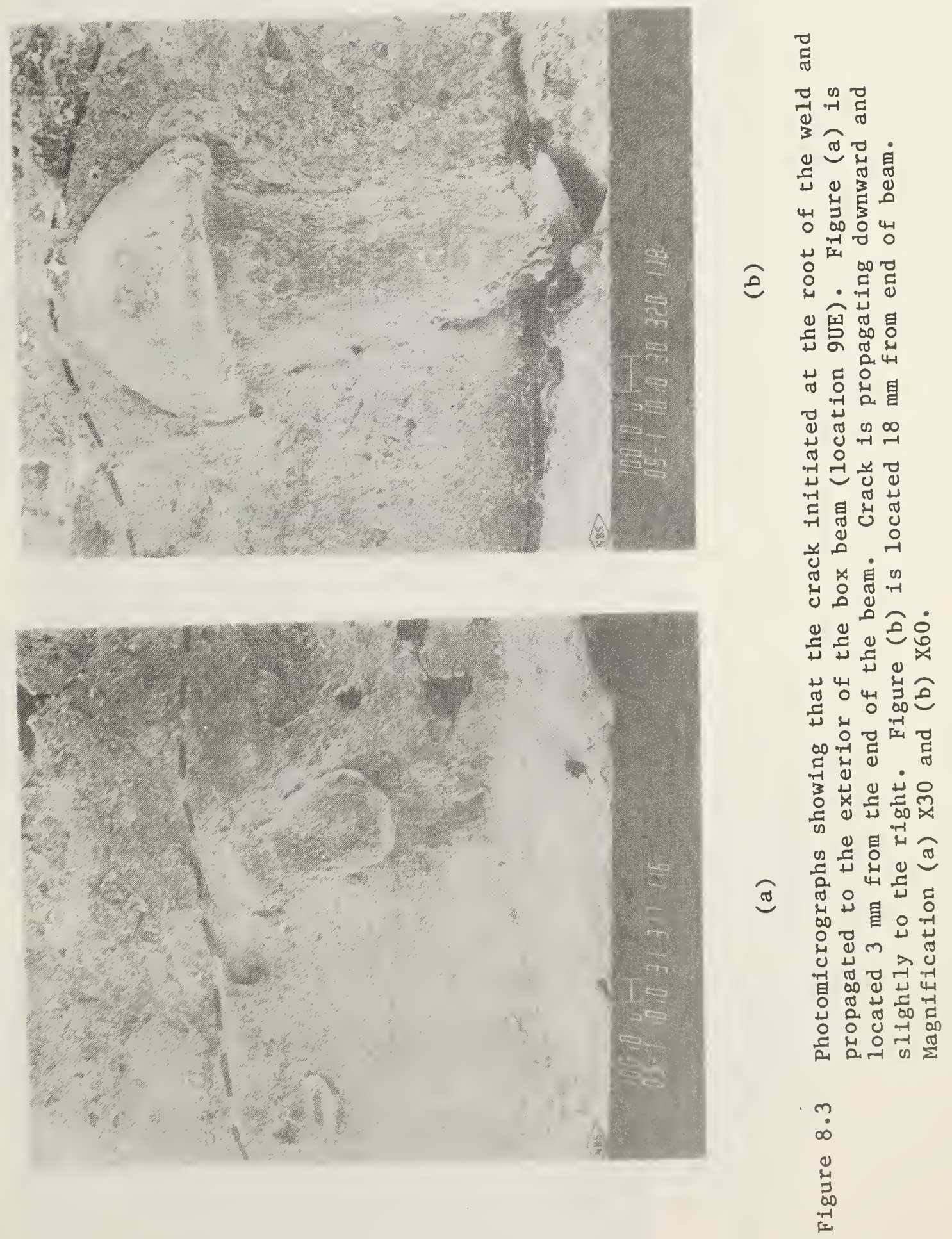


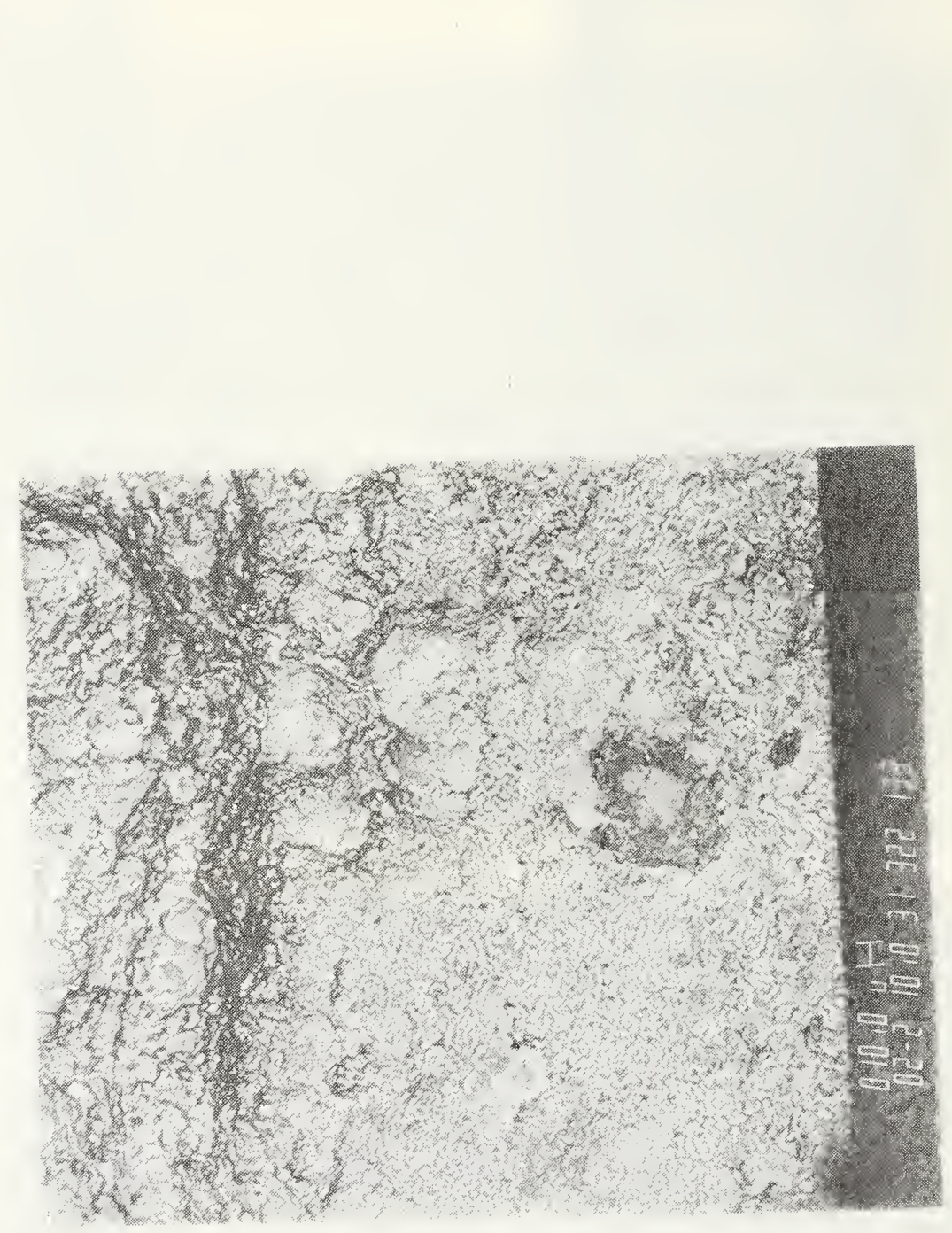

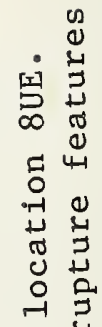

崩

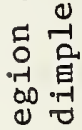

4

머

- $\frac{5}{0}$

芯先

is 4

인

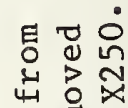

ช

가 0

요월

* म

4 㟔

- $\frac{\pi}{0} \sum^{\pi}$

돛.

का 0 -

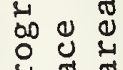

내

댕 औ्य

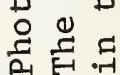

+
$\infty$
0
$\vdots$
5
0
$0-1$
01
01 

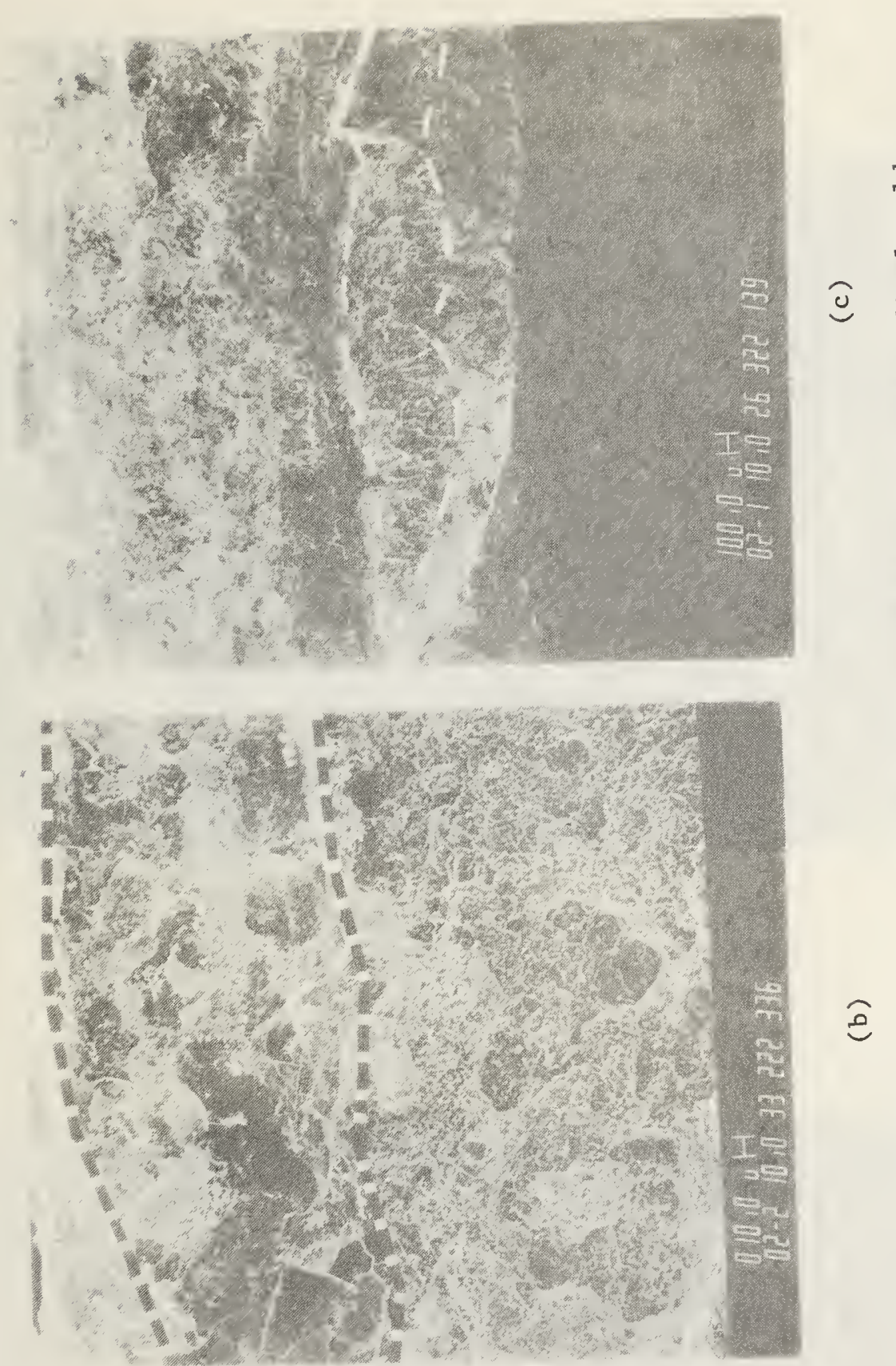

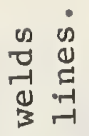

吾

00

엄요

苛究

㟧

(1)

思

ํㅜㅇ

它

ग

ते

空

त)

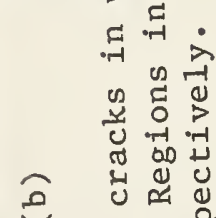

อ

先客离

แू ब

$\circ$

으ำ

ב

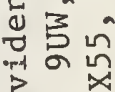

ये

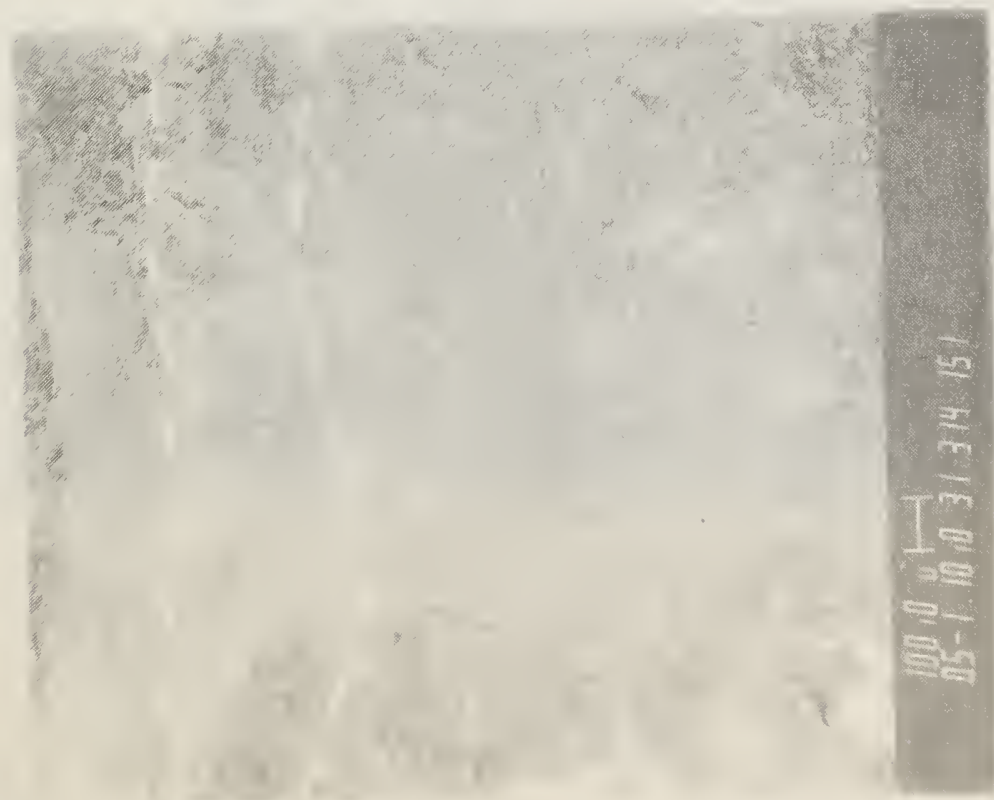

걸

क 口

ส.

$00 \pi$

궁

U न

幽崩崩

$\rightarrow$

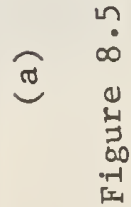




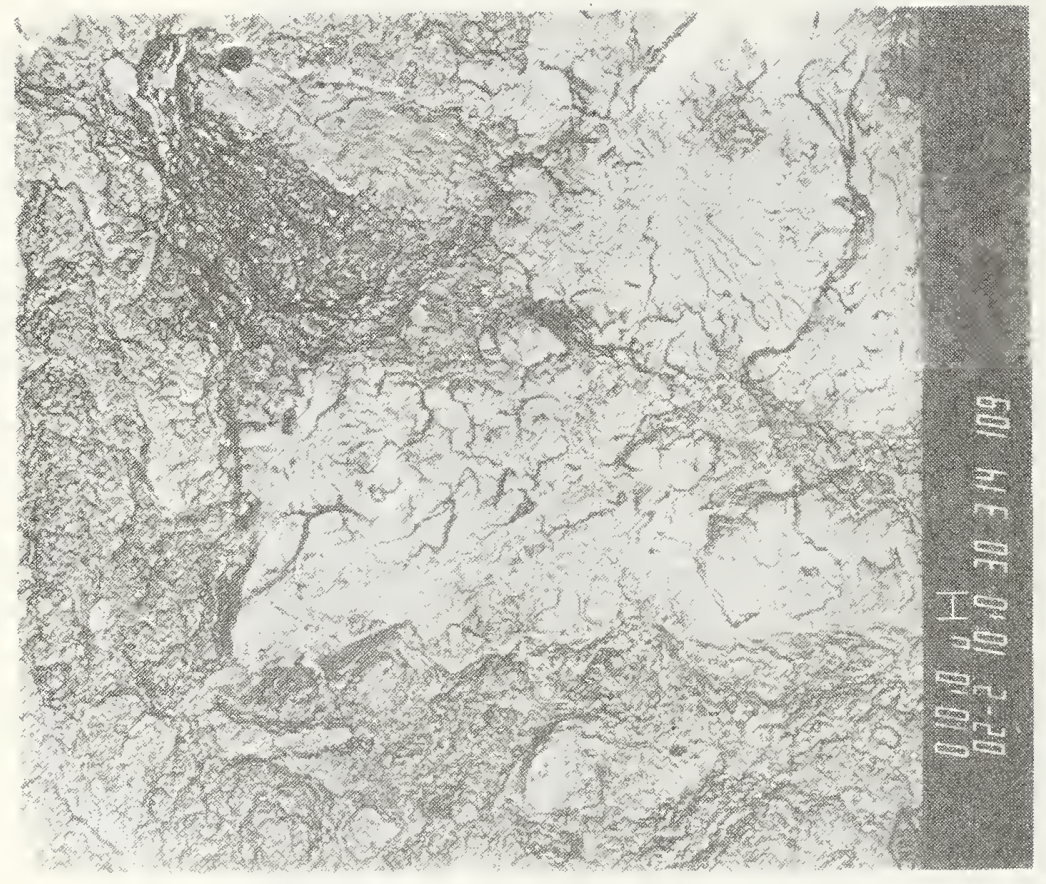

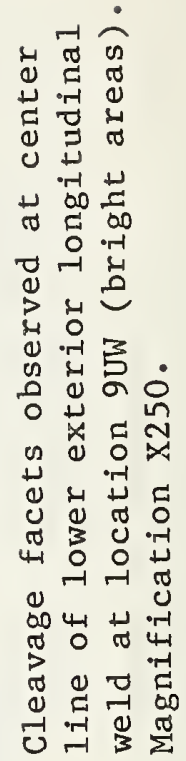

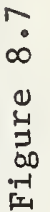
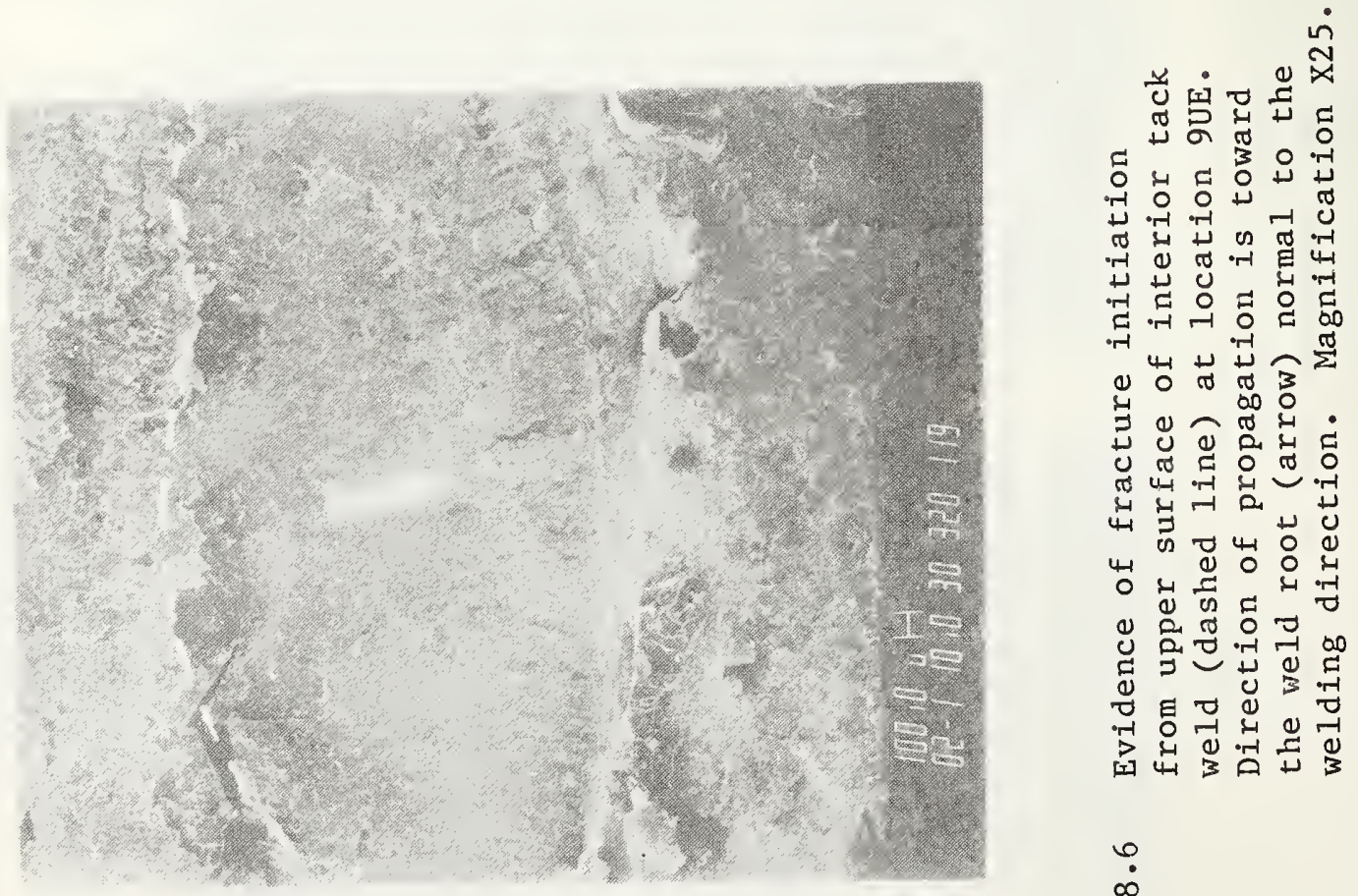

0
$\infty$
0
0
0
0
01
01
01 


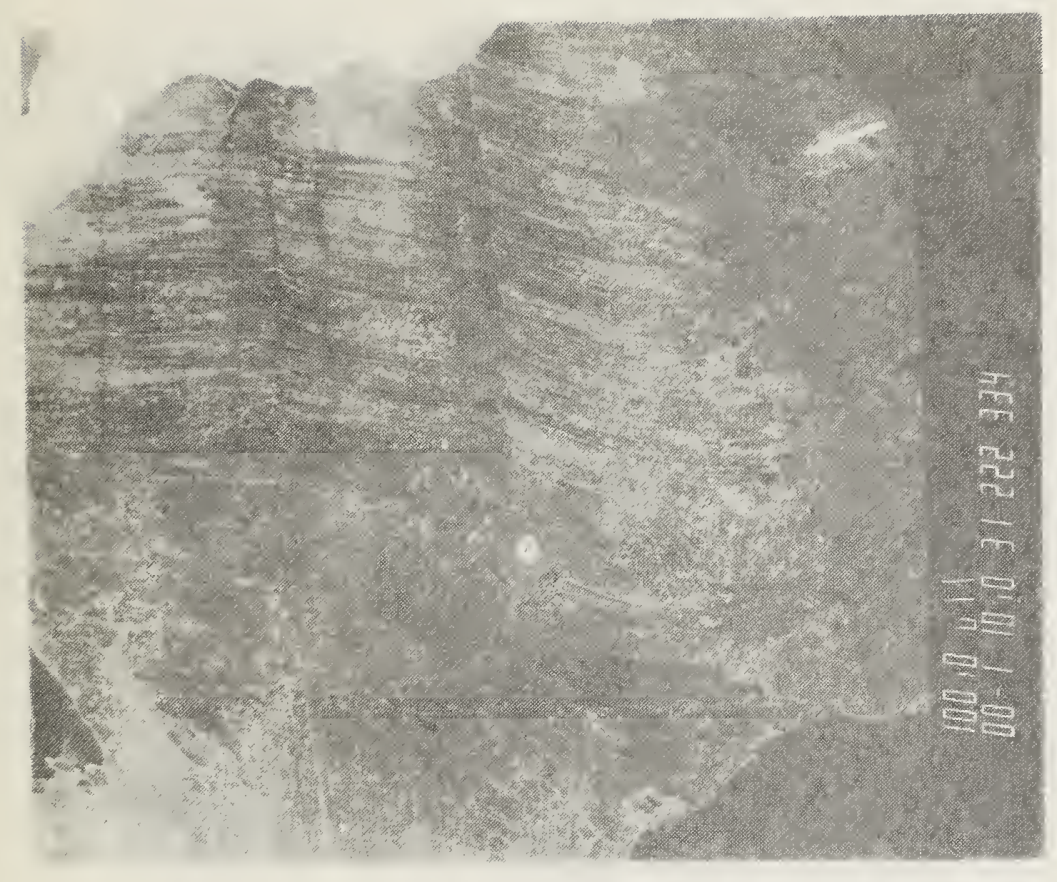

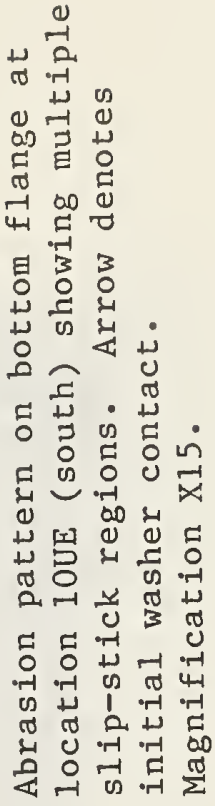

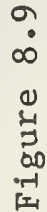
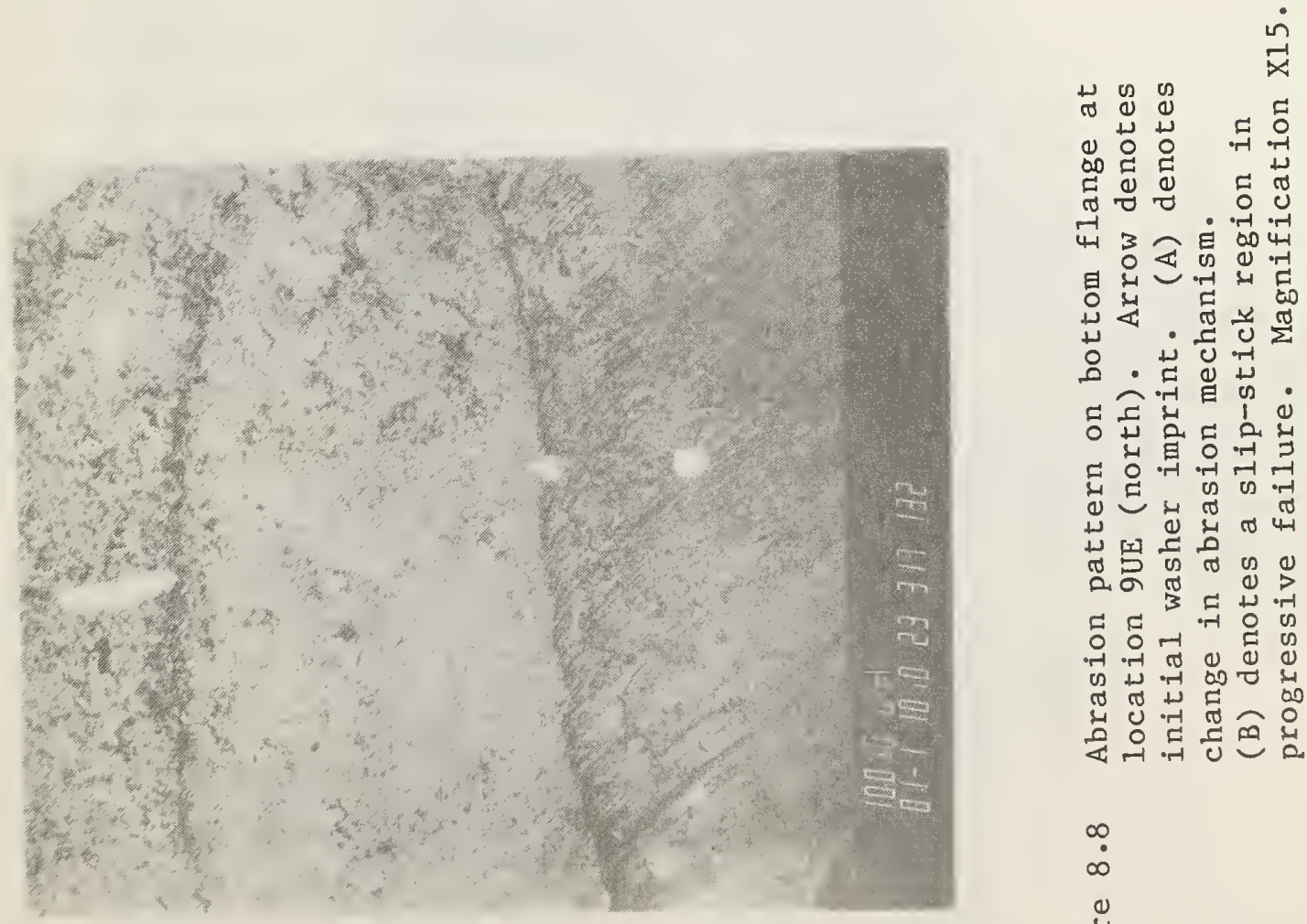

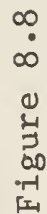



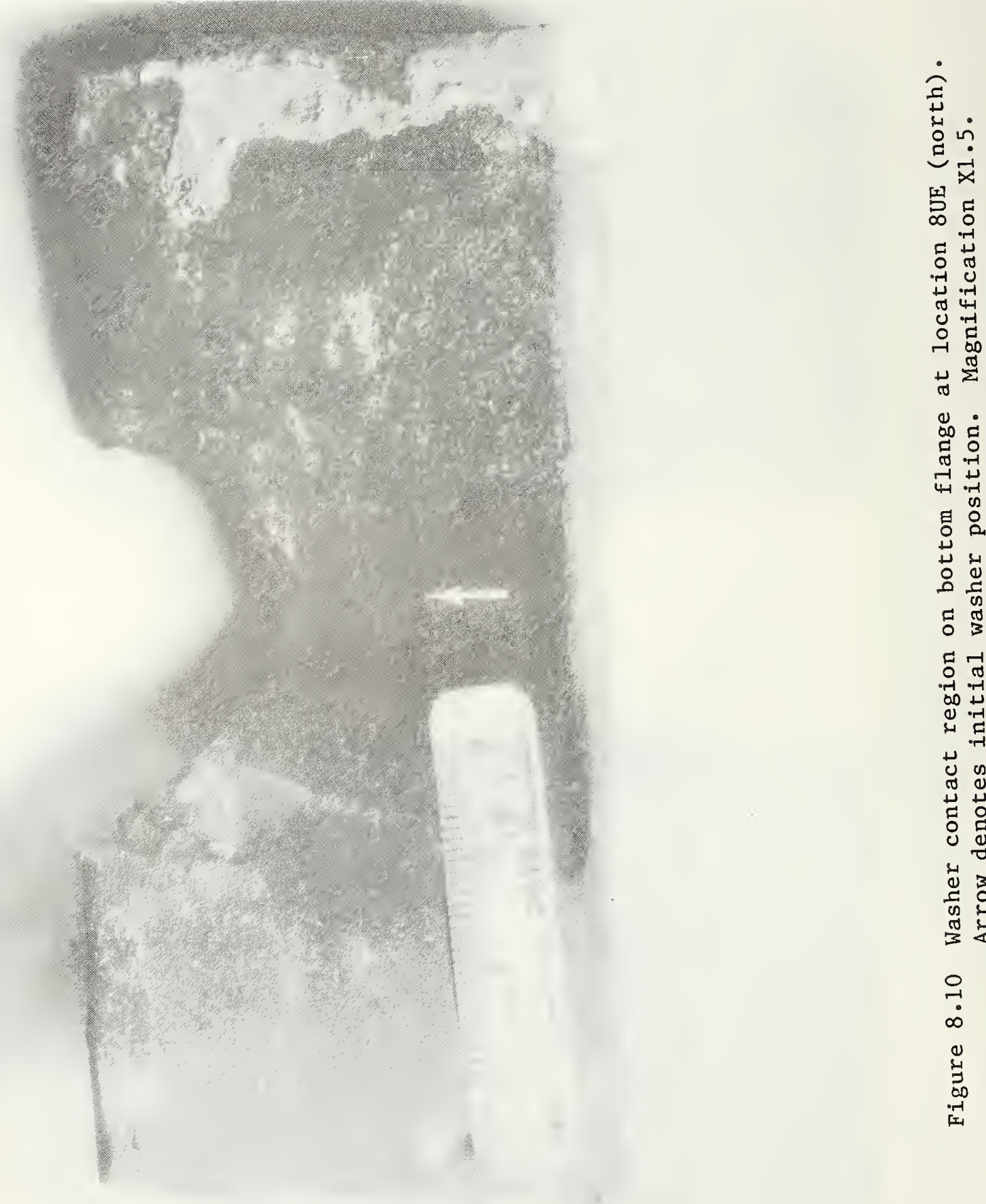

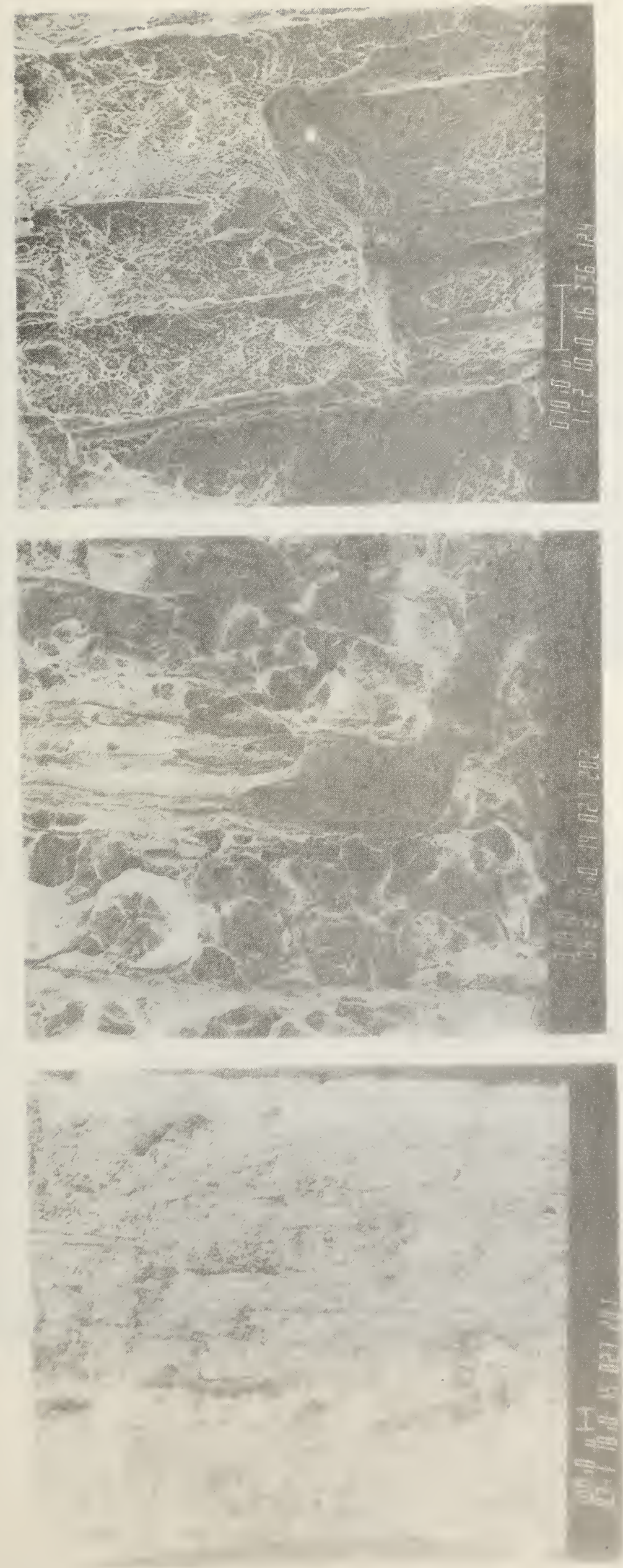

हू

हू

出。豆

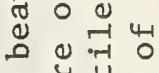

U

甪的㫕

ब

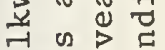

उत

山岂䒕

记

क

을

记

(4)

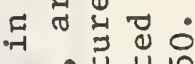

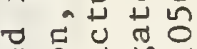

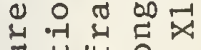

$\exists+40$

岂范。成

प्र

4㫕苍这

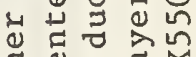

क ग 0

药 0

อ 导

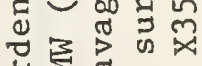

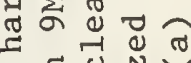

더

फै०

(1)

0 U

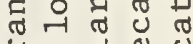

岁 + न

0 政

듈

त 0 -

บ न

단

क्ष

मू. व व वै

مै

+ 品

岇

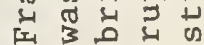

ฮ) 

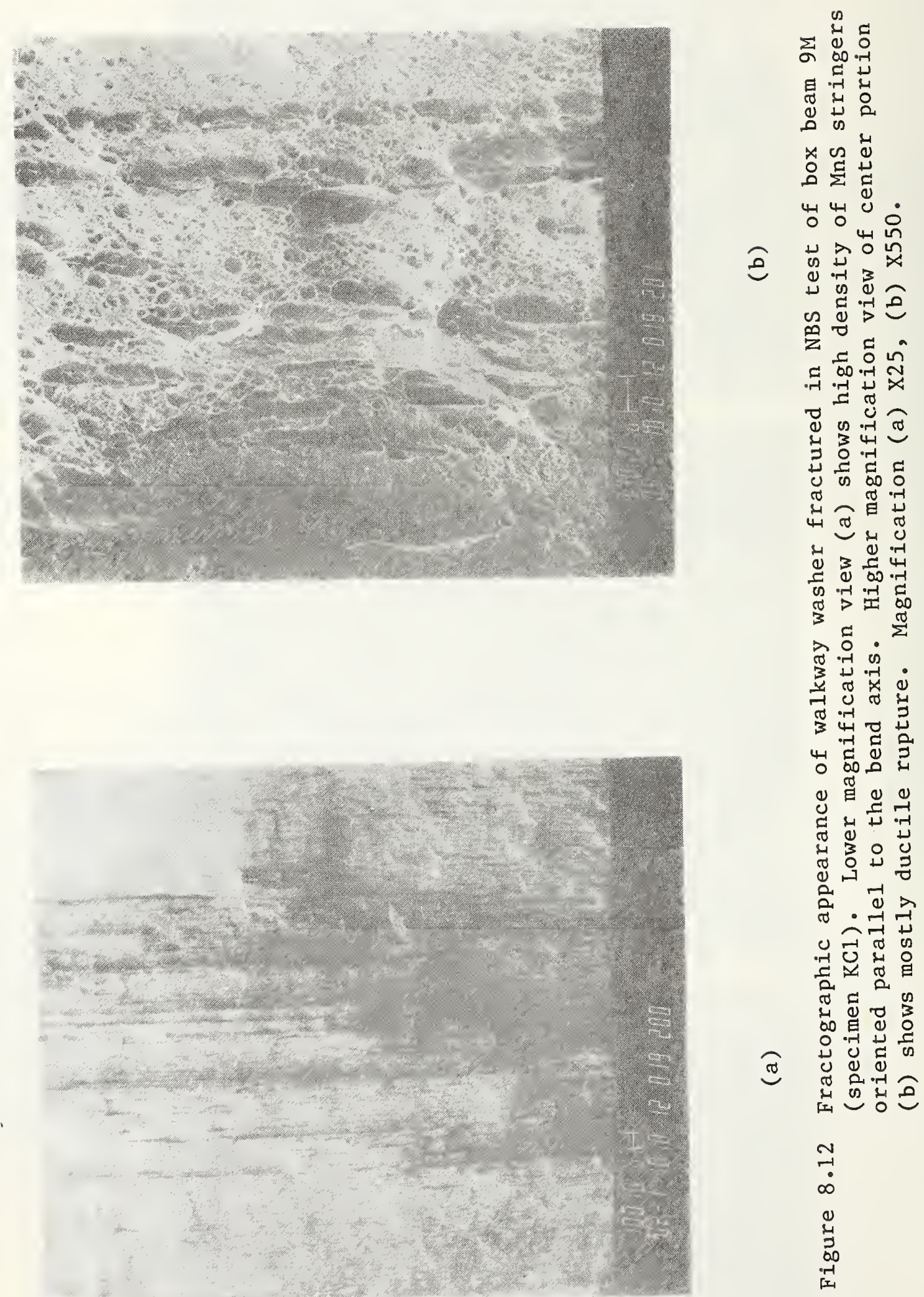

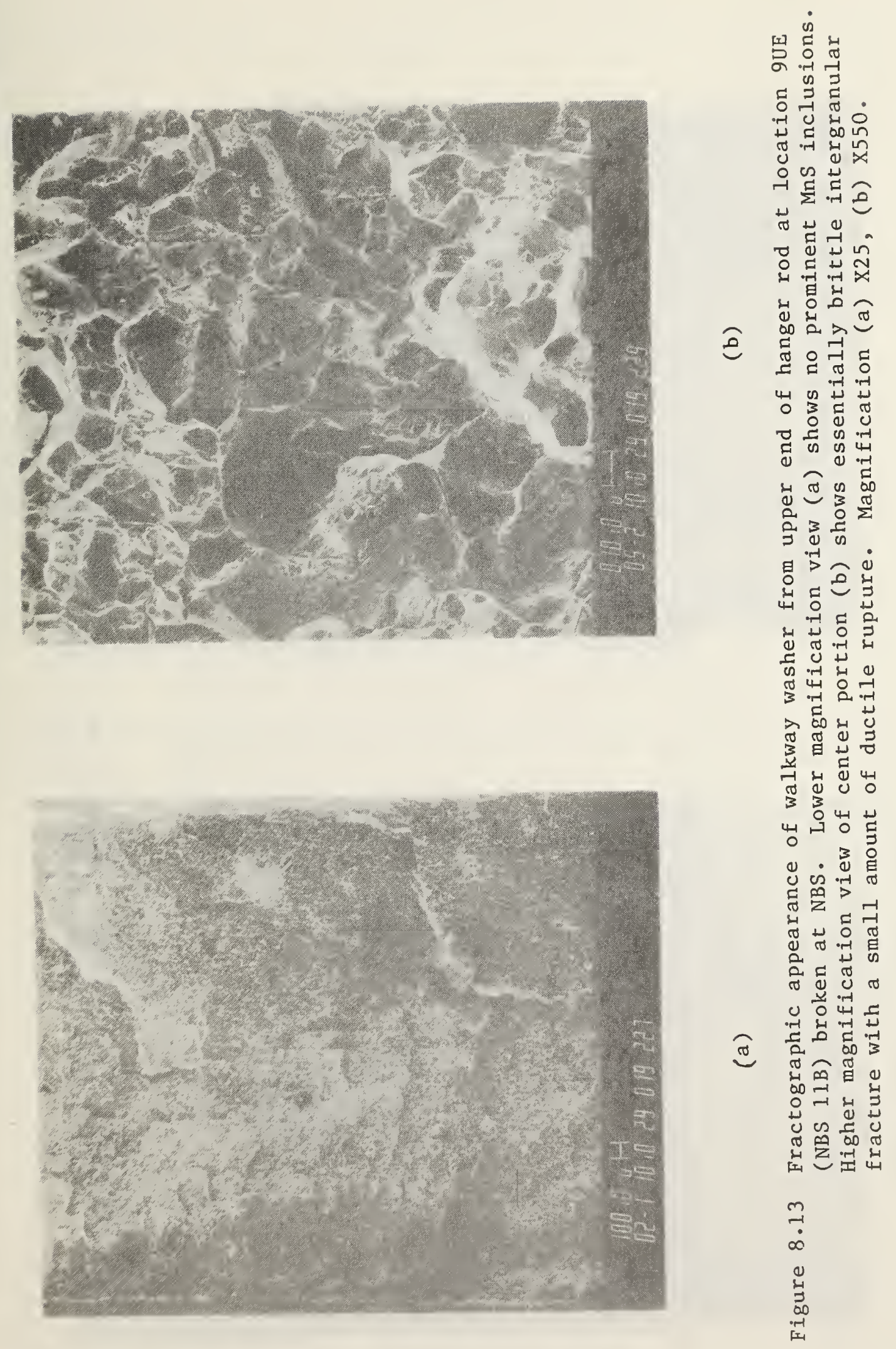

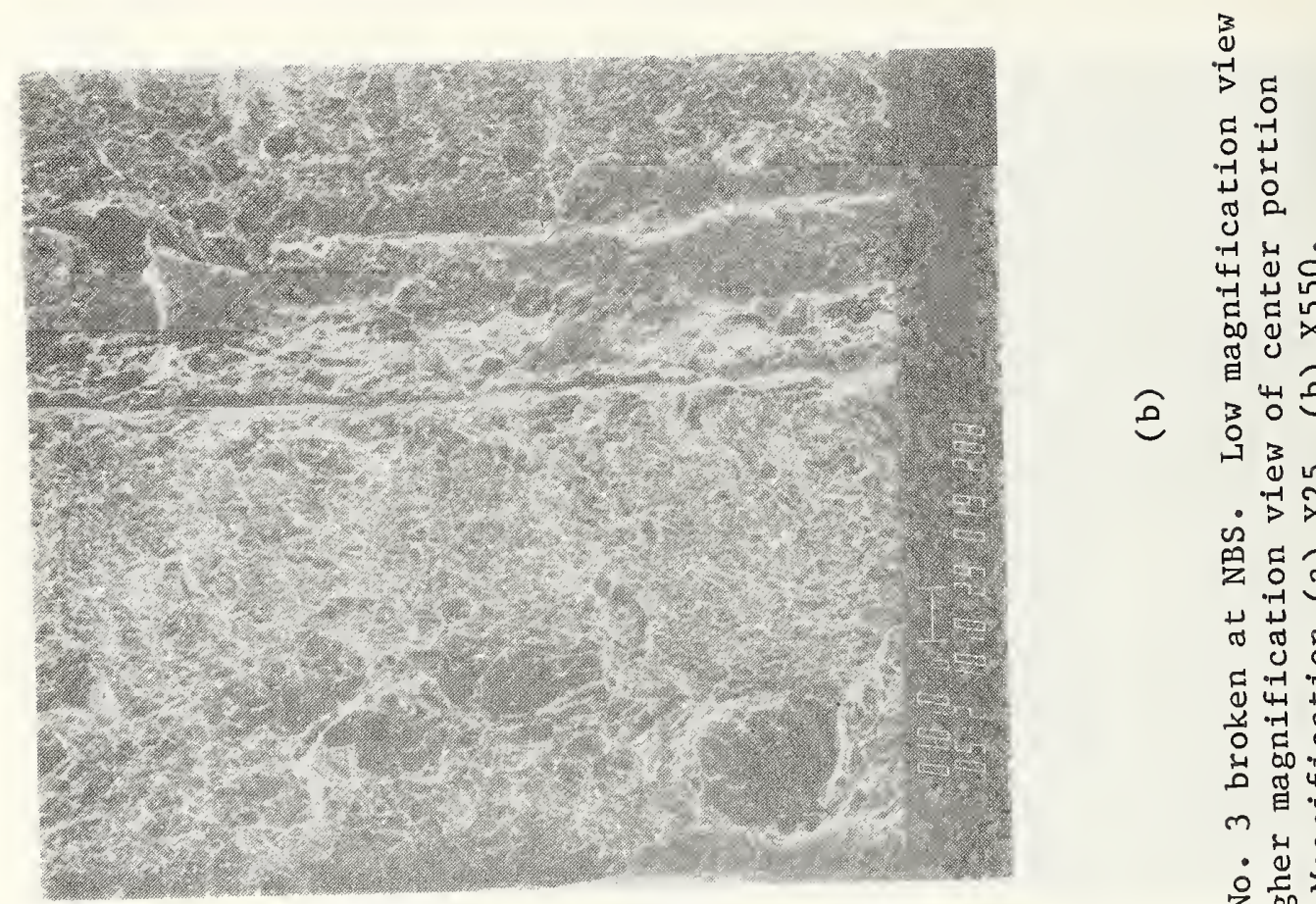

อ 30

$1 \underbrace{3}_{0}$

.$\rightarrow x$

品䓃

弪

崩

व.$=1$

(1)

ชै

范

o

- 100

这 $\frac{0}{00} \sum^{\frac{\pi}{2}}$

4 望.

过娄

की

3 등

c)

兒算。

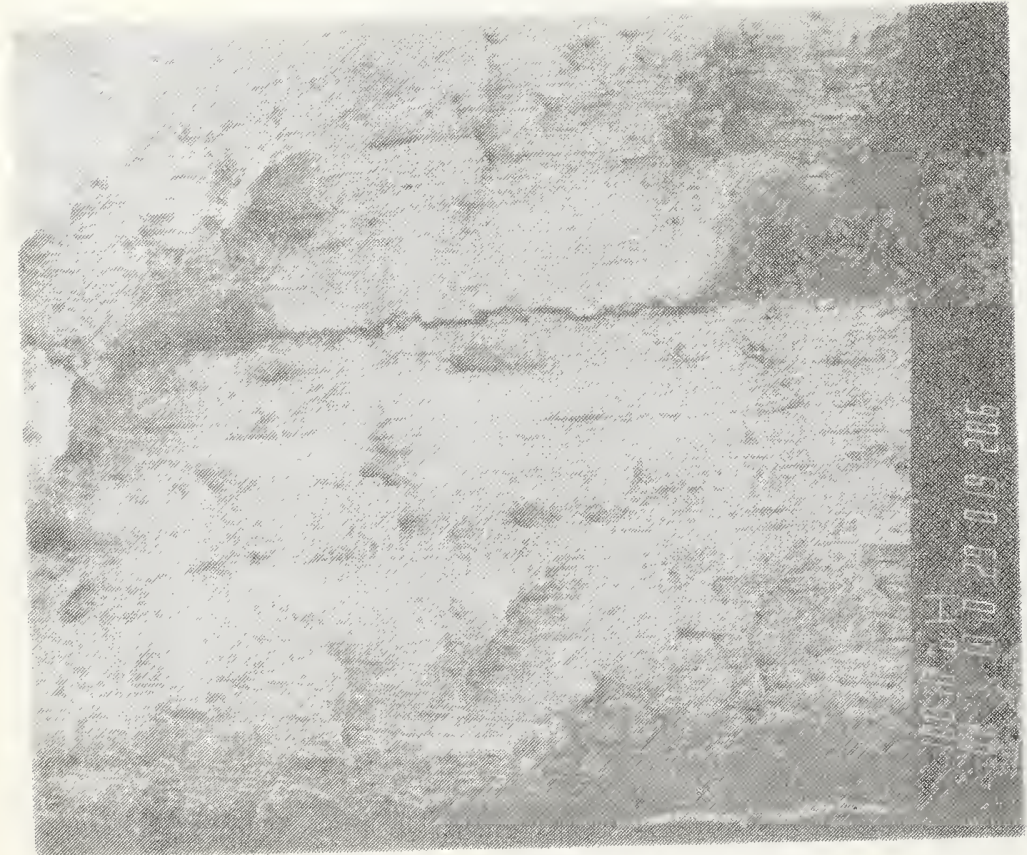

떵렬

的寻

ฮ

幽

ฮี

늠

$\sigma 0$

ङ $\begin{array}{ccc}0 & 0 \\ -1 & 0 & 0 \\ 0 & 0 & 0\end{array}$

品 n थ

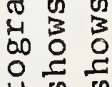

मे क

幽

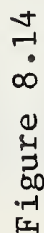



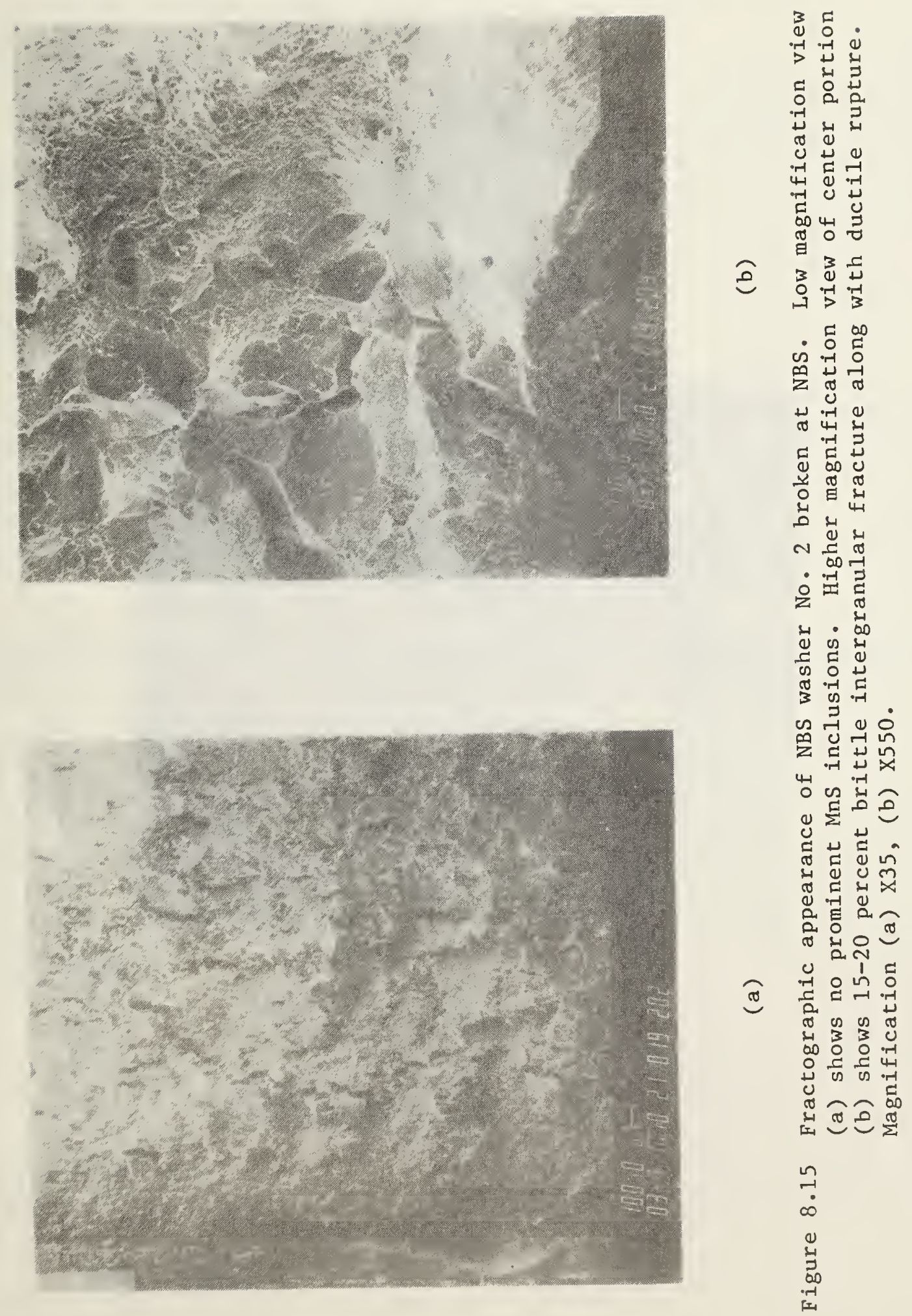


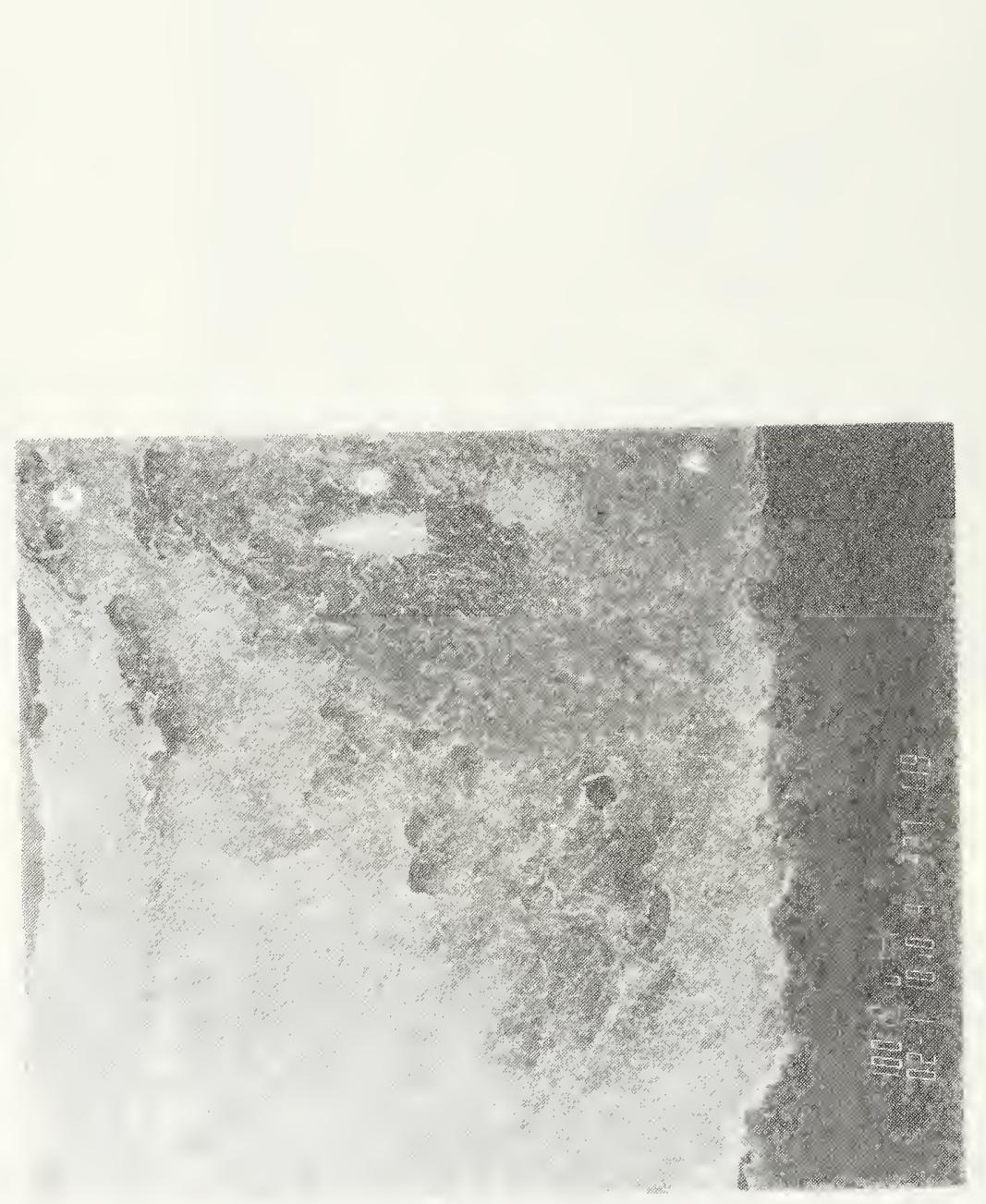

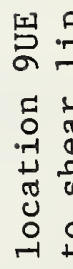

䑻

동다

罗

บิ

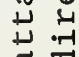

D.

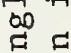

范

跡

त्-

峁题

त्ञ

嵌

I)

거 궁ำ

山

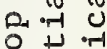

䒹藏

芹

1. $\sum^{\pi}$

岂志

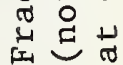

$\stackrel{0}{\circ}$

苟 

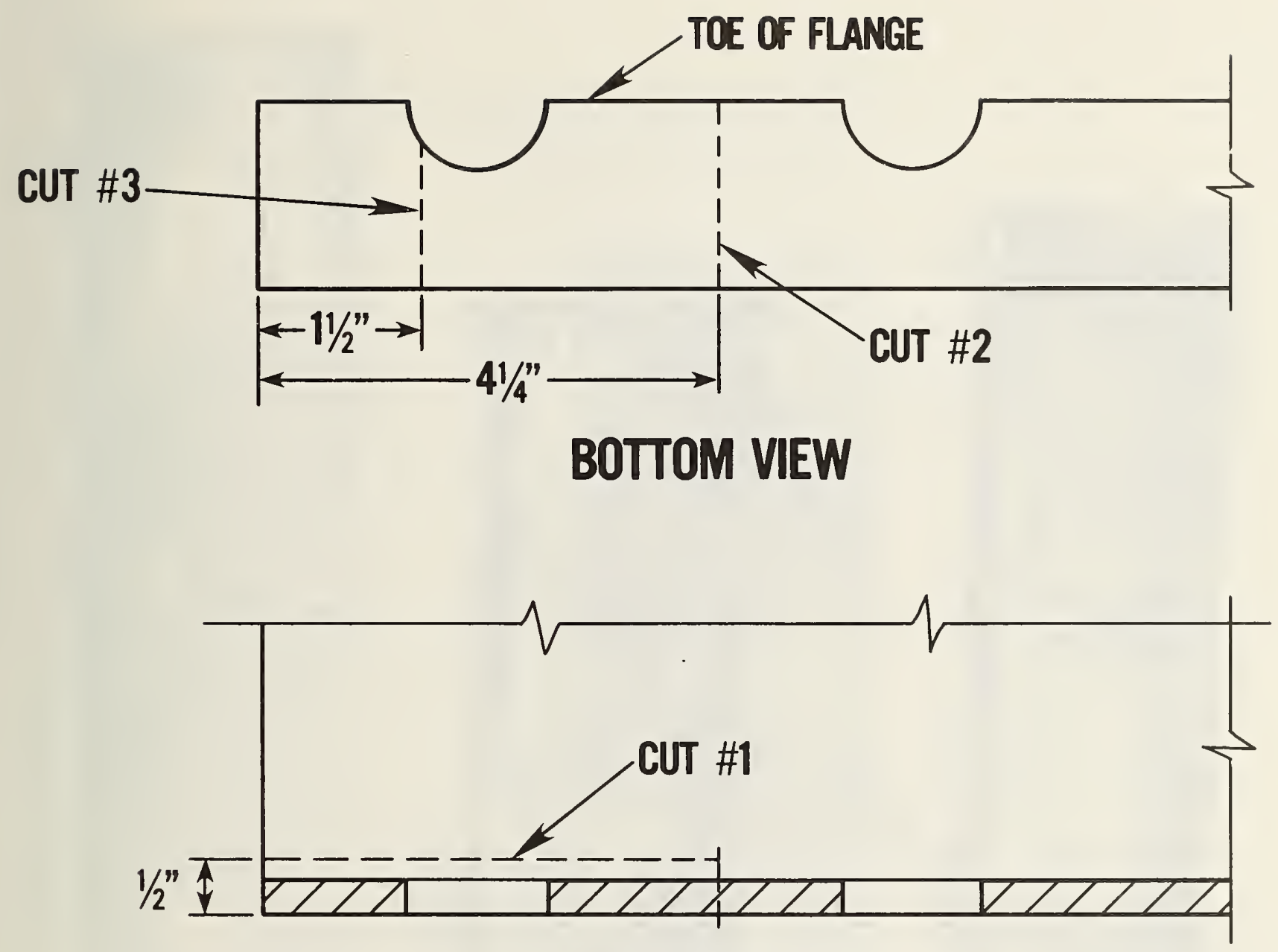

SIDE VIEW

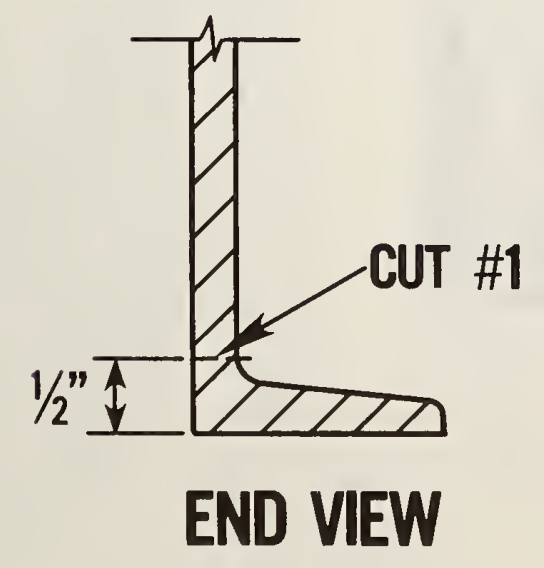

Figure 8.17 Schematic of cuts performed to remove one half of the lower fracture surfaces for fractographic analysis. 

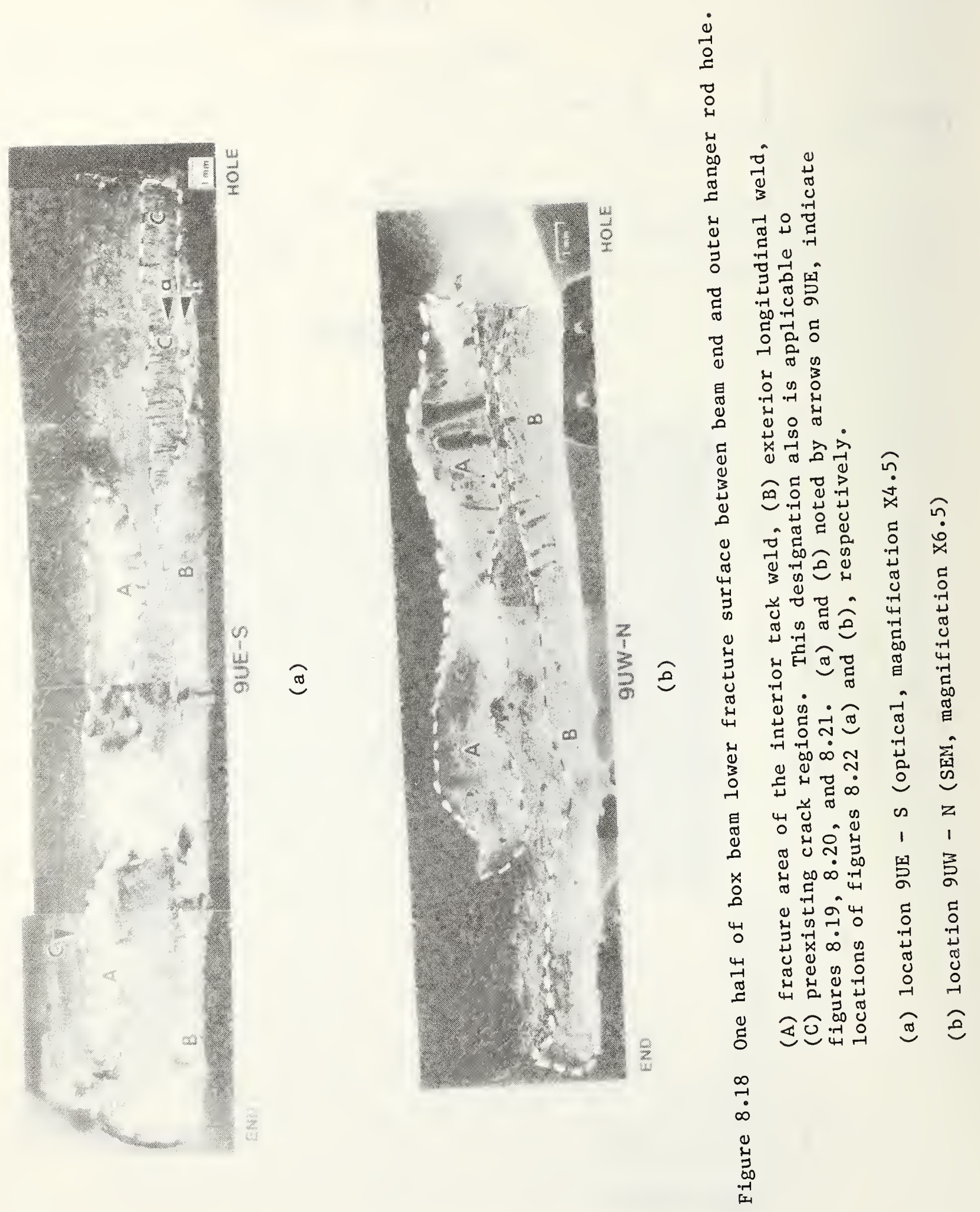

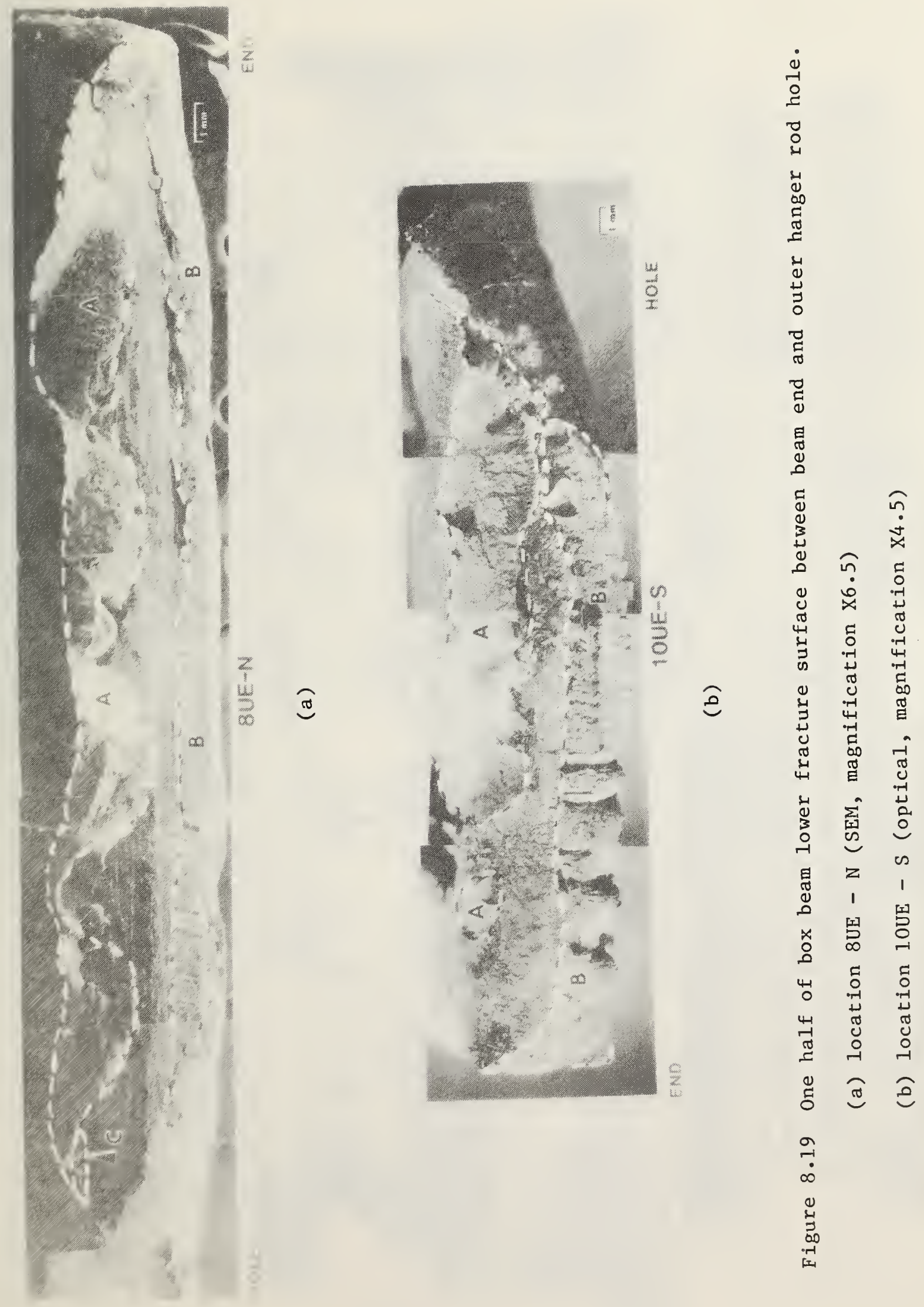

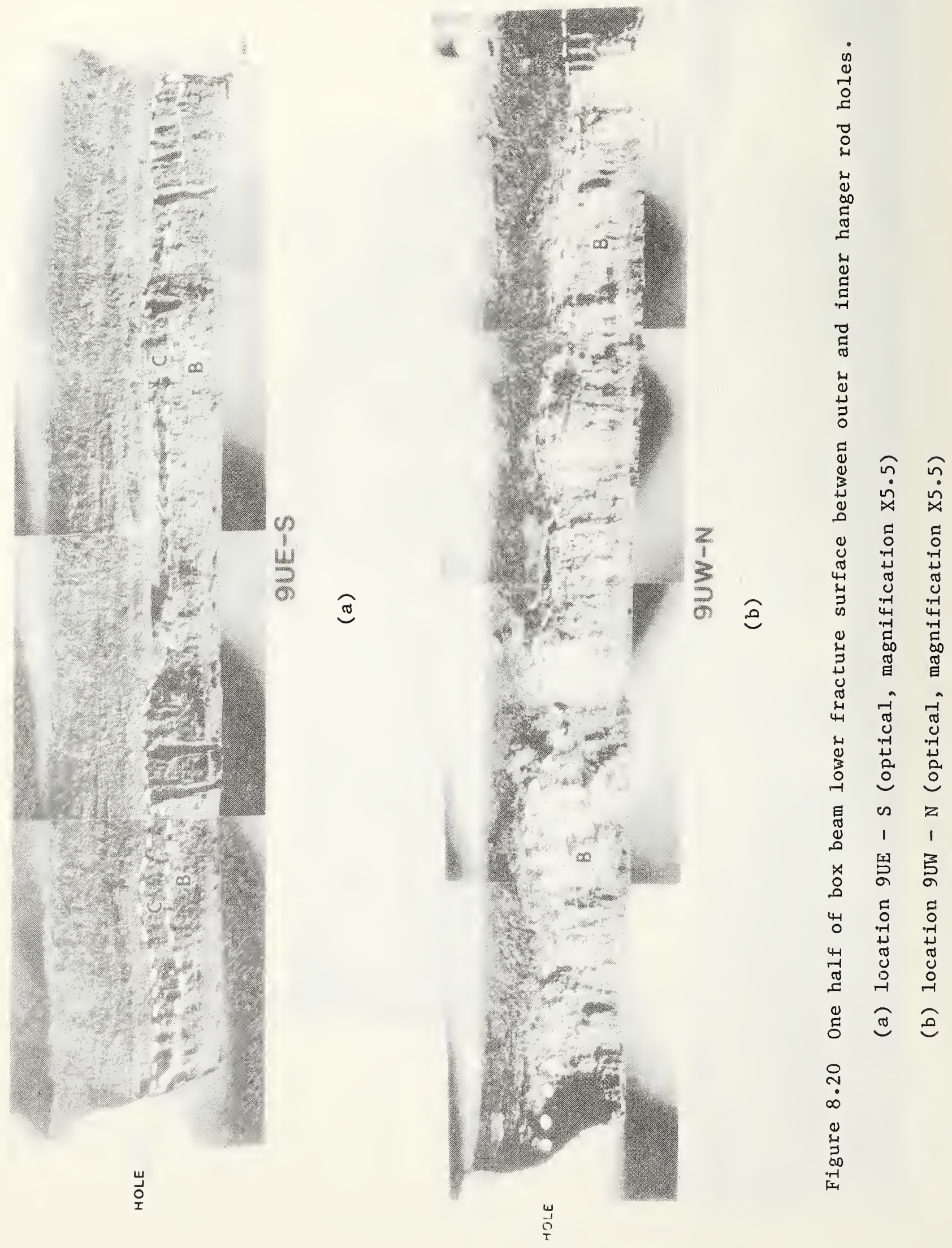

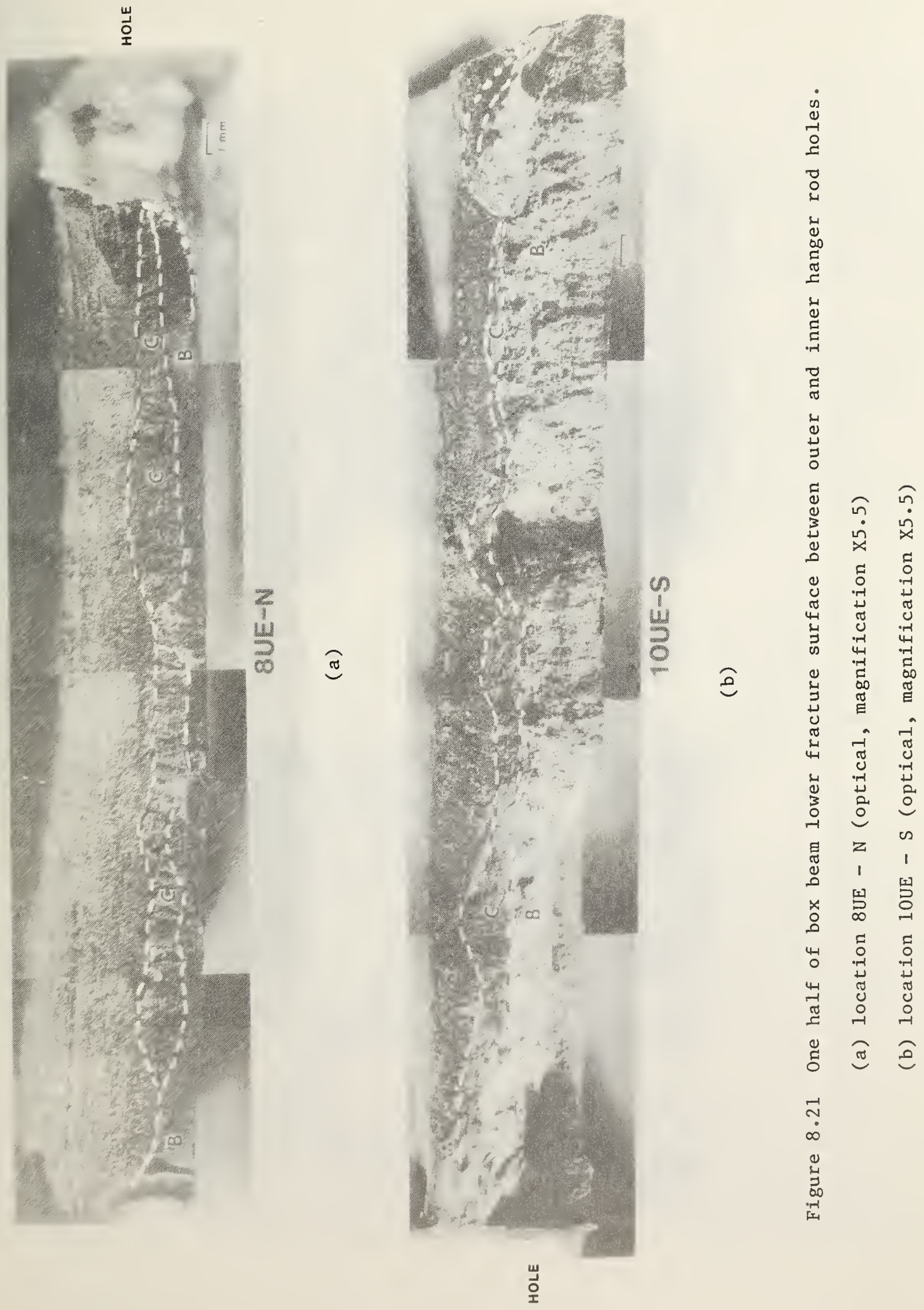

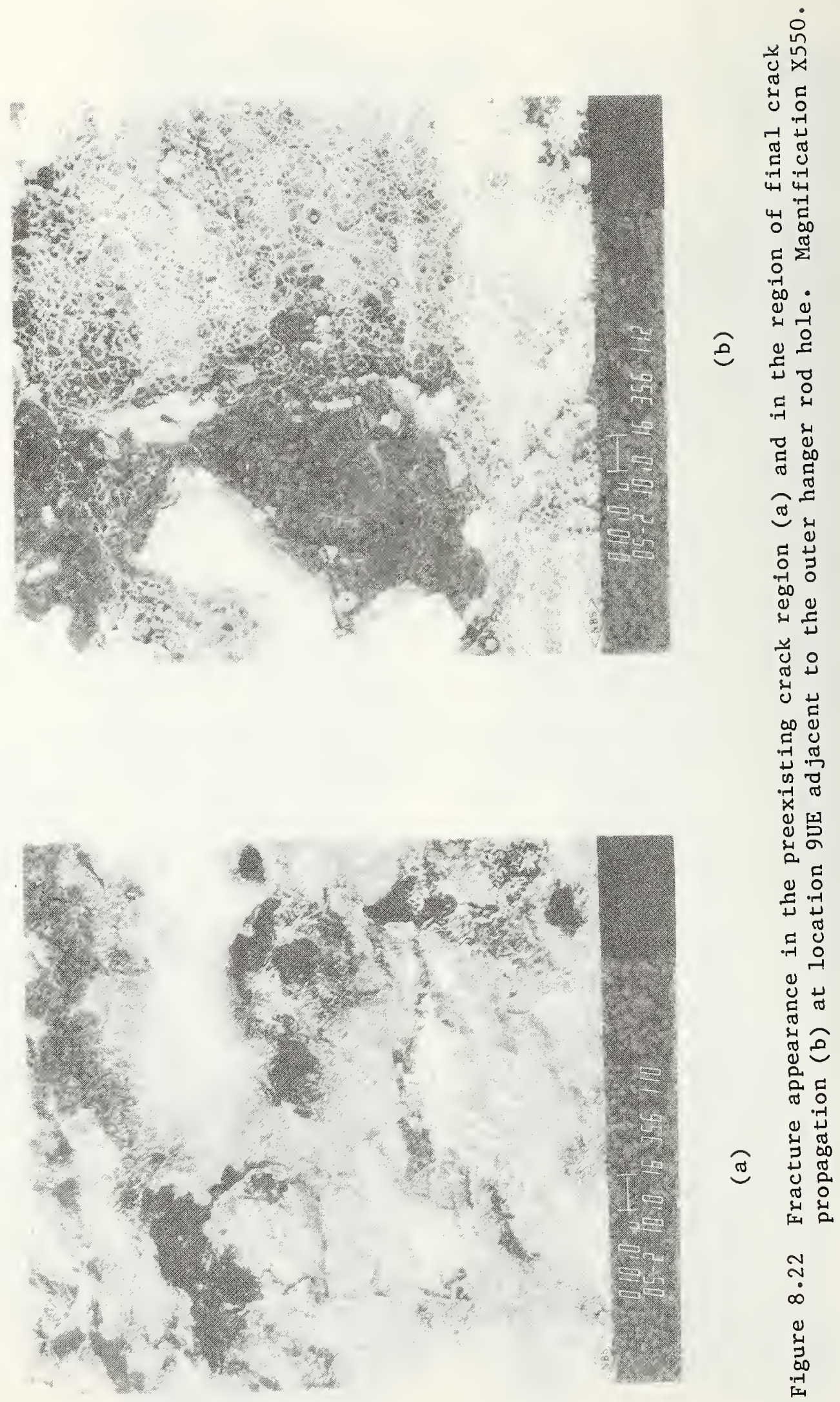


\section{STRUCTURAL ANALYSIS}

\section{$9.1 \quad$ INTRODUCTION}

The walkway design loads and the loads believed to have been acting on the walkways at the time of collapse are discussed in this chapter. Also discussed are the adequacy of structural components and connections, walkway deflections and the significance of dynamic loads.

Section 9.2 addresses dead loads, design live loads and the upper-bound live loads associated with walkway occupancy at the time of collapse.

Section 9.3 presents the results of analyses carried out on walkway components and connections to establish their compliance with the project specifications as set out in reference 2.1. Forces believed to have been acting on the box beamhanger rod connections at the time of collapse are addressed in section 9.4. Section 9.5 describes the procedure used to determine walkway deflections at the hanger rod locations due to dead load. Section 9.6 considers the matter of dynamic excitation of the walkways and the significance of dynamic effects when compared with the static loads discussed in section 9.2. Findings reported in this chapter are summarized in section 9.7 .

\subsection{LOADS}

In this section the walkway design loads and the loads believed to have been acting on the walkway system at the time of collapse are discussed. While the loads at the time of collapse will never be known exactly, it is possible to place reasonable bounds on their intensity and distribution. For purposes of structural analysis and comparisons with code-specified design loads, it is convenient to differentiate between dead load and live load. Each of these load categories is discussed separately in the following subsections.

\subsubsection{Deäd Load}

The dead load includes the weight of all structural and architectural components and materials that are permanently fastened to or supported by the walkways. Normally the dead loads can be determined with sufficient accuracy simply by preparing a list of quantities of materials from "as built" drawings and then calculating total weights from nominal unit weights. As has been discussed in section 5.3.6, the observed variability in the thickness of the concrete deck and topping material, the limited number of representative thickness measurements that could be made, and uncertainty with regard to unit weights prompted the weighing of selected walkway spans.

The approach used to obtain dead load estimates was to take the total weights of the damaged spans as listed in table 5.9 and deduct the estimated weights of all walkway materials, including all debris on the decks, but excluding the concrete deck with topping, shear studs and welded wire fabric. Weights of the damaged concrete decks so calculated were then corrected for loss of concrete and topping material during the collapse or during the rescue operation. The total weight of each span prior to collapse was then estimated by adding on 
the weights of all materials other than the deck that went into the "as built" configuration. Details of these calculations are presented in section A9.2.1 of the appendix. It should be pointed out that any errors in estimating weights of other materials attached to the damaged spans are reflected in the estimated concrete deck weights.

Results of these calculations are presented as estimated weights of undamaged spans in table 9.1. Allowing for the second to fourth floor hanger rods, the upper walkway spans average some $550 \mathrm{lbs}(249 \mathrm{~kg})$ more than the lower spans. This is consistent with the observation that more topping material was used to level the upper decks. With regard to errors in the estimated span weights, it is to be expected that the gypsum board could be a major contributor. Even though selected gypsum board assemblies were weighed, it is likely that the estimated weights are in error by as much as $t 5$ percent. This is also the case for other walkway components and architectural features such as the handrail assembly, footlights and carpeting. Weights of structural shapes could be expected to vary from their nominal weights by \pm 2.5 percent. Based on this, errors in the estimated span weights of the order of $+3001 \mathrm{bs}$ (136 kg) are to be expected.

To provide an independent check on the above calculations, the estimated concrete deck weights from table 9.1 are compared with calculated deck weights based on a nominal deck thickness of $31 / 4$ in $(83 \mathrm{~mm})$ and an air-dry unit weight of $113.5 \mathrm{pcf}\left(1,820 \mathrm{~kg} / \mathrm{m}^{3}\right)$ for the concrete as was determined in section 7.6. An allowance of $200 \mathrm{lbs}(91 \mathrm{~kg}$ ) per span has been made to account for the weight of shear studs and welded wire fabric. For a valid comparison, it is necessary to deduct the weight of the topping material from the estimated deck weight as is indicated in table 9.2. This adjustment is based on the topping thicknesses listed in table 5.12 and on an air-dry unit weight of $116.8 \mathrm{pcf}\left(1,870 \mathrm{~kg} / \mathrm{m}^{3}\right)$ for the topping material.

It is seen from table 9.2 that the estimated deck weights (excluding span L8-9) average 500 lbs $(227 \mathrm{~kg}$ ) more than the calculated weights. In the case of span U8-9, this difference is $1,1301 \mathrm{bs}(513 \mathrm{~kg})$. If the average thickness of the concrete cores (table 7.17) is substituted for the nominal deck thickness, the calculated deck weights increase by approximately 150 lbs (68 kg), resulting in an average difference between estimated and calculated deck weights of $3501 \mathrm{bs}(159 \mathrm{~kg})$. In view of the uncertainties involved in assessing the weights of the damaged spans, the topping thickness, and the unit weight of the topping material, this difference is not considered to be excessive. Based on the average estimated deck weight of $39.0 \mathrm{psf}\left(190 \mathrm{~kg} / \mathrm{m}^{2}\right)$ for seven spans, the deck weight and total in-place weight of span L8-9 have been back-calculated as indicated in tables 9.1 and 9.2. From table 9.1, the average estimated in-place weight of a walkway span is $17,7501 \mathrm{bs}(8,050 \mathrm{~kg})$.

In design calculations, the precise unit weights would not be known. If a nominal unit weight of $110 \mathrm{pcf}\left(1,760 \mathrm{~kg} / \mathrm{m}^{3}\right)$ is assumed for lightweight concrete and if no allowance is made for the weight of the topping material, the calculated weight of the concrete deck with shear studs and welded wire fabric averages $8,4001 \mathrm{bs}(3,810 \mathrm{~kg})$ per span. Assuming that the weight of all other materials that make up a walkway span are as listed in table 9.1 , the nominal 
dead load due to each upper walkway span would be about 16,500 1bs (73 kN), and about 200 lbs $(890 \mathrm{~N})$ less for the lower walkway spans, as will be described in further detail in section 9.3.1. Thus the actual span weights would, on average, exceed the nominal span weight by approximately 1,300 1bs (590 kg), or about 8 percent.

In section 2.6 it was noted that a modification of the walkways, involving the addition of gypsum board to meet fire endurance requirements, was agreed to on Apri1 4, 1978. It was also noted in section 2.3 that structural drawings 5303 through S305 were issued March 30, 1978. Although these same drawings were issued for review on May 26 and June 30, 1978, it is not clear what, if any, changes were made to the walkway structural details because of the addition of gypsum board. Failure to account for this component of the dead load could be significant as can be seen in table 9.3 which lists the principal contributions to the dead load for a typical walkway interior span.

\subsubsection{Live Loads}

Live loads are those loads produced by the use and occupancy of the structure. They include loads produced during maintenance and during the life of the structure by movable objects and by people. The project design criteria listed on structural drawing $\$ 601$ imply a walkway design live load of 100 psf $(4.79 \mathrm{kPa})$. Section 2306 of the Uniform Building Code [2.3] allows for the reduction of unit live loads based on the extent of floor area supported by a structural member. However, it specifically excludes live load reductions in the case of places of public assembly or where the design live loads are in excess of 100 psf. The atrium and adjoining balconies in the hotel tower section and function block are clearly places of public assembly. The walkways are located within and connect places of public assembly and, therefore, it would be inappropriate to apply a live load reduction factor.

In section 4.4 an assessment was made of the second floor walkway occupancy based on the analysis of selected videotape frames. It was concluded that approximately 40 people occupied this walkway shortly before the collapse. In addition, it was concluded that 63 people, distributed as indicated in table 4.1, represented a credible upper bound for the combined second and fourth floor walkway occupancy at the time of collapse. To translate this occupancy into an equivalent distributed live load, it is necessary to make certain assumptions regarding body weight and centroidal position. Data presented in reference 9.1 and summarized in reference 9.2 suggests a body weight of 159 lbs $(72 \mathrm{~kg}$ ) for an average adult. Reference 9.3 presents data on centroidal locations (also summarized in reference 9.2) which suggest that for people standing along the walkway railing, the distance from railing to body center of gravity is approximately 16 in $(406 \mathrm{~mm})$. Given the box beam dimensions of figure 3.10 , it follows that approximately 80 percent of the live load distributed along the east railing as described above is carried by the east line of walkway hanger rods and end supports. Live loads due to people standing near the center of the walkway were assumed to be distributed equally between the east and west line of walkway hanger rods and end supports. 
Using the average body weight and centroidal location indicated above, the upper-bound walkway occupancy described in table 4.1 is translated into east and west live load components acting in the plane of the fourth floor to ceiling hanger rods. These loads, which in the following analysis are assumed to be uniformly distributed over the length of a given span, are listed as total span live loads in table 9.4 .

\subsection{ANALYSIS OF WALKWAY STRUCTURAL COMPONENTS}

\subsubsection{General}

As a part of this investigation, the walkway structural components and their connections were checked for compliance with the project specifications [2.1]. Specifically, this involved the checking of structural details and stresses against the geometric limitations and working stress provisions of the AISC Specification for the Design, Fabrication and Erection of Structural Steel for Buildings [2.4] using the nominal dead load and specified design live load discussed in section 9.2 . In this analysis the walkway system was assumed to be statically determinate, i.e., all stringer to box beam connections and the shear connections at column line 7 were considered to be pinned. The nominal dead loads are based on a unit weight of $110 \mathrm{pcf}\left(1,760 \mathrm{~kg} / \mathrm{m}^{3}\right)$ for concrete, a deck thickness of $31 / 4$ in $(83 \mathrm{~mm})$ and the estimated weight of all other materials for each span as listed in table 9.1. The area over which the 100 psf ( $4.79 \mathrm{kPa}$ ) live load acts is based on the clear width of walkway (inside face to inside face of railing glass) which is $8.25 \mathrm{ft}(2.51 \mathrm{~m})$ for the second and fourth floor walkways. These loads are listed in table 9.5. Under the combined action of nominal dead load and design live load, the maximum load acting on a fourth floor box beam-hanger rod connection would be $40.7 \mathrm{kips}$ ( $181 \mathrm{kN}$ ). The maximum load on a second floor box beam-hanger rod connection would be 20.3 kips $(90 \mathrm{kN})$. From this analysis of the walkway system, it was concluded that the box beam-hanger rod connections and the fourth floor to ceiling hanger rods do not satisfy the requirements of the AISC Specification.

\subsubsection{Box Beam-Hanger Rod Connections}

The box beam-hanger rod connection detail used in the walkway construction is not among the connection details suggested in the AISC Manual of Steel Construction [9.4]. Without a properly validated analytical model or supporting test data, there can be no reasonable certainty as to the load capacity of such a connection.

The hanger rods apply concentrated loads to the flanges of the box beam. It is well recognized that concentrated loads may cause a problem in steel structures unless their effects are taken into account properly in design. Section 1.10 of the AISC Specification addresses this point. Section 1.10.5 indicates that bearing stiffeners shall be provided, where required, at points of concentrated load. Section 1.10.10 limits the compressive stress at the web toe of fillets resulting from concentrated loads not supported by bearing stiffeners to $0.75 \mathrm{~F}_{\mathrm{y}}$; otherwise, bearing stiffeners shall be provided. It is common practice to limit this compressive stress by providing a bearing plate for the concentrated load. The purpose of these provisions is to distribute the effects of concentrated load over a larger area of the structural member and, by doing 
so, prevent instability or local plastification of the web. It is implicit in these provisions that the loads are applied in the plane of the web. These provisions do not anticipate intentional and significant eccentricities of applied load, as in the case of the box beam-hanger rod connections.

The absence of any stiffeners or bearing plates in the box beam-hanger rod connections indicates that the effects of concentrated load were not given proper attention. By depending solely on the channel flanges to transfer load from the hanger rod to the webs, there can be no assurance that the webs are stable or that the web stresses are not critical. It is therefore concluded that this connection detail does not satisfy the intent of the AISC Specification with regard to the proportioning of such connections.

\subsubsection{Hanger Rods}

With regard to hanger rod stresses, section 1.5 .2 of the AISC Specification allows a tensile stress equal to $0.60 \mathrm{~F}_{\mathrm{y}}$ applied to a tensile stress area equal to

$$
0.7854\left(D-\frac{0.9743}{n}\right)^{2}
$$

where $D$ is the major thread diameter and $n$ is the number of threads per inch. For the $11 / 4$ in ( $32 \mathrm{~mm}$ ) diameter rods used in the walkway construction, $\mathrm{F}_{\mathrm{y}}=36 \mathrm{ksi}$ (250 MPa) and the allowable load per hanger rod is $21.3 \mathrm{kips}$ $(95 \mathrm{kN})$. The combined nominal dead loads and design live loads of table 9.5 call for a design capacity of $20.3 \mathrm{kips}(90 \mathrm{kN})$ for the second to fourth floor hanger rods and $40.7 \mathrm{kips}(181 \mathrm{kN})$ for the fourth floor to ceilling hanger rods. Under dead load alone, the fourth floor to ceiling hanger rods are loaded to approximately 75 percent of allowable design load. The required design capacity for the third floor walkway hanger rods would be approximately 23.1 kips $(103 \mathrm{kN})$.

\subsubsection{Summary of Analysis}

To summarize the analysis of walkway components under the action of nominal dead load plus specified design live load, it is concluded that without a properly validated analytical model or supporting test data, there can be no reasonable certainty as to the load capacity of the box beam-hanger rod connection used in the walkway construction. It is further concluded that the connection detail does not satisfy the intent of the AISC provisions for the proportioning of such connections.

With regard to hanger rods, it is concluded that the second to fourth floor hanger rods complied with the the AISC provisions for allowable stresses, but the fourth floor to ceiling hanger rods and the third floor walkway hanger rods did not. 


\subsection{FORCES ACTING ON THE HANGER RODS AT TIME OF COLLAPSE}

A two-dimensional finite element representation of the walkway system was used to obtain estimates of forces acting on the hanger rods at the time of collapse. At the box beams it was assumed that the length of channel flanges acting in longitudinal walkway bending induced by the stringers was equal to 30 times the average flange thickness. Both top and bottom box beam flanges were assumed to be effective. This is consistent with the idealization used in the dynamic analysis to be discussed in section 9.6.1. For the distribution of loads applied after placement of the concrete deck, composite action was assumed. The transformed section for one stringer was based on an effective width of concrete deck equal to the sum of the stringer flange width and six times the total depth of the deck [9.4]. The walkways were assumed to be pin-connected at column line 7 and the hanger rod stiffnesses were modified to account for the load/deformation characteristics of the box beam-hanger rod connections as described in chapter 6 . The computer code used in the analysis is an in-house version of GIFTS [9.5].

Dead loads due to the span weights listed in table 9.1 were applied in three stages. The first stage loading included the hanger rods, structural steel and formed steel deck. Loads were distributed to the hanger rods with the assumption that the connections at the ends of each stringer were pinned. The second stage loading consisted of the concrete deck weights without topping material as listed in table 9.2. In this case the box beam flanges were considered to be acting in longitudinal walkway bending as previously described. The final stage included the topping material and all other walkway components with the stringers and deck assumed to be acting as a composite.

The two-dimensional finite element model of the walkway system was also used to distribute the upper-bound live loads of table 9.4 to the hanger rods and walkway end supports. Implicit in this approach is the assumption that the east and west halves of the walkway system are uncoupled and compatibility between east- and west-side vertical deflections can be ignored. In view of the small load differential between east and west sides as indicated in table 9.4, this is not considered to be a serious limitation. The resultant forces acting on the walkway hanger rods and end supports due to combined dead load and upper-bound live load are listed in table 9.6. It is seen from table 9.6 that the estimated maximum load acting on a fourth floor to ceiling hanger rod is $21.4 \mathrm{kips}$ (95 kN) at location 8UE. The estimated maximum load acting on a second to fourth floor hanger rod is 11.5 kips $(51 \mathrm{kN})$ at location $8 \mathrm{LE}$.

\subsection{WALKWAY DEFLECT IONS}

Walkway dead load deflections at the hanger rod positions are listed in table 9.7 according to the composition of span weight listed in table 9.3. Although little information is available regarding the walkway construction sequence, it is reasonable to assume that the walkways were brought into final vertical alignment after placement of the formed steel deck. Subsequent placement of the concrete and topping material would have caused an initial vertical displacement of approximately 0.33 in $(8.4 \mathrm{~mm})$ at location 9L. Addition of the 
handrail assembly would have increased this to 0.41 in $(10.5 \mathrm{~mm})$ and the addition of gypsum board and various finish materials would have resulted in a total vertical displacement of approximately $0.5 \mathrm{in}(13 \mathrm{~mm})$ at location 9L. As has been noted in section 3.4, the handrail assembly was adjusted to compensate for midspan deflections, and it is reasonable to assume that a similar procedure was followed during installation of the gypsum board. Thus the cumulative displacements due to dead load would be apparent only at the hanger rod locations. Given the length of the walkways, it is doubtful that these displacements, if detected, would have been cause for concern.

\subsection{EFFECTS OF DYNAMIC EXCITATION}

Thus far in this chapter the emphasis has been on statically applied loads and their effect on various components of the walkway system. As has been noted in chapter 4, there was at least one report of people dancing on the walkways at the time of collapse. It is the purpose of this section to examine the dynamic characteristics of the walkways, the manner in which activities such as dancing could have excited the walkway system, and the significance of the resulting forces when compared with the static load effects discussed earlier in this chapter.

\subsubsection{Dynamic Characteristics of the Walkways}

Preliminary to investigating the role of dynamic excitation in the collapse, the walkway system, consisting of the second and fourth floor walkways, was modeled analytically to determine the undamped natural frequencies. This work, which involved the development of a three-dimensional discrete element analytical model, is reported in reference 9.6 .

Procedures used in the analysis were verified by modeling the third floor walkway first. Results were then compared with field measurements reported in reference 2.5. Essential features of the idealized third floor walkway are as follows:

- Walkway end supports: All supports are constrained in the vertical direction. No rotational constraints are imposed. North-south translation is constrained at location 7ME. East-west translation is constrained at locations $7 \mathrm{ME}$ and $11 \mathrm{ME}$.

- Longitudinal beams: Assumed to be of continuous composite construction (W16 × 26 stringer and portion of concrete deck). Longitudinal continuity is provided at each box beam by a short flexural element consisting of portions of the deck and of the top and bottom flanges of the box beam.

- Deck: Portions of composite concrete deck act with longitudinal beams in resisting vertical and horizontal flexure. Deck also provides horizontal shearing resistance and, for this purpose, is idealized as an equivalent truss web of crossed diagonals. 
Masses: Masses are lumped at the nodes which correspond to the locations of the stringer to box beam and stringer to cross beam connections. Assumed weight per span is $19,0001 \mathrm{bs}(8,620 \mathrm{~kg})$. Live load is assumed to be zero.

Calculated and measured dynamic characteristics of the third floor walkway are compared in table 9.8. For those modes that could be clearly identified in the measured acceleration spectra of reference 2.3 the agreement is exceptionally good.

With this confirmation of the analytical technique, the next step was to model the second and fourth floor walkways as a combined system using essentially the same idealization outlined above. In the resulting model there were 610 static and 120 dynamic degrees of freedom. Two cases were considered: (1) dead load equal to $17,5001 \mathrm{bs}(7,940 \mathrm{~kg})$ per span and (2) dead load plus a superimposed live load of 20 psf ( $958 \mathrm{~Pa})$. Results of these analyses for the first 10 modes and the second horizontal mode (mode no. 17) are listed in table 9.9. Note that the first two modes are essentially identical and correspond to horizontal excitation of the second and fourth floor walkways, respectively.

Three other frequencies associated with the walkway system are of interest in assessing dynamic effects:

- In addition to those constraints as described for the third floor walkway end supports, constraints on north-south and east-west translations at locations $7 \mathrm{UW}$ and $7 \mathrm{LW}$.

- Dead load only, first horizontal mode. $\mathrm{f}=4.98 \mathrm{~Hz}$

- Dead load plus superimposed live load of 20 psf ( $960 \mathrm{~Pa}$ ), first horizontal mode. $\mathrm{f}=4.43 \mathrm{~Hz}$

Simply supported walkway stringer with corresponding dead load, vertical mode. $\mathrm{f}=8.24 \mathrm{~Hz}$

- Vertical vibration of hanger rod and masses due to dead load on associated second and fourth floor influence areas (2 degrees of freedom). $f=8.11 \mathrm{~Hz}$

\subsubsection{Sources of Dynamic Excitation}

In assessing the significance of dynamic excitation, the walkway system is considered to be represented adequately by a single degree of freedom, viscously damped system. The magnification factor, or ratio of the dynamic deflection to the zero frequency deflection, is determined for the frequency of harmonic excitation using the most critical walkway natural frequency. The ratio of the induced force to the applied force is taken to be equal to the magnification factor.

Given the range of frequencies of the walkway system, both steady state harmonic oscillations and transient vibrations need to be addressed. Considering first the case of harmonic oscillations, the lowest natural frequency of the walkway 
system in the vertical mode is $6.6 \mathrm{~Hz}$ for the case of a 20 psf (958 Pa) live load. The corresponding frequency for the upper-bound live load, assumed to be uniformly distributed over the two walkways, is approximately $7.1 \mathrm{~Hz}$. Estimates of the damping ratio, obtained from time histories of the third floor walkway vertical mode accelerations presented in reference 2.5 , ranged from 0.012 to 0.028 . Considering the fact that these time histories were obtained at very low levels of response, it is reasonable to select a damping ratio of at least 0.02 for this analysis.

Although no reference to actual measurements of dynamic excitation associated with dancing could be found in the literature, reference 9.7 presents response spectra for floor systems excited by a person treading at a fixed point. For lack of a better model, this motion will be taken as an acceptable approximation of vertical motions due to dancing. A recording of the music being played at the time of the collapse was analyzed and the tempo corresponds to a treading frequency of about $1.1 \mathrm{~Hz}$. For a natural frequency of $7.1 \mathrm{~Hz}$ and a damping ratio of 0.02 , the magnification factor from reference 9.7 is 0.6 . Taking the dynamic component of the treading load to be equal to body weight as suggested by reference 9.7 , the corresponding effective dynamic force is 0.6 times 159 , or $951 \mathrm{bs}(422 \mathrm{~N})$ per person. The force imposed on a hanger rod would depend upon the mode shape of the walkway system and body location, but it can be conservatively taken to be divided equally between a hanger rod pair, or $951 \mathrm{bs}$ $(422 \mathrm{~N})$ per hanger rod for each couple dancing.

While the effects of horizontal vibrations on hanger rod forces would be expected to be negligible, they are examined here for completeness. It is shown in reference 9.6 that the walkways essentially respond as uncoupled structures. From table 9.9, the lowest natural frequency for the horizontal mode is $2.87 \mathrm{~Hz}$ for the case of a $20 \mathrm{psf}(958 \mathrm{~Pa})$ live load. The corresponding frequency for the estimated fourth floor walkway dead load and upper-bound live load is approximately $3.2 \mathrm{~Hz}$. Taking the frequency of the horizontal excitation to be one-half that of the vertical excitation, or $0.55 \mathrm{~Hz}$, the corresponding magnification factor is 1.03. When the north-south and east-west translations at location 7UW are constrained (pinned connections at column line 7), the natural frequency is approximately $4.9 \mathrm{~Hz}$ and the magnification factor is 1.01 . Assuming the higher harmonics of the horizontal component of forces applied by dancing to be negligible, the walkway would be expected to respond in a quasistatic manner. Reference 9.8 presents data that suggest a horizontal component of contact force equal to 32 percent of body weight for the case of right angle turns while walking. Using this to approximate the horizontal component of force due to dancing, the corresponding applied force would be approximately $1001 \mathrm{bs}(445 \mathrm{~N})$ for each couple dancing. Unlike the vertical forces, the horizontal forces would tend to be randomly directed and would not be directly additive.

Based upon this brief analysis, it does not appear that dancing involving a reasonable number of walkway occupants would give rise to steady state oscillations that would warrant a more detailed analysis.

Transient vibrations arise from impulse loads such as heel drop (sudden release from tiptoe position, landing on heels). These forces are of short duration 
(less than $0.060 \mathrm{sec}$ ) and their magnitude is strongly influenced by the hardness of the contact surface. Reference 9.7 presents response spectra for heel drop loading on floor systems and suggests a contact force equal to 3.75 times the static contact force. The largest magnification factors occur at natural frequencies of approximately $16 \mathrm{~Hz}$. In section 9.6 .1 the vertical mode frequencies for a simply supported walkway stringer and a hanger rod with tributary masses are listed as 8.24 and $8.11 \mathrm{~Hz}$, respectively. Taking a heel drop directly adjacent to a hanger rod as the worst case, the corresponding magnification factor from reference 9.7 is approximately 1.05 . With body position taken to be along the railing as described in section 9.2.2, the increase in hanger rod loading due to heel drop would be approximately $0.8[(1.05)(3.75)(159)-159]=$ 375 lbs $(1.7 \mathrm{kN})$. Because of their short duration time, simultaneous heel drops by two or more people would be dfficult to achieve.

Considering the fact that the fourth floor box beam-hanger rod connections would respond inelastically at a load level equal to dead load plus upper-bound live load and the fact that the walkway surface was covered with a commercial grade carpet and underlying pad, the actual increase in hanger rod load would be less than 375 lbs. With only a modest attenuation of $-3 \mathrm{~dB}$, the increment of hanger rod load due to heel drop would be reduced to approximately $0.71 \times 375=$ $2651 \mathrm{bs}(1.2 \mathrm{kN})$ or about 1 percent of the average hanger rod load at the fourth floor level under dead load plus upper-bound live load (see table 9.6). This is within the range of uncertainty for estimates of span weights as pointed out in section 9.2 .1 .

\subsection{SUMMARY}

Based on load data, relevant codes and standards, and analytical studies, the following conclusions regarding the walkway system were drawn:

1. The average estimated in-place weight of a walkway span is $17,7501 \mathrm{bs}$ $(8,050 \mathrm{~kg})$.

2. Actual span weights would, on average, exceed the nominal span weights by approximately $1,3001 \mathrm{bs}(590 \mathrm{~kg})$ or about 8 percent.

3. Under the combined action of nominal dead load and design live load, the maximum load acting on a fourth floor box beam-hanger rod connection would be $40.7 \mathrm{kips}(181 \mathrm{kN})$. The maximum load on a second floor box beam-hanger rod connection would be $20.3 \mathrm{kips}(90 \mathrm{kN})$.

4. The box beam-hanger rod connection detail used in the walkway construction does not satisfy the intent of the AISC provisions for the proportioning of such connections.

5. The fourth floor to ceiling hanger rods and the third floor walkway hanger rods do not comply with the AISC provisions for allowable stresses. 
6. The maximum load believed to have been acting on a fourth floor to ceiling hanger rod at the time of collapse is approximately $21.4 \mathrm{kips}$ $(95 \mathrm{kN})$ at location 8UE. For the second to fourth floor hanger rods, this load is approximately $11.5 \mathrm{kips}(51 \mathrm{kN})$ at location $8 \mathrm{LE}$.

7. The maximum walkway deflection due to dead load was approximately 0.5 in $(13 \mathrm{~mm})$.

8. Dynamic loads induced by walking or dancing on the walkways would not have been significant in comparison to the static loads. 
Table 9.1 Summary of Span Weights

\begin{tabular}{|c|c|c|c|c|c|c|}
\hline \multirow[b]{2}{*}{$\begin{array}{c}\text { Span } \\
\text { Number }\end{array}$} & \multicolumn{3}{|c|}{$\begin{array}{c}\text { Weight in Damaged Condition } \\
\text { (1bs) }\end{array}$} & \multicolumn{3}{|c|}{$\begin{array}{c}\text { Estimated Weights of Undamaged Spans } \\
\text { (1bs) }\end{array}$} \\
\hline & $\begin{array}{c}\text { Measured } \\
\text { Span Weight }\end{array}$ & $\begin{array}{l}\text { Calculated Weights } \\
\text { of Materials Other } \\
\text { Than Deck }\end{array}$ & $\begin{array}{l}\text { Concrete } \\
\operatorname{Deck}(a)\end{array}$ & $\begin{array}{l}\text { Concrete } \\
\operatorname{Deck}(a)\end{array}$ & $\begin{array}{l}\text { All other } \\
\text { Materials }\end{array}$ & $\begin{array}{l}\text { Total Weight } \\
\text { of Span }\end{array}$ \\
\hline $\mathrm{U} 7-8$ & 15,760 & 6,130 & 9,630 & 9,630 & 8,090 & 17,720 \\
\hline U8-9 & 15,950 & 6,240 & 9,710 & 10,140 & 8,200 & 18,340 \\
\hline U9-10 & 14,600 & 4,850 & 9,750 & 9,950 & 8,210 & 18,160 \\
\hline U10-11 & 14,000 & 4,530 & 9,470 & 10,150 & 8,120 & 18,270 \\
\hline $\mathrm{L} 7-8$ & 15,130 & 5,630 & 9,500 & 9,500 & 7,960 & 17,460 \\
\hline L8-9 & Span & weight not measured & & 10,050 (b) & 7,940 & 17,990 \\
\hline L9-10 & 14,160 & 4,800 & 9,360 & 9,380 & 7,950 & 17,330 \\
\hline L10-11 & 13,170 & 4,570 & 8,600 & 8,700 & 7,990 & 16,690 \\
\hline
\end{tabular}

Note: (a) Includes topping material, shear studs and welded wire fabric.

(b) Deck weight based on average unit deck weight of all other spans as indicated in table 9.2 .

$1 \mathrm{lb}=0.4536 \mathrm{~kg}$ 
Table 9.2 Comparison of Concrete Deck Weights Based on Measured Span Weights and on Measured Unit Weights

\begin{tabular}{|l|c|c|c|c|}
\hline \multirow{2}{*}{$\begin{array}{c}\text { Span } \\
\text { Number }\end{array}$} & $\begin{array}{c}\text { Estimated Weight } \\
\text { of Deck (a) } \\
\text { (see table 9.1) }\end{array}$ & $\begin{array}{c}\text { Weight of } \\
\text { Topping Material } \\
(\gamma=116.8 \text { pcf })\end{array}$ & $\begin{array}{c}\text { Weight of Deck } \\
\text { Without Topping (a) }\end{array}$ & $\begin{array}{c}\text { Calculated Deck } \\
\text { Weight (a) } \\
(\gamma=113.5 \text { pcf })\end{array}$ \\
\hline U7-8 & 9,630 & 360 & 9,270 & 8,640 \\
U8-9 & 10,140 & 450 & 9,690 & 8,560 \\
U9-10 & 9,950 & 860 & 9,090 & 8,560 \\
U10-11 & 10,150 & 1,080 & 9,070 & 8,650 \\
L7-8 & 9,500 & 390 & 9,110 & 8,640 \\
L8-9 & 10,050 & 990 & $9,060(b)$ & 8,560 \\
L9-10 & 9,380 & 450 & 8,930 & 8,560 \\
L10-11 & 8,700 & 90 & 8,610 & 850 \\
\hline
\end{tabular}

Note: (a) Includes shear studs and welded wire fabric.

(b) Based on average unit deck weight of 39.0 psf for seven other spans.

$1 \mathrm{lb}=0.4536 \mathrm{~kg}$

$1 \mathrm{pcf}=16.02 \mathrm{~kg} / \mathrm{m}^{3}$ 
Table 9.3 Composition of Span Weight for Typical Walkway Interior Span

\begin{tabular}{|l|c|c|}
\hline $\begin{array}{c}\text { Walkway } \\
\text { Component }\end{array}$ & $\begin{array}{c}\text { Weight } \\
\text { (lbs) }\end{array}$ & $\begin{array}{c}\text { Percent of } \\
\text { Total }\end{array}$ \\
\hline Walkway deck(a) & 9,880 & 55.0 \\
Handrail assembly & 2,450 & 13.6 \\
Structural steel & 2,370 & 13.2 \\
Gypsum board & 2,310 & 12.9 \\
Other(b) & 950 & 5.3 \\
Total & 17,960 & 100.0 \\
\hline
\end{tabular}

Notes: (a) Includes topping material, shear studs and welded wire fabric.

(b) Includes formed metal deck, footlights, carpet, sprinkler pipes and aluminum slats.

$1 \mathrm{lb}=0.4536 \mathrm{~kg}$ 
Table 9.4 Upper-Bound Live Loads for Second and Fourth Floor Walkway Spans

\begin{tabular}{|c|c|c|}
\hline \multirow[b]{2}{*}{$\begin{array}{c}\text { Span } \\
\text { Number }\end{array}$} & \multicolumn{2}{|c|}{ Resultant Live Load Acting in Plane of Hanger Rods } \\
\hline & $\begin{array}{c}\text { East Side } \\
\text { (1bs) }\end{array}$ & $\begin{array}{c}\text { West Side } \\
\text { (1bs) }\end{array}$ \\
\hline $\mathrm{U} 7-8$ & 382 & 95 \\
\hline U8-9 & 254 & 64 \\
\hline U9-10 & 127 & 32 \\
\hline U10-11 & 127 & 32 \\
\hline L7 -8 & 2,162 & 1,018 \\
\hline L8-9 & 2,003 & 859 \\
\hline L9-10 & 1,590 & 636 \\
\hline L10-11 & 509 & 127 \\
\hline
\end{tabular}


Table 9.5 Span Loadings Based on Nominal Dead Load and Design Live Load

\begin{tabular}{|c|c|c|c|}
\hline $\begin{array}{c}\text { Span } \\
\text { Number }\end{array}$ & $\begin{array}{c}\text { Nominal } \\
\text { Dead Load } \\
\text { (1bs) }\end{array}$ & $\begin{array}{c}\text { Design } \\
\text { Live Load } \\
\text { (1bs) }\end{array}$ & $\begin{array}{c}\text { Tota1 } \\
\text { Design Load } \\
\text { (1bs) }\end{array}$ \\
\hline U7-8 & 16,500 & 24,400 & 40,900 \\
U8-9 & 16,500 & 24,100 & 40,600 \\
U9-10 & 16,500 & 24,100 & 40,600 \\
U10-11 & 16,500 & 24,400 & 40,900 \\
L7-8 & 16,300 & 24,400 & 40,700 \\
L8-9 & 16,200 & 24,100 & 40,300 \\
L9-10 & 16,300 & 24,100 & 40,400 \\
L10-11 & 16,400 & 24,400 & 40,800 \\
\hline
\end{tabular}

$10001 \mathrm{bs}=4.448 \mathrm{kN}$ 
Table 9.6 Forces Acting on Walkway Hanger Rods and End Supports Due to Combined Dead Load and Upper-Bound Live Load

\begin{tabular}{|c|c|c|c|}
\hline Location & $\begin{array}{c}\text { Dead Load } \\
\text { Component } \\
\text { (1bs) }\end{array}$ & $\begin{array}{c}\text { Upper-Bound Live } \\
\text { Load Component } \\
\text { (1bs) }\end{array}$ & $\begin{array}{l}\text { Total } \\
\text { (lbs) }\end{array}$ \\
\hline 7UE & 3,800 & 200 & 4,000 \\
\hline 7UW & 3,800 & 60 & 3,860 \\
\hline $8 U E$ & 18,900 & 2,490 & 21,390 \\
\hline $8 \mathrm{UW}$ & 18,900 & 1,060 & 19,960 \\
\hline 9UE & 18,210 & 2,080 & 20,290 \\
\hline 9UW & 18,210 & 830 & 19,040 \\
\hline 1OUE & 18,600 & 1,190 & 19,790 \\
\hline 10UW & 18,600 & 420 & 19,020 \\
\hline 11UE & 3,930 & 60 & 3,990 \\
\hline $11 \mathrm{UW}$ & 3,930 & 20 & 3,950 \\
\hline 7LE & 3,850 & 950 & 4,800 \\
\hline $7 \mathrm{LW}$ & 3,850 & 450 & 4,300 \\
\hline $8 \mathrm{LE}$ & 9,270 & 2,200 & 11,470 \\
\hline $8 \mathrm{LW}$ & 9,270 & 1,000 & 10,270 \\
\hline $9 \mathrm{LE}$ & 9,040 & 1,860 & 10,900 \\
\hline $9 \mathrm{LW}$ & 9,040 & 770 & 9,810 \\
\hline 10LE & 8,860 & 1,060 & 9,920 \\
\hline $10 \mathrm{LW}$ & 8,860 & 380 & 9,240 \\
\hline $11 \mathrm{LE}$ & 3,690 & 180 & 3,870 \\
\hline $11 \mathrm{LW}$ & 3,690 & 40 & 3,730 \\
\hline
\end{tabular}

$10001 \mathrm{bs}=4.448 \mathrm{kN}$ 
Table 9.7 Walkway Vertical Displacements Due to Dead Load

\begin{tabular}{|c|c|c|c|c|}
\hline \multirow[b]{3}{*}{ Dead Load Component } & \multicolumn{4}{|c|}{ Vertical Displacements (inches) } \\
\hline & \multicolumn{4}{|c|}{ Location } \\
\hline & $8 \mathrm{U} \& 10 \mathrm{U}$ & $9 \mathrm{U}$ & $8 \mathrm{~L} \& 10 \mathrm{~L}$ & $9 \mathrm{~L}$ \\
\hline Concrete deck and topping & .22 & .23 & .32 & .33 \\
\hline Handrail assembly & .06 & .06 & .08 & .08 \\
\hline Gypsum board & .05 & .05 & .08 & .08 \\
\hline Other items & .01 & .01 & .02 & .02 \\
\hline
\end{tabular}

1 in $=25.4 \mathrm{~mm}$ 
Table 9.8 Calculated and Measured Characteristics of the Third Floor Walkway

\begin{tabular}{|c|c|c|c|c|c|}
\hline \multirow[b]{2}{*}{$\begin{array}{l}\text { Mode } \\
\text { No. }\end{array}$} & \multicolumn{3}{|c|}{ Calculated } & \multicolumn{2}{|c|}{ Measured } \\
\hline & Classification* & $\begin{array}{l}\text { Period } \\
\text { (Sec.) }\end{array}$ & $\begin{array}{c}\text { Frequency } \\
(\mathrm{Hz})\end{array}$ & Classification* & $\begin{array}{c}\text { Frequency } \\
(\mathrm{Hz})\end{array}$ \\
\hline 1 & Hor. & .266 & 3.76 & Hor. & $3-3 / 4$ \\
\hline 2 & Vert. & .127 & 7.88 & Vert. & 7 \\
\hline 3 & Tors. & .127 & 7.88 & & \\
\hline 4 & Vert. & .122 & 8.20 & Vert. & $8-1 / 4$ \\
\hline 5 & Tors. & .118 & 8.46 & & \\
\hline 6 & Vert. & .112 & 8.91 & Vert. & 10 \\
\hline 7 & Vert. & .106 & 9.46 & & \\
\hline 8 & Tors. & .103 & 9.70 & & \\
\hline 9 & Tors. & .094 & 10.65 & & \\
\hline 10 & Hor. & .068 & $14 \cdot 64$ & Hor. & 12 \\
\hline
\end{tabular}

* Predominant motion. 
Table 9.9 Calculated Characteristics of the Second and Fourth Floor Walkways

\begin{tabular}{|c|c|c|c|c|c|}
\hline \multirow[b]{2}{*}{$\begin{array}{l}\text { Mode } \\
\text { No. } \\
\end{array}$} & \multirow[b]{2}{*}{ Classification* } & \multicolumn{2}{|c|}{ No Live Load } & \multicolumn{2}{|c|}{20 psf Live Load } \\
\hline & & $\begin{array}{l}\text { Period } \\
\left(\mathrm{Sec}_{.}\right)\end{array}$ & $\begin{array}{c}\text { Frequency } \\
(\mathrm{Hz})\end{array}$ & $\begin{array}{l}\text { Period } \\
(\text { Sec.) }\end{array}$ & $\begin{array}{c}\text { Frequency } \\
(\mathrm{Hz})\end{array}$ \\
\hline 1 & Hor . & .310 & 3.23 & .349 & 2.87 \\
\hline 2 & Hor. & .310 & 3.23 & .349 & 2.87 \\
\hline 3 & Vert. & .135 & 7.42 & .152 & 6.60 \\
\hline 4 & Vert. & .134 & 7.44 & .151 & 6.62 \\
\hline 5 & Vert. & .129 & 7.76 & .145 & 6.90 \\
\hline 6 & Tors. & .125 & 7.98 & .141 & 7.10 \\
\hline 7 & Tors. & .124 & 8.03 & .141 & 7.14 \\
\hline 8 & Tors. & .123 & 8.14 & .138 & 7.23 \\
\hline 9 & Vert/Tors & .122 & 8.21 & .137 & 7.30 \\
\hline 10 & Tors. & .122 & 8.21 & .137 & 7.30 \\
\hline 17 & Hor. & .079 & 12.65 & .089 & 11.25 \\
\hline
\end{tabular}

* Predominant motion. 


\section{INTERPRETATION OF TESTS, ANALYSES AND OBSERVATIONS}

\subsection{INTRODUCTION}

This chapter evaluates the results of structural tests and the analysis of the walkway system for the purpose of determining the most probable cause of the collapse. The probable sequence of collapse, effect of change in hanger rod arrangement, and quality of materials and workmanship are also addressed.

Section 10.2 makes a direct comparison of estimated fourth floor box beam-hanger rod connection capacities with loads believed to have been acting on the connections at the time of collapse.

Section 10.3 compares the mean ultimate capacities of the box beam-hanger rod connections with the ultimate capacity that would be expected of a connection designed in accordance with the AISC Specification.

Section 10.4 combines observations of damage described in chapter 5 of this report to establish the probable sequence of the collapse.

Section 10.5 addresses the significance of the change from a continuous hanger rod to interrupted rods in the second and fourth floor walkway construction. Quality of materials and workmanship is discussed in section 10.6. The findings and conclusions of this chapter are summarized in section 10.7 .

\subsection{COMPARISON OF LOADS AND BOX BEAM-HANGER ROD CONNECTION CAPACITIES}

A layout of the 6 fourth floor box beam-hanger rod connections is shown in figure 10.1. Two bar diagrams, one for load capacity of the connection and one for imposed load, are shown adjacent to each hanger rod. The bar diagram on the left side of the figure will be discussed in section 10.3.

Location $8 \mathrm{UE}$ is described in detail to illustrate the meaning of the diagrams. The bar diagram to the left of the hanger rod denotes load capacity of the connection. The range from 16.3 to $20.2 \mathrm{kips}$ (73 to $90 \mathrm{kN}$ ) is the 95 percent confidence interval estimate for the ultimate capacity of this particular box beam-hanger rod connection based on tests conducted on NBS fabricated specimens as reported in section 6.13 . The estimated mean ultimate capacity of 18.2 kips $(81 \mathrm{kN})$ is also shown. The connection at location 8UE was required to support forces imposed by combined dead and live load actions. These forces are shown in the bar diagram to the right of the hanger rod. Of the 6 fourth floor box beam-hanger rod connections, the connection at location 8UE was the most heavily loaded. The estimated dead load action at location $8 \mathrm{UE}$ is $18.9 \mathrm{kips}$ ( $84 \mathrm{kN}$ ) and the contribution of the upper-bound live load at the time of collapse is 2.5 kips $(11 \mathrm{kN})$, resulting in a total load of $21.4 \mathrm{kips}(95 \mathrm{kN})$ as addressed in section 9.4 and as listed in table 9.6. Under the action of nominal dead load plus code-specified live load, this load would have been 40.7 kips $(181 \mathrm{kN})$. Thus the maximum load acting on a fourth floor box beam-hanger rod connection at the time of collapse was 53 percent of what was required for design under the Kansas City Building Code. 
Figure 10.1 presents similar information for the other fourth floor box beamhanger rod connections. This figure shows that, with the exception of locations 8UE and 10UW, the estimated mean ultimate capacity of each fourth floor box beam-hanger rod connection either equals or slightly exceeds the estimated dead load effect. However, the estimated mean ultimate capacity is exceeded by the sum of the estimated dead load and upper-bound live load in every case.

As noted in section 6.12 .2 , the data base for connections tested using box beam specimens, nuts and washers removed from the walkway debris consists of only three points. When compared with the NBS box beam test series, all three points are within or near the 95 percent confidence band, but there is a tendency toward the upper limit of the band. The MC8 88.5 shapes used in the walkway box beams are slightly heavier than those used to fabricate the NBS specimens (see table 6.6). Of particular significance is the larger average web thickness $(0.190$ vs 0.184 in $(4.83$ vs $4.67 \mathrm{~mm})$ ) which would increase the bending resistance of the webs. It is also possible that the actual live load on the walkways at the time of collapse was less than the upper-bound live load used to arrive at the estimated hanger rod loads shown in figure 10.1. Recall from chapter 4 that approximately 40 people were observed on the second floor walkway shortly before the collapse and that 63 people are considered to be a credible upper bound on combined second and fourth floor walkway occupancy.

Regardless of these qualifications on estimated loads and ultimate capacities, it is clear that each of the 6 fourth floor box beam-hanger rod connections had a high probability of failure; each connection was a candidate for initiation of walkway collapse. Failure of any one of the connections would have been accompanied by a redistribution or transfer of load to other hanger rods. With no apparent significant reserve capacity to accommodate this redistribution, progressive failure of the remaining connections was assured. Thus, failure of any one connection would have led to complete collapse of the walkway system.

\subsection{ULT IMATE CAPACITY BASED ON CODE REQU IREMENTS}

It is important to point out that the load capacities described in figure 10.1 are ultimate values. As noted in section 9.3.3, the design load (estimated nominal dead load plus code-specified design live load) for a fourth floor to ceiling hanger rod is 40.7 kips ( $181 \mathrm{kN}$ ). This is the load that should be used in a working stress approach to design in which the nominal strengths of materials are reduced by an appropriate factor of safety.

Because of the safety factor, the resulting connection would be expected to have an ultimate load capacity substantially higher than the working stress value of $40.7 \mathrm{kips}(181 \mathrm{kN})$. Using a factor of safety of 1.67 , which is the lowest value that would govern any part of the design of the box beam-hanger rod connections under the applicable provisions of the AISC Specification, it would be expected that the ultimate load capacity of the resulting connection would be at least 1.67 times 40.7 , or $68 \mathrm{kips}(302 \mathrm{kN})$. Thus any given box beam-hanger rod connection in the fourth floor walkway should have been able to support an ultimate load of at least $68 \mathrm{kips}(302 \mathrm{kN})$ instead of the average ultimate capacity of 18.6 kips $(83 \mathrm{kN})$ estimated for the 6 fourth floor walkway connections. Since 
the AISC Specification is the basis for the steel design provisions of the Kansas City Building Code, this same ultimate load capacity would be expected of a connection designed under the Kansas City Building Code. The hanger rod load to be applied in working stress design under the Kansas City Building Code and the expected ultimate load capacity are shown in the bar diagram on the left in figure 10.1 .

\subsection{PROBABLE SEQUENCE OF COLLAPSE}

While the collapse could have initiated at any of the connections, the physical evidence described in chapter 5 points to 9UE as the initiating point. To summarize that evidence, the observed mirror symmetry of distortions about box beam $9 \mathrm{U}$ is a compelling argument for initiation of collapse at column line 9. As has been discussed in sections 5.2 .5 and 5.3 .2 , observations made in the atrium and on the debris at the warehouse strongly suggest that the west side box beam-hanger rod connections of each of the three fourth floor box beams failed after the corresponding east side connection.

The sequence of collapse is believed to have been loss of support at location 9UE with loads being transferred to locations 8UE, 9UW, and 10UE. It is not entirely certain which of these three connections failed next, but it is clear that all three box beams rotated downward about the west line of hanger rods. With the failure of connection 9UW, spans U8-9 and U9-10 would have rotated downward about box beams $8 \mathrm{U}$ and 10U, respectively, and in the process, would have pulled span U10-11 off of its bearing seats at column line 11. The nature of the clip-angle weld failures on box beam $9 U$ suggests that spans U8-9 and U9-10 separated during their downward rotation. At that same time the fourth floor walkway would have experienced severe negative bending at column lines 8 and 10. However, the evidence suggests that the clip-angle welds at these locations did not fail until after the box beam-hanger rod connections at locations $8 \mathrm{UW}$ and 10UW had failed (see section 5.3.4). In both cases the clipangle fillet welds fractured from bottom to top, indicating positive bending moments in the walkway at column lines 8 and 10 . In the case of box beam $8 \mathrm{U}$ it is likely that positive moment was induced by the north end of span U8-9 striking the second floor walkway while span U7-8 was rotating downward about the shear connections at column line 7. The behavior of the second floor walkway during the collapse is much less clear, but it is believed to have generally followed the progression of failure in the fourth floor walkway.

\subsection{EFFECT OF CHANGE IN HANGER ROD ARRANGEMENT}

As has been noted in chapters 3 and 5, the hanger rod detail actually used in the construction of the second and fourth floor walkways is a departure from the detail shown on the contract drawings (Dwgs. A412 and A508). In the original arrangement each hanger rod was to be continuous from the second floor walkway to the hanger rod bracket attached to the atrium roof framing. The design load to be transferred to each hanger rod at the second floor walkway would have been one-half the sum of the dead load and the resultant live load for a single span, or approximately $20.3 \mathrm{kips}(90 \mathrm{kN}$ ) (see table 9.5). An essentially identical load would have been transferred to each hanger rod at the fourth floor walkway. Thus the design load acting on the upper portion of 
a continuous hanger rod would have been twice that acting on the lower portion, but the required ultimate capacity of the box beam-hanger rod connections would have been the same for both walkways ( $20.3 \mathrm{kips}$ ).

As has been described in chapter 3 , the hanger rod configuration actually used consisted of two hanger rods: the fourth floor to ceiling hanger rod segment as originally detailed and the second to fourth floor segment offset 4 in (102 mm) inward along the axis of the box beam (see figure 10.2). The washer and nut arrangement called for in the original connection detail as shown on Dwg. S405.1 was retained in the actual construction. With this modification the design load to be transferred by each second floor box beam-hanger rod connection was unchanged, as were the loads in the upper and lower hanger rod segments. However, the load to be transferred from the fourth floor box beam to the upper hanger rod under this arrangement was essentially doubled, thus compounding an already critical condition. The design load for the fourth floor box beamhanger rod connection would be 40.7 kips (181 kN) for this configuration.

Had this change in hanger rod detail not been made, the ultimate capacity of the box beam-hanger rod connection would still have been far short of that expected of a connection designed in accordance with the AISC Specification. In terms of ultimate load capacity of the connection, the minimum value should have been 1.67 times 20.3 or 33.9 kips $(151 \mathrm{kN})$. Based on test results reported in chapter 6 , the mean ultimate capacity of a single-rod connection is approximately 20.5 kips $(91 \mathrm{kN})$, depending on the weld area. Thus the ultimate capacity actually available using the original connection detail would have been approximately 60 percent of that expected of a connection designed in accordance with the AISC Specification. Note that, because of the greater dead load and design live load, the third floor walkway connection would have had approximately 53 percent of the expected ultimate capacity. Had the change in hanger rod arrangement not been made, the third floor walkway would have been the most critical of the three.

\subsection{QUALITY OF MATERIALS AND WORKMANSHIP}

With the possible exception of the box beam longitudinal welds, there is no evidence to indicate that either quality of materials or quality of workmanship played any significant role in initiating the collapse. As noted in chapter 7 , tensile properties and chemical compositions of the walkway box beams and hainger rods were found to comply with the requirements of ASTM Standard A36 for structural steel which was specified. Microstructure and hardness of the box beam welds and the box beam and hanger rod materials were normal. Compressive strength of the lightweight concrete used in the walkway decks exceeded the requirement of the project design criteria.

Although misalignment of the embedded plates at column line 7 required a retrofit of the stringer bearing pads on the north span of the fourth floor walkway, direct measurements and observed scratch marks indicate that the walkways were properly aligned with the bearing seats prior to collapse. There was sufficient room to install a nut and washer on the lower end of each fourth floor to ceiling hanger rod, and there is clear evidence that all hanger rod washers were installed. 
In general, the structural welding exhibited good workmanship. Although certain deficiencies were observed in the fleld welding of the clip angles to the embedded plates at column line 7 , these connections experienced large rotational distortions prior to failure of the fillet welds, thus indicating good weld performance. Dimensions of fillet welds were, with few exceptions, in agreement with what was called for on the shop drawings.

The welding symbol and field observations relevant to the box beam longitudinal welds have been discussed in sections 3.3 and 5.3 .3 , respectively. As noted in section 3.3 , the welding symbol used on the shop drawings is interpreted to require a prequalified partial joint penetration groove weld. However, the geometry of the mating surfaces as discussed in section 5.3 .3 and as illustrated in figure 10.3 does not satisfy the dimensional tolerances for a prequalified partial joint penetration groove weld as stated in section 2.10 of AWS D1.1-79; the root face is less than $3 \mathrm{~mm}$ (Item 2.10.2.4), and the required minimum root opening was not provided.

For the case of an MC8 $\times 8.5$ shape, flange thickness at the toe is approximately $3 / 16$ in $(5 \mathrm{~mm}$ ). According to AWS D1.1-79 (table 2.10.3), the corresponding minimum effective throat for partial joint penetration groove welds is $3 \mathrm{~mm}$. As noted in section 7.4 .1 of this report, joint penetration averaged $2.2 \mathrm{~mm}$ at interior sections of the fourth floor walkway box beams. Data obtained from fracture surfaces at the ends of the box beams indicate average joint penetrations of from 1.5 to $2.4 \mathrm{~mm}$ in the region between the outer hanger rod hole and the beam end. Because of reductions in area at fracture, the latter represent minimum values of joint penetration.

To evaluate the significance of the weld actually provided, the effect on ultimate capacity of the box beam-hanger rod connections must be examined. For an effective throat of $3 \mathrm{~mm}$ and a weld length of $13 / 8$ in $(35 \mathrm{~mm})$, the corresponding weld area is $105 \mathrm{~mm}^{2}$. From the plot of estimated peak upper rod load vs index weld area on figure 6.37, the expected ultimate capacity is approximately $17.3 \mathrm{kips}(77 \mathrm{kN})$. With the contribution of the interior tack weld, estimates for the mean ultimate capacities of the actual fourth floor box beam-hanger rod connections range from 18.2 to $19.3 \mathrm{kips}$ ( 81 to $86 \mathrm{kN}$ ).

Based on observations of the fracture surfaces and on the relationship between connection load capacity and index weld area, it is concluded that the actual connection load capacities were probably higher than the capacity that would be expected for a partial joint penetration groove weld having an effective throat of $3 \mathrm{~mm}$ and acting alone. It is therefore concluded that quality of workmanship did not play any significant role in initiating the collapse.

\subsection{SUMMARY}

The following are the major points resulting from the structural tests, analysis, and observations of damage.

1. The maximum load acting on a fourth floor box beam-hanger rod connection at the time of collapse was 53 percent of what was required for design under the Kansas City Building Code. 
2. With the exception of locations 8UE and 10UW, the estimated mean ultimate capacity of each fourth floor box beam-hanger rod connection either equals or slightly exceeds the estimated dead load effect. However, the estimated ultimate capacity is exceeded by the sum of the estimated dead load and upper-bound live load in every case.

3. Each of the 6 fourth floor box beam-hanger rod connections had a high probability of failure; each connection was a candidate for initiation of walkway collapse.

4. Failure of any one of the fourth floor box beam-hanger rod connections would have been accompanied by a redistribution or transfer of load to other hangers. With no apparent significant reserve capacity to accommodate this redistribution, progressive failure of the remaining connections was assured. Thus, failure of any one connection would have led to complete collapse of the walkway system.

5. The design of a fourth floor box beam-hanger rod connection under the AISC Specification would be expected to result in a connection with an ultimate capacity of at least 68 kips $(302 \mathrm{kN})$. The average ultimate capacity of the 6 fourth floor walkway connections is estimated to have been 18.6 kips $(83 \mathrm{kN})$.

6. Observed distortions of the fourth floor to ceiling hanger rods and the fourth floor walkway box beams strongly support the initiation of the collapse at box beam-hanger rod connection $9 \mathrm{UE}$.

7. The change in hanger rod arrangement from a continuous rod to interrupted rods essentially doubled the load to be transferred by the fourth floor box beam-hanger rod connections.

8. For the continuous hanger rod arrangement, the design load to be transferred to each hanger rod at the second and fourth floor levels would have been approximately $20.3 \mathrm{kips}(90 \mathrm{kN})$.

9. For the continuous hanger rod arrangement, a box beam-hanger rod connection designed in accordance with the AISC Specification would be expected to provide an ultimate capacity of at least 33.9 kips $(151 \mathrm{kN})$.

10. Had the change in hanger rod arrangement not been made, the third floor walkway would have been the most critical of the three, the ultimate capacity of the connections being approximately 53 percent of that which would be expected of a connection designed in accordance with the AISC Specification. 
11. Average joint penetration for the box beam longitudinal welds was less than that required by AWS D1.1-79 for a prequalified partial joint penetration groove weld. However, it is concluded that due to the presence of tack welds the actual ultimate capacities of the box beamhanger rod connections probably were higher than would be expected for a partial joint penetration groove weld with the prescribed minimum effective throat acting alone.

12. There is no evidence to indicate that either quality of workmanship or materials played any significant role in initiating the collapse. 


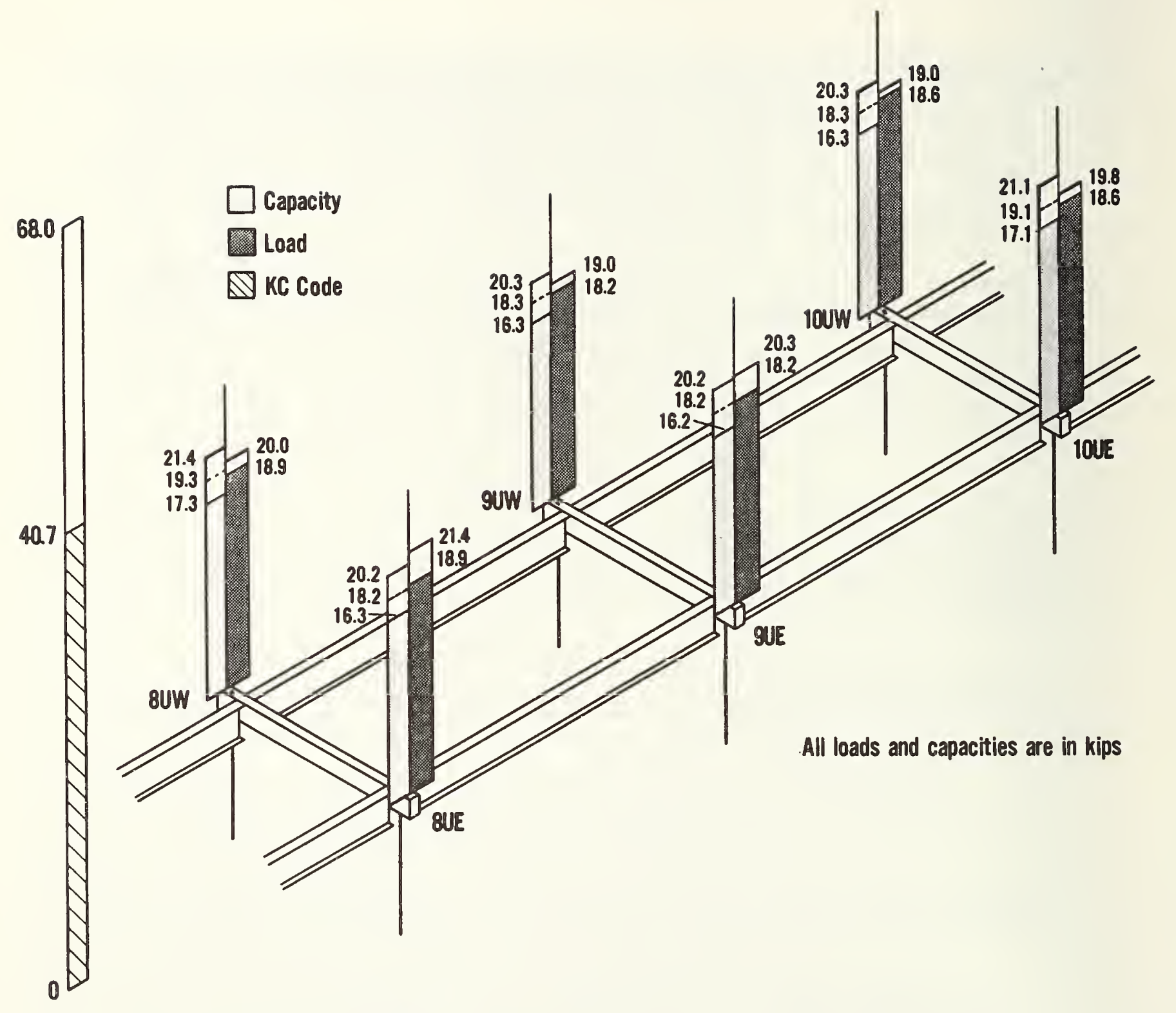

Figure 10.1 Comparison of fourth floor walkway box beam-hanger rod connection capacities with loads believed to have been acting at time of collapse. 


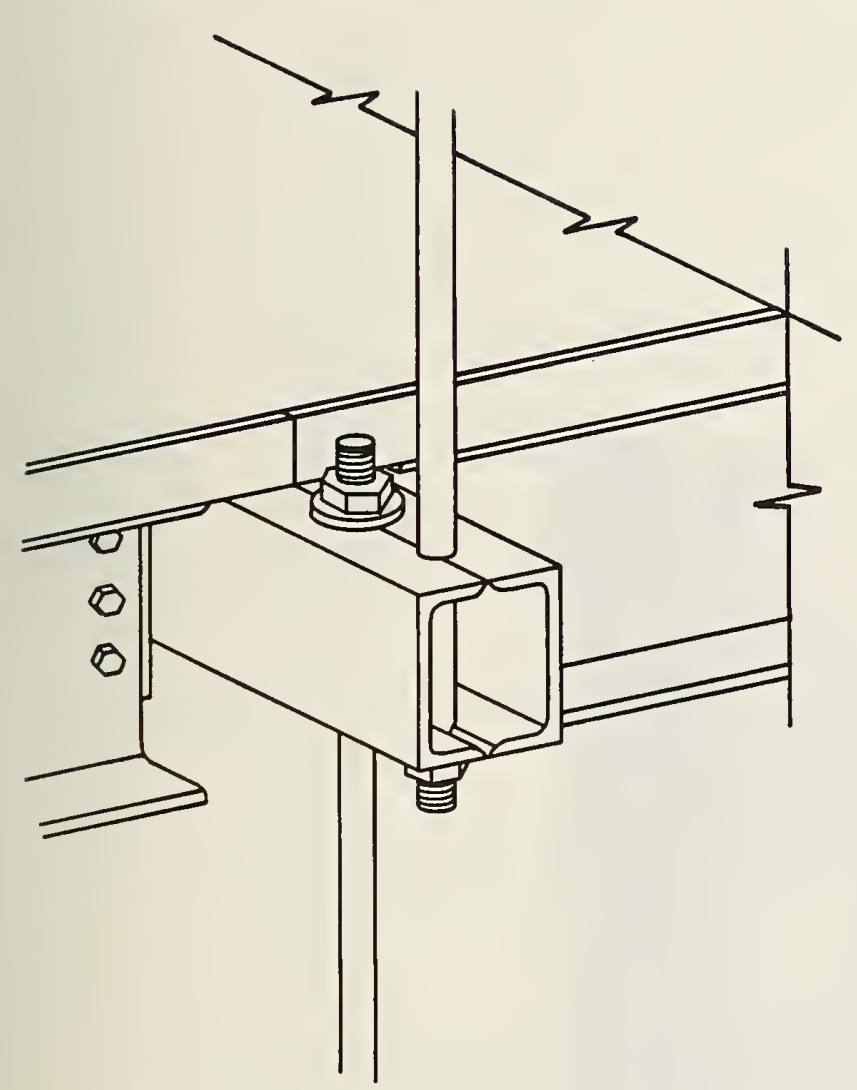

As Built

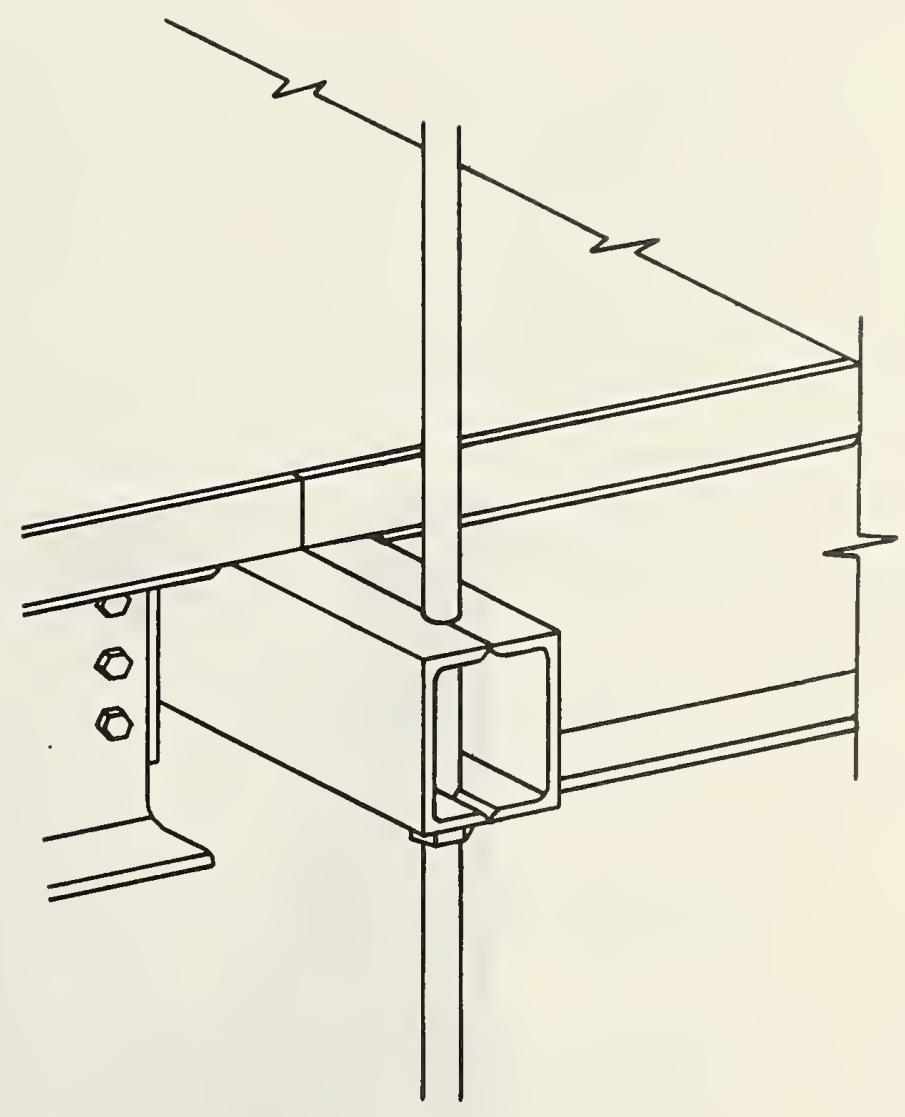

Original Detail

Figure 10.2 Comparison of interrupted and continuous hanger rod details. 


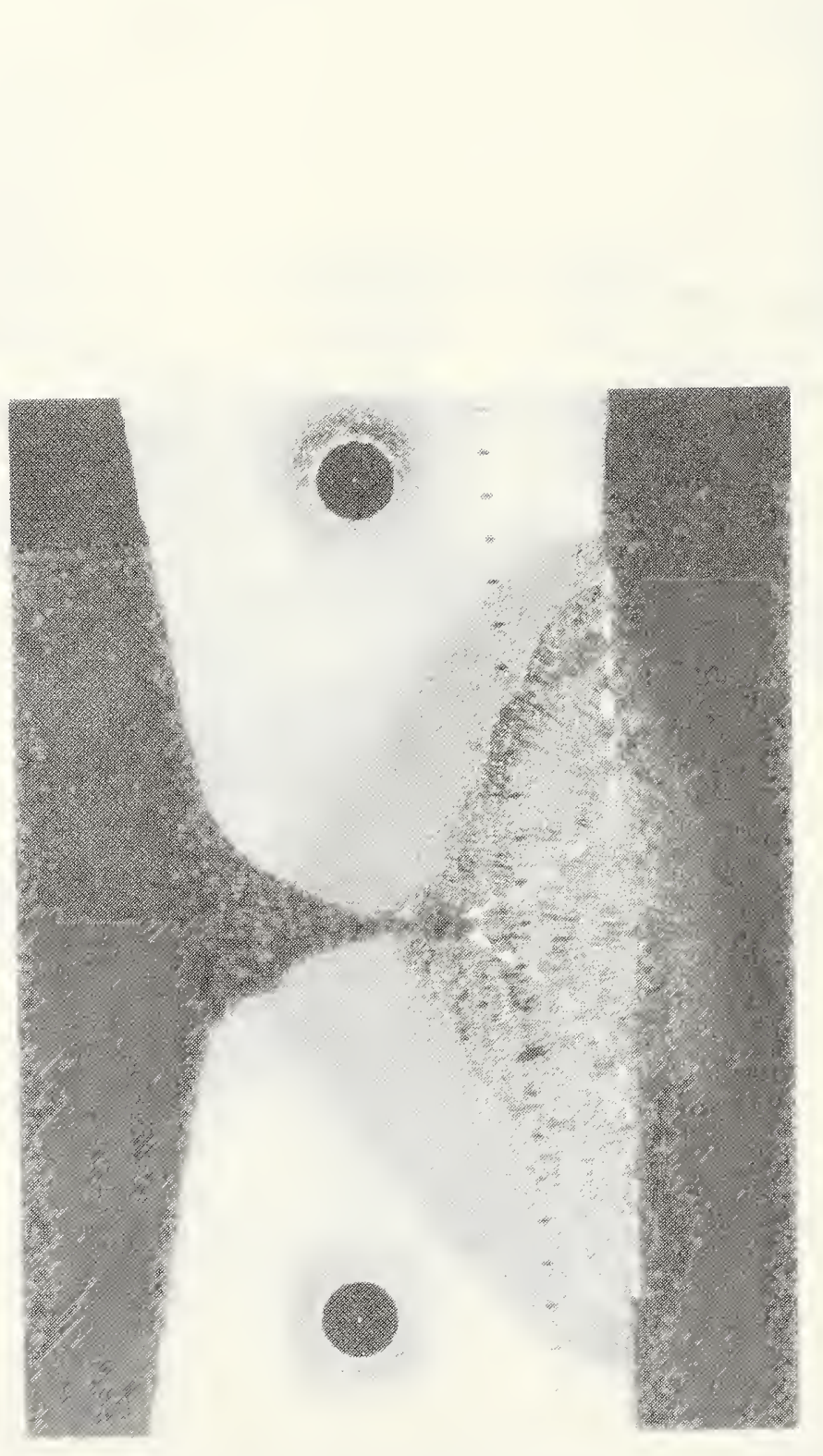

웜

D.

त.

क

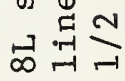

园 শ્d

ป

م

x。ํㅇ i

-

ते

3 号

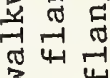

世

$0 \pm \frac{1}{ \pm}$

مب

- 100

ये 단

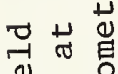

उ

동ㅁำ

$\overrightarrow{0} \cdot \pi$

달

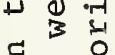

당 거

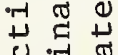

记 四

ब I

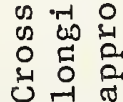

ํㅜㅁ

造

다 


\section{SUMMARY AND CONCLUSIONS}

Following the collapse of two suspended walkways within the atrium area of the Kansas City Hyatt Regency Hotel in Kansas City, Mo., Mayor Richard L. Berkley formally requested the National Bureau of Standards (NBS) to independently ascertain the most probable cause of the collapse. In response to this request, NBS carried out an extensive field investigation to reconstruct events preceding the collapse and to establish the condition of the walkways at the time of collapse. This included review of documents related to the design and construction of the walkways and measurements and inspections of the debris remaining after the collapse. NBS also conducted comprehensive laboratory studies of materials and mockups representative of the walkway construction and laboratory studies of specimens removed from the debris. These studies were supported by structural analyses of the walkways under the loading condition believed to have existed at the time of collapse. Conclusions drawn from this investigation are summarized in the following statements:

1. Collapse of the walkways occurred under the action of loads that were substantially less than the design loads specified by the Kansas City Building Code.

(a) It is concluded that a total of 63 people represents a credible upper-bound combined occupancy of the second and fourth floor walkways at the time of collapse.

(b) Based upon measured weights of damaged walkway spans, the dead load prior to collapse averaged $17.8 \mathrm{kips}(79 \mathrm{kN})$ per walkway span. This is approximately 8 percent higher than the nominal dead load that would be estimated on the basis of the contract drawings.

(c) Dynamic loads induced by walking or dancing on the walkways would not have been significant in comparison to the static loads.

(d) The maximum load (estimated dead load plus upper-bound live load) believed to have been acting on a fourth floor box beam-hanger rod connection at the time of collapse is $21.4 \mathrm{kips}$ ( $95 \mathrm{kN}$ ). Under the action of nominal dead load plus code-specified live load, this load would have been $40.7 \mathrm{kips}(181 \mathrm{kN})$. Thus the maximum load acting on a connection at the time of collapse was 53 percent of what was required for design under the Kansas City Building Code.

2. The ultimate capacity of box beam-hanger rod connections can be predicted on the basis of laboratory test results.

(a) Extensive structural tests show that ultimate capacity varies linearly with an index weld area.

(b) Welding process has little effect on ultimate capacity.

(c) Mean ultimate capacities of the fourth floor box beam-hanger rod connections were estimated on the basis of the NBS test series and 
these capacities ranged from 18.2 kips ( $81 \mathrm{kN}$ ) to $19.3 \mathrm{kips}(86 \mathrm{kN})$ with an average value of $18.6 \mathrm{kips}(83 \mathrm{kN})$.

3. Under the action of the loads estimated to have been present on the walkways at the time of collapse, all fourth floor box beam-hanger rod connections were candidates for initiation of walkway collapse.

(a) With the exception of locations 8UE and 10UW, the estimated ultimate capacity of each connection either equals or slightly exceeds the estimated dead load effect. However, the estimated ultimate capacity is exceeded by the sum of the estimated dead load and upper-bound live load in every case.

(b) Because of the small reserve load capacity of the connections and because of load redistribution that would have accompanied initial failure, progressive failure of the walkway system was assured.

4. Observed distortions of structural components strongly suggest that failure of the walkway system initiated in the box beam-hanger rod connection at location $9 U E$ (east end of middle box beam in fourth floor walkway).

(a) The lower ends of the west side hanger rods were bent to the west, while those along the east side showed no such distortion, indicating that the box beam-hanger rod connections along the east side of the fourth floor walkway failed first.

(b) Mirror symmetry of distortions about the longitudinal axis of the middle box beam in the fourth floor walkway, coupled with the hanger rod distortions, indicate initiation of failure at location 9UE.

5. As constructed, the box beam-hanger rod connections, the fourth floor to ceiling hanger rods, and the third floor walkway hanger rods did not satisfy the design provisions of the Kansas City Building Code.

(a) The AISC Specification for the Design, Fabrication and Erection of Structural Steel for Buildings forms the basis for the steel design provisions of the Kansas City Building Code.

(b) The box beam-hanger rod connection detail used in the walkway construction does not satisfy the intent of the AISC provisions for the proportioning of such connections.

(c) The design of a fourth floor box beam-hanger rod connection under the AISC Specification would be expected to result in a connection with an ultimate capacity of at least 68 kips ( $302 \mathrm{kN}$ ). The average ultimate capacity of the six fourth floor walkway connections as constructed is estimated to have been $18.6 \mathrm{kips}(83 \mathrm{kN})$.

(d) The fourth floor to ceiling hanger rods and the third floor walkway hanger rods do not comply with the AISC provisions for allowable stresses. 
6. The change in hanger rod arrangement from a continuous rod to interrupted rods essentially doubled the load to be transferred by the fourth floor box beam-hanger rod connections.

(a) For the continuous hanger rod arrangement, the design load to be transferred to each hanger rod at the second and fourth floor levels would have been approximately $20.3 \mathrm{kips}(90 \mathrm{kN})$.

(b) For the interrupted hanger rod arrangement, the design load to be transferred by a fourth floor box beam-hanger rod connection would have been 40.7 kips (181 kN) (see item $1(\mathrm{~d})$ ).

7. The box beam-hanger rod connection would not have satisfied the Kansas City Building code under the original hanger rod detail (continuous rod).

(a) See items $5(a)$ and $5($ b).

(b) Under the original hanger rod arrangement (continuous rod), a box beam-hanger rod connection designed in accordance with the AISC Specification would be expected to provide an ultimate capacity of at least 33.9 kips $(151 \mathrm{kN})$.

(c) Based on NBS structural tests, the mean ultimate capacity of a single-rod connection as detailed on the contract drawings is estimated to be 20.5 kips $(91 \mathrm{kN})$.

(d) Had the change in hanger rod arrangement not been made, the third floor walkway would have been the most critical of the three, the ultimate capacity of the connections being approximately 53 percent of that which would be expected of a connection designed in accordance with the AISC Specification.

8. Under the original hanger rod arrangement (continuous rod) the box beamhanger rod connections as shown on the contract drawings would have had the capacity to resist the loads estimated to have been acting at the time of collapse.

(a) The maximum load (estimated dead load plus upper-bound live load) believed to have been acting on a second floor box beam-hanger rod connection at the time of collapse is $11.5 \mathrm{kips}(51 \mathrm{kN})$.

(b) The ultimate capacity of a single-rod connection is estimated to be 20.5 kips $(91 \mathrm{kN}$ ) (see item $7(\mathrm{c})$ ).

9. Neither the quality of workmanship nor the materials used in the walkway system played a significant role in initiating the collapse.

(a) Tensile properties and chemical compositions of the walkway box beam channels and hanger rod materials satisfy the requirements of ASTM Standard A36 for structural steel. 
(b) Microstructure and hardness of the walkway box beam channels, box beam longitudinal welds, and hanger rod materials were normal.

(c) Average joint penetration for the box beam longitudinal welds was less than that required by AWS D1.1-79 for a prequalified partial joint penetration groove weld. However, it is concluded that due to the presence of tack welds the actual ultimate capacities of the box beamhanger rod connections probably were higher than would be expected for a partial joint penetration groove weld with the prescribed minimum effective throat acting alone.

(d) Evidence indicates that hanger rod washers at locations 8UE and 9UE, missing after the collapse, had been installed. 
12. REFERENCES

2.1 "Specifications, Hyatt Regency, Kansas City," PBNDML, Kansas City, MO, August 1978.

2.2 "Kansas City Building Code," Kansas City, MO, June 1, 1977.

2.3 "Uniform Building Code," 1976 Edition, International Conference of Building Officials, Whittier, CA, 1976.

2.4 "Specification for the Design, Fabrication and Erection of Structural Steel for Buildings," American Institute of Steel Construction, New York, NY, February 1969.

2.5 "Summary of Data from Vibration Testing of the Third Level Skybridge in the Kansas City Hyatt Regency Hote1," Wiss, Janney, Elstner and Associates Confidential Report WTE No. 81553 (with supplement of data), September 28, 1981, Northbrook, IL.

3.1 "Structural Welding Code-Steel," Third Edition, AWS D1.1-79, American Welding Society, Miami, FL, 1978.

5.1 "Miscellaneous Locations, Hyatt Regency Hotel, Kansas City, Jackson County, Missouri," The Tuttle-Ayers-Woodward Co., Project No. 220587, August 5, 1981, Kansas City, Missouri.

5.2 "Symbols for Welding and Nondestructive Testing," AWS A2.4-79, American Welding Society, Miami, FL, 1979.

6.1 "Welding Terms and Definitions," AWS A3.0-80, American Welding Society, Miami, FL, 1980.

6.2 Lipson, C. and Sheth, W. J., Statistical Design and Analysis of Engineering Experiments, McGraw Hill, New York, 1973.

7.1 Annual Book of ASTM Standards, Parts 4, 6, 10 and 14, American Society for Testing and Materials, Philadelphia, PA, 1981.

9.1 Diffrient, N., Tilley, A. and Bardagjy, J., Humanscale 1/2/3, MIT Press, Massachusetts Institute of Technology, Cambridge, MA, 1974 .

9.2 Fattal, S. G., Cattaneo, L. E., Turner, G. E. and Robinson, S. N., "Personnel Guardrails for the Prevention of 0ccupational Accidents," NBSIR 76-1132, National Bureau of Standards, Washington, D.C., July 1976.

9.3 Swearingen, J. J., "Determination of Centers of Gravity of Man," Report 62-14, Aviation Medical Service, Federal Aviation Service, Oklahoma City, OK, August 1962 .

9.4 Manual of Steel Construction, Seventh Edition, American Institute of Steel Construction, New York, NY, 1970 . 
9.5 Kame1, H. A. and McCabe, N. W., "Graphics-Oriented Interactive Finite Element Time-Sharing System," Version 5.0 User's Manual, University of Arizona, Tucson, AZ, May 1979.

9.6 McGuire, W., "Dynamic Response Characteristics of the Kansas City Hyatt Regency Hotel Skybridges," Consultant's Report to the National Bureau of Standards, December 3, 1981, Ithaca, NY.

9.7 Becker, R., "Simplified Investigation of Floors Under Foot Traffic," Journal of the Structural Division, ASCE, Vol. 106, No. ST11, Proc. Paper 15804, Nov. 1980, pp. 2221-2234.

9.8 Harper, F. C., Warlow, W. J. and Clarke, B. L., "The Forces Applied to the Floor by the Foot in Walking," National Building Studies Research Paper 32, Department of Scientific and Industrial Research, Building Research Station, London, 1961 . 
NBS-114A (REV. 2-8C)

\begin{tabular}{|c|c|c|c|}
\hline $\begin{array}{l}\text { U.S. DEPT. OF COMM. } \\
\text { BIBLIOGRAPHIC DATA } \\
\text { SHEET (See instructions) }\end{array}$ & $\begin{array}{l}\text { 1. PUBLICATION OR } \\
\text { REPORT NO. } \\
\text { NBSIR } 82-2465\end{array}$ & 2. Performing Organ. Report No. & $\begin{array}{l}\text { 3. Publication Date } \\
\text { February } 1982\end{array}$ \\
\hline \multicolumn{4}{|l|}{$\begin{array}{l}\text { 4. TITLE AND SUBTITLE } \\
\text { Investigation of } t\end{array}$} \\
\hline \multicolumn{4}{|c|}{$\begin{array}{l}\text { 5. AUTHOR(S)R D. Marsha 11, E.0. Pfrang, E.V. Leyendecker, K.A. Woodward, } \\
\text { R.P. Reed, M.B. Kasen, and T. R. Shives }\end{array}$} \\
\hline \multicolumn{3}{|c|}{$\begin{array}{l}\text { 6. PERFORMING ORGANIZATION (If joint or other than NBS, see instructions) } \\
\text { NATIONAL BUREAU OF STANDARDS } \\
\text { DEPARTMENT OF COMMERCE } \\
\text { WASHINGTON, D.C. } 20234\end{array}$} & 8. Type of Report \& Period Covered \\
\hline
\end{tabular}

9. SPONSORING ORGANIZATION NAME AND COMPLETE ADDRESS (Street. City, State, ZIP)

10. SUPPLEMENTARY NOTES

[Document describes a computer program; SF-185, FIPS Software Summary, is attached.

11. ABSTRACT (A 200-word or less foctual summary of most significant information. If document includes a significant bibliography or literature survey, mention it here)

An investigation into the collapse of two suspended walkways within the atrium area of the Hyatt Regency Hotel in Kansas City, Mo., is presented in this report. The investigation included on-site inspections, laboratory tests and analytical studies.

Three suspended walkways spanned the atrium at the second, third, and fourth floor levels. The second floor walkway was suspended from the fourth floor walkway which was directly above it. In turn, this fourth floor walkway was suspended from the atrium roof framing by a set of six hanger rods. The third floor walkway was offset from the other two and was independently suspended from the roof framing by another set of hanger rods. In the collapse, the second and fourth floor walkways fell to the atrium floor with the fourth floor walkway coming to rest on top of the lower walkway.

Based on the results of this investigation, it is concluded that the most probable cause of failure was insufficient load capacity of the box beam-hanger rod connections. Observed distortions of structural components strongly suggest that the failure of the walkway system initiated in the box beam-hanger rod connection on the east end of the fourth floor walkway's middle box beam.

(continued on attached)

12. KEY WORDS (Six to twelve entries; alphabetical order; capitalize only proper names; and separate key words by semicolons)

building; collapse; connection; construction; failure, steel; walkway.

13. AVAILABILITY

Unlimited

For Official Distribution. Do Not Release to NTIS

[ Order From Superintendent of Documents, U.S. Government Printing Office, Washington, D.C. 20402.

14. NO. OF PRINTED PAGES

[] Order From National Technical Information Service (NTIS), Springfield, VA. 2216I 
"Investigation of the Kansas City Hyatt Regency Walkways Collapse"

ABSTRACT - (continued)

Two factors contributed to the collapse: inadequacy of the original design for the box beam-hanger rod connection which was identical for all three walkways, and a change in hanger rod arrangement during construction that essentially doubled the load on the box beam-hanger rod connections at the fourth floor walkway. As originally approved for construction, the contract drawings called for a set of continuous hanger rods which would attach to the roof framing and pass through the fourth floor box beams and on through the second floor box beams. As actually constructed, two sets of hanger rods were used, one set extending from the fourth floor box beams to the roof framing and another set from the second floor box beams to the fourth floor box beams.

Based on measured weights of damaged walkway spans and on a videotape showing occupancy of the second floor walkway just before the collapse, it is concluded that the maximum load on a fourth floor box beam-hanger rod connection at the time of collapse was only 31 percent of the ultimate capacity expected of a connection designed under the Kansas City Building Code. It is also concluded that had the original hanger rod arrangement not been changed, the connection capacity would have been approximately 60 percent of that expected under the Kansas City Building Code. With this change in hanger rod arrangement, the ultimate capacity of the walkways was so significantly reduced that, from the day of construction, they had only minimal capacity to resist their own weight and had virturally no capacity to resist additional loads imposed by people.

Supplementary material is contained in an appendix to this report and published as NBSIR 82-2465A. 


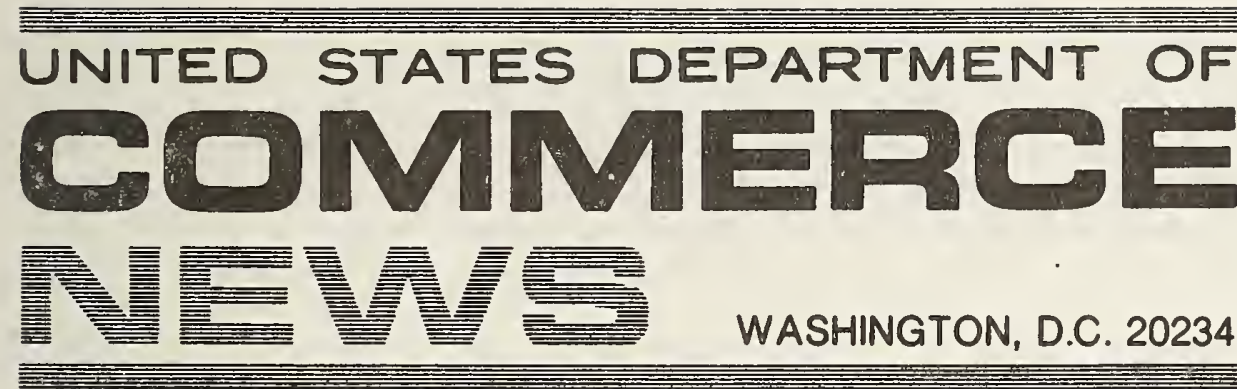

HOLD FOR RELEASE

9:30 a.m., February 25, 1982
NATIONAL BUREAU OF STANDARDS

Mat Heyman $301 / 921-3181$

\section{CONNECTIONS IN COLLAPSED WALKWAYS AT KANSAS}

\section{CITY HOTEL FAR FROM ADEQUATE, NBS REPORTS}

Critical connections in two Kansas City Hyatt Regency Hotel walkways which collapsed July 17, 1981, were capable of supporting less than onethird of the load expected to be carried by a connection designed under the Kansas City, Mo., building code. That was one of the major conclusions in a report issued today by the Commerce Department's National Bureau of Standards (NBS).

Dr. Edward 0. Pfrang, who headed up an NBS investigation of the nation's worst building collapse, today identified the two factors related to those box beam-hanger rod connections which were critical in causing the walkways' failure.

First, Pfrang said, the "connections as initially detailed and approved for construction provided a capacity far below the capacity that would have been required to satisfy the Kansas City Building Code." Second, a change in the supporting hanger rod arrangement "essentially doubled the load to be transferred" by the connections, "thus further aggravating an already critical situation." 
Shortly after the accident which killed 113 people and injured 186 others, Kansas City Mayor Richard L. Berkley asked NBS to investigate the failure. The mayor's request was endorsed by members of the Missouri congressional delegation. NBS, a federal science and engineering research laboratory which traditionally has served in a third party role to resolve technical controversies, agreed to determine the most probable cause of the collapse.

The NBS investigation included a review of various constructionrelated documents, on-site and laboratory structural and materials investigations--including testing of selected parts of the walkways' debris and NBS replicas of important walkway components--and extensive engineering analyses.

The bureau's findings are given in a 349-page report submitted today to Mayor Berkley in Kansas City and reviewed by Pfrang, Chief of the NBS Structures Division, at a news conference in Gaithersburg, Md.

\section{Walkway's Structure}

Three suspended walkways spanned the Hyatt Regency atrium, which connected a high-rise section and a lower "function block." The second floor walkway was suspended from the fourth floor walkway directly above it by six steel hanger rods. In turn, this fourth floor walkway was suspended from the atrium roof framing by another six hanger rods.

The third floor walkway, which was not involved in the collapse, was offset from the other two walkways and was independently suspended from the roof framing by another set of hanger rods.

The hanger rods from the roof and from the second floor walkway passed through the ends of the fourth floor walkway box beams. These box beams were made up of pairs of 8 -inch steel channels which were welded together. The hanger rods were secured by washers and nuts after passing through the box beams. Under this arrangement, the fourth floor box beam-hanger rod connections transmitted the loads of both the second and fourth floor walkways.

In the collapse, the second and fourth floor walkways fell to the atrium floor after the fourth floor to ceiling hanger rods pulled through at the walkway box beam connections.

\section{The NBS Investigation}

To meet requirements of the Kansas City Building Code, Pfrang said, the fourth floor connections between the walkways' box beams and supporting hanger rods each should have been designed to handle 40,700 pounds-including the weight of the walkways and a specified design live load of people. However, the Kansas City code also incorporates a margin of safety for steel components. Walkway connections designed according to the code to have a capacity of 40,700 pounds would actually be expected to have an ultimate capacity of at least 68,000 pounds. 
After weighing the damaged walkway spans and estimating the number of people on the walkways at the time of the collapse, NBS researchers concluded that the maximum load on any of the six connections at the time of the collapse was 21,400 pounds. Thus, the load on the walkways was far below that required to be handled under the Kansas City Building Code.

After conducting extensive structural and materials tests on selected parts of the walkways and NBS-fabricated replicas, bureau researchers determined that the average ultimate capacity of each fourth floor hanger rod-box beam connection was just 18,600 pounds compared to the expected ultimate capacity of 68,000 for code-complying connections. Thus, the connections were capable of supporting only 27 percent of the load expected to be supported by connections designed under the Kansas City Building Code.

Since the loads on the connections from the weight of the walkways and people on the walkways at the time of the collapse were so near to or in excess of the estimated ultimate capacity of the actual connections, failure could have begun at any of the fourth floor box beam-hanger rod connections, NBS researchers determined. Progressive failure of the other connections and the walkways' collapse was assured after any one of the connections failed and the load from that connection was distributed to the other connections. Based on studies of the walkways debris, NBS researchers were able to pinpoint a connection at the middle fourth floor box-beam as the most likely to have failed first.

A key factor contributing to the collapse, the NBS report noted, was that the walkways were not constructed in accordance with the contract drawings. As originally approved for construction by the Kansas City Codes Administration Office, the plan for the walkways called for a single set of hanger rods (attached to the roof framing) which would pass through the fourth floor beams and on through the second floor beams. Under this arrangement, each box beam would transfer its own load directly into the hanger rods.

However, during construction the hanger rod arrangement was changed to an "interrupted" hanger rod scheme so that the fourth floor box beam connections were required to transfer the load of both the fourth and the second floor walkways.

This change essentially doubled the load on those fourth floor connections. While NBS researchers concluded that this original hanger rod-box beam connection detail still would not have satisfied the Kansas City Building Code, they also determined that the original connections as shown on the contract drawings would have had the capacity to resist the loads estimated to have been acting on them at the time of the collapse.

Based on a variety of materials tests of walkway components-including the welds, nuts and washers, steel channels, and hanger rods-NBS researchers determined that "Neither the quality of workmanship nor the materials used in the walkway system played a significant role in initiating the collapse." 
The bureau's report also notes that in addition to the box beamhanger rod connections, the fourth floor to ceiling hanger rods and the third floor walkway hanger rods violated the design provisions of the Kansas City Building Code. According to NBS investigators, though, the hanger rod code violations were not a factor in the collapse. 
